\title{
Enhanced Flue Gas Conditioning Study
}

Final Report for Task $\mathbf{7 . 2 0}$

Stanley J. Miller
Dennis L. Laudal

November 1991

Work Performed Under Contract No.: DE-FC21-86MC10637

For

U.S. Department of Energy

Office of Fossil Energy

Morgantown Energy Technology Center

Morgantown, West Virginia

By

University of North Dakota

Energy and Environmental Research Center

Grand Forks, North Dakota 


\section{DISCLAIMER}

This report was prepared as an account of work sponsored by an agency of the United States Government. Neither the United States Government nor any agency thereof, nor any of their employees makes any warranty, express or implied, or assumes any legal liability or responsibility for the accuracy, completeness or usefulness of any information, apparatus, product, or process disclosed, or represents that its use would not infringe privately owned rights. Reference herein to any specific commercial product, process, or service by trade name, trademark, manufacturer, or otherwise, does not necessarily constitute or imply its endorsement, recommendation, or favoring by the United States Government or any agency thereof. The views and opinions of authors expressed herein do not necessarily state or reflect those of the United States Government or any agency thereof.

This report has been reproduced directly from the best available copy.

Available to DOE and DOE contractors from the Office of Scientific and Technical Information, P.O. Box 62, Oak Ridge, TN 37831; prices available from (615)576-8401, FTS 626-8401.

Available to the public from the National Technical Information Service, U.S. Department of Commerce, 5285 Port Royal Rd., Springfield, VA 22161. 


\title{
Enhanced Flue Gas Conditioning Study
}

Final Report for Task 7.20

Stanley J. Miller Dennis L. Laudal

Work Performed Under Contract No.: DE-FC21-86MC10637

For

U.S. Department of Energy

Office of Fossil Energy

Morgantown Energy Technology Center

P.O. Box 880

Morgantown, West Virginia 26507-0880

\author{
By \\ University of North Dakota \\ Energy and Environmental Research Center \\ Box 8213, University Station \\ Grand Forks, North Dakota 58202
}

November 1991 


\section{TABLE OF CONTENTS}

$\underline{\text { Page }}$

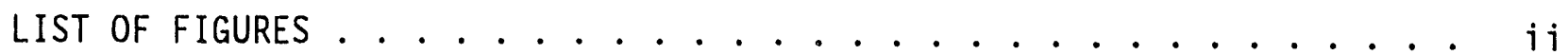

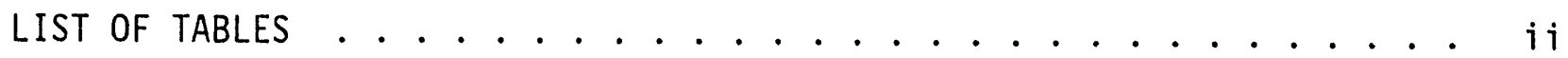

1.0 INTRODUCTION AND SUMMARY $\ldots \ldots \ldots \ldots \ldots$

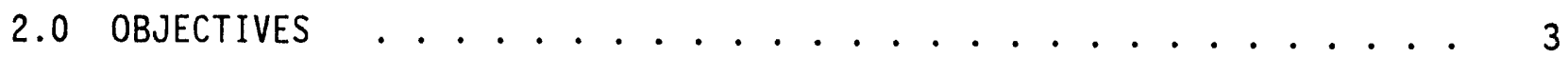

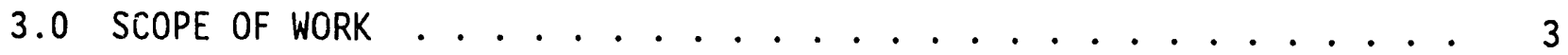

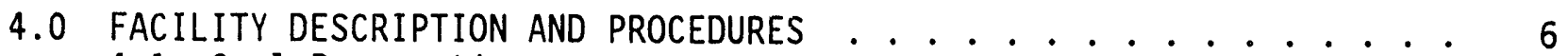

4.1 Coal Preparation . . . . . . . . . . . . . . 6

4.2 Particulate Test Combustor (PTC) . . . . . . . . . 6

4.3 Electrostatic Precipitator (ESP) . . . . . . . . . 7

4.4 Resistivity Measurement . . . . . . . . . . . . . 9

4.5 Particulate Sampling and Measurement ........... 11

4.6 Sulfur Trioxide and Ammonia Injection .......... 15

4.7 Cohesive Tensile Strength Measurements . . . . . . . 17

4.8 Sample Analyses . . . . . . . . . . . . . . 19

5.0 RESULTS AND DISCUSSION ............... 20

5.1 Big Brown: $\mathrm{SO}_{3}$ and Dual Conditioning (Runs 344-348) . . . 20

5.2 Hunter Valley: $\mathrm{SO}_{3}$ and Dual Conditioning

(Runs 349-354, 364, 365) ............. 25

5.3 Hudson Bituminous: $\mathrm{SO}_{3}$ and Dual Conditioning (Runs 355-360) $~ 35$

5.4 Pleasant Prairie: $\mathrm{SO}_{3}$ and Dual Conditioning (Runs 361-363) . 40

5.5 Enhanced Flue Gas Conditioning with Big Brown Coal

(Runs 368-370, 377) .............. . . 42

5.6 Enhanced Flue Gas Conditioning with Hudson Bituminous Coal

5.7 Enhanced Flue Gas Conditioning with Hunter Valiey Coal . . . 44

(Runs 375, 376, 396-398) ............. 45

6.0 CONCLUSIONS AND RECOMMENDATIONS .............. 53

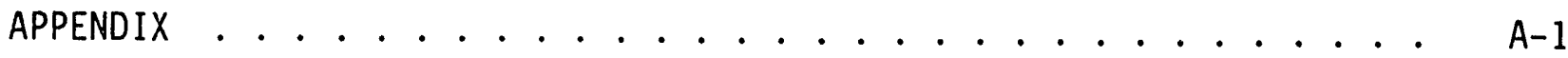




\section{LIST OF FIGURES}

Figure

$\underline{\text { Page }}$

1 Schematic of combustion system used for tests . . . . . . . . 8

2 Schematic of resistivity probe . . . . . . . . . . . . 10

3 Schematic of Aerodynamic Particle Sizer . . . . . . . . . . . 12

4 Schematic of particle-sampling system (APS 33, DMPS, and dilution system) ....................... 15

5 Sulfur trioxide and ammonia injection system using $\mathrm{SO}_{3}$ generator . 16

6 Schematic of Cohetester . . . . . . . . . . . . . . 18

7 Comparison of fly ash morphology between Big Brown fly ash from Run 344 (top) and Hunter Valley fly ash from Run 349 (bottom) at 500x magnification ................

8 Comparison of fly ash morphology between Big Brown fly ash from Run 344 (top) and Hunter Valley fly ash from Run 349 (bottom) at 2510x magnification................ . . . 28

9 Comparison of fly ash morphology between Big Brown fly ash from Run 344 (top) and Hunter Valley fly ash from Run 349 (bottom) at 10,000x magnification

\section{LIST OF TABLES}

$\underline{\text { Table }}$

1 ESP Flow Rates ....................... . . . 9

2 ACGIH Respirable Mass Definition ............... 14 


\section{ENHANCED FLUE GAS CONDITIONING STUDY FINAL PROJECT REPORT}

\subsection{INTRODUCTION AND SUMMARY}

This project was conducted by the University of North Dakota Energy and Environmental Research Center (EERC) for Wahlco, Inc. and the U.S. Department of Energy Pittsburgh Energy Technology Center (DOE/PETC). The DOE/PETC share of the project was funded through Cooperative Agreement No. DE-FC21-86MC10637 under the Joint Venture portion of the Agreement.

Many electrostatic precipitators (ESPs) do not achieve acceptable particulate removal efficiencies because of high-resistivity ash. One method to improve ESP performance is to employ chemical conditioning agents to reduce fly ash resistivity. Widely used agents include sulfur trioxide $\left(\mathrm{SO}_{3}\right)$ and ammonia, which are sometimes used simultaneously. For some fly ashes, that have a low affinity for $\mathrm{SO}_{3}$, conditioning with $\mathrm{SO}_{3}$ alone is not adequate to reduce resistivity without excessive amounts of $\mathrm{SO}_{3}$ exiting the stack. In such cases, the use of ammonia in addition to $\mathrm{SO}_{3}$ may reduce the amount of required $\mathrm{SO}_{3}$ and prevent the emission of excess $\mathrm{SO}_{3}$ out of the stack.

The general objective of the work was to test enhanced flue gas conditioning methods to improve the performance of ESPs. Specific objectives were to 1) verify the relationship between the required $\mathrm{SO}_{3}$ injection rates to maintain the desired fly ash resistivity and temperature for four coals, 2) verify that dual conditioning with both ammonia and $\mathrm{SO}_{3}$ promotes $\mathrm{SO}_{3}$ utilization and allows for resistivity modification with moderate $\mathrm{SO}_{3}$ injection rates, and 3 ) verify the effectiveness and practicality of an enhanced flue gas conditioning (EFGC) method. The EFGC method is a proprietary development of Wahlco, Inc.

Tests were conducted at EERC with a pilot-scale pulverized coal-fired combustor and single-wire tubular ESP. A total of 37 one-day runs were completed, each run usually consisting of four two-hour tests. The primary independent variables were 1) conditioning method-- $\mathrm{SO}_{3}$ alone, dual, and $\mathrm{EFGC}$; 2) coal type--Big Brown, iexas lignite, Hunter Valley Australian subbituminous, Hudson bituminous, and Pleasant Prairie subbituminous; 3) ESP 
temperature- $-250^{\circ}, 325^{\circ}$, and $400^{\circ} \mathrm{F}$; and 4) concentrations of $\mathrm{SO}_{3}$ and ammonia--

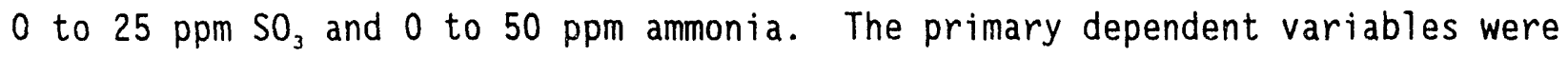
particulate emissions, ESP electrical conditions, ash resistivity, sulfur retention, and ash tensile strength. A velocity of $5 \mathrm{ft} / \mathrm{s}$ corresponding to a specific collection area (SCA) of $124 \mathrm{ft}^{2} / 1000 \mathrm{acfm}$ was held constant for all tests.

Superior performance was achieved with dual conditioning, compared to $\mathrm{SO}_{3}$ alone with all four coals. The improved performance with dual conditioning is attributed to several effects. For many tests, resistivity was lower with dual conditioning, compared to $\mathrm{SO}_{3}$ alone using the same amount of $\mathrm{SO}_{3}$. This means that better transfer of the $\mathrm{SO}_{z}$ to the fly ash was achieved, and the amount of $\mathrm{SO}_{3}$ in the flue gas downstream of the ESP was reduced, which should correspond to reduced submicron emissions. In cases where resistivity cannot be adequately controlled with $\mathrm{SO}_{3}$ alone, a reduction in resistivity with dual conditioning should directly result in lower particulate emissions because of a higher allowable electric field strength. Another primary mechanism of reduced particulate emissions with dual conditioning is the effect on the cohesive properties of the ash. Quantitative measurements show that dual conditioning results in a greater ash tensile strength than $\mathrm{SO}_{3}$ alone. The increased tensile strength of the ash with dual conditioning results in reduced continuous reentrainment and lower rapping puffs. The net result is that, for some coals, significantly lower particulate emissions can be achieved with dual conditioning.

Three of the coals--Big Brown, Hunter Valley, and Hudson bituminous-were difficult to condition with $\mathrm{SO}_{3}$ alone, and significant improvements in ESP performance were achieved with dual conditioning. Pleasant Prairie coal was readily conditioned with $\mathrm{SO}_{3}$ alone, but some reduction in particulate emissions resulted from using dual conditioning.

The EFGC results indicated some improvement in ESP performance over $\mathrm{SO}_{3}$ alone, but much less improvement than was seen with dual conditioning. Nevertheless, further development of the EFGC concept would appear warranted, because changes can be made that will likely enhance the results with EFGC. 


\subsection{OBJECTIVES}

The general objective of the proposed work was to determine the effectiveness of three conditioning methods in controlling fly ash resistivity as a function of temperature. Specific objectives were as follows:

1. Determine the required $\mathrm{SO}_{3}$ injection rates to control ash resistivity for four coals, each at three ESP temperatures.

2. Determine the effectiveness of dual conditioning ( $\mathrm{SO}_{3}$ and ammonia) in controlling fly ash resistivity for four coals as a function of ESP temperature, and compare the effectiveness with $\mathrm{SO}_{3}$ conditioning alone.

3. Evaluate potential EFGC approaches and select, design, construct, and install one or more EFGC systems on the EERC pilot combustor.

4. Determine the effectiveness of EFGC in controlling fly ash resistivity for four coals, each at three ESP temperatures and one $\mathrm{SO}_{3}$ add rate, and compare the effectiveness with $\mathrm{SO}_{3}$ conditioning alone and dual conditioning.

\subsection{SCOPE OF WORK}

The work was divide into 5 tasks. Task 1, Project Management and Preparation, was for the purpose of procuring test coals, preparing the experimental facility for testing, writing reports, and general project management. Task 2, Baseline $\mathrm{SO}_{3}$ Effectiveness, consisted of tests with four coals to evaluate the effectiveness of $\mathrm{SO}_{3}$ in controlling ash resistivity at several temperatures. Task 3, Dual Conditioning, consisted of tests with the same coals and ESP temperatures as in Task 2 for the purpose of comparing the effectiveness of using only $\mathrm{SO}_{3}$ to the effectiveness of $\mathrm{SO}_{3}$ and ammonia used in combination. Task 4, Design and Installation of EFGC, was for the purpose of evaluation, design, construction, and installation of one or more EFGC systems. Task 5, EFGC Testing, consisted of tests with the same four coals 
and ESP temperatures to evaluate the effectiveness of one or more EFGC approaches, compared to the baseline $\mathrm{SO}_{3}$ and dual conditioning results.

A total of 36 one-day runs were originally planned, including 12 runs each for rasks 2, 3, and 5. The one-day runs were planned for seven to ten hours of test time. Each day of testing was with the same coal and one ESP temperature; however, four to five separate tests were completed on most days. A total of 37 one-day runs have been completed, including an initial shakedown run, 22 one-day runs evaluating $\mathrm{SO}_{3}$ and dual conditioning, and 14 one-day runs evaluating EFGC.

The primary independent variables for the study were as follows:

1. Conditioning Method: This was the main purpose of the study and included the three different methods: $\mathrm{SO}_{3}$ alone, dual, and EFGC. In addition, several configurations within each of the three main methods were tested, such as concentrations of conditioning agents. At the end of the test program, several tests were also conducted with ammonia alone.

2. Coal Type: The basoline resistivity and amount of $\mathrm{SO}_{3}$ required to control resistivity are highly dependent on the coal type and corresponding fly ash chemistry. The exact test coals, selected by Wahlco, included Big Brown Texas lignite, Hunter Valley Australia subbituminous, Hudson bituminous, and Pleasant Prairie subbituminous. The original plan was for identical tests to be conducted with each of the four coals, consisting of three main conditioning methods with each coal. Of the 36 runs reported (not including an initial shakedown run), 9 runs were completed with Big Brown, 13 runs with Hunter Valley, 3 runs with Pleasant Prairie, and 11 runs with Hudson bituminous. After consultation with Wahlco personnel, it was decided to complete more tests with the other coals, rather than to complete the original plan with the Pleasant Prairie, because the resistivity of the Pleasant Prairie ash is relatively easy to control with conditioning. 
3. ESP Temperature: Since fly ash resistivity is highly temperature dependent, the amount of $\mathrm{SO}_{3}$ required to control resistivity is also temperature dependent. In addition, mass transfer of the $\mathrm{SO}_{3}$ to the surface of the ash particles is temperature dependent. Therefore, tests were conducted over a range of temperatures typical of cold side ESPS. Three main ESP temperatures, $250^{\circ}, 325^{\circ}$, and $400^{\circ} \mathrm{F}$, were tested. However, several EFGC tests were also conducted with a $275^{\circ} \mathrm{F}$ ESP temperature.

4. $\mathrm{SO}_{3}$ Concentration: The $\mathrm{SO}_{3}$ concentrations were chosen to cover a reasonably wide range. Initial $\mathrm{planned}$ concentrations were 0,5 , 10, 15, and $25 \mathrm{ppm}$, but, after the first test, it was decided to test four concentrations each day to allow longer test times. For most of the remaining tests, $\mathrm{SO}_{3}$ concentrations were $0,5,15$, and $25 \mathrm{ppm}$; however, with Hunter Valley, some tests were conducted at 45 ppm because little effect was noted at lower concentrations.

5. Ammonia Concentration: Ammonia was employed for Task 3 and for several tests at the end of Task 5. Planned concentrations were at ammonia/ $/ \mathrm{SO}_{3}$ ratios of $0.5,1$, and 2 , with one $\mathrm{SO}_{3}$ concentration based on results from Task 2 . Some tests were also conducted with ammonia at a second $\mathrm{SO}_{3}$ concentration. In addition, a secondary variable was the ammonia injection location relative to the $\mathrm{SO}_{3}$ injection. Two tests were conducted to evaluate results with ammonia injection downstream of the $\mathrm{SO}_{3}$ injection. For all other tests with ammonia, the ammonia was injected upstream from the $\mathrm{SO}_{3}$ injection location.

The primary dependent variables were particulate emissions, ESP electrical conditions, ash resistivity, sulfur retention, and ash tensile strength. A velocity of $5 \mathrm{ft} / \mathrm{s}$ corresponding to an SCA of $124 \mathrm{ft}^{2} / 1000 \mathrm{acfm}$ was held constant for all tests.

For each 2-hour test, particulate emissions were monitored continuously as a function of time with both the Aerodynamic Particle Sizer (APS) and Condensation Nucleus Counter (CNC). In addition, EPA Method 5 dust loadings were conducted at the ESP inlet and outlet; however, they were not completed 
for each 2-hour test. Electrical measurements of the ESP included applied electrode voltage, corona current (measured at the plate), supply power, and sparking voltage.

\subsection{FACILITY DESCRIPTION AND PROCEDURES}

\subsection{Coal Preparation}

The four coals, Big Brown Texas 1ignite, Hudson bituminous coal, Pleasant Prairie subbituminous coal, and an Australian Hunter Valley bituminous coal, used for the tests were shipped to EERC by truck. The -4-inch coal was unloaded and stored in 25-ton bunkers. Prior to the tests, the coal was removed from the bunkers, crushed to -8 mesh, and then pulverized to $70 \%-200$ mesh in a hammer mill pulverizer. Sieve analysis was used to document the final size distribution of the coal and to maintain quality control. The pulverized coal was then stored in sealed tote bins until needed for the tests.

\subsection{Particulate Test Combustor (PTC)}

The pilot-scale furnace, known as the particulate test combustor (PTC), is a $550,000-B t u / h r$ pulverized coal-fired unit designed specifically to generate fly ash representative of that produced in a full-scale utility boiler. The combustor is oriented vertically to minimize wall deposits. A refractory lining helps to ensure adequate flame temperature for complete combustion and prevents rapid quenching of the coalescing or condensing fly ash. The mean residence time of a particle in the combustor is approximately three seconds, based on the superficial gas velocity. Combustor efficiencies of $99+\%$, based upon loss on ignition of the fly ash and the co concentration in the flue gas, are evidence that incomplete combustion is not normally a problem with this combustor. However, for the initial Hunter Valley tests, higher than normal carbolı carryover was observed. To correct this, a controlled swirl burner was installed for later tests.

The coal nozzle of the PTC fires axially upward from the bottom of the combustor, and secondary air is introduced concentric to the primary air with 
turbulent mixing. In addition, tertiary air is supplied above the base of the combustor. Coal is introduced to the primary air stream via a screw feeder and ejector. An electric air preheater is used for precise control of the combustion air temperature. Water-jacketed heat-exchangers provide flue gas temperature control to the ESP. An extra piping loop was added to provide additional cooling when necessary. The PTC instrumentation permits system temperatures, pressures, flow rates, flue gas constituent concentrations, and ESP operating data to be monitored continuously and recorded on a data logger. Figure 1 illustrates the PTC schematically.

Flue gas samples were taken at three system sample points: the furnace exit and at the ESP inlet and outlet. After passing through sample conditioners to remove the moisture, the flue gas was analyzed for $\mathrm{O}_{2}, \mathrm{CO}_{2}$, $\mathrm{SO}_{2}, \mathrm{NO}_{x}$, and $\mathrm{CO}$. Except for the $\mathrm{CO}_{2}$ and $\mathrm{CO}$, each constituent was analyzed at both the inlet and outlet of the ESP simultaneously using two analyzers. Flue gas concentration data for all of the instruments were recorded continuously using circle charts. In addition, all data were recorded at set time intervals by the EERC operations personnel. $\mathrm{NO}_{\mathrm{x}}$ was determined using two Thermo Electron chemiluminescent $\mathrm{NO}_{x}$ analyzers. The $\mathrm{O}_{2}, \mathrm{CO}$, and $\mathrm{CO}_{2}$ analyzers are made by Beckman, and the $\mathrm{SO}_{2}$ analyzers are manufactured by DuPont. Each of these analyzers are regularly calibrated and maintained to provide accurate flue gas concentrations.

\subsection{Electrostatic Precipitator (ESP)}

A vertical single-wire tubular ESP was used for these tests. A schematic of the unit is shown in Figure 1 . The stainless steel ESP has a plate length of 79 inches and an inside diameter of 8.3 inches. The gas velocity through the ESP was held constant at $5 \mathrm{ft} / \mathrm{sec}$, giving a specific collection area (SCA) of $124 \mathrm{ft}^{2}$ of plate area/1000 acfm. To keep the gas velocity constant at different ESP operating temperatures, part of the flue gas was bypassed. Table 1 gives the flue gas flow rate through the ESP at the different operating temperatures.

The wire electrode was a $1 / 8$-inch stainless steel wire attached at the top and weighted at the bottom. All connections were electrically isolated using ceramic materials and teflon. Silicone-insulated cable heaters were 


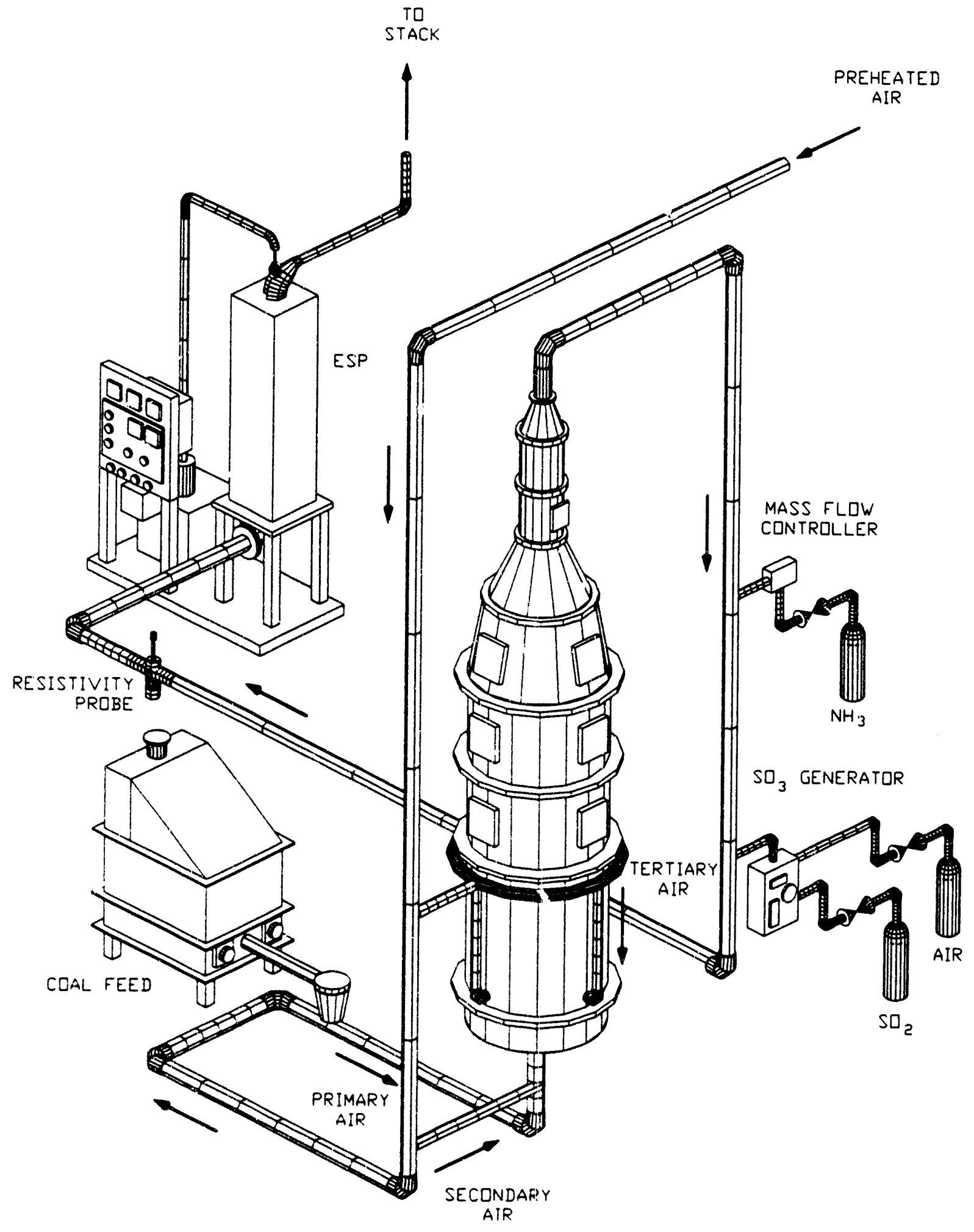

Figure 1. Schematic of combustion systern used for tests (showing PTC and ESP). 
TABLE 1

ESP Flow Rates

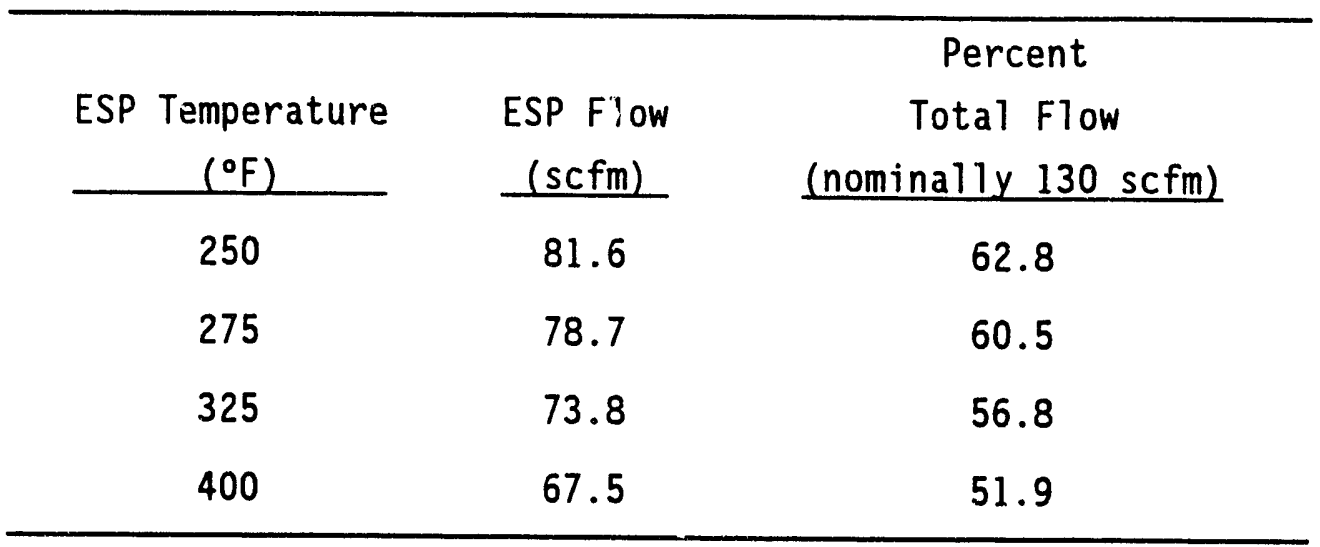

used for initial heatup of the ESP and to maintain the temperature during testing. Following each test, the ESP was cleaned by rapping with two electrically insulated pneumatic hammers, after which the ash hopper was removed, and the ESP manually cleaned using a steel wire brush.

The ESP power supply was manufactured by KiloVolt Corporation and has a range of 0-70 kilovolts at a maximum current of 10 milliamps. The power supply can be operated either in a current or voltage mode. For these tests, a manual voltage mode was used. Unless sparking occurred, the voltage was usually held constant at $50 \mathrm{kV}$. If sparking occurred, then the test was run at the highest voltage that could be maintained without sparking.

Prior to each day of testing, a clean plate voltage-current density (VI) curve was generated. Each test generally lasted 2 hours, after which the ESP was rapped once, and then a VI curve was generated while at the test conditions, beginning at the highest voltage obtainable without sparking. In addition, during the test, the voltage, current, and ESP inlet and outlet temperatures were continuously monitored.

\subsection{Resistivity Measurement}

In situ resistivity measurements were completed with the Wahlco resistivity device installed just upstream of the ESP. The device, shown in Figure 2, consists of a cyclone to collect an ash sample in a cylindrical 


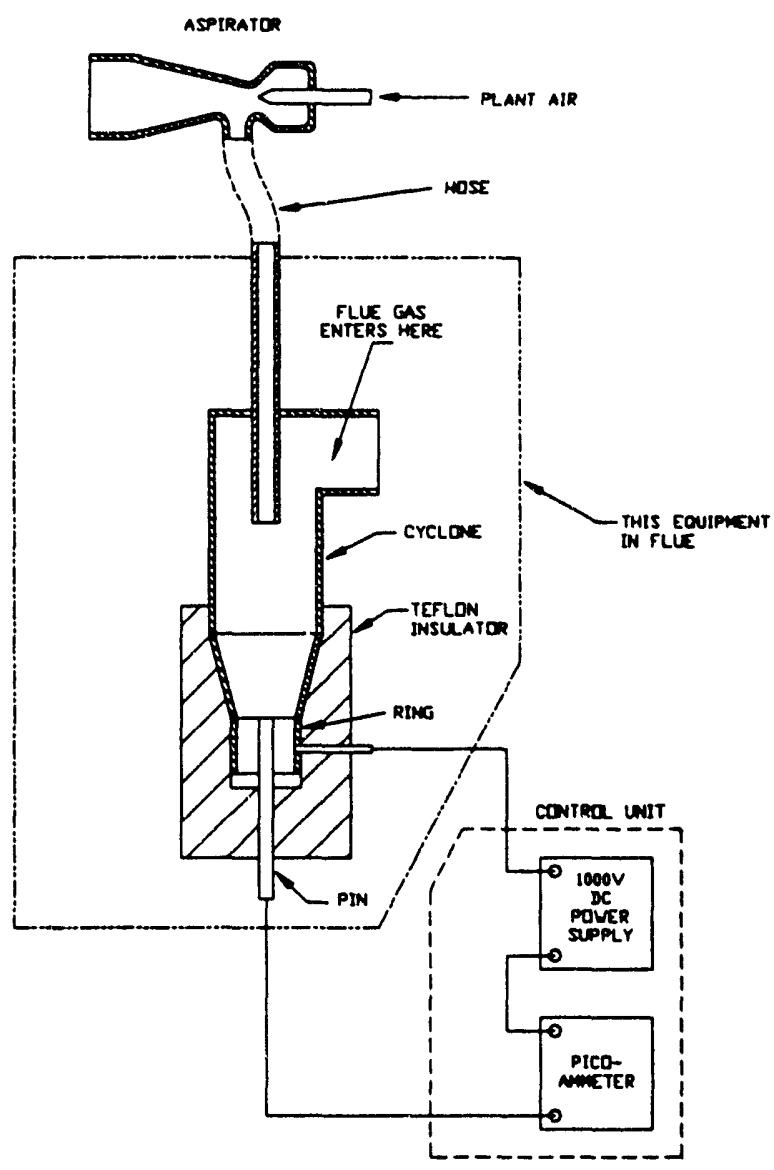

Figure 2. Schematic of resistivity probe.

teflon cup. A high-voltage pin electrode is on the central axis of the cup and is electrically insulated. The second electrode is annular in shape and placed along the wall of the cyclone cup. As ash is collected in the cyclone, it falls into the cup until it fills the space between the two electrodes. A high voltage (1000 volts) is then applied between the pin and outside electrode, and the resistivity of the collected sample is determined by measurement of the current through the collected dust sample.

The dust sample is drawn into the cyclone by using an eductor, driven by pressurized air of at least 60 psig. During sampling, the device is tapped with a hammer to facilitate packing of the dust into the annular space between the electrodes. After several trial runs, the length of time needed to 
collect an adequate sample (usually 15 to 20 minutes) can be determined. The cyclone is fitted with an air purge to clean the cup after a test, so multiple tests can be conducted without removing the cyclone from the duct.

The device is simple to operate and has many advantages, but it also has characteristics that may lead to variable data. The ash will be sizefractionated because the cyclone collects only particles larger than the cyclone cut point. The cut point of a cyclone depends primarily on the size, shape, and gas-sampling rate. The cut point, as a function of flow rate, was not known, but, based on comparisons with other sampling cyclones, would appear to be about 5 micrometers. If the collected ash is somewhat different than the ash collected in the ESP, resistivity measurements may not be correct. Another possible cause of variable measurements is the unknown flow rate through the cyclone which may vary as the eductor becomes plugged with ash. A vacuum gauge was installed between the eductor and cyclone to help maintain a steady flow rate, but periodically the eductor had to be cleaned to maintain an adequate vacuum. Therefore, some variability in cyclone flow rate likely occurred. In general, the sampling with the cyclone is nonisokinetic which may also lead to a nonrepresentative ash sample. Other factors which may affect the resistivity readings include how well the sample packs into the annular space between electrodes and the residence time of the ash in the cyclone cup before a measurement is taken. With dual conditioning, the ash was generally more porous and did not pack as well. The effect of poor packing on the resistivity readings is unknown. Residence time in the cup could also be a factor if the $\mathrm{SO}_{3}$ reacts with alkaline ash constituents. Typically, the sampling time was held constant from test to test to minimize residence time effects. During each test, three or four repeat resistivity measurements were usually taken. In general, resistivity readings were repeatable with reasonable standard deviations. The most difficulty was experienced when the LOI of the ash was high, which resulted in unreasonably low current readings, most likely because of larger amounts of conductive carbon in the ash.

\subsection{Particulate Sampling and Measurement}

Near real-time measurements were conducted with an Aerodynamic Particle Sizer (APS 33), manufactured by TSI Inc., shown schematically in Figure 3. 


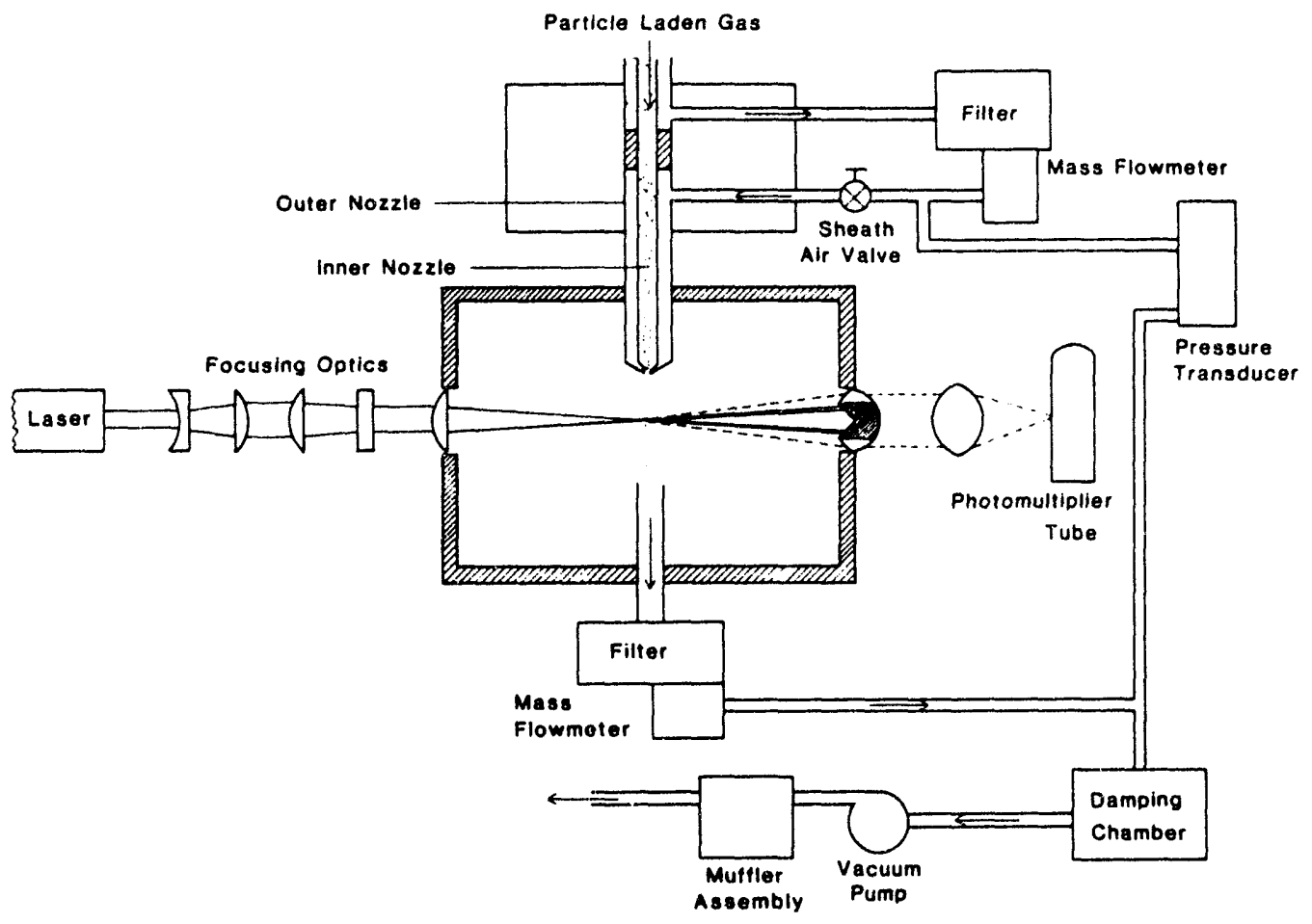

Figure 3. Schematic of Aerodynamic Particle Sizer.

The primary advantages of this system are the high resolution and short sampling time. In the APS, particle-laden air is passed through a thin-walled orifice, and, because of their higher inertia, the particles lag behind the gas. The velocity $\mathrm{lag}$ is uniquely related to the aerodynamic diameter of the particles. Therefore, the aerodynamic diameter of a particle can be determined by measuring the particle velocity as it exits the orifice. To measure the particle velocity, the APS employs a laser which is split into two beams. The light scattered by a particle passing through these beams is collected, and two pulses are emitted, separated by the time taken for the particle to cross the distance between the two beams. From this time interval, which is measured electronically, the aerodynamic diameter is calculated. For most applications, the particle-size distribution for particles ranging in size from $0.5 \mu \mathrm{m}$ to $30 \mu \mathrm{m}$ can be obtained within 20 seconds, giving near real-time measurements.

The APS system includes a computer from which the particle-size distribution can be obtained on the basis of either a number or mass 
concentration. However, rather than looking at emissions of several particle sizes, fine particle emissions can be combined by using a calculated value of respirable mass. The American Council of Governmental and Industrial Hygienists (ACGIH) definition of respirable mass, as given in Table 2, is used. The ACGIH definition is extrapolated and interpolated to calculate the percentage at the midpoint of each channel for that particle size. The respirable mass from all of the channels is added to obtain the total respirable mass. This provides a convenient and effective method of plotting fine particle emissions as a function of time.

To determine the concentration of submicron particles $(0.01$ to $1.0 \mu \mathrm{m})$, a Differential Mobility Particle Sizer (DMPS), also manufactured by TSI Inc., was used. Electrical mobility is a measure of how rapidly an electrically charged particle responds to an electric field. This response time is related to the particle diameter and the number of charges carried by the particle. The DMPS system consists of two primary sections: an electrostatic classifier and a Condensation Nucleus Counter (CNC). The purpose of the electrostatic classifier is to remove a predictable fraction of the particles within a narrow size range to pass these to the CNC, where the particles are counted. Aerosols are initially passed through a Krypton-85 neutralizer, which exposes the particles to high levels of both positive and negative ions. The particles acquire a charge distribution that is described by the Boltzmann equilibrium charge distribution equation. A voltage is applied to the electrostatic classifier which maintains a center electrode at a precise negative potential which attracts the positively charged particles. Only those particles with a narrow predictable mobility range pass through a slit near the bottom of the center electrode.

A small air flow ( 0.3 liters/min) carries these particles to the CNC. The CNC measures particle number concentration by using the light-scattering technique. Since the dry submicron particles are too small to be easily detected by light scattering, the particles pass through an alcohol vapor which condenses on the particle, forming a droplet. Each droplet is large enough to scatter a detectable amount of light when it passes through a light beam. The droplet size is nearly independent of the size of the original particle over a wide range of particle sizes, so the light scattered is a function of number concentration only, not of size distribution. This 
TABLE 2

ACGIH Respirable Mass Definition

\begin{tabular}{cc}
\hline $\begin{array}{c}\text { Aerodynamic Diameter } \\
\text { (micrometers) }\end{array}$ & $\begin{array}{c}\text { Respirable Mass Fraction } \\
\text { (percent) }\end{array}$ \\
2.0 & 90 \\
2.5 & 75 \\
3.5 & 50 \\
5.0 & 25 \\
10.0 & 0 \\
\hline
\end{tabular}

instrument was also used independently of the electrostatic classifier as a continuous real-time monitor of the number of fine particles present in the flue gas. An impactor, prior to the gas stream entering the CNC, removed the larger particles, giving the number concentration of submicron particles.

For both the APS 33 and DMPS particle analyzers, a dilution system was employed. Dilution of the flue gas is necessary to prevent moisture condensation in the sensors and to reduce particle concentration, which, if too high, may exceed the maximum output of the CNC and may cause coincidence error in the APS. To be effective, the dilution system must provide a constant flow of aerosol through the nozzle, regardless of the pressure in the stack. A schematic of the particulate sampling system with diluter is shown in Figure 4. The APS pump draws the sample into the diluter volume. A second pump is used to draw off a portion of the flue gas to recycle it back as dilution gas after it has been cleaned and the moisture removed. As is shown in the figure, both the APS and DMPS were operated simultaneously using this dilution system. The maximum dilution that can be obtained with this system is about 10 to 1 ; if higher dilutions are needed, as was the case for these tests, the system is operated in conjunction with a Model 3302 TSI diluter. With both systems operating, dilutions up to 1000 to 1 can be obtained.

In addition to the DMPS and APS, a modified EPA Method 5 was used to obtain dust loadings at the inlet and outlet of the ESP to determine the overall ESP particulate collection efficiency. The particle-size distribution of the bulk fly ash was determined using a Coulter Counter. 


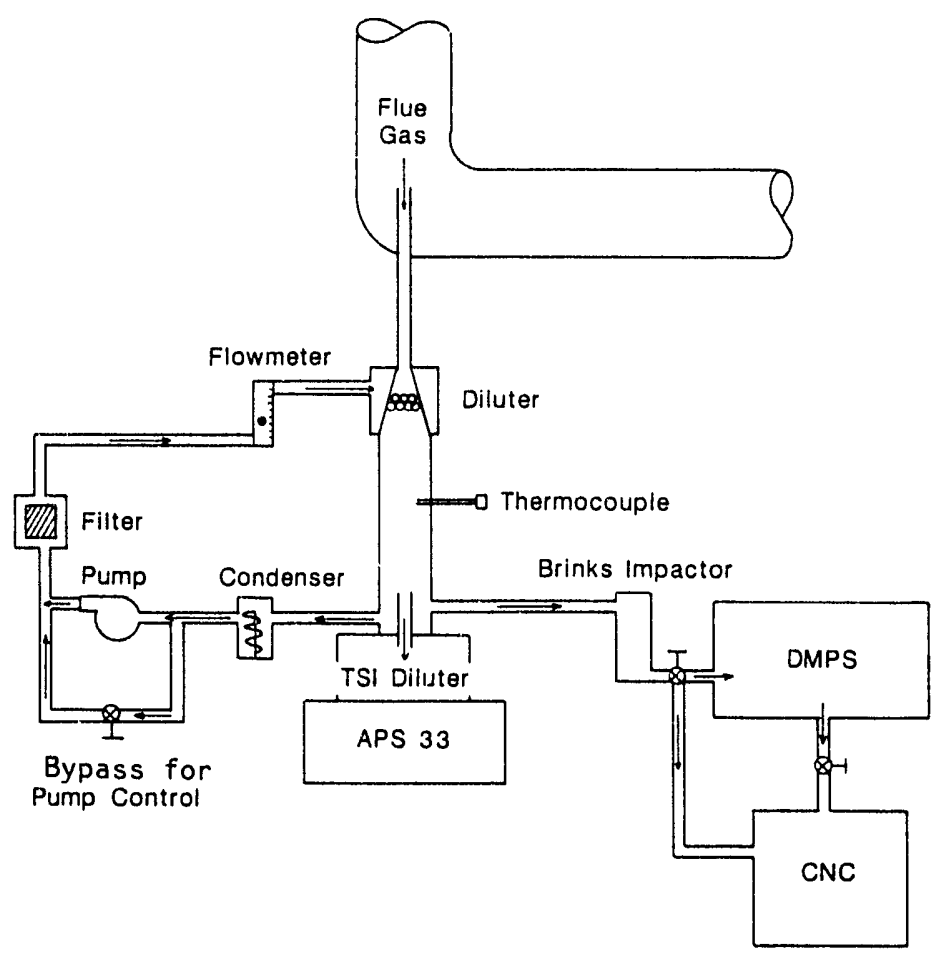

Figure 4. Schematic of particle-sampling system (APS 33, DMPS, and dilution system).

The outlet particulate concentration was recorded every 10 minutes during a test with both the APS and CNC. In addition, one DMPS measurement requiring approximately a 25 -minute sample time was taken during each 2-hour test period. During the remainder of the test period, the CNC wis operated on a continuous basis. Two inlet and two outlet EPA Method 5 dust loadings were completed each day of testing. To determine the particulate concentration during the rapping puff, an APS sample was taken immediately following the rap. While data were collected to generate the VI curve, a respirable mass value was also obtained, at each voltage setting, using the APS.

\subsection{Sulfur Trioxide and Ammonia Injection}

To provide $\mathrm{SO}_{3}$, a catalytic $\mathrm{SO}_{3}$ generator, shown in Figure 5 , was used. Air and $\mathrm{SO}_{2}$ are passed through a vanadium-catalyst-filled reactor that is heated to $850^{\circ} \mathrm{F}$, thereby oxidizing the $\mathrm{SO}_{2}$ to $\mathrm{SO}_{3}$. Conversion was measured using $\mathrm{SO}_{2}$ analyzers and was determined to be $70 \% \pm 10 \%$. To help verify the 


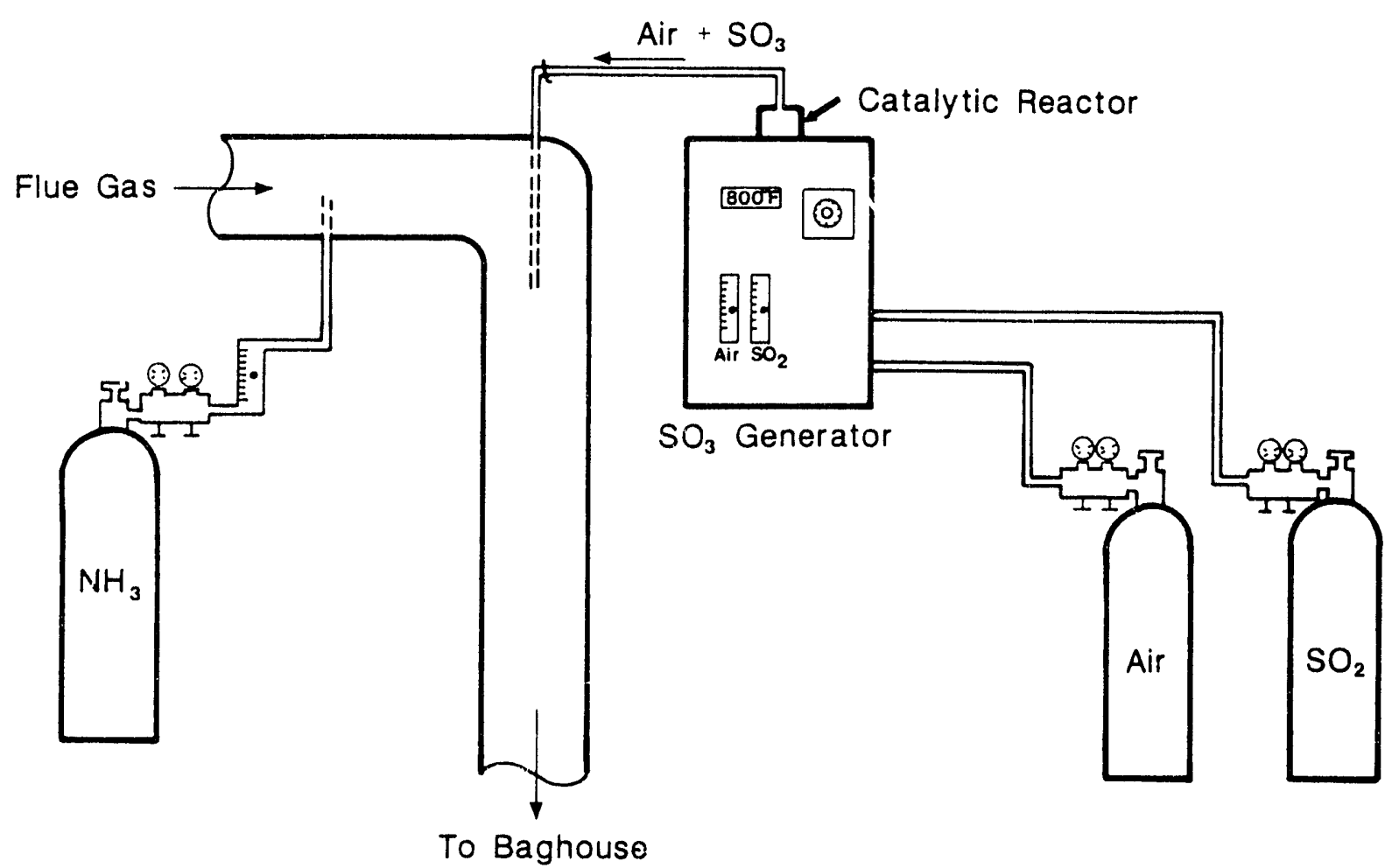

Figure 5. Sulfur trioxide and ammonia injection system using $\mathrm{SO}_{3}$ generator.

actual $\mathrm{SO}_{3}$ concentration in the flue gas, the selective condensation $\mathrm{SO}_{3}$ measurement method was used during one of the tests. Two $\mathrm{SO}_{3}$ samples were collected with the $\mathrm{SO}_{3}$ generator set to provide 15- $\mathrm{ppm} \mathrm{SO}_{3}$ to the flue gas. The results from these two samples showed that the $\mathrm{SO}_{3}$ concentrations in the flue gas were 14 and $19 \mathrm{ppm}$, respectively. These values are within the combined error of the measurement method and the $\mathrm{SO}_{3}$ generator.

Ammonia (from a tank of anhydrous ammonia) was injected upstream of the $\mathrm{SO}_{3}$, with the flow rate to the ESP controlled using a mass flow controller calibrated for ammonia. The relative location of the ammonia and $\mathrm{SO}_{3}$ injection points is shown schematically in Figure 1 . The $\mathrm{SO}_{3}$ injection point was 20 feet and the ammonia 31 feet from the inlet of the ESP. This gives residence times, prior to reaching the ESP, of 0.6 seconds and 1.0 second, respectively.

One concern with ammonia injection is the amount of ammonia that is not transferred to the fly ash and exits the stack as ammonia slip. The ammonia 
exiting the ESP was measured by extracting a known quantity of flue gas through impingers which contained $0.1 \mathrm{~N}$ sulfuric acid. The ammonia in the extracted flue gas is absorbed by the sulfuric acid. The solution was diluted to a known volume and the ammonia concentration measured using a selective ion electrode. To ensure that all the ammonium ions in the solution were converted to ammonia, the $\mathrm{pH}$ of the solution was increased to 11 using $6 \mathrm{~N}$ sodium hydroxide. Multiple ammonia slip measurements were taken, but almost all indicated less than $1 \mathrm{ppm}$ of ammonia slip. The accuracy of the method is probably no better than $\pm 2 \mathrm{ppm}$. It should be recognized that the method detects only gas-phase ammonia and does not account for any ammonium sulfate or bisulfate in particulate phase.

\subsection{Cohesive Tensile Strength Measurements}

A Cohetester, manufactured by Hosokawa Micron International, was used to quantify the cohesive properties of the ESP fly ash. The Cohetester provides a direct measurement of the tensile strength of the fly ash as a function of compaction pressure. These data can be used to optimize conditioning agent concentrations for improved ESP performance and, possibly, to predict the ESP collection efficiency for a particular fly ash.

A schematic of the Cohetester is shown in Figure 6 . It consists of a horizontal split cell $5 \mathrm{~cm}$ in diameter, with one half of the cell movable and the other half fixed. The cell is suspended so that it can be pulled apart with minimal force when no sample is in the cell, thus minimizing any error due to external frictional forces. When the strain motor is turned on, the powder bed is pulled and extended in the same direction as the tensile force. The displacement (extension) of the powder bed and tensile stress are plotted on an $x-y$ recorder. The maximum value on the vertical axis is the cohesive tensile strength of the powder in grams of force per square centimeter $\left(g_{f} / \mathrm{cm}^{2}\right)$ at that compaction force.

The following procedure was used for making a tensile strength measurement with the Cohetester. Because relative humidity significantly affects the cohesive properties of fly ash, the samples are prepared by sifting them through a 60-mesh-screen and storing them overnight in a humidity-controlled chamber at $10 \%$ relative humidity. A weighed amount of sample (based on 


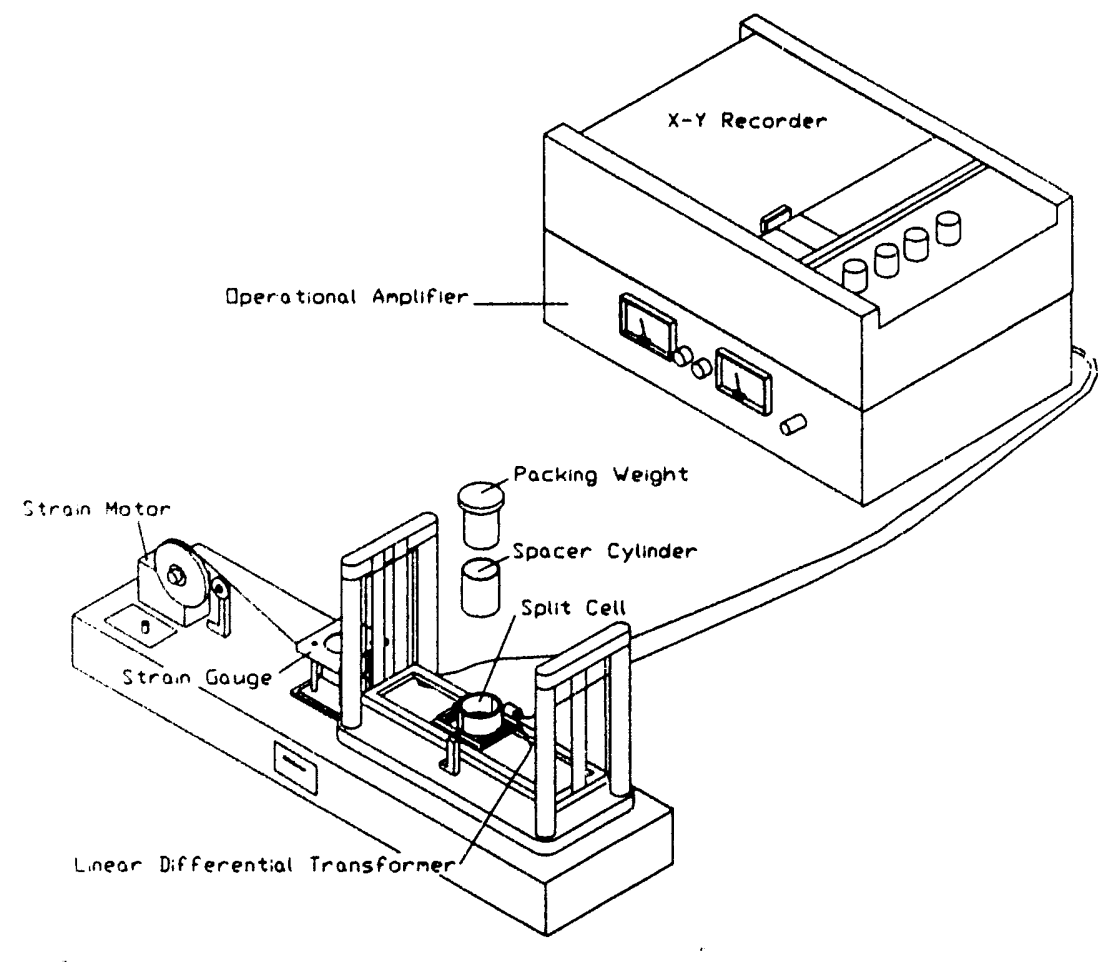

Figure 6. Schematic of Cohetester.

experience) is carefully poured into the cell and compacted by guiding the packing weight carefully into the extension tube. Additional weights (up to amaximum total compaction weight of approximately $5 \mathrm{~kg}$ ) are placed on the first weight until the lip of the packing weight rests on the cell extension tube. With the sample properly compacted, the weights and cell extension tube are removed. After zeroing the recorder pen and releasing the securing knob, the strain motor is turned on, and the fracture curve is recorded.

Compaction weights over a range from 320 to 5000 grams were used to compress the samples, which corresponds to compaction pressures of 16 to 255 $g_{f} / \mathrm{cm}^{2}$. The upper value of the compaction weight is 1 imited by the structural integrity of the suspended cell. It is necessary to compact the ash so that it will break along a plane when it is pulled, giving a valid tensile strength measurement. The range in porosity for a given fly ash sample is determined by the range in compaction force, which is the same for each sample. For a particular ash sample, at least five tensile strength measurements over the full range of compaction force are required to plot the tensile strength as a function of porosity. The percent porosity of the powder cake for each test 
was determined from the particle density (measured by helium-air pycnometry), the sample weight, and the cell volume occupied by the compacted powder (supplied by the manufacturer).

\subsection{Sample Analyses}

To provide documentation as to the type of coals used in these tests, ultimate and proximate analyses were completed for each coal. Carbon, hydrogen, nitrogen, and sulfur values were obtained using a Leco CHN analyzer and a Leco sulfur analyzer. A higher heating value was obtained for each coal using a bomb calorimeter (ASTM Method D2015-77). In addition, inorganic constituents of the coal were determined using $x$-ray fluorescence analysis (XRFA), with the coal ash samples prepared by ASTM Method D3174-82. To determine carbon carryover, since several of the coals seemed to have carbon in the ash, loss on ignition (ASTM Method D3174-82) was performed on several fly ash samples.

Sulfur retention on the fly ash was determined using a Leco SC132 IR sulfur analyzer. Using this data along with the $\mathrm{SO}_{3}$ injection rates and other process parameters, the relative effectiveness of the $\mathrm{SO}_{3}$ transfer to the fly ash surface was determined.

To determine the particle-size distribution of the pulverized coal, as well as to maintain quality control of the pulverizing system, a standard ASTM sieve analyses was completed for each coal. Sieve sizes used for the test were 100 mesh, 140 mesh, 170 mesh, 200 mesh, 270 mesh, and 325 mesh.

Surface area of the fly ash was measured using a BET surface area analyzer for several of the Hunter Valley tests. This was to help quantify the nonspherical characteristics of the Hunter Valley fly ash. As a comparison, the surface area of one of the Big Brown fly ash samples (highly spherical) was also measured. Helium-air pycnometry was used to determine the density of the fly ash from each of the coals. 


\subsection{RESULTS AND DISCUSSION}

Coal and ash analyses are given in Tables $A-1$ and $A-2$ in the Appendix. A summary of all of the primary results from each test is given in Tables A-3 and A-4 in the Appendix. Run numbers are sequential numbers assigned to the PTC for each day of operation. Test numbers are sequential numbers issigned to individual tests within each day or run. Most runs included four tests with different test parameters. Results are identified by both run number and test number throughout the text and in the Appendix. The Appendix also contains a total of 177 figures, which include results from all of the tests.

\subsection{Big Brown: $\mathrm{SO}_{3}$ and Dual Conditioning (Runs 344-348)}

Results for Big Brown tests with $\mathrm{SO}_{3}$ and dual conditioning are given in summary tables in the Appendix and in Figures $A-1.1$ through $A-1.46$. Note that for these first runs, initial operating voltage was usually set at $54 \mathrm{kV}$, but several tests were run at $60 \mathrm{kV}$. For each run, respirable mass emissions are plotted as a function of time with and without the rapping puff, as a function of voltage, and as a function of current density. Respirable mass measurements as a function of voltage and current density were taken prior to rapping at the end of each test after two hours of dust accumulation on the plate.

Runs 344,345 , and 346 were with $\mathrm{SO}_{3}$ conditioning alone at respertive ESP temperatures of $325^{\circ}, 400^{\circ}$, and $250^{\circ} \mathrm{F}$. Five tests were conducted during Run 344 each for 1.5 hours. However, for subsequent runs, the number of tests was reduced to four and the test time increased to two hours. The primary indicators of the effect of conditioning are emissions as a function of time, emissions as a function of voltage, emissions as a function of current density, resistivity as a function of $\mathrm{SO}_{3}$ injection rate, and sulfur retention of the ESP hopper ash as a function of $\mathrm{SO}_{3}$ injection rate. For Run 344 at $325^{\circ} \mathrm{F}$, Figures $A-1.1$ through $A-1.4$ show that emissions drop with increasing $\mathrm{SO}_{3}$, except there is little difference between 15 and $25 \mathrm{ppm}$ of $\mathrm{SO}_{3}$. Resistivity (Figure A-1.32) and sulfur retention (Figure A-1.34) results, however, indicate that somewhat more $\mathrm{SO}_{3}$ was transferred to the fly ash at $25 \mathrm{ppm}$. For Run 345 at $400^{\circ} \mathrm{F}$, respirable mass as a function of time for the three tests with $\mathrm{SO}_{3}$ was fairly constant, but looking at emissions as a 
function of voltage or current density indicates emissions decreased with increasing $\mathrm{SO}_{3}$ (Figures $\mathrm{A}-1.5$ through $\mathrm{A}-1.9$ ). Again, the resistivity and sulfur retention graphs suggest $\mathrm{SO}_{3}$ transfer increases as a function of the $\mathrm{SO}_{3}$ injection rate. However, submicron mass increased significantly at 15 and $25 \mathrm{ppm}$, indicating substantial $\mathrm{SO}_{3}$ slip at this temperature. For Run 346 at $250^{\circ} \mathrm{F}$, emissions as a function of time did not appear to depend highly on the amount of $\mathrm{SO}_{3}$; however, the baseline and $5 \mathrm{ppm}$ tests were conducted at $60 \mathrm{kV}$, compared to $54 \mathrm{kV}$ for the other tests. Looking at emissions as a function of voltage clearly shows decreasing emissions with increasing $\mathrm{SO}_{3}$ (Figures $\mathrm{A}-1.10$ through A-1.15). Resistivity and sulfur retention graphs also confirm this result. Comparing sulfur retention for the three temperatures suggests that $\mathrm{SO}_{3}$ transfer at $250^{\circ} \mathrm{F}$ is better than transfer at $325^{\circ} \mathrm{F}$, which, in turn, is better than transfer at $400^{\circ} \mathrm{F}$. Submicron emissions indicate substantial $\mathrm{SO}_{3}$ slip at $400^{\circ} \mathrm{F}$ and very little slip at $250^{\circ} \mathrm{F}$. Only one data point was available at $325^{\circ} \mathrm{F}$, which indicates little $\mathrm{SO}_{3}$ slip at $15 \mathrm{ppm}$, compared to $400^{\circ} \mathrm{F}$.

Comparing the respirable mass emissions and the EPA Method 5 results for Runs 344-346 (see summary tables) raises a question of the consistency of the data. For example, the collection efficiencies for Tests 3 and 4 of Run 346 at $250^{\circ} \mathrm{F}$ are much lower than for the other tests. The suspected reason is that the resistivity device was rapped during these dust loadings, causing some dust to be dislodged and increasing the dust loading. For later tests, rapping the resistivity device was avoided during outlet dust loading measurements, and this problem was apparently corrected. Another possible cause of inconsistent dust-loading measurements was that the ESP was not handcleaned for these early tests. If the ESP rapping did not sufficiently remove dust deposits, the buildup on the plate may have been greater at the end of Test 4 compared to the end of Test 1 . This is the apparent reason why the minimum respirable mass was lower for Run 344 at $325^{\circ} \mathrm{F}$ compared to Run 346 at $250^{\circ} \mathrm{F}$. The minimum respirable mass readings were taken at $70 \mathrm{kV}$ for Run 344 compared to $54 \mathrm{kV}$ for Run 346 because of sparking limitations. This raises the question, "Why was there sparking at a lower voltage at $250^{\circ} \mathrm{F}$, when the resistivity was also lower at $250^{\circ}$ than at $325^{\circ} \mathrm{F}$ ?" An explanation is that there was greater dust accumulation at $250^{\circ} \mathrm{F}$. In both cases, dust was removed from the plates only by normal rapping, but the tensile strength curves (Figures $A-1.37$ through $A-1.46$ ) show that, at $250^{\circ} \mathrm{F}$, tensile strength was much 
greater. Therefore, very likely, less dust was removed at $250^{\circ} \mathrm{F}$ by rapping, which explains why the sparking voltage was also lower than for the $325^{\circ} \mathrm{F}$ test. A more valid comparison is the respirable mass at a constant voltage (Figures $A-1.3$ and $A-1.13$ ) of $50 \mathrm{kV}$, which shows that emissions are lower at $250^{\circ} \mathrm{F}$, as would be expected.

A question also exists as to the basis for lower emissions with increasing $\mathrm{SO}_{3}$ when the voltage-current curves for Runs 344-346 (Figures A1.27 through A-1.31) show higher current at a given voltage for the baseline tests than tests with $\mathrm{SO}_{3}$. This implies that the added $\mathrm{SO}_{3}$ produced a spacecharge effect to suppress corona current. For example, the graphs of respirable mass as a function of voltage clearly show lower emissions with increasing $\mathrm{SO}_{3}$. This occurred even though the current density was highest without any $\mathrm{SO}_{3}$. These results would appear to be inconsistent. However, looking at respirable mass as a function of current density (Figures A-1.4, A1.9, and A-1.15) clearly shows that, at constant current density, emissions are lower when $\mathrm{SO}_{3}$ is used. If the particle-size distribution and cohesive properties remain constant and there is no back corona, emissions should be determined primarily by current density and should be constant at constant current density. Lower emissions at constant current density when $\mathrm{SO}_{3}$ is used imply that either there was a shift in particle-size distribution or in cohesive properties. The tensile strength graphs (Figures A-1.37 through A1.39) show that there is a shift in the tensile strength with increasing $\mathrm{SO}_{3}$ for all three temperatures. The greatest shift occurs at $250^{\circ} \mathrm{F}$, which is consistent with the sulfur retention data. Therefore, an explanation for lowest emissions at constant currert density is that the ash was more cohesive at higher $\mathrm{SO}_{3}$ concentrations and less subject to reentrainment. Small shifts in the particle-size distribution, due to agglomeration in the duct between the injection location and the ESP, may also explain why emissions were lower at higher $\mathrm{SO}_{3}$. However, in situ particle-size distribution data are not available.

Results with both ammonia and $\mathrm{SO}_{3}$ injection from Runs 347 and 348 show that emissions were significantly lower with dual conditioning compared to $\mathrm{SO}_{3}$ alone. Lower emissions with dual conditioning are evident from the graphs of respirable mass vs. time, voltage, and current density, as well as from the EPA Method 5 measurements (Figure A-1.16 through A-1.25). In addition, the 
rapping puffs are significantly lower with dual conditioning (Figure A-1.26). Again, the reduction in enissions when ammonia is added appears to be the result of a significant shift in the tensile strength which may be an indicator of reduced reentrainment. Resistivity results indicate that dual conditioning is more effective at reducing resistivity than $\mathrm{SO}_{3}$ alone at $325^{\circ}$ and at $400^{\circ} \mathrm{F}$. At both temperatures, resistivity was almost one order of magnitude lower with dual conditioning compared to $15 \mathrm{ppm}$ of $\mathrm{SO}_{3}$ alone (Figure $A-1.33)$. Looking at sulfur retention as a function of ammonia injection rate at a constant $15 \mathrm{ppm} \mathrm{SO}$ (Figure A-1.35) shows that ammonia enhances $\mathrm{SO}_{3}$ transfer to the fly ash. Concerning the amount of required ammonia, at $325^{\circ} \mathrm{F}$ there was little difference between ammonia concentrations of $30 \mathrm{ppm}$ and 15 $\mathrm{ppm}$, both at $15 \mathrm{ppm} \mathrm{SO}$. However, the data at $400^{\circ} \mathrm{F}$ indicate that lower emissions can be achieved at $30 \mathrm{ppm}$ of ammonia, compared to $15 \mathrm{ppm}$ or $7.5 \mathrm{ppm}$ of ammonia. For all tests with dual conditioning, emissions were substantially reduced compared to $\mathrm{SO}_{3}$ alone.

Some explanation is necessary to understand the operating current and sparking voltage data for Runs 347 and 348 . For Run 347 at $325^{\circ} \mathrm{F}$, the highest operating current was with $\mathrm{SO}_{3}$ alone, which is confirmed by the voltagecurrent curve in Figure A-1.30. However, for Run 348 at $400^{\circ} \mathrm{F}$, operating current was lowest with $\mathrm{SO}_{3}$ alone. Lowest current at constant voltage should occur when corona current suppression is greatest, which is expected to occur when the largest numbers of submicron particles are present. The DMPS number concentration data confirm that the greatest submicron particle concentration occurred with $\mathrm{SO}_{3}$ alone at $400^{\circ} \mathrm{F}$ and with dual conditioning at $325^{\circ} \mathrm{F}$. A possible explanation is that, at $400^{\circ} \mathrm{F}$, much of the injected $\mathrm{SO}_{3}$ remains in the flue gas as fine particles, providing greater current suppression. However, at $325^{\circ} \mathrm{F}$, the greater corona current suppression apparently occurs with dual conditioning. These data provide strong evidence that reduced emissions with dual conditioning are the result of changed cohesive properties, because, whether current density was highest with $\mathrm{SO}_{3}$ alone (Run 347 ) or lowest with $\mathrm{SO}_{3}$ alone (Run 348 ), particulate emissions were much lower with dual conditioning.

The sparking voltage data in Runs 347 and 348 are inconsistent with the resistivity data. Resistivity data (Figure A-1.33) show that the addition of ammonia to $15 \mathrm{ppm}$ of $\mathrm{SO}_{3}$ lowered resistivity by almost an order of magnitude, 
but sparking voltage was higher at the higher resistivities. The explanation is that the $\mathrm{SO}_{3}$ alone tests were the first tests each day. Dust accumuiation for these tests was only from the first test. Even though the plate was rapped between tests, some dust remained and contributed to the total dust layer for subsequent tests. Poor cleaning by rapping was especially evident when dual conditioning was employed, which is consistent with the increased tensile strength. Therefore, even though resistivity may have been less with dual conditioning, because of increased dust accumulation, sparking occurred at a lower voltage. The same explanation applies to Run 346 at $250^{\circ} \mathrm{F}$. Lower sparking voltage likely occurred when resistivity was lowest because of increased dust accumulation in Tater tests.

In summary, dual conditioning with Big Brown ash results in much lower particulate emissions than $\mathrm{SO}_{3}$ injection alone. The reduced emissions are the result of several effects. At constant voltage or current density, emissions are likely reduced because of a shift in the tensile strength curve which leads to reduced continuous reentrainment. The significant reduction in rapping reentrainment gives dual conditioning an even greater advantage. Furthermore, lower resistivity with dual conditioning should allow operation at higher voltages leading to even lower particulate emissions.

$\mathrm{SO}_{3}$ injection alone is somewhat effective in controlling resistivity for all three temperatures, since resistivity decreased with increasing $\mathrm{SO}_{3}$ injection rate for all three cases. Resistivity and sulfur retention data show that $\mathrm{SO}_{3}$ alone is most effective at $250^{\circ} \mathrm{F}$, which would be expected.

Cohetester results provide a quantitative determination of the effects of conditioning on the cohesive properties of fly ash. Tests show that $\mathrm{SO}_{3}$ alone increases tensile strength at constant porosity. Therefore, we can conclude that $\mathrm{SO}_{3}$ reduces emissions by reducing reentrainment in addition to lowering resistivity. Dual conditioning results in a greater increase in tensile strength than $\mathrm{SO}_{3}$ alone, which likely leads to still lower emissions because of reduced reentrainment. 
5.2 Hunter Valley: $\mathrm{SO}_{3}$ and Dual Conditioning (Runs 349-354, 364, 365)

In contrast to the Big Brown tests, difficulties were encountered with the Hunter Valley coal. These difficulties resulted in deviation from the original test plan. For example, no tests were conducted at a temperature of $400^{\circ} \mathrm{F}$, because, even at lower temperatures, resistivity could not be effectively controlled. After consultation with Wahlco, a decision was made to perform additional tests at the lower temperatures, rather than the original planned $400^{\circ} \mathrm{F}$ tests. Including the additional tests, a total of eight runs were completed with Hunter Valley coal investigating $\mathrm{SO}_{3}$ and dual conditioning at $250^{\circ} \mathrm{F}$ and $325^{\circ} \mathrm{F}$.

A somewhat surprising result was high loss on ignition (LOI) of the ESP ash, indicating high carbon in the ash. Past experience with combustion of numerous coals with this combustor has not indicated poor carbon burnout. The high LOI of the ash apparently did not significantly affect precipitator performance, but it did make resistivity measurement difficult. Initial LOI of the ESP hopper ash was approximately $10 \%$, but LOI of the resistivity cyclone catch was in the range of $18 \%$ to $29 \%$. Under these high LOI conditions, the resistivity current readings were typically about $1 \mathrm{~mA}$, which corresponds to a resistivity between $10^{7}$ and $10^{8} \mathrm{ohm}-\mathrm{cm}$, even though sparking and back corona were occurring. The low resistivity readings were attributed to the high carbon content of the ash collected in the resistivity cyclone. A cyclone such as the resistivity cyclone is a size-fractionating device which will collect primarily particles larger than $5 \mu \mathrm{m}$. Since the unburned carbon is mainly present as larger particles, the higher LOI of the resistivity cyclone ash is not surprising. For Run 365, an adjustable swirl burner was installed on the combustor, which resulted in an LOI of only 3.45\%. When particulate emission results were compared to previous results with the same test parameters, little difference was noted. Therefore, the initial ESP tests with high LOI ash appear to be valid.

Another unexpected result was the physical consistency of the Hunter Valley fly ash. The ash was light and fluffy and did not exhibit typical spherical ash morphology. A comparison of SEM micrographs between the Big Brown ash and the Hunter Valley ash at three different magnifications is shown in Figures 7-9. The Big Brown particles are primarily spherical over a wide 
particle-size range, indicating the particles were in a liquid state at some time during combustion. In contrast, the SEM micrographs show that some of the Hunter Valley particles are spherical, but many are irregular in shape. This indicates that part of the ash did not reach a liquid state during combustion and particle formation. Ash fusion measurements were not completed on these samples, but ash fusion temperatures for this coal ash apparently can be as high as $2800^{\circ} \mathrm{F}$ (based on discussions with Wahlco personnel). Ash morphology such as this has never occurred with this combustor with previously tested coals. One short test was conducted at the end of Run 353 to see if the combustor could be operated hot enough to change the morphology of the fly ash. The coal feed rate and air flow were increased so that the furnace exit temperature reached $2000^{\circ} \mathrm{F}$, compared to a typical exit temperature of $1700^{\circ} \mathrm{F}$ with the large combustor bottom. Nevertheless, the LOI increased at the higher exit temperature (possibly due to lower residence time), and there was no change in the ash morphology. For the test with the adjustable swirl burner, a smaller bottom was used, and the furnace exit temperature was about $1850^{\circ} \mathrm{F}$. With the swirl burner, a very hot, intense flame could be seen through the furnace sight ports, indicating good combustion, and the LOI was only 3.45\%. However, there was still no change in ash morphology. There were no other obvious changes in the combustor that could have been implemented to increase the temperature of the ash. Whether the somewhat abnormal ash morphology affected ESP performance is not known.

Another result of the fluffy ash was extensive deposition and buildup on the piping walls between the furnace and the ESP. This made control of temperature at the inlet of the ESP difficult. For Run 365, an extra piping loop was installed on the PTC to help control the ESP inlet temperature at $250^{\circ} \mathrm{F}$. The result was a very steady ESP temperature. Comparing results of Run 365 with previous tests with the same parameters, however, showed only minor differences, implying that the earlier results are valid despite some temperature variations.

Five runs were completed at an ESP temperature of $325^{\circ} \mathrm{F}$ (Runs $349-352$ and 364). The three primary indicators of the effectiveness of conditioning for these initial Hunter Valley tests were particulate emissions, whether back corona could be avoided, and whether constant voltage could be maintained. Initial starting voltage for the first baseline test in Run 349 was $50 \mathrm{kV}$, 

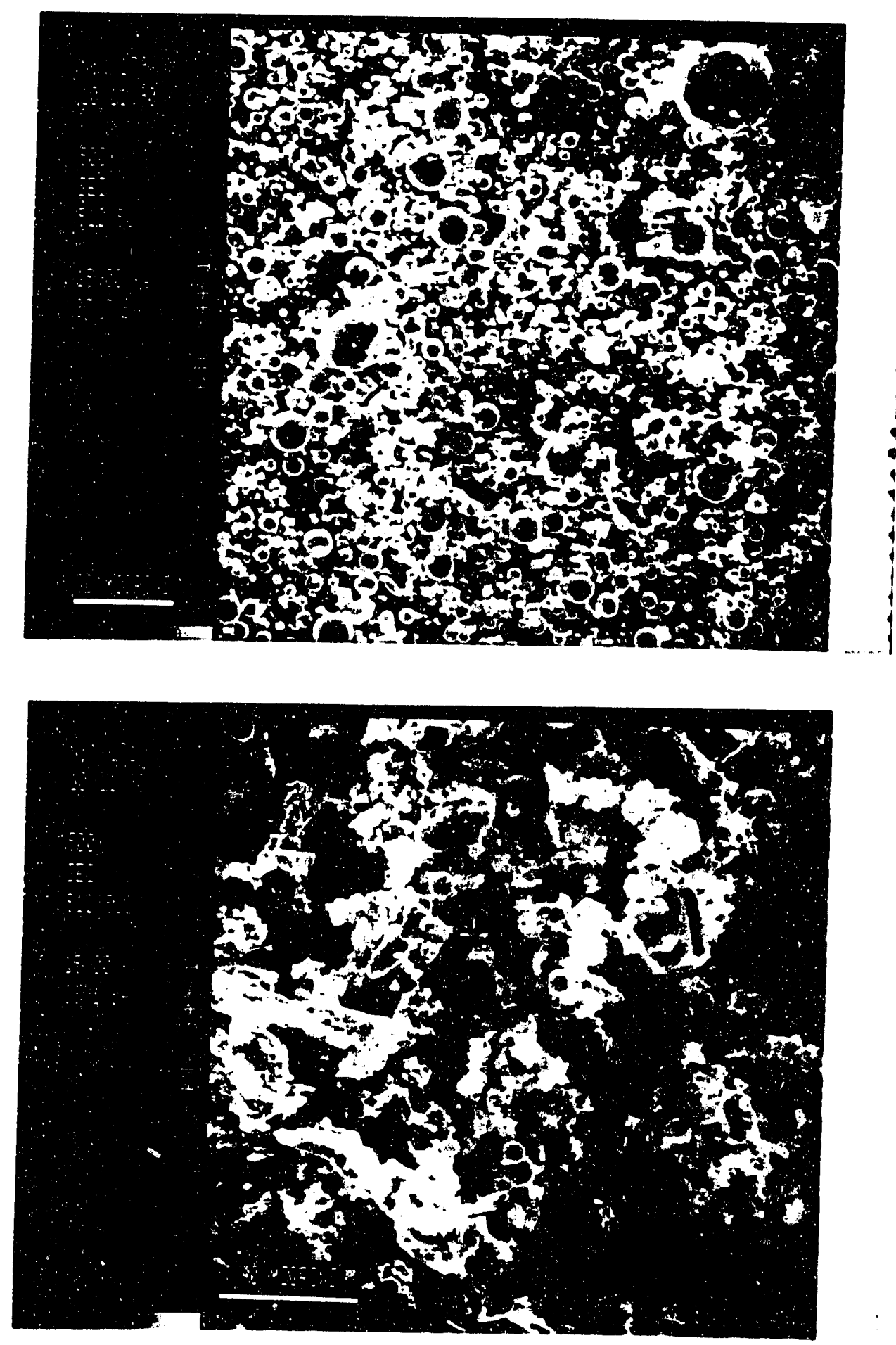

Figure 7. Comparison of fly ash morphology between Big Brown fly ash from Run 344 (top) and Hunter Valley fly ash from Run 349 (bottom) at $500 x$ magnification. 

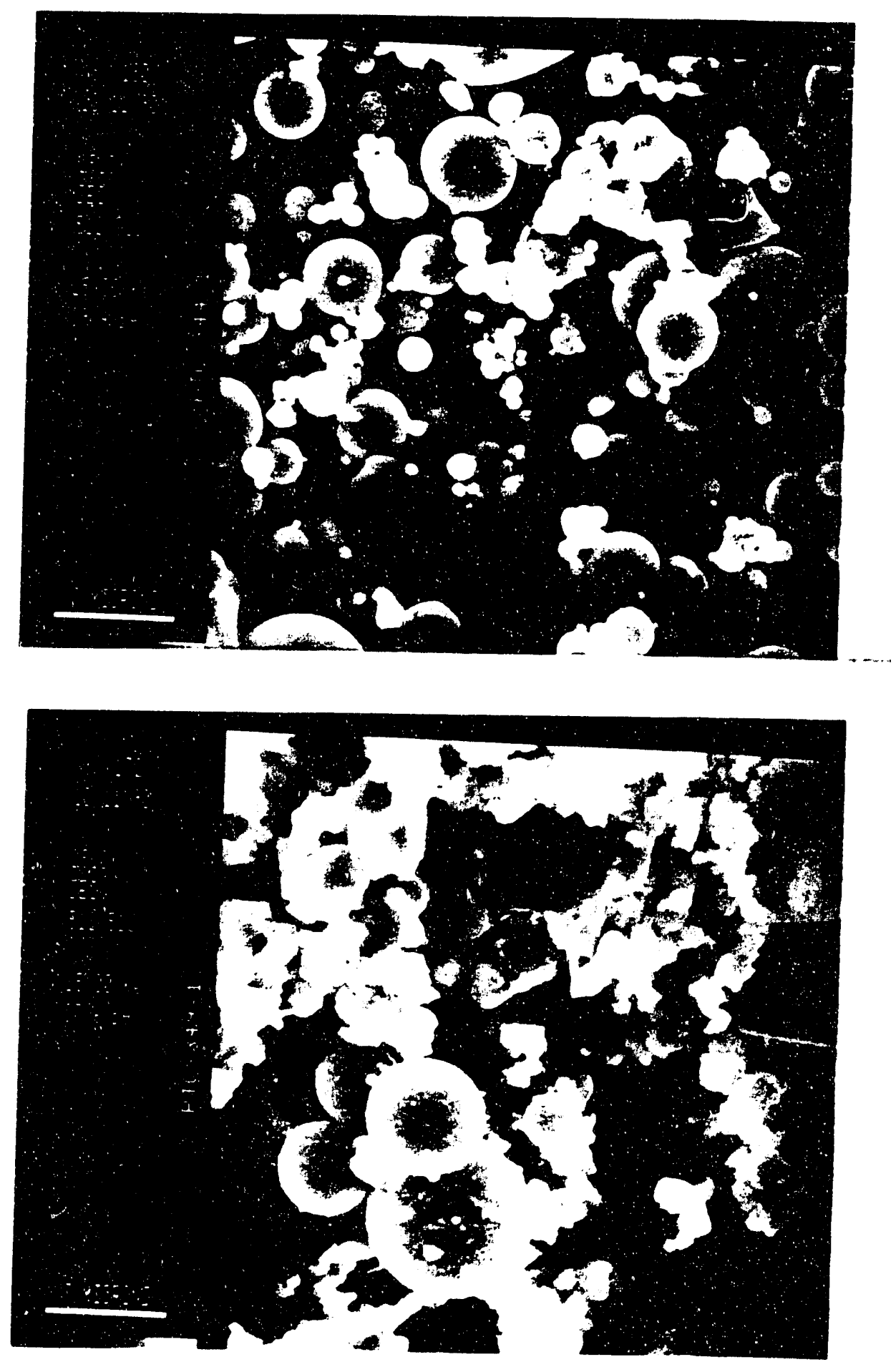

Figure 8. Comparison of fly ash morphology between Big Brown fly ash from Run 344 (top) and Hunter Valley fly ash from Run 349 (bottom) at 2510x magnification. 

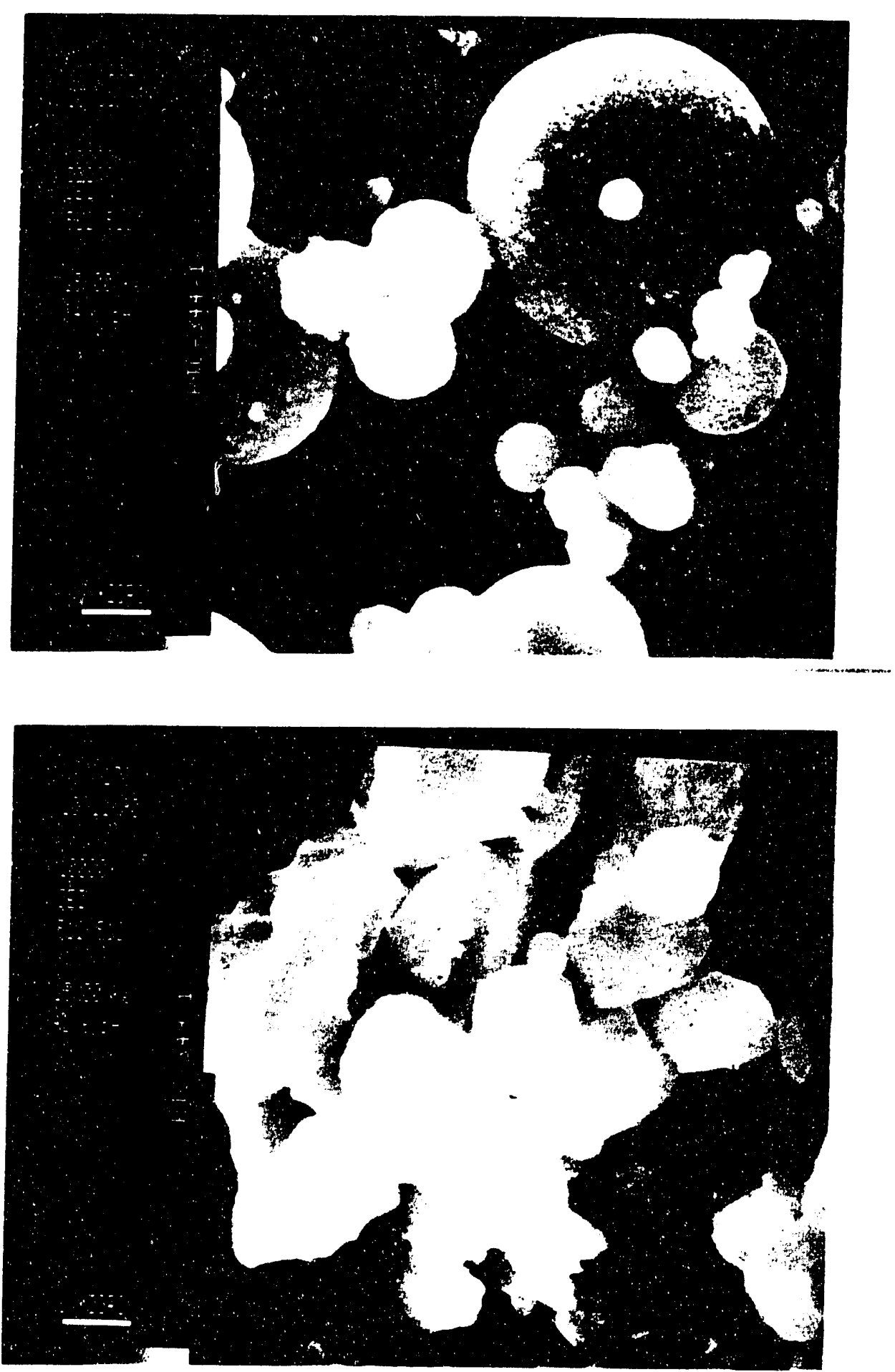

Figure 9. Comparison of fly ash morphology between Big Brown fly ash from Run 344 (top) and Hunter Valley fly ash from Run 349 (bottom) at $10,000 x$ magnification. 
but within five minutes the ESP went into back corona, and the voltage had to be reduced. The ESP was considered to be in back corona if the current exceeded the clean-plate current at the same temperature and voltage. Figure A-2.1 shows that, for the baseline test, particulate emissions were very high. Voltage was dropped down to $20 \mathrm{kV}$, but, even at this voltage, back corona was still present. When conditioning was started, $5 \mathrm{ppm}$ of $\mathrm{SO}_{3}$ had no noticeable effect on emissions, so the $\mathrm{SO}_{3}$ was increased to $25 \mathrm{ppm}$. At $25 \mathrm{ppm}$ of $\mathrm{SO}_{3}$, there was a slight reduction in emissions, but back corona was still present all the way down to $15 \mathrm{kV}$. The fourth test in Run 349 was with dual conditioning (25 ppm of both ammonia and $\mathrm{SO}_{3}$ ). The result was a clear improvement in ESP performance. Particulate emissions were reduced, and the plate current was also reduced. Current readings indicated some back corona, but not nearly to the extent with $25 \mathrm{ppm}$ of $\mathrm{SO}_{3}$ alone. For the final test in Run 349 , the ammonia and $\mathrm{SO}_{3}$ were each set at $10 \mathrm{ppm}$, with the result that particulate emissions and current increased, indicating more severe back corona.

The data from the first run (Run 349) with Hunter Valley coal indicated that, at $325^{\circ} \mathrm{F}, \mathrm{SO}_{3}$ alone was ineffective in controlling resistivity, and that dual conditioning at the higher concentrations was at least somewhat effective. However, because of the extremely high resistivity of the ash, there was concern that the baseline test may have biased the results if there was a thin layer of ash next to the plate. Therefore, an extended test was conducted for the next run (Run 350) with $25 \mathrm{ppm}$ each of ammonia and $\mathrm{SO}_{3}$ injected for the entire run (see Figures A-2.1 and A-2.2). Initial voltage was $50 \mathrm{kV}$, but sparking occurred within 10 minutes, so voltage was reduced to $40 \mathrm{kV}$. Current readings indicated that, initially at $40 \mathrm{kV}$, back corona was avoided, but, by two hours into the test, back corona was present, and sparking was beginning, so the voltage was further reduced to $35 \mathrm{kV}$. Back corona was still present at $35 \mathrm{kV}$ even after rapping the ESP. After 300 minutes, the ESP was bypassed and cleaned off-line. After cleaning, current was somewhat reduced, but again quickly climbed well into the back corona region, and, by the end of the test, sparking was occurring at $35 \mathrm{kV}$.

Results from Run 350 indicated that dual conditioning with $25 \mathrm{ppm}$ of ammonia and $\mathrm{SO}_{3}$ was somewhat effective in reducing particulate emissions, but back corona could not be avoided, and sparking occurred at a fairly low 
voltage. Therefore, the decision was made to increase concentrations to 45 $\mathrm{ppm}$ of ammonia and $\mathrm{SO}_{3}$ for Run 351. Starting voltage was set at $40 \mathrm{kV}$ and was maintained for nearly 5 hours before it had to be reduced to $35 \mathrm{kV}$ because of sparking. However, particulate emissions were substantially reduced (Figures $A-2.1$ and $A-2.2)$, and current readings indicated that the ESP was not in back corona. Part of the reason why the conditioning started to lose effectiveness may have been that the average ESP temperature increased to $370^{\circ} \mathrm{F}$ after 6 hours. For the first 4 hours of the test, the ESP temperature was close to $325^{\circ} \mathrm{F}$. Nevertheless, results showed that $45 \mathrm{ppm}$ of ammonia and $\mathrm{SO}_{3}$ were effective in reducing particulate emissions and keeping the ESP out of back corona. Resistivity, however, was still apparently high enough to require a setback in voltage to avoid sparking. For Test 2 in Run 351, the conditioning was shut off which resulted in an immediate, drastic increase in particulate emissions (Figure A-2.2) and an increase in current, indicating back corona. The great difference between no conditioning and dual conditioning with $45 \mathrm{ppm}$ of ammonia and $\mathrm{SO}_{3}$ demonstrates that dual conditioning is, at least, somewhat effective. Results from Run 364, which was conducted at a later time, also show the ineffectiveness of $\mathrm{SO}_{3}$ alone. Run 364 was conducted primarily to see if the LOI could be reduced with burner modifications. The first two tests of Run 364 were with no conditioning. LOI for Test 2 was reduced to $5.6 \%$. Test 3 was conducted at $45 \mathrm{ppm}$ of $\mathrm{SO}_{3}$ alone to see if the ineffectiveness of $\mathrm{SO}_{3}$ in previous tests may have been caused by the high LOI of the fly ash. However, even at the lower $\mathrm{LOI}, 45 \mathrm{ppm}$ of $\mathrm{SO}_{3}$ was ineffective, as indicated by high emissions and back corona. A comparison of particulate emissions from Run 364 with results from earlier tests with the same conditions is shown in Figure A2.3. Since particulate emissions are about the same with either high or low LOI fly ash, the ineffectiveness of $\mathrm{SO}_{3}$ cannot be attributed to the high LOI in the earlier tests.

For Run 352 , starting concentrations were $45 \mathrm{ppm}$ of $\mathrm{SO}_{3}$ and $90 \mathrm{ppm}$ of ammonia, for comparison with results at $45 \mathrm{ppm}$ of both ammonia and $\mathrm{SO}_{3}$. Starting voltage was again $40 \mathrm{kV}$, but this had to be reduced to $35 \mathrm{kV}$ after only one hour, compared to 5 hours for Run 351. This would indicate that a 1:1 ratio of ammonia to $\mathrm{SO}_{3}$ is better than a 2:1 ratio. For Test 2, the ratio was cut back to $1: 1$. Results were not substantially different, except Figure A-2.4 indicates that emissions do not increase as fast as at a 2:1 ratio and that starting emissions were lower for Test 1 at a 2:1 ratio. The lower 
emissions at the start of Test 1 , however, may be a result of starting Test 1 with a clean plate, while Test 2 was started with some residual ash on the plate. Another indication that a $1: 1$ ratio is better than a $2: 1$ ratio is the lower DMPS submicron mass emissions at a $1: 1$ ratio. Both were measured at an ESP voltage of $35 \mathrm{kV}$, so the comparison should be valid. For Test 3 , the ammonia was shut off to see if a concentration as high as $45 \mathrm{ppm}$ of $\mathrm{SO}_{3}$ would be effective. Results showed that particulate emissions greatly increased and the ESP went into back corona, indicating that $\mathrm{SO}_{3}$ alone is ineffective in controlling resistivity for this ash and temperature. All test results at $325^{\circ} \mathrm{F}$ with Hunter Valley coal indicate that controlling resistivity at this temperature is difficult. While $\mathrm{SO}_{3}$ alone in concentrations up to $45 \mathrm{ppm}$ was not effective in preventing back corona, it did provide some improvement compared to no conditioning. Dual conditioning with $25 \mathrm{ppm}$ each of ammonia and $\mathrm{SO}_{3}$ showed a significant improvement over $45 \mathrm{ppm}$ of $\mathrm{SO}_{3}$, but back corona could not be avoided. Concentrations of $45 \mathrm{ppm}$ each of ammonia and $\mathrm{SO}_{3}$ resulted in the best ESP performance in terms of low particulate emissions and avoiding back corona at a reasonable operating voltage.

Hunter Valley tests with $\mathrm{SO}_{3}$ and dual conditioning at $250^{\circ} \mathrm{F}$ included Runs 353, 354, and 365. For the baseline test during Run 353, the ESP quickly went into back corona, and particulate emissions were very high, as shown in Figure A-2.5. Test 2 results at $25 \mathrm{ppm}$ of $\mathrm{SO}_{3}$ alone indicated that the $\mathrm{SO}_{3}$ was ineffective at controlling resistivity, but emissions were substantially reduced from the baseline test. With dual conditioning at $25 \mathrm{ppm}$ of ammonia and $\mathrm{SO}_{3}$, emissions were further reduced, but back corona could not be avoided. Possibly, the residual high-resistivity dust left on the plate from Tests 1 and 2 contributed to the poor performance with dual conditioning. To avoid influence from previous tests, Run 354 was started at concentrations of $45 \mathrm{ppm}$ each of ammonia and $\mathrm{SO}_{3}$. At these concentrations, emissions were low, and back corona was avoided (Figure A-2.6). Voltage did not have to be reduced from the starting voltage of $40 \mathrm{kV}$. At the end of the 2-hour test, sparking voltage was $46 \mathrm{kV}$, indicating that the entire test could have been conducted at $45 \mathrm{kV}$. These results show that dual conditioning at concentrations of 45 ppm each of ammonia and $\mathrm{SO}_{3}$ is reasonably effective, even though a higher sparking voltage is desirable. Test 2 at $45 \mathrm{ppm}$ of $\mathrm{SO}_{3}$ alone indicated that back corona could not be avoided, but part of the reason may have been high temperature. By the end of Test 2, the inlet ESP temperature was $320^{\circ} \mathrm{F}$. High 
temperature was also a problem for Test 3 and may have affected the results. Particulate emissions with $22 \mathrm{ppm}$ of ammonia and $45 \mathrm{ppm}$ of $\mathrm{SO}_{3}$ were lower than with $\mathrm{SO}_{3}$ alone, but back corona was still a problem.

A repeat run (Run 365 ) was conducted at $250^{\circ} \mathrm{F}$, after the adjustable swirl burner to reduce LOI and an extra piping loop to help control temperature were installed. Particulate emissions from Run 365 are shown in Figure A-2.7. Another procedural change that was implemented between Run 354 and Run 365 was better cleaning of the ESP plate between tests. Following each test in Run 365, the ESP plate was thoroughly cleaned to prevent bias on successive tests from residual dust on the plate. Therefore, results from Run 365 should be considered the most valid for those runs at $250^{\circ} \mathrm{F}$. The baseline test in Run 365 with no conditioning resulted in very high emissions and back corona, similar to the previous tests. For Test 2 at $25 \mathrm{ppm}$ of $\mathrm{SO}_{3}$ alone, particulate emissions were significantly reduced, but back corona could not be avoided. At $45 \mathrm{ppm}$ of $\mathrm{SO}_{3}$ alone, particulate emissions were further reduced, and back corona was avoided. This is the only test conducted with Hunter Valley in which back corona was avoided with $\mathrm{SO}_{3}$ alone. However, for Run 365 , the submicron mass emissions were highest with $45 \mathrm{ppm}$ of $\mathrm{SO}_{3}$, indicating substantial $\mathrm{SO}_{3}$ slip. Respirable mass particulate emissions were much lower in Test 4 with $45 \mathrm{ppm}$ of both ammonia and $\mathrm{SO}_{3}$, and submicron mass emissions were significantly reduced compared to $45 \mathrm{ppm}$ of $\mathrm{SO}_{3}$ alone. Back corona was also avoided with dual conditioning. Results clearly show that superior performance can be achieved with dual conditioning compared to $\mathrm{SO}_{3}$ alone. $\mathrm{A}$ comparison of results from Run 365 with earlier tests in which the LOI was higher is shown in Figure A-2.8. In both cases, the lowest emissions are with dual conditioning. The difference at $45 \mathrm{ppm}$ of $\mathrm{SO}_{3}$ alone may be the result of higher ESP temperature with the conventional burner. The difference between the two baseline tests is not clear, but, in both cases, emissions were very high, and the ESP was well into back corona. Results of the tests at $250^{\circ} \mathrm{F}$ indicate that ESP performance can be somewhat improved by injecting high concentrations of $\mathrm{SO}_{3}$ alone. However, particulate emissions were much lower with dual conditioning. In addition, rapping puffs, shown in Figure A-2.9, are much lower, further indicating superior performance with dual conditioning. 
Current density as a function of voltage for some of the tests is shown in Figures A-2.10 through A-2.13. Conditions where the ESP was operating in back corona are clear by comparing with the clean-plate curves. In cases where back corona was avoided, the significant reduction in current from the clean-plate curve demonstrates that the ash is high resistivity and difficult to collect.

Valid in situ resistivity measurements were not available because of the high LOI of the resistivity samples for Runs 349-354. However, laboratory resistivity measurements were conducted with an ASTM resistivity cell on several ESP hopper ash samples. These measurements indicated that, for Run 351 , the resistivity was above $10^{12} \mathrm{ohm}-\mathrm{cm}$, even with dual conditioning concentrations of $45 \mathrm{ppm}$ each of ammonia and $\mathrm{SO}_{3}$. For Runs 364 and 365 , some in situ resistivity measurements were completed with the resistivity cyclone. These measurements indicated that baseline resistivities were in the range of $10^{13}$ to $10^{14} \mathrm{ohm}-\mathrm{cm}$; however, current readings were not steady. For the baseline Test 2 in Run 364, the resistivity cup with ash sample retained was taken into a laboratory for resistivity measurement with a more sensitive electrometer. The sample may have cooled somewhat, but the measurement was taken when the outside of the teflon cup was still hot. This measurement indicated that the resistivity was $2 \times 10^{15} \mathrm{ohm}-\mathrm{cm}$. The in situ resistivity measurements indicated a reduction in resistivity when $\mathrm{SO}_{3}$ was added; however, no reduction in resistivity was indicated at $45 \mathrm{ppm}$ of both $\mathrm{SO}_{3}$ and ammonia in Run 365. Higher porosity ash is expected with dual conditioning which may have affected resistivity measurement, but inspection of the resistivity cup revealed that ash was present in the space between the electrodes, indicating that the resistivity measurement should be valid. Therefore, the explanation for a high resistivity measurement with dual conditioning is not obvious.

Sulfur retention data for Runs 364 and 365 are shown in Figure A-2.14. Because of lower LOI in the fly ash compared to earlier tests, these data should be more valid. As expected, greater $\mathrm{SO}_{3}$ retention at $45 \mathrm{ppm}$ of $\mathrm{SO}_{3}$ alone is indicated at $250^{\circ} \mathrm{F}$ compared to $325^{\circ} \mathrm{F}$. However, an unexpected result is that $\mathrm{SO}_{3}$ retention was somewhat less (or about the same) when dual conditioning was used. This might indicate that the same amount of $\mathrm{SO}_{3}$ was transferred to the fly ash with $\mathrm{SO}_{3}$ alone and with dual conditioning, but the submicron mass emissions data were higher with $\mathrm{SO}_{3}$ alone, indicating less $\mathrm{SO}_{3}$ 
transfer. An explanation for this apparent inconsistency in the data is not obvious.

Part of the reason for significantly reduced emissions with dual conditioning is a change in cohesive properties of the fly ash. Tensile strength tests were conducted on the samples from Runs 364 and 365 (Figures A2.15 and $\mathrm{A}-2-16)$. For both runs, the results show that $\mathrm{SO}_{3}$ alone produces a shift in the tensile strength curve. The greatest tensile strength, however, is with dual conditioning, indicating that one of the mechanisms of particulate emissions reduction is reduced continuous reentrainment.

\subsection{Hudson Bituminous: $\mathrm{SO}_{3}$ and Dual Conditioning (Runs 355-360)}

For Hudson bituminous coal, 6 runs were completed, including one run each with $\mathrm{SO}_{3}$ alone and dual conditioning at each of the three temperatures. In general, these runs were completed without major difficulties, and extensive data are available to evaluate the effects of conditioning on ESP performance. One procedural change that was implemented for these runs was hand-cleaning of the ESP between all tests. The purpose was to minimize any bias that could be caused by a small amount of high-resistivity residual ash left on the plate from previous tests. Some problems were encountered with the resistivity measurements, similar in nature to the Hunter Valley tests, where low current readings were obtained; however, enough measurements were completed to obtain valid resistivity measurements for most of the tests.

Starting voltage was $50 \mathrm{kV}$ for all tests, but, in cases of sparking, the operating voltage was reduced in multiples of $5 \mathrm{kV}$ to avoid sparking conditions. Therefore, listed operating voltages in the summary tables for Runs 355-360 are either 50, 45, or $40 \mathrm{kV}$. In cases where sparking voltage exceeded $50 \mathrm{kV}$, additional current and respirable mass data are available at higher voltages. These data were taken at the end of each 2-hour test where current and respirable mass were measured as a function of voltage. Respirable mass emissions measured with the APS as a function of time, voltage, and current are shown in Figures A-3.1 through A-3.22 for Runs 355360. Current density as a function of voltage is shown in Figures $A-3.23$ through A-3.28. 
Results from Run 355, with $\mathrm{SO}_{3}$ alone at $325^{\circ} \mathrm{F}$, showed that $5 \mathrm{ppm}$ of $\mathrm{SO}_{3}$ had little effect, but $15 \mathrm{ppm}$ and $25 \mathrm{ppm}$ were effective in that operating voltage did not have to be reduced from the starting voltage of $50 \mathrm{kV}$. With $25 \mathrm{ppm}$ of $\mathrm{SO}_{3}$, sparking voltage was at least $70 \mathrm{kV}$, indicating that better performance could be achieved compared to $15 \mathrm{ppm}$. Figure A-3.1 shows that respirable mass emissions were about the same for the $15 \mathrm{ppm}$ and $25 \mathrm{ppm}$ tests, but, at the end of the test, emissions were slightly higher at $25 \mathrm{ppm}$. Graphs of respirable mass as a function of voltage or current density (Figures A-3.2 and $A-3.3$ ) also indicate that lower emissions were achieved at $15 \mathrm{ppm}$. The DMPS submicron mass data is much higher at $25 \mathrm{ppm}$ than $15 \mathrm{ppm}$, likely caused by higher $\mathrm{SO}_{3}$ slip at $25 \mathrm{ppm}$. However, submicron mass emissions data also indicate some $\mathrm{SO}_{3}$ slip at. $15 \mathrm{ppm}$.

Results from Run 356 with dual conditioning show that emissions are much lower when ammonia is added. Figures A-3.4 and A-3.5 (which is the same data with expanded scale) show that emissions were only $4 \mathrm{mg} / \mathrm{m}^{3}$ with $15 \mathrm{ppm}$ or 30 $\mathrm{ppm}$ of ammonia and were somewhat higher $\left(7 \mathrm{mg} / \mathrm{m}^{3}\right)$ at $8 \mathrm{ppm}$ of ammonia. $\mathrm{SO}_{3}$ injection was held constant at 15 ppm for all tests in Run 356 . Tests 1 and 2 were identical except for that, in Test 2, the ammonia was injected donnstream from the $\mathrm{SO}_{3}$ injection location, instead of the normal upstream ammonia injection location. From the respirable mass data, it might appear that there was no difference between upstream and downstream ammonia injection. The submicron emissions on both a mass basis and number basis, however, are somewhat higher with downstream ammonia injection. Current density was somewhat lower (see Figure A-3.24), indicating greater corona suppression which is consistent with a greater number of submicron particles. These data indicate that somewhat better transfer of conditioning agents to the fly ash is achieved with upstream ammonia injection. The respirabie mass data give stro.ig evidence that dual conditioning results in the best ESP performance. Rapping puffs were also much lower with ammonia injection, showing a further advantage of dual conditioning over $\mathrm{SO}_{3}$ alone at this temperature.

Runs 357 and 358 were conducted with $\mathrm{SO}_{3}$ alone and dual conditioning at $400^{\circ} \mathrm{F}$. With $\mathrm{SO}_{3}$ alone, emissions were higher than at $325^{\circ} \mathrm{F}$, and voltage could not be maintained at $50 \mathrm{kV}$, even at the highest injection rate of $25 \mathrm{ppm}$ of $\mathrm{SO}_{3}$. The submicron mass data indicted $\mathrm{SO}_{3} \mathrm{slip}$ at concentrations of $15 \mathrm{ppm}$ and $25 \mathrm{ppm}$. Therefore, $\mathrm{SO}_{3}$ conditioning alone for this ash at $400^{\circ} \mathrm{F}$ appears 
to be inadequate in controlling resistivity without excessive $\mathrm{SO}_{3}$ remaining in the flue gas downstream of the precipitator. With dual conditioning at concentrations of $15 \mathrm{ppm}$ each of ammonia and $\mathrm{SO}_{3}$, the voltage had to be reduced to $45 \mathrm{kV}$ after 25 minutes into the test (Figures $\mathrm{A}-3.12$ and $\mathrm{A}-3.13$ ). Emissions were much lower than with $\mathrm{SO}_{3}$ alone, but, because the voltage had to be reduced, concentrations were increased to $25 \mathrm{ppm}$ each of ammonia and $\mathrm{SO}_{3}$ for Test 2. At the higher concentrations, $50 \mathrm{kV}$ could be maintained for the entire 2-hour test, and emissions were much lower. Test 3 was conducted with ammonia injected downstream of the $\mathrm{SO}_{3}$ for comparison with upstream injection in Test 2. Respirable mass emissions were not significantly different between upstream and downstream ammonia injection, but submicron emissions on both a mass and number basis were higher with downstream injection. Current density as a function of voltage was also Jower with downstream injection (Figure A3.24) which is consistent with a higher concentration of submicron particles. These results are in agreement with the results at $325^{\circ} \mathrm{F}$, indicating that upstream ammonia injection gives better transfer of conditioning agents to the fly ash particles. Comparing rapping emissions between $\mathrm{SO}_{3}$ alone and dual conditioning shows that dual conditioning results in substantially lower emissions at $400^{\circ} \mathrm{F}$, similar to results at $325^{\circ} \mathrm{F}$.

Runs 359 and 360 were conducted with $\mathrm{SO}_{3}$ alone and dual conditioning at a $250^{\circ} \mathrm{F}$ ESP temperature. $\mathrm{SO}_{3}$ alone at $250^{\circ} \mathrm{F}$ was more effective than at $325^{\circ} \mathrm{F}$ or $400^{\circ} \mathrm{F}$, which was expected. At $5 \mathrm{ppm}$ of $\mathrm{SO}_{3}$, some benefit was noted (Figure A3.16 ), but operating voltage had to be reduced to $45 \mathrm{kV}$ by 90 minutes into the test. Higher concentrations of $15 \mathrm{ppm}$ and $25 \mathrm{ppm}$ of $\mathrm{SO}_{3}$ were more effective at controlling resistivity, but an increase in submicron emissions was again noted, indicating $\mathrm{SO}_{3}$ slip. Results with dual conditioning (Figures $\mathrm{A}-3.19$ and $A-3.20$ ) show that respirable mass emissions, at concentrations of $8 \mathrm{ppm}$ each of ammonia and $\mathrm{SO}_{3}$, were about the same as respirable mass emissions at concentrations of $15 \mathrm{ppm}$ and $25 \mathrm{ppm}$ of $\mathrm{SO}_{3}$ alone. However, submicron emissions were lower with dual conditioning indicating that dual conditioning, at $8 \mathrm{ppm}$ each of ammonia and $\mathrm{SO}_{3}$ is superior to higher concentrations of $\mathrm{SO}_{3}$ alone. Lower particulate emissions were achieved by increasing the ammonia and $\mathrm{SO}_{3}$ concentration each to $15 \mathrm{ppm}$ or $25 \mathrm{ppm}$; however, submicron emissions increased at concentrations of $25 \mathrm{ppm}$, indicating that, at $250^{\circ} \mathrm{F}$, these concentrations are higher than is necessary. Rapping puffs were again much lower with dual conditioning compared to $\mathrm{SO}_{3}$ alone. 
Each of the dual conditioning runs included one test at a $2: 1$ ratio of ammonia to $\mathrm{SO}_{3}$ for comparison with a $1: 1$ ratio. For all three temperatures, there was a slight reduction in respirable mass at the 2:1 ratio. However, submicron mass emissions were higher at the $2: 1$ ratio for the $325^{\circ} \mathrm{F}$ and $400^{\circ} \mathrm{F}$ tests, and they were unchanged from the $1: 1$ ratio for the $250^{\circ} \mathrm{F}$ test.

Therefore, there appears to be no strong advantage in using a 2:1 ratio for Hudson bituminous coal. In some cases, respirable mass emissions may be lower, but at the expense of higher submicron emissions. With no obvious benefit in ESP performance, the cost of the extra ammonia at a 2:1 ratio compared to a $1: 1$ ratio would appear unjustified.

The respirable mass data as a function of time from all of the runs provide very strong evidence that dual conditioning significantly reduces continuous reentrainment resulting in reduced particulate emissions. Looking at the difference between rapping puffs with $\mathrm{SO}_{3}$ alone and dual conditioning (Figure A-3.29) further shows the superiority of dual conditioning. Most of the rapping puffs with dual conditioning with Hudson bituminous coal were no greater than respirable emissions just before the rap. This indicates that the ash was removed in larger agglomerates and was not reentrained as separate particles.

Submicron emissions were also substantially reduced with dual conditioning, compared to $\mathrm{SO}_{3}$ alone (Figure A-3.30). This means that, in cases where resistivity cannot be adequately controlled with $\mathrm{SO}_{3}$ because of high $\mathrm{SO}_{3}$ slip, dual conditioning can be implemented as a means to control submicron emissions. Since submicron emissions can be a major contributor to high opacity, it is imperative that they not be allowed to increase as a result of conditioning.

The sulfur retention data (Figures A-3.31 through A-3.34) agree reasonably well with the submicron emissions data. With $\mathrm{SO}_{3}$ alone, the best sulfur retention was at $250^{\circ} \mathrm{F}$, as indicated by the greater slope of the ash sulfur concentration as a function of $\mathrm{SO}_{3}$. Figures $\mathrm{A}-3.32$ and $\mathrm{A}-3.33$ show that sulfur retention is increased with dual conditioning, and Figure A-3.30 shows that this correlates with lower submicron emissions, as would be expected. At $250^{\circ} \mathrm{F}$ (Figure A-3.34), the data indicate better sulfur retention at $25 \mathrm{ppm}$ each of ammonia and $\mathrm{SO}_{3}$, but at $15 \mathrm{ppm}$ each of ammonia and $\mathrm{SO}_{3}$ and 
at $30 \mathrm{ppm}$ ammonia and $15 \mathrm{ppm}$ of $\mathrm{SO}_{3}$, the sulfur retention was the same as at $15 \mathrm{ppm}$ of $\mathrm{SO}_{3}$ alone. An explanation is that the sulfur retention measurement at $15 \mathrm{ppm}$ of $\mathrm{SO}_{3}$ alone may be slightly high, based on the shape of the curves in Figure A-3.31.

Resistivity results for Runs $355-360$ are shown in Figures A-3.35 and A3.36. Using $\mathrm{SO}_{3}$ alone, at $325^{\circ} \mathrm{F}$ and $400^{\circ} \mathrm{F}$, some reduction in measured resistivity was noted, but not enough to adequately improve ESP performance. At $250^{\circ} \mathrm{F}$, the resistivity data indicate that $\mathrm{SO}_{3}$ is effective, achieving a 2 order of magnitude reduction in resistivity. However, excessive $\mathrm{SO}_{3} \mathrm{slip}$ at the higher $\mathrm{SO}_{3}$ injection rates may 1 imit ESP performance. Figure A-3.36 shows the effect of dual conditioning on resistivity. At $325^{\circ} \mathrm{F}$ and $400^{\circ} \mathrm{F}$, most of the resistivity measurements were lower with dual conditioning than the corresponding tests with $\mathrm{SO}_{3}$ alone. At both temperatures, however, the tests at a $2: 1$ ratio of ammonia to $\mathrm{SO}_{3}$ resulted in the highest resistivity measurements. Possible explanations are that, at a $2: 1$ ratio, the ash is more porous and does not pack into the resistivity cup as well, resulting in higher measurements or that the actual resistivity is somewhat higher at a 2:1 ratio. Inspection of the Big Brown and Pleasant Prairie resistivity data also reveals slightly higher resistivity at a 2:1 ratio of ammonia to $\mathrm{SO}_{3}$, compared to a $1: 1$ ratio. Again, the cause could be more porous ash, but there does appear to be a real difference. At $250^{\circ} \mathrm{F}$, the data do not indicate that ammonia significantly affects resistivity, but resistivities were already in the $10^{9}$ to $10^{10}$-ohm-cm range with $\mathrm{SO}_{3}$ alone.

Tensile strength measurements for Runs 355-360 are shown in Figures A3.37 through A-3.39. The data are similar to the Big Brown data, showing that $\mathrm{SO}_{3}$ alone produces a small shift in the curve, but dual conditioning results in a much greater shift. The highest tensile strengths at all three temperatures are at a 2:1 ratio of ammonia to $\mathrm{SO}_{3}$. This may explain why lowest respirable mass emissions were seen at the 2:1 ratio. Since lowest continuous emissions and lowest rapping emissions were seen with dual conditioning, and the tensile strength curves are significantly shifted with dual conditioning compared to $\mathrm{SO}_{3}$ alone, the logical conclusion is that the lower emissions are a direct result of the change in cohesive properties. 
In summary, a large amount of data shows that dual conditioning is far superior to $\mathrm{SO}_{3}$ alone with Hudson bituminous coal. Data also indicate that upstream ammonia conditioning is preferred to injecting the ammonia downstream of the $\mathrm{SO}_{3}$. Data further indicate that a $1: 1$ ratio of ammonia to $\mathrm{SO}_{3}$ is preferred over a $2: 1$ ratio. The optimum concentrations of conditioning agents can be based on the lowest combination of respirable mass and submicron emissions. Conditioning with $\mathrm{SO}_{3}$ alone does not appear to work well with this coal. Excessive submicron emissions were noted with $\mathrm{SO}_{3}$ concentrations of 15 ppm or greater, indicating that $\mathrm{SO}_{3}$ alone will not satisfactorily control resistivity without substantial $\mathrm{SO}_{3} \mathrm{slip}$. The one exception is at $250^{\circ} \mathrm{F}$, where $5 \mathrm{ppm}$ of $\mathrm{SO}_{3}$ may provide reasonable ESP performance improvement without excess $\mathrm{SO}_{3}$ going up the stack. At an ESP temperature of $325^{\circ} \mathrm{F}$, dual conditioning agent concentrations of $15 \mathrm{ppm}$ each of ammonia and $\mathrm{SO}_{3}$ provided excellent ESP performance. Very likely, these concentrations could be reduced down to $10 \mathrm{ppm}$ each while maintaining adequate ESP performance. At an ESP temperature of $400^{\circ} \mathrm{F}$, data indicate that higher concentrations of ammonia and $\mathrm{SO}_{3}$ are necessary to maintain good ESP performance. At concentrations of $15 \mathrm{ppm}$ each of ammonia and $\mathrm{SO}_{3}$, good performance was noted, but much better ESP performance was achieved at concentrations of $25 \mathrm{ppm}$ each. Therefore, optimum concentrations at $400^{\circ} \mathrm{F}$ would appear to be between $15 \mathrm{ppm}$ and $25 \mathrm{ppm}$ each of ammonia and $\mathrm{SO}_{3}$. At an ESP temperature of $250^{\circ} \mathrm{F}$, concentrations of 8 ppm each of ammonia and $\mathrm{SO}_{3}$ provided good ESP performance. Emissions were somewhat lower at concentrations of $15 \mathrm{ppm}$ each of ammonia and $\mathrm{SO}_{3}$, but increasing the concentrations to $25 \mathrm{ppm}$ resulted in increased submicron emissions. Therefore, data indicate optimum concentrations at $250^{\circ} \mathrm{F}$ are about $8 \mathrm{ppm}$ each of ammonia and $\mathrm{SO}_{3}$.

\subsection{Pleasant Prairie: $\mathrm{SO}_{3}$ and Dual Conditioning (Runs 361-363)}

Three runs were completed with Pleasant Prairie coal, one run each with $\mathrm{SO}_{3}$ alone and dual conditioning at $325^{\circ} \mathrm{F}$, and one run with $\mathrm{SO}_{3}$ alone at $400^{\circ} \mathrm{F}$. Only three runs were completed with Pleasant Prairie coal because results from the first three runs indicated that this coal is fairly easy to condition and more information was needed with Hunter Valley coal. After consultation with Wahlco personnel, the decision was made to perforin more Hunter Valley runs rather than complete all six originally planned tests with Pleasant Prairie coal. 
Respirable mass emissions as a function of time, voltage, and current density from Runs 361-363 are shown in Figures A-4.1 through A-4.14. Current density as a function of voltage is given in Figures A-4.15 through A-4.17. Emissions as a function of time at $325^{\circ} \mathrm{F}$ were not significantly affected by $\mathrm{SO}_{3}$ injection as shown in Figure A-4.1. Operating current was somewhat reduced at $15 \mathrm{ppm}$ of $\mathrm{SO}_{3}$, likely because of some corona current suppression. Submicron mass emissions were also somewhat increased at $15 \mathrm{ppm}$ of $\mathrm{SO}_{3}$. For all tests at $325^{\circ} \mathrm{F}$, the sparking voltage was at least $70 \mathrm{kV}$, indicating that ESP performance was not 1 imited by resistivity. Evident1y, 2 hours of dust accumulation on the plate was not enough time to see a deterioration in performance because of dust resistivity. The respirable mass data indicate that no conditioning is necessary at $325^{\circ} \mathrm{F}$, but longer-term tests may have given different results. The resistivity data (Figure A-4.18) show almost an order of magnitude decrease in resistivity with $\mathrm{SO}_{3}$ injection, but this was not evident from the ESP performance data. With dual conditioning in Run 362 , particulate emissions were lower than with $\mathrm{SO}_{3}$ alone. Since ESP performance was not limited by resistivity, this implies that the reduction in emissions was caused by other factors, such as a change in tensile strength of the ash. Resistivity results with dual conditioning indicate that, at a $1: 1$ ratio of ammonia to $\mathrm{SO}_{3}$, resistivity is somewhat lower than $\mathrm{SO}_{3}$ alone. However, at a $2: 1$ ratio of ammonia to $\mathrm{SO}_{3}$, there was no change in resistivity compared to $\mathrm{SO}_{3}$ alone. Higher resistivity at a $2: 1$ ratio of ammonia to $\mathrm{SO}_{3}$ compared to a $1: 1$ ratio, is consistent with results from the Big Brown and Hudson bituminous coals. Optimal concentrations of conditioning agents would appear to be $5 \mathrm{ppm}$ each of ammonia and $\mathrm{SO}_{3}$ based on respirable mass, submicron mass, and resistivity measurements. The data indicate that emissions can be reduced by using dual conditioning compared to $\mathrm{SO}_{3}$ alone, but the difference is not as dramatic as with the other coals. The difference in rapping puffs with dual conditioning (Figure A-4.19) was also not as significant as with the other coals.

Results for the $\mathrm{SO}_{3}$ conditioning test at $400^{\circ} \mathrm{F}$ (Run 363) indicate little effect of the $\mathrm{SO}_{3}$ on particulate emissions. The best performance in terms of respirable mass, submicron mass, and resistivity appears to be with $5 \mathrm{ppm}$ of $\mathrm{SO}_{3}$. At higher concentrations of $15 \mathrm{ppm}$ and $25 \mathrm{ppm}$, there is no improvement in respirable mass, but submicron mass increases, indicating $\mathrm{SO}_{3}$ slip. Graphs of submicron emissions and sulfur retention are shown in Figures A-4.20 and A- 
4.21. Sulfur retention was better at $325^{\circ} \mathrm{F}$ than $400^{\circ} \mathrm{F}$ with $\mathrm{SO}_{3}$ alone, as indicated from the slope of the lines in Figure A-4.21. Addition of ammonia did not improve sulfur retention, which does not appear to be consistent with the lower resistivity. However, the Pleasant Prairie ash has very high alkalinity which could neutralize some of the $\mathrm{SO}_{3}$, making it ineffective in lowering resistivity. When ammonia is present first (upstream injection), the $\mathrm{SO}_{3}$ may react with the ammonia on the surface of the ash, with a net reduction in resistivity, compared to $\mathrm{SO}_{3}$ alone. Tensile strength measurements for the tests at $325^{\circ} \mathrm{F}$ are shown in Figure $\mathrm{A}-4.22$. Results show that $\mathrm{SO}_{3}$ causes a shift in the tensile strength curve compared to no conditioning, and, with dual conditioning, the shift is somewhat greater. Again, the difference between dual conditioning and $\mathrm{SO}_{3}$ alone is not as great as with the other coals.

Results do indicate some benefit in using dual conditioning compared to $\mathrm{SO}_{3}$ alone with Pleasant Prairie coal, but this ash can likely be effectively conditioned with $\mathrm{SO}_{3}$ alone. The primary benefits of using dual conditioning would appear to be a shift in tensile strength, resulting in some reduction in reentrainment and lower resistivity than $\mathrm{SO}_{3}$ alone.

\subsection{Enhanced Flue Gas Conditioning with Big Brown Coal (Runs 368-370, 377)}

The enhanced flue gas conditioning tests included an enhanced method of using $\mathrm{SO}_{3}$ conditioning. The exact details of the method are a proprietary development of Wahlco and are not disclosed in this report. However, results from all of the enhanced flue gas conditioning (EFGC) tests are presented in the summary tables and graphs in the Appendix. EFGC tests were conducted under conditions in which conditioning with $\mathrm{SO}_{3}$ alone would not be expected to work well to see if performance improvements could be achieved. In general, tests were conducted with and without EFGC at constant $\mathrm{SO}_{3}$ concentrations during the same run so that a valid evaluation could be made of the effect of EFGC on ESP performance compared to $\mathrm{SO}_{3}$ alone. The test of the effectiveness of EFGC is determined primarily by its effect on particulate emissions, ash resistivity, sulfur retention, and submicron mass emissions. 
Four runs were completed testing EFGC with Big Brown coal, all at an ESP temperature of $400^{\circ} \mathrm{F}$ (Runs $368-370,377$ ). Initial tests in Runs 368 and 369 included tests with and without EFGC at $\mathrm{SO}_{3}$ concentrations of $0,7,15$, and 25 ppm. From these first two runs, the best results with EFGC were obtained at $25 \mathrm{ppm}$ of $\mathrm{SO}_{3}$. For the third run (Run 370), several different configurations of EFGC were tested, all at $25 \mathrm{ppm}$ of $\mathrm{SO}_{3}$. However, no significant differences were noted among the different configurations, so the original configuration was used for subsequent tests. After EFGC tests with Hudson bituminous and Hunter Valley coals, a repeat run (Run 377 ) was conducted with Big Brown to see if earlier results with $25 \mathrm{ppm}$ of $\mathrm{SO}_{3}$ and EFGC could be repeated.

Respirable mass emissions as a function of time, voltage, and current density are given for the Big Brown EFGC tests in Figures A-5.1 through A5.21. Respirable mass as a function of time was not affected by $\mathrm{EFC}$ at $\mathrm{SO}_{3}$ concentrations of 0,7 , and $15 \mathrm{ppm}$; however, at $25 \mathrm{ppm}$, emissions were reduced by EFGC (Figure A-5.4). When results at 25 ppm from Runs 369 and 370 were combined (Figure A-5.5), a clear reduction in emissions with the EFGC appears. The repeat tests in Run 377 (Figures A-5.6 and A-5.7) also show some reduction in emissions with EFGC, but not as much as in Runs 369 and 370 . Inspection of the graphs of respirable mass versus voltage or current density (Figures A5.14 through $\mathrm{A}-5.21$ ) also indicate that, at $25 \mathrm{ppm}$ of $\mathrm{SO}_{3}$, EFGC results in lower emissions. If the reduction in emissions is the result of EFGC, other data should verify the results. Current density as a function of voltage graphs are given in Figures A-5.22 through A-5.26. From these data, EFGC has no apparent effect on current density. Resistivity results (Figure A-5.27) indicate a slight reduction in resistivity for Runs 368-370. For Run 377, the measured resistivities were somewhat higher, but resistivity results from only Run 377 also indicate a slight reduction in resistivity with EFGC. The submicron mass emissions data are inconclusive because results from Run 368 indicate lower emissions with EFGC and results from Run 377 show higher submicron emissions comparing Tests 1 and 2 , and lower submicron emissions comparing Tests 3 and 4 . The sulfur retention data, shown in Figure A-5.28, are also inconclusive because of the data scatter when all data are included.

In summary, some of the data indicate that EFGC produces a benefit in lower emissions, but the effect appears to be marginal. If EFGC does 
significantly enhance transfer of the $\mathrm{SO}_{3}$ to the fly ash, then resistivity should be reduced, submicron mass emissions should be reduced, and sulfur retention should be greater. The reduction in resistivity appears to be small, and the effects on submicron emissions and sulfur retention are not clear because of data scatter. The possibility exists that the reduction in respirable mass emissions is the result of additional deposition in the flue gas pipes between the injection location and the ESP. Longer-term tests would be needed to verify this possibility. Results indicate the potential of EFGC to provide some benefit over $\mathrm{SO}_{3}$ conditioning alone, but much more development work is apparently needed to optimize this method. Dual conditioning, on the other hand, produced a significant benefit over $\mathrm{SO}_{3}$ alone that could be explained by a large amount of supporting data. From this initial evaluation with Big Brown coal, EFGC does not appear to provide the improved ESP performance that can be achieved with dual conditioning.

\subsection{Enhanced Flue Gas Conditioning with Hudson Bituminous Coal (Runs $371-374,378$ )}

A total of five runs were completed testing EFGC with Hudson bituminous coal. Results are shown in Figures A-6.1 through A-6.13. The first two runs were conducted at an ESP temperature of $400^{\circ} \mathrm{F}$ testing EFGC at $\mathrm{SO}_{3}$ concentrations of $0,7,15$, and $25 \mathrm{ppm}$. Results from Runs 371 and 372 at $400^{\circ} \mathrm{F}$, however, did not show any improvement in particulate emissions with EFGC compared to $\mathrm{SO}_{3}$ alone (Figures $\mathrm{A}-6.1$ through $\mathrm{A}-6.3$ ). At the highest $\mathrm{SO}_{3}$ concentration of $25 \mathrm{ppm}$, voltage had to be reduced to avoid sparking with both $\mathrm{SO}_{3}$ alone and EFGC. In addition, submicron mass emissions indicated excessive $\mathrm{SO}_{3}$ slip with both $\mathrm{SO}_{3}$ alone and $\mathrm{EFGC}$, implying that neither was effective at controlling resistivity under these conditions. After consultation with Wahlco personnel, a decision was made to reduce the ESP temperature to $325^{\circ} \mathrm{F}$ for subsequent EFGC tests with Hudson bituminous coal. Runs 373,374 , and 378 were conducted at the lower temperature, to investigate the effect of EFGC at $\mathrm{SO}_{3}$ concentrations of 7 and $15 \mathrm{ppm}$ of $\mathrm{SO}_{3}$. Run 378 was a repeat test with a modification to the EFGC in an effort to obtain better results. Since Runs 373,374 , and 378 all included tests at $15 \mathrm{ppm}$ of $\mathrm{SO}_{3}$ with and without EFGC, these results are combined in Figures $A-6.4, A-6.9, A-6.10$, and A-6.12. These data show that respirable mass emissions as a function of time are lower with EFGC. In addition, respirable mass as a function of voltage is lower with 
$E F G C$, indicating that somewhat higher currents were obtained with EFGC. Respirable mass as a function of current density is the same with $\mathrm{SO}_{3}$ alone or $E F G C$, which would be expected if the mechanism of EFGC is to enhance transfer of $\mathrm{SO}_{3}$ to the fly ash. Current density as a function of voltage is slightiy higher with EFGC, further indicating that the effect of EFGC is an increase in current at constant voltage. Run 378 provides encouraging results in that better performance was obtained with EFGC at both 7 and $15 \mathrm{ppm}$ of $\mathrm{SO}_{3}$. Results from Run 378 should be considered the most valid, because improvements were made to the EFGC for this run. Respirable mass and submicron mass were lower with EFGC at both $\mathrm{SO}_{3}$ concentrations. Measured resistivity was also lower for both EFGC tests, but caution must be exercised interpreting the resistivity measurements because of data scatter. Sparking voltage was higher for the EFGC tests, which is another indication that resistivity was reduced with EFGC. Sulfur retention data are too scattered to form any conclusion concerning the effect of EFGC. Therefore, all of the data from Run 378, with the exception of sulfur retention, indicate that EFGC improved precipitator performance. Because of the nature of the short-term tests, these results should be interpreted with caution, but they do indicate the potential of EFGC to improve ESP performance with Hudson bituminous coal at an ESP temperature of $325^{\circ} \mathrm{F}$. Therefore, further development efforts to optimize the improvements of EFGC over $\mathrm{SO}_{3}$ alone would appear warranted. While the EFGC results did not demonstrate the level of improvement over $\mathrm{SO}_{3}$ conditioning alone, as was observed with dual conditioning, they, nevertheless, imply that EFGC does produce some benefits.

\subsection{Enhanced Flue Gas Conditioning with Hunter Valley Coal (Runs 375, $376,396-398$ )}

Initially, two EFGC runs were completed with Hunter Valley coal at an ESP temperature of $275^{\circ} \mathrm{F}$, because this is the temperature at which $\mathrm{SO}_{3}$ alone begins to lose effectiveness. This temperature was thought to provide the best evaluation of the effectiveness of EFGC compared to $\mathrm{SO}_{3}$ alone. The first run (Run 375) was completed with and without EFGC at $\mathrm{SO}_{3}$ concentrations of 0 and $25 \mathrm{ppm}$. Results from Run 375 at $25 \mathrm{ppm}$ of $\mathrm{SO}_{3}$ appeared promising because both respirable mass and submicron particulate emissions were reduced with EFGC, resistivity was lower with EFGC, sparking voltage was somewhat lower with EFGC, and sulfur retention was better with EFGC. Run 376 was an attempt 
to repeat these results, but results could not be verified (Figures $A-7.1$ through A-7.5). One difference between the two runs was the order of tests. In Run 375 the EFGC test was the first test of the day, while, in Run 376, the $\mathrm{SO}_{3}$ test was the first test of the day. Because of the excessive ash buildup on the pipes with Hunter Valley coal, the possibility existed that the order of the tests could have influenced the results. Particulate emissions in Test 2 of Run 376 with EFGC were much higher than in Test 1 with $\mathrm{SO}_{3}$ alone. No logical reason other than a significant change in dust loading could explain this result. The actual dust loading for Test 2 was much higher, likely because of variation in the coal. Therefore, Test 2 was terminated, and Tests 3 and 4 were again repeat tests without and with EFGC at $25 \mathrm{ppm}$ of $\mathrm{SO}_{3}$. For Tests 3 and 4 , the inlet dust loadings were about the same, so differences in particulate emissions would have to be attributed to other effects. However, comparing Tests 3 and 4, particulate emissions were again higher with EFGC. An explanation other than system variability is not clear. Because of the possible influence of test order, a comparison was made between Test 1 of Run 375 with EFGC and Test 1 of Run 376 without EFGC. This comparison should remove bias because of test order. Results of this comparison (Figure A-7.2) show that particulate emissions are slightly higher with EFGC, which is opposite of the results observed when considering the data from Run 375. Therefore, from these first two runs, we do not have corroborating evidence that EFGC is effective with Hunter Valley coal. Sulfur retention data from these two runs, shown in Figure A-7.5, are also within the limits of data variability and do not indicate an advantage with EFGC.

Because of the variable test results from the first two runs, three additional runs (Runs 396-398) were completed with longer test times and with a modified EFGC approach. Results from these three additional runs are shown in Figures A-7.6 through A-7.13. The ESP temperature was again set at $275^{\circ} \mathrm{F}$ for Runs 396 and 397 , but was increased to $350^{\circ} \mathrm{F}$ for Run 398 . In addition to EFGC tests, each of these last three runs included a test with ammonia alone without $\mathrm{SO}_{3}$ or EFGC. All previous tests with ammonia were conducted with dual conditioning where both ammonia and $\mathrm{SO}_{3}$ were injected simultaneously.

Run 396 was intended to include only two test conditions: a baseline condition with $25 \mathrm{ppm} \mathrm{SO}$ and a test with $45 \mathrm{ppm}$ of ammonia alone. The first test was the baseline condition, which was scheduled to run at least 4 hours. 
However, shortly after starting the test at an ESP voltage of $50 \mathrm{kV}$, back corona was indicated by increased corona current. Voltage was reduced to $40 \mathrm{kV}$, and then to $30 \mathrm{kV}$, but back corona was still present. Finally, after one hour of testing, the applied voltage was reduced to $25 \mathrm{kV}$ to eliminate the back corona. Particulate emissions were high, and there was concern that $25 \mathrm{kV}$ was too low a voltage to compare the baseline and EFGC tests. Because of how rapidly the ESP went into back corona, there was concern that the plate may not have been adequately cleaned prior to the start of the test.

Therefore, the first test (Tes't 1A) was terminated after two hours of operation, and the ESP was thoroughly cleaned before the next test, including water washing of the plate (ESP walls). The second test (Test 1B) was a repeat of the baseline test. Test $1 B$ was again started with an applied voltage of $50 \mathrm{kV}$, but, after 40 minutes, back corona was observed, so the voltage was reduced to $40 \mathrm{kV}$. After 70 minutes into the test, back corona was again noticed, so the ESP was rapped. However, rapping did not el iminate the back corona, so the voltage was set back to $30 \mathrm{kV}$ at 80 minutes into the test. At $30 \mathrm{kV}$, the current climbed somewhat with increased dust buildup, but was controlled by rapping. Therefore, the voltage was held at $30 \mathrm{kV}$ for the remaining hour of the 3 -hour test. A comparison of the respirable mass particulate emissions for Tests $1 A$ and $1 B$ from Run 396 is shown in Figure A7.6 .

Test 2 in Run 396 was with 45 ppm of ammonia without any $\mathrm{SO}_{3}$. After 25 minutes, the voltage was reduced from the starting value of $50 \mathrm{kV}$ to $40 \mathrm{kV}$, not because of back corona, but because of sparking. At 60 minutes into the test, the voltage was increased to $45 \mathrm{kV}$ because back corona was clearly not occurring. For the next 45 minutes of the test, ESP performance was steady with no sign of back corona. At this point ( 1 hour and 45 minutes into the test), the ammonia was shut off to see if the ESP performance would deteriorate immediately. Particulate emissions started to increase slowly and the ESP started sparking after 5 minutes, so the voltage was reduced to $40 \mathrm{kV}$. After an additional 5 minutes (at 2 hours into the test), the ESP was rapped. The rapping momentarily stopped the current climb that had started when the ammonia was shut off, but ESP performance was clearly deteriorating. For the last 5 minutes of the test, the ammonia was again turned on, which resulted in reduced emissions and current. These observations indicated that $45 \mathrm{ppm}$ of ammonia alone resulted in much better ESP performance than $25 \mathrm{ppm}$ of $\mathrm{SO}_{3}$ 
alone. However, since this was the first test with ammonia alone, it was thought that a test with ammonia should be repeated during the next run for verification of the results.

Run 397 included two tests: Test 1 was an EFGC test with $25 \mathrm{ppm}$ of $\mathrm{SO}_{3}$ for comparison with the baseline tests of Run 396, and Test 2 was a repeat test with $45 \mathrm{ppm}$ of ammonia alone. For the EFGC test, a 50-kV voltage was maintained for 80 minutes compared to only 40 minutes for the Run 396-1B baseline test. The voltage was initially set back to $45 \mathrm{kV}$, but back corona was still present, so the voltage was reduced to $33 \mathrm{kV}$ to avert back corona conditions. By 2 hours and 20 minutes into the test, voltage was reduced to $30 \mathrm{kV}$, where it remained for the duration of the 5-hour test. At $30 \mathrm{kV}$, back corona was completely avoided based on the corona current readings. Since a $50-k V$ voltage was maintained for twice as long and since back corona was completely avoided at $30 \mathrm{kV}$, it appeared that EFGC resulted in better ESP performance than $\mathrm{SO}_{3}$ alone. Particulate emissions data also indicated that better ESP performance was achieved with EFGC.

The second test in Run 397 was a repeat test with 45 ppm of ammonia alone. Initial starting voltage was again $50 \mathrm{kV}$, but it had to be reduced to $45 \mathrm{kV}$ after 10 minutes. However, a $45-\mathrm{kV}$ electrode potential was maintained for the remainder of the 3-hour test without any indication of back corona. Because of the higher voltage maintained with ammonia injection, particulate emissions were significantly lower than with $25 \mathrm{ppm}$ of $\mathrm{SO}_{3}$ and EFGC. This test confirmed the results with ammonia injection from the previous run, leading to the conclusion that, for Hunter Valley coal and a $275^{\circ} \mathrm{F}$ ESP temperature, injection of $45 \mathrm{ppm}$ of ammonia results in superior ESP performance compared to either $25 \mathrm{ppm}$ of $\mathrm{SO}_{3}$ alone or $25 \mathrm{ppm}$ of $\mathrm{SO}_{3}$ with EFGC. Respirable mass emissions, shown in Figure A-7.7, for the two ammonia tests were similar during the time period from 70 minutes to 100 minutes when the voltage for both tests was set at $45 \mathrm{kV}$, indicating that this result was repeatable.

A comparison of respirable mass emissions for the baseline, EFGC, and ammonia tests is shown in Figure A-7.8, which includes the baseline Test $1 B$ from Run 396, the EFGC test from Run 397, and the ammonia test from Run 397. The relative reductions in particulate emissions with EFGC and ammonia are 
clear from the graph. The respirable mass data are in good agreement with the EPA Method 5 dust-loading data which show the highest emissions for the baseline test, somewhat lower emissions for the EFGC test, and significantly lower emissions for the ammonia test.

Since there was only a small improvement in ESP performance with EFGC, a further analysis of all of the data will help to verify the results. Four types of particulate emissions data (given in Table A-3) are available, the APS, the CNC, EPA Method 5, and the DMPS. APS results were already mentioned to indicate better ESP performance with EFGC. The CNC data reported are average values taken from the last half of each test when the voltage was held constant. The CNC data are in agreement with the APS data showing lower emissions with EFGC. The EPA Method 5 data also confirm the lower emissions with EFGC; however, the inlet dust loading was somewhat higher for the baseline test. To normalize this difference, a comparison should be made of the ESP collection efficiencies based on the inlet dust loadings during the individual test periods. Table A-3 shows that ESP collection efficiency was $77.35 \%$ for the basel ine test compared to $86.52 \%$ for the EFGC test, which shows that better ESP performance was achieved with EFGC. The DMPS mass data shown in Table A-3 indicate lower submicron mass for the baseline test, but this discrepancy can be explained. The DMPS data shown in Table A-3 for the baseline test were from early during the test before the voltage was reduced to $30 \mathrm{kV}$. A second DMPS measurement during the baseline test at $30 \mathrm{kV}$ was invalid because of a sampling problem. For the EFGC test, two DMPS measurements were taken (the average value is reported in Table A-3), both at a voltage of $30 \mathrm{kV}$. Therefore, a direct comparison of the DMPS data between the baseline and EFGC tests is not valid, but all of the other particulate measurements indicate better ESP performance with EFGC.

Comparing the ESP electrical conditions between the baseline and EFGC tests also indicates better performance with EFGC. At an applied voltage of $30 \mathrm{kV}$, the ESP was well into back corona for the baseline test, but operated without back corona with EFGC, as shown in Figure A-7.10. Sparking voltage was the same for the baseline and EFGC tests at $44 \mathrm{kV}$, but this may not be a significant indicator of ESP performance because the ESP was well into back corona at $44 \mathrm{kV}$ for both cases. Valid resistivity readings were not available because of the fairly high carbon content of the fly ash. The LOI of the ESP 
hopper ash was $11.9 \%$ for the baseline test and $8.5 \%$ for the EFGC test. From previous tests (for example, see Figure A-2.8), this difference in LOI did not likely have a significant effect on the results. While the LOI of the resistivity cyclone ash was not measured, from previous data, it would be expected to be higher than the LOI of the hopper ash. From past tests, we know that high carbon content of ash collected in the resistivity cyclone can result in high resistivity currents and invalid resistivity measurements.

One additional important result is the effect of EFGC on sulfur retention. Sulfur analysis was completed on the ESP hopper ash for each of the tests, and two sulfur analyses were completed on separate ash samples from the EFGC test. For the Test $I A$ and $I B$ baseline tests in Run 396, the respective sulfur contents were $0.66 \%$ and $0.56 \%$ for an average of $0.61 \%$. For the EFGC test in Run 397, the two sulfur analyses were $0.75 \%$ and $0.64 \%$ for an average of $0.70 \%$. The respective sulfur analyses for the ammonia tests in Runs 396 and 397 were $0.40 \%$ and $0.36 \%$. At first glance, it might appear that the sulfur retention data are too variable to form a conclusion concerning the effect of $\mathrm{EFGC}$ on $\mathrm{SO}_{3}$ transfer. However, the data must be normalized, to account for differences in dust loadings among the different tests. The amount of sulfur in the ash for the case when no $\mathrm{SO}_{3}$ was added should al so be subtracted to consider only the amount of injected $\mathrm{SO}_{3}$ that was transferred to the fly ash. Therefore, to compare $\mathrm{SO}_{3}$ transfer for the baseline and EFGC conditions, the first step is to subtract the $0.40 \%$ sulfur value with no $\mathrm{SO}_{3}$ injection from the Tests $\mathrm{IA}$ and $\mathrm{IB}$ baseline sulfur values with $25 \mathrm{ppm}$ of $\mathrm{SO}_{3}$ injection. This leaves $0.26 \%$ sulfur for Test $1 A$ and $0.16 \%$ sulfur for Test $1 B$. Next these values need to be normalized to account for the differences in dust loadings. Inlet dust loadings were calculated based on the actual amount of ash collected in the ESP hopper for each test added to the outlet dust loading from each test. For Tests $1 A$ and $1 B$, the respective dust loadings were 1.88 and 3.20 grains/scf. If these dust loadings are multiplied by the respective sulfur concentrations of $0.26 \%$ and $0.16 \%$, we obtain values of 0.0049 grains/scf and 0.0051 grains/scf of sulfur transfer. Completing the same analysis for the EFGC test produces sulfur transfer values of 0.0087 and 0.0064 grains/scf. If the average of the two baseline values $(0.0050$ grains/scf) is compared with the average of the two EFGC values $10.0076 \%$ grains/scf), there is a $50 \%$ improvement in sulfur transfer with EFGC. Sulfur retention data, therefore, indicate that better results are achieved with EFGC 
over $\mathrm{SO}_{3}$ injection alone. The difference in sulfur retention values for the two EFGC samples can also be explained. During the time the first sample was collected, the starting ESP voltage was $50 \mathrm{kV}$, but was $30 \mathrm{kV}$ by the end of this period. During the entire time the second sample was collected, the voltage was constant at $30 \mathrm{kV}$. Therefore, the average voltage while the first sample was collected was higher than the average voltage for the second sample. At a higher ESP voltage, a larger fraction of any $\mathrm{SO}_{3}$ mist would be expected to reach the plate, and, subsequently, the ESP hopper ash would be higher in sulfur retention.

One further source of available data to assess the effect of EFGC is the tensile strength measurements. A comparison of tensile strengths for the baseline and EFGC samples from Runs 396 and 397 is shown in Figure A-7.12. Results show that the tensile strengths for the two baseline samples are similar, but that the tensile strength is increased with EFGC. Interestingly, the highest tensile strength was observed for the first EFGC sample with the highest sulfur retention. From previous tensile strength data with $\mathrm{SO}_{3}$ injection alone, tensile strength was found to increase with increased sulfur retention (for example, see Figure A-2.16). The tensile strength data not only indicate increased sulfur retention with EFGC, but also indicate higher sulfur retention for the first EFGC sample than the second EFGC sample. The tensile strength data are in complete agreement with the measured sulfur retention data, both indicating better $\mathrm{SO}_{3}$ transfer with EFGC. Therefore, the particulate emissions' data, the ESP electrical data, the sulfur retention data, and the tensile strength data, all considered together, provide strong evidence that, with Hunter Valley coal and a $275^{\circ} \mathrm{F}$ ESP temperature, improved ESP performance can be achieved with EFGC compared to $\mathrm{SO}_{3}$ injection alone.

The promising results at $275^{\circ} \mathrm{F}$ lead to the question of whether the benefit of EFGC can be retained when the ESP is operated at a higher temperature. Run 398 was conducted to address this question and included two 4-hour tests: Test 1 was an EFGC experiment with $25 \mathrm{ppm}$ of $\mathrm{SO}_{3}$ at an ESP temperature of $350^{\circ} \mathrm{F}$, and Test 2 was an experiment with $45 \mathrm{ppm}$ of ammonia alone at the same ESP temperature. Respirable mass emissions for the two tests, shown in Figure A-7.9, indicate that particulate emissions were higher with EFGC at $350^{\circ} \mathrm{F}$ than for the EFGC test at $275^{\circ} \mathrm{F}$. The EPA Method 5 dust loadings, the CNC data, and the DMPS data all confirm that particulate 
emissions were higher at $350^{\circ} \mathrm{F}$. During the last half of both EFGC tests, the ESP voltage was held at $30 \mathrm{kV}$. At $275^{\circ} \mathrm{F}$ with EFGC, back corona was avoided, but, at $350^{\circ} \mathrm{F}$ with EFGC, the ESP was well into back corona. Both the particulate emissions data and the ESP electrical data reflect a deterioration in ESP performance at the higher temperature. Since no baseline test was conducted with $25 \mathrm{ppm}$ of $\mathrm{SO}_{3}$ at $350^{\circ} \mathrm{F}$, we cannot conclude that EFGC had no benefit at $350^{\circ} \mathrm{F}$. The fact that ESP performance for the EFGC test at $350^{\circ} \mathrm{F}$ was not as good as performance for the EFGC test at $275^{\circ} \mathrm{F}$ simply indicates that the benefit of EFGC was not adequate to overcome the increased resistivity problem at the higher temperature.

Comparing the EFGC results at $350^{\circ} \mathrm{F}$ with the results with $45 \mathrm{ppm}$ of ammonia alone (see Figure A-7.9) indicates much better ESP performance with ammonia injection. Current density as a function of voltage, given in Figure A-7.11, shows that back corona was avoided with ammonia injection, which also indicates better ESP performance with ammonia alone. Therefore, we have two ammonia injection tests at an ESP temperature of $275^{\circ} \mathrm{F}$ and one ammonia injection test at an ESP temperature of $350^{\circ} \mathrm{F}$ that all resulted in better ESP performance than either $\mathrm{SO}_{3}$ injection alone or $\mathrm{SO}_{3}$ injection with EFGC.

There are two general mechanisms by which ammonia conditioning is known to improve ESP performance. One mechanism is a change in the cohesive properties of the ash which results in significantly reduced reentrainment. A second general mechanism is a change in the electrical conditions within the ESP which may include a reduction in ash resistivity as well as space-charge effects. Tensile strength measurements, shown in Figure A-7.13, show higher tensile strength for the EFGC tests with $25 \mathrm{ppm}$ of $\mathrm{SO}_{3}$, indicating that a change in cohesive properties was not the mechanism of improvement. This is in contrast to the previously mentioned tensile strength data which showed dual conditioning with both ammonia and $\mathrm{SO}_{3}$ resulted in increased tensile strength compared to $\mathrm{SO}_{3}$ alone. In the case of ammonia injection alone with the Hunter Valley coal, there was apparently not enough natural $\mathrm{SO}_{3}$ present for the ammonia injection to produce an increased tensile strength. The sulfur analysis data also indicate that there was much less sulfur retained in the fly ash for the ammonia injection tests compared to the $\mathrm{SO}_{3}$ injection tests. This implies that the improvement must be the result of changed 
electrical conditions. Since valid resistivity measurements are not available, a direct comparison of resistivity with ammonia injection and $\mathrm{SO}_{3}$ injection is not possible. However, since the sulfur retention was much less with ammonia injection, the ash resistivity with ammonia would be expected to be higher than the resistivity with $\mathrm{SO}_{3}$ injection. Lowered ash resistivity with ammonia in the absence of $\mathrm{SO}_{3}$ would not occur unless there was a more conductive path through the deposited ash layer. This would appear to have to be the result of either ammonia ion adsorption on the fly ash or a high enough ammonia concentration in the interstitial spaces in the deposited ash layer. It should be recognized that the void space or percent porosity of the deposited ash layer with Hunter Valley ash is expected to be in the range of about $70 \%$ to $75 \%$, based on the tensile strength vs. porosity measurements. Whether sufficient ammonia adsorption on the fly ash or high enough ammonia concentration in the void spaces could alter the effective resistivity of the ash layer is not known. What does appear to have occurred is that the ammonia suppressed the formation of back corona such that the ESP could be operated at higher voltages without back corona, with a net result of higher particulate collection efficiency.

\subsection{CONCLUSIONS AND RECOMMENDATIONS}

The strongest conclusion that can be drawn from this study is that, with the four test coals, dual conditioning with ammonia and $\mathrm{SO}_{3}$ is superior to $\mathrm{SO}_{3}$ conditioning alone in improving ESP performance. The better performance with dual conditioning is attributed to several effects. One effect is better transfer of the $\mathrm{SO}_{3}$ to the fly ash which results in lower resistivity and less $\mathrm{SO}_{3}$ in the flue gas downstream of the ESP. In cases where resistivity cannot be adequately controlled with $\mathrm{SO}_{3}$ alone, a reduction in resistivity with dual conditioning should directly result in lower particulate emissions because of a higher allowable electric field strength. Another primary mechanism of reduced particulate emissions with dual conditioning is the effect on the cohesive properties of the ash. Quantitative measurements show that dual conditioning results in a greater ash tensile strength than $\mathrm{SO}_{3}$ alone. The increased tensile strength of the ash with dual conditioning results in reduced continuous reentrainment and lower rapping puffs. The net result is significantly lower particulate emissions with dual conditioning. A third 
mechanism of superior performance with dual conditioning may occur in cases where the $\mathrm{SO}_{3}$ reacts with and is partially neutralized by the fly ash. In such cases, injection of ammonia upstream of the $\mathrm{SO}_{3}$ may allow the $\mathrm{SO}_{3}$ to react with the ammonia rather than the fly ash and have a greater effect on ash resistivity than the same concentration of $\mathrm{SO}_{3}$ alone.

Limited data indicate that upstream injection of ammonia is preferred to injection of the ammonia downstream of the $\mathrm{SO}_{3}$. Lower submicron emissions and slightly lower resistivity indicate that somewhat better transfer of conditioning agents to the fly ash was achieved with upstream ammonia injection.

Data indicate no clear advantage to using a 2:1 molar ratio of ammonia to $\mathrm{SO}_{3}$, compared to a $1: 1$ ratio. While some tests indicated a slight reduction in respirable mass emissions at the 2:1 ratio, submicron mass emissions for some tests were higher at the 2:1 ratio. Resistivity measurements indicated that resistivity was somewhat higher at a $2: 1$ ratio compared to a $1: 1$ ratio. Several tests also were conducted at a ratio of 0.5:1 of ammonia to $\mathrm{SO}_{3}$, but ESP performance was not as good as with a $1: 1$ ratio. Therefore, the preferred ratio appears to be a $1: 1$ ratio of ammonia to $\mathrm{SO}_{3}$.

The EFGC results indicated some improvement in ESP performance over $\mathrm{SO}_{3}$ alone for all three coals tested; but much less improvement than was seen with dual conditioning. Therefore, the effectiveness of EFGC remains somewhat in question. Nevertheless, further development of the EFGC concept would appear warranted, because tests indicated improved ESP performance, and changes can be made to the EFGC system that would likely further improve results with EFGC.

One somewhat surprising result was the improved ESP performance achieved with Hunter Valley coal with ammonia injection alone. Since ammonia injection alone was not tested with the other coals, no general conclusion can be drawn as to the effectiveness of ammonia alone compared to the other methods. However, from the Hunter Valley results, it appears that the most effective conditioning method is dual conditioning followed by ammonia alone, EFGC, and 
$\mathrm{SO}_{3}$ alone. Further work is needed to explain the mechanisms of improvement with ammonia alone to predict when ammonia conditioning is applicable.

A question that was not addressed in the study is the effect of dual conditioning on rapping efficiency. Since dual conditioning increases the tensile strength of the ash, it is possible that the plates will not clean well, and excessive ash buildup may occur. Therefore, a further recommendation is to evaluate the effect of dual conditioning on rapping efficiency in longer-term tests. 
I

I

I

I

I

I

I

I

I

I

I

I

I

I

I

I

I

I

I

APPENDIX 


\begin{tabular}{|c|c|c|c|c|}
\hline \multicolumn{5}{|c|}{$\begin{array}{c}\text { TABLE A-1 } \\
\text { COAL ANALYSES FOR DOE/WAHLCO TESTS }\end{array}$} \\
\hline \multirow[b]{2}{*}{ Collection Pt. } & \multirow[b]{2}{*}{$\begin{array}{c}\text { Run } \\
\text { Composite }\end{array}$} & \multirow{2}{*}{$\frac{\begin{array}{c}\text { Hunter } \\
\text { Valley }\end{array}}{\begin{array}{c}\text { Run } \\
\text { Composite }\end{array}}$} & \multirow{2}{*}{$\begin{array}{l}\text { Hudson } \\
\text { Storage } \\
\text { Bunker }\end{array}$} & \multirow{2}{*}{$\begin{array}{c}\begin{array}{c}\text { Pleasant } \\
\text { Prairie }\end{array} \\
\text { Storage } \\
\text { Bunker }\end{array}$} \\
\hline & & & & \\
\hline \multicolumn{5}{|c|}{ PROXIMATE (\% moisture free) } \\
\hline Ash & 12.86 & 16.99 & 5.28 & 6.34 \\
\hline Volatile Matter & 47.81 & 31.74 & 23.47 & 44.71 \\
\hline Fixed Carbon & 39.33 & 51.27 & 71.25 & 48.95 \\
\hline $\begin{array}{l}\text { Coal Moisture } \\
\text { (as received) }\end{array}$ & 21.00 & 2.60 & 0.90 & 29.50 \\
\hline \multicolumn{5}{|c|}{ ULTIMATE (\% moisture free) } \\
\hline Carbon & 61.71 & 69.29 & 86.56 & 70.59 \\
\hline Hydrogen & 4.80 & 4.47 & 3.35 & 5.20 \\
\hline Nitrogen & 1.15 & 1.60 & 1.73 & 1.09 \\
\hline Sulfur & 0.98 & 0.51 & 0.85 & 0.46 \\
\hline Oxygen (diff) & 18.48 & 7.12 & 2.21 & 16.30 \\
\hline Ash & 12.86 & 16.99 & 5.28 & 6.34 \\
\hline \multicolumn{5}{|c|}{ HEATING VALUE (moisture free) } \\
\hline Btu/lb & 10686 & 12089 & 14120 & 12823 \\
\hline \multicolumn{5}{|c|}{ XRF COAL ASH ANALYSES (\% conc. as oxides) } \\
\hline SiO2 & 35.5 & 84.5 & 52.0 & 27.0 \\
\hline $\mathrm{Al} 2 \mathrm{O} 3$ & 15.8 & 12.3 & 30.8 & 16.9 \\
\hline $\mathrm{Fe} 2 \mathrm{O} 3$ & 5.5 & 0.9 & 6.7 & 5.0 \\
\hline $\mathrm{TiO} 2$ & 1.4 & 0.6 & 2.1 & 1.9 \\
\hline P2O5 & 0.7 & 0.0 & 0.5 & 1.3 \\
\hline $\mathrm{CaO}$ & 19.6 & 0.3 & 2.9 & 27.2 \\
\hline $\mathrm{MgO}$ & 4.1 & 0.6 & 1.8 & 5.5 \\
\hline $\mathrm{Na} 2 \mathrm{O}$ & 0.8 & 0.0 & 0.6 & 1.4 \\
\hline $\mathrm{K} 2 \mathrm{O}$ & 0.2 & 0.2 & 1.1 & 0.1 \\
\hline $\mathrm{SO} 3$ & 16.4 & 0.6 & 1.5 & 13.7 \\
\hline \multicolumn{5}{|c|}{ SIEVE TEST (\% retained) } \\
\hline 100 mesh & 7.00 & 4.85 & 5.32 & 6.35 \\
\hline 140 mesh & 13.59 & 9.79 & 8.89 & 12.67 \\
\hline 170 mesh & 5.46 & 4.12 & 6.49 & 4.47 \\
\hline 200 mesh & 10.94 & 9.67 & 9.58 & 11.51 \\
\hline 270 mesh & 21.39 & 13.34 & 15.13 & 13.63 \\
\hline 325 mesh & 4.95 & 6.30 & 22.36 & 6.37 \\
\hline Pan & 36.57 & 51.93 & 33.41 & 45.00 \\
\hline$\%<200$ mesh & 62.91 & 71.57 & 70.90 & 65.00 \\
\hline
\end{tabular}




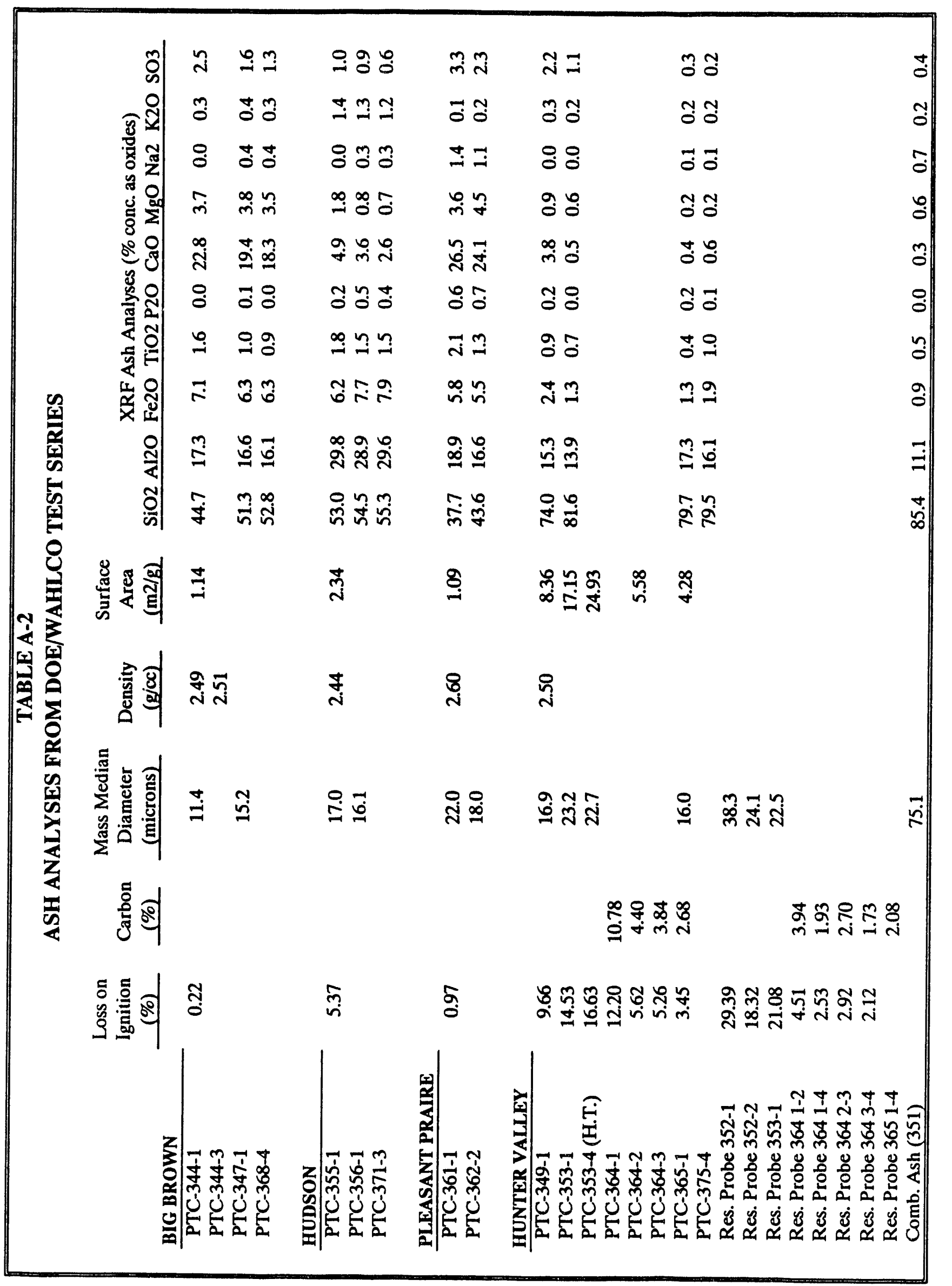




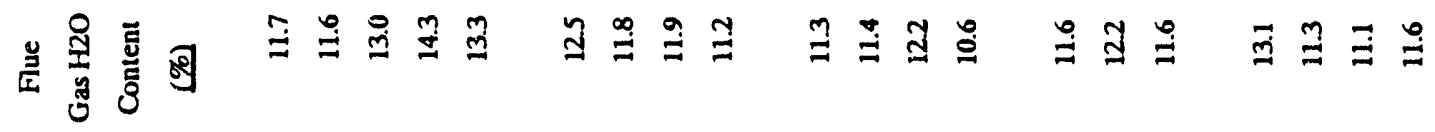

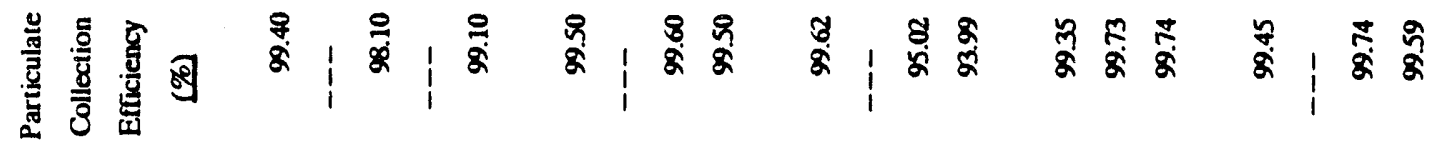

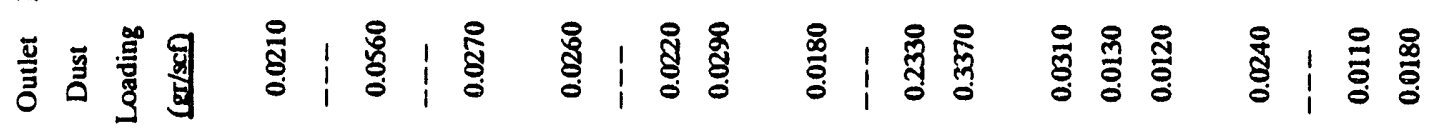

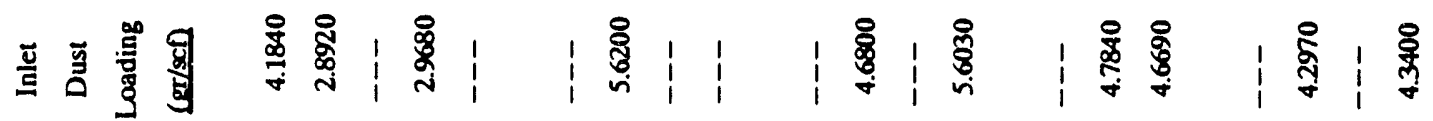

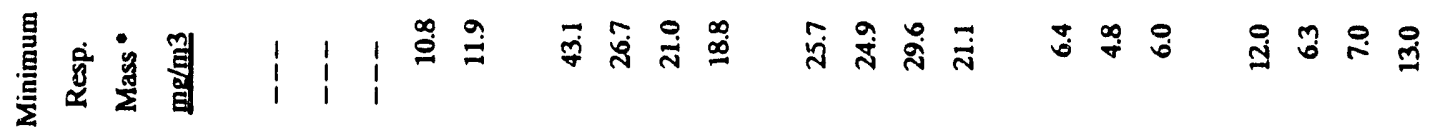

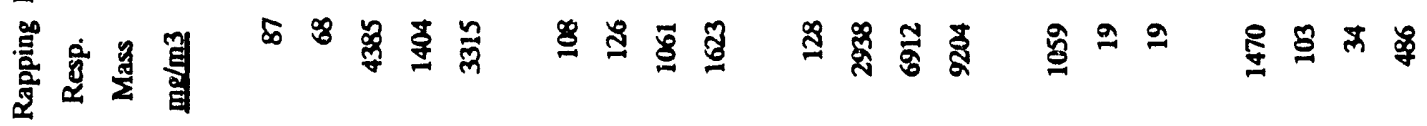

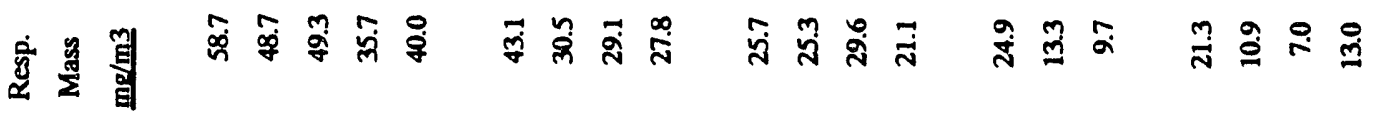

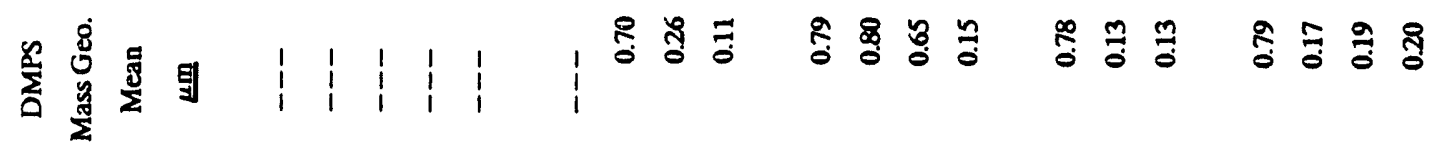

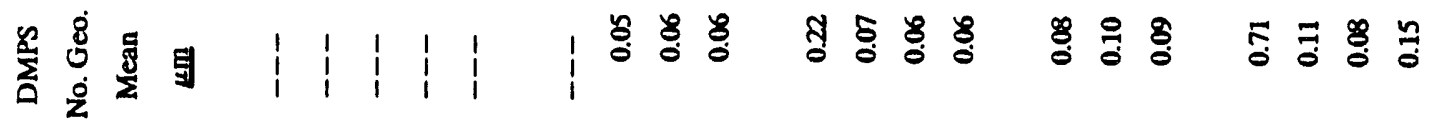

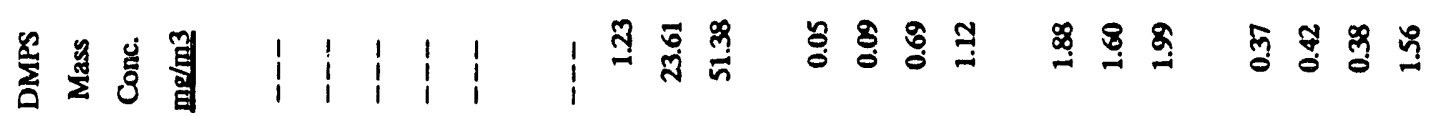

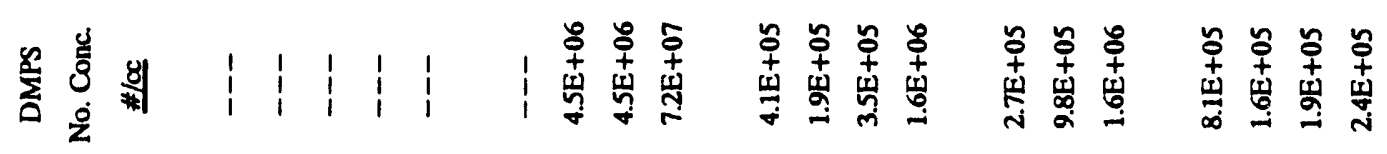

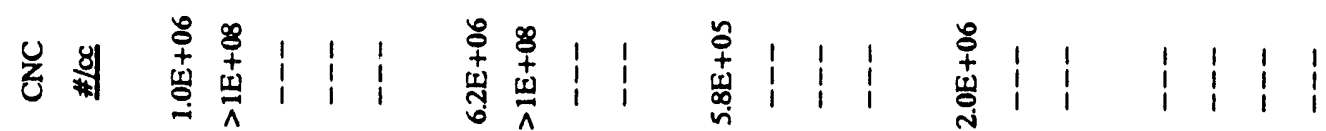

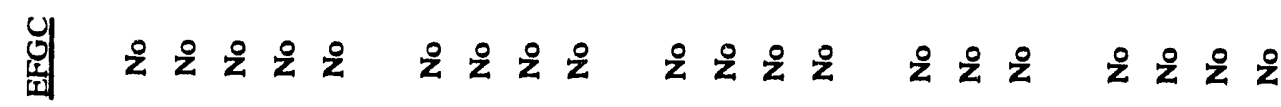

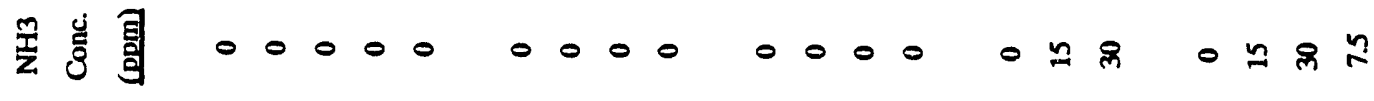
总岁罗

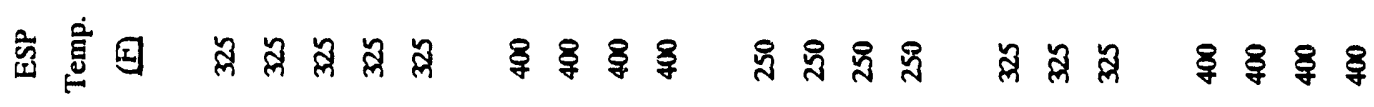

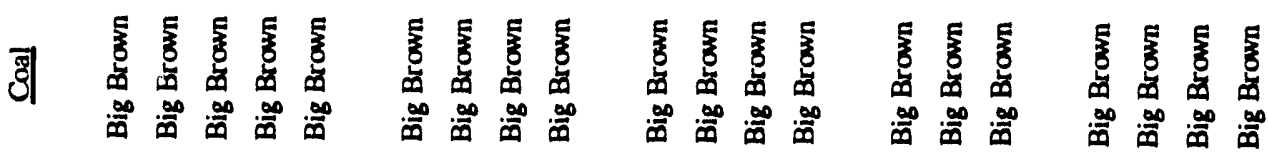

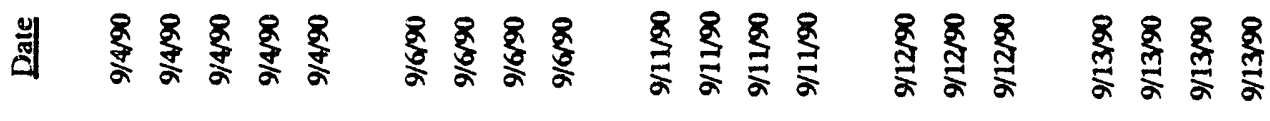




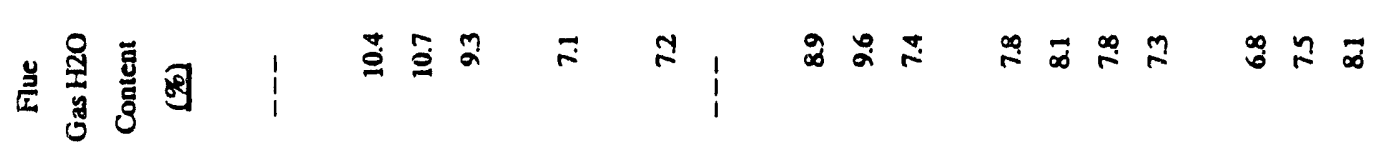

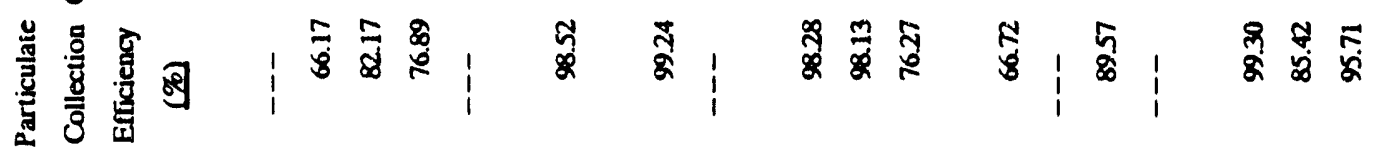

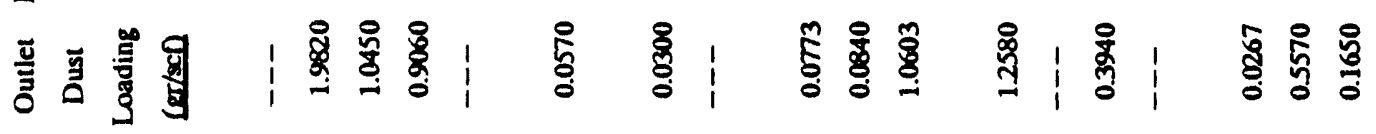

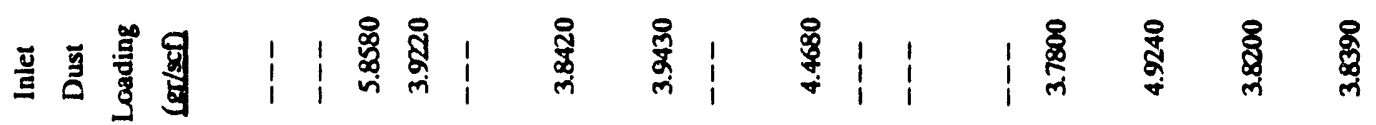

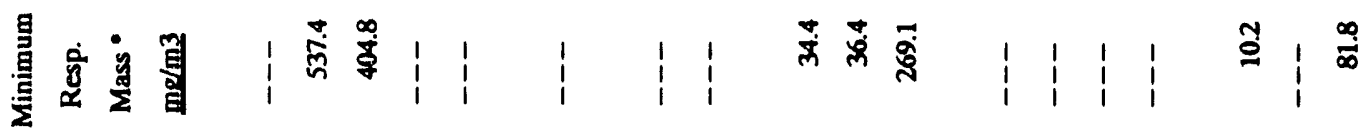

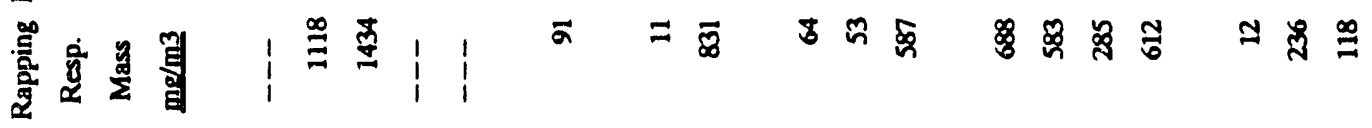

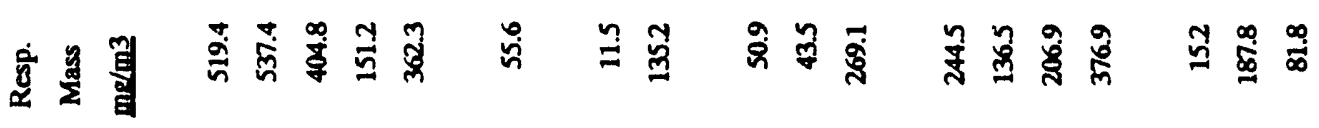

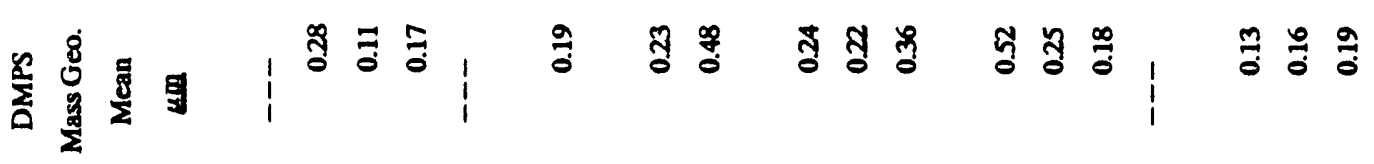

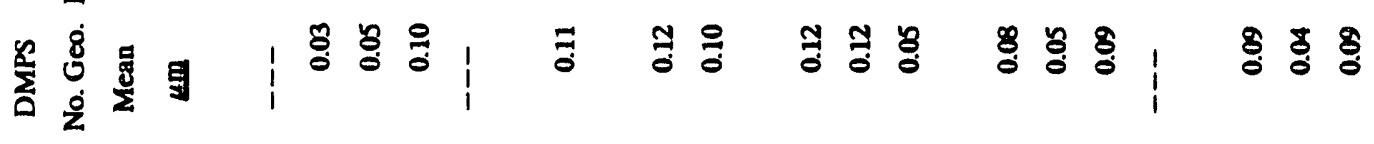

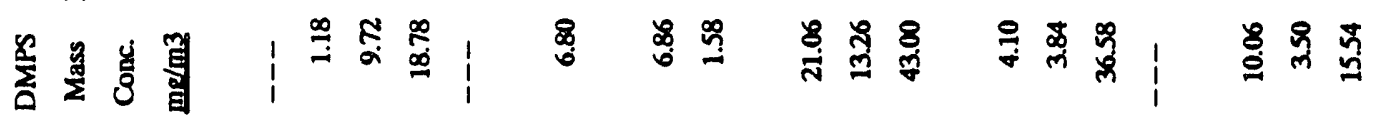

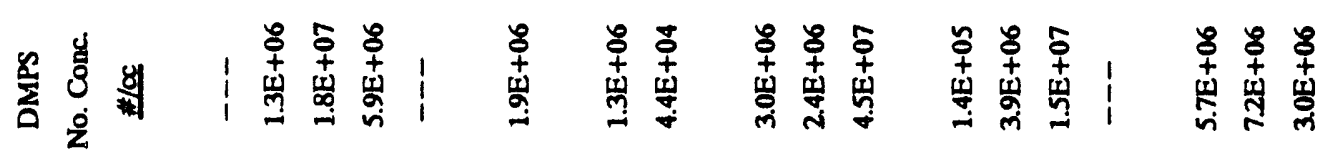

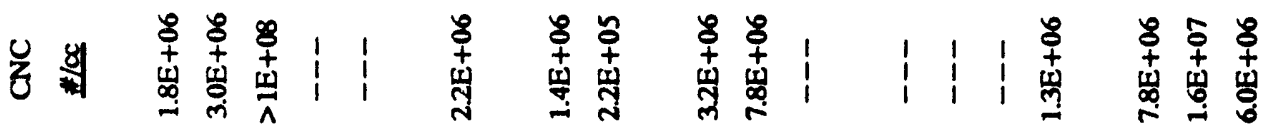

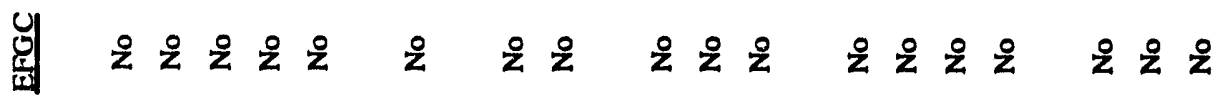

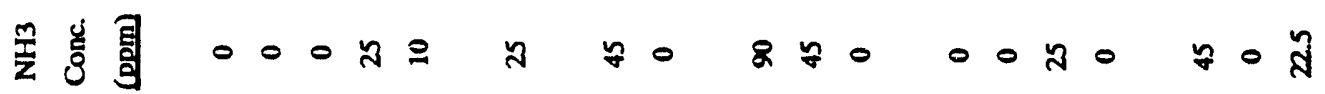

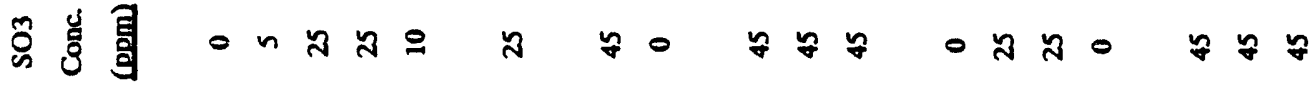

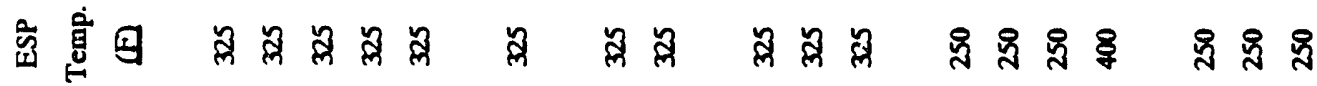

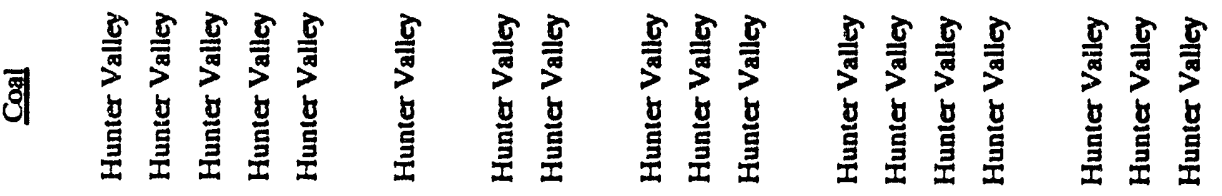

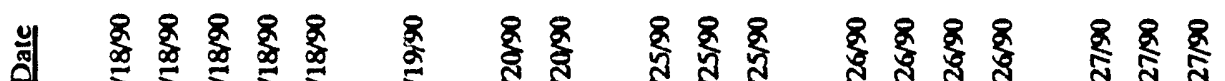
ga $\cdots \cdots \cdots \cdots \cdots \cdots$

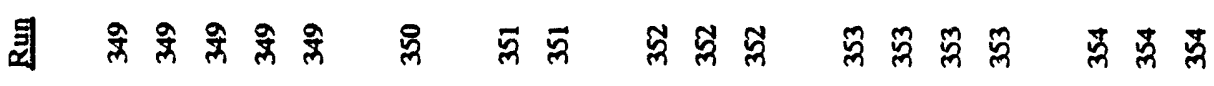




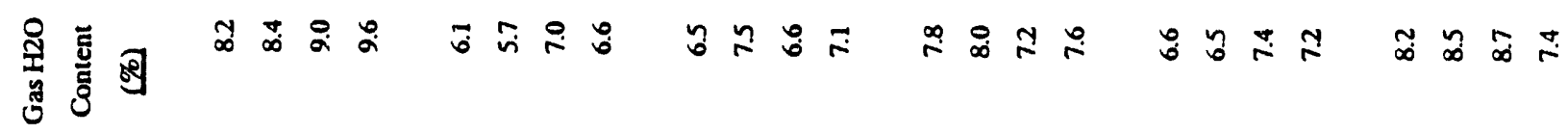

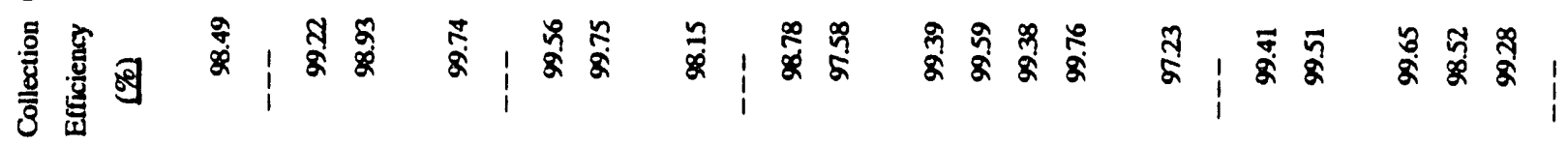

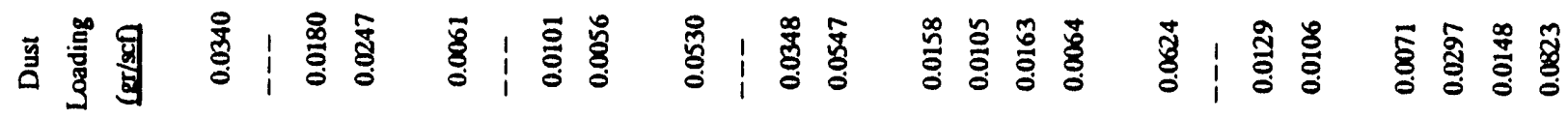

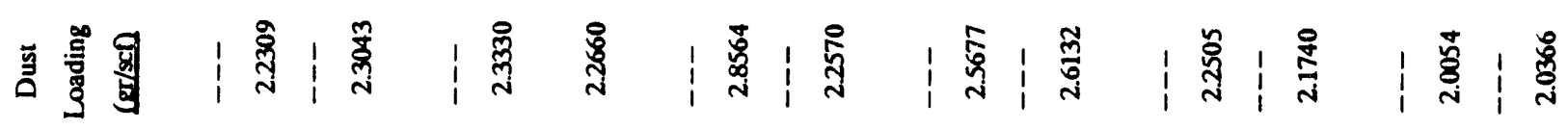

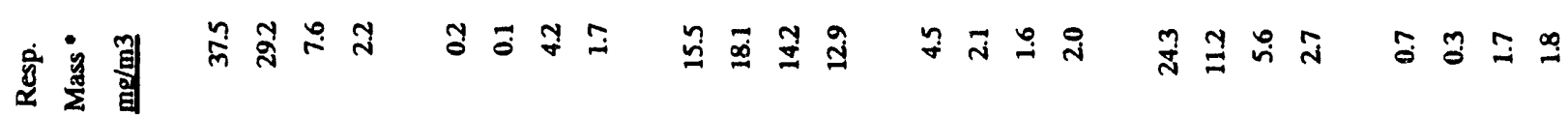

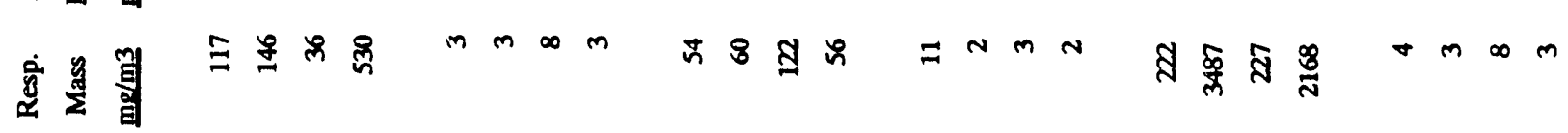

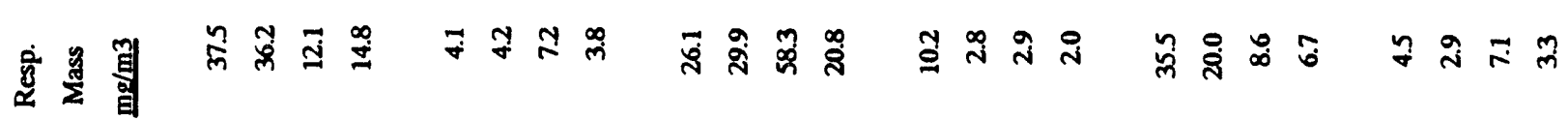

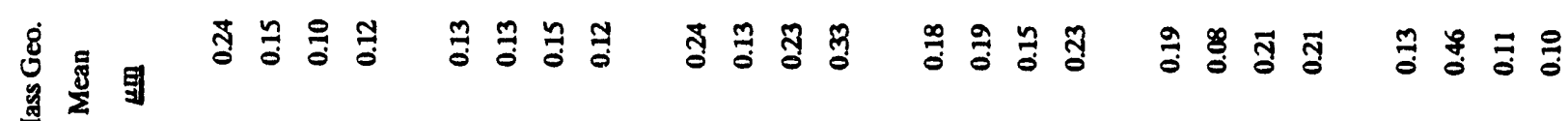

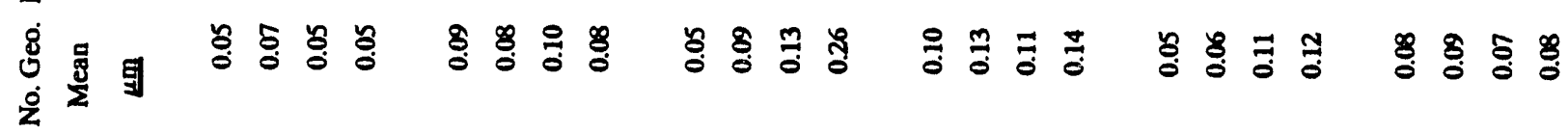

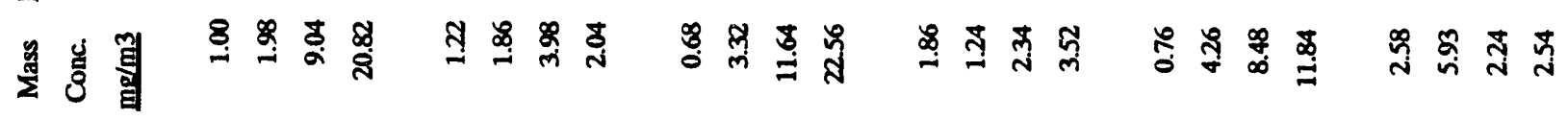

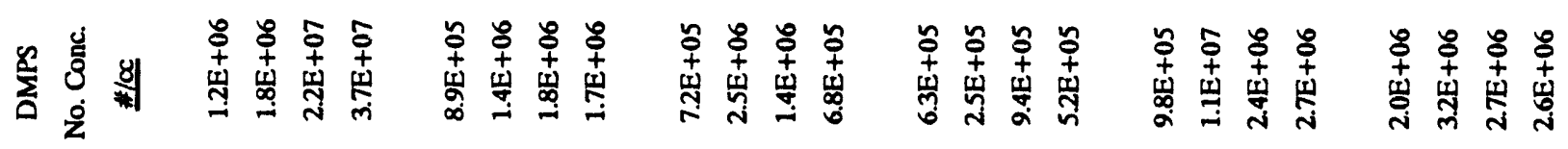

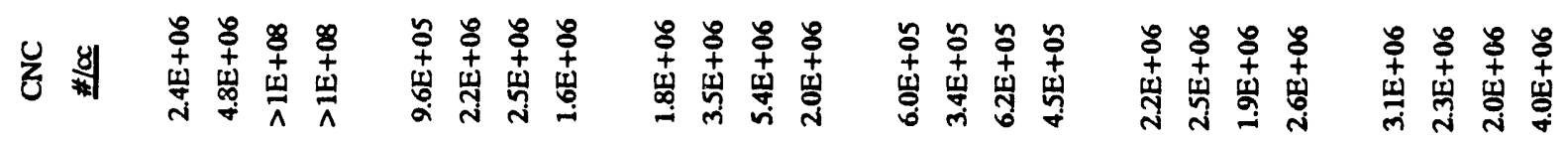

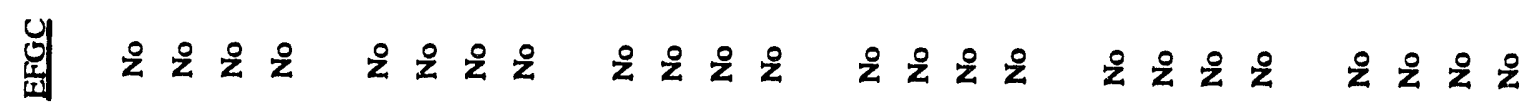

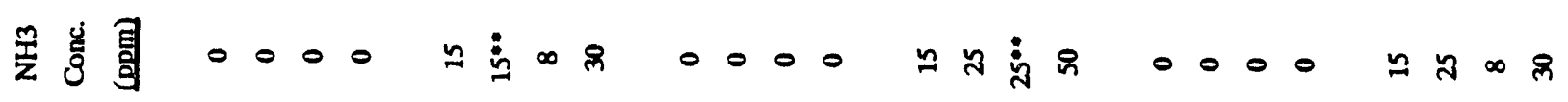

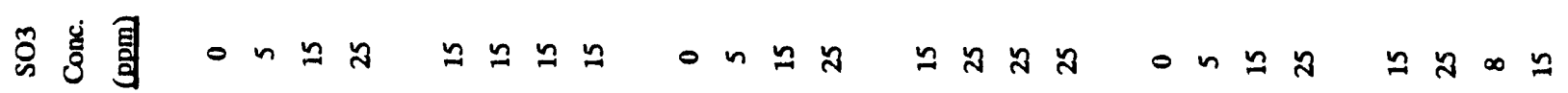

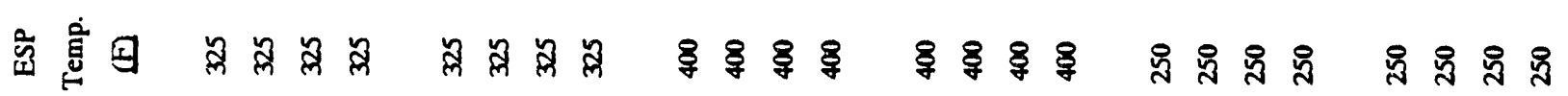

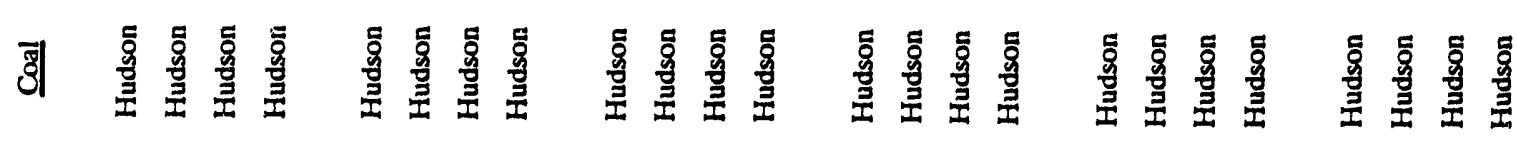

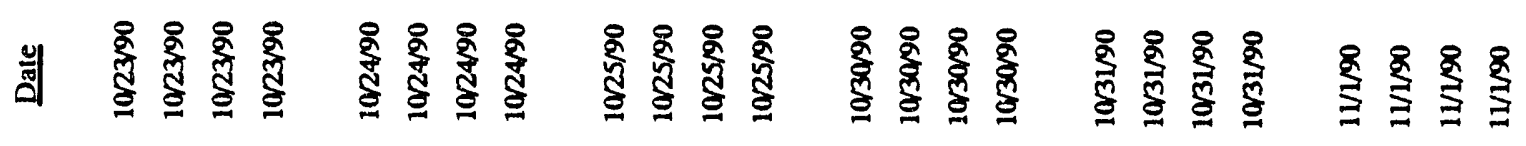

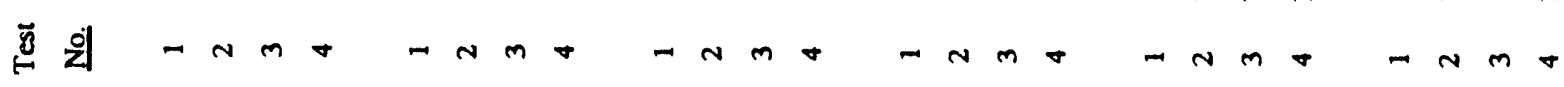

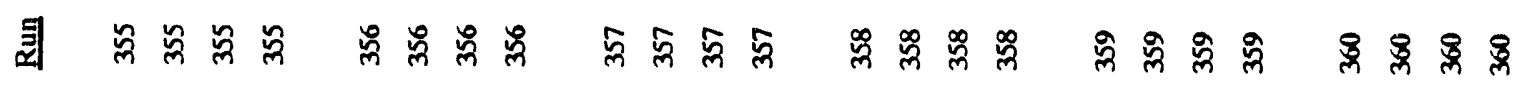




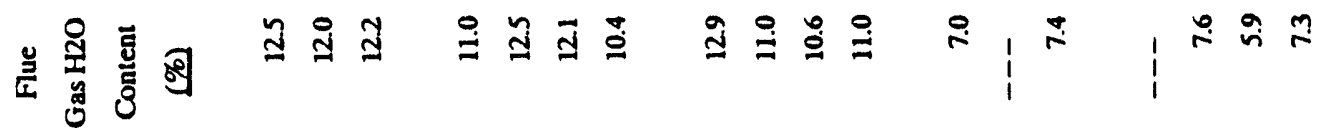

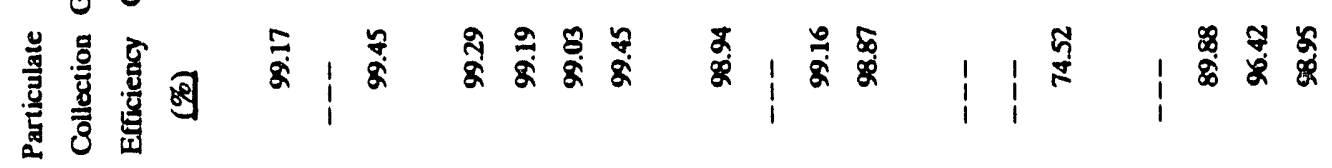

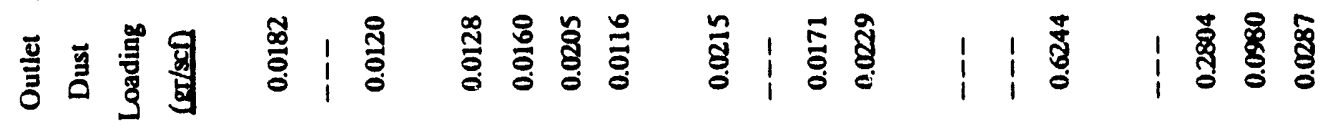

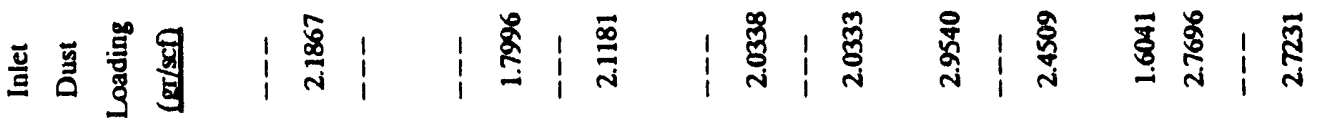
重量重置 喜重重置

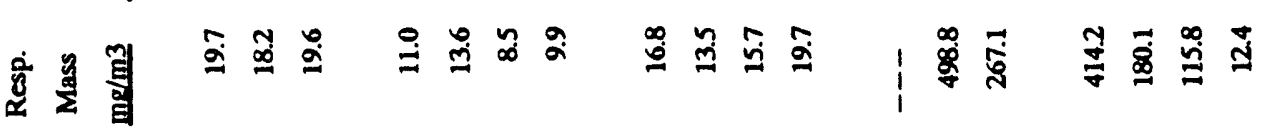

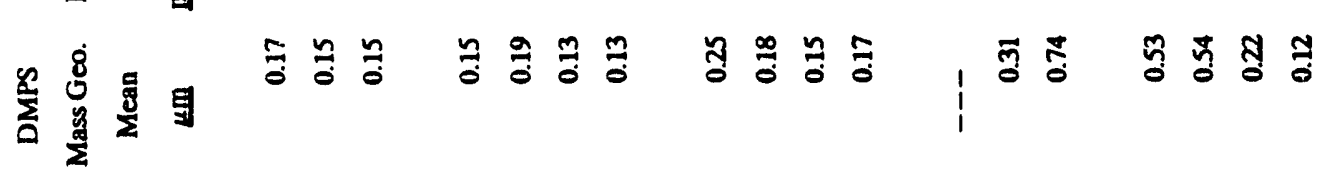

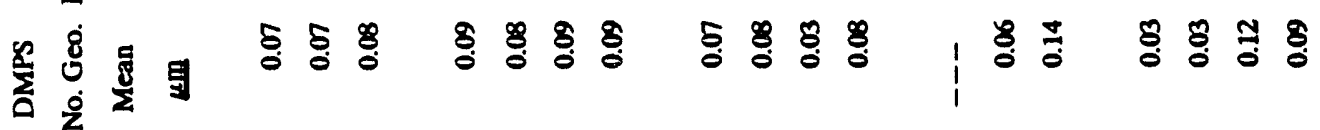

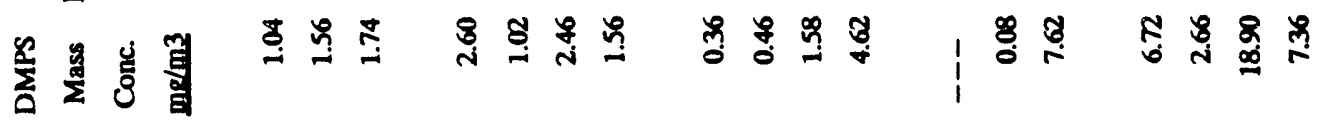

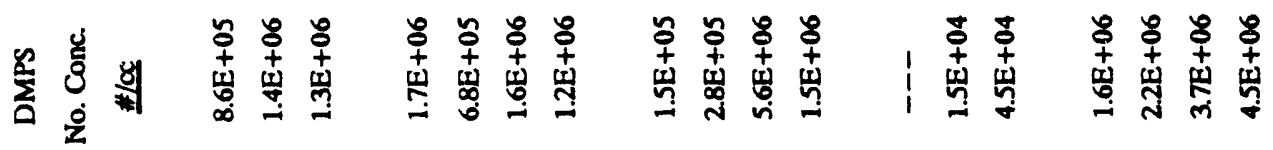

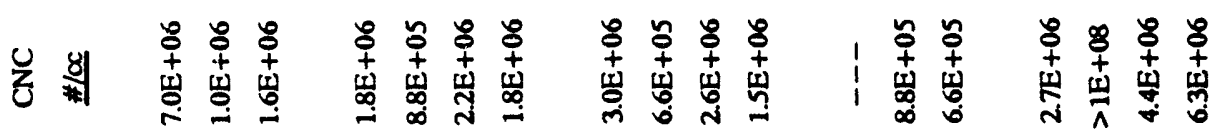

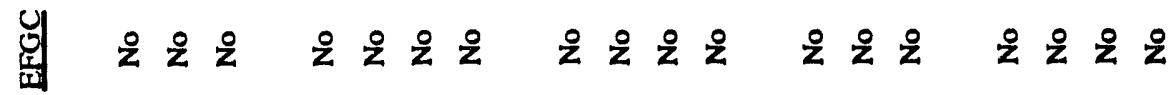

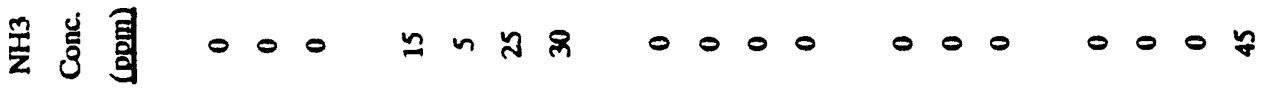

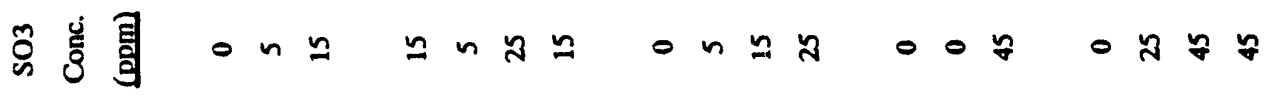

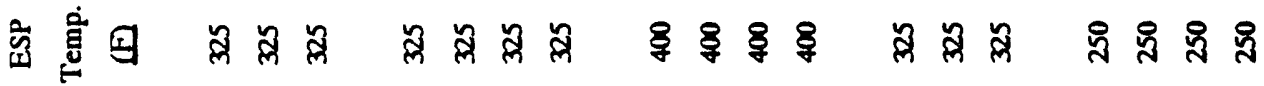

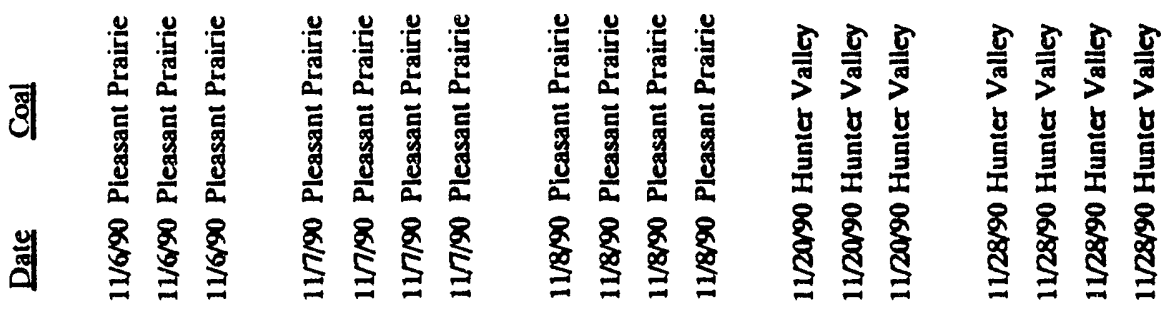
용

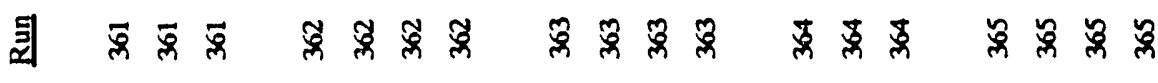




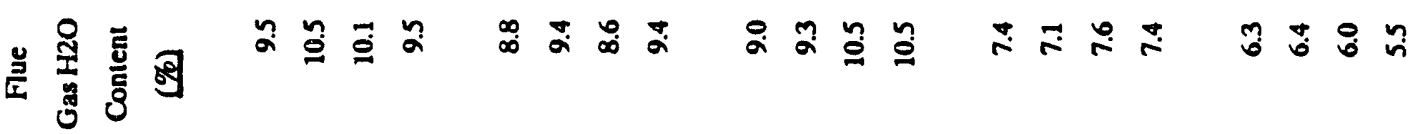

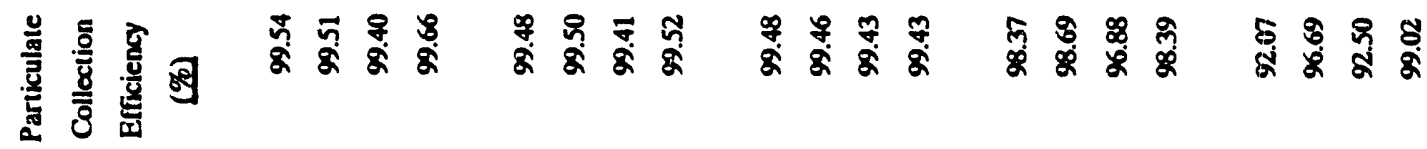

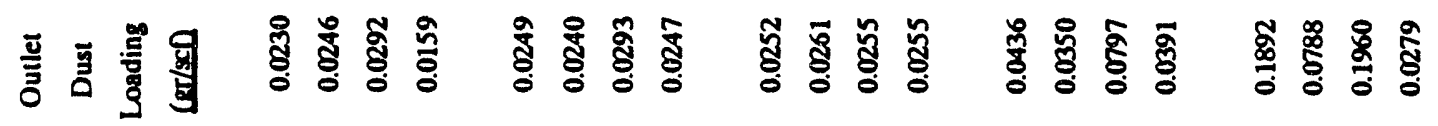

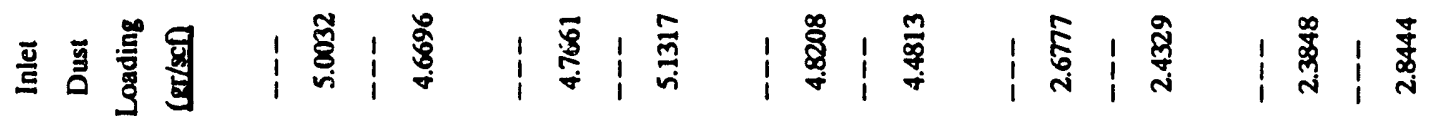

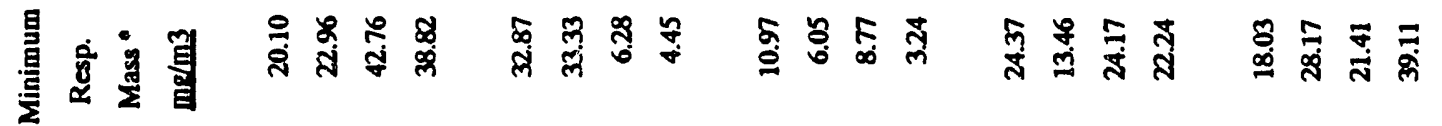

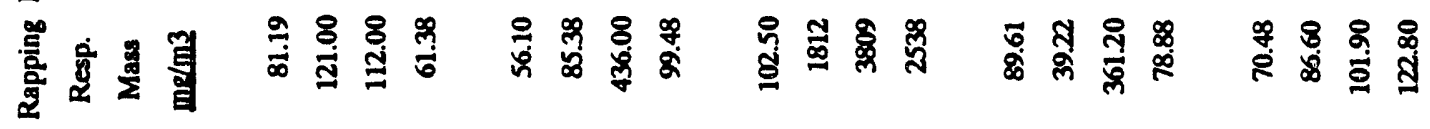

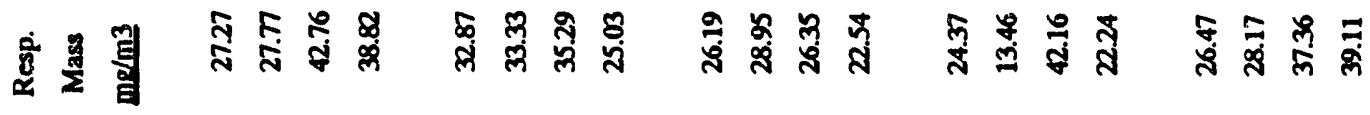

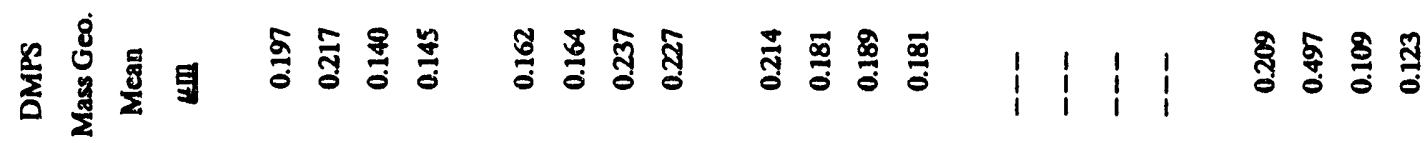

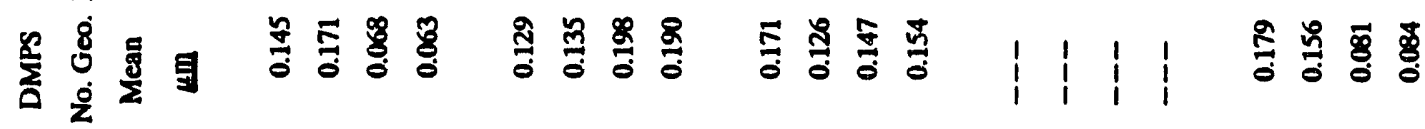

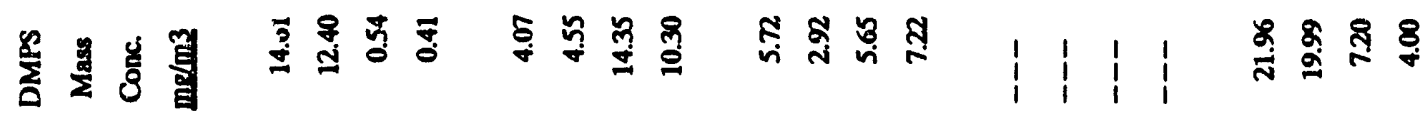

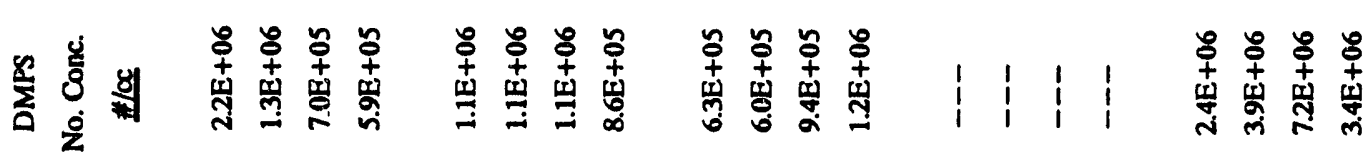

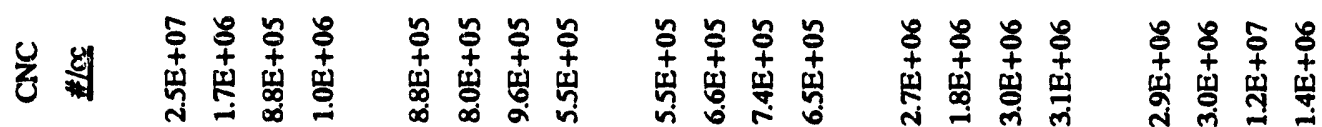

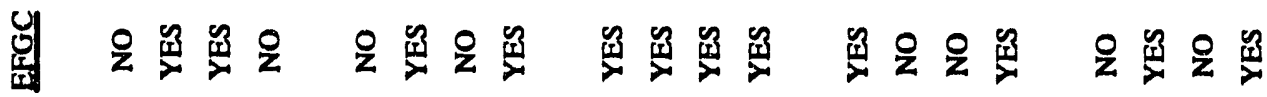

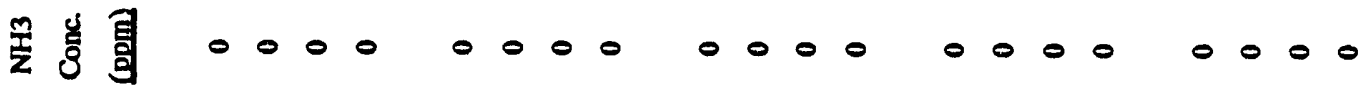

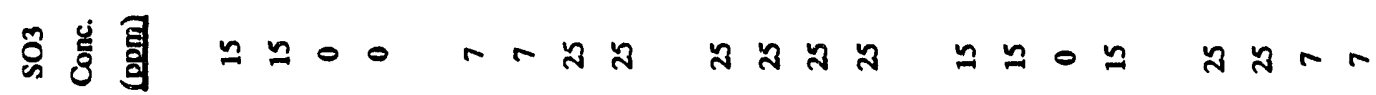

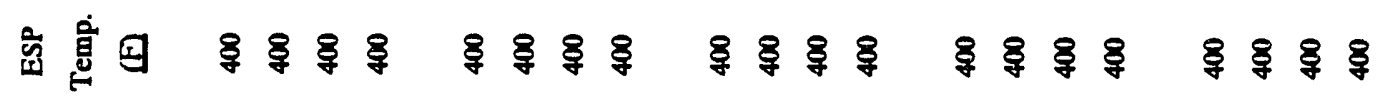

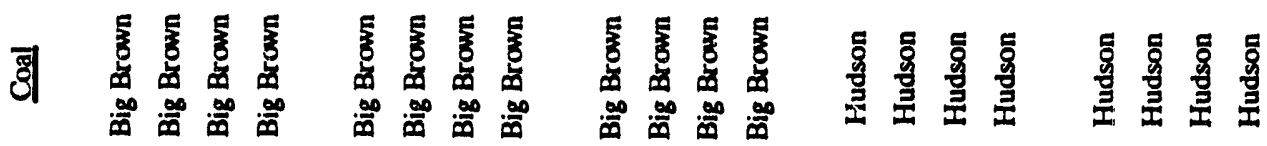

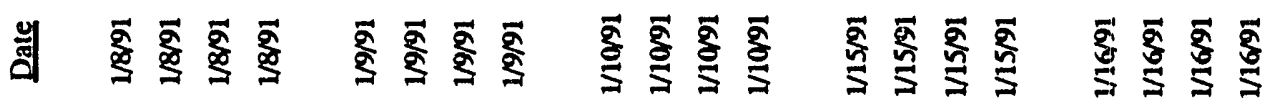

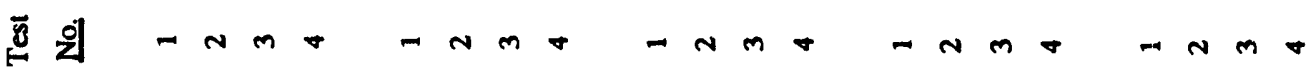

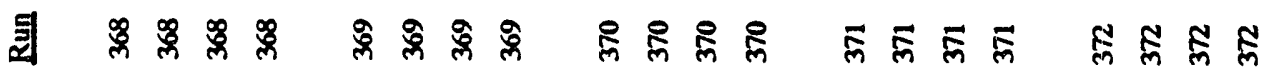




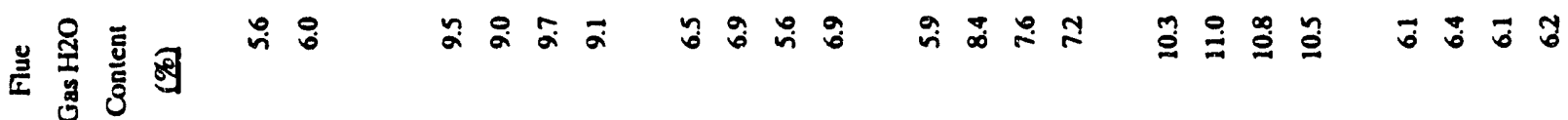

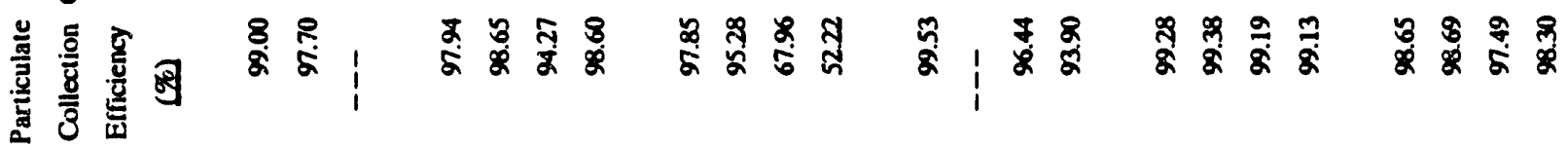

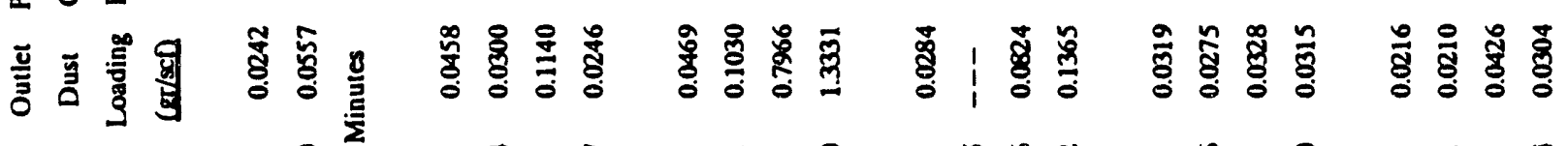

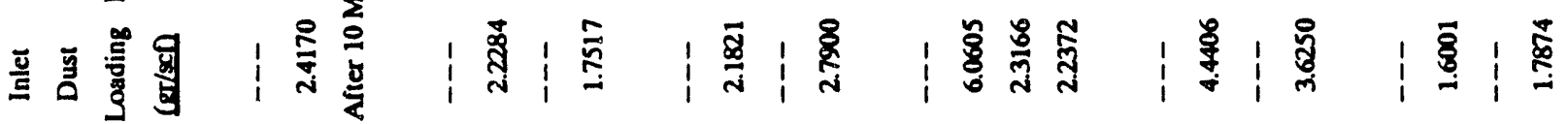

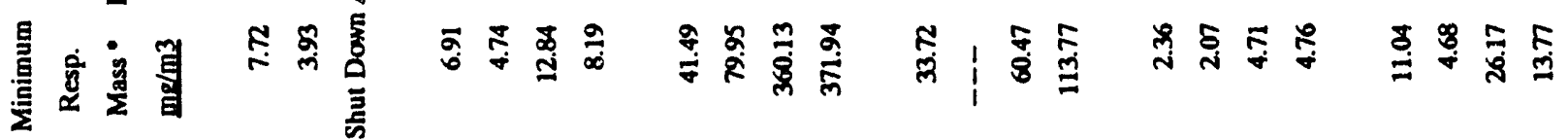

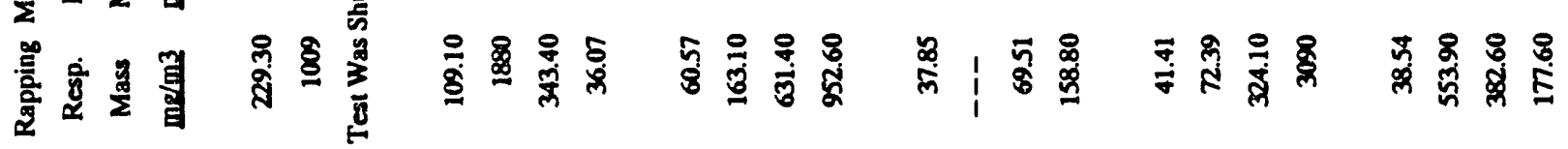

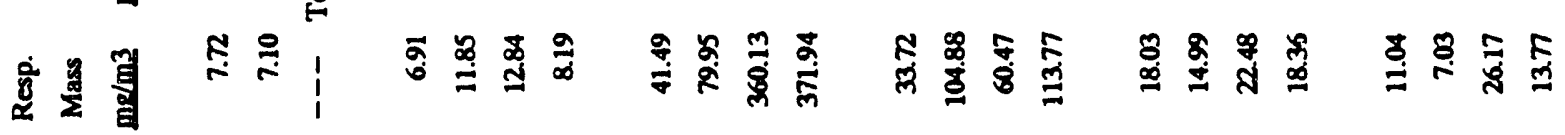

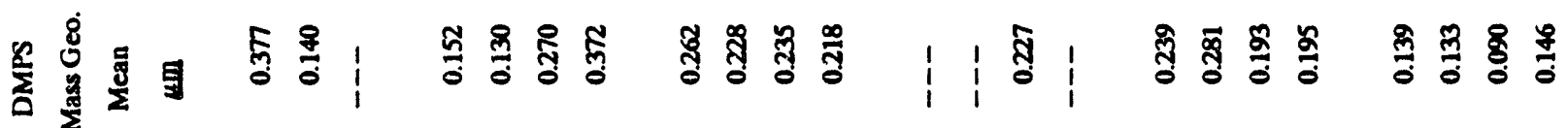

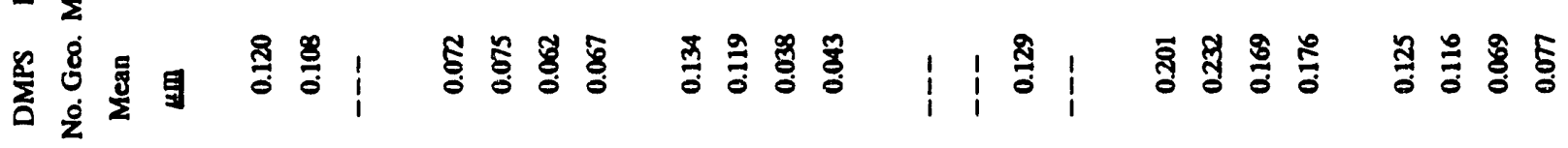

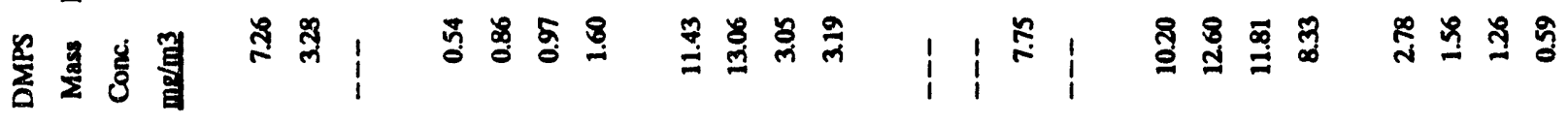

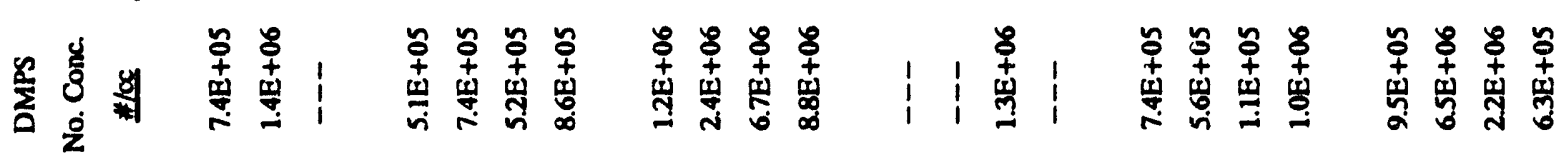

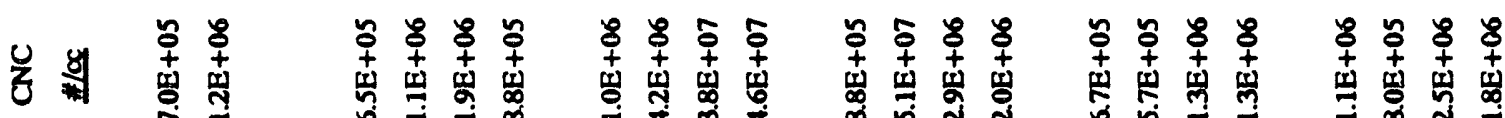

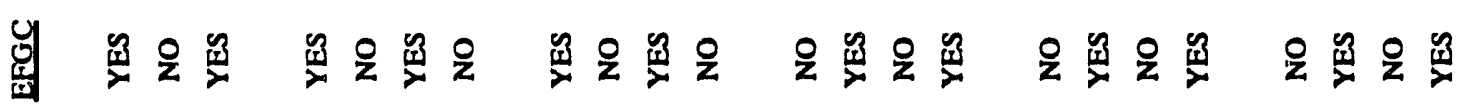

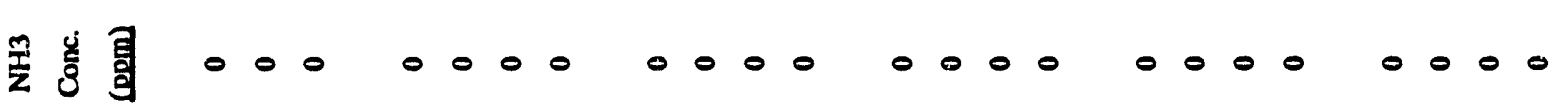

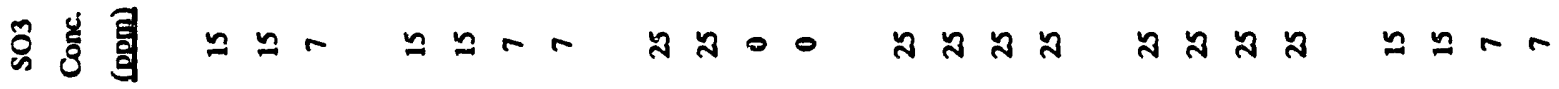

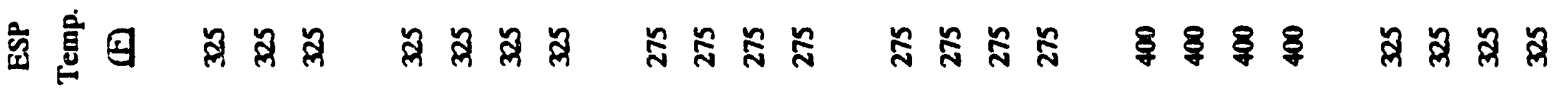

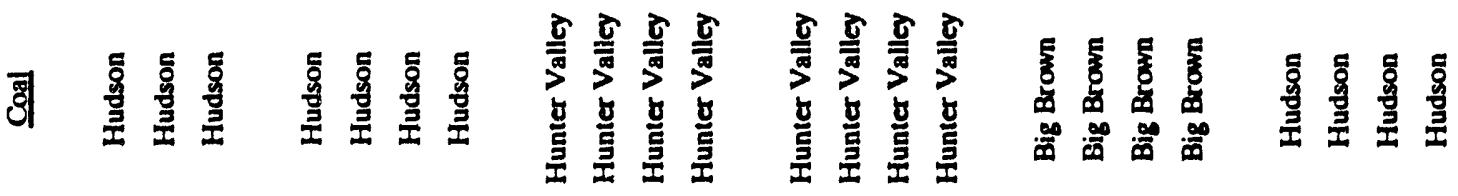

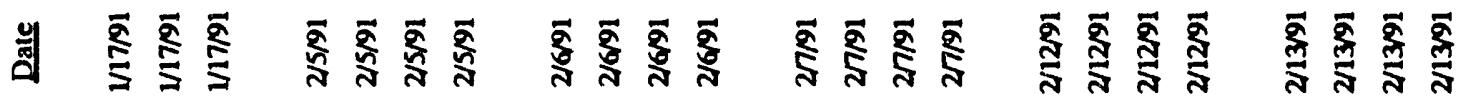

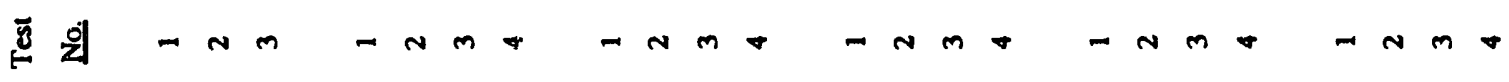

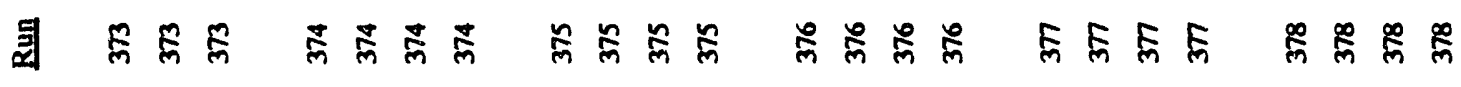




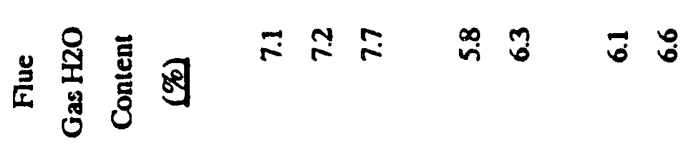

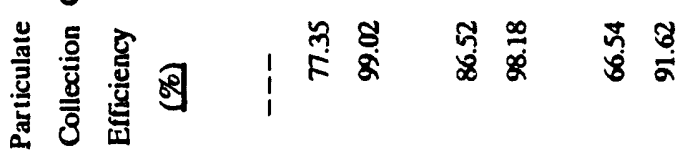

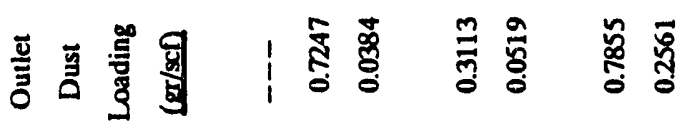

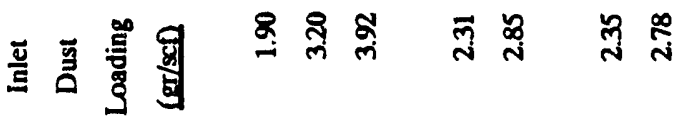

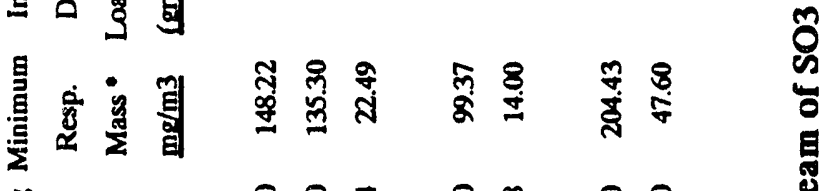

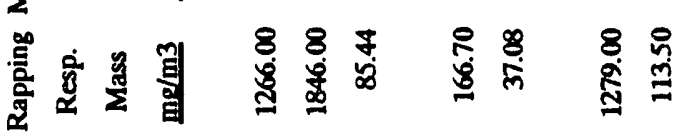

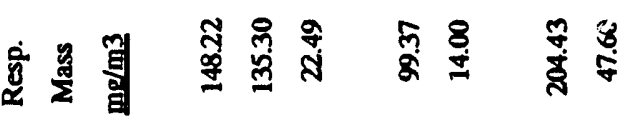

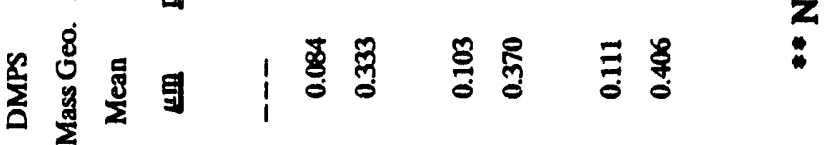

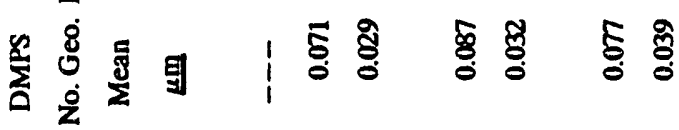

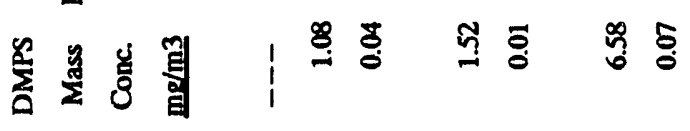

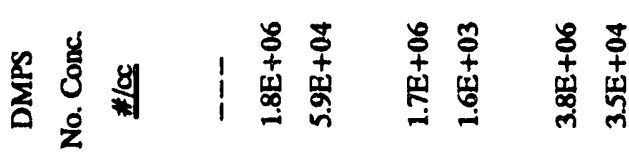

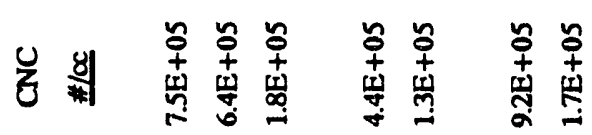

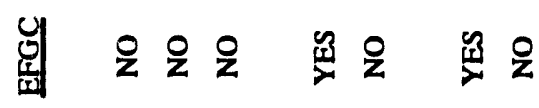

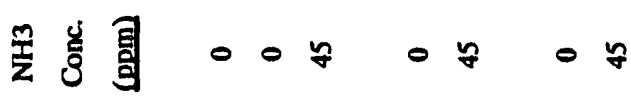

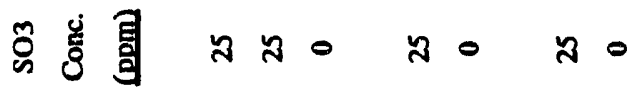

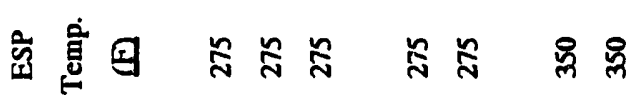

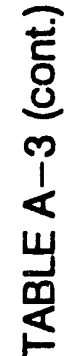

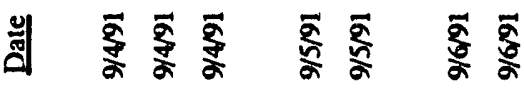

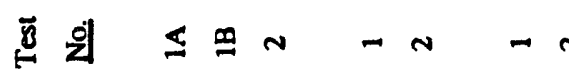

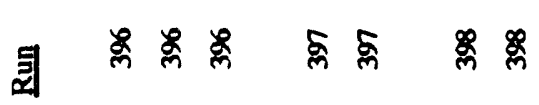




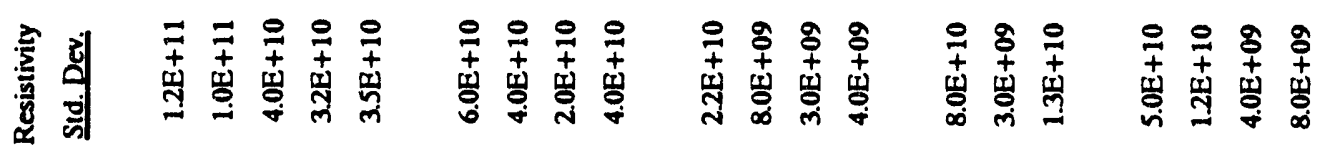

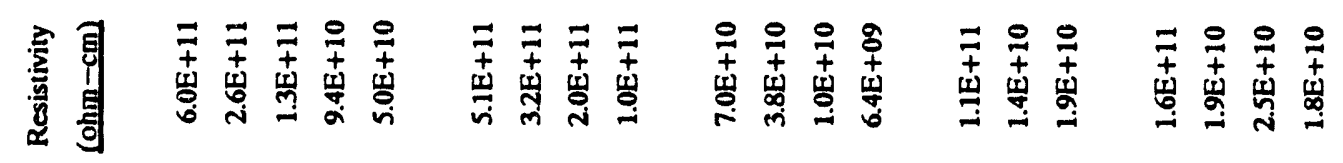

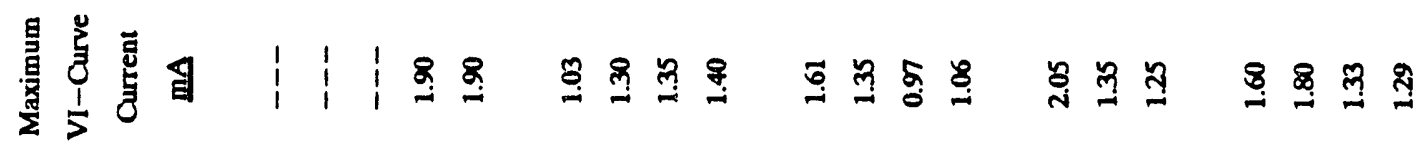

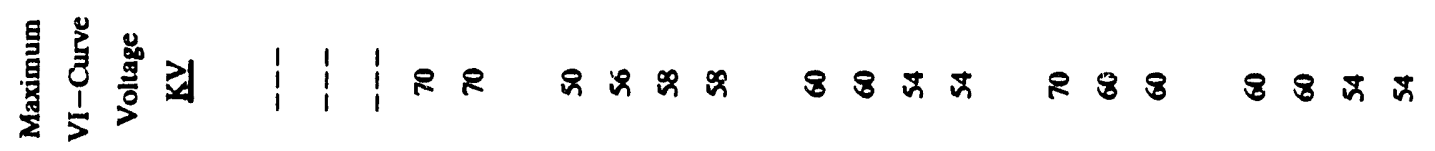

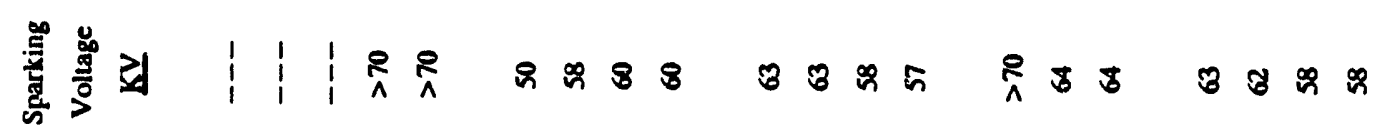

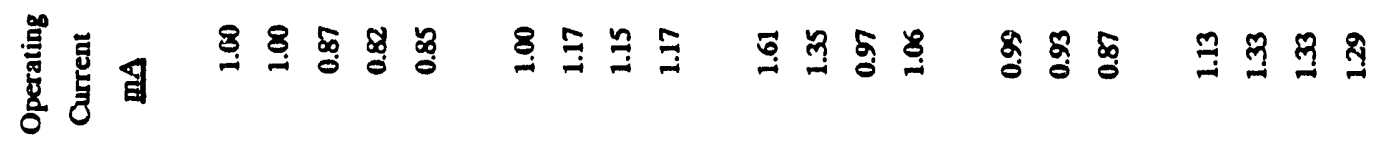

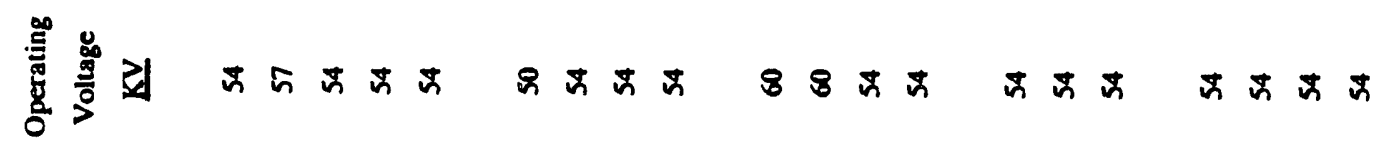

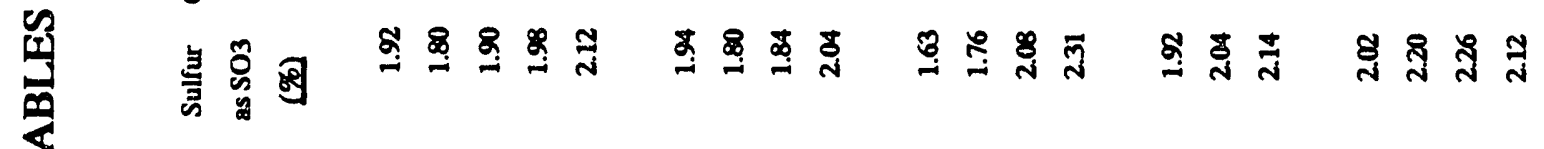

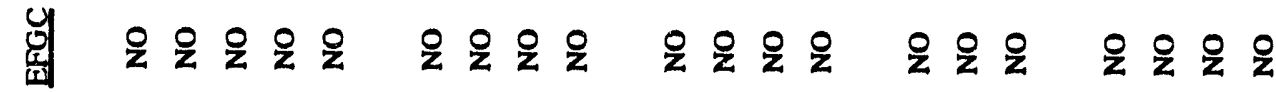

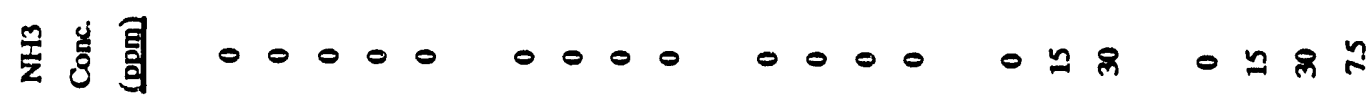

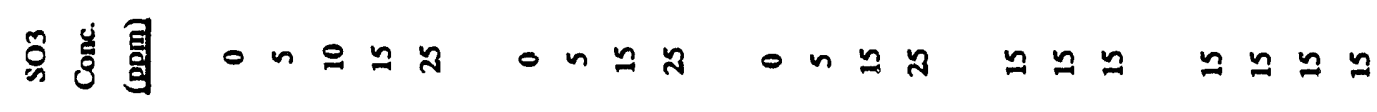

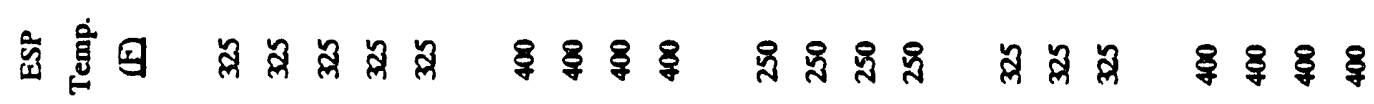

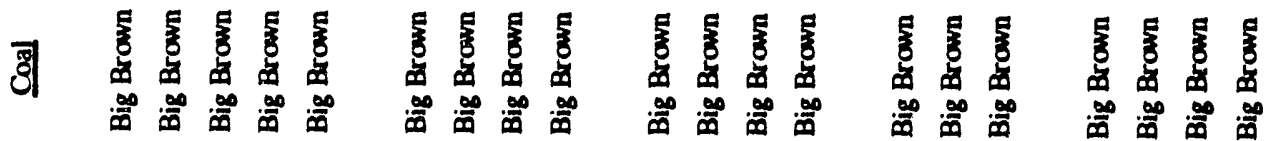

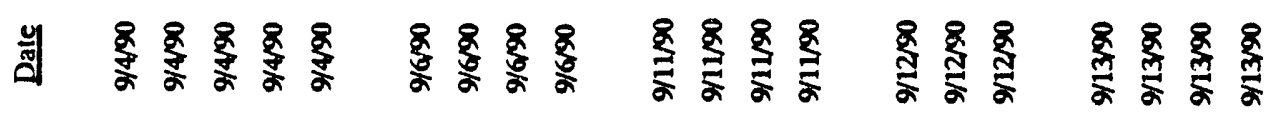

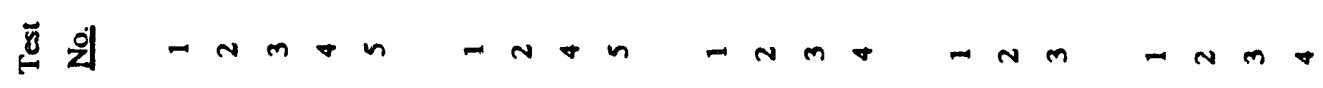

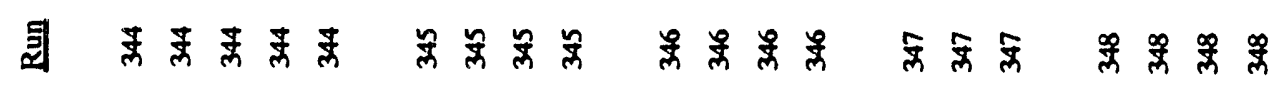




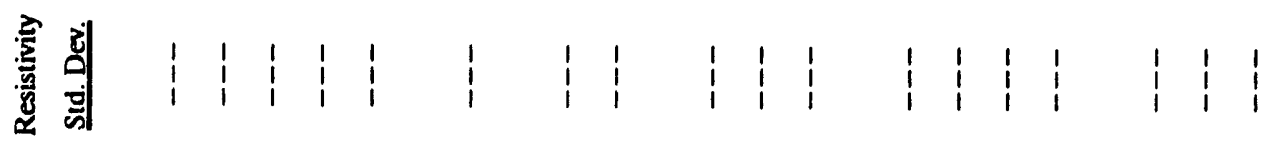

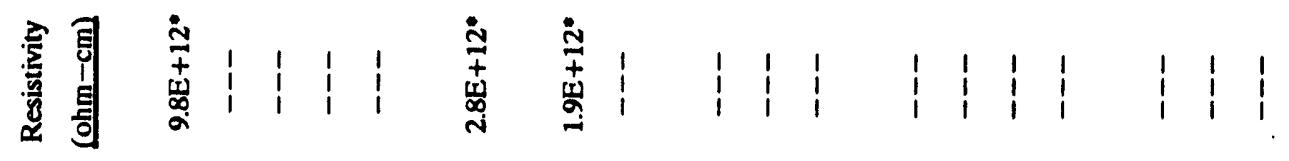

骨量高国

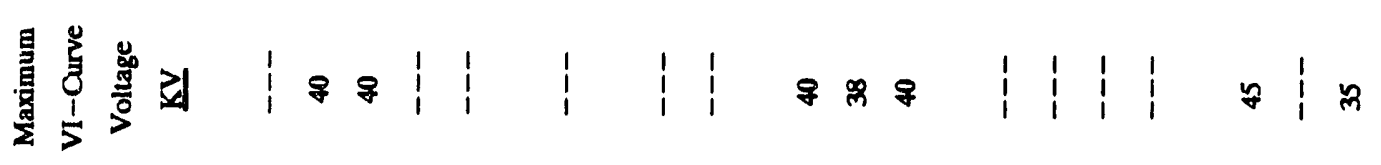

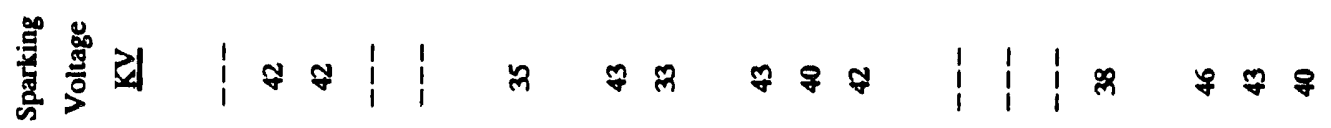
僖重国

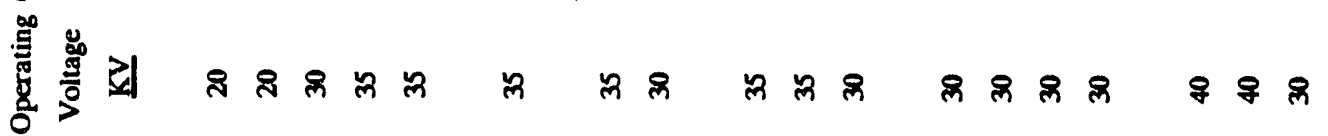

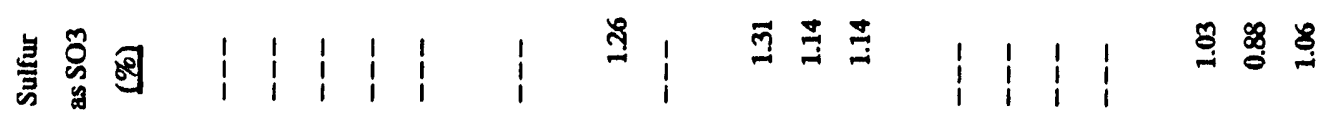

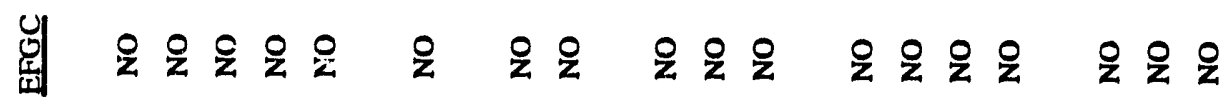

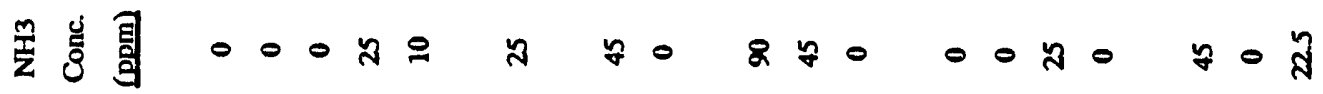

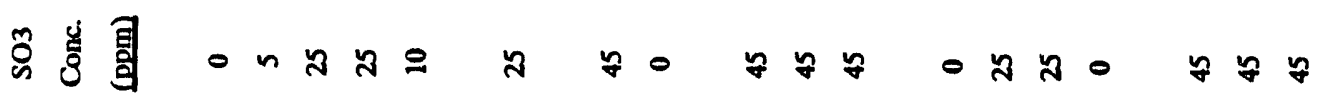

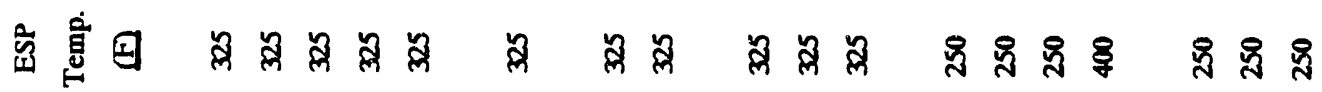

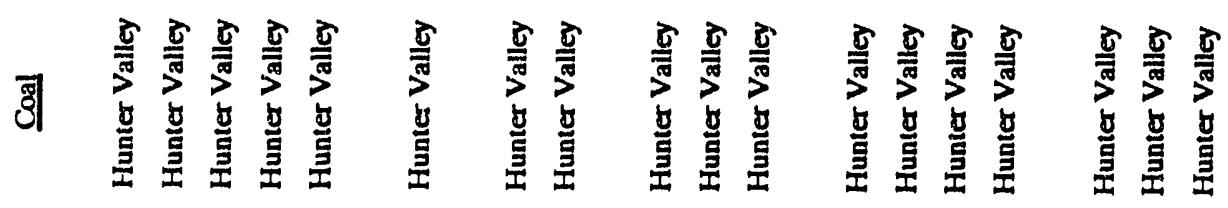

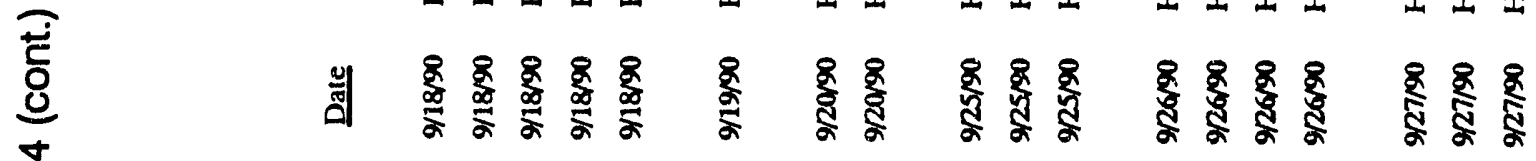
$\frac{⿱ 亠 䒑}{\frac{1}{4}}$ s

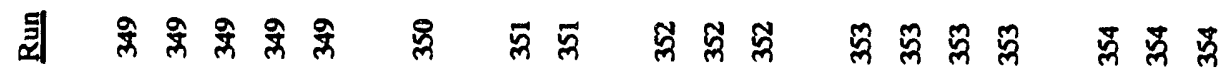




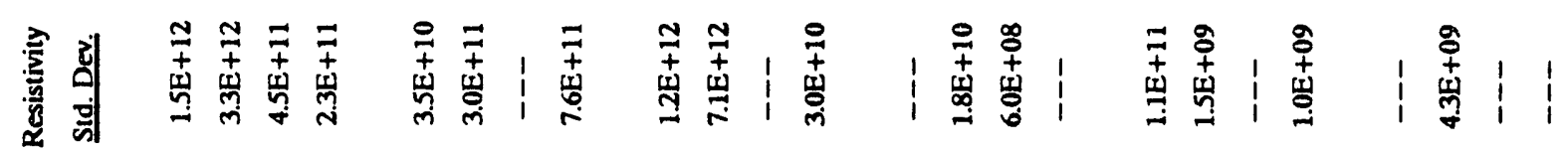

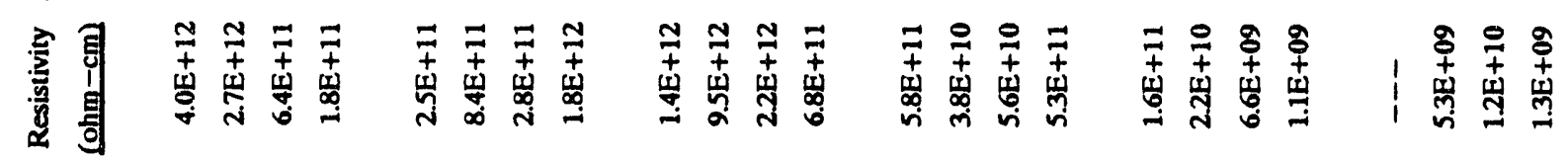

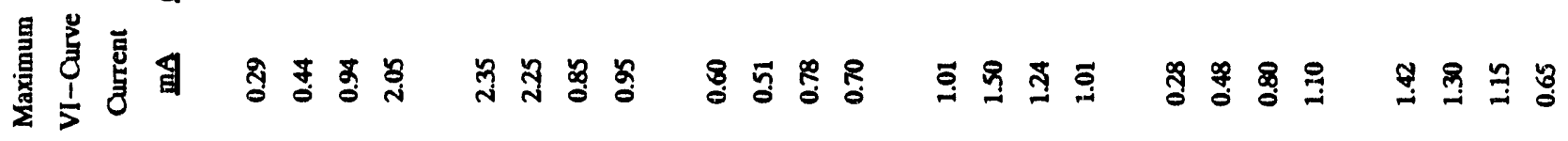

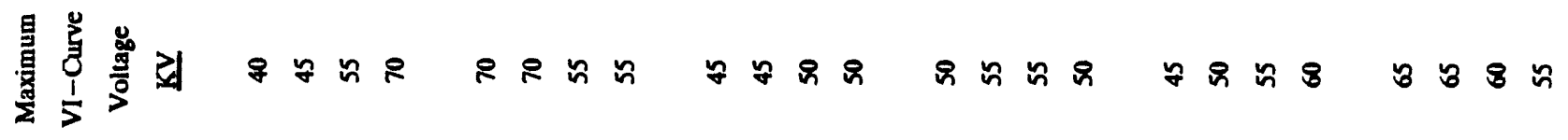

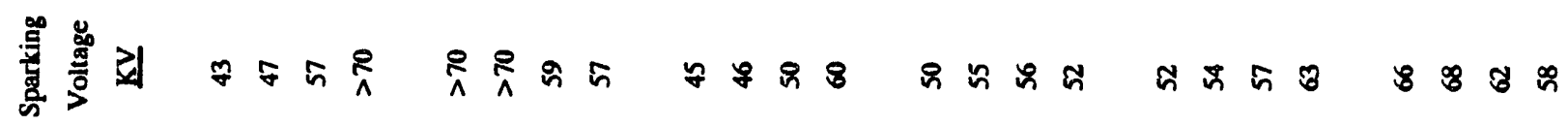

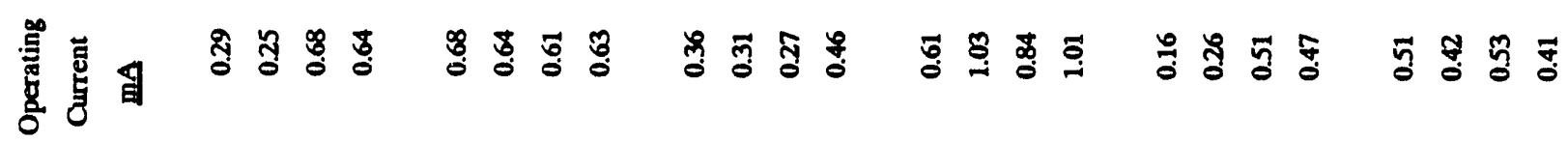

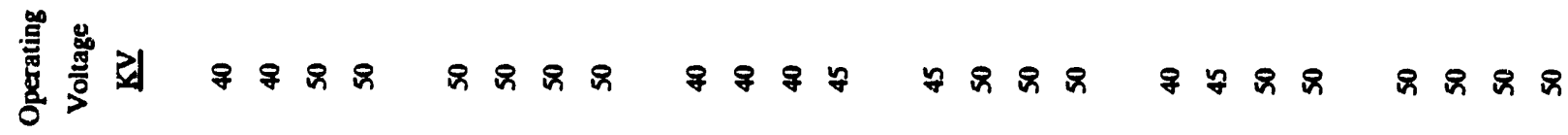
衰臀国

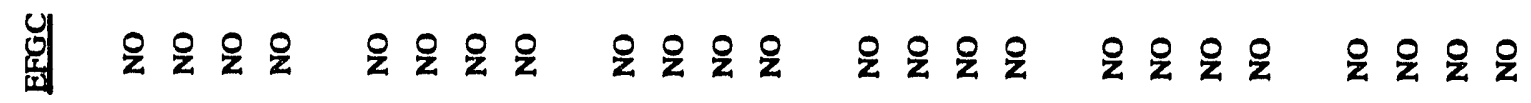

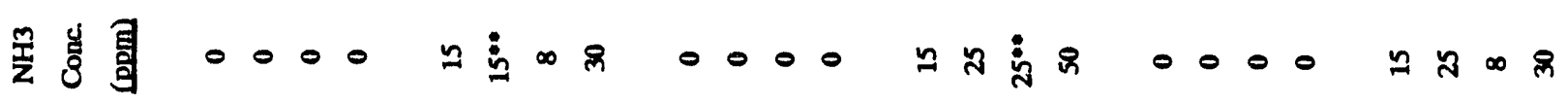
总数基

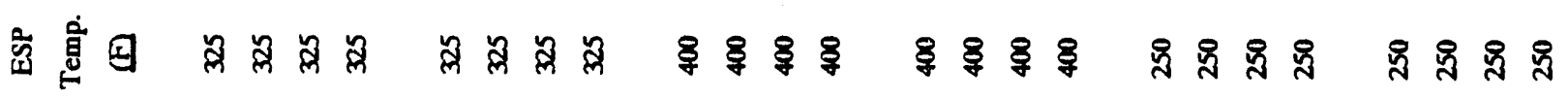

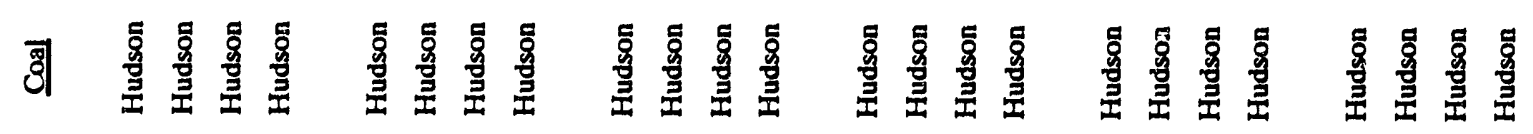

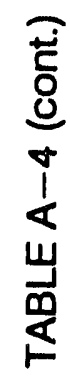

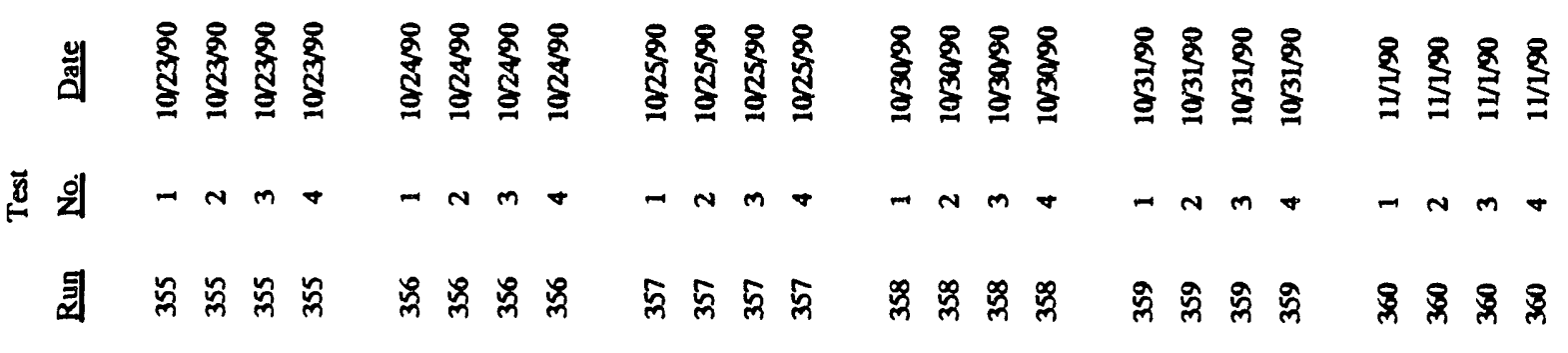




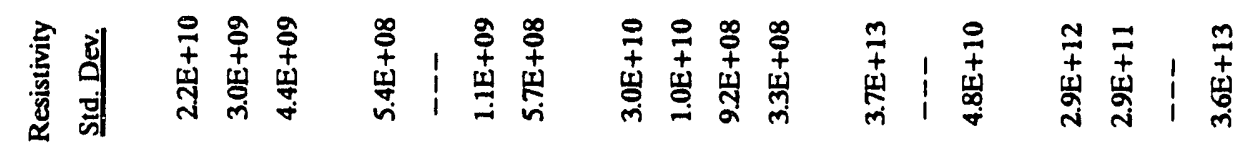

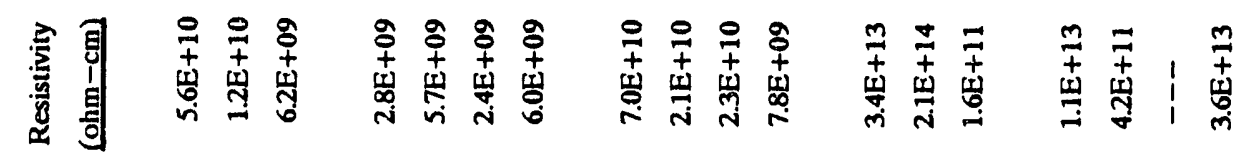

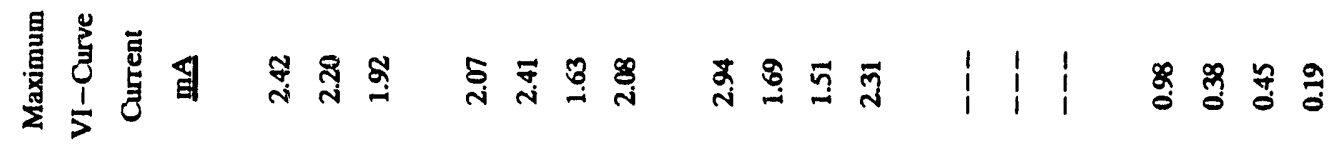

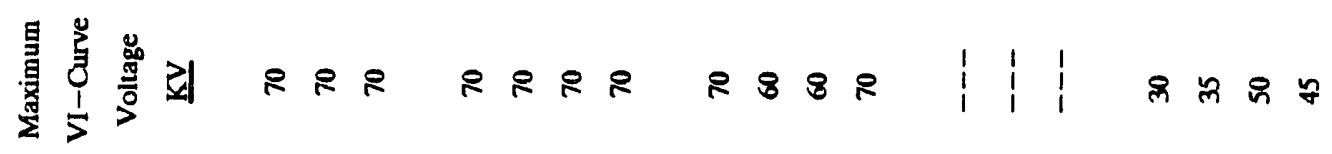

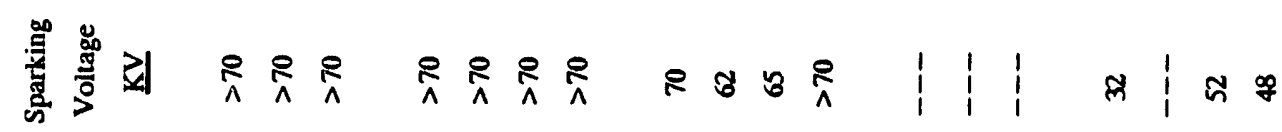

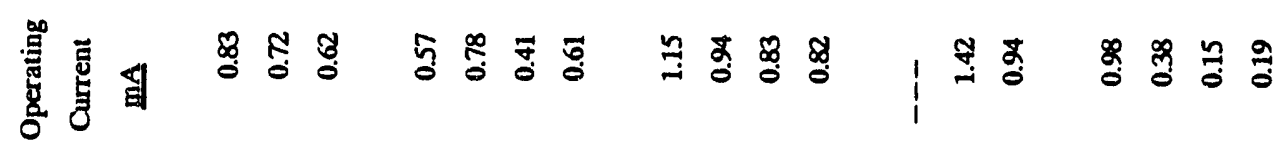

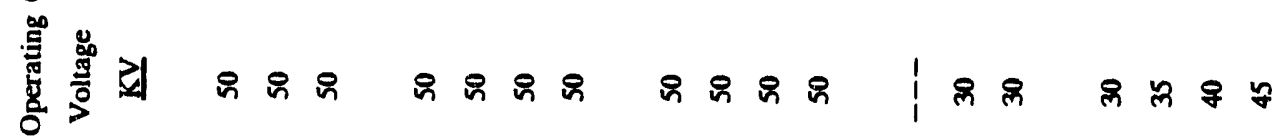

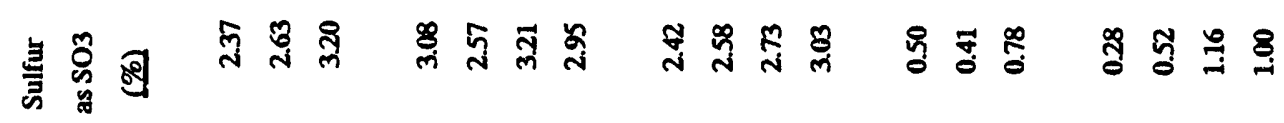

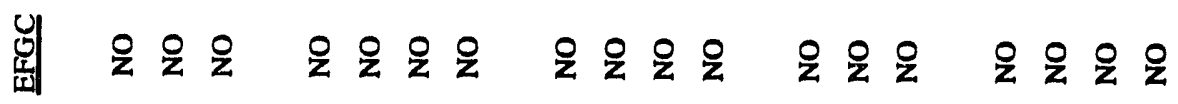

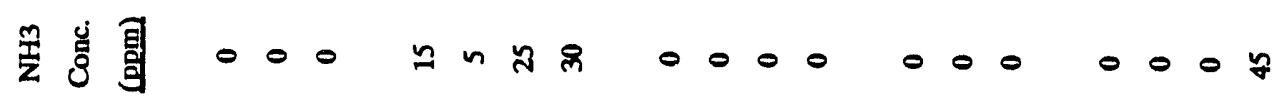

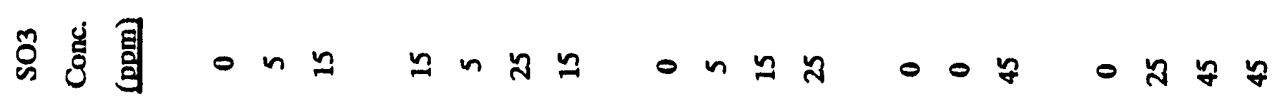

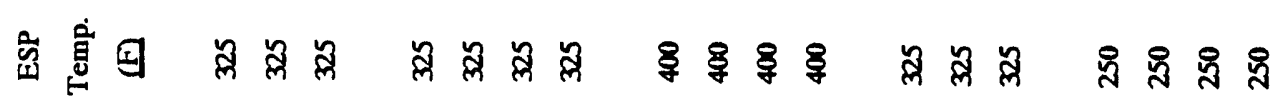

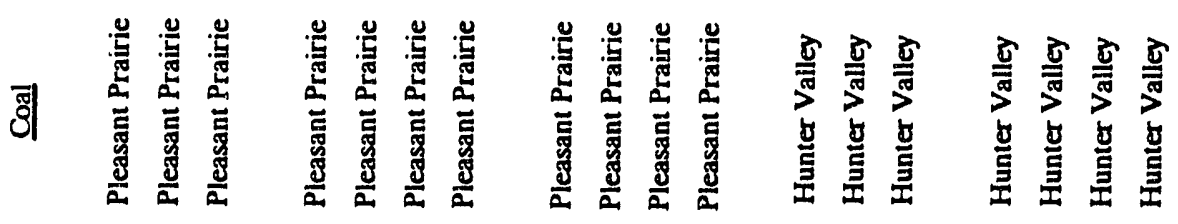

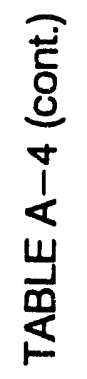

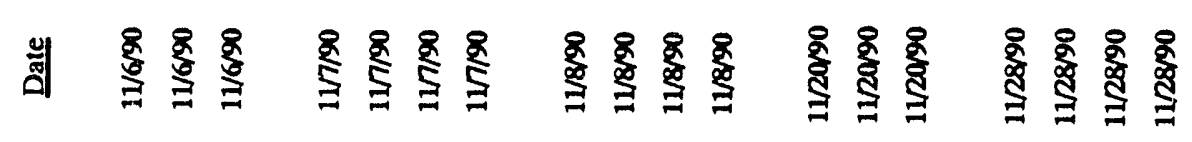
蛋

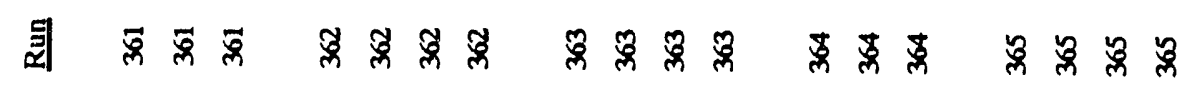




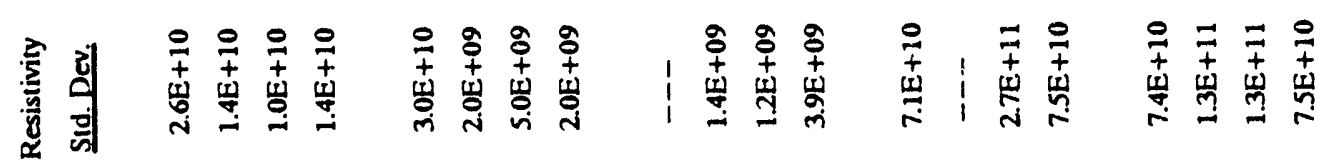

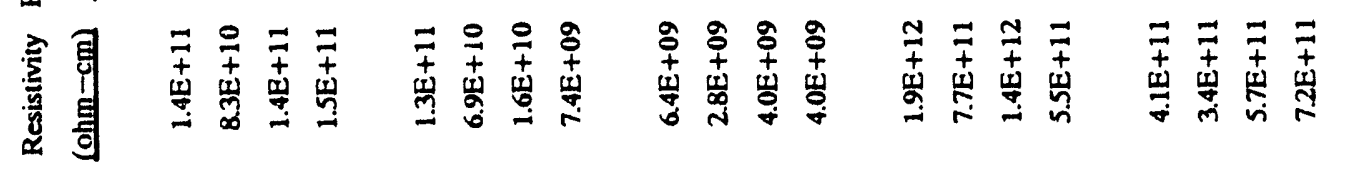

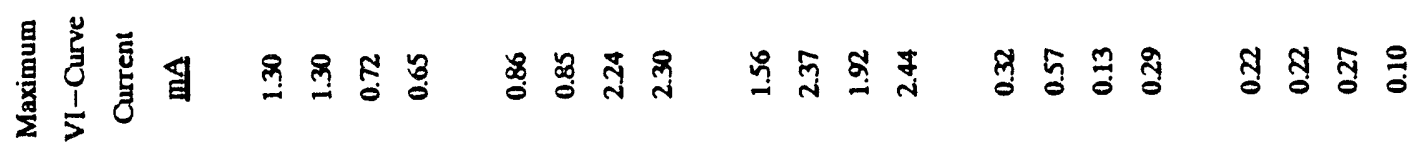

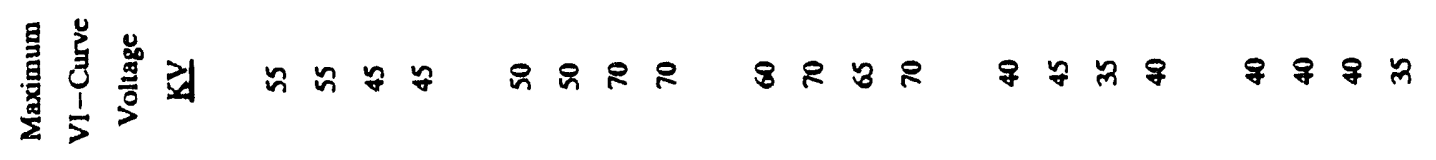

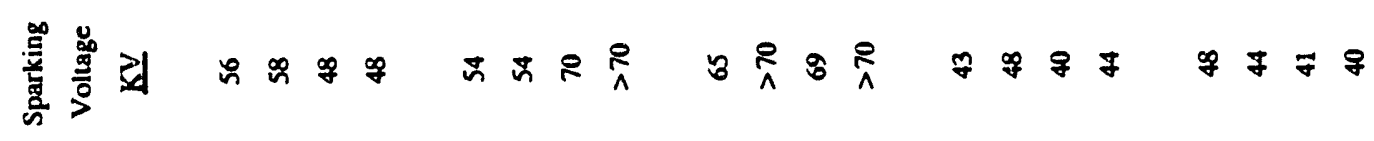

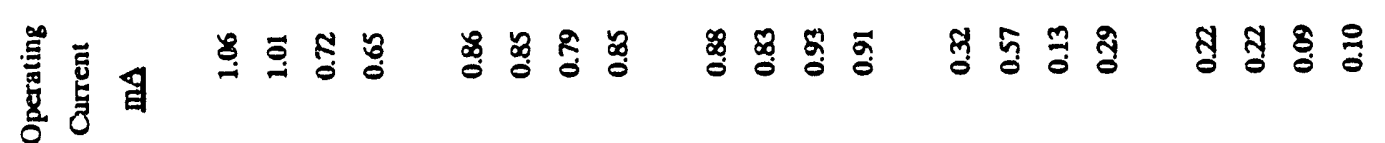

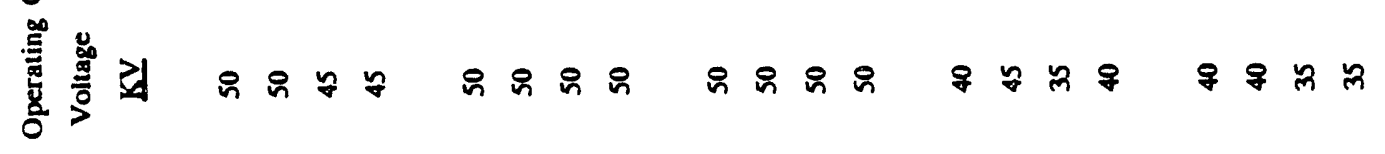

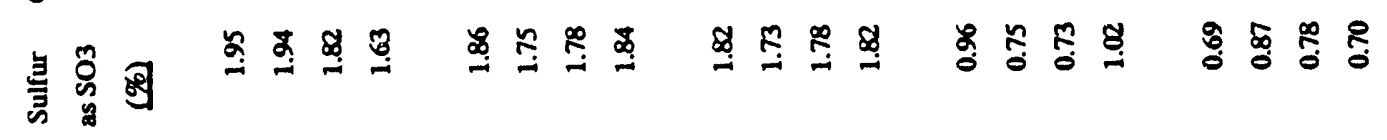

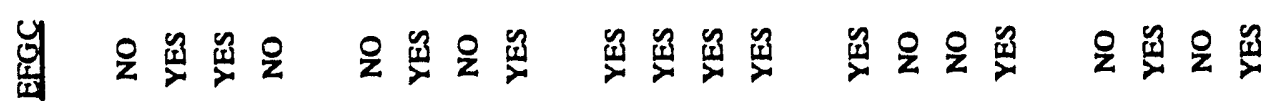

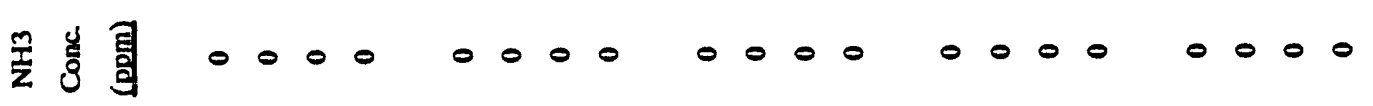

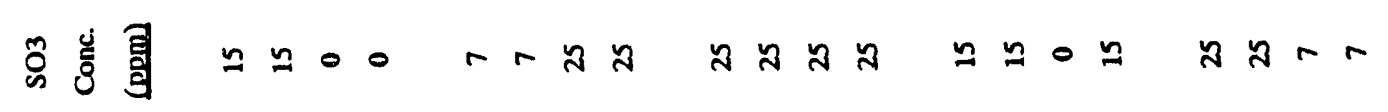

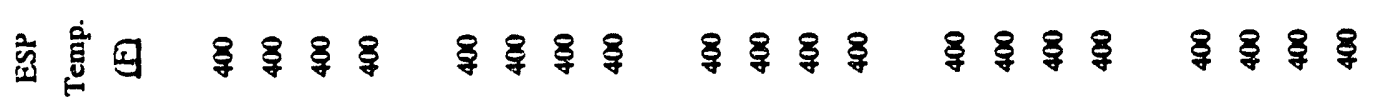

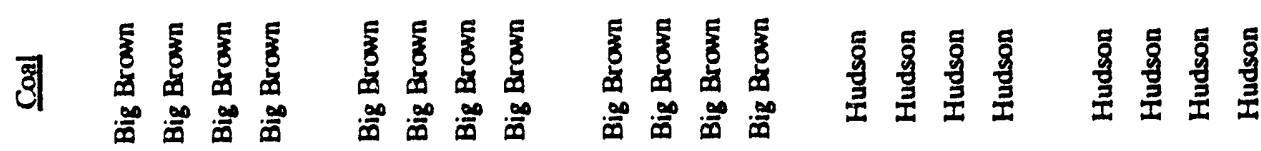

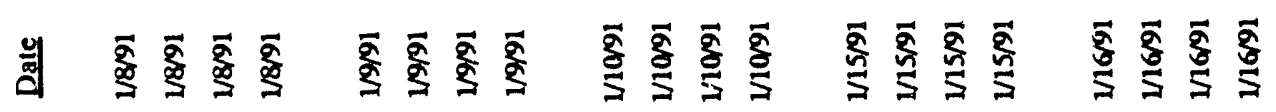

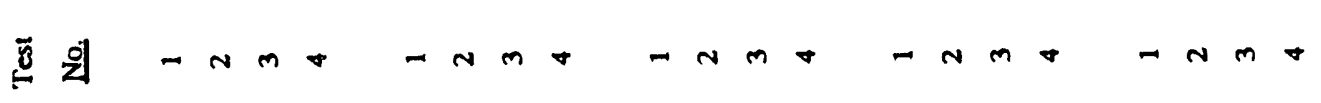

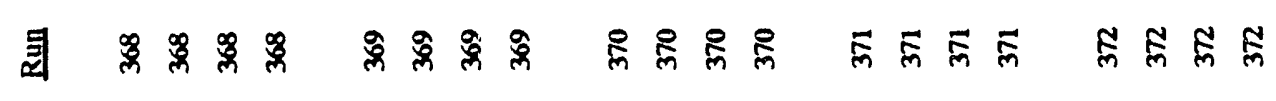




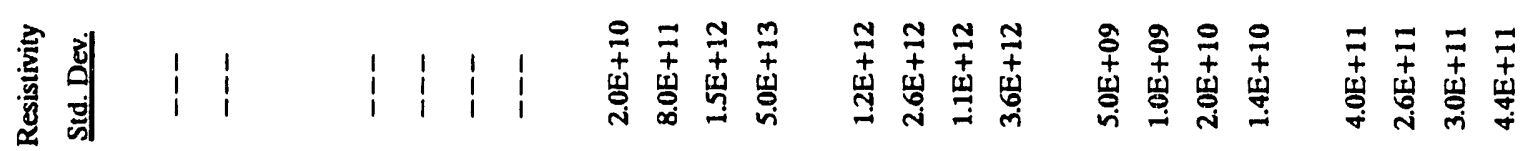

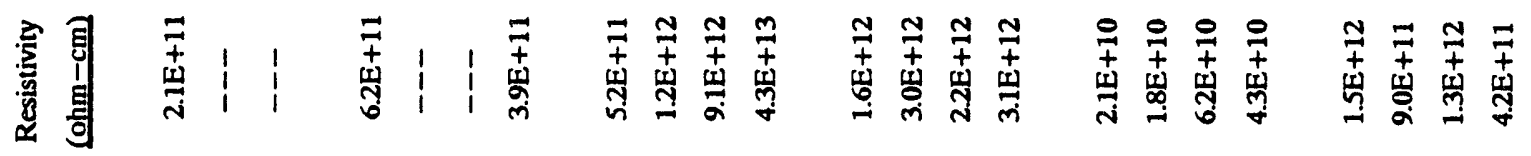

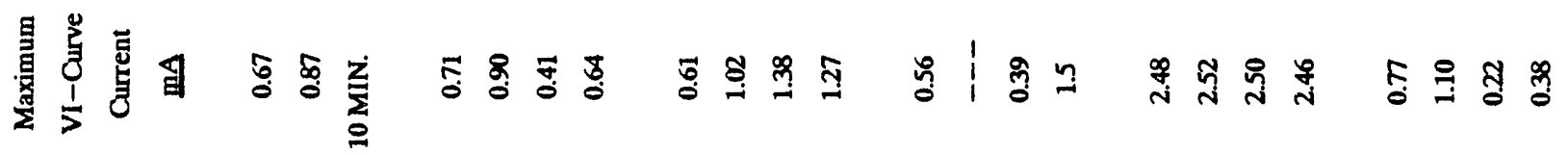

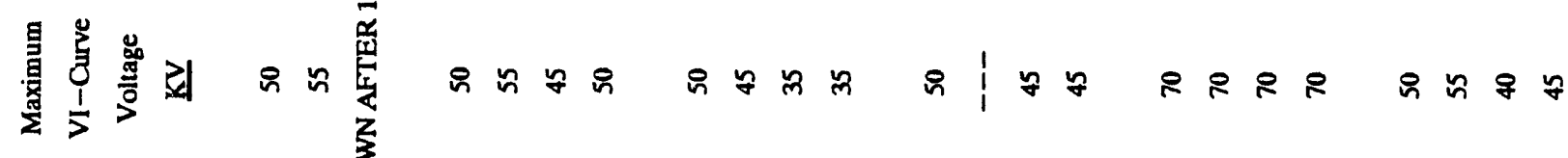

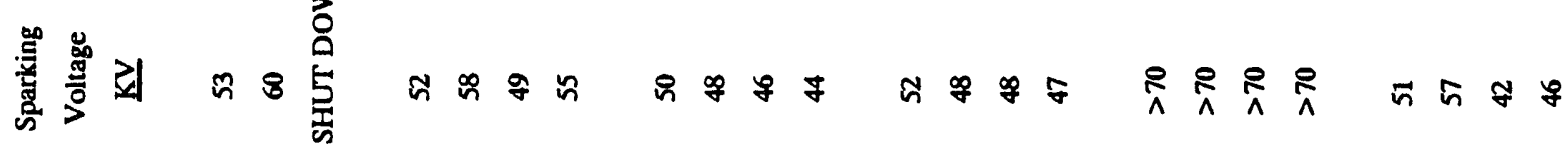

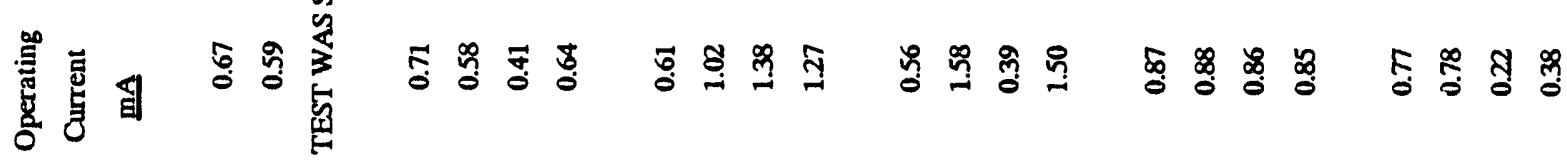

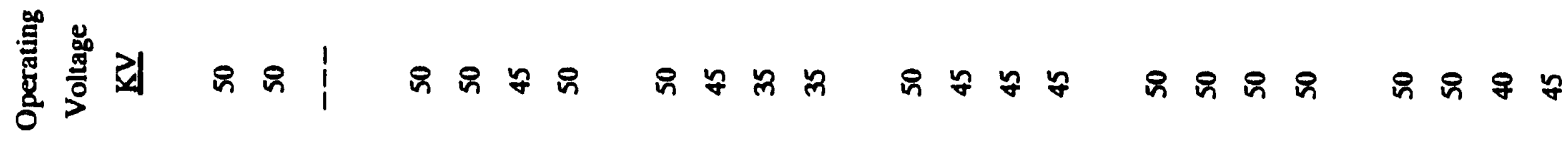

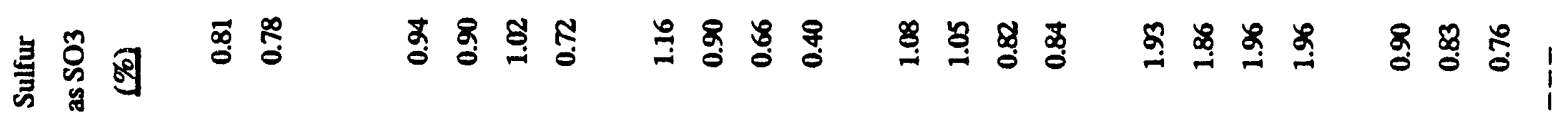

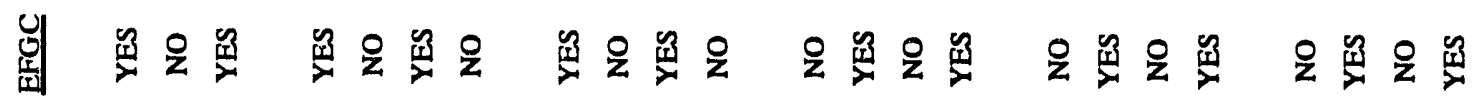

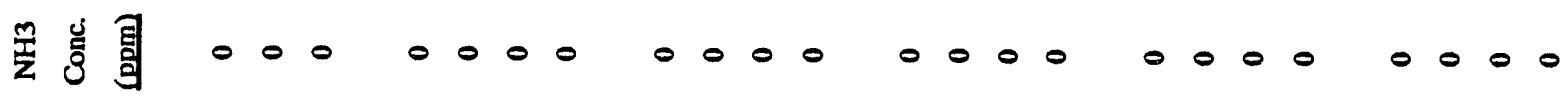
总岁基

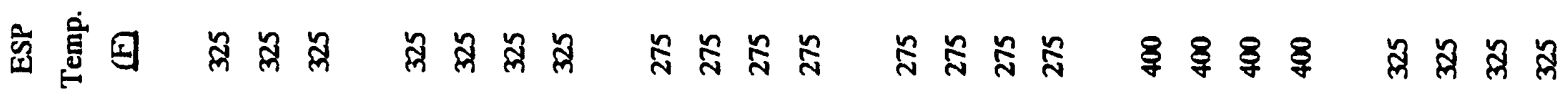

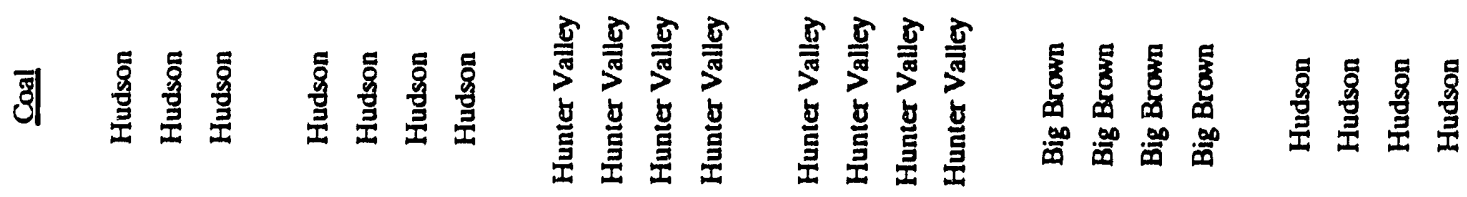

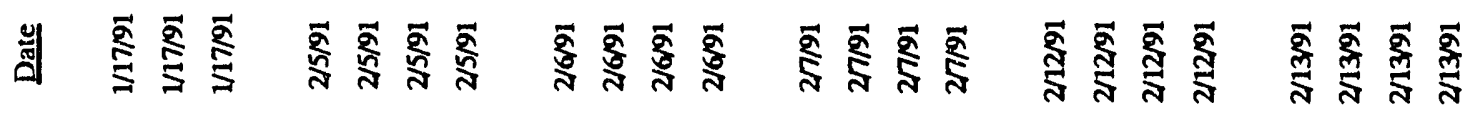

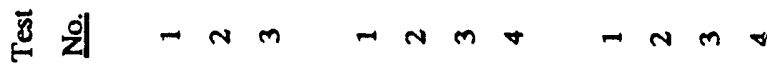

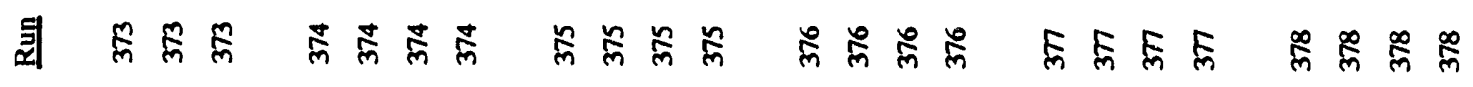




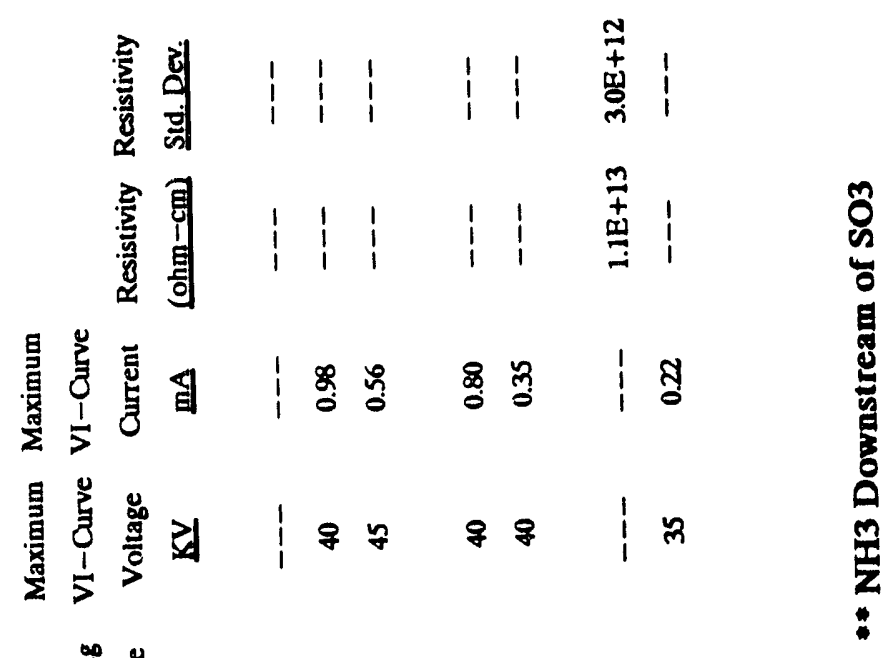

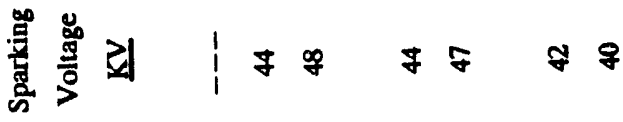

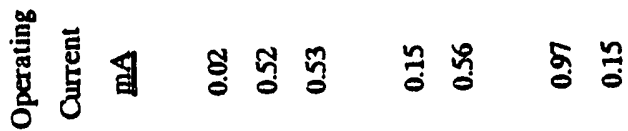

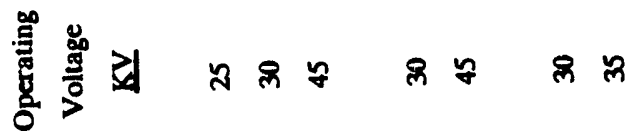

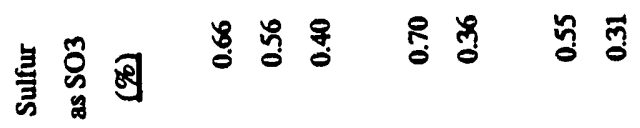

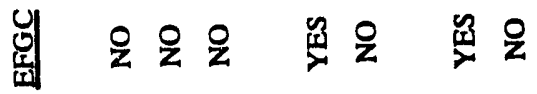

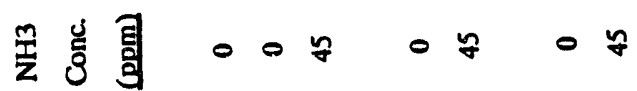
ชั่

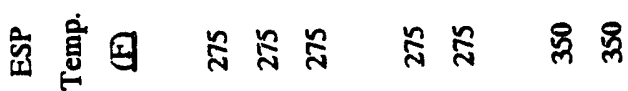

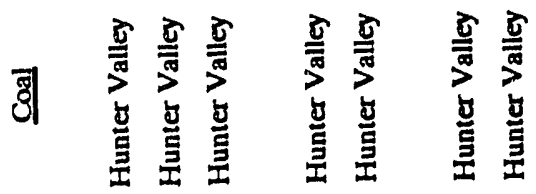

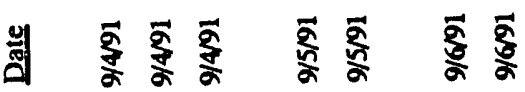
丞

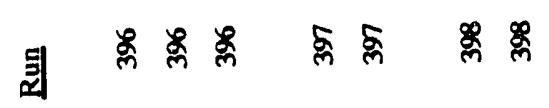

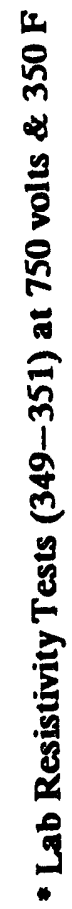




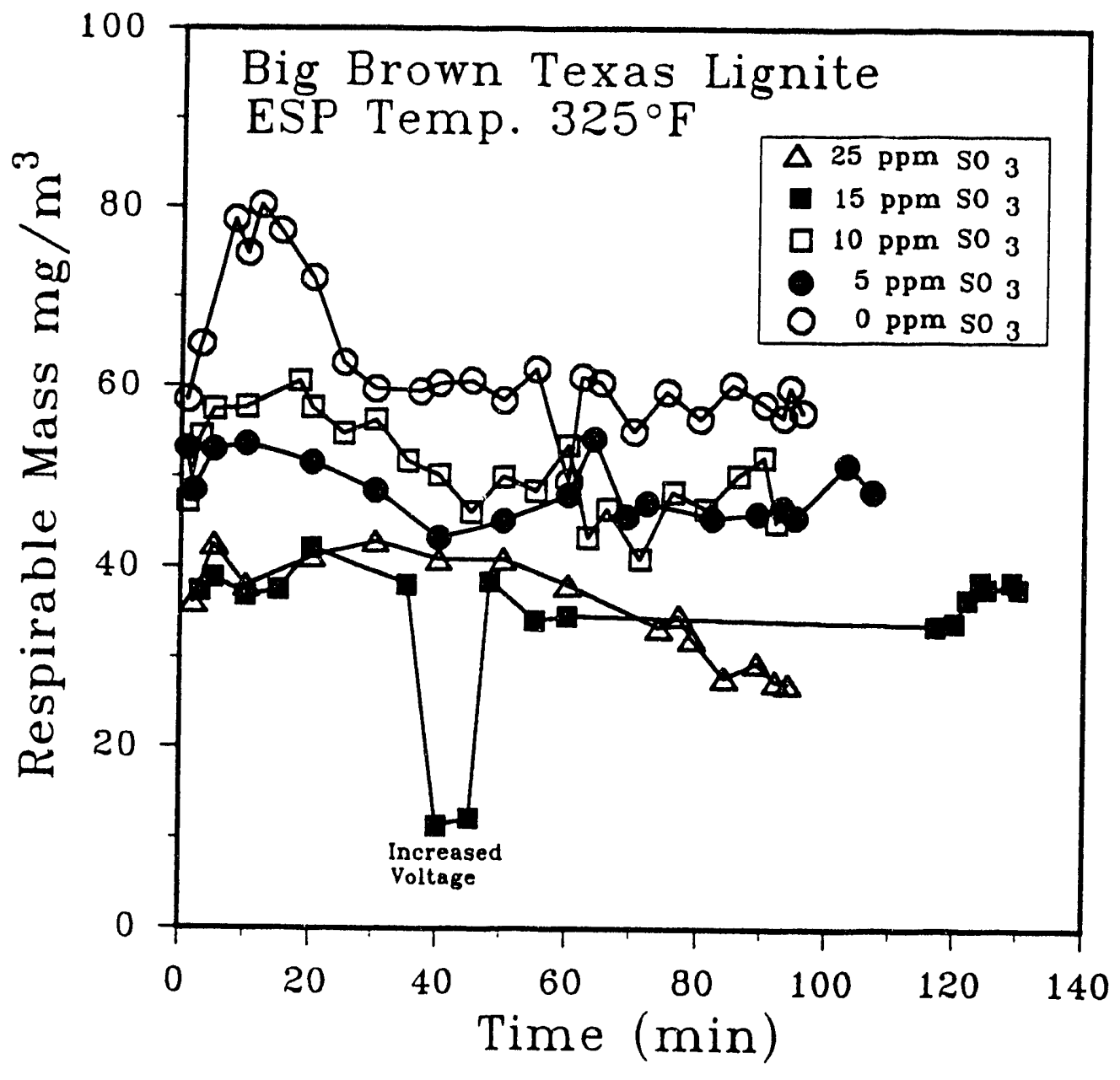

Figure A-1.1. Respirable mass emissions as a function of time for Big Brown coal for Run 344. 


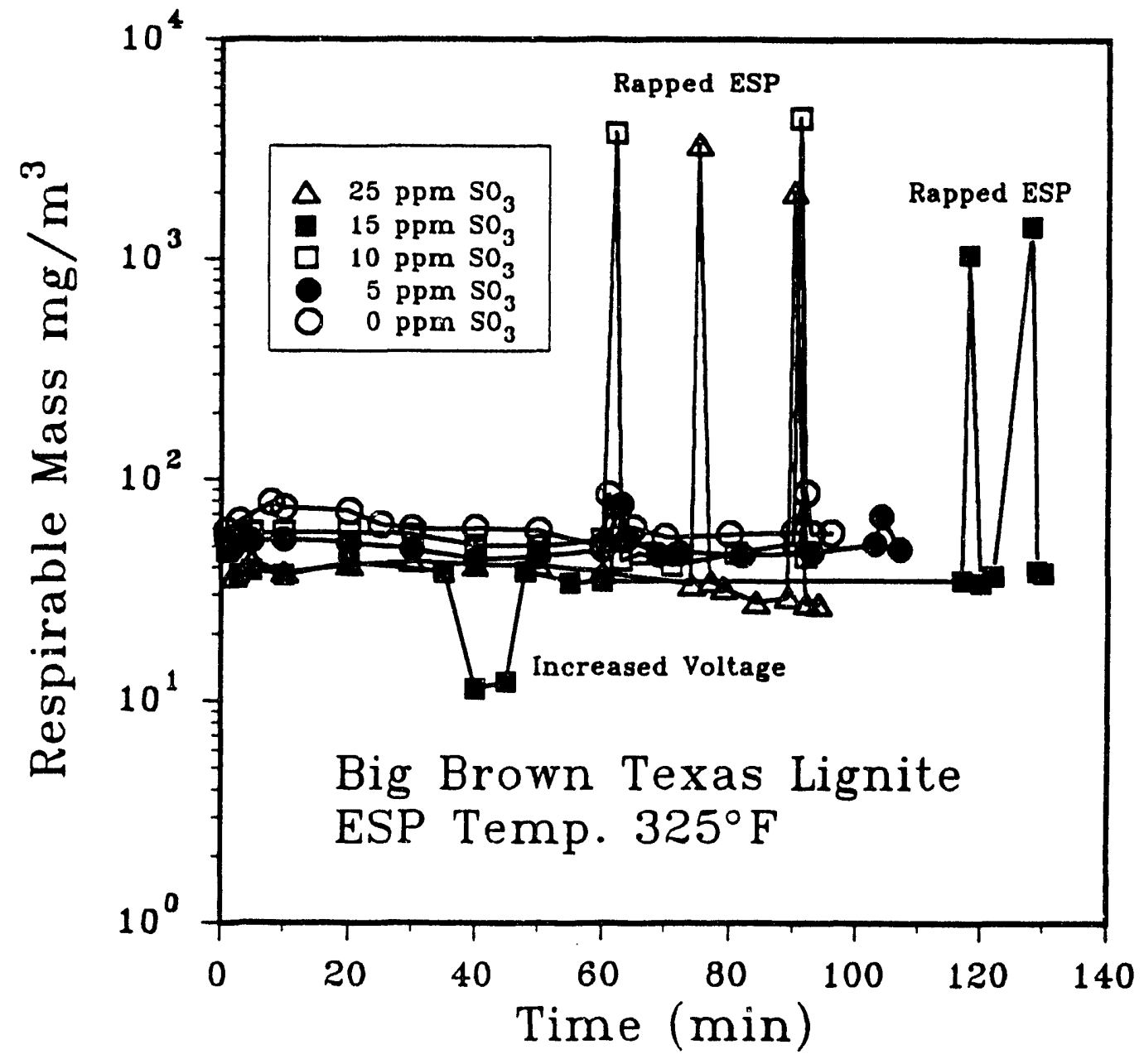

Figure A-1.2. Respirable mass emissions as a function of time, including rapping puff for Big Brown coal for Run 344. 


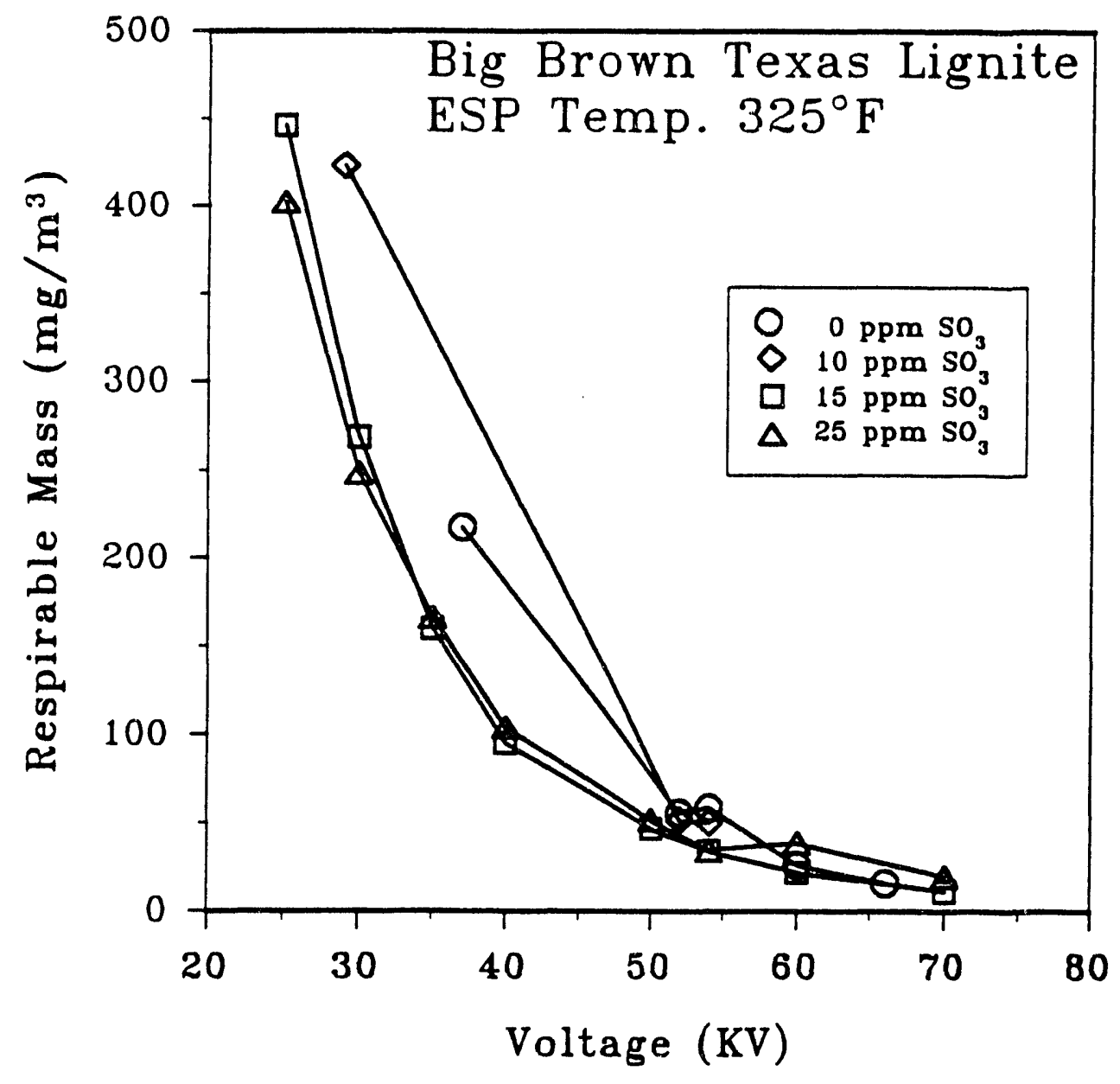

Figure A-1.3. Respirable mass emissions as a function of voltage for Big Brown coal for Run 344. 


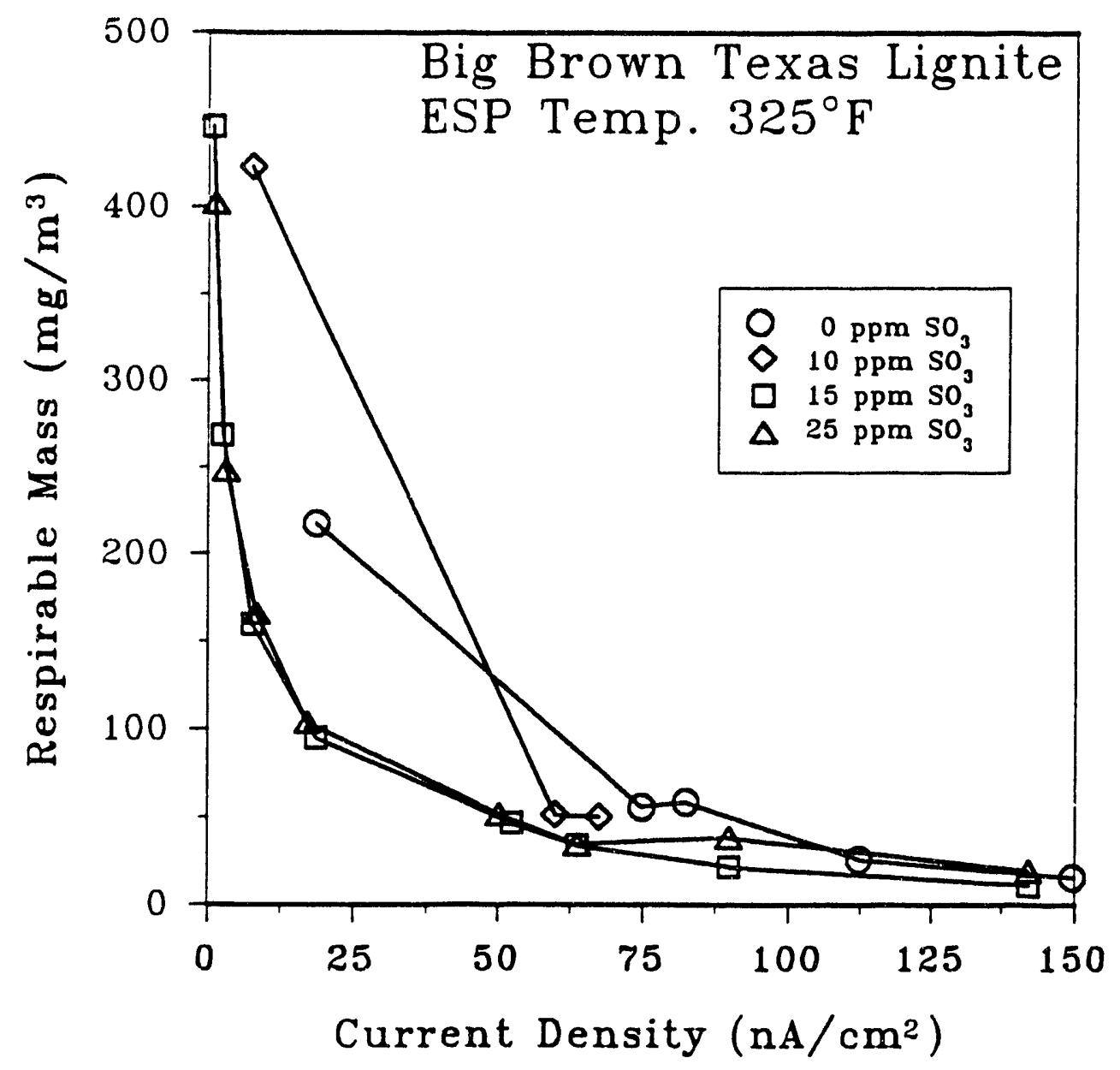

Figure A-1.4. Respirable mass emissions as a function of current density for Big Brown coal for Run 344 . 


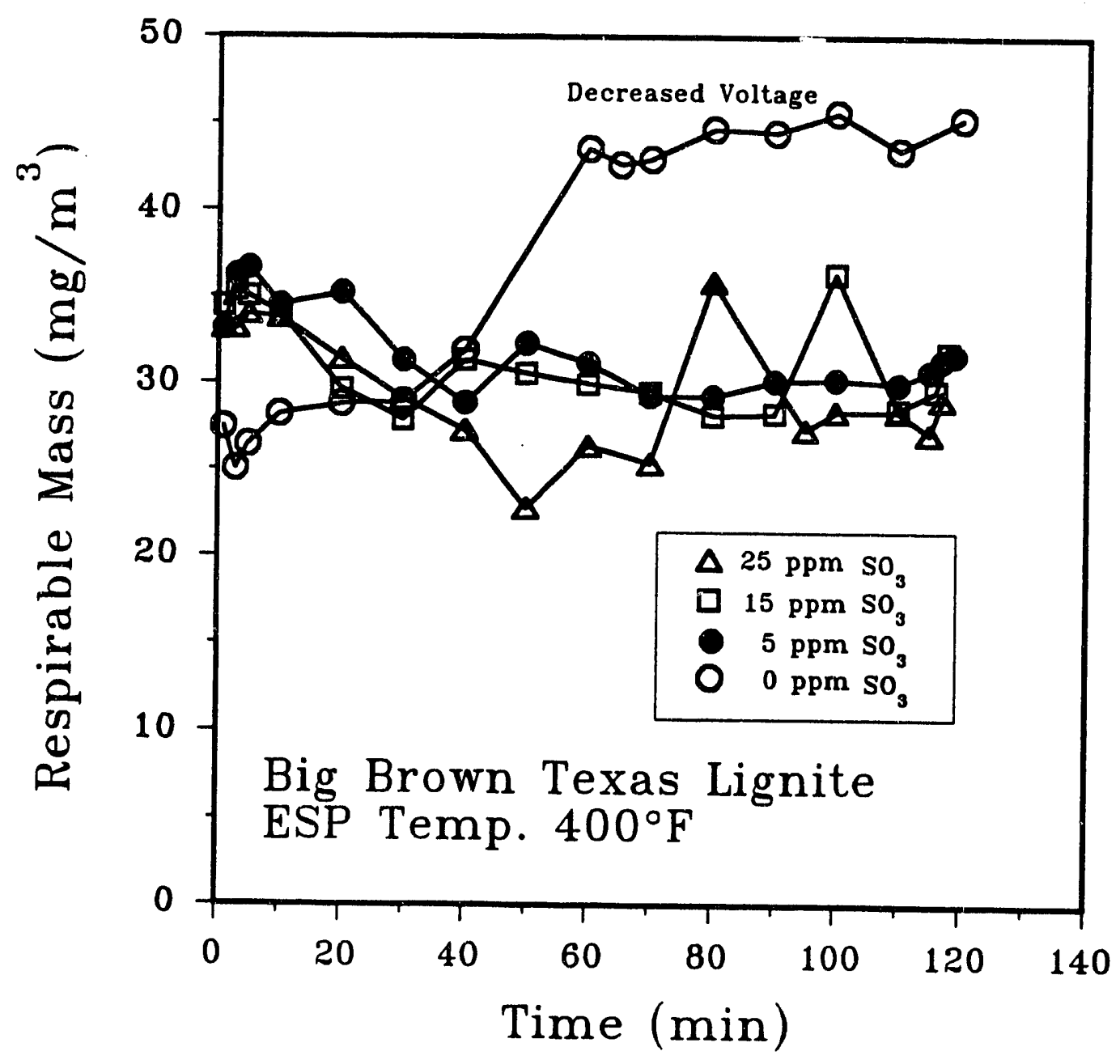

Figure A-1.5. Respirable mass emissions as a function of time for Big Brown coal for Run 345 . 


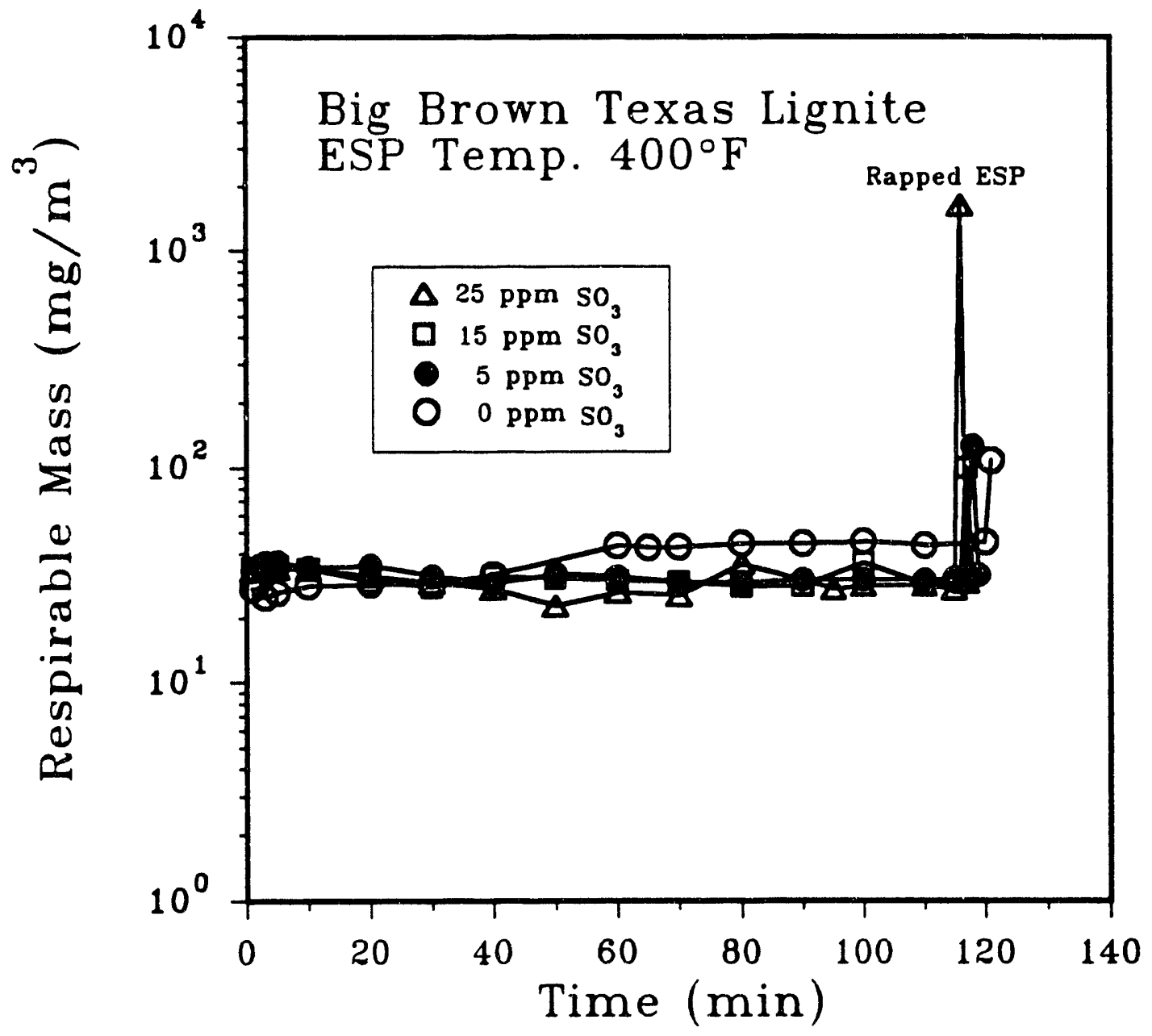

Figure A-1.6. Respirable mass emissions as a function of time, including rapping puff for Big Brown coal for Run 345 . 


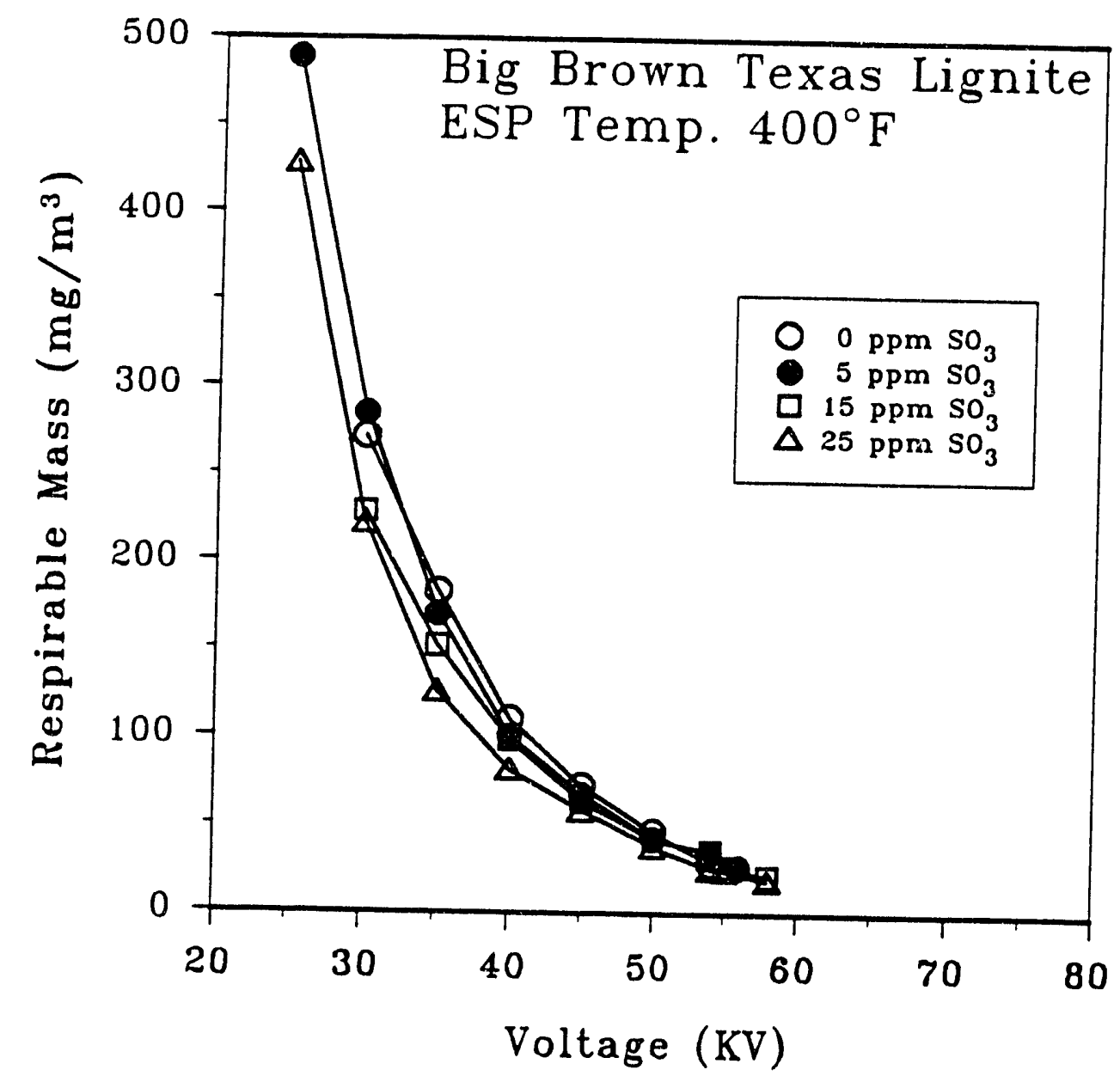

Figure A-1.7. Respirable mass emissions as a function of voltage for Big Brown coal for Run 345. 


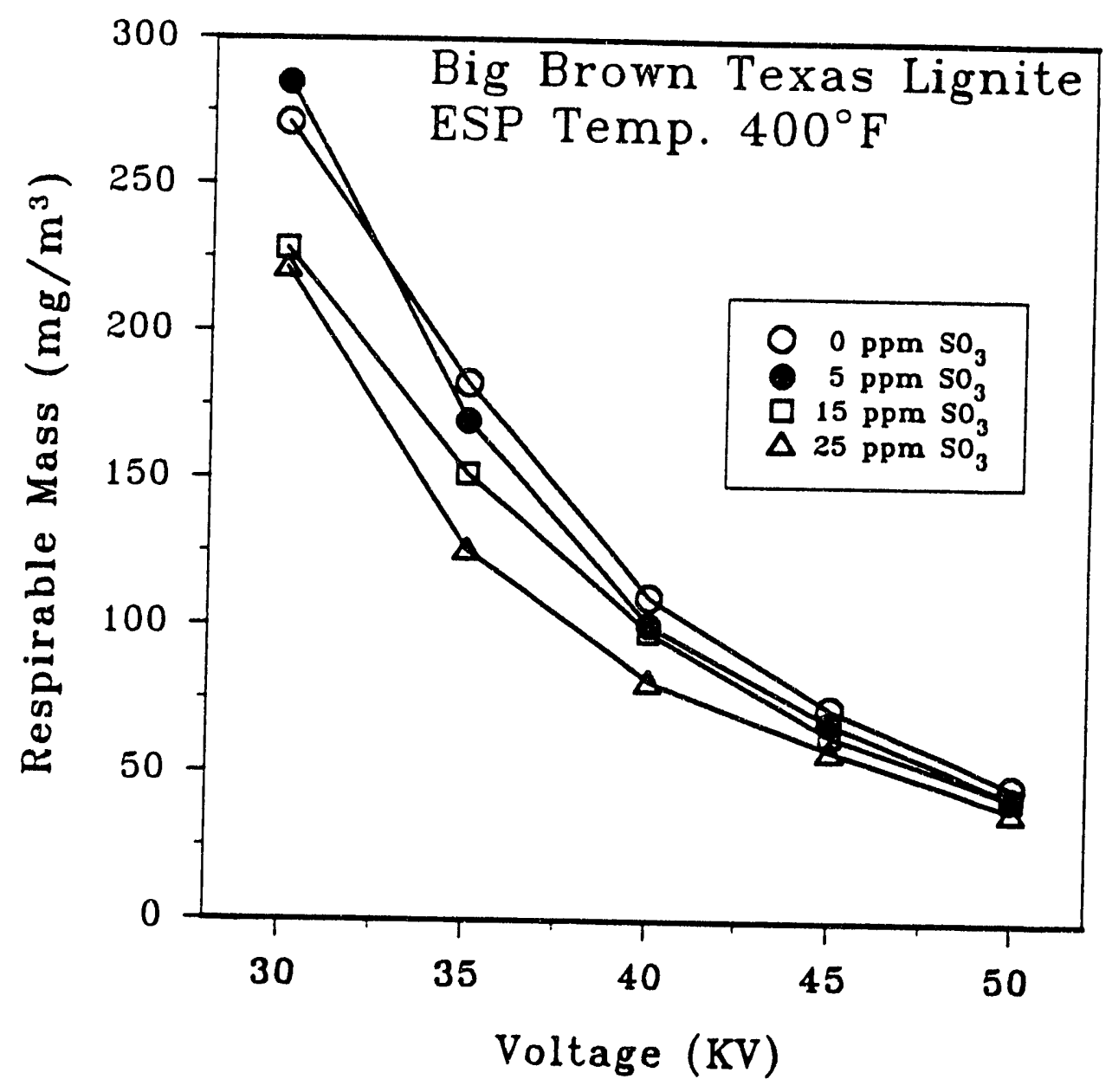

Figure A-1.8. Respirable mass emissions as a function of voltage (expanded scale) for Big Brown coal for Run 345. 


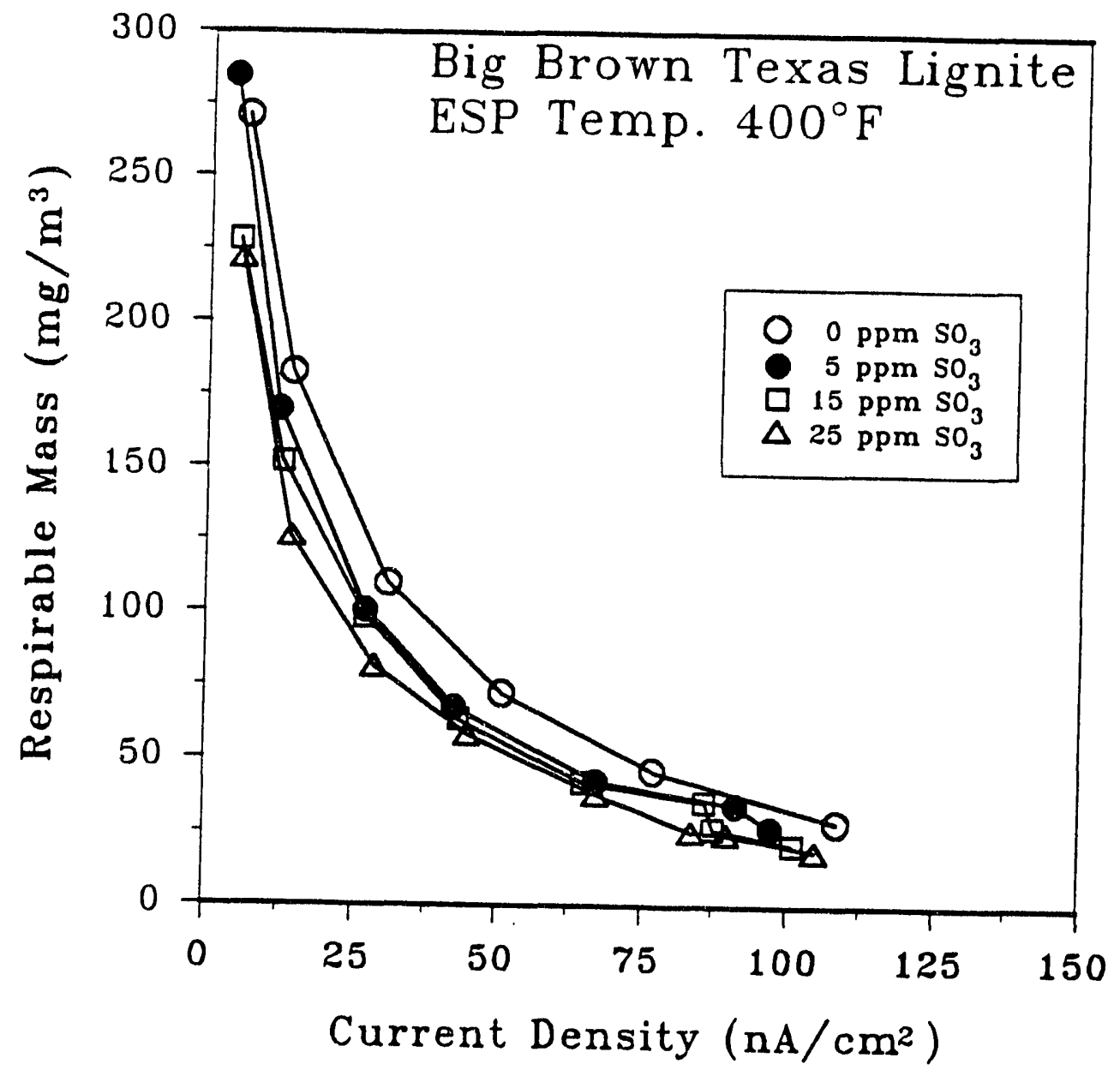

Figure A-1.9. Respirable mass emissions as a function of current density for Big Brown coal for Run 345. 


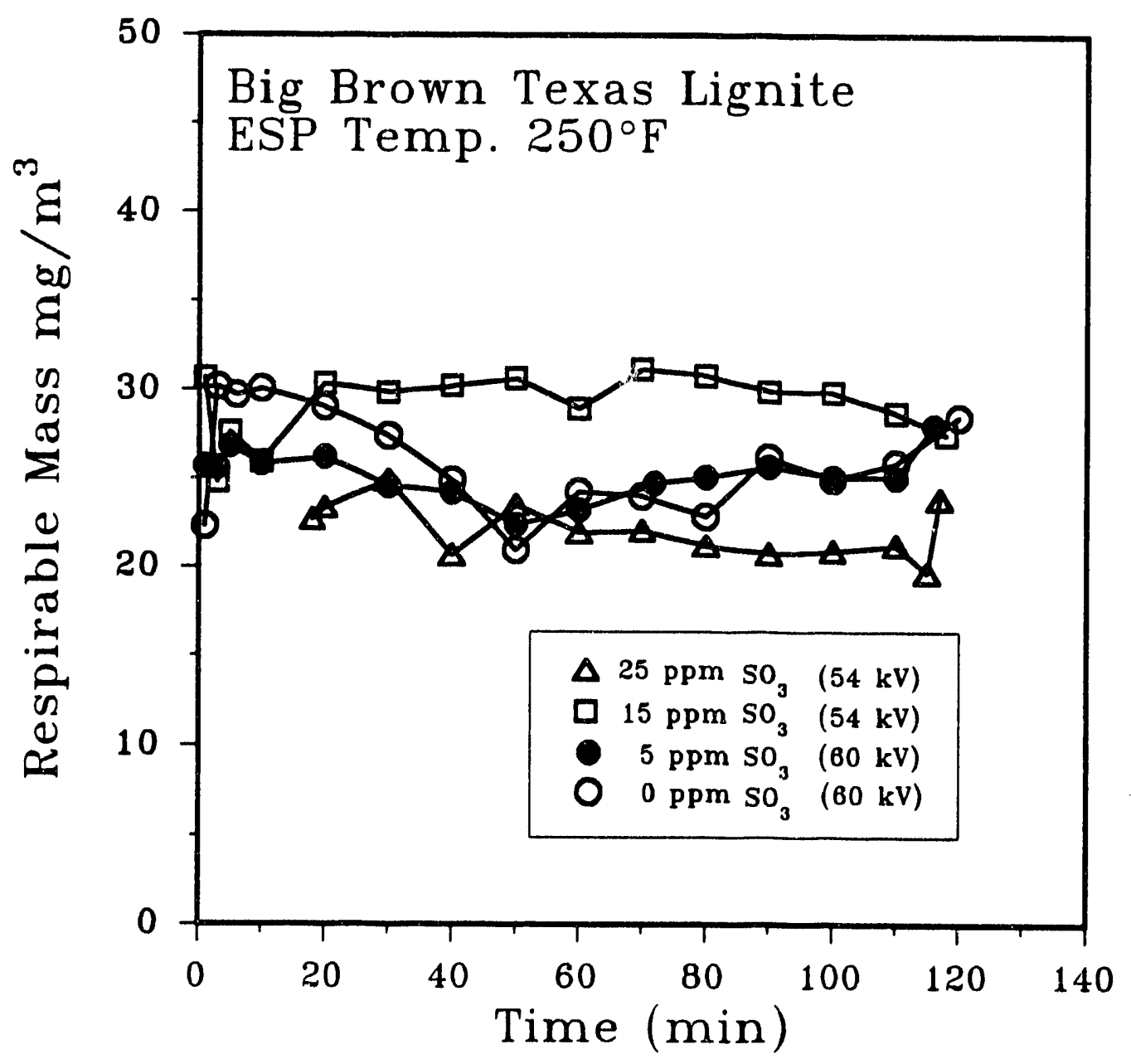

Figure A-1.10. Respirable mass emissions as a function of time for Big Brown coal for Run 346. 


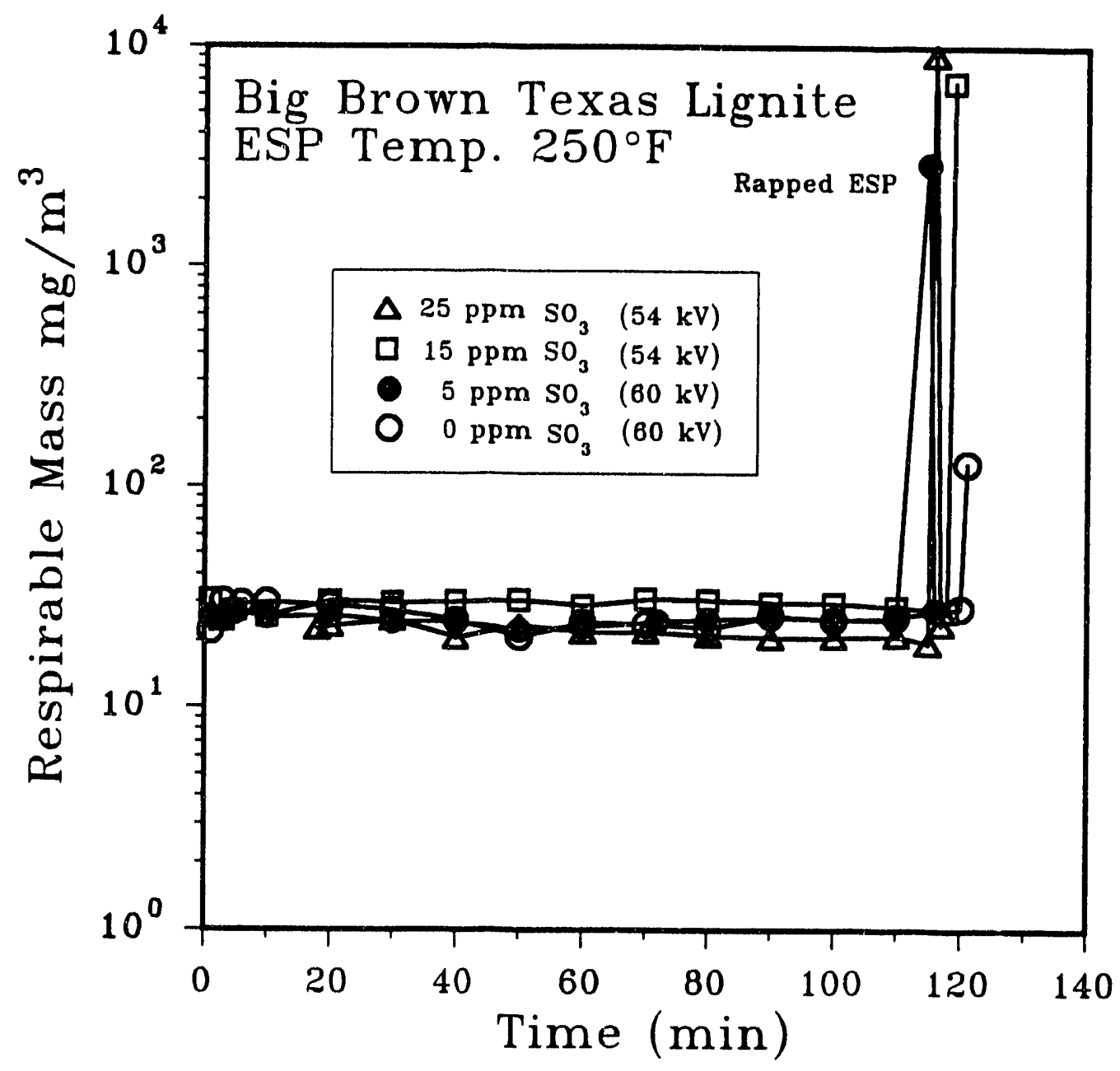

Figure A-1.11. Respirable mass emissions as a function of time, including rapping puff for Big Brown coal for Run 346. 


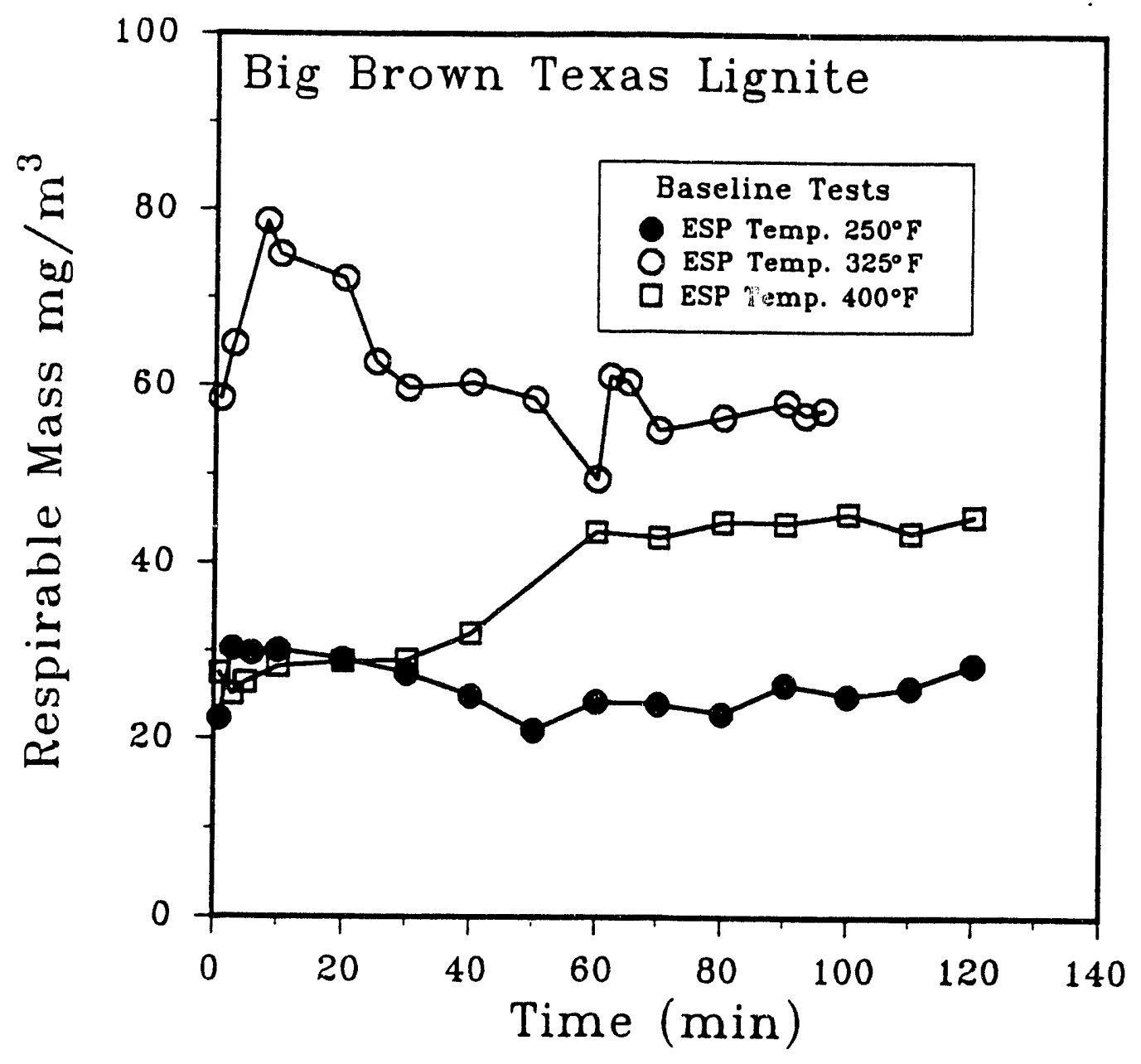

Figure A-1.12. Respirable mass emissions as a function of time for Big Brown coal for Runs 344,345 , and 346. 


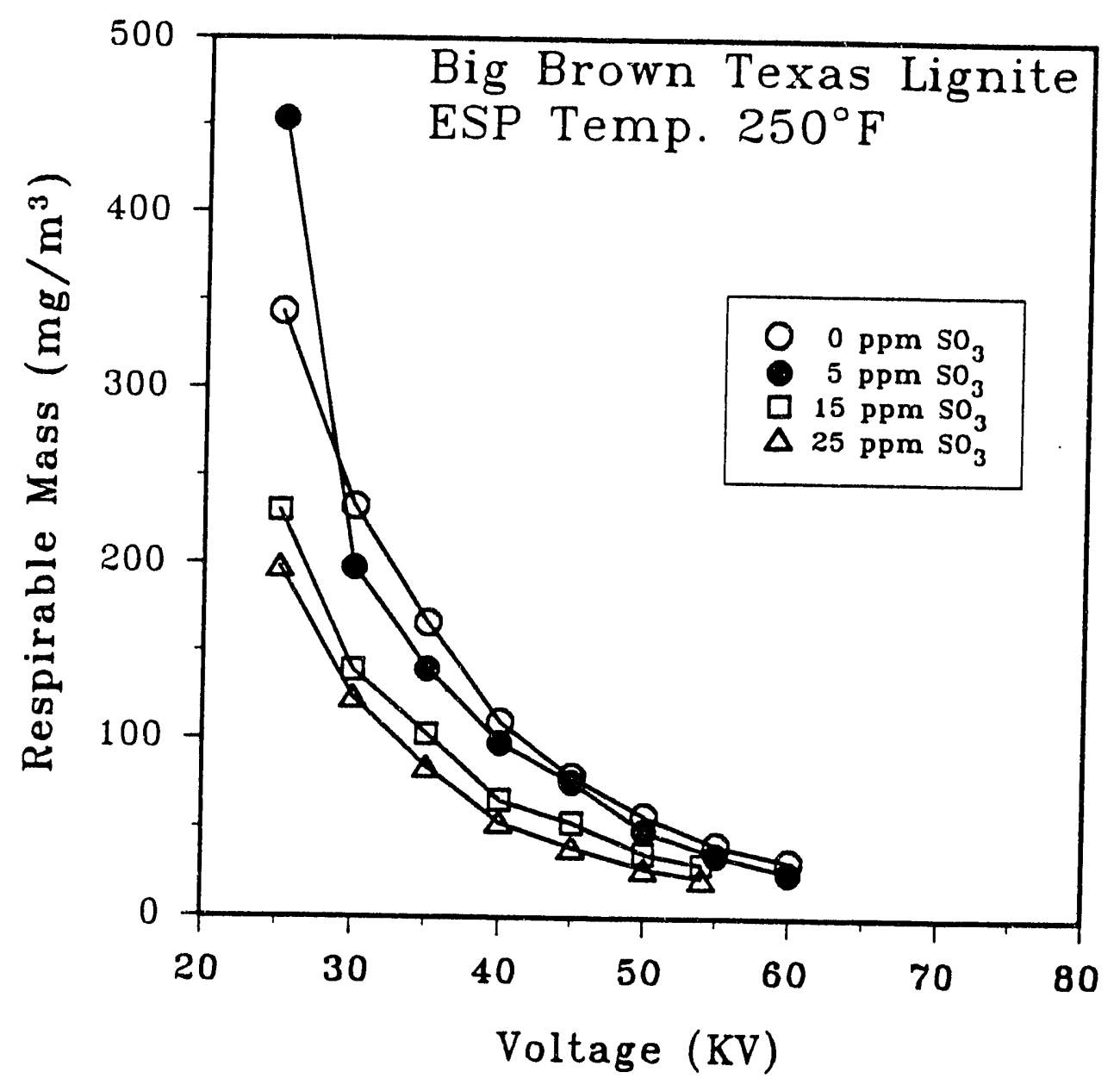

Figure A-1.13. Respirable mass emissions as a function of voltage for Big Brown coal for Run 346. 


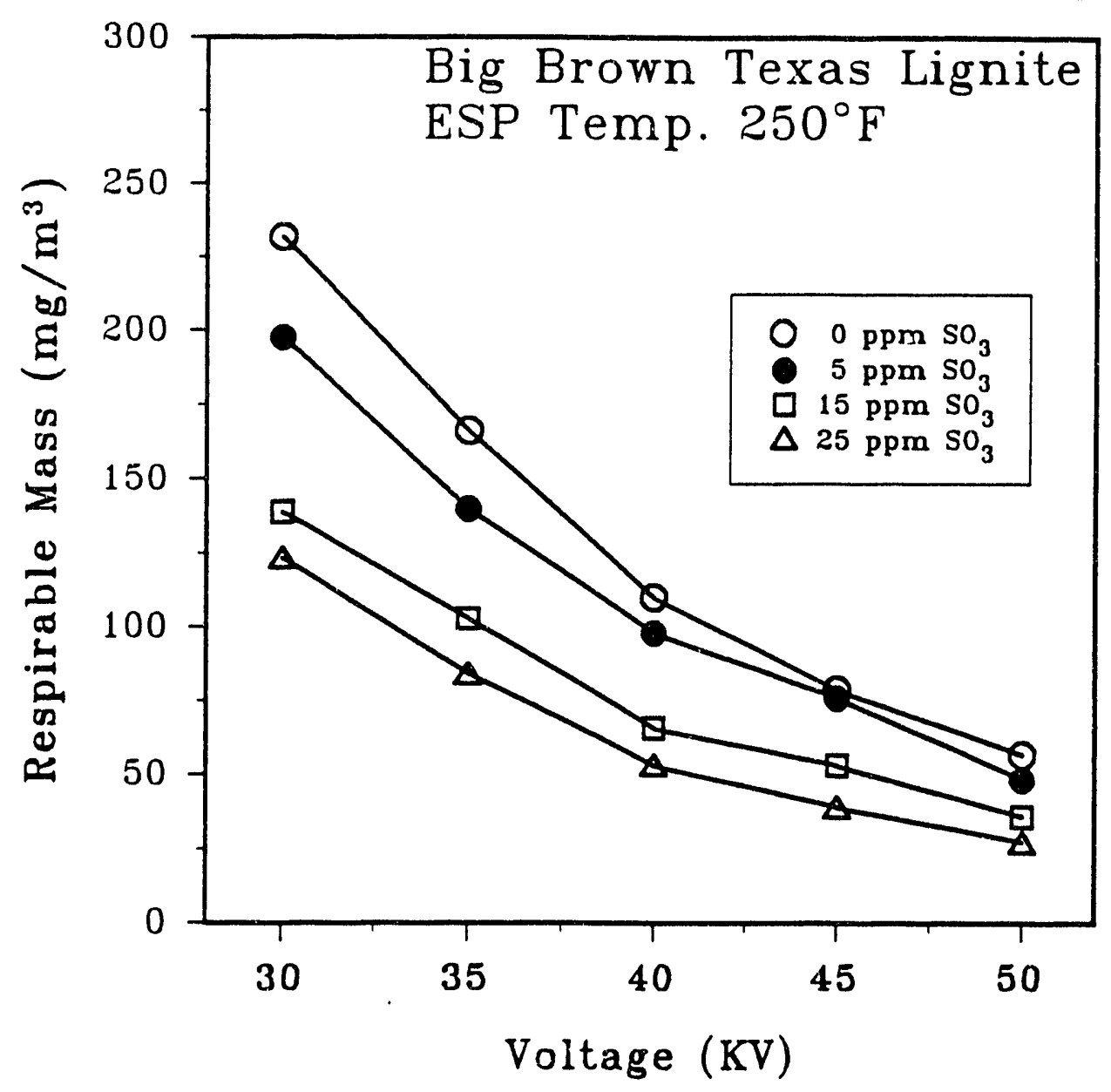

Figure A-1.14. Respirable mass emissions as a function of voltage (expanded scale) for Big Brown coal for Run 346. 


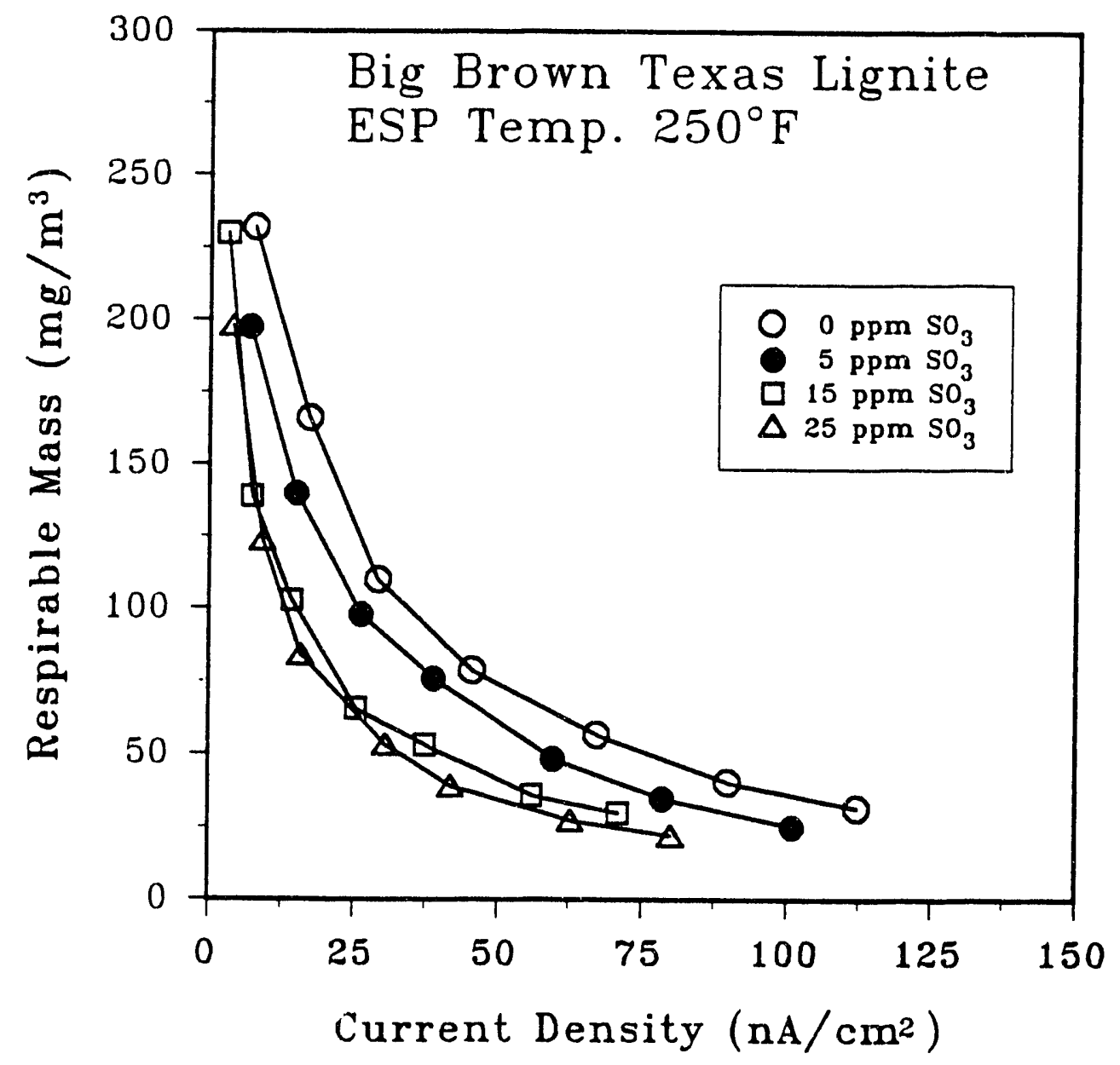

Figure A-1.15. Respirable mass emissions as a function of current density for Big Brown coal for Run 346. 


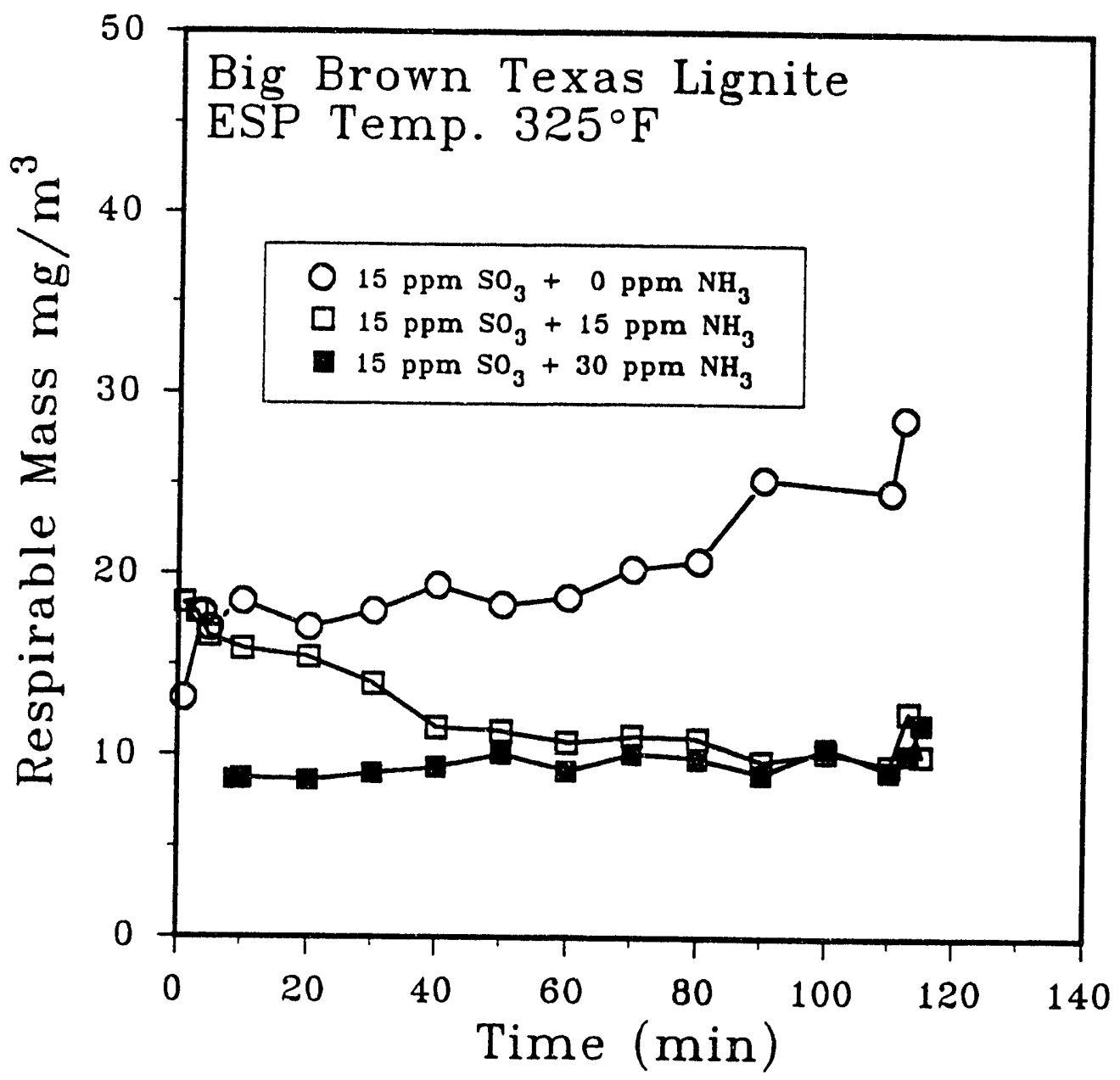

Figure A-1.16. Respirable mass emissions as a function of time for Big Brown coal for Run 347. 


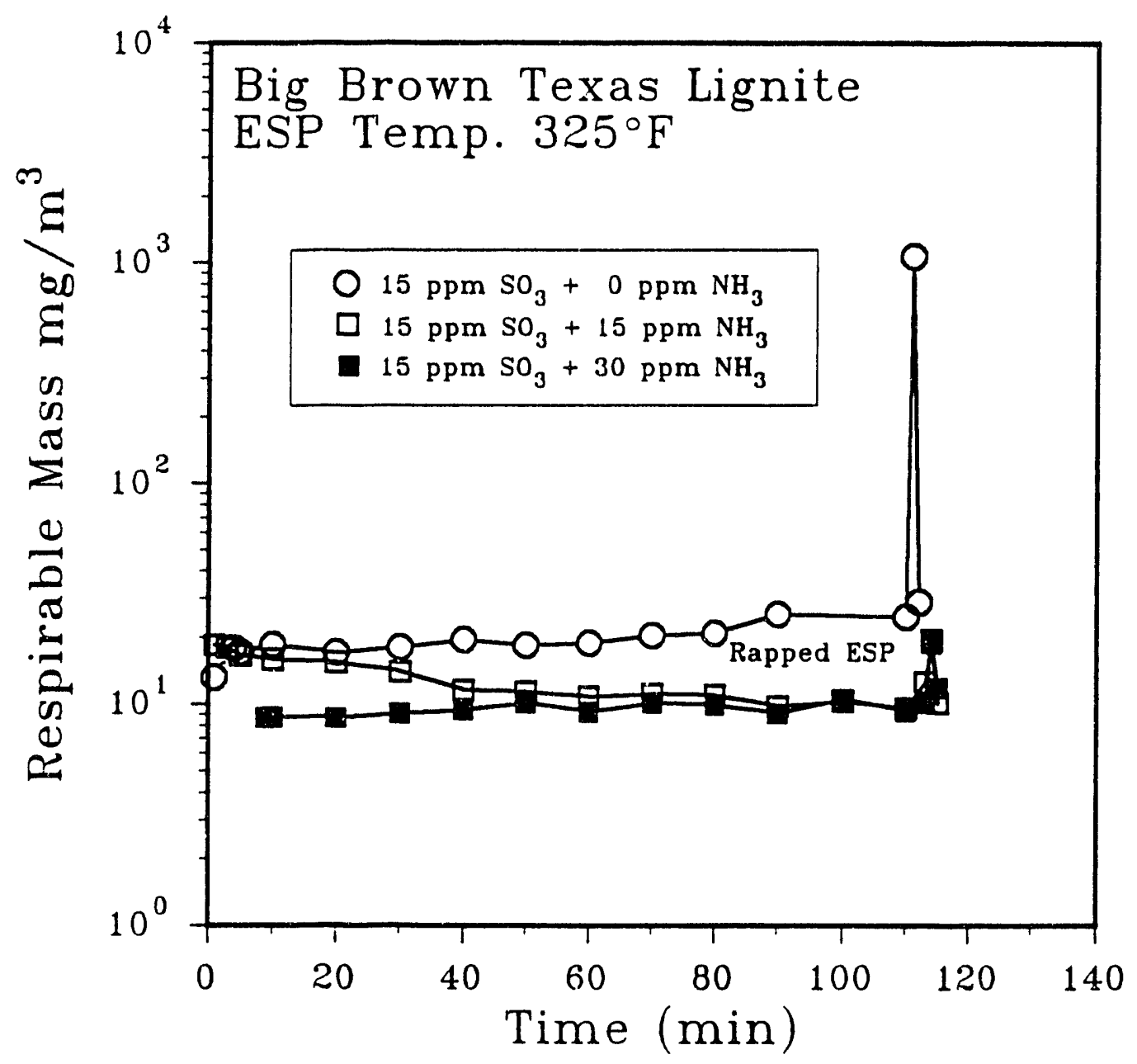

Figure A-1.17. Respirable mass emissions as a function of time, including rapping puff for Big Brown coal for Run 347. 


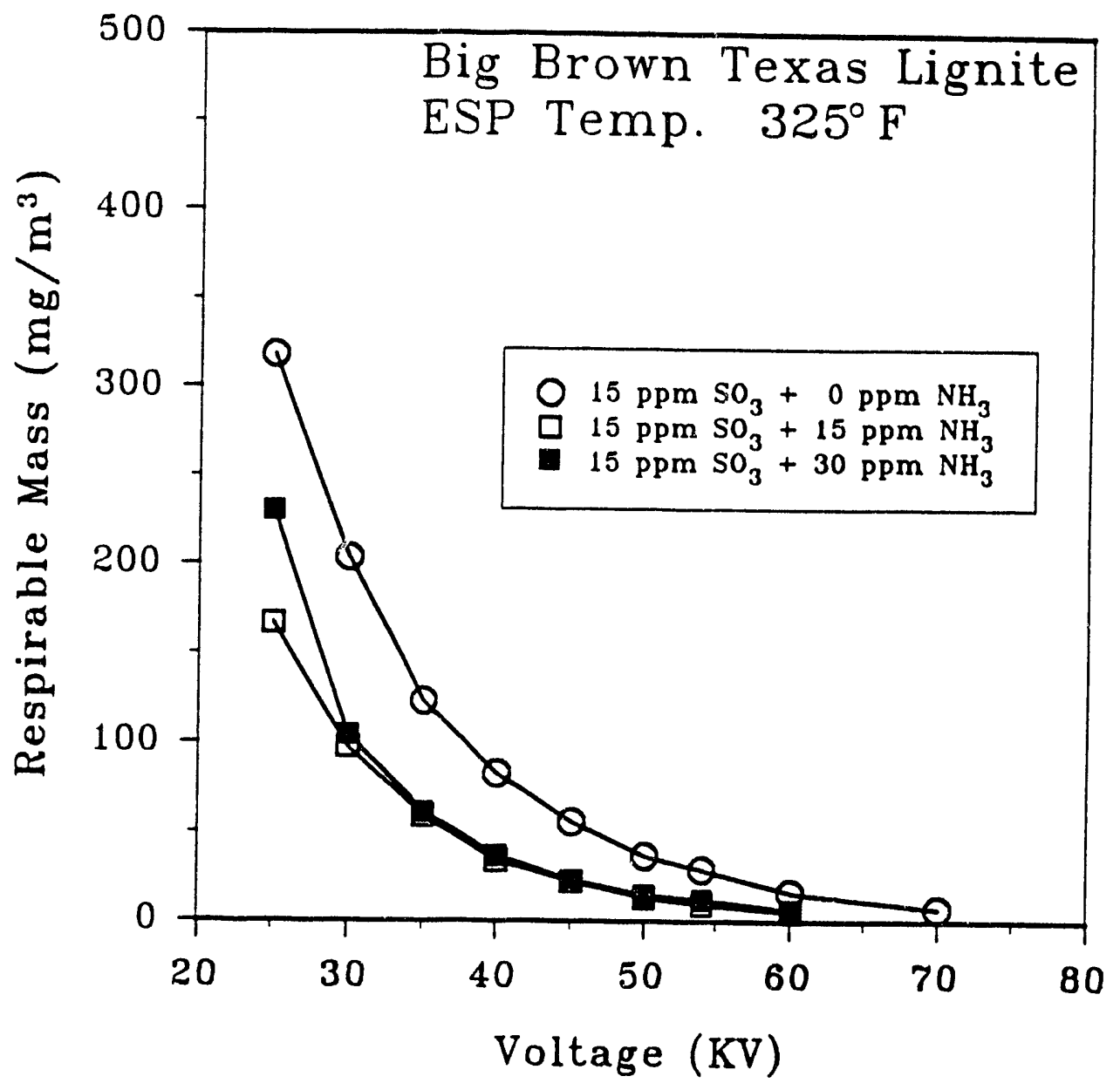

Figure A-1.18. Respirable mass emissions as a function of voltage for Big Brown coal for Run 347. 


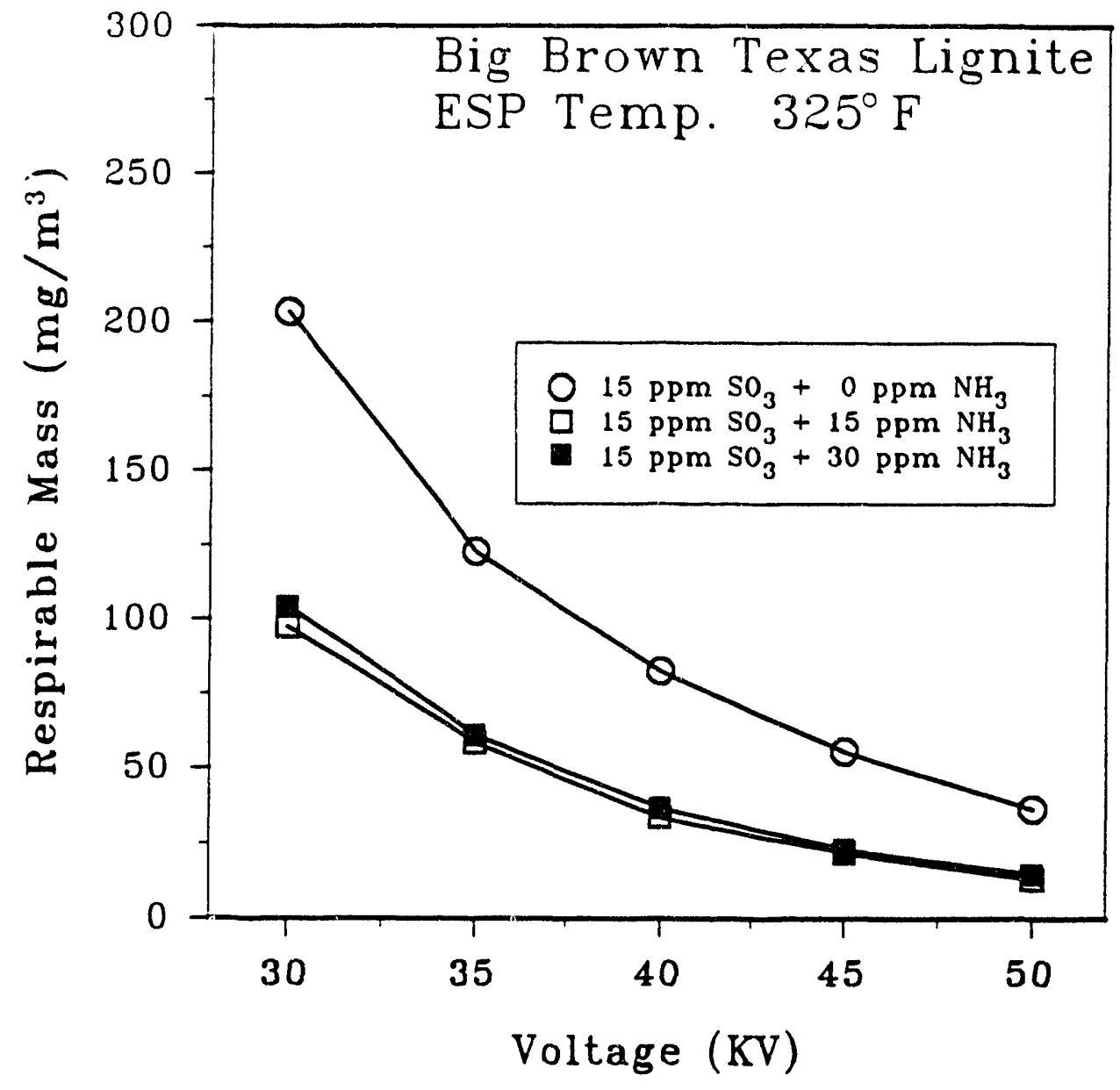

Figure A-1.19. Respirable mass emissions as a function of voltage (expanded scale) for Big Brown coal for Run 347. 


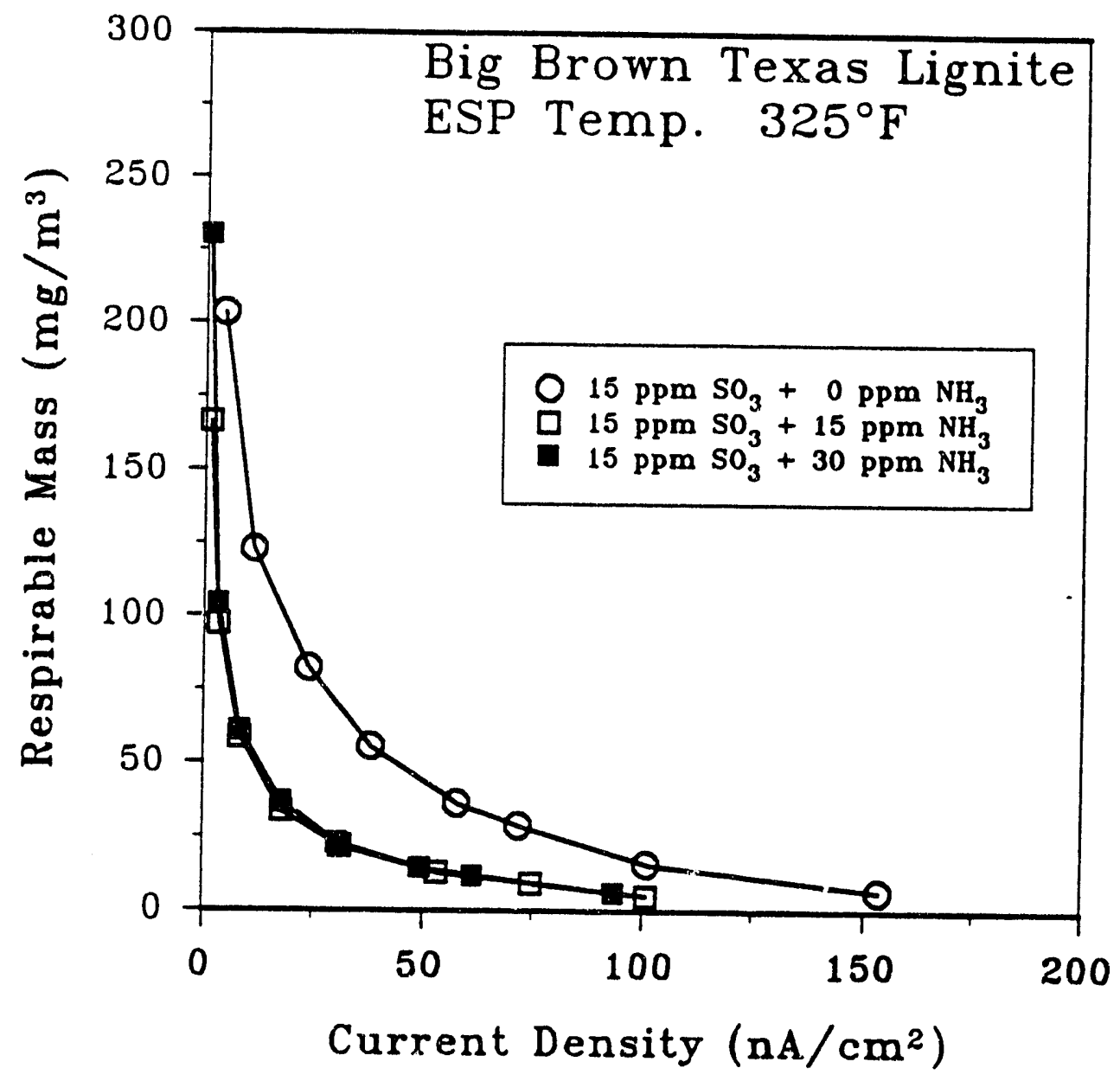

Figure A-1.20. Respirable mass emissions as a function of current density for Big Brown coal for Run 347. 


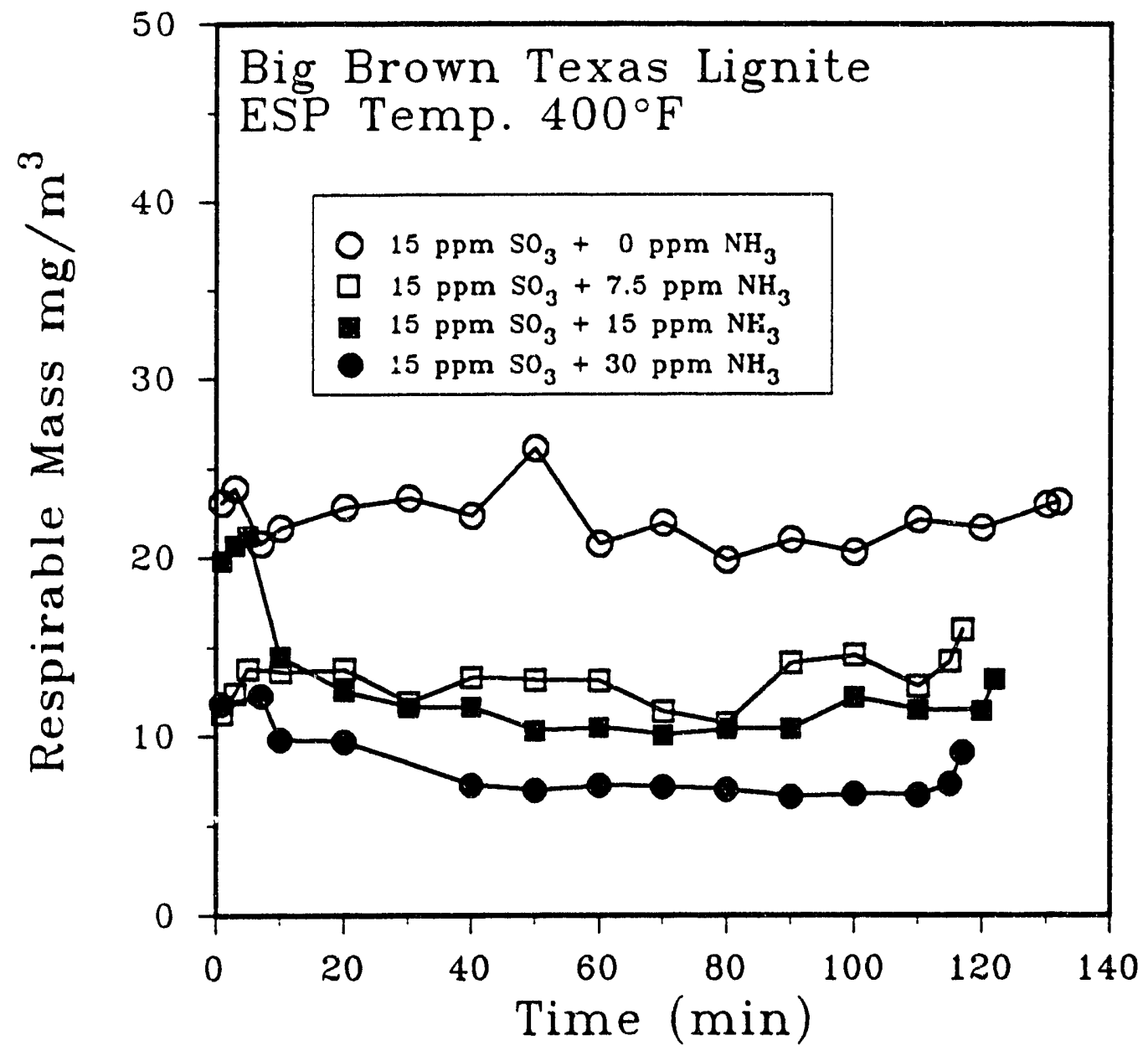

Figure A-1.21. Respirable mass emissions as a function of time for Big Brown coal for Run 348 . 


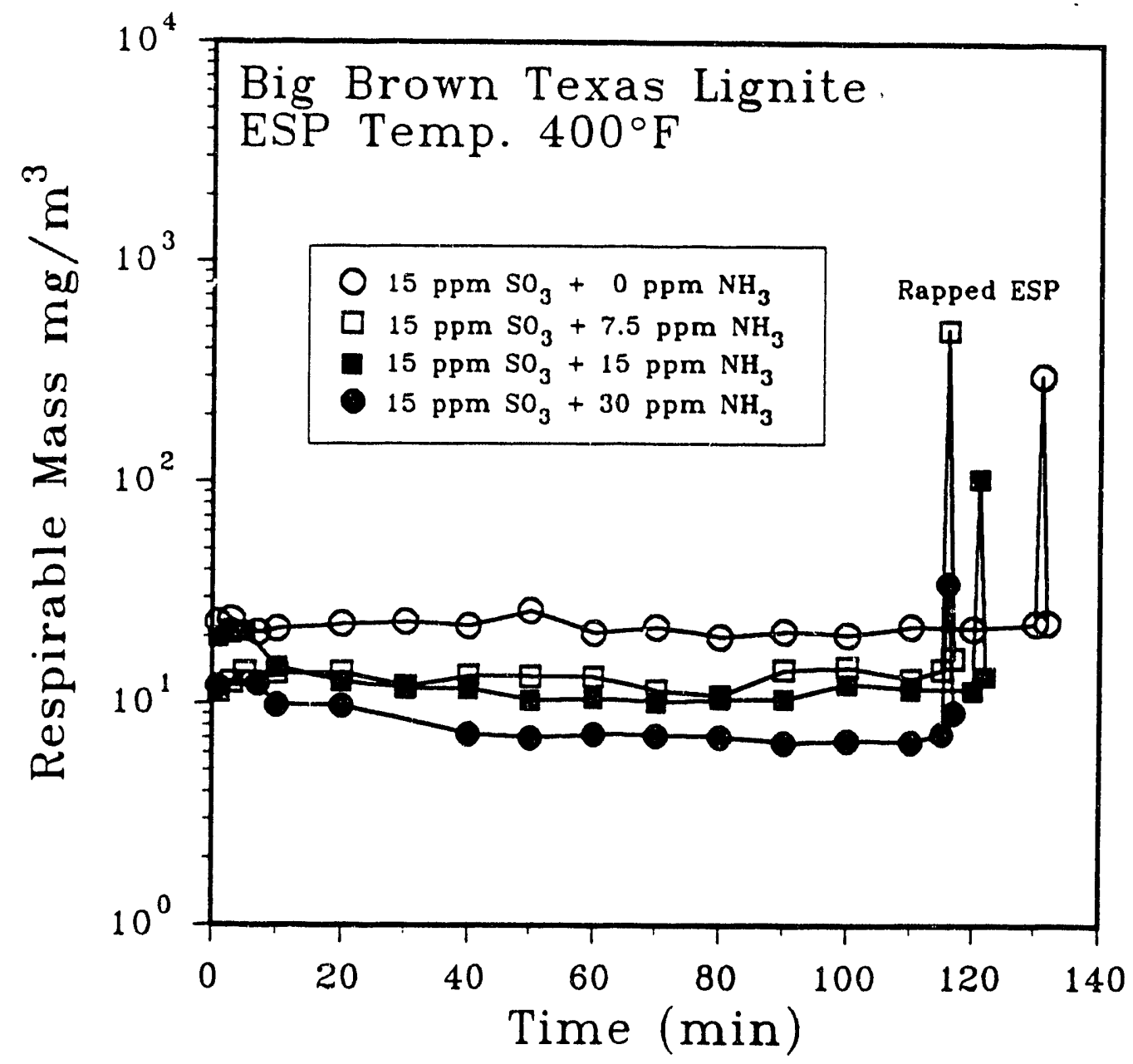

Figure A-1.22. Respirable mass emissions as a function of time, including rapping puff for Big Brown coal for Run 348. 


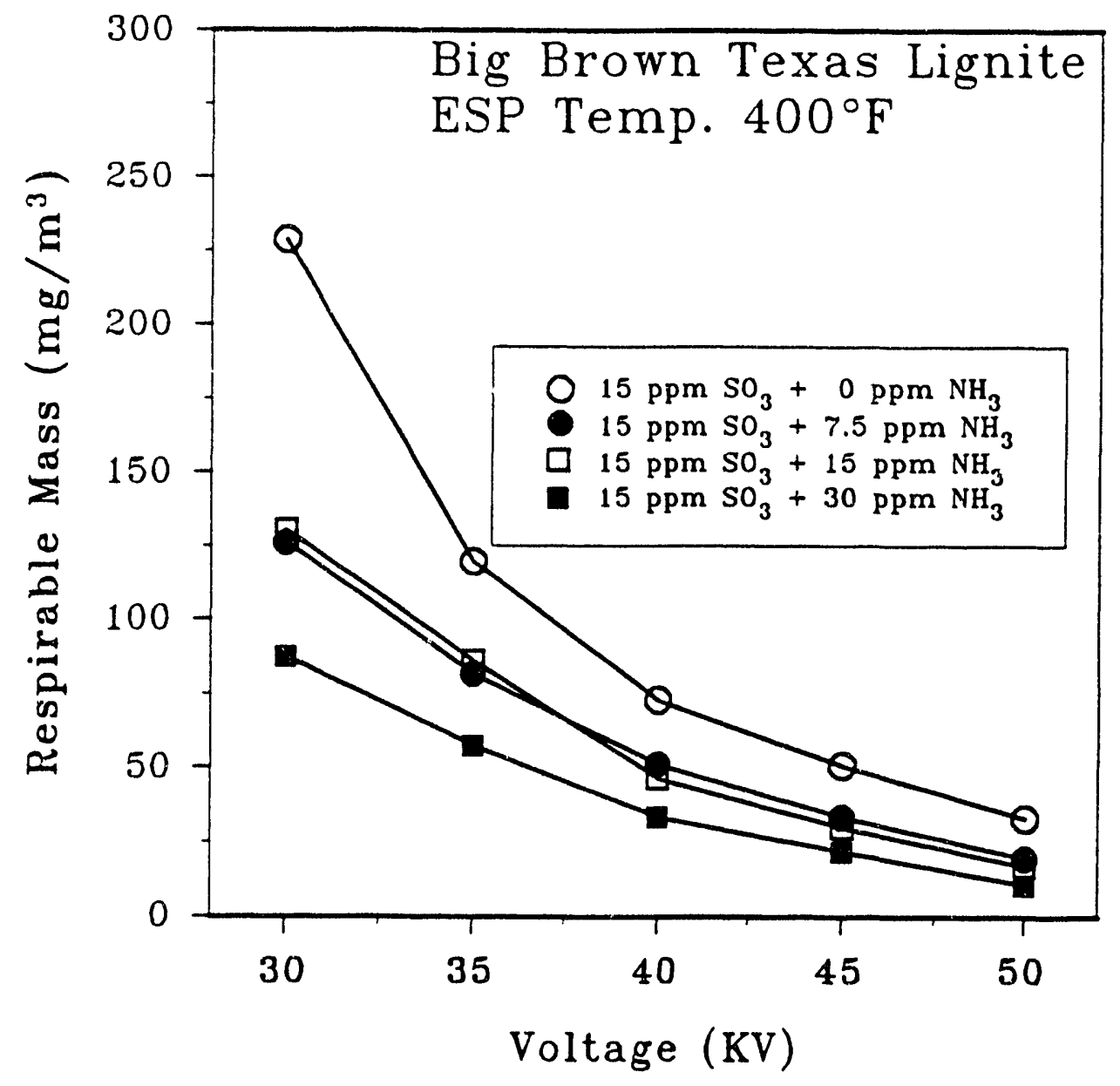

Figure A-1.23. Respirable mass emissions as a function of voltage for Big Brown coal for Run 348 . 


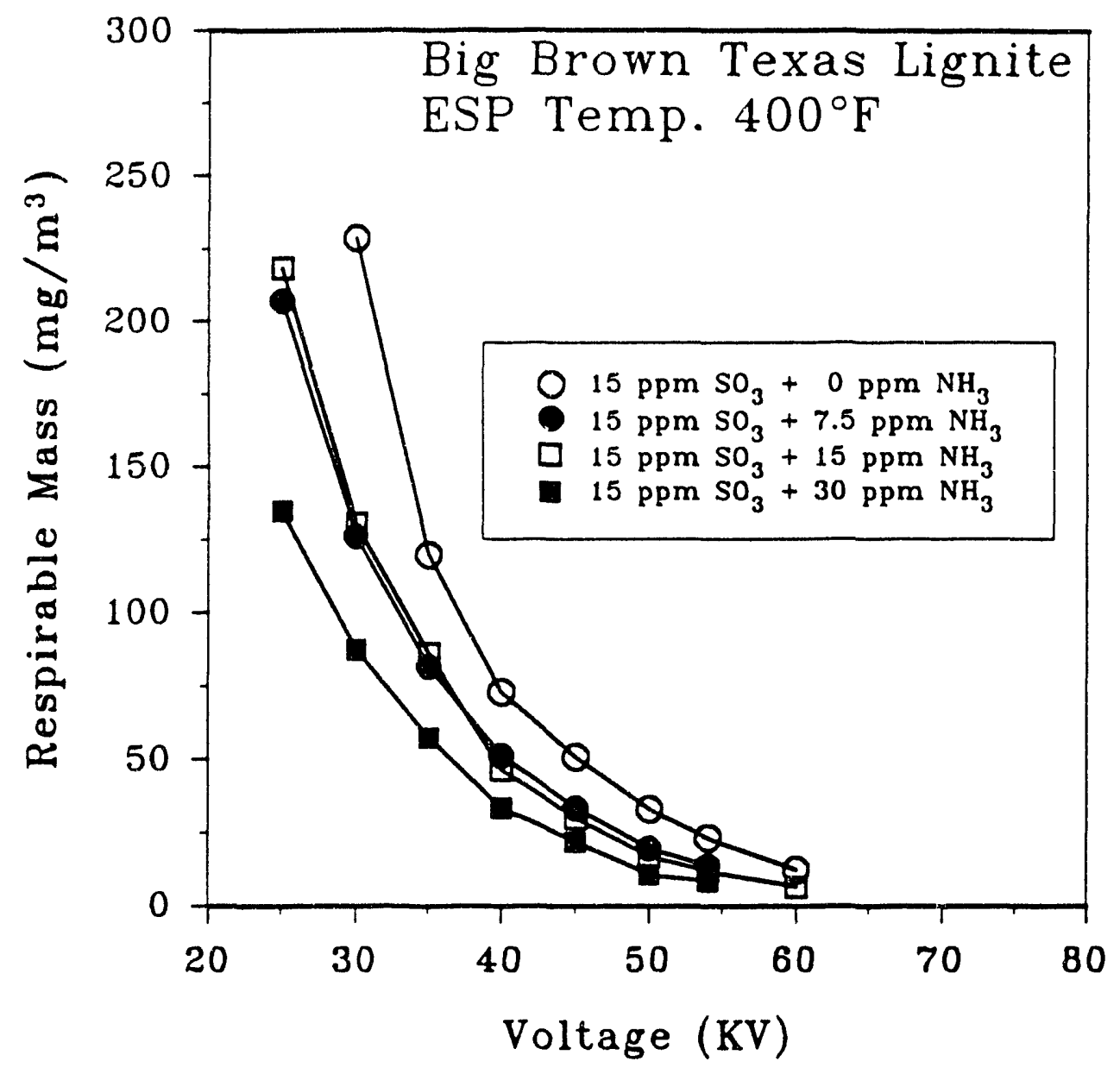

Figure A-1.24. Respirable mass emissions as a function of voltage (expanded scale) for Big Brown coal for Run 347. 


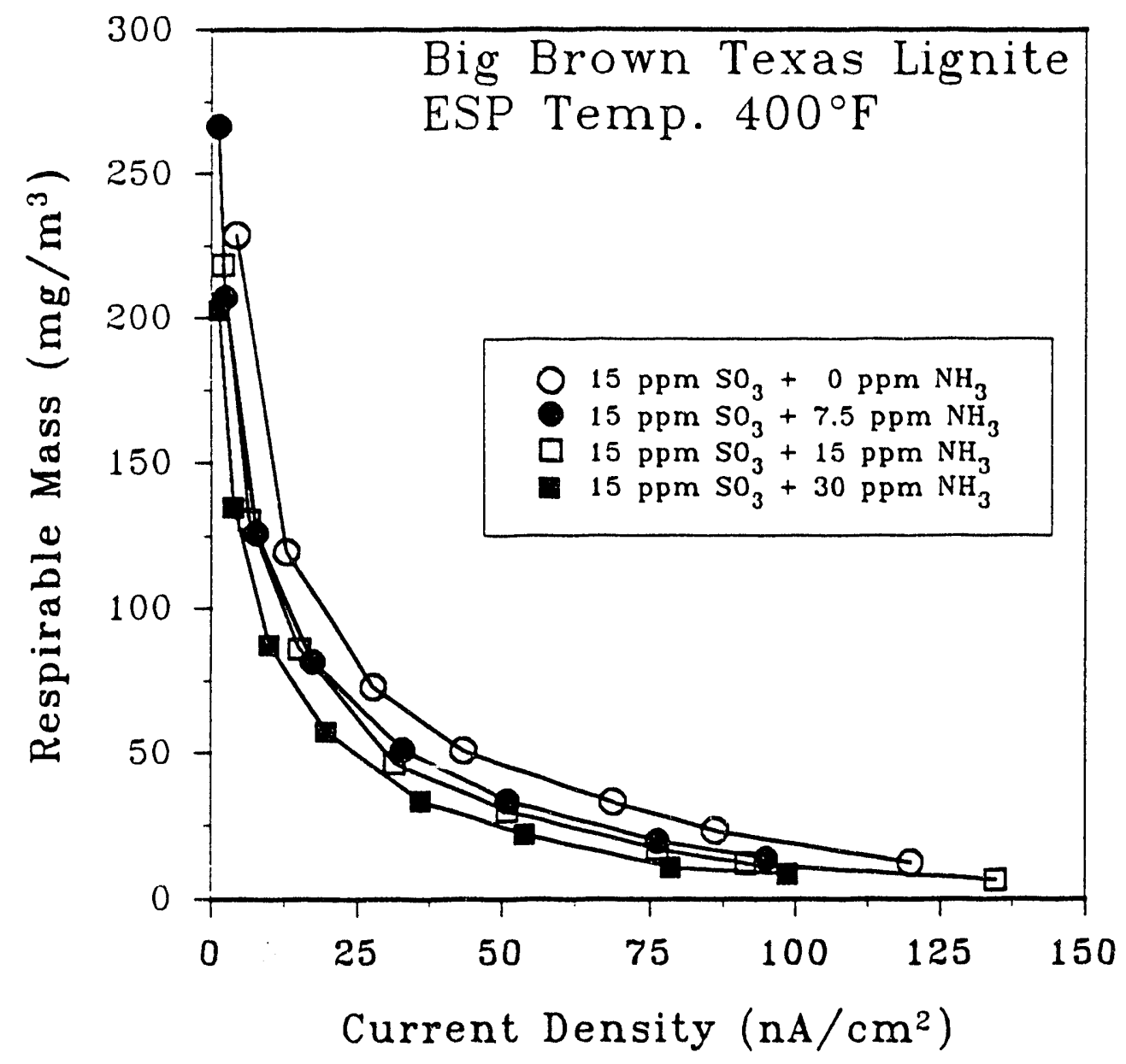

Figure A-1.25. Respirable mass emissions as a function of current density for Big Brown coal for Run 348. 


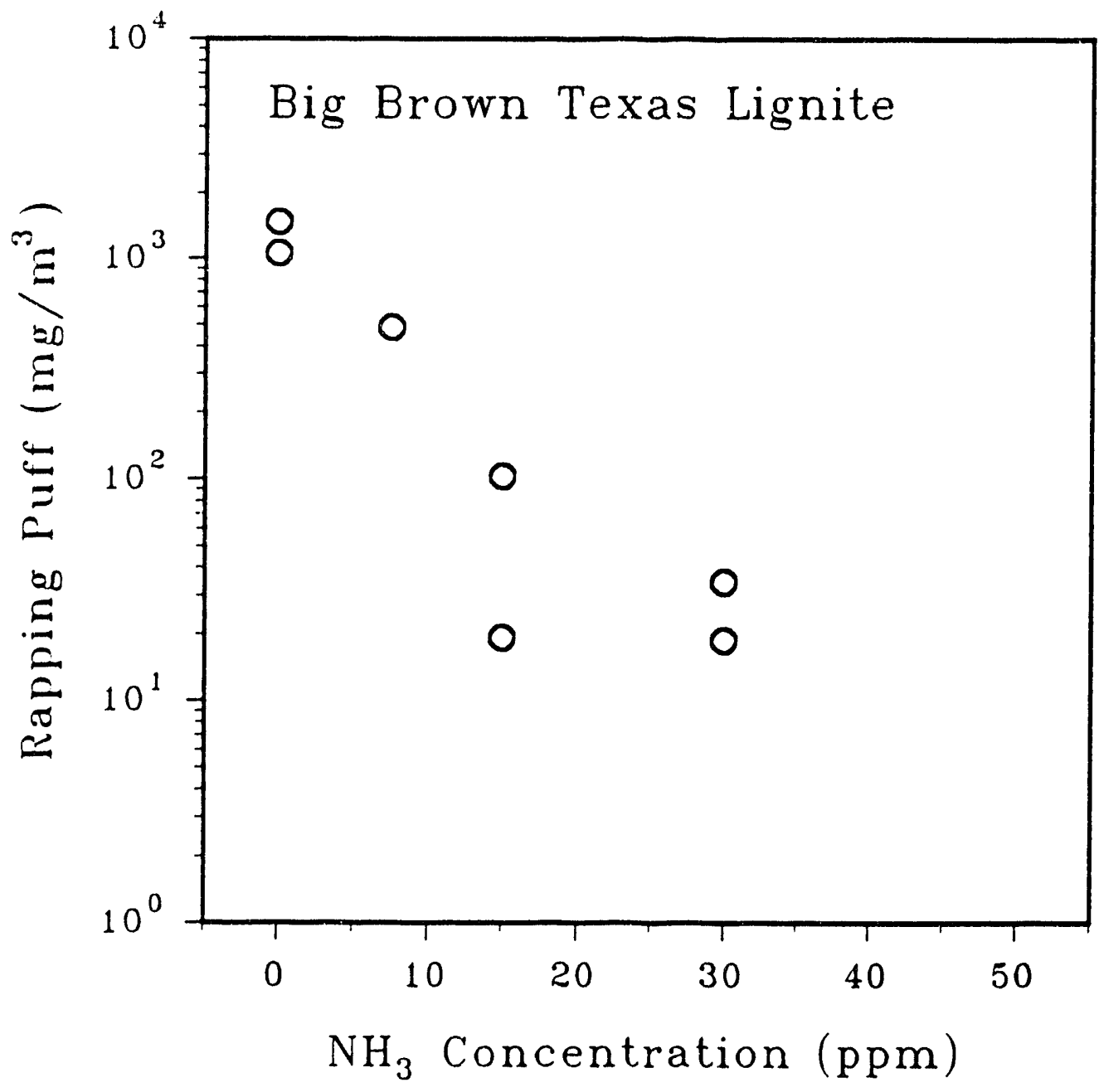

Figure A-1.26. Rapping puff emissions as a function of ammonia concentrations for Big Brown coal for Runs 347 and 348. 


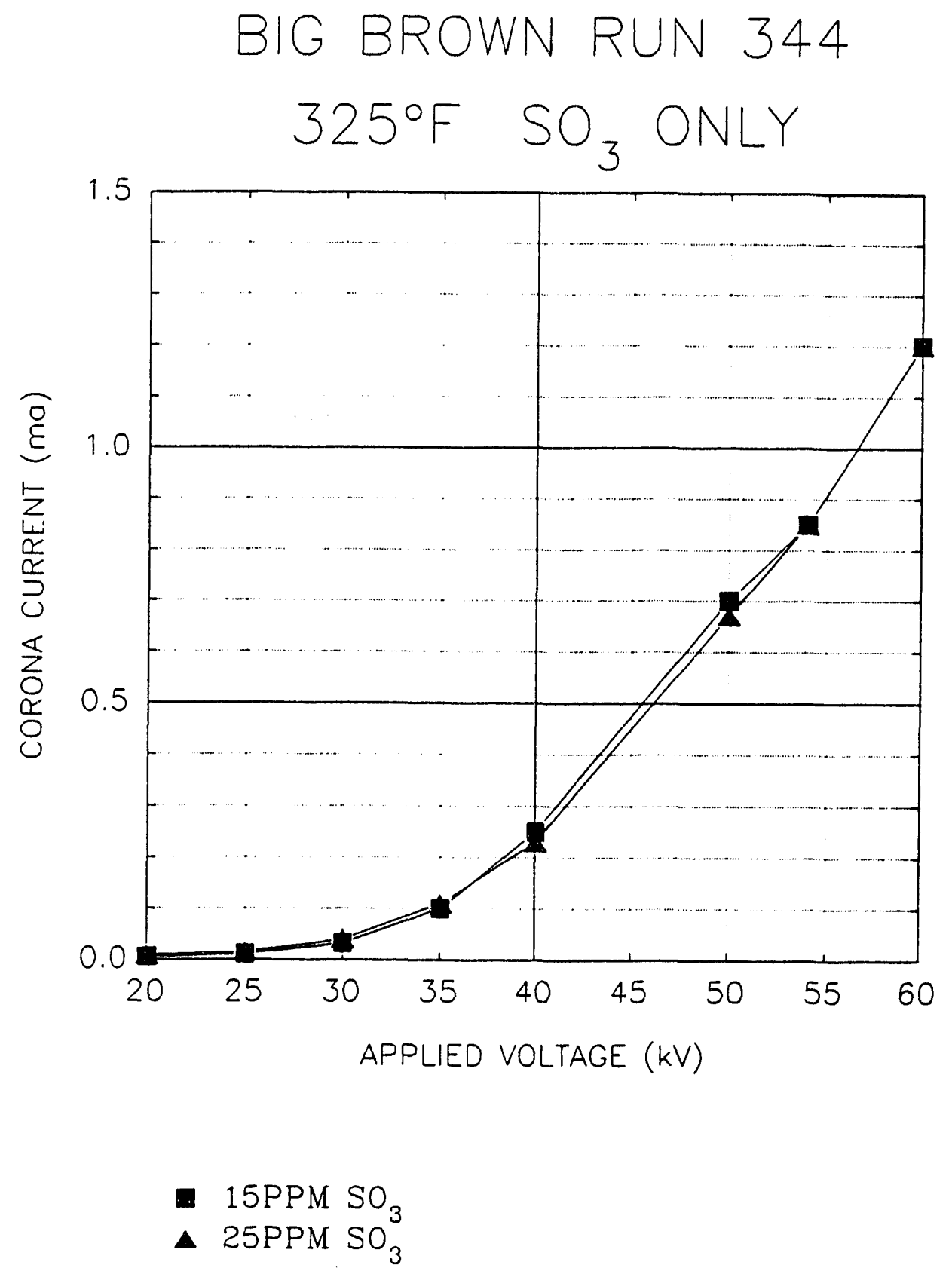

Figure A-1.27. Current-voltage curves for Big Brown coal for Run 344. 


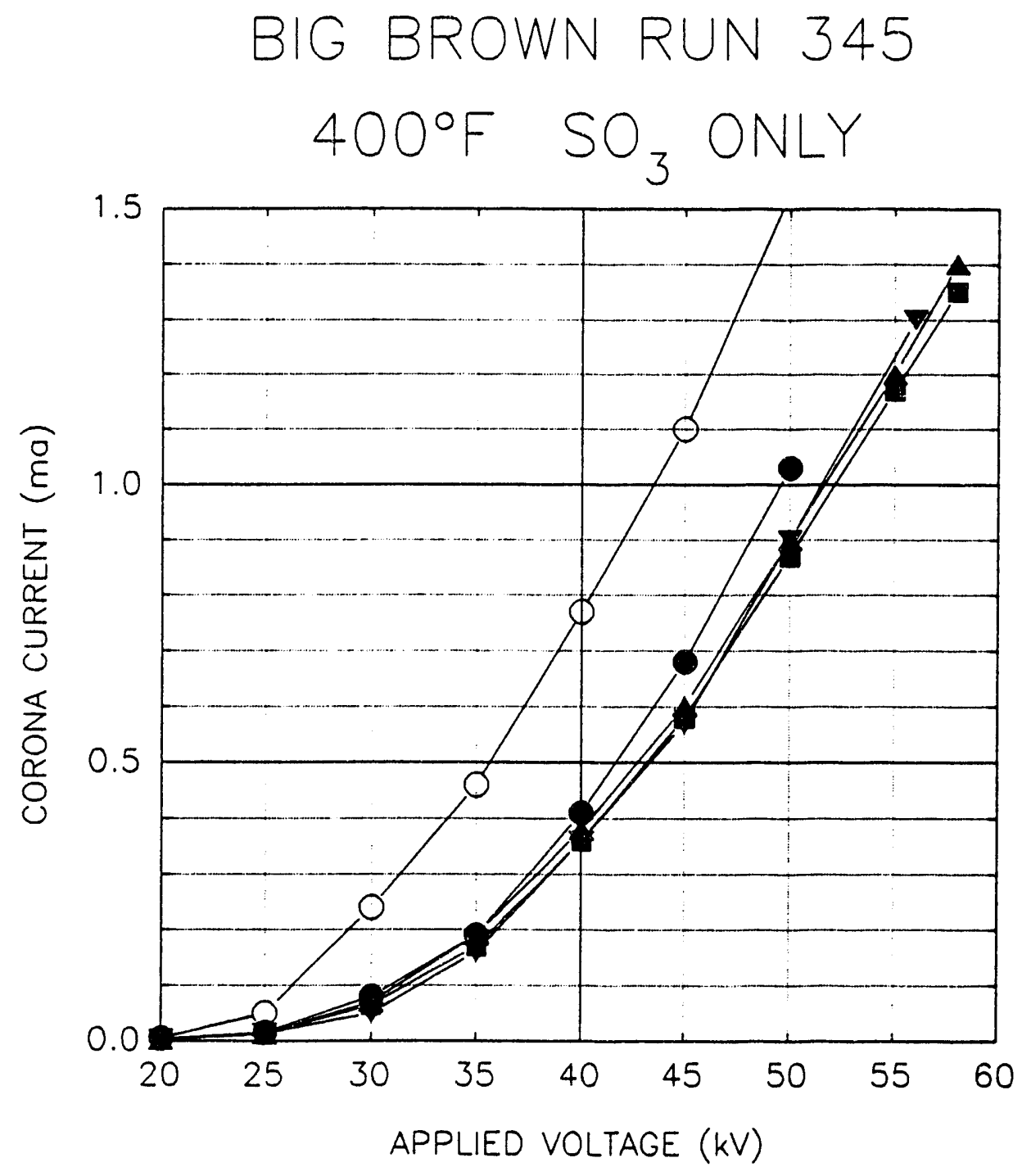

CLEAN WIRE AND PLATE

- OPPM $\mathrm{SO}_{3}$

$\checkmark$ 5PPM SO

- 15PPM SO

$\triangle 25 \mathrm{PPM} \mathrm{SO}_{3}$

Figure A-1.28. Current-voltage curves for Big Brown coal for Run 345 . 


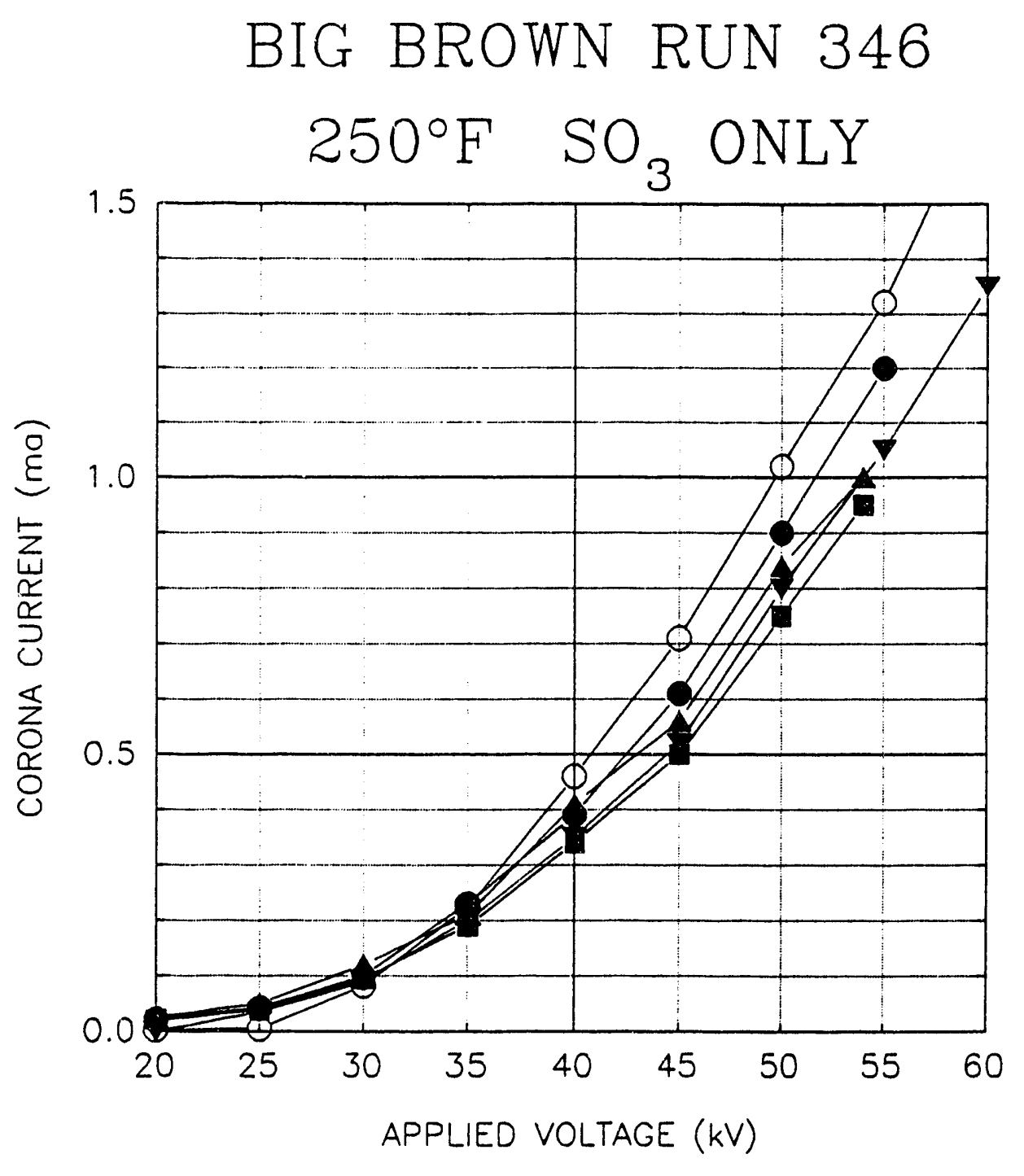

CLEAN WIRE AND PLATE

- $\mathrm{NO} \mathrm{SO}_{3}$

$\checkmark 5 \mathrm{PPM}^{3} \mathrm{SO}_{3}$

- $15 \mathrm{PPM} \mathrm{SO}_{3}$

$\Delta 25 \mathrm{PPM} \mathrm{SO}_{3}$

Figure A-1.29. Current-voltage curves for Big Brown coal for Run 346 . 


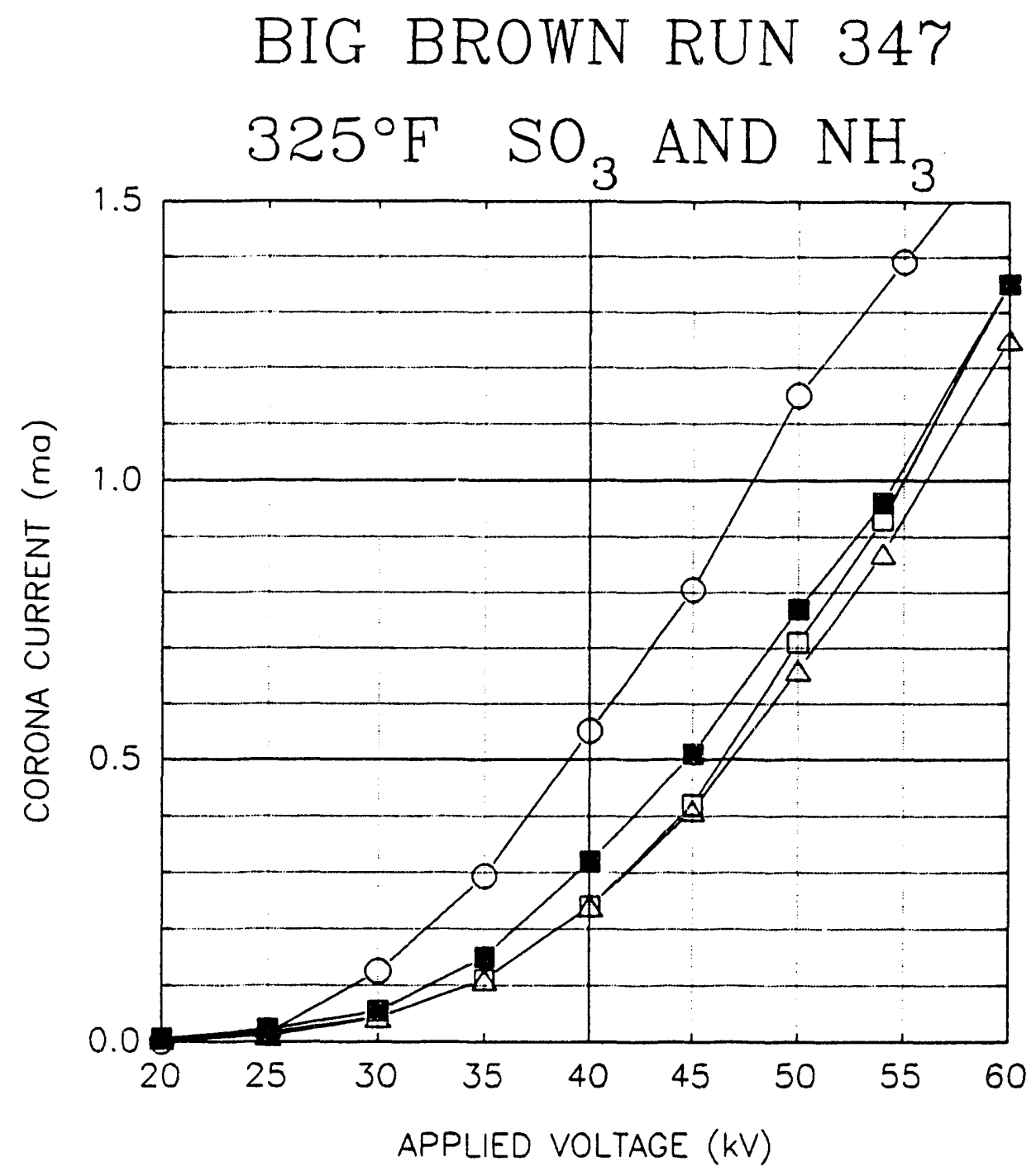

O CLEAN WIRE AND PLATE

- $15 \mathrm{PPM} \mathrm{SO} \mathrm{SO}_{3} \mathrm{ONLY}$

- 15PPM SO $\mathrm{PND}_{3}$ 15PPM NH

$\triangle 15 \mathrm{PPM} \mathrm{SO}_{3}$ AND 30PPM NH $\mathrm{PH}_{3}$

Figure A-1.30. Current-voltage curves for Big Brown coal for Run 347. 


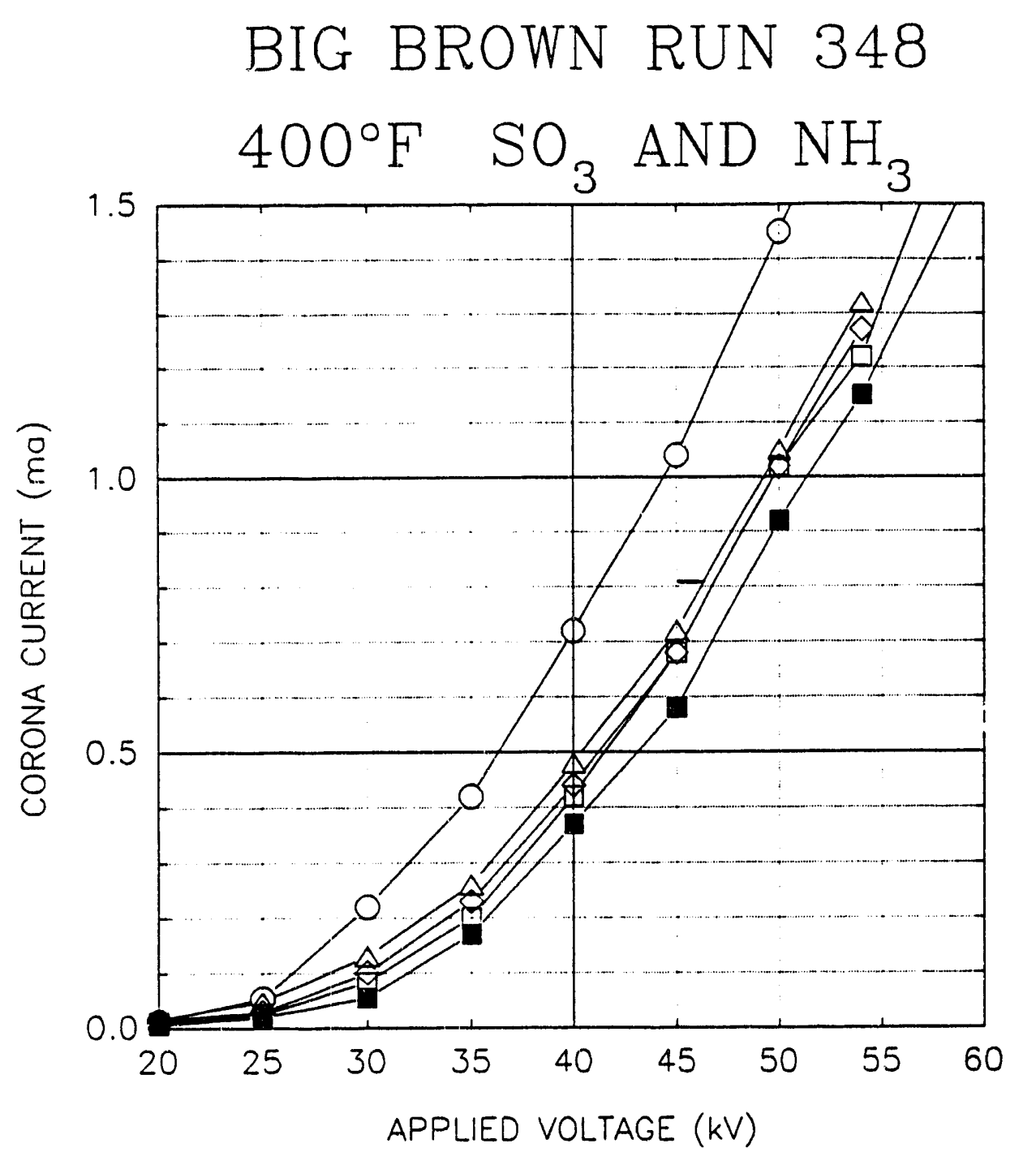

O CLEAN WIRE AND PLATE

- 15PPM SO $\mathrm{SONLY}_{3}$

$\square \quad 15 \mathrm{PPM} \mathrm{SO}_{3}$ AND 15PPM NH

$\triangle 15 \mathrm{PPM} \mathrm{SO}_{3}$ AND 30PPM NH

$\diamond 15 \mathrm{PPM} \mathrm{SO}_{3}$ AND 7.5PPM NH

Figure A-1.31. Current-voltage curves for Big Brown coal for Run 348. 
Big Brown $344 \quad 325 \mathrm{~F}$

$\nabla$ Big Brown $345 \quad 400 F$

$\square$ Big Brown $346 \quad 250 \mathrm{~F}$

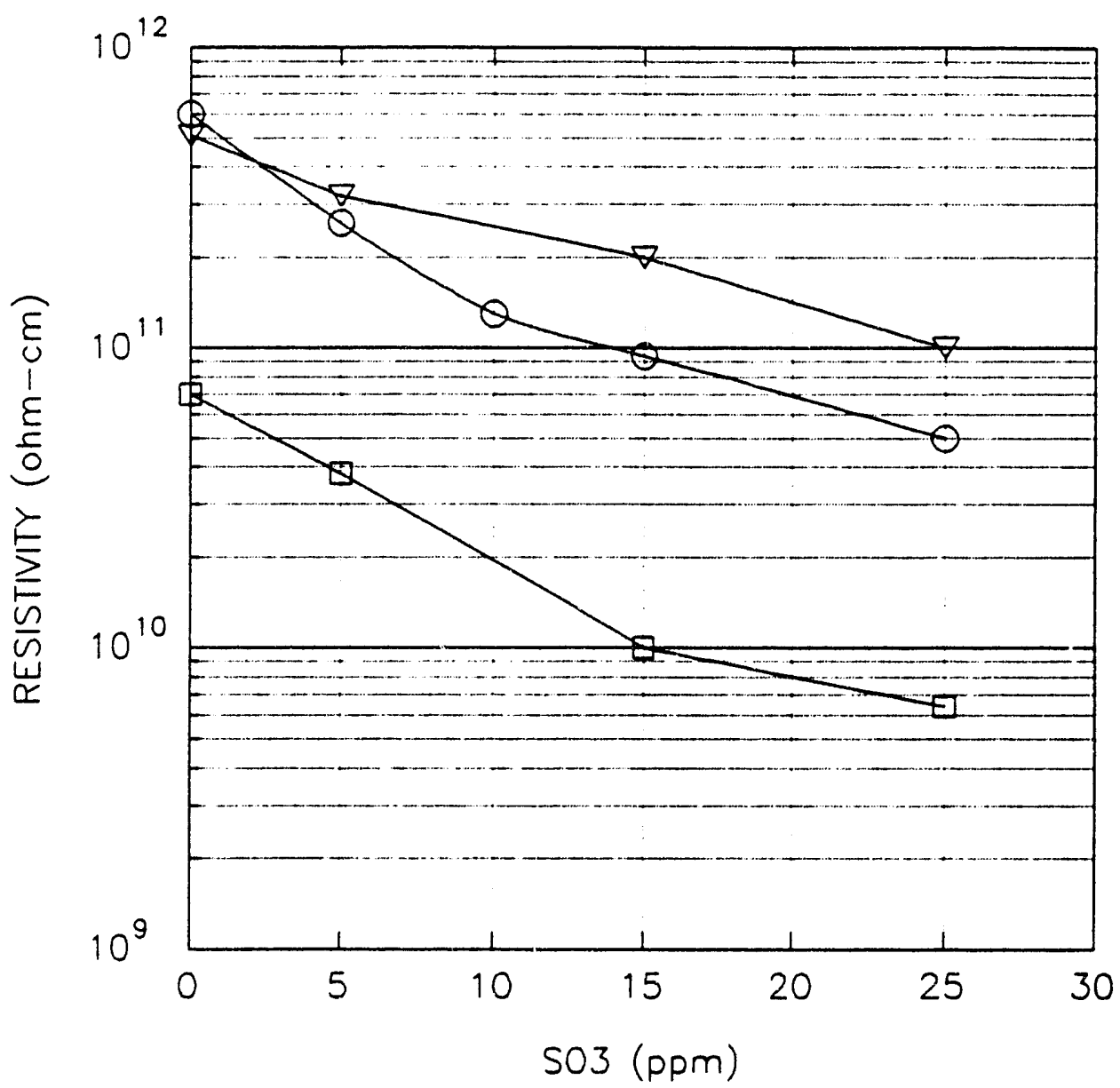

Figure A-1.32. Resistivity as a function of $\mathrm{SO}_{3}$ concentration for Big Brown coal for Runs 344,345 , and 346. 


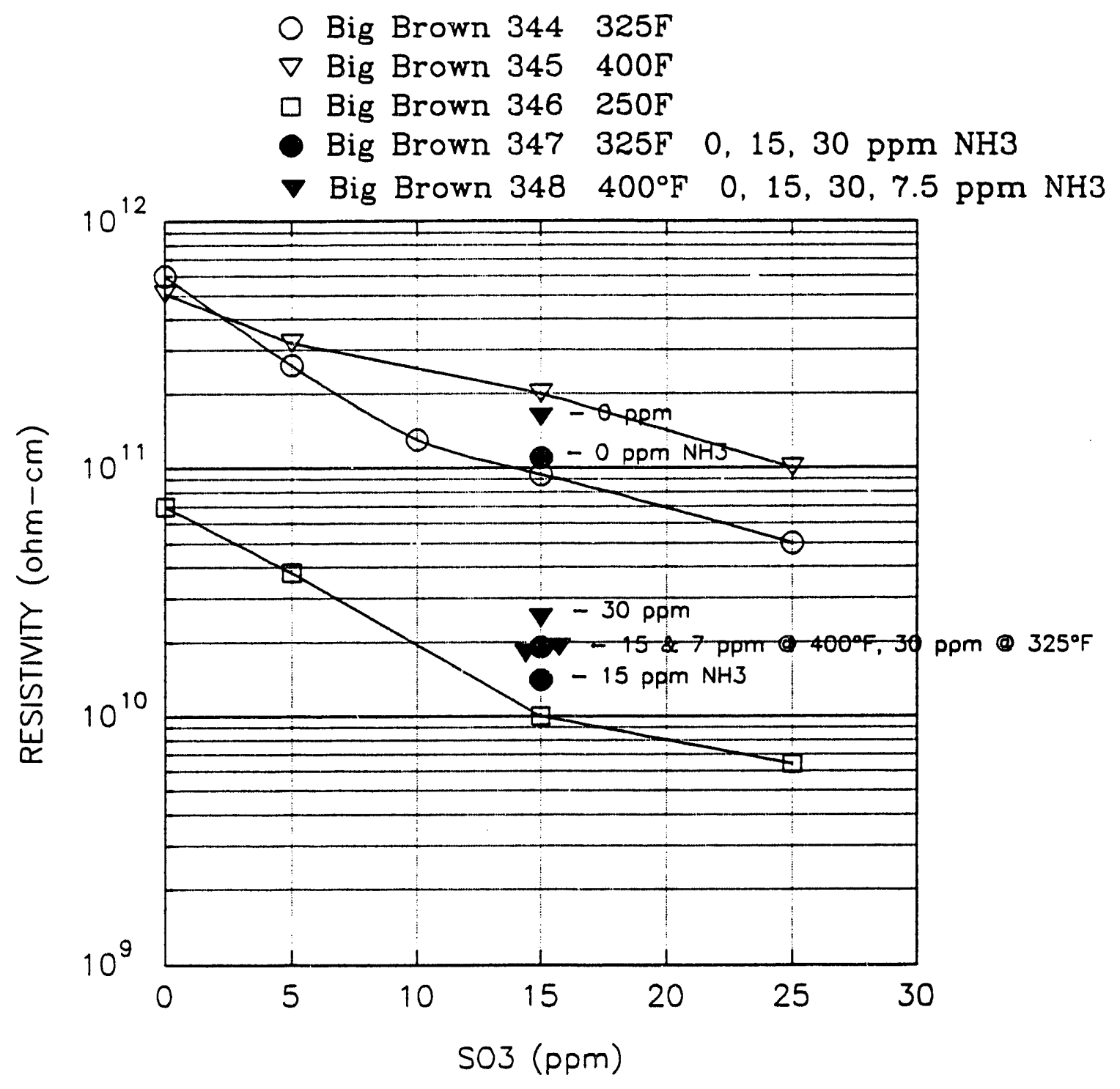

Figure A-1.33. Resistivity as a function of $\mathrm{SO}_{3}$ and ammonia concentration for Big Brown coal for Runs 344-348. 


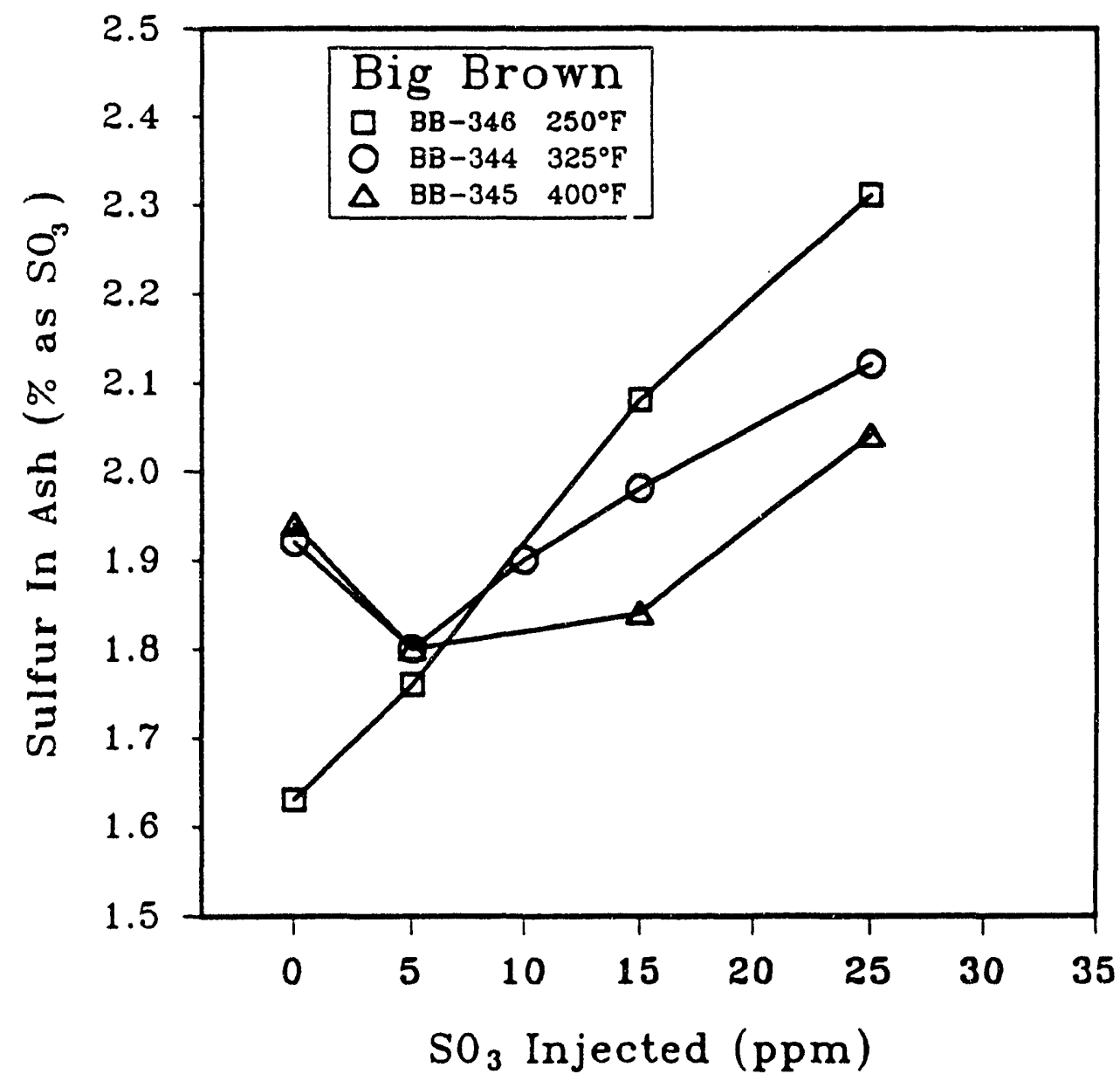

Figure $\mathrm{A}-1.34$. Sulfur retention as a function of $\mathrm{SO}_{3}$ concentration for Big Brown coal for Runs 344, 345, and 346. 


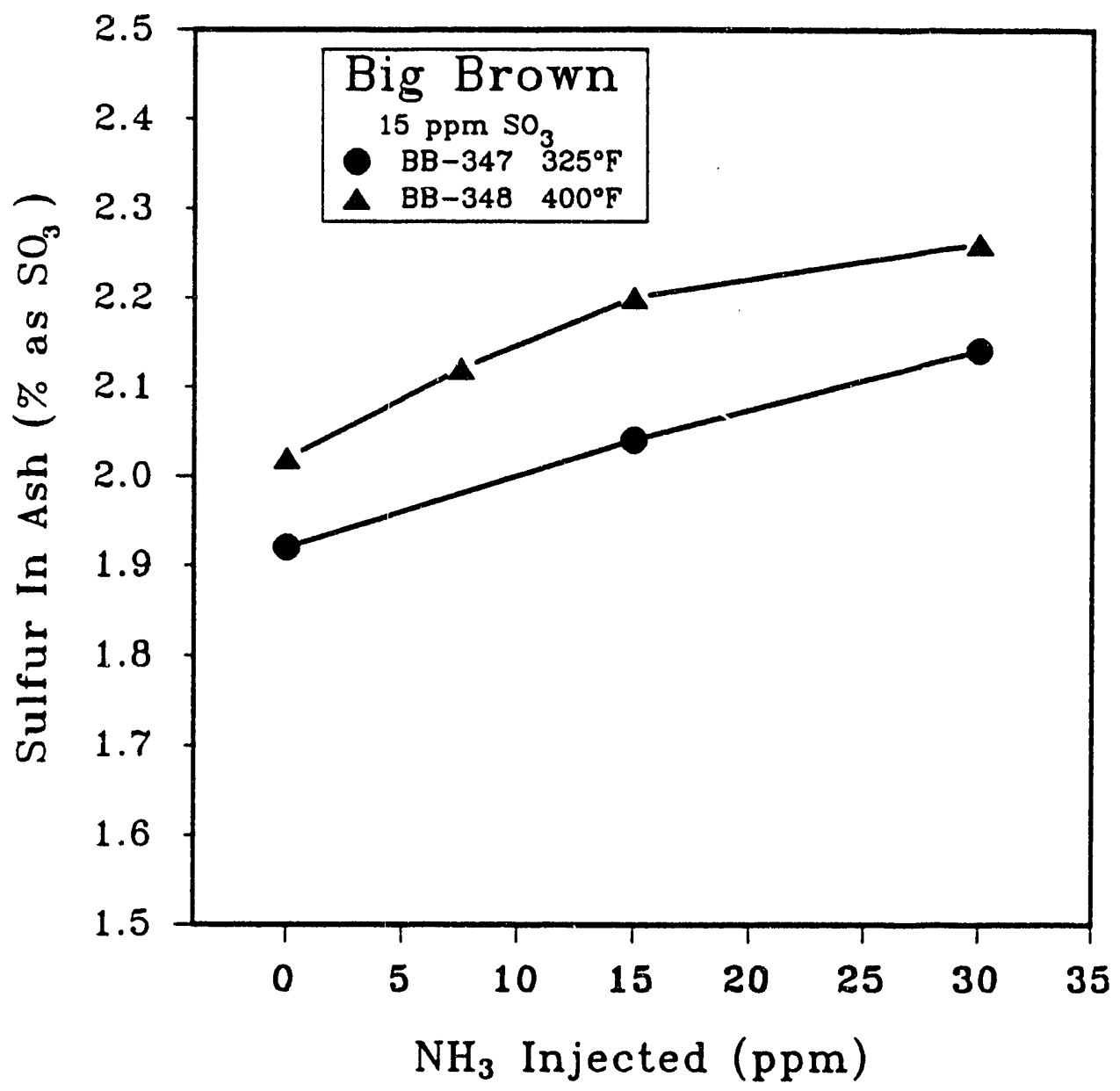

Figure A-1.35. Sulfur retention as a function of ammonia injection at a constant 15 ppm SO ${ }_{3}$ for Big Brown coal for Runs 347 and 348. 


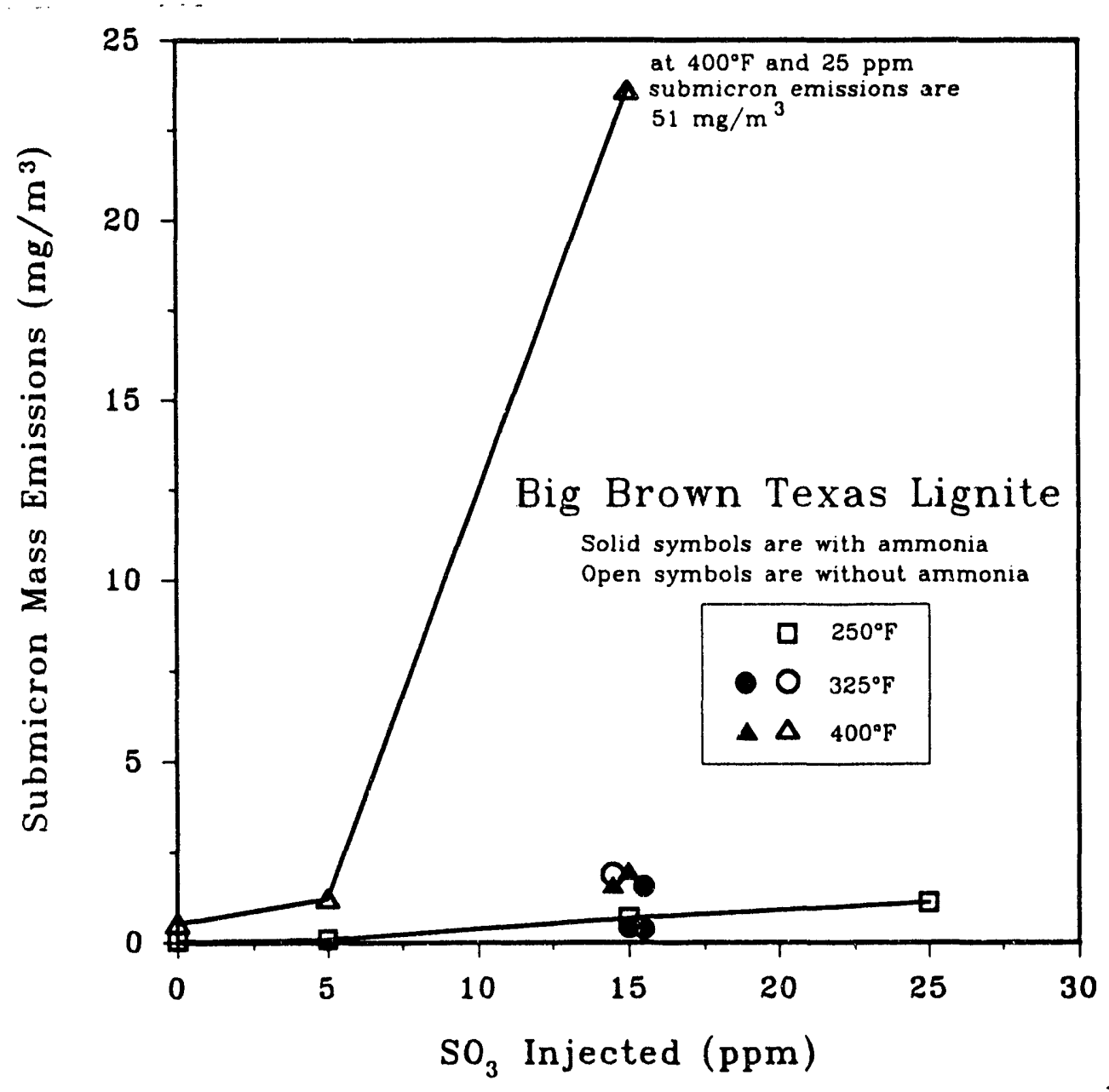

Figure A-1.36. Submicron mass emissions as a function of $\mathrm{SO}_{3}$ concentration for Big Brown coal for Runs 344-348. 


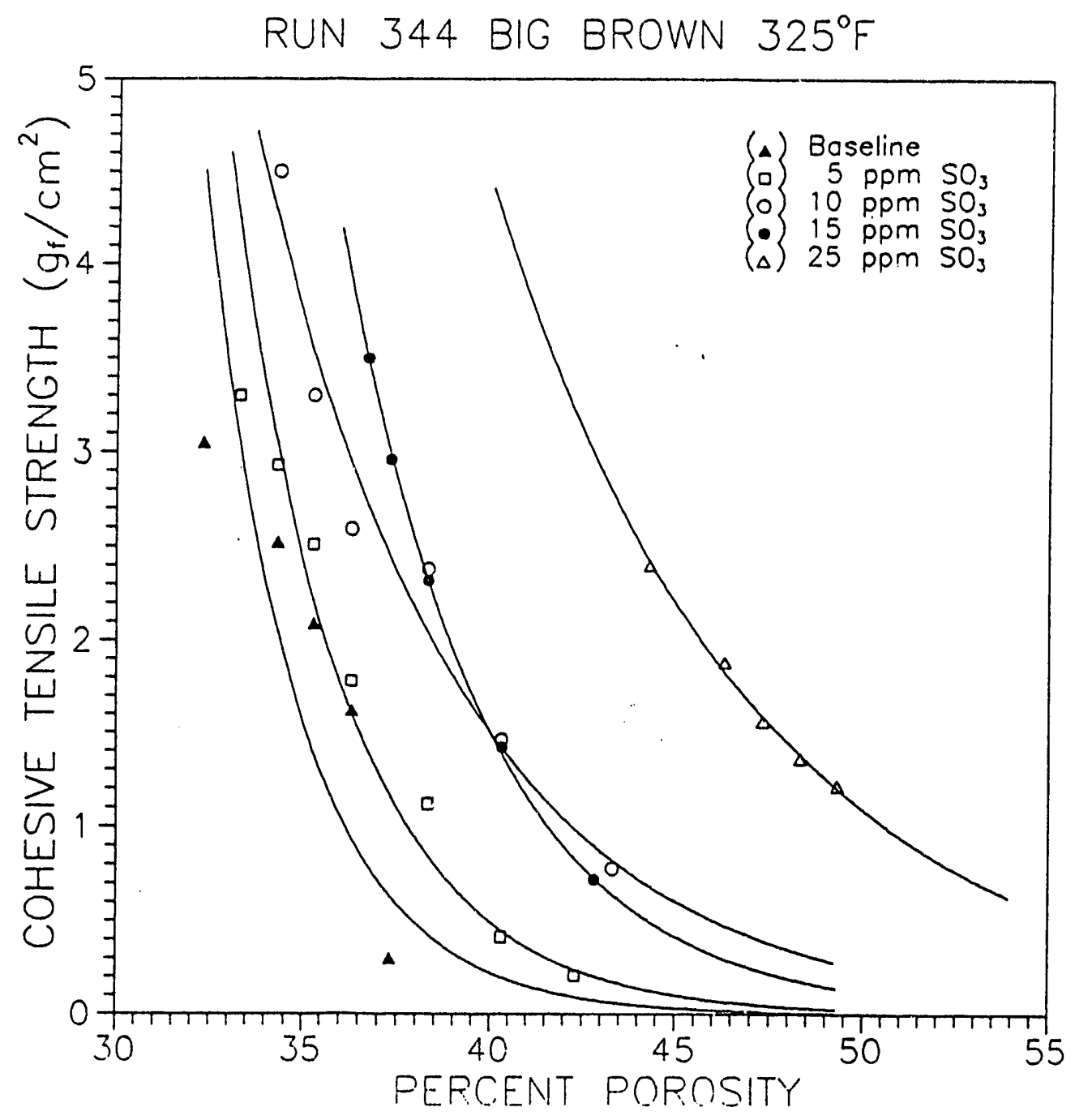

Figure A-1.37. Fly ash tensile strength as a function of ash porosity with $\mathrm{SO}_{3}$ alone for Big Brown coal for Run 344 . 


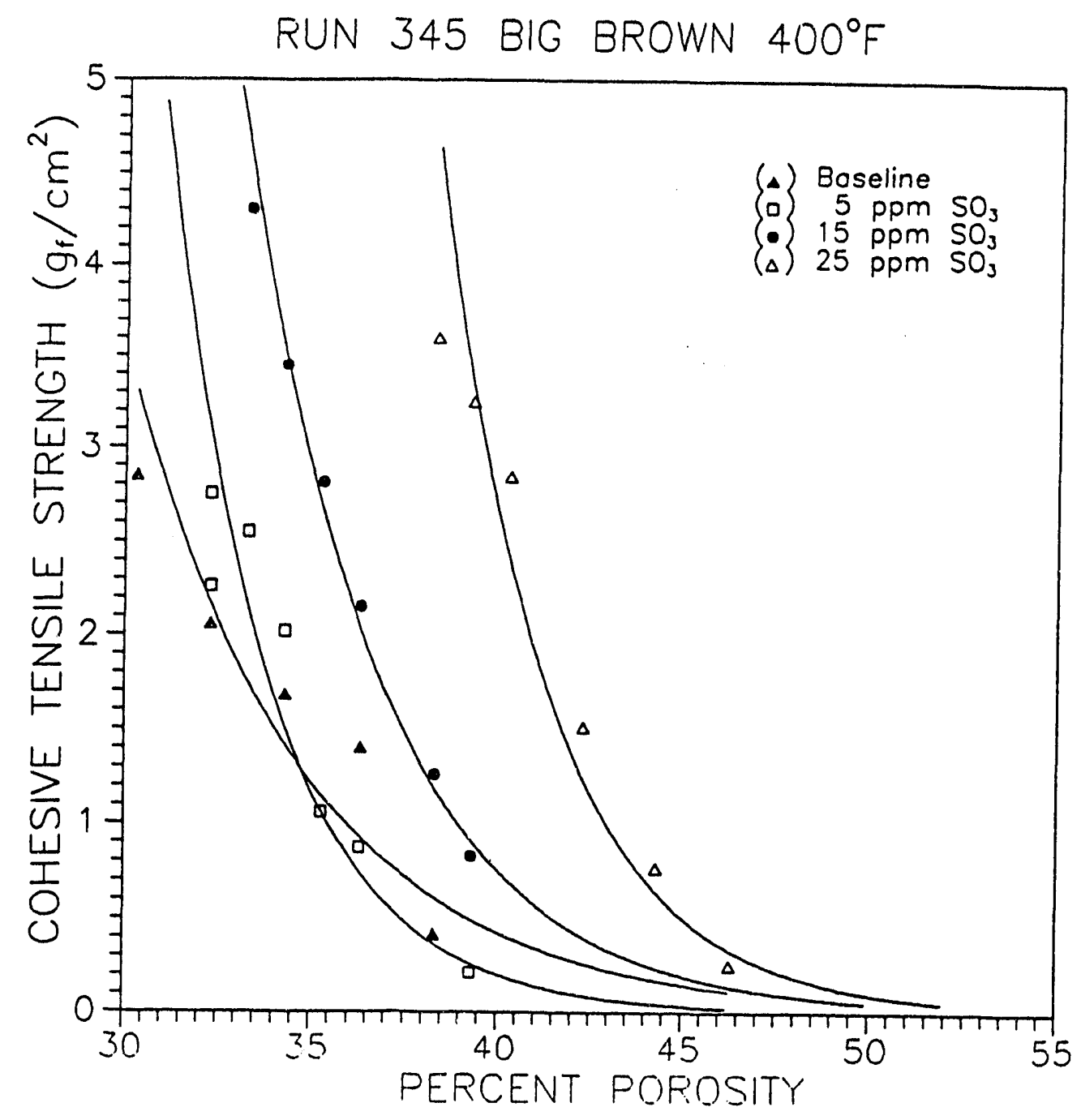

Figure A-1.38. Fly ash tensile strength as a function of ash porosity with $\mathrm{SO}_{3}$ alone for Big Brown coal for Run 345. 


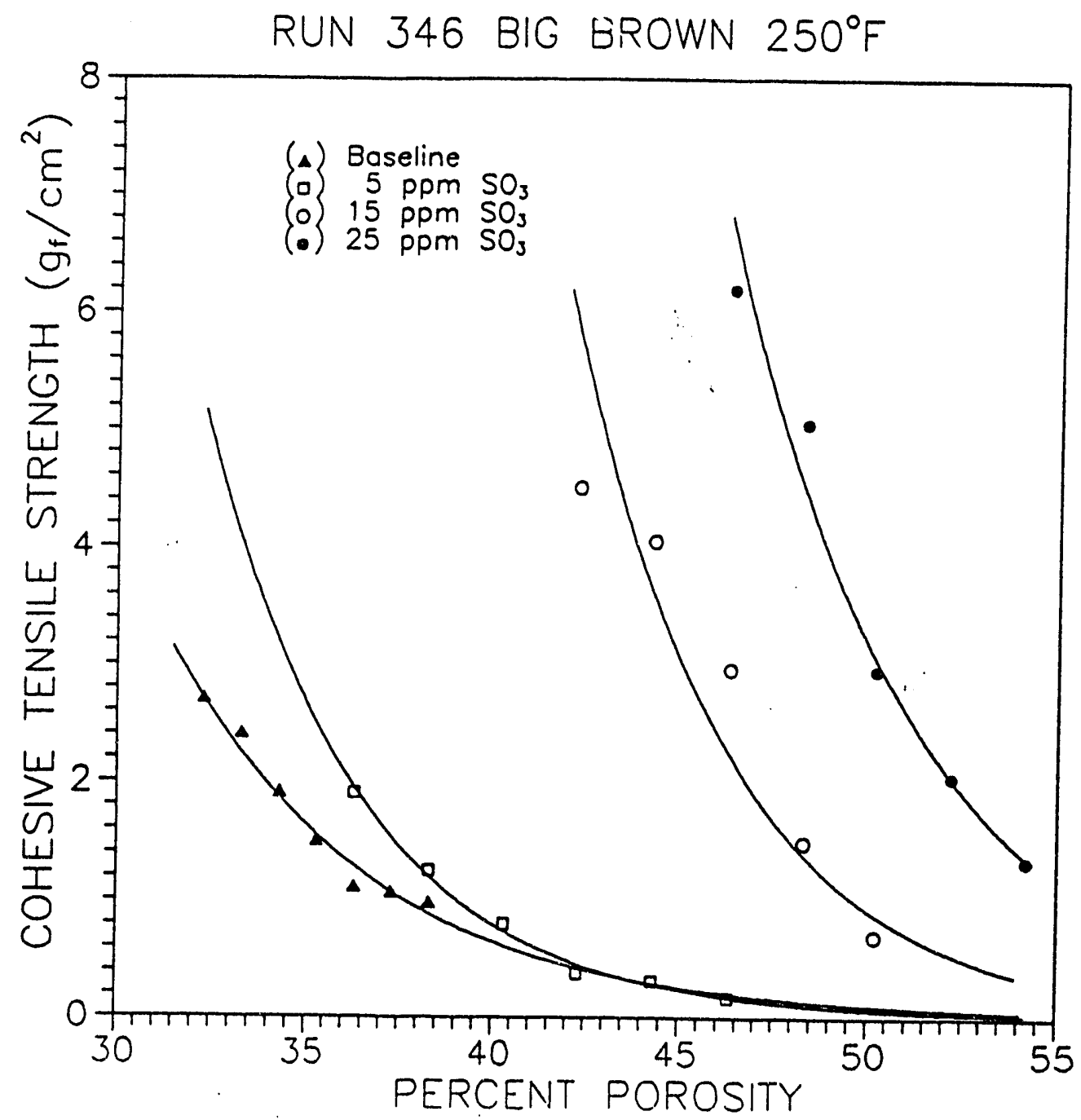

Figure A-1.39. Fly ash tensile strength as a function of ash porosity with $\mathrm{SO}_{3}$ alone for Big Brown coal for Run 346 . 


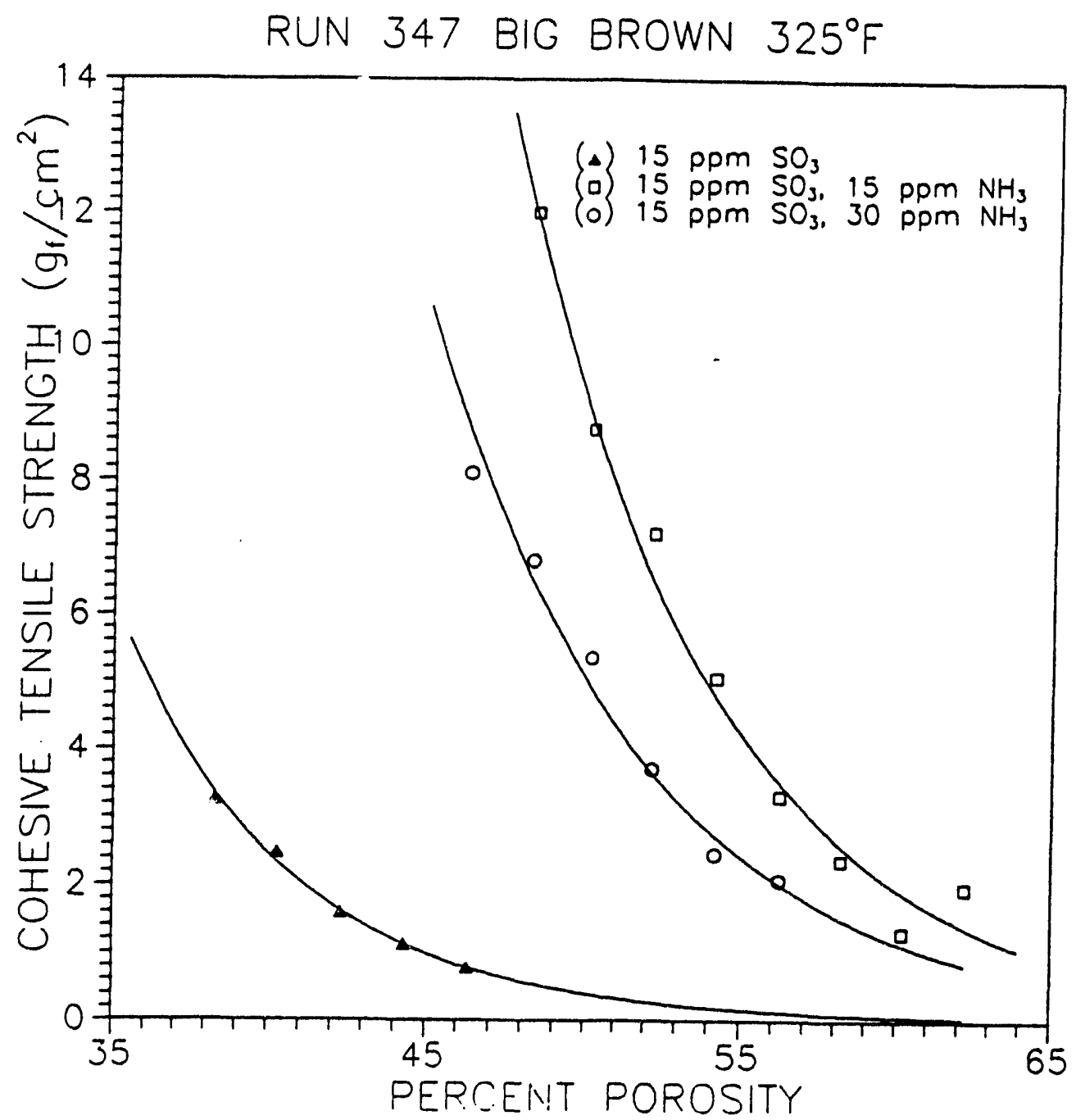

Figure A-1.40. Fly ash tensile strength as a function of ash porosity with dual conditioning for Big Brown coal for Run 347. 


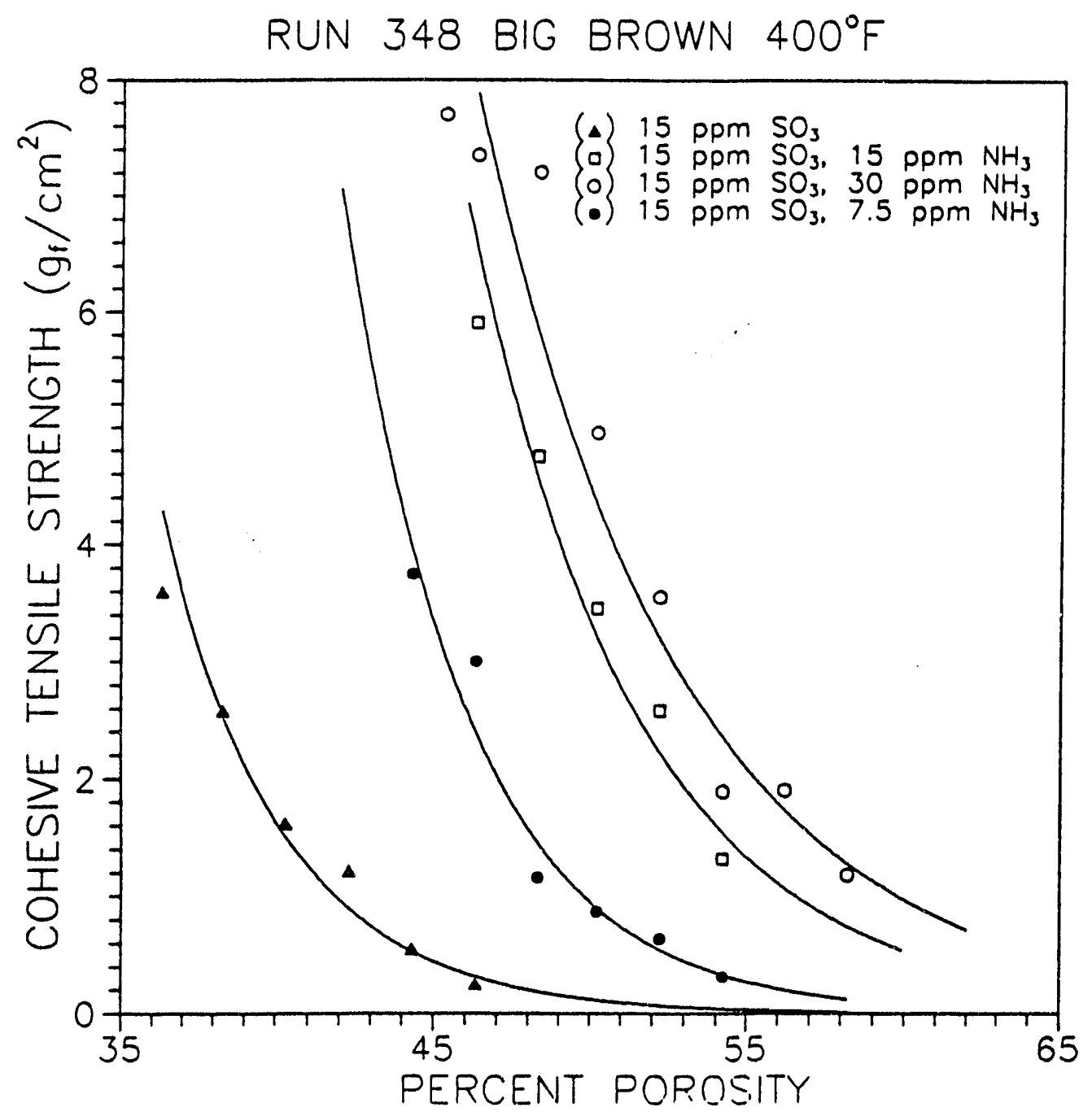

Figure A-1.41. Fly ash tensile strength as a function of ash porosity with dual conditioning for Big Brown coal for Run 348. 


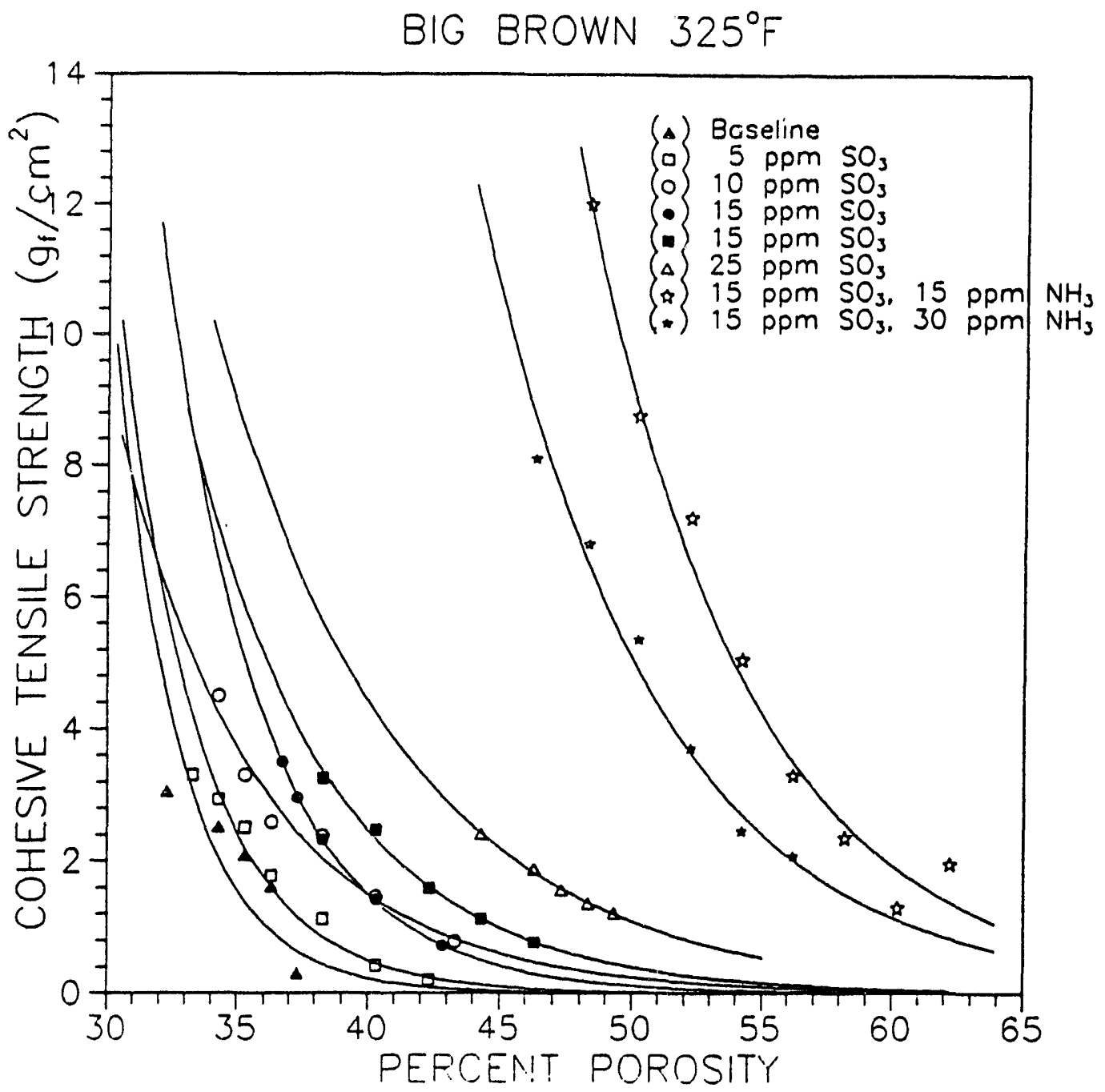

Figure A-1.42. Fly ash tensile strength as a function of ash porosity with $\mathrm{SO}_{3}$ alone and with dual conditioning at $325^{\circ} \mathrm{F}$ for Big Brown coal for Runs 344 and 347 . 


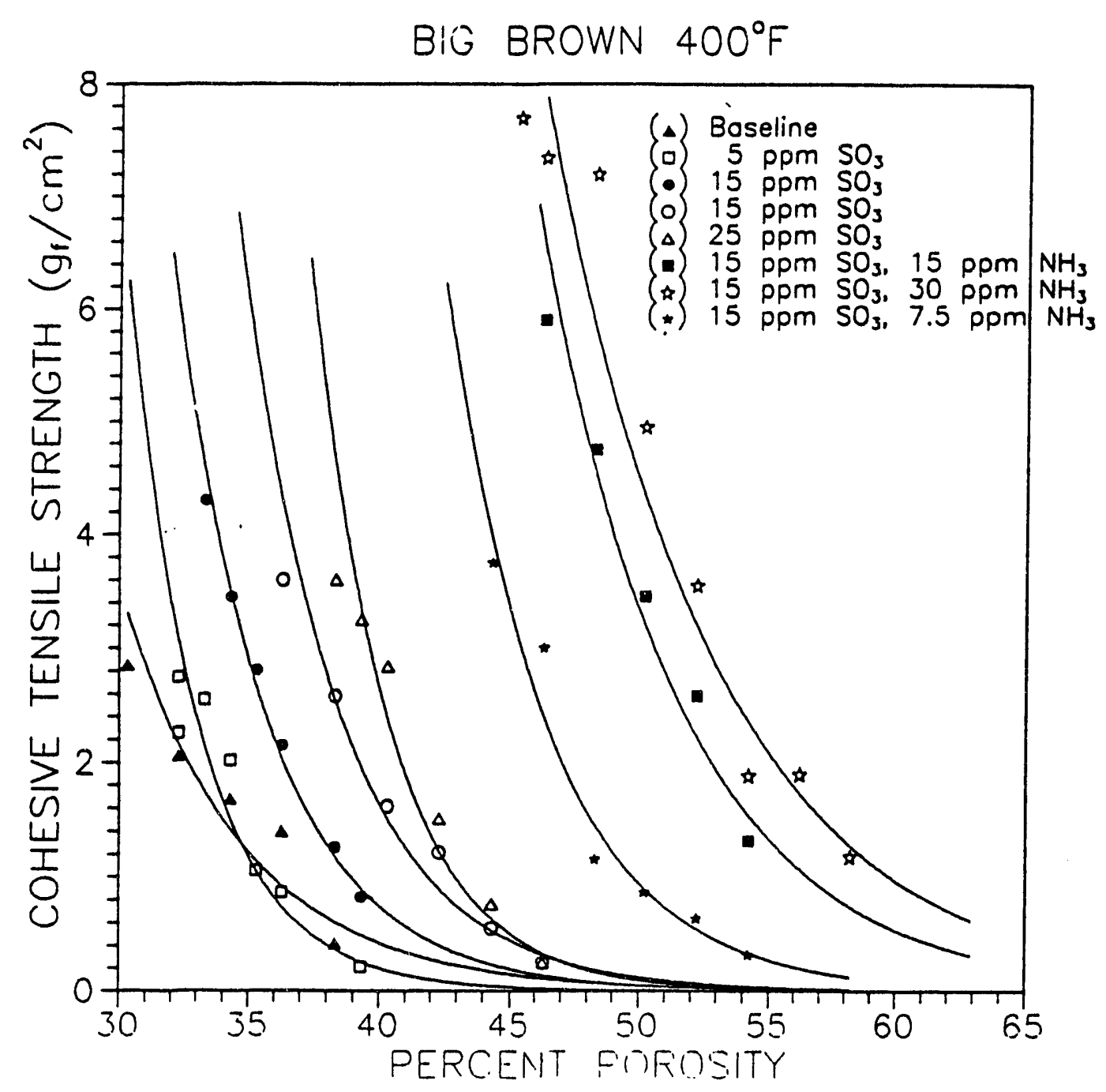

Figure A-1.43. Fly ash tensile strength as a function of ash porosity with $\mathrm{SO}_{3}$ alone and with dual conditioning at $400^{\circ} \mathrm{F}$ for Big Brown coal for Runs 345 and 348 . 
BASELINE BIG BROWN

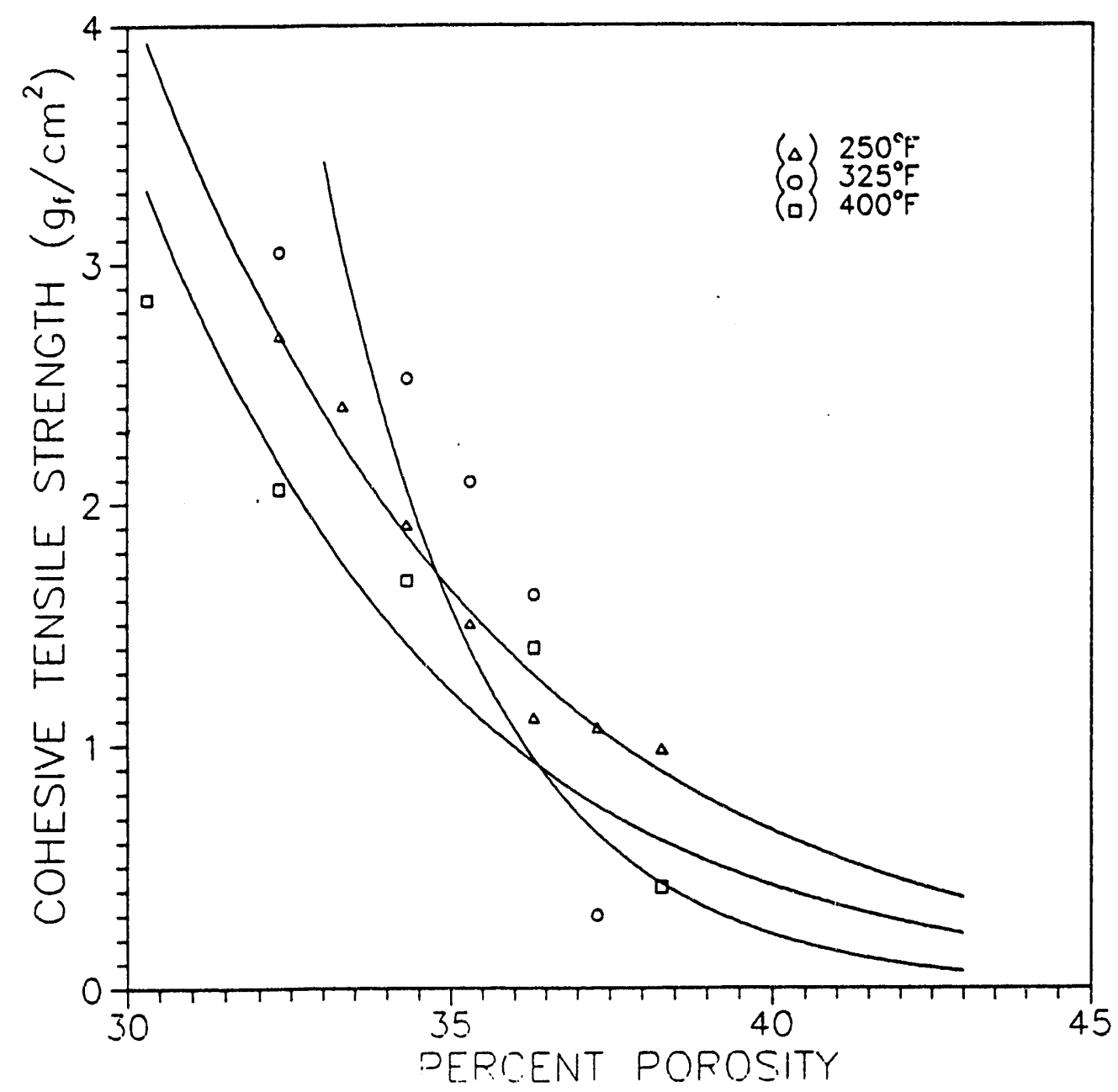

Figure A-1.44. Fly ash tensile strength as a function of ash porosity with baseline tests for Big Brown coal for Runs 344, 345, and 346. 
BIG BROWN 15 PPM SO

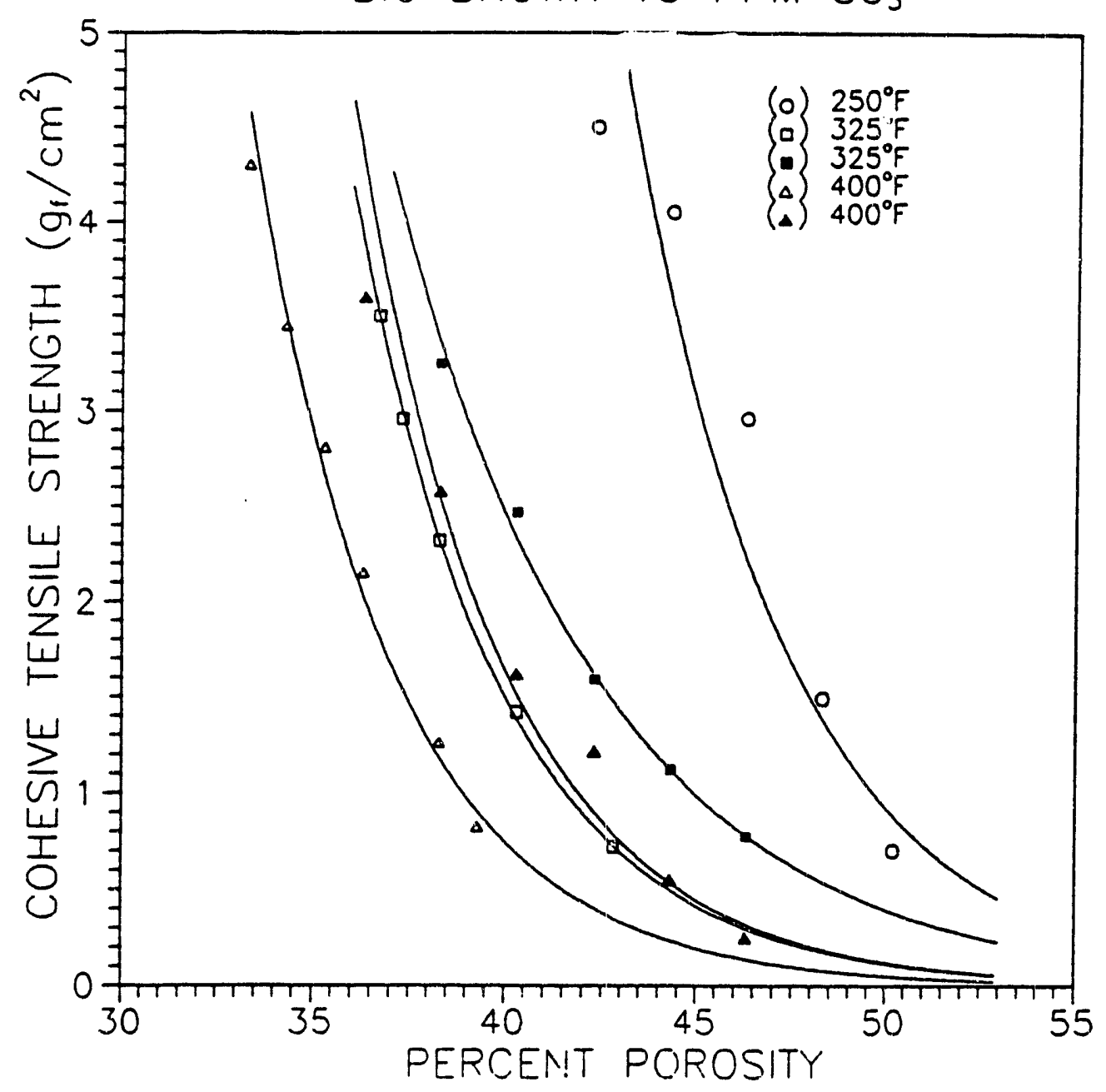

Figure A-1.45. Fly ash tensile strength as a function of ash porosity with 15 ppm of $\mathrm{SO}_{3}$ for Big Brown coal for Runs 344-348. 


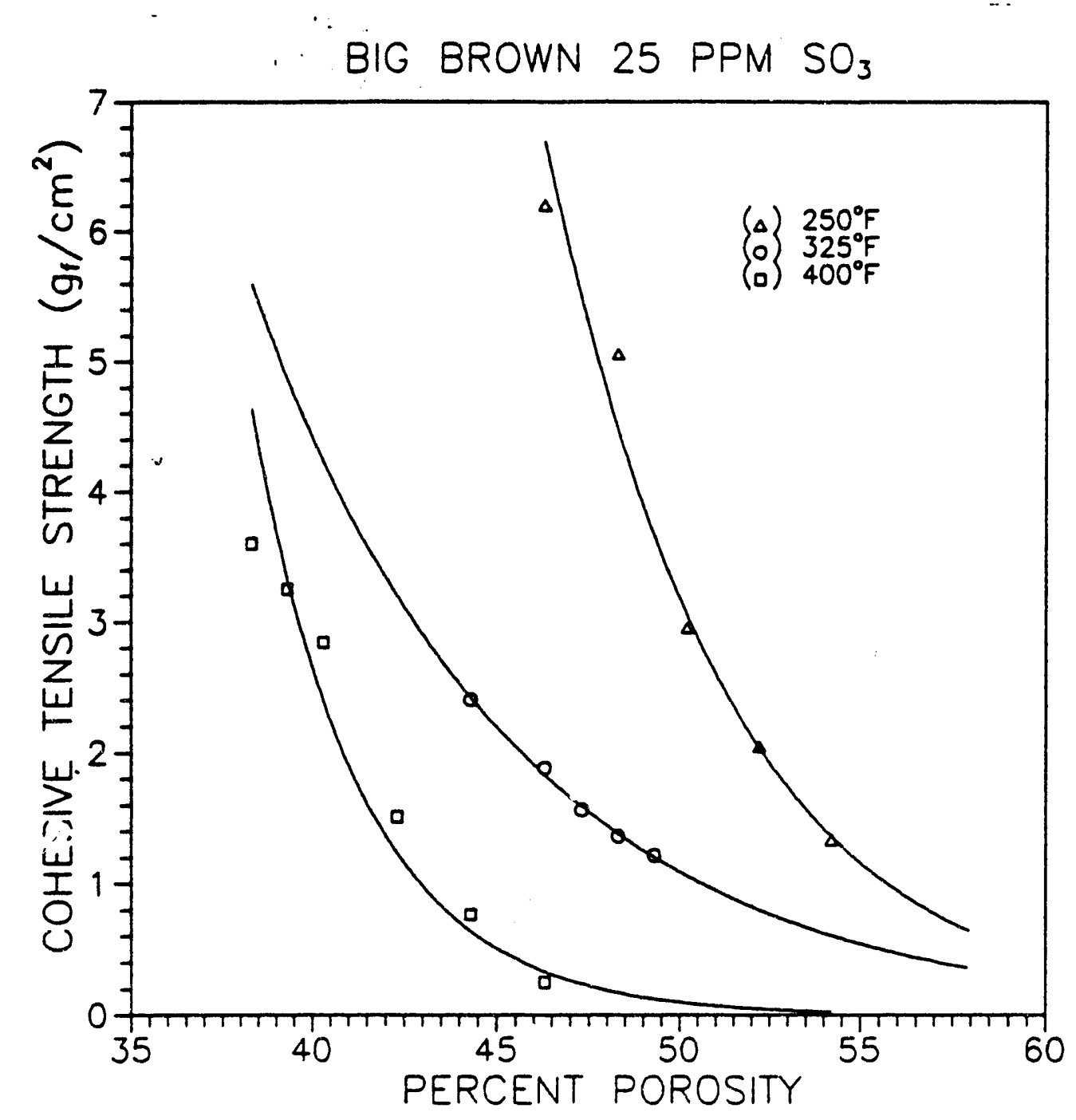

Figure A-1.46. Fly ash tensile strength as a function of ash porosity with 25 ppm of $\mathrm{SO}_{3}$ for Big Brown coal for Runs 344, 345, and 346. 


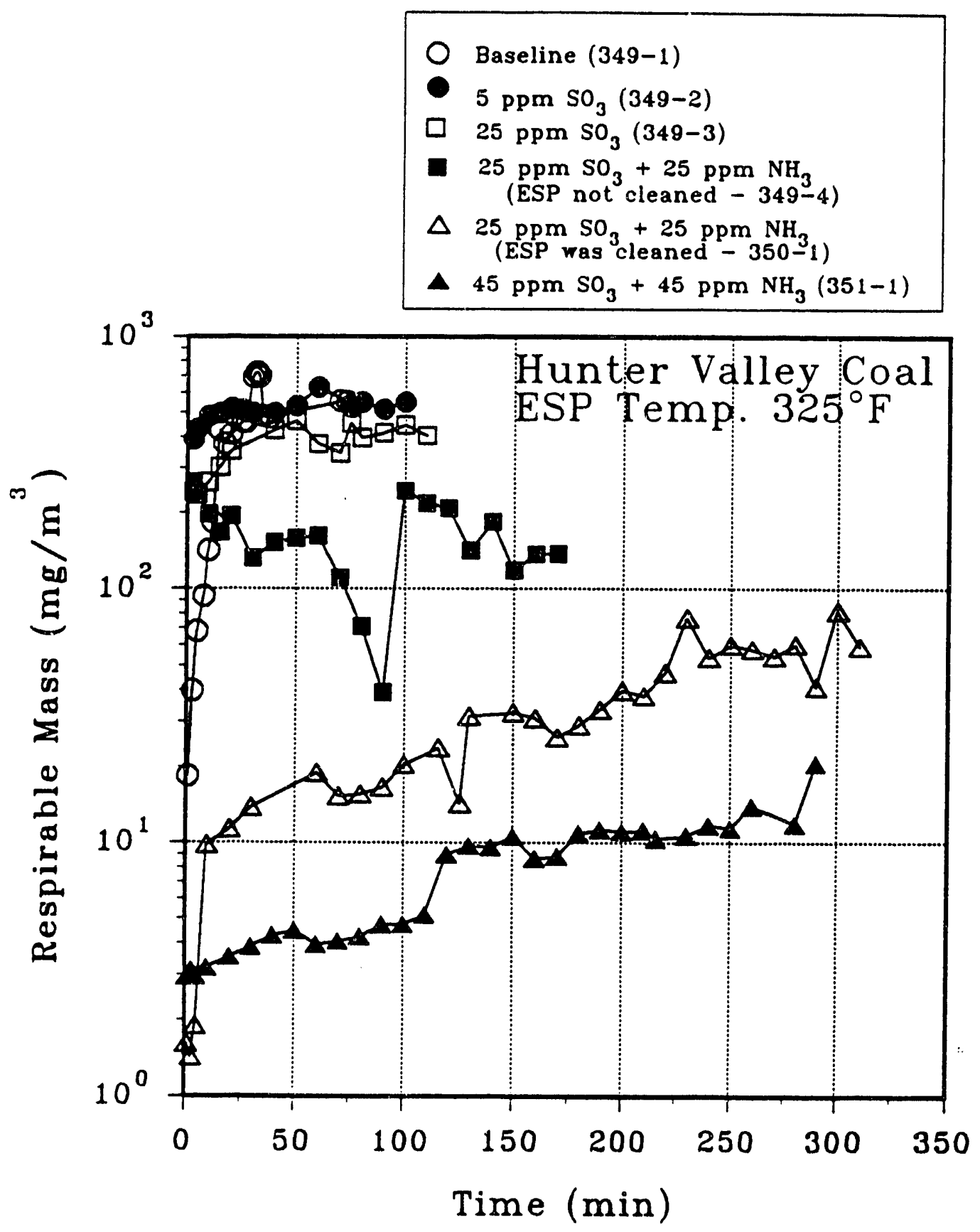

Figure A-2.1. Respirable mass emissions as a function of time for Hunter Valley coal for Runs 349-351. 


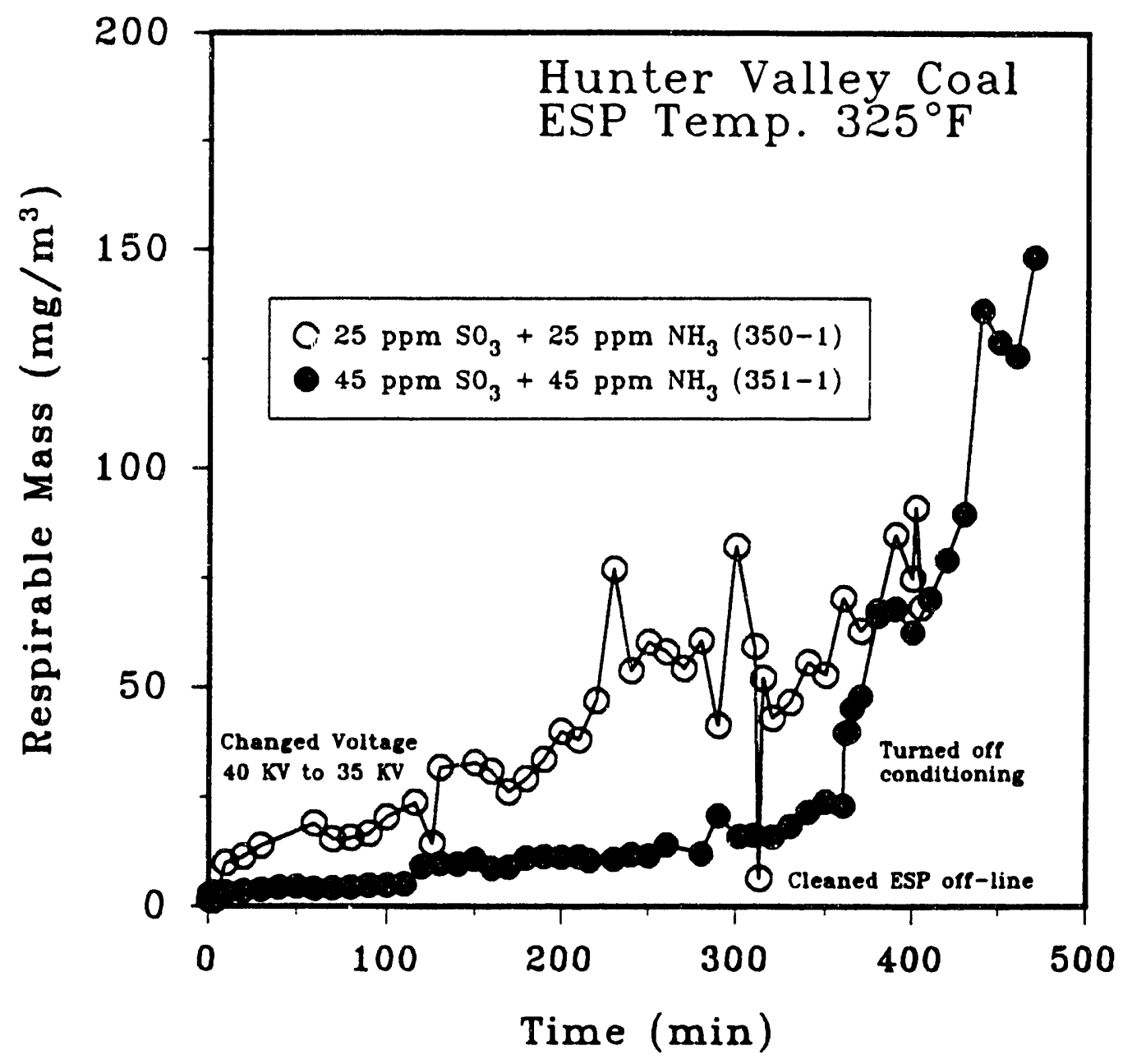

Figure A-2.2. Respirable mass emissions as a function of time for Hunter Valley coal for Runs 350 and 351 . 


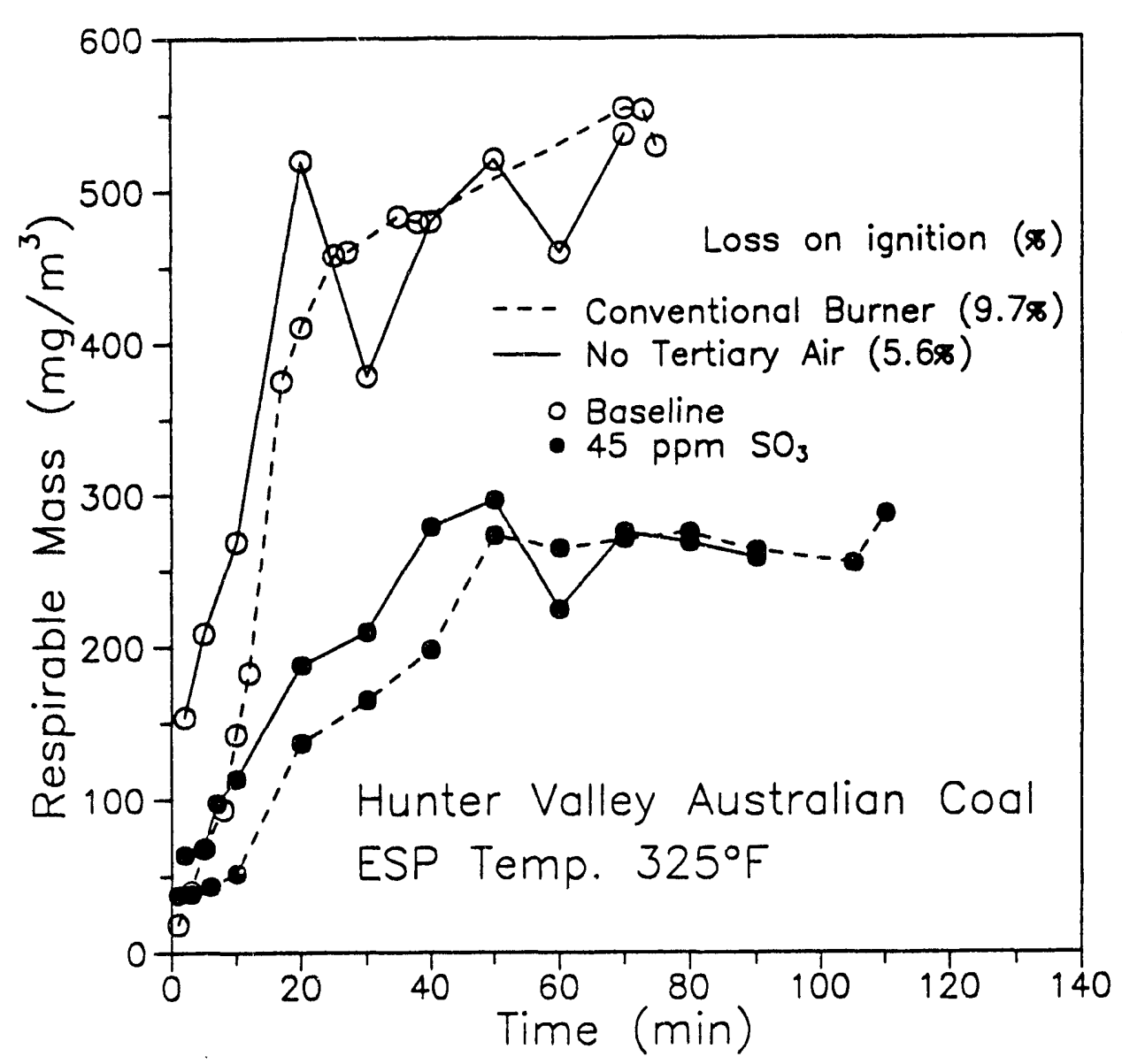

Figure A-2.3. Respirable mass emissions as a function of time for Hunter Valley coal at $325^{\circ} \mathrm{F}$, comparing results of burner modification for Runs 349,351 , and 364 . 


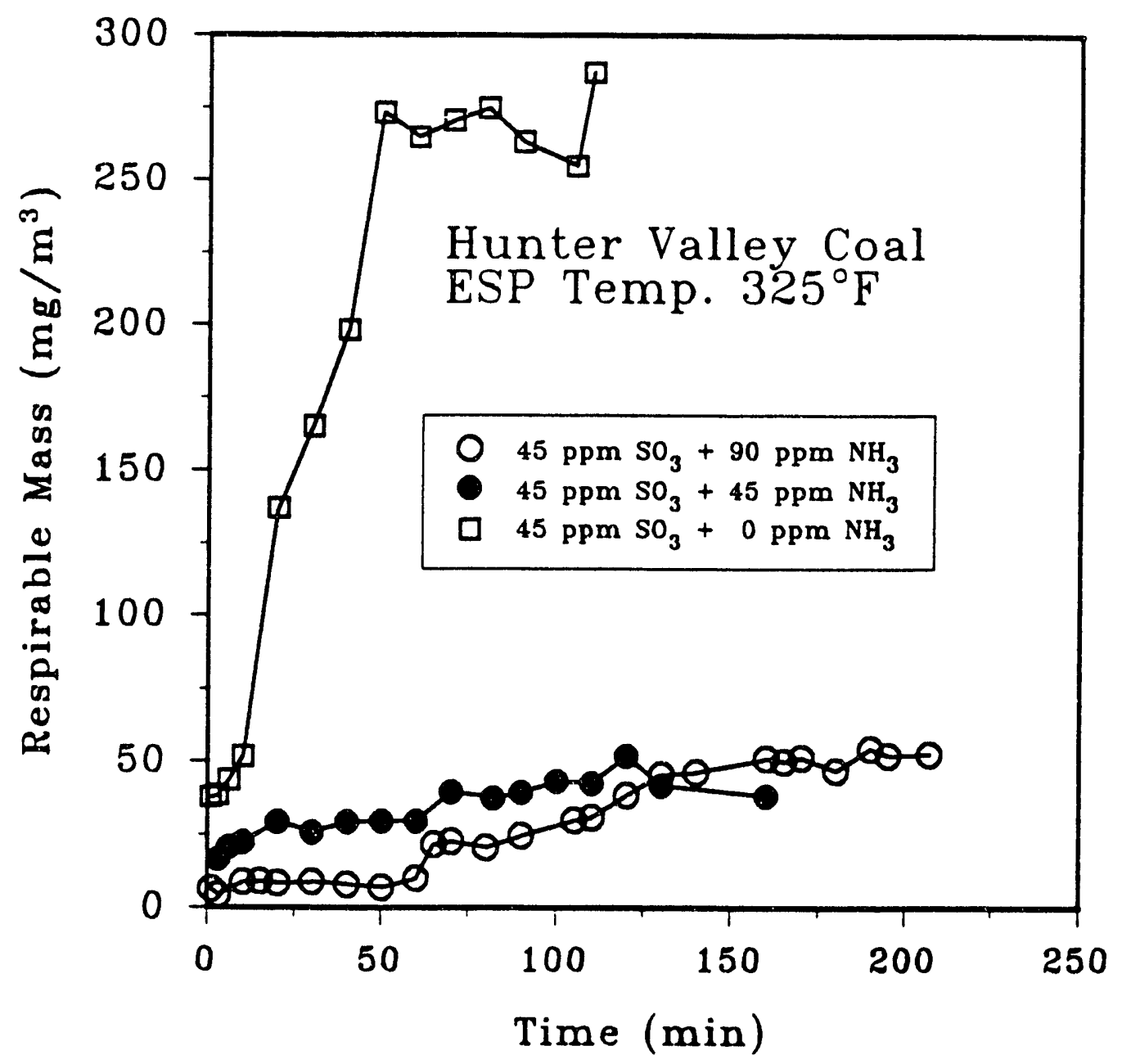

Figure A-2.4. Respirable mass emissions as a function of time for Hunter Valley coal for Run 352. 


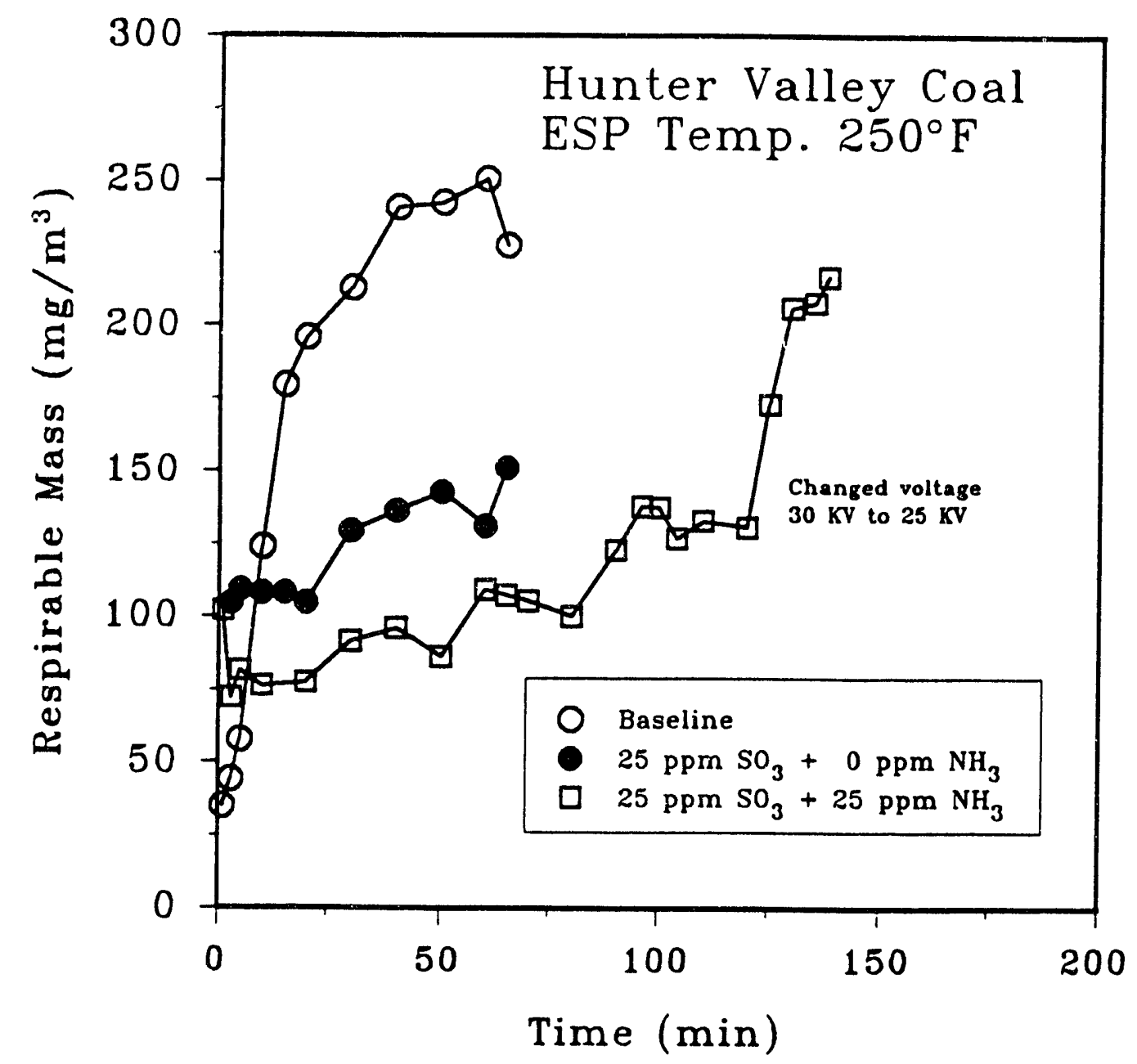

Figure A-2.5. Respirable mass emissions as a function of time for Hunter Valley coal for Run 353 . 


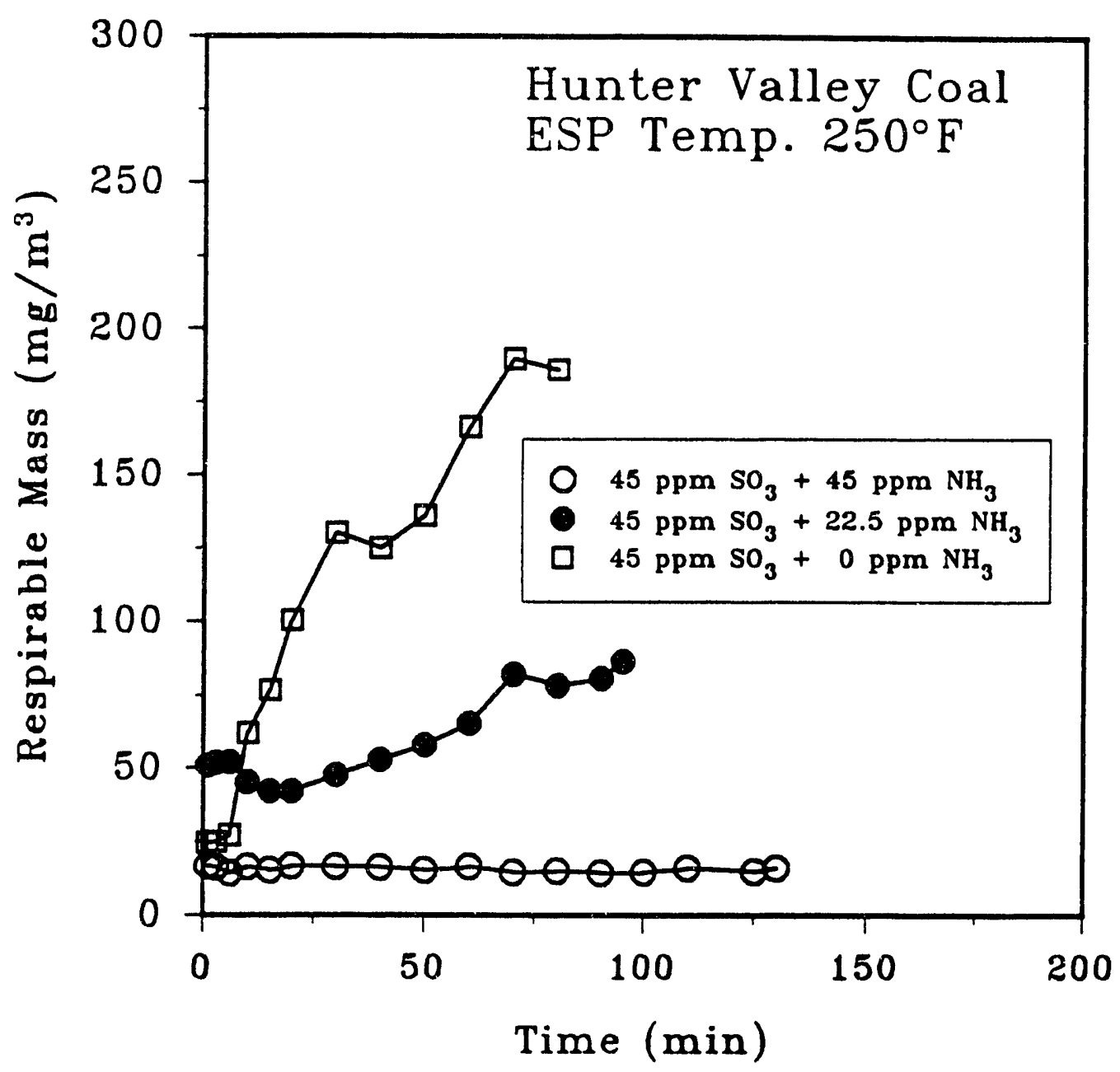

Figure A-2.6. Respirable mass emissions as a function of time for Hunter Valley coal for Run 354 . 


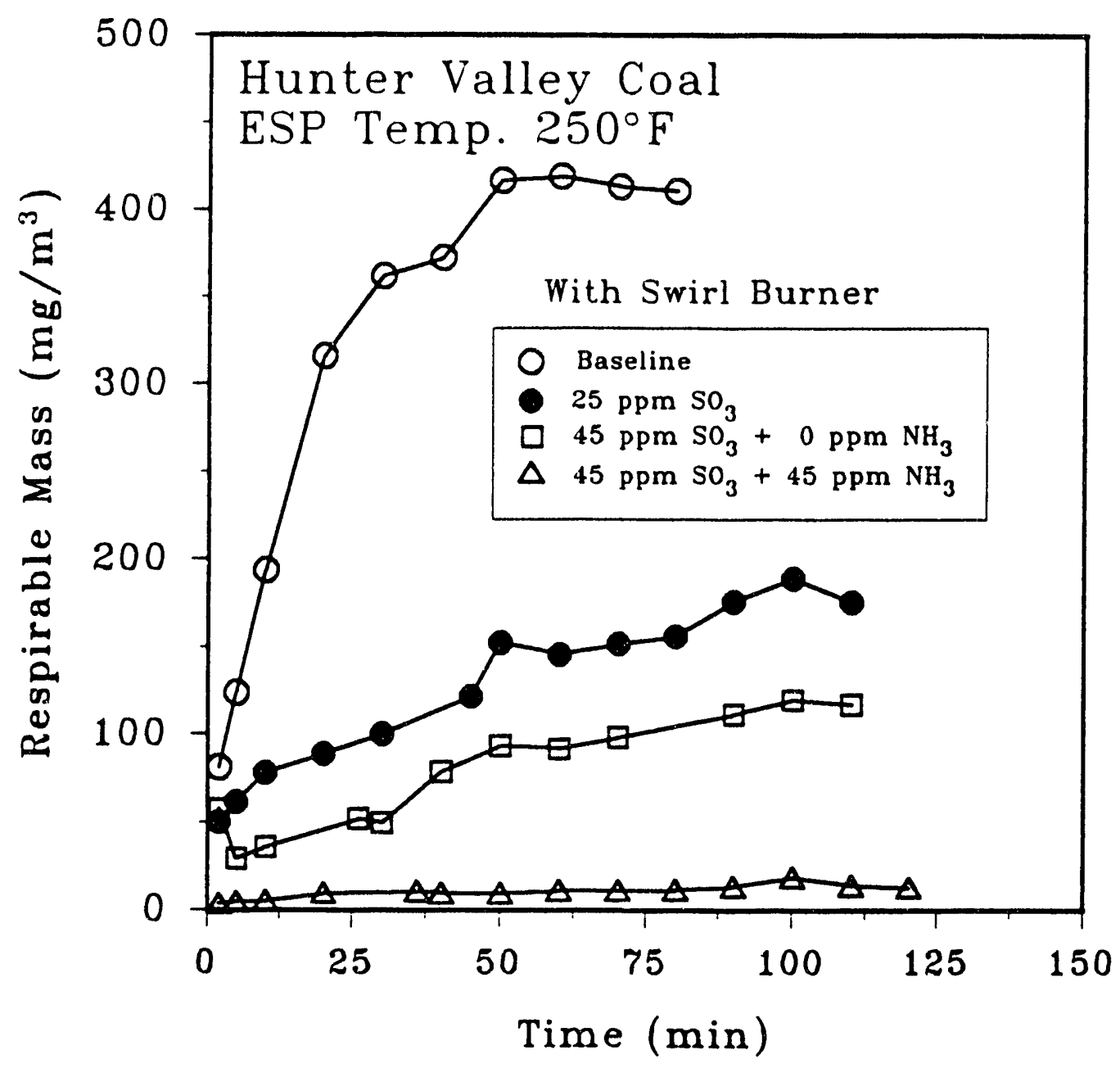

Figure A-2.7. Respirable mass emissions as a function of time with swirl burner for Hunter Valley coal for Run 365. 


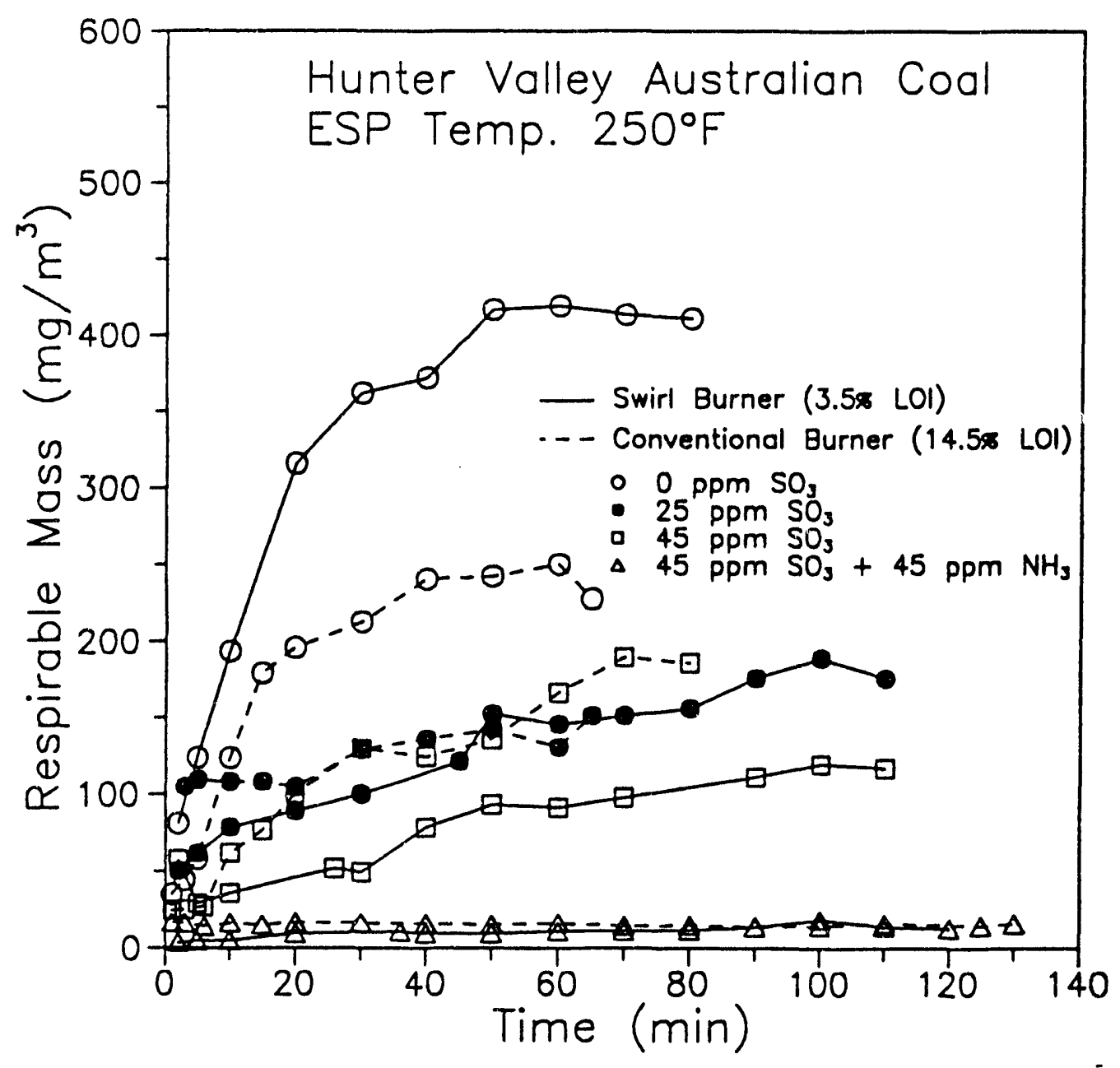

Figure A-2.8. Respirable mass emissions as a function of time for Hunter Valley coal at $250^{\circ} \mathrm{F}$, comparing results of swirl burner with conventional burner for Runs 353, 354, and 365 . 


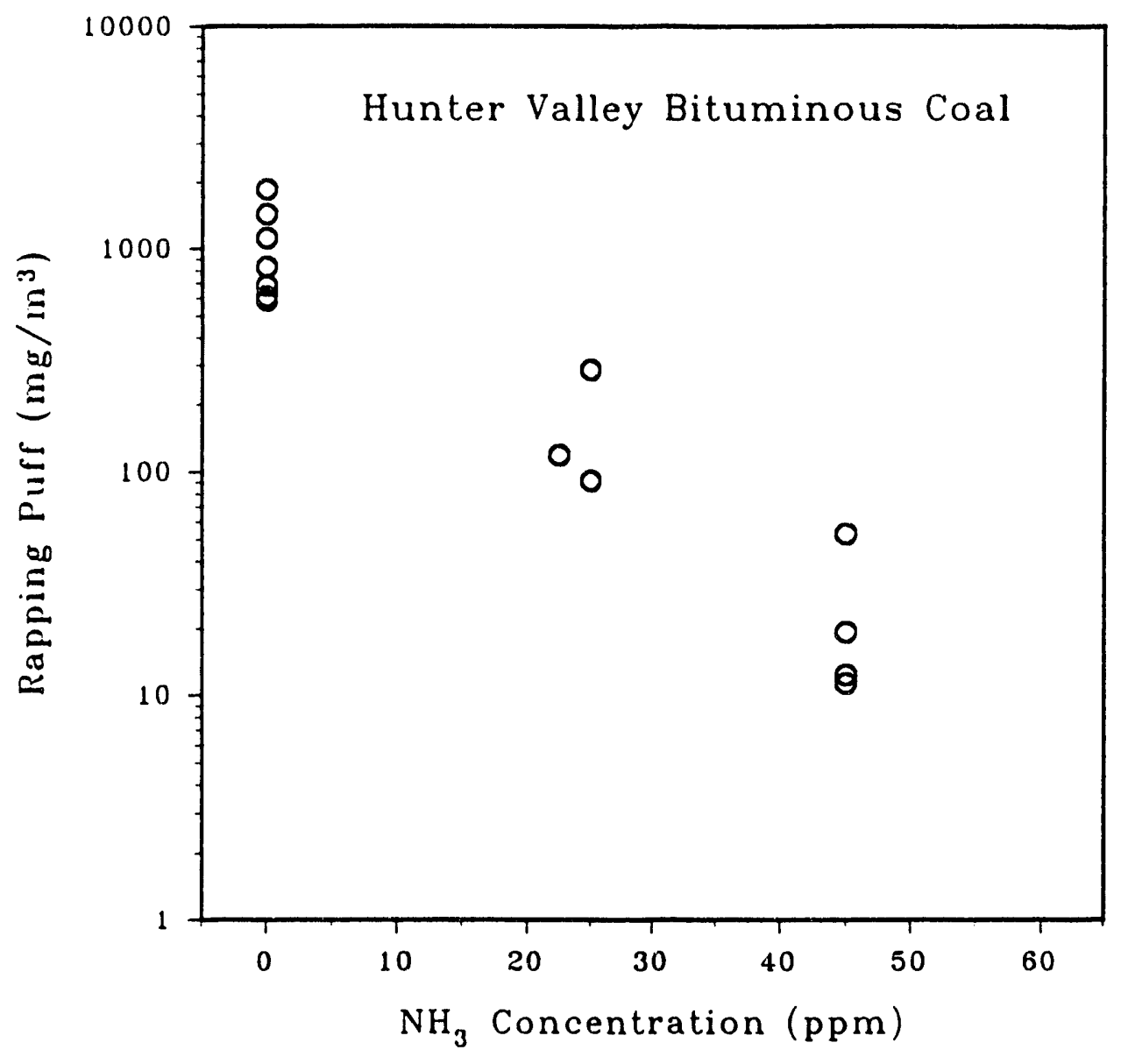

Figure A-2.9. Rapping puff emissions as a function of ammonia concentrations for Hunter Valley coal for Runs 350-354 and 365. 


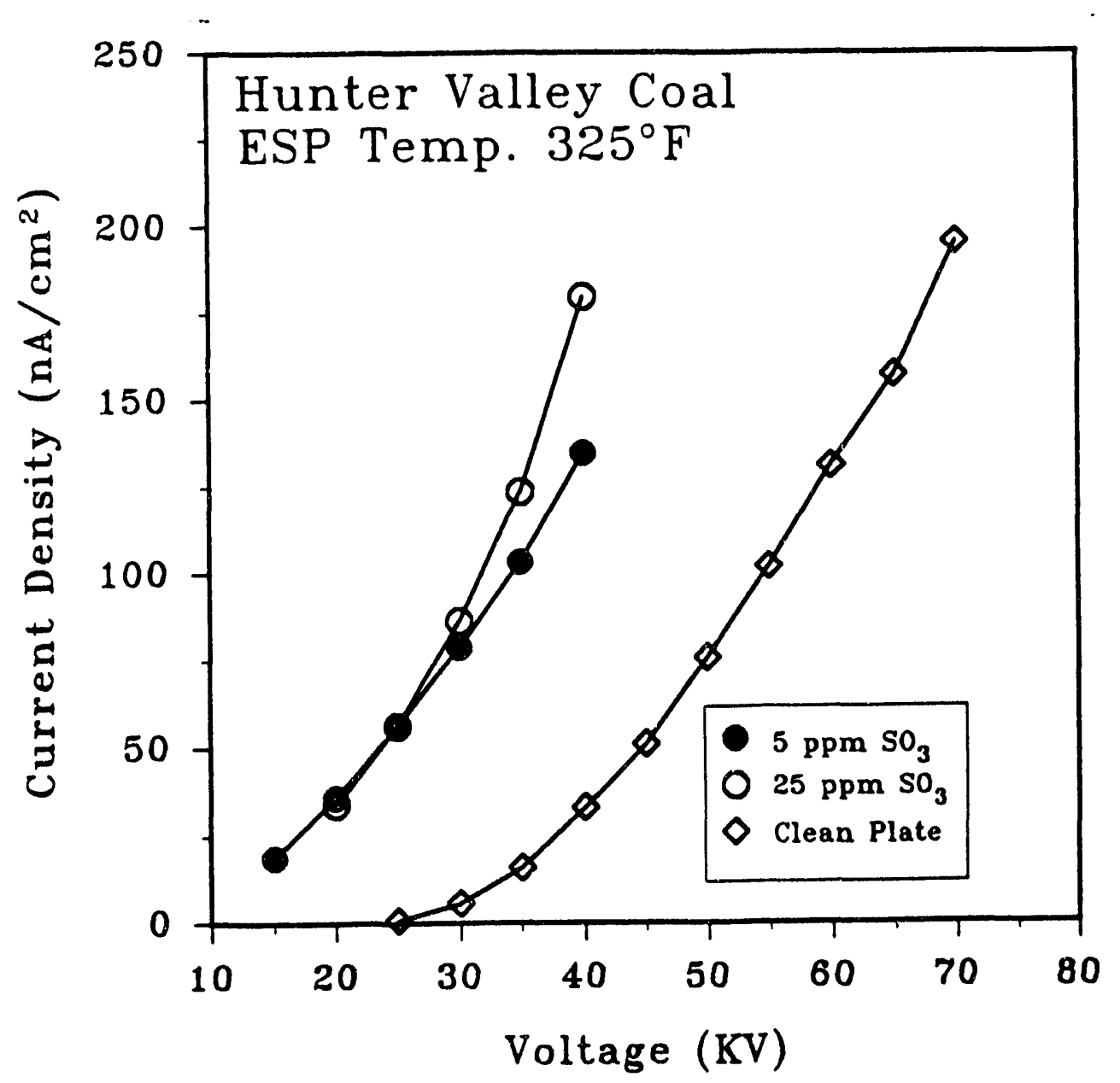

Figure A-2.10. Current-voltage curves for Hunter Valley coal for Run 349. 


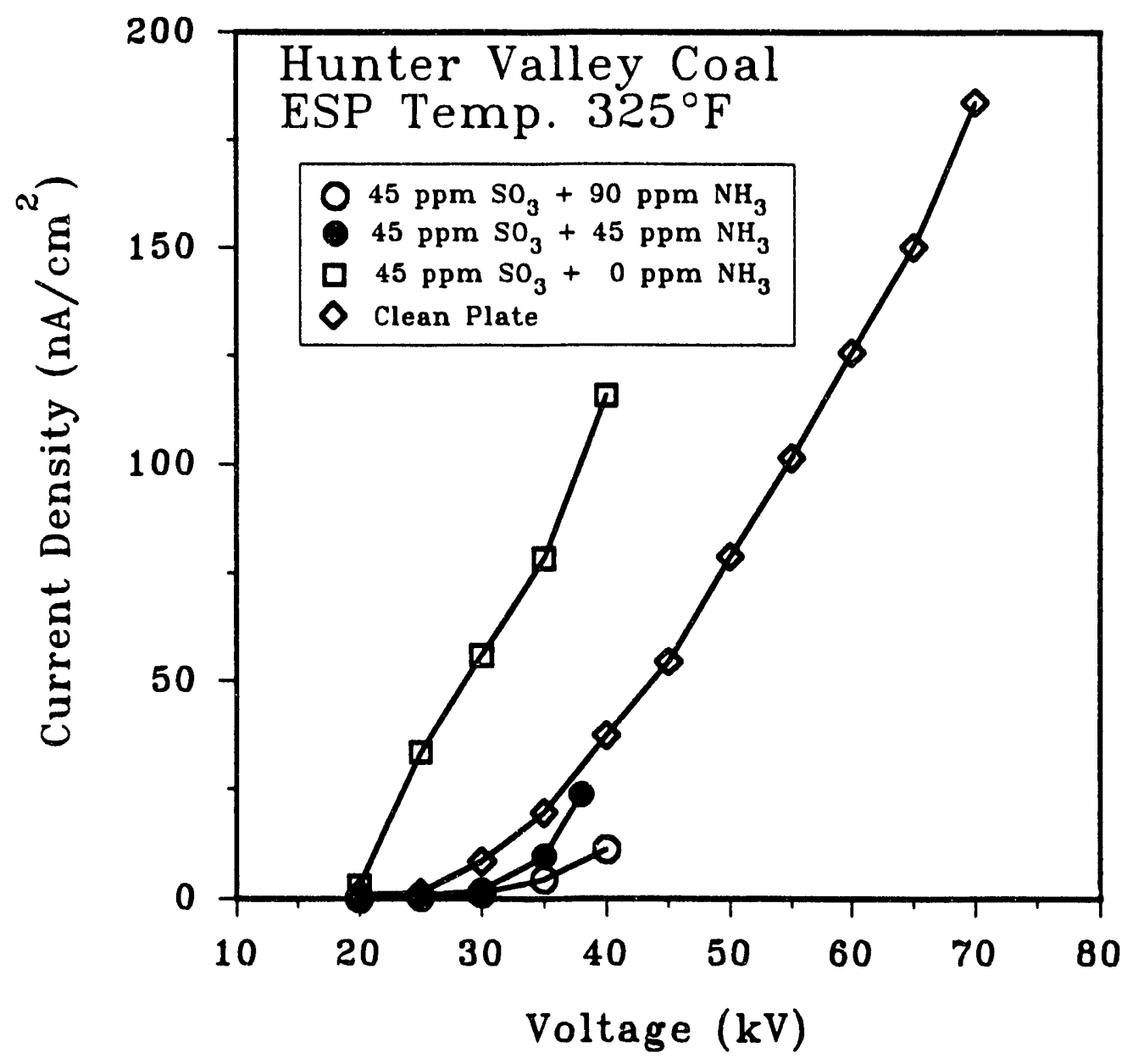

Figure A-2.11. Current-voltage curves for Hunter Valley coal for Run 352 . 


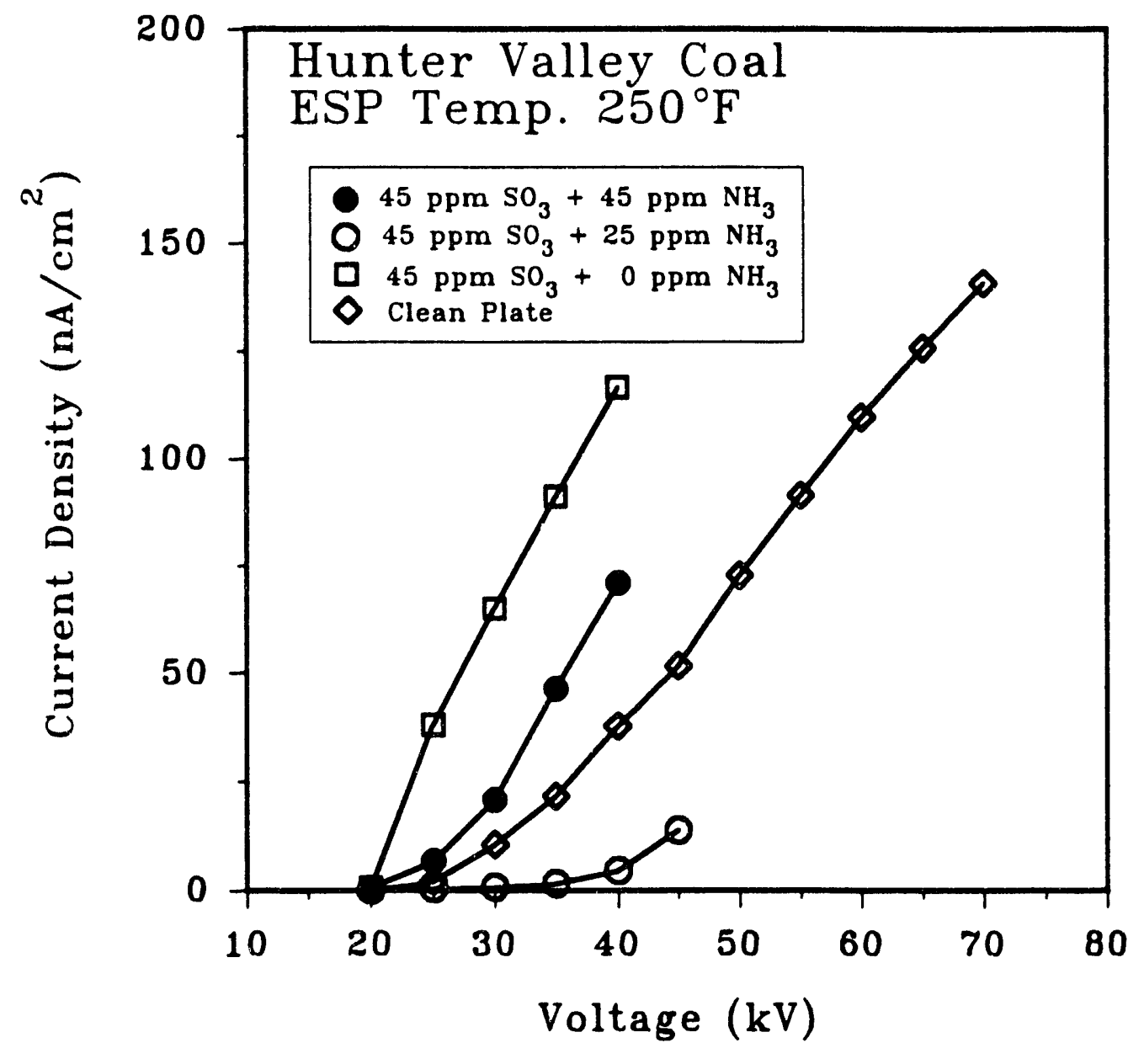

Figure A-2.12. Current-voltage curves for Hunter Valley coal for Run 354 . 


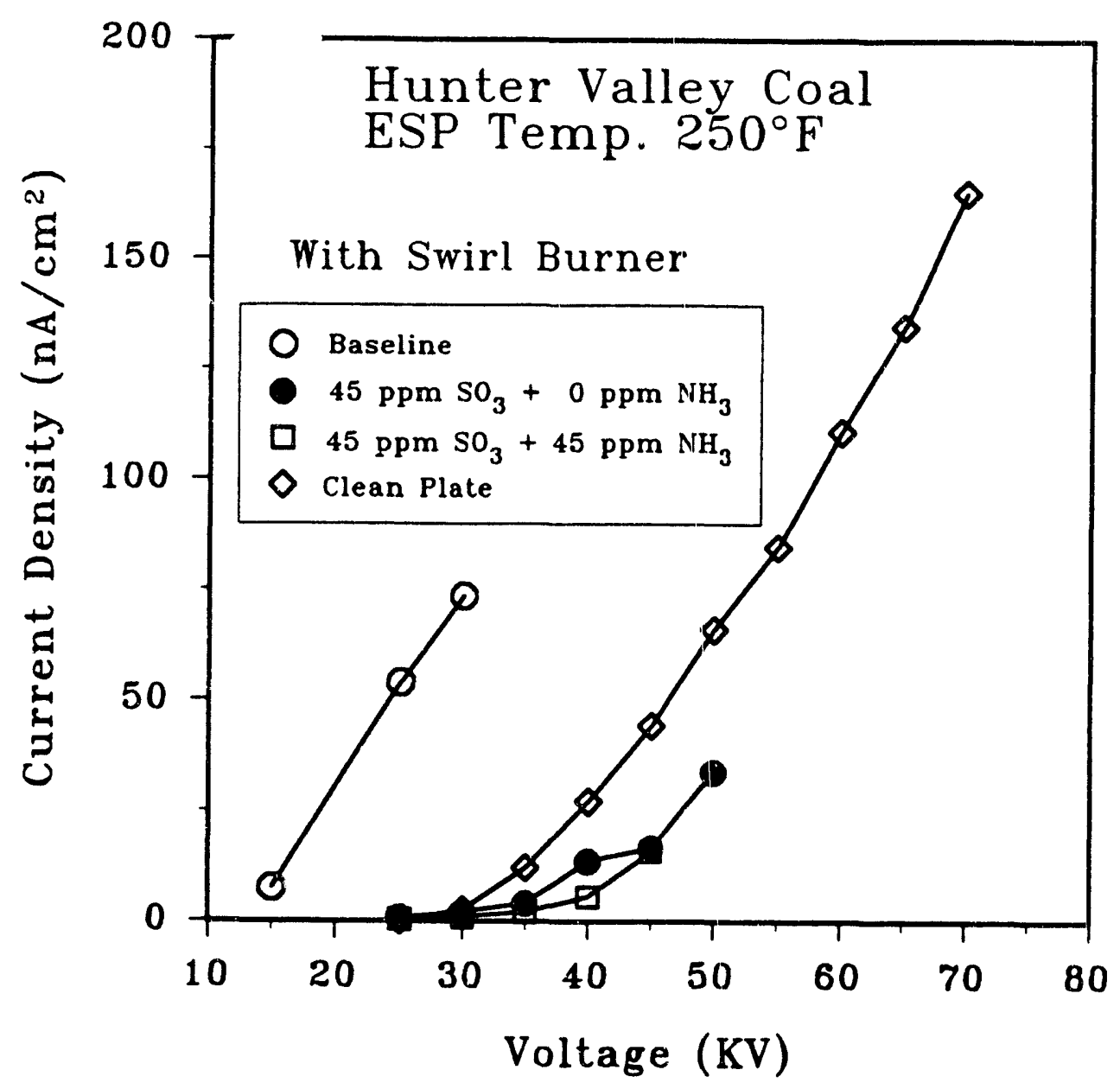

Figure A-2.13. Current-voltage curves for Hunter Valley coal for Run 365. 


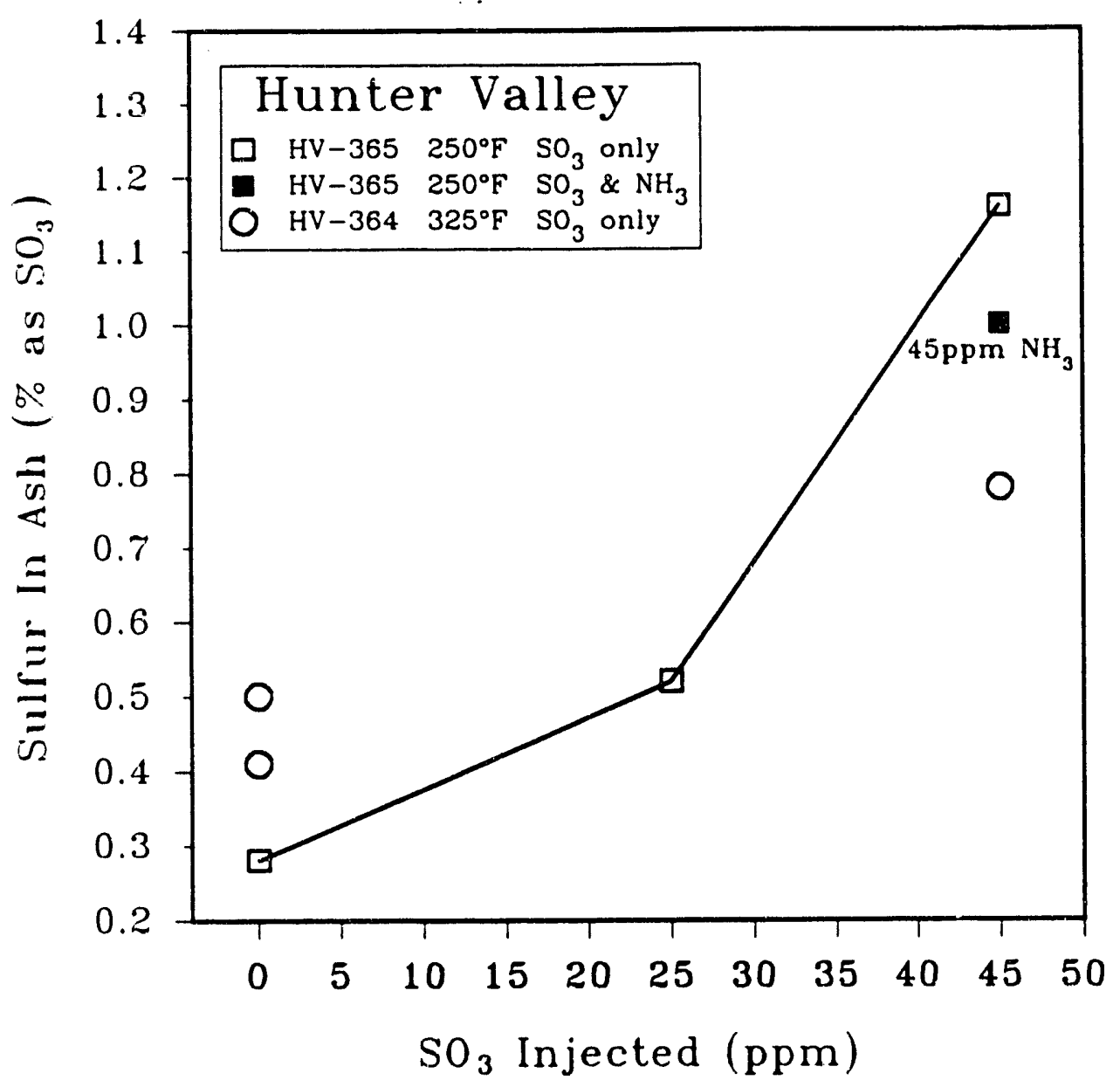

Figure A-2.14. Sulfur retention as a function of $\mathrm{SO}_{3}$ concentration for Hunter Valley coal for Runs 364 and 365. 


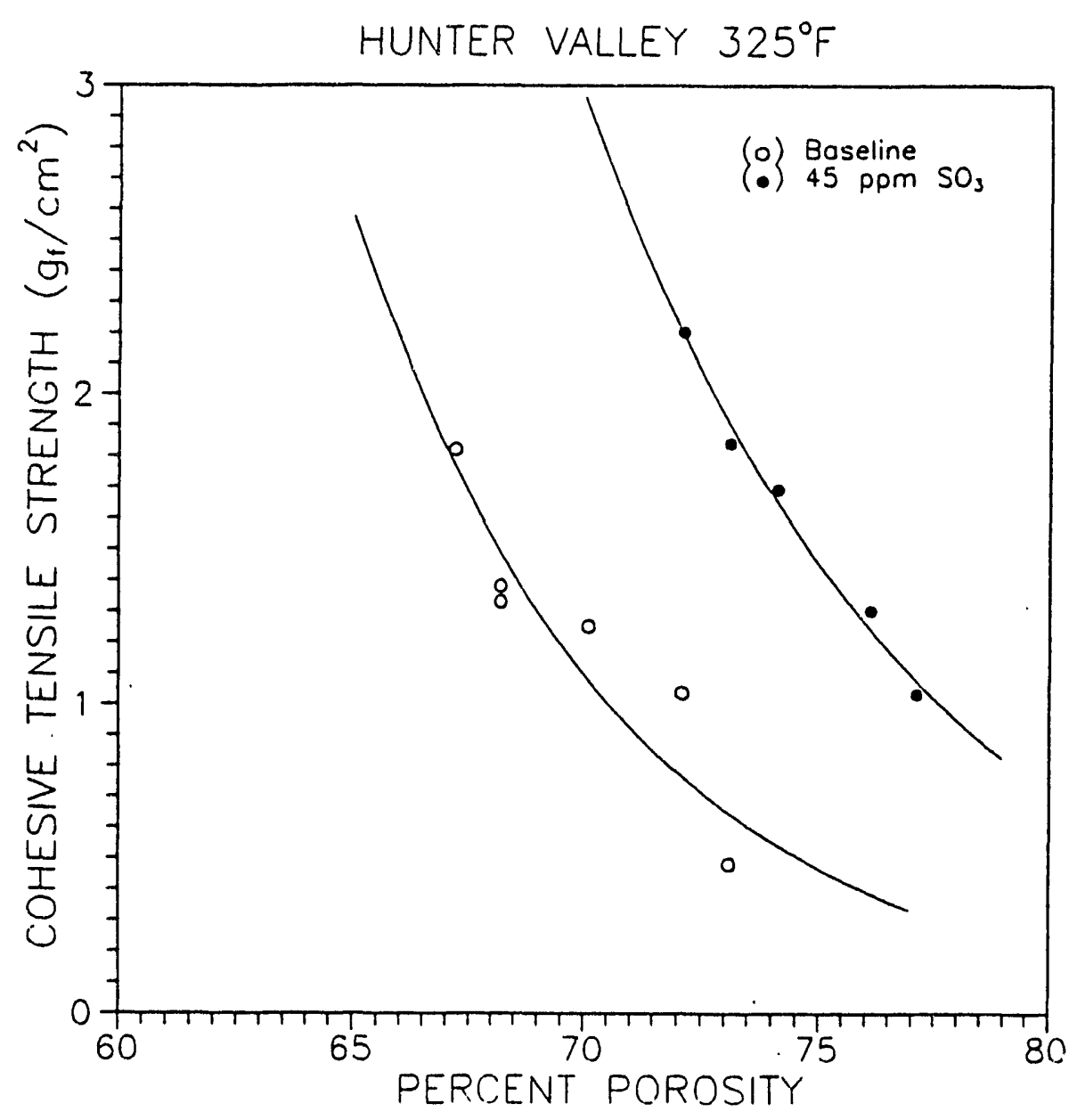

Figure A-2.15. Fly ash tensile strength as a function of ash porosity for Hunter Valley coal for Run 364. 
HUNTER VALLEY $250^{\circ} \mathrm{F}$

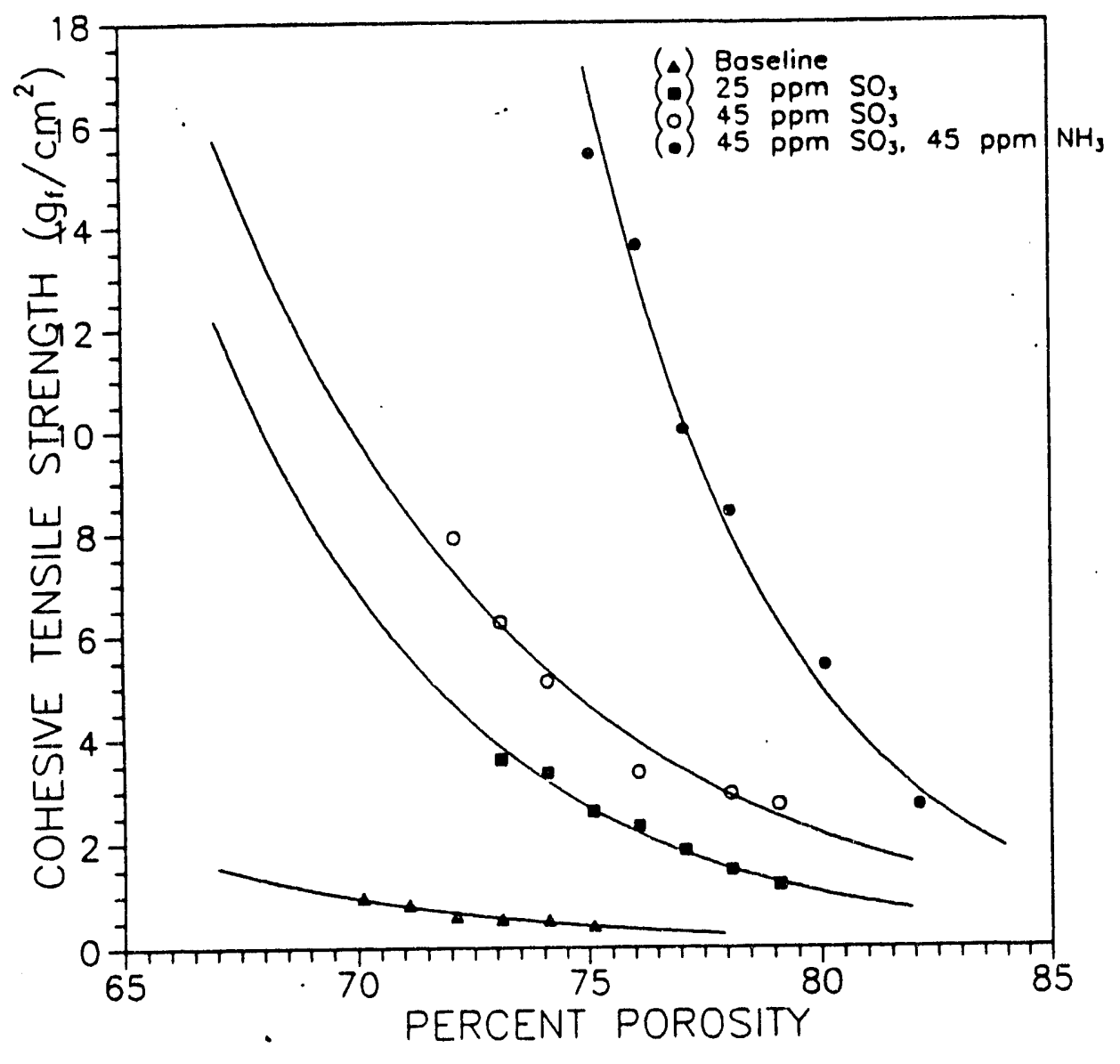

Figure A-2.16. Fly ash tensile strength as a function of ash porosity for Hunter Valley coal for Run 365 . 


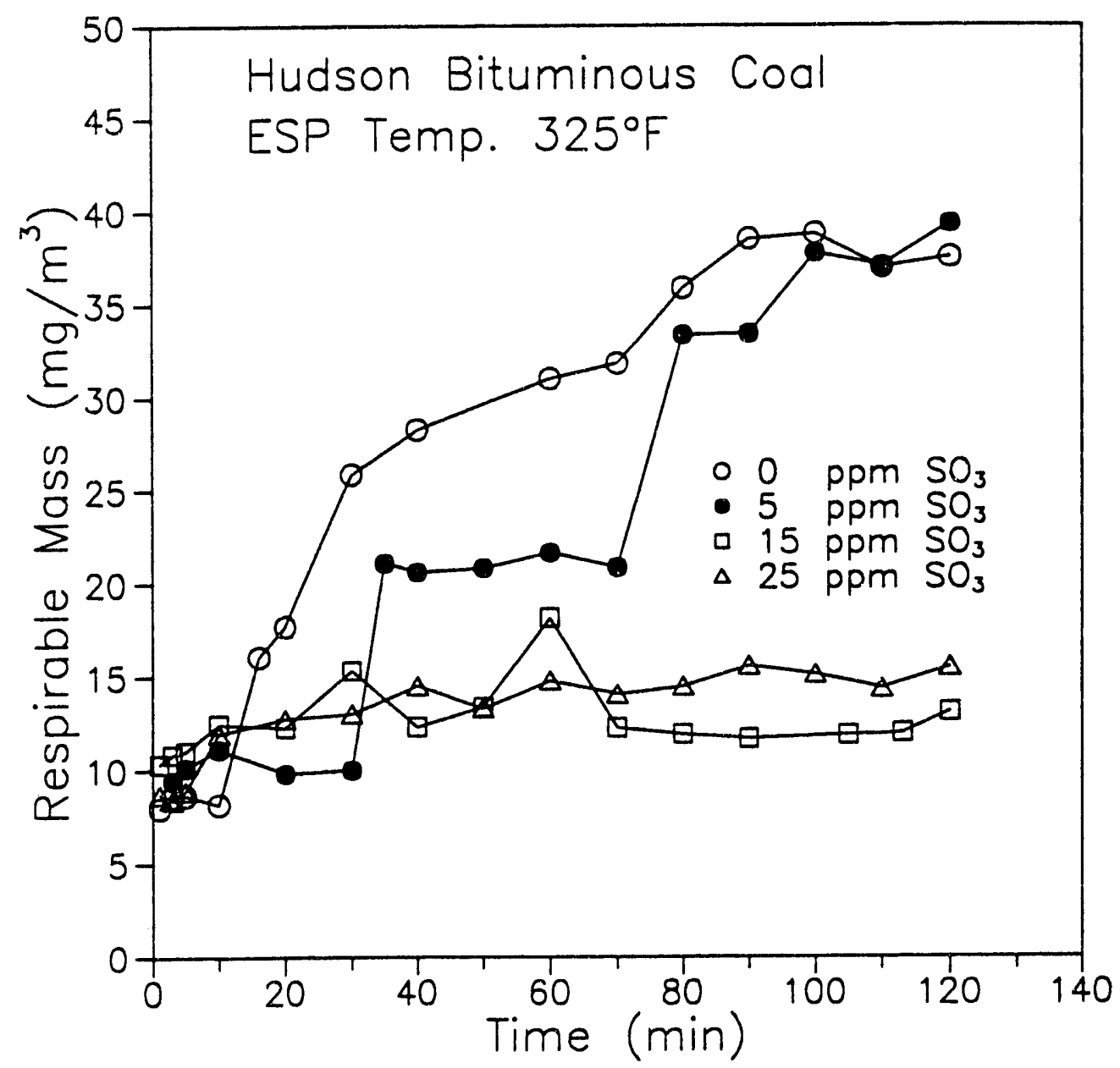

Figure A-3.1. Respirable mass emissions as a function of time for Hudson bituminous coal for Run 355 . 


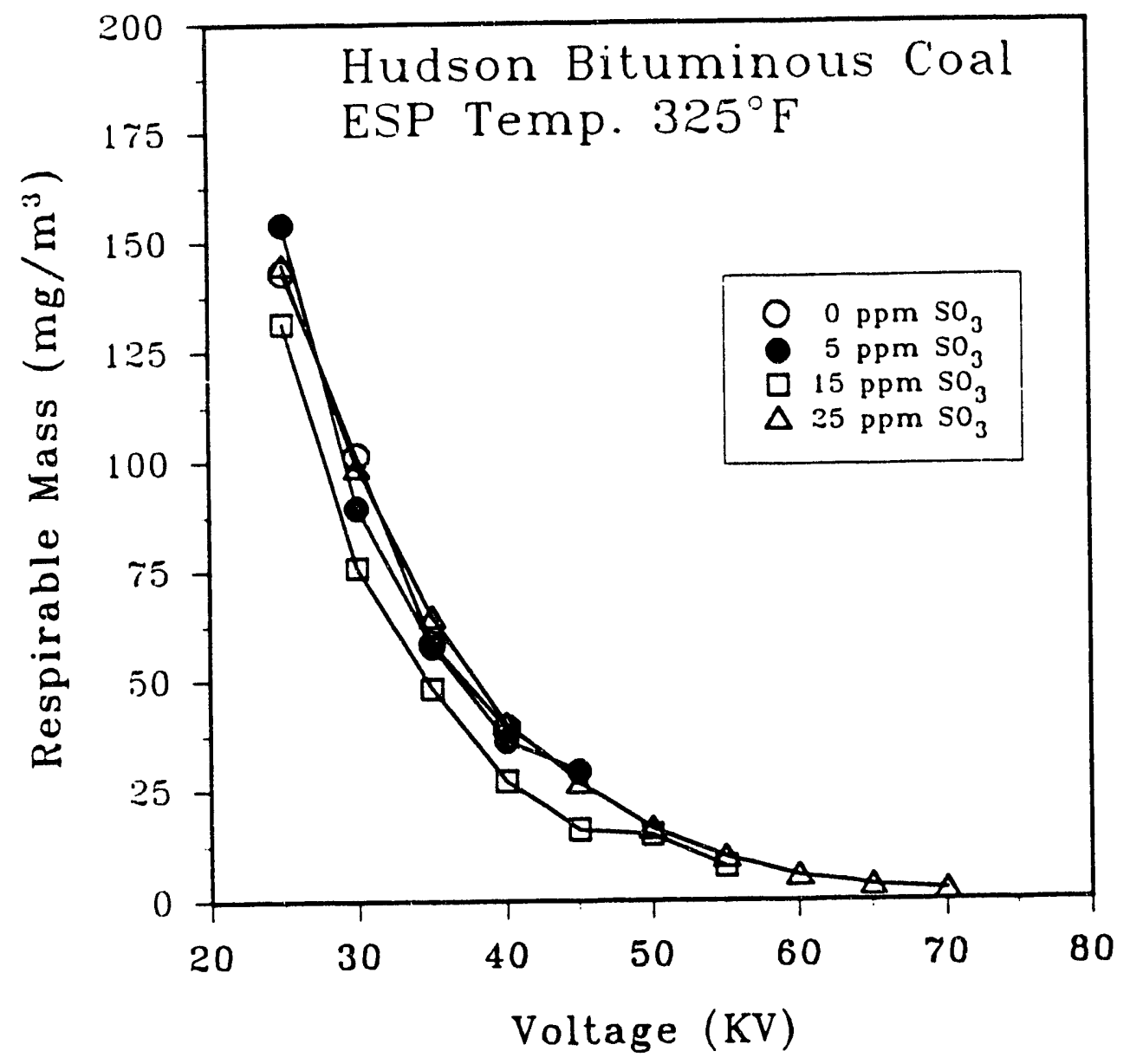

Figure A-3.2. Respirable mass emissions as a function of voltage for Hudson bituminous coai for Run 355 . 


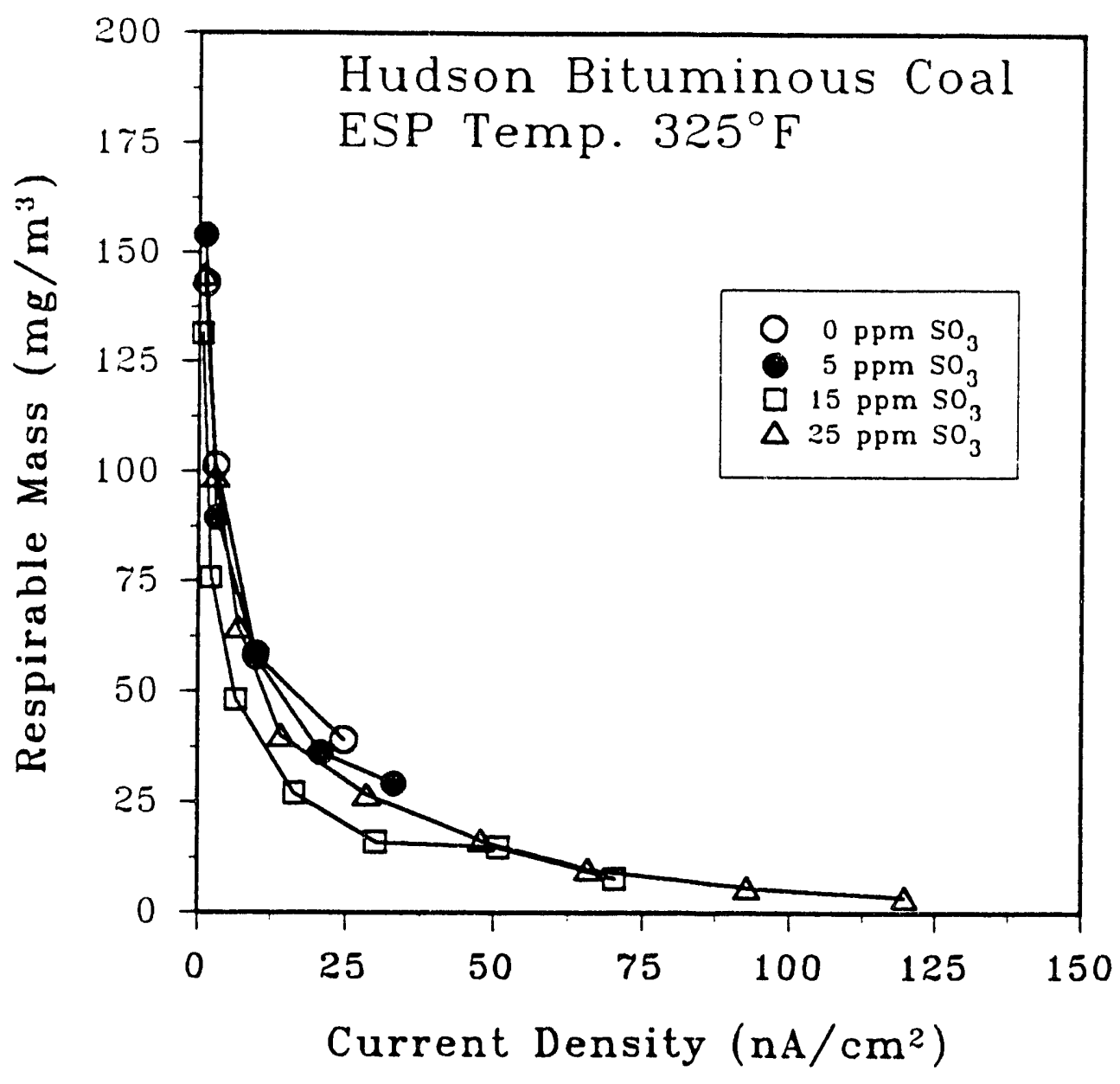

Figure A-3.3. Respirable mass emissions as a function of current density for Hudson bituminous coal for Run 355 . 


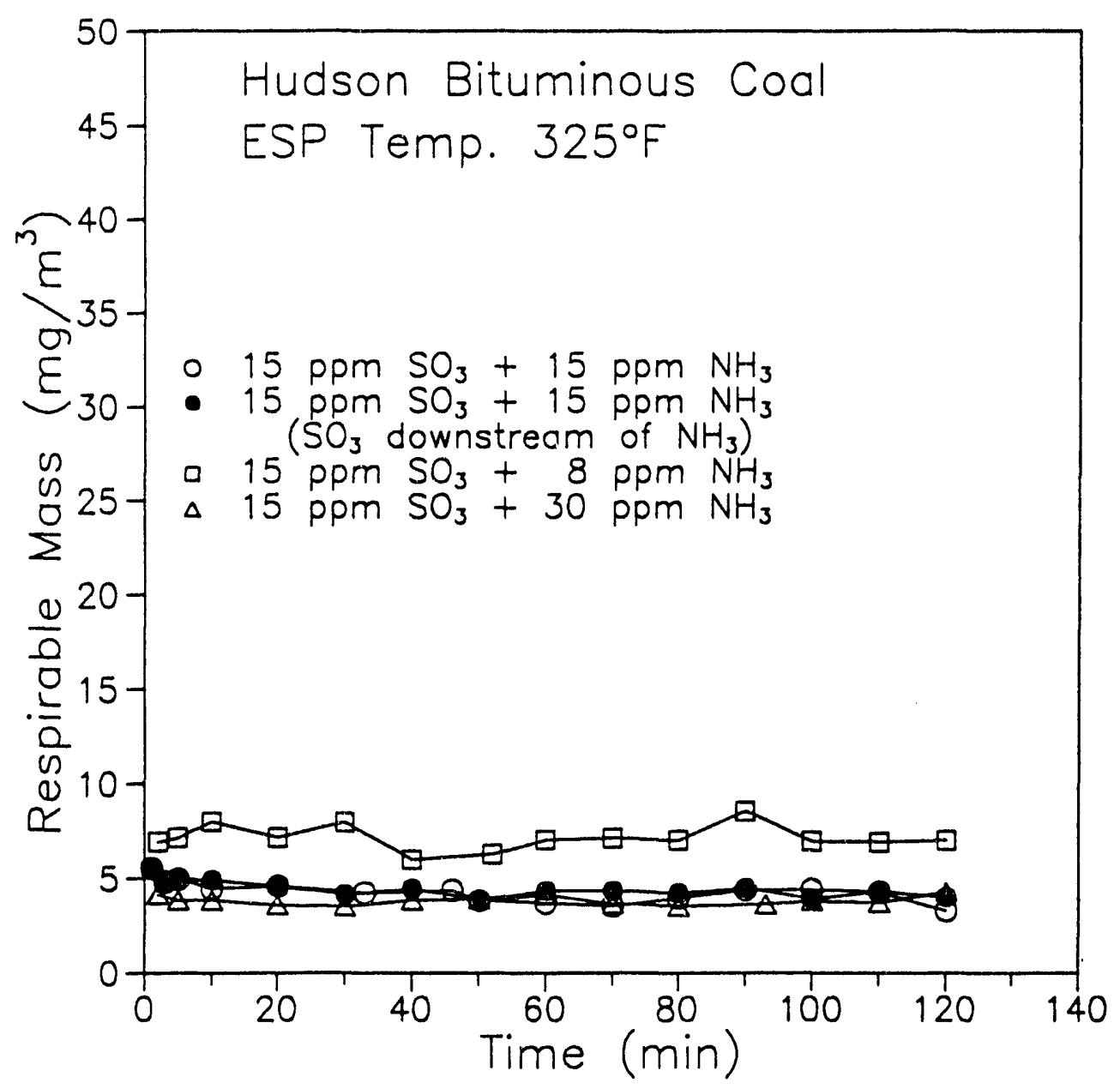

Figure A-3.4. Respirable mass emissions as a function of time for Hudson bituminous coal for Run 356 . 


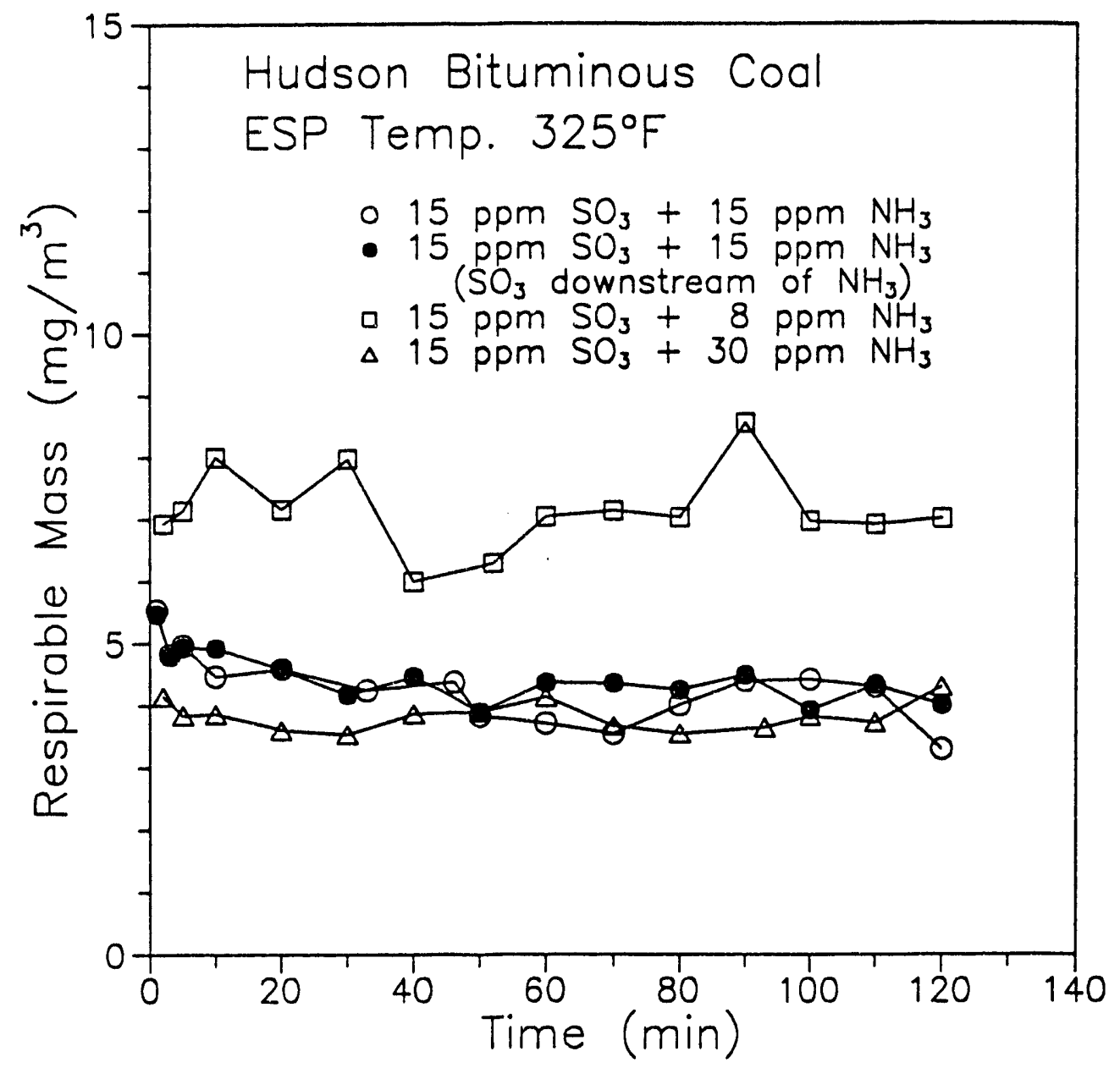

Figure A-3.5. Respirable mass emissions as a function of time (expanded scale) for Hudson bituminous coal for Run 356. 


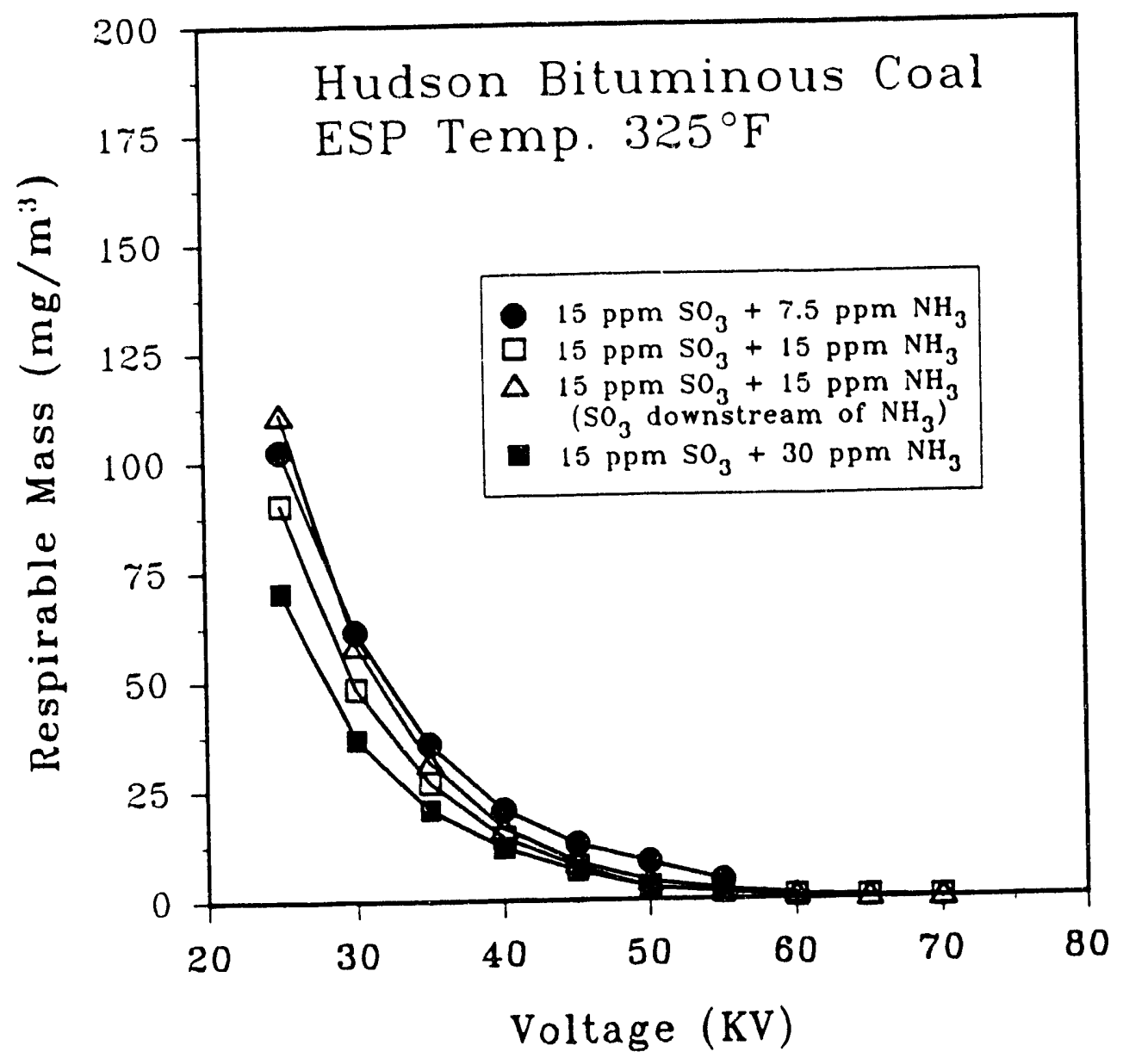

Figure A-3.6. Respirable mass emissions as a function of voltage for Hudson bituminous coal for Run 356 . 


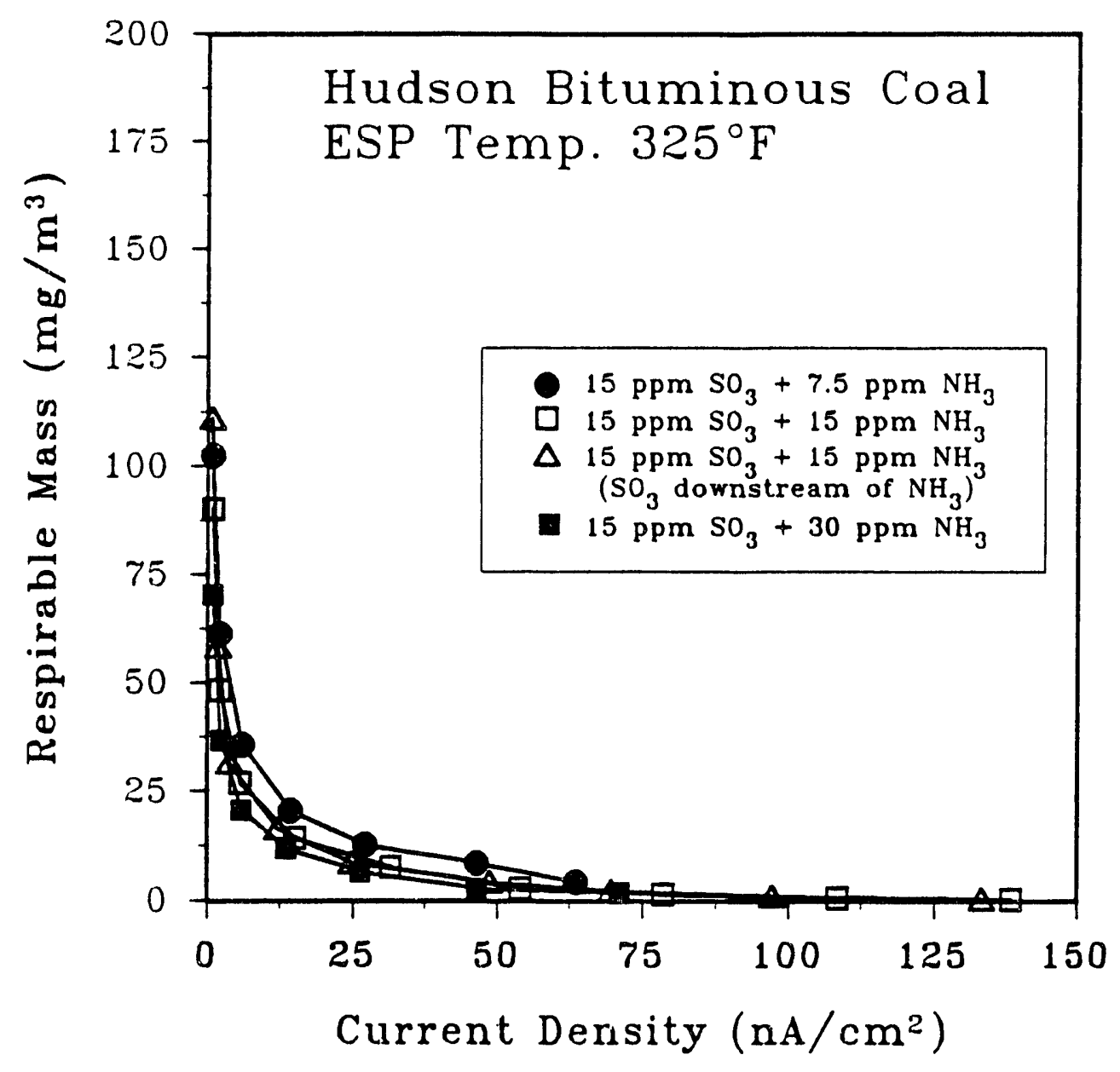

Figure A-3.7. Respirable mass emissions as a function of current density for Hudson bituminous coal for Run 356 . 


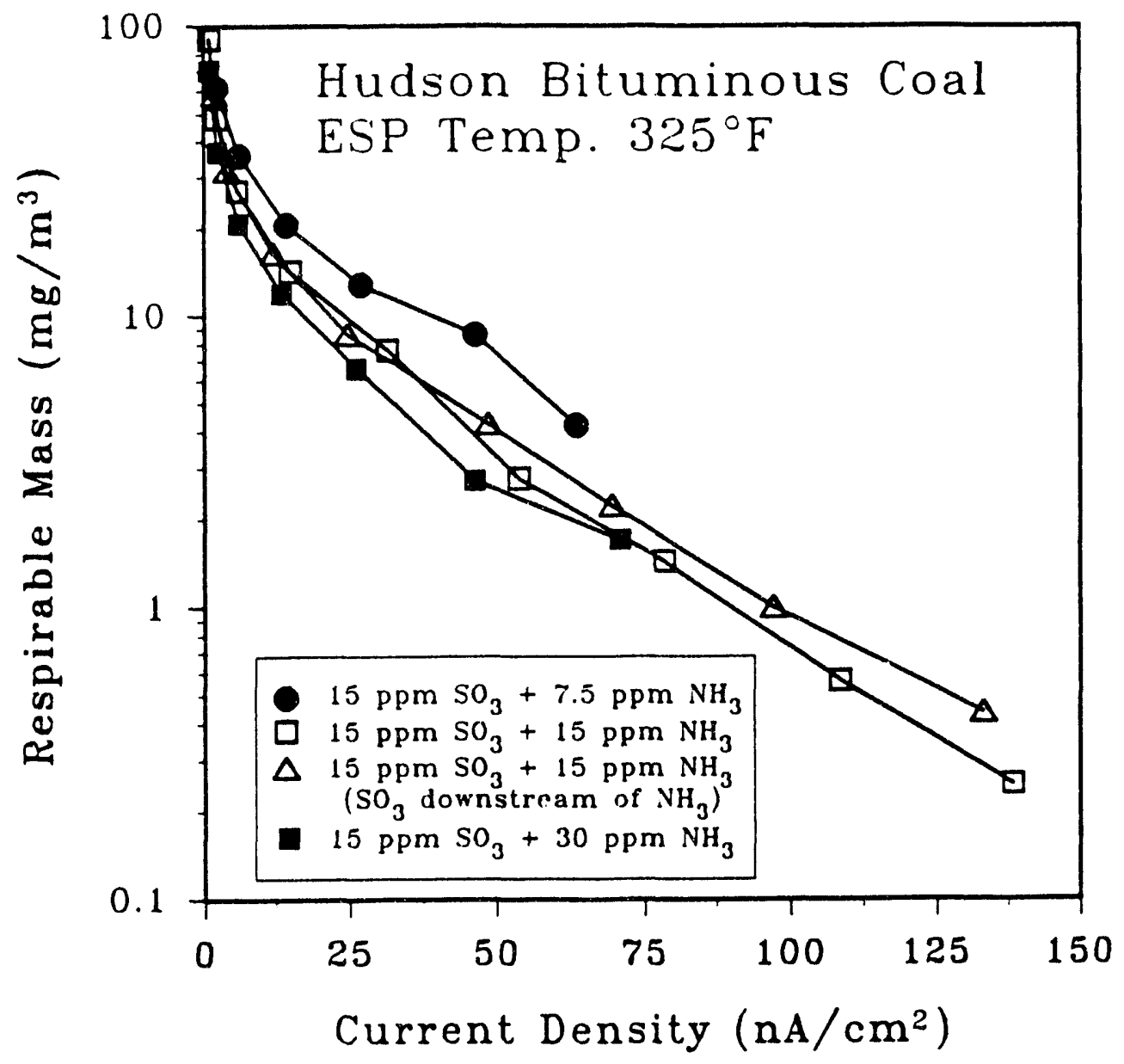

Figure A-3.8. Respirable mass emissions as a function of current density (expanded scale) for Hudson bituminous coal for Run 356 . 


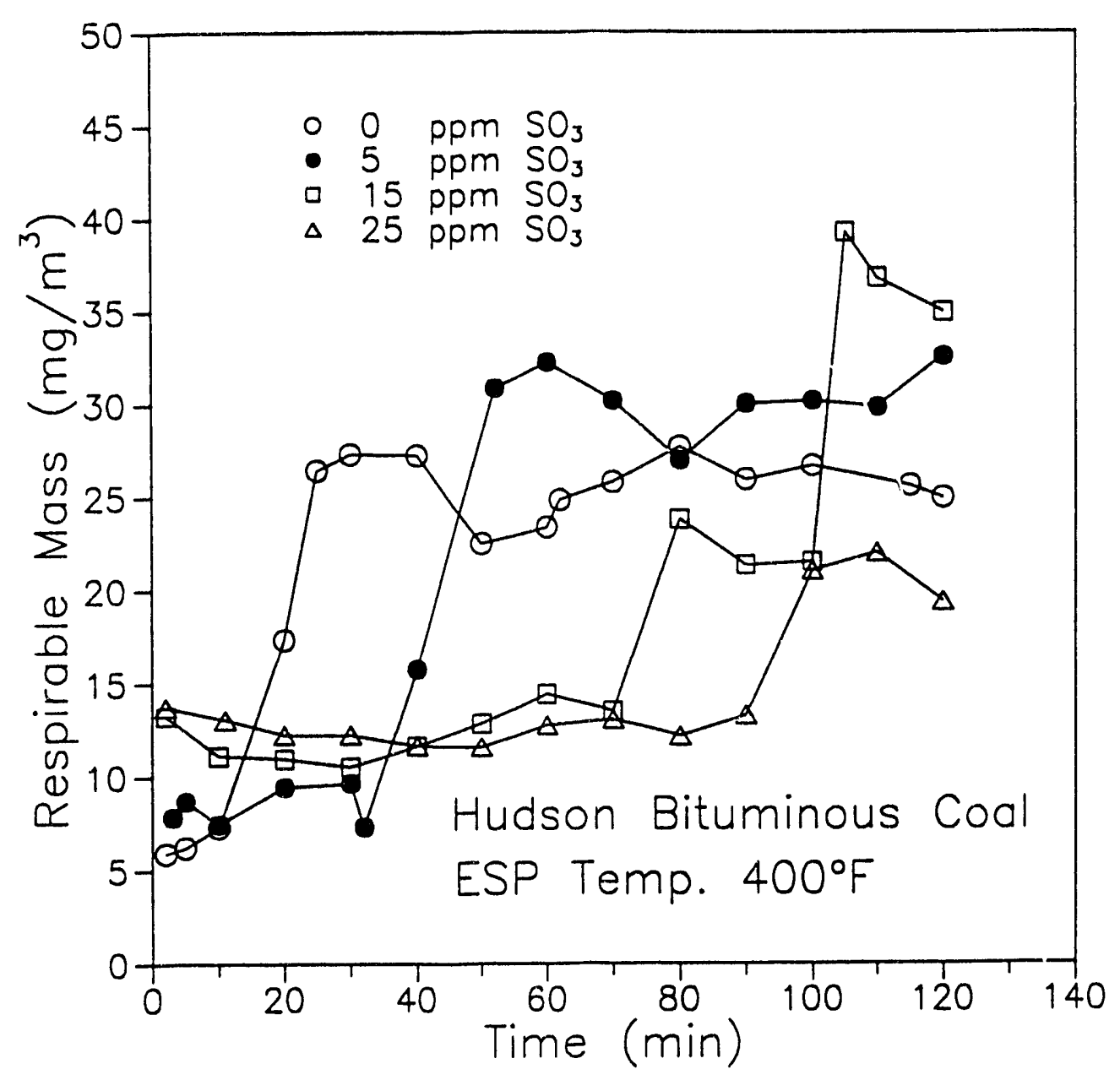

Figure A-3.9. Respirable mass emissions as a function of time for Hudson bituminous coal for Run 357. 


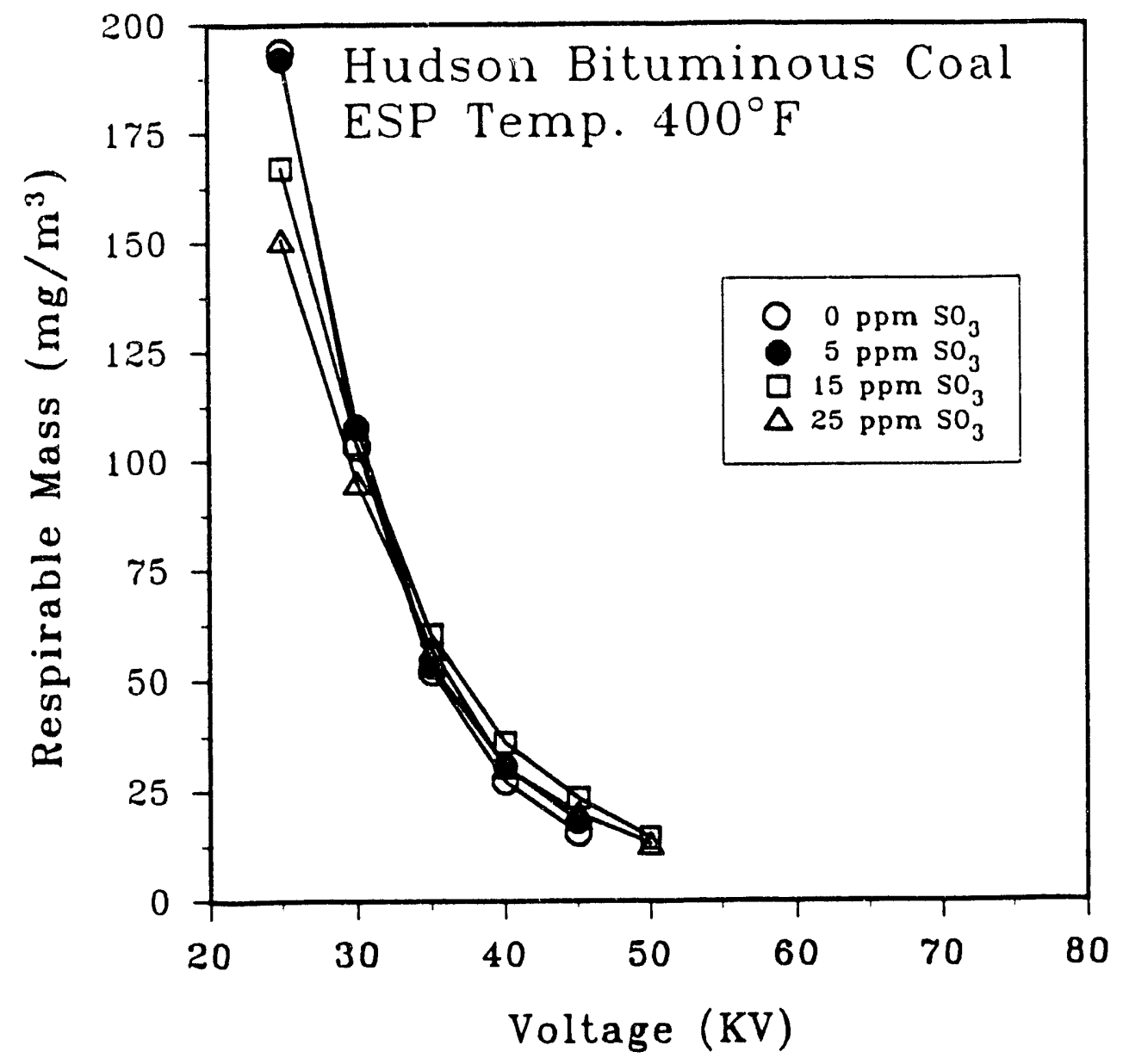

Figure A-3.10. Respirable mass emissions as a function of voltage for Hudson bituminous coal for Run 357 . 


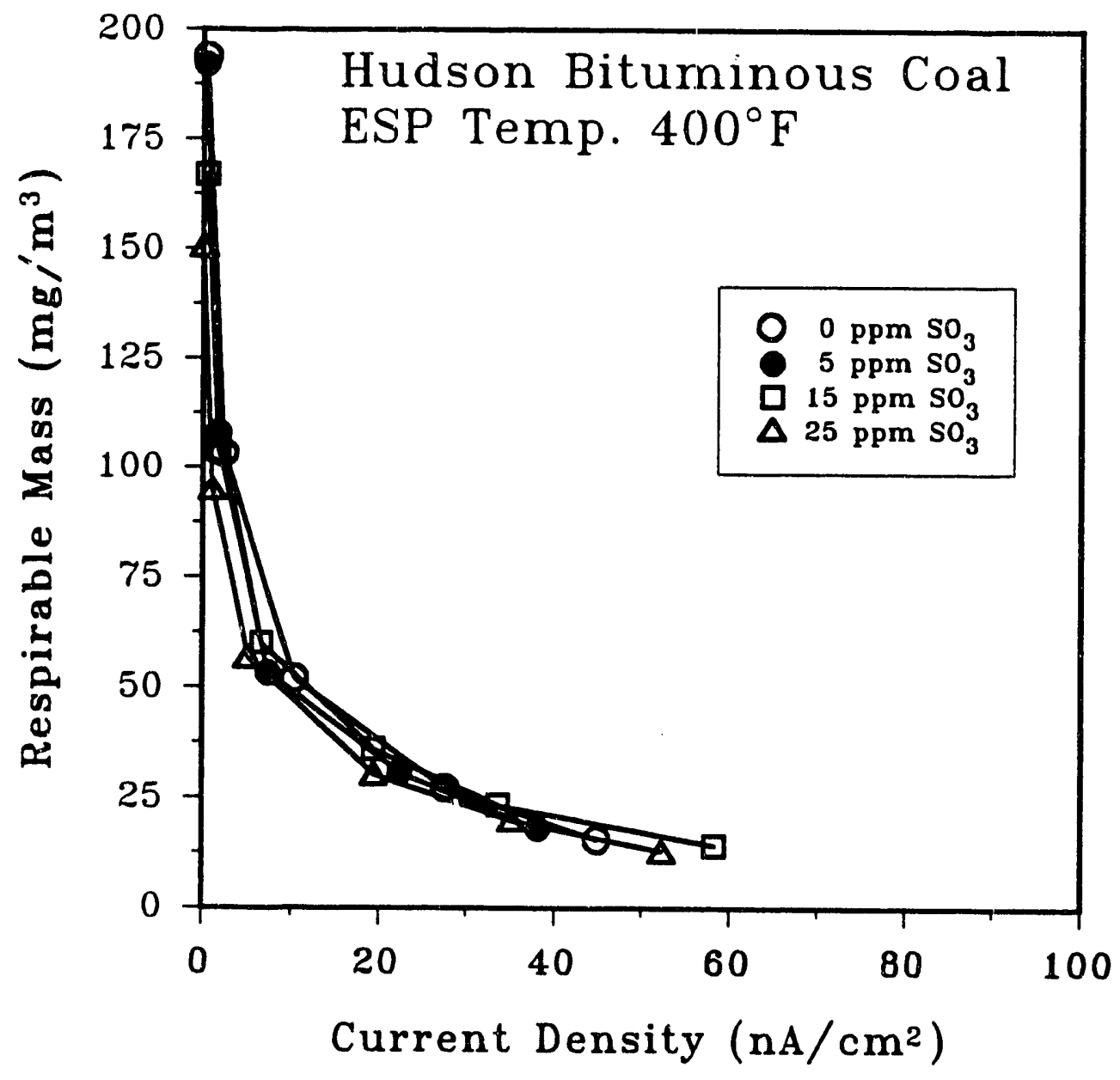

Figure A-3.11. Respirable mass emissions as a function of current density for Hudson bituminous coal for Run 357 . 


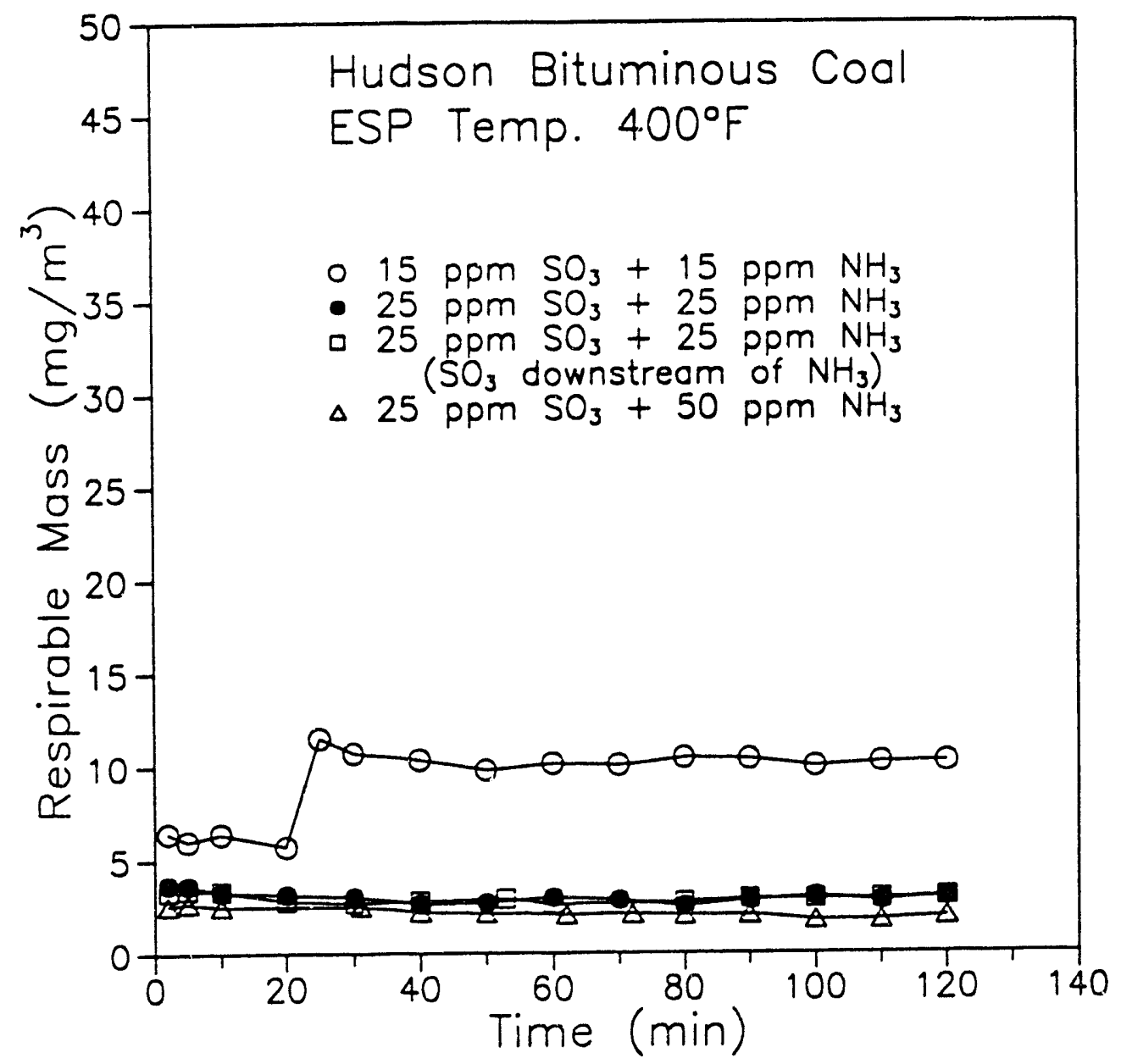

Figure A-3.12. Respirable mass emissions as a function of time for Hudson bituminous coal for Run 358 . 


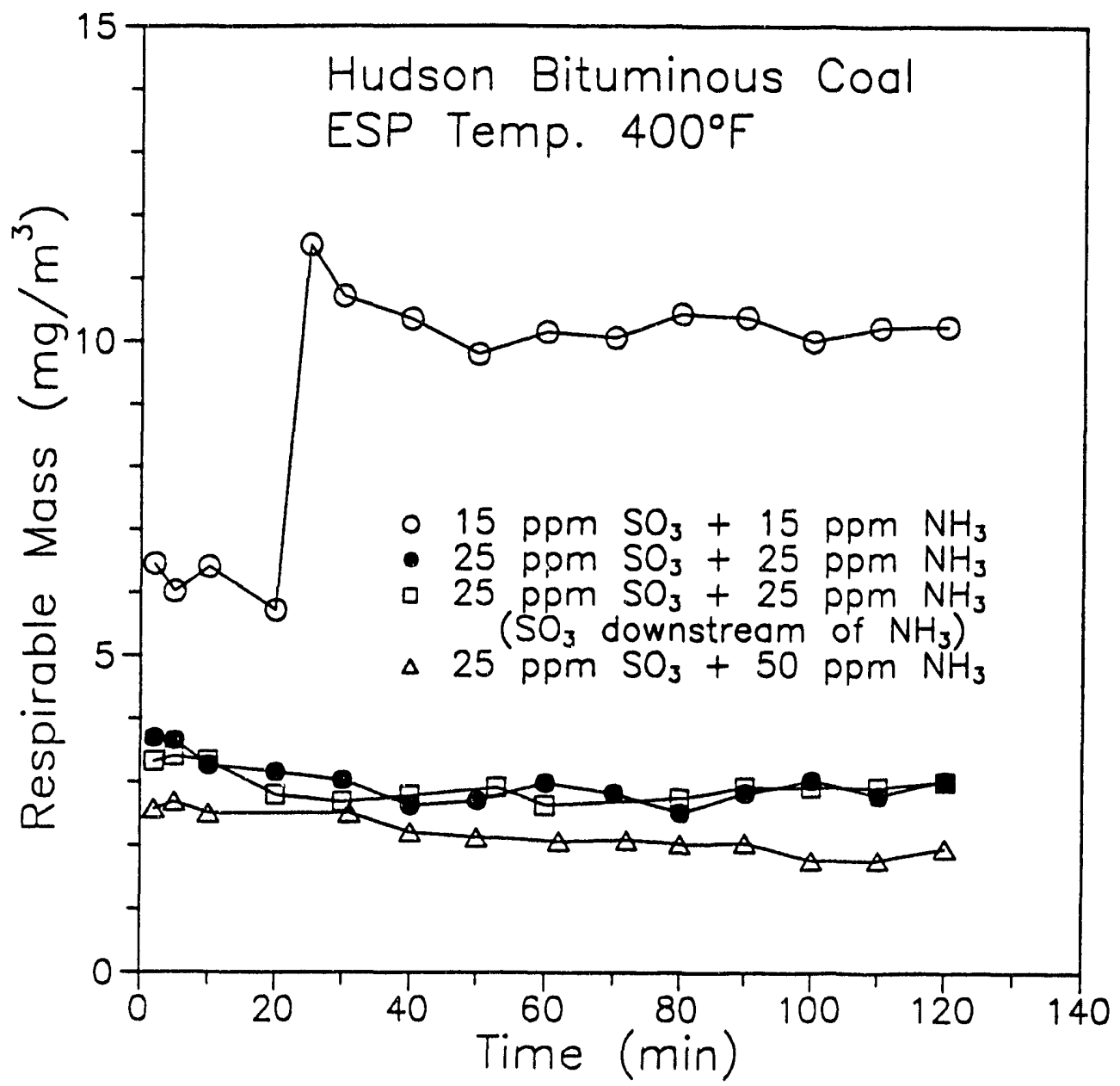

Figure A-3.13. Respirable mass emissions as a function of time (expanded scale) for Hudson bituminous coal for Run 358 . 


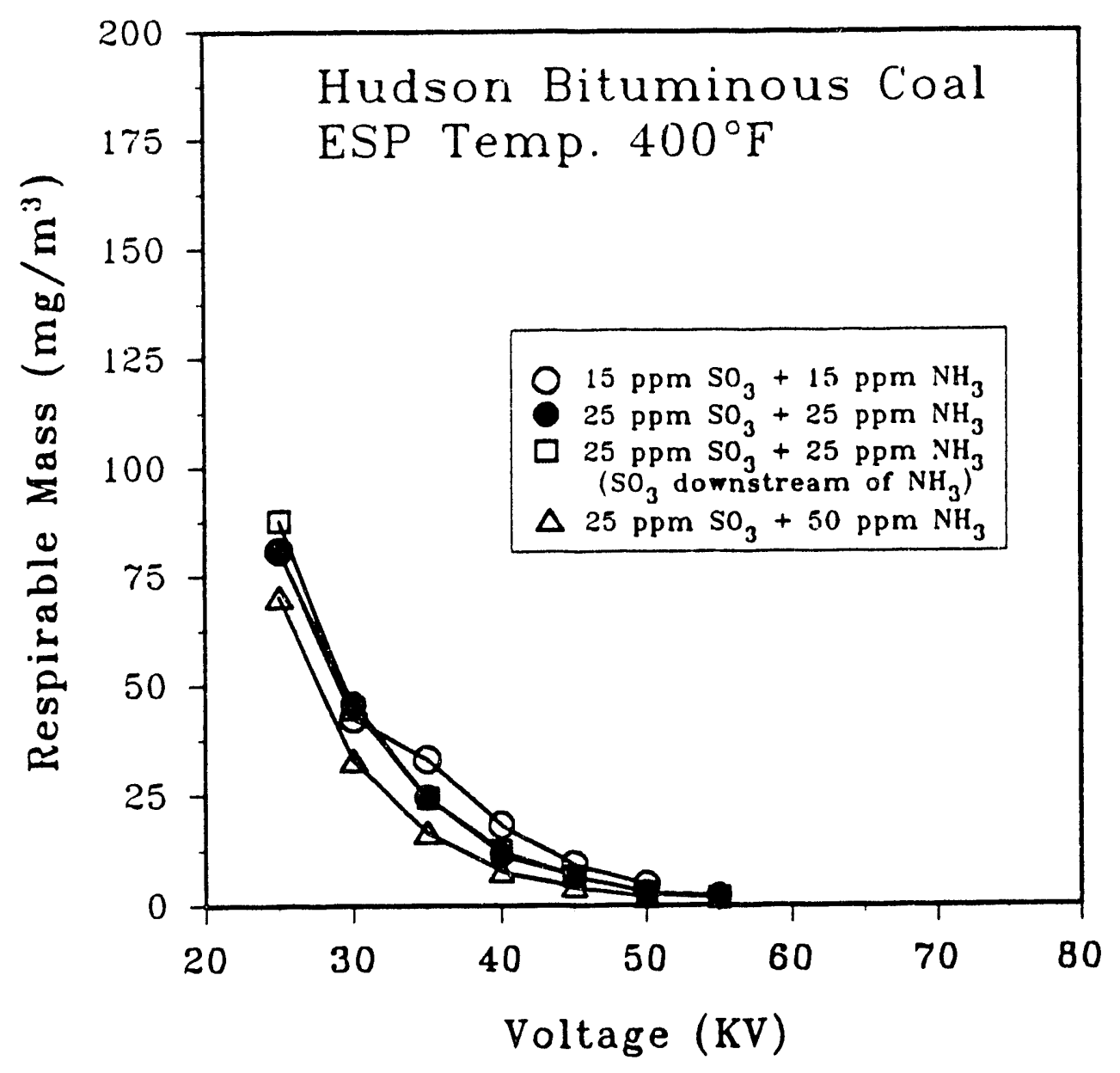

Figure A-3.14. Respirable mass emissions as a function of voltage for Hudson bituminous coal for Run 358 . 


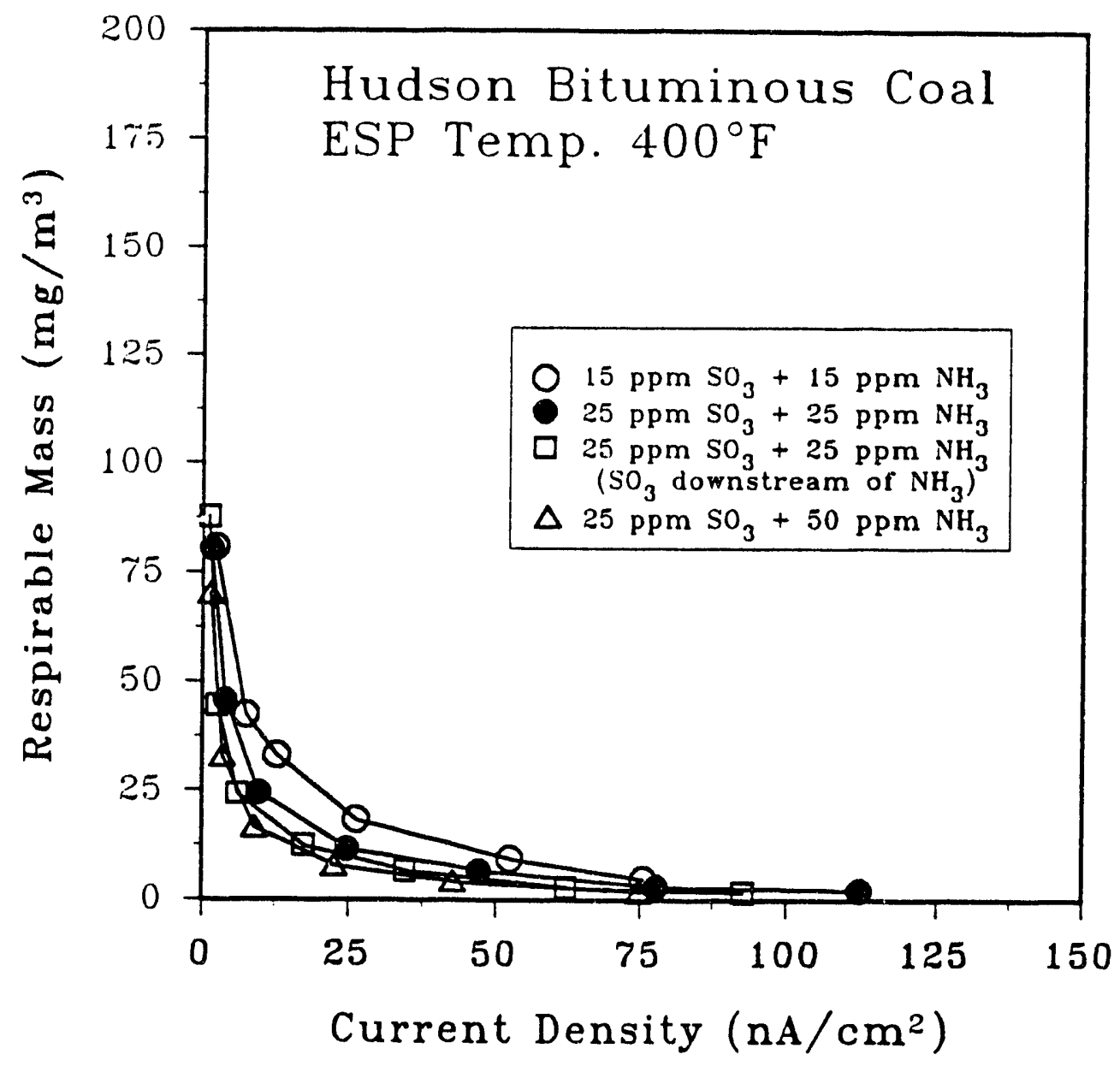

Figure A-3.15. Respirable mass emissions as a function of current density for Hudson bituminous coal for Run 358 . 


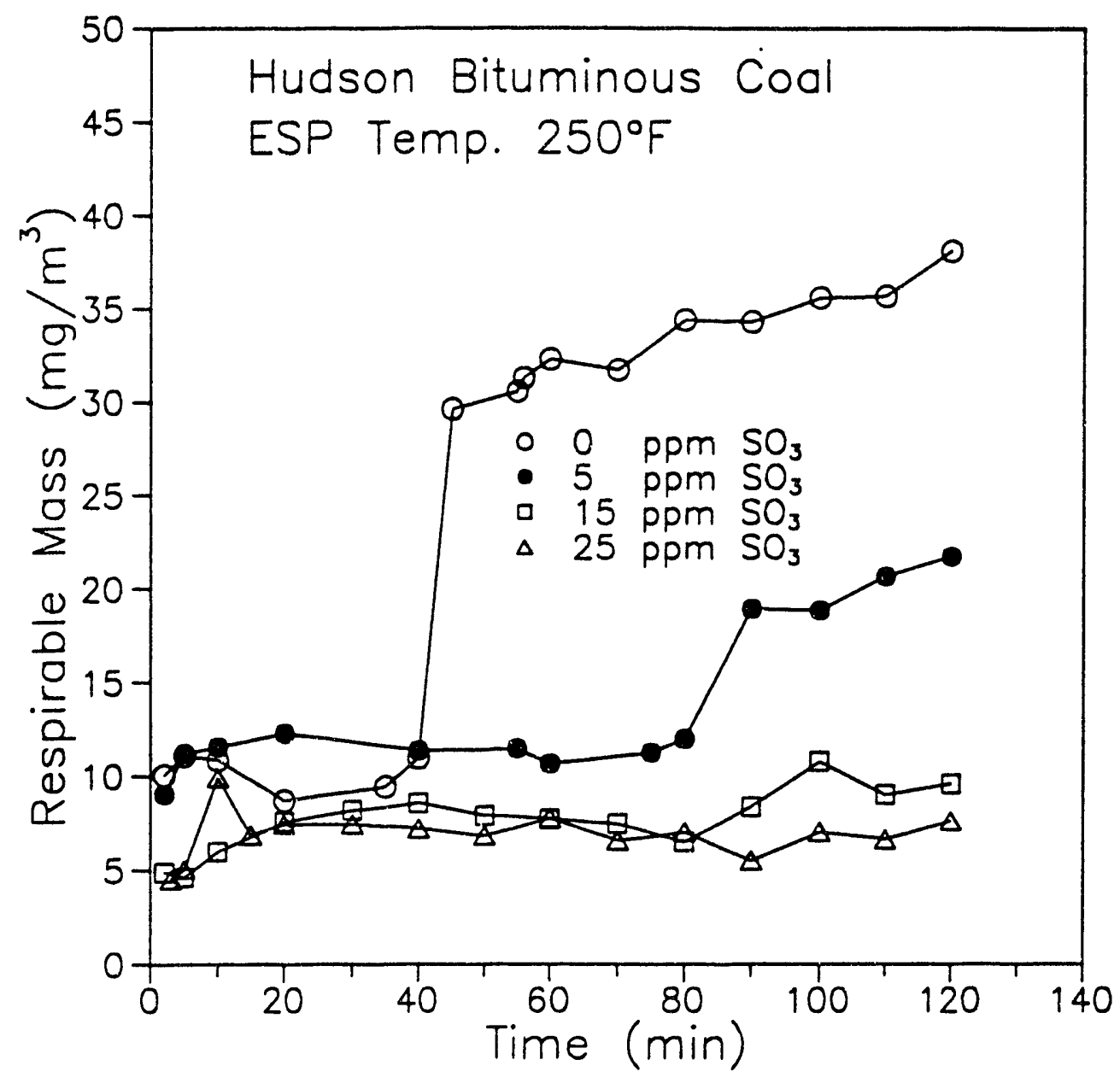

Figure A-3.16. Respirable mass emissions as a function of time for Hudson bituminous coal for Run 359 . 


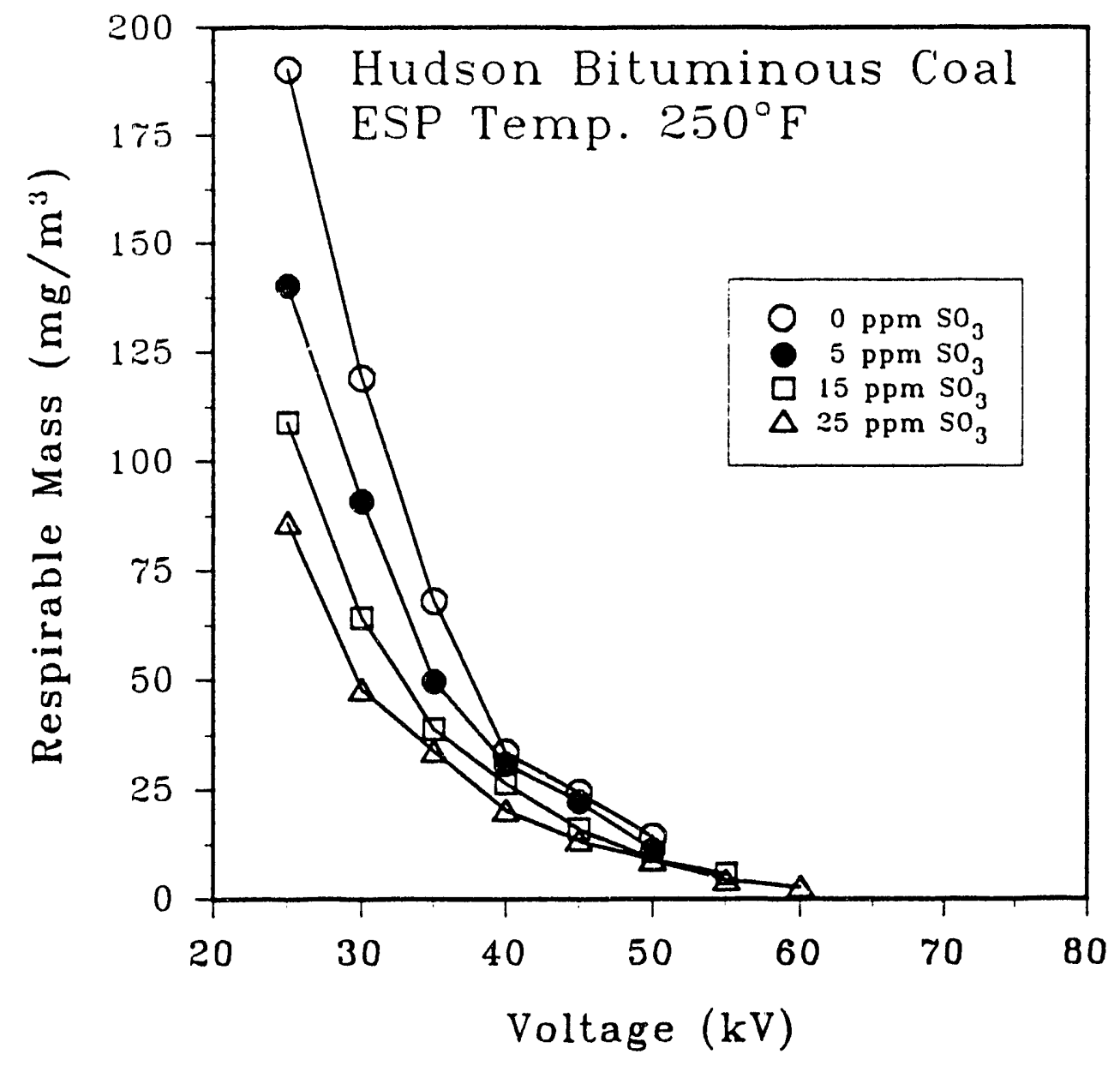

Figure A-3.17. Respirable mass emissions as a function of voltage for Hudson bituminous coal for Run 359 . 


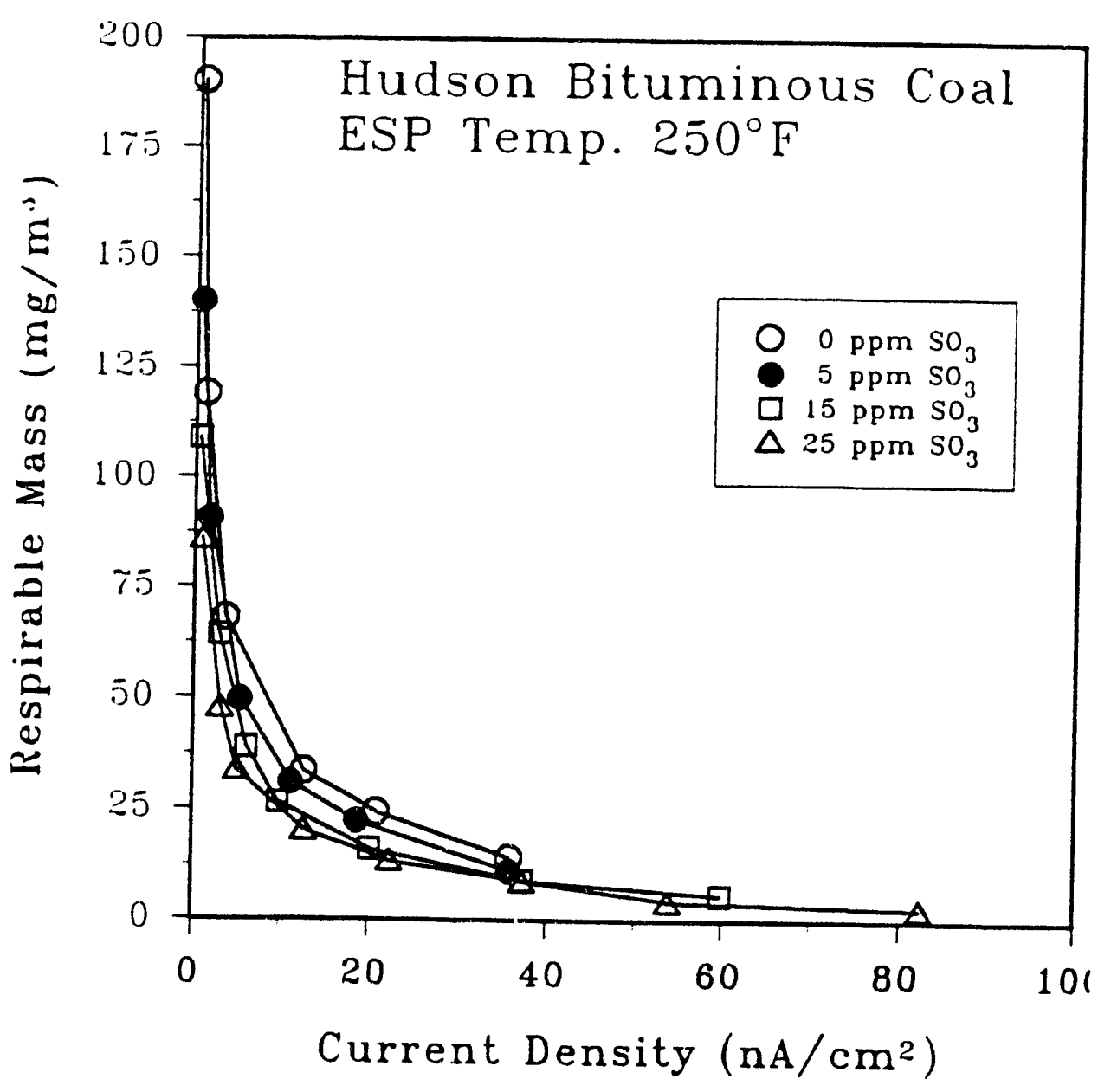

Figure A-3.18. Respirable mass emissions as a function of current density for Hudson bituminous coal for Run 359 . 


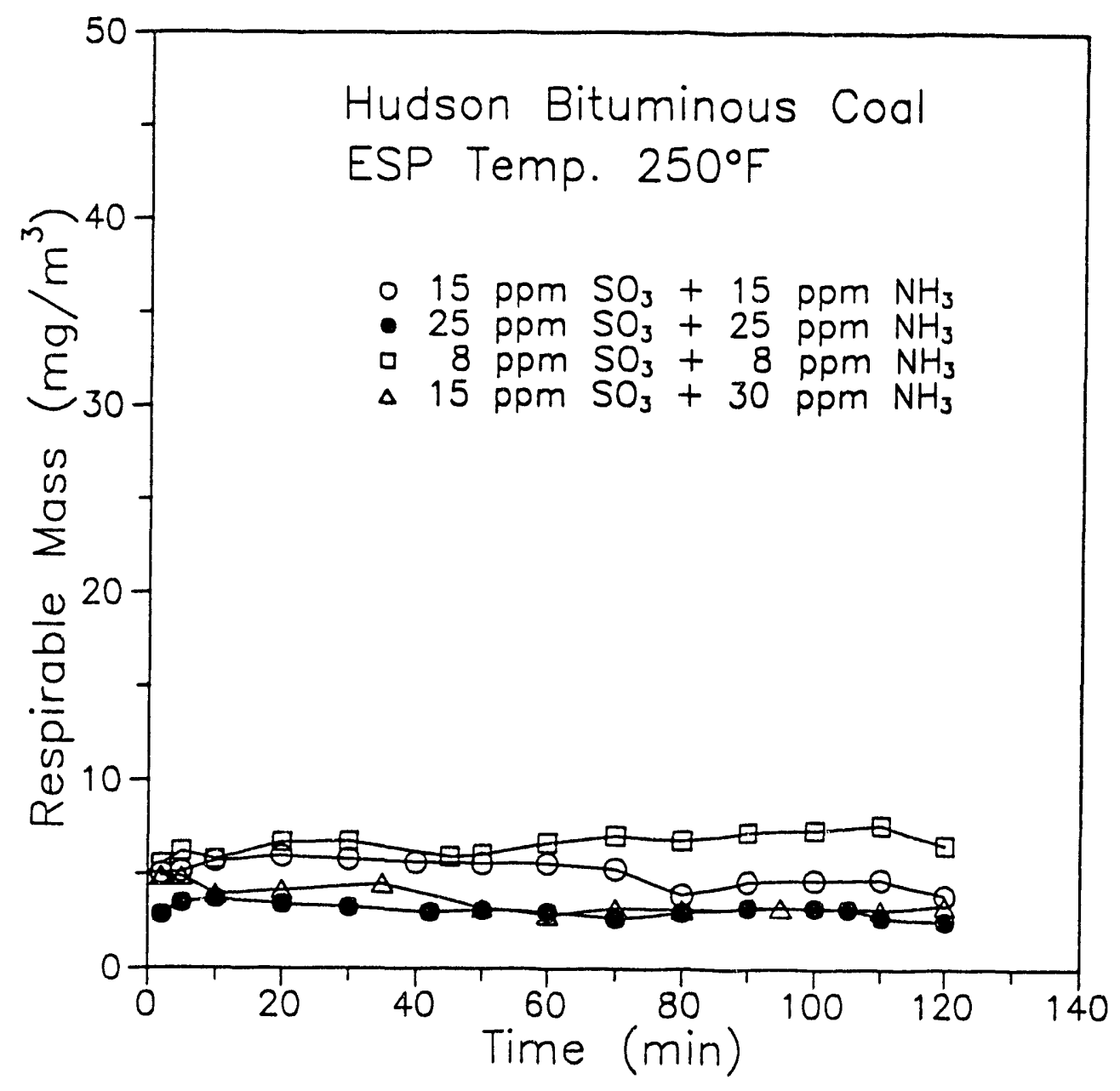

Figure A-3.19. Respirable mass emissions as a function of time for Hudson bituminous coal for Run 360 . 


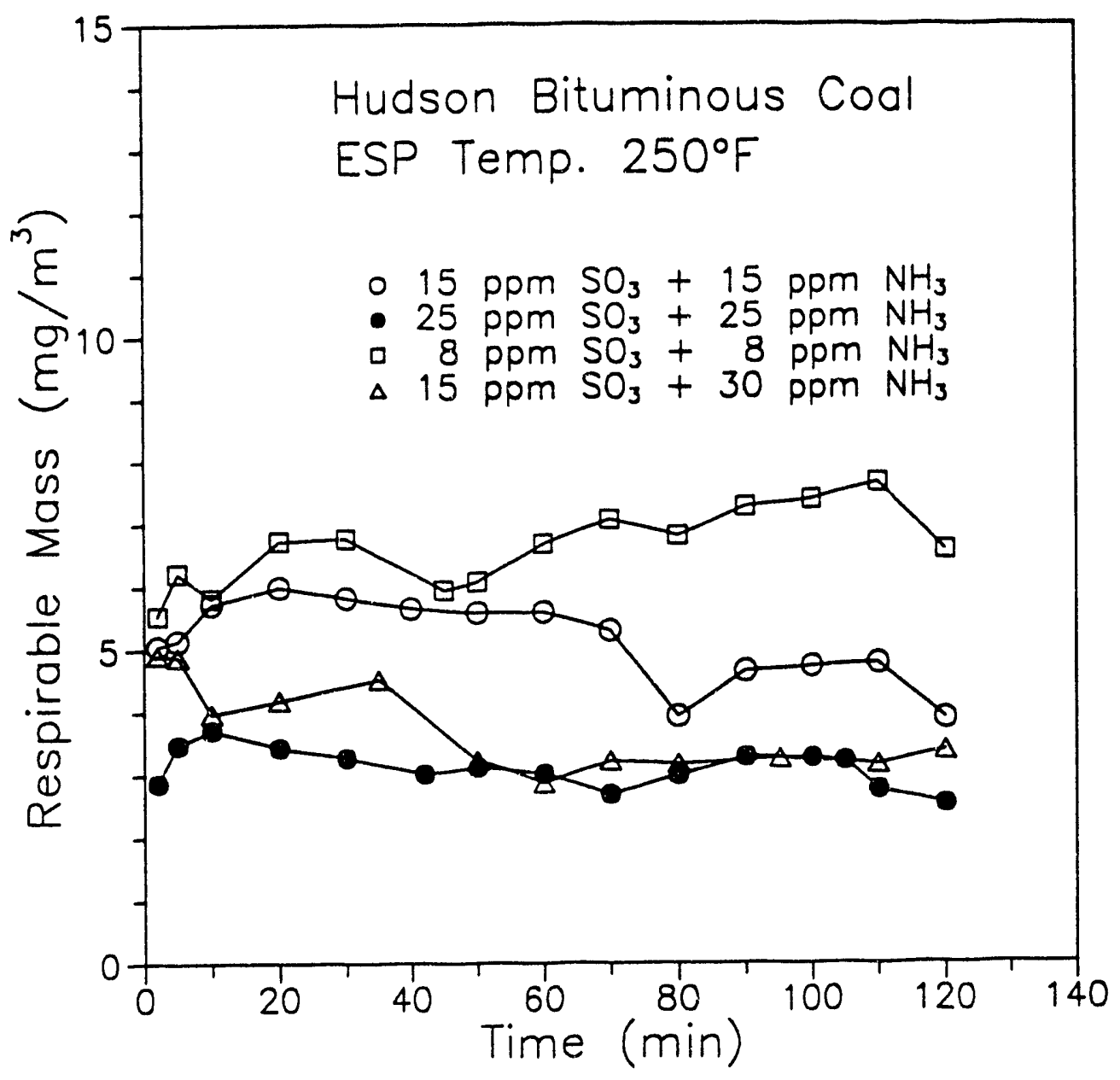

Figure A-3.20. Respirable mass emissions as a function of time (expanded scale) for Hudson bituminous coal for Run 360 . 


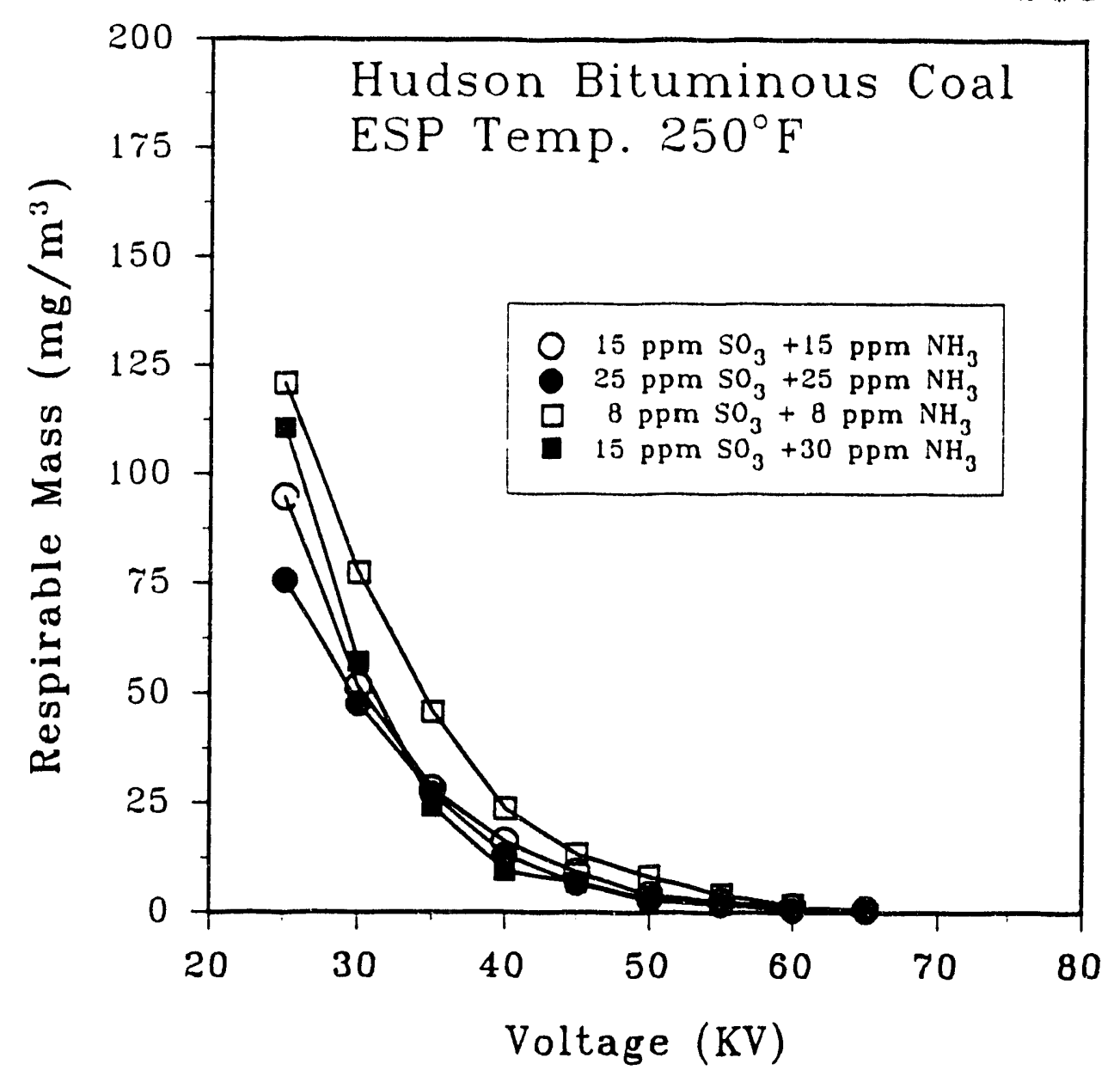

Figure A-3.21. Respirable mass emissions as a function of voltage for Hudson bituminous coal for Run 360 . 


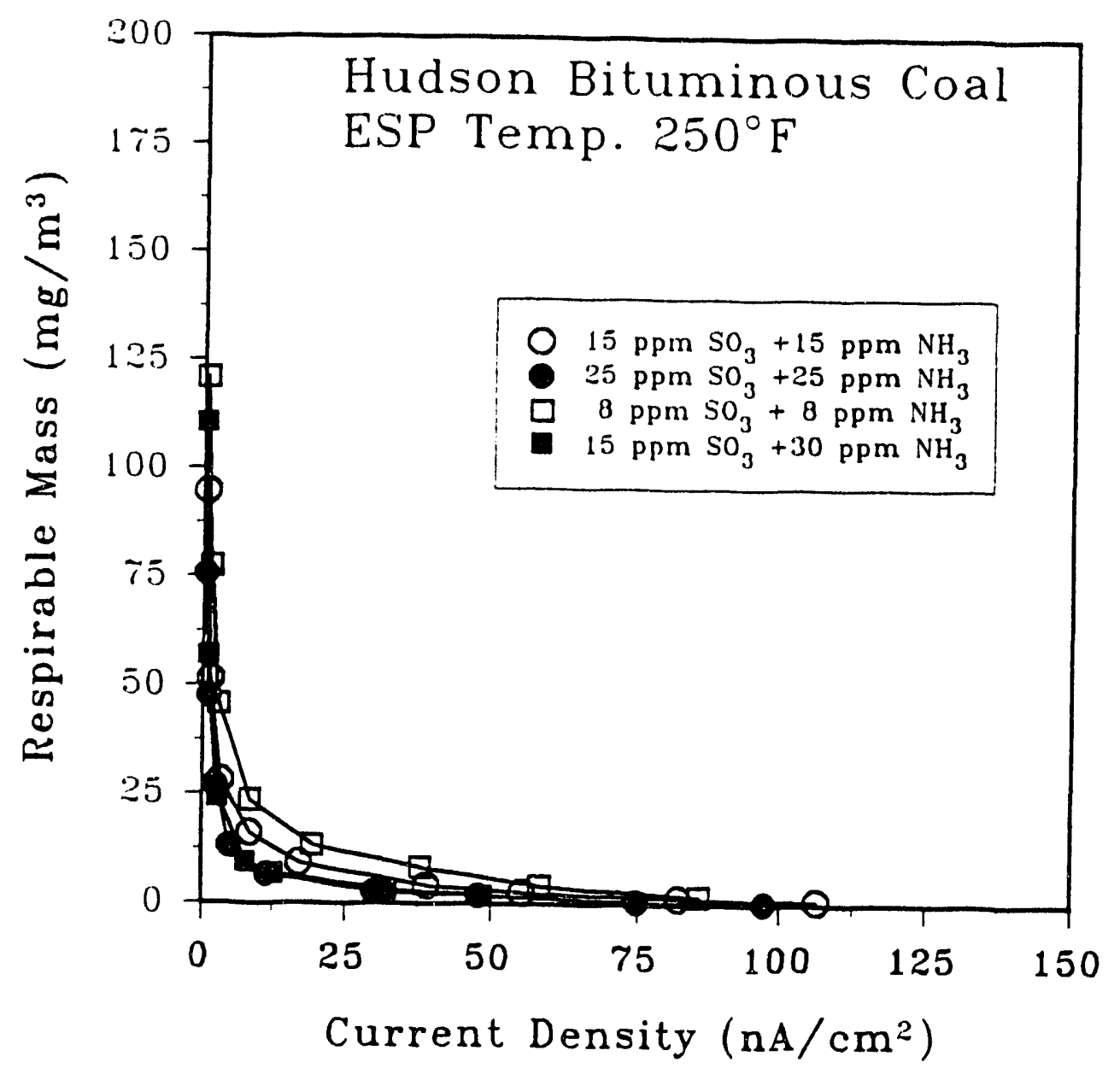

Figure A-3.22. Respirable mass emissions as a function of current density for Hudson bituminous coal for Run 360 . 


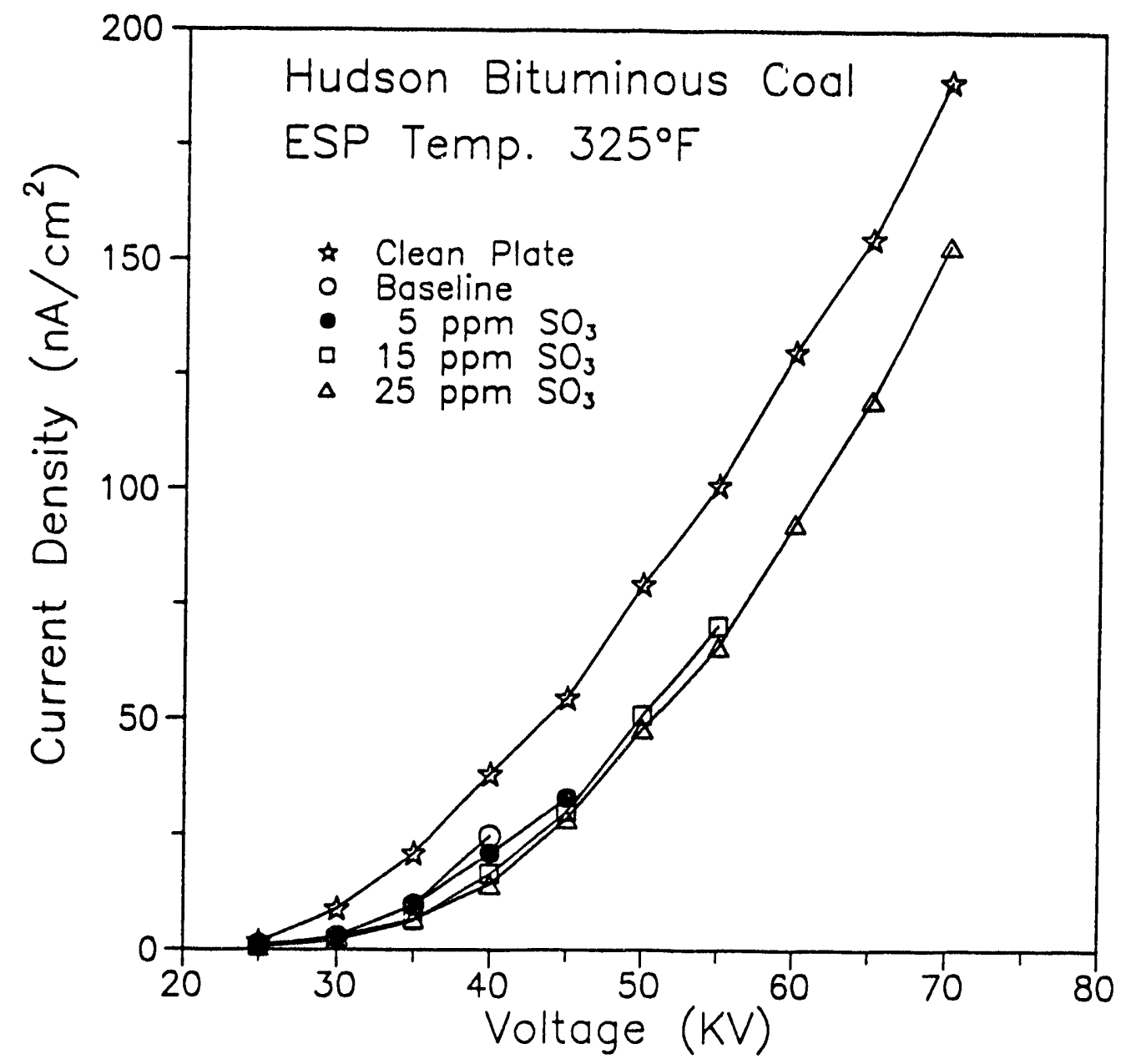

Figure A-3.23. Current-voltage curves for Hudson bituminous coal for Run 355 . 


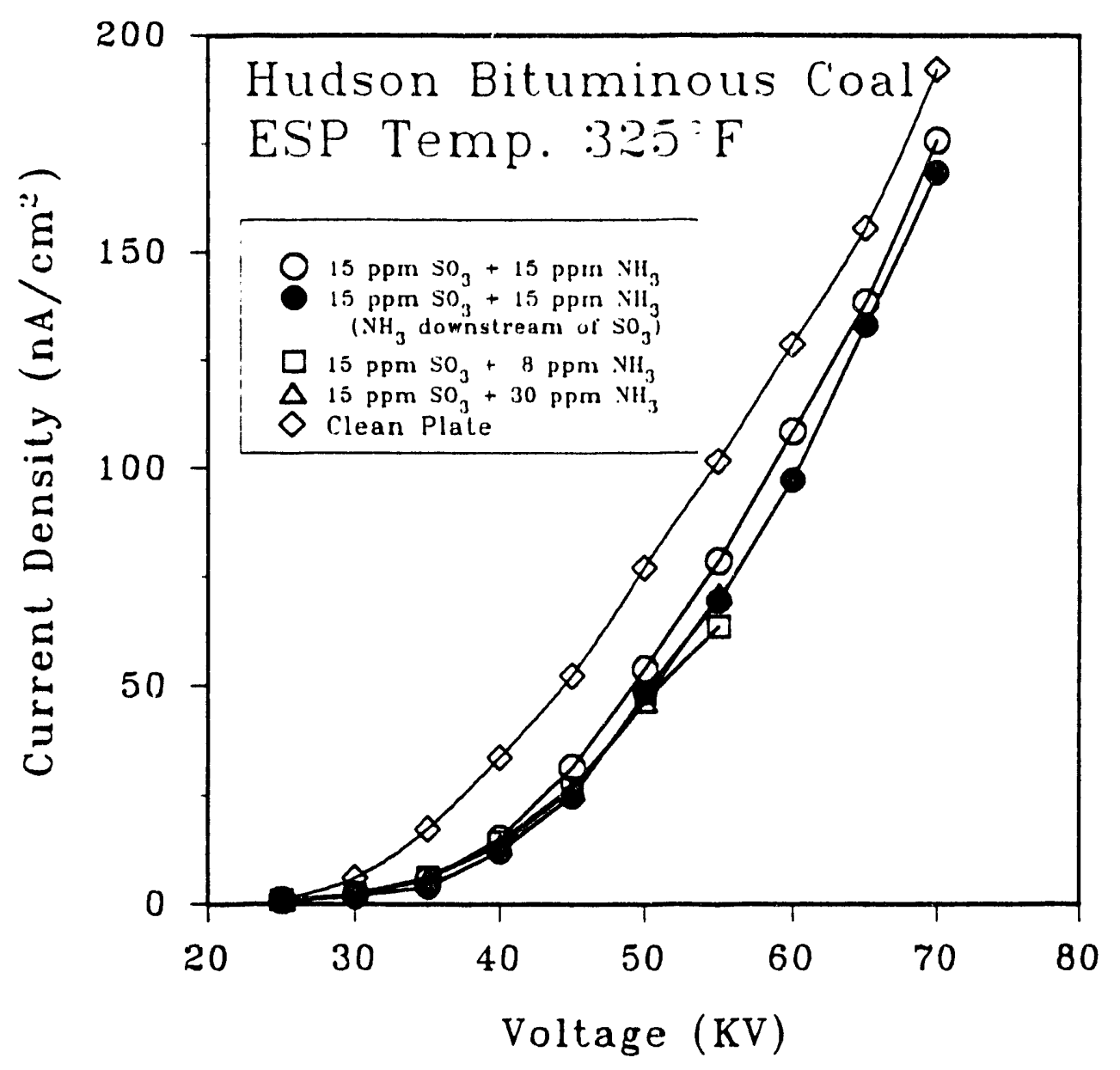

Figure A-3.24. Current-voltage curves for Hudson bituminous coal for Run 356 . 


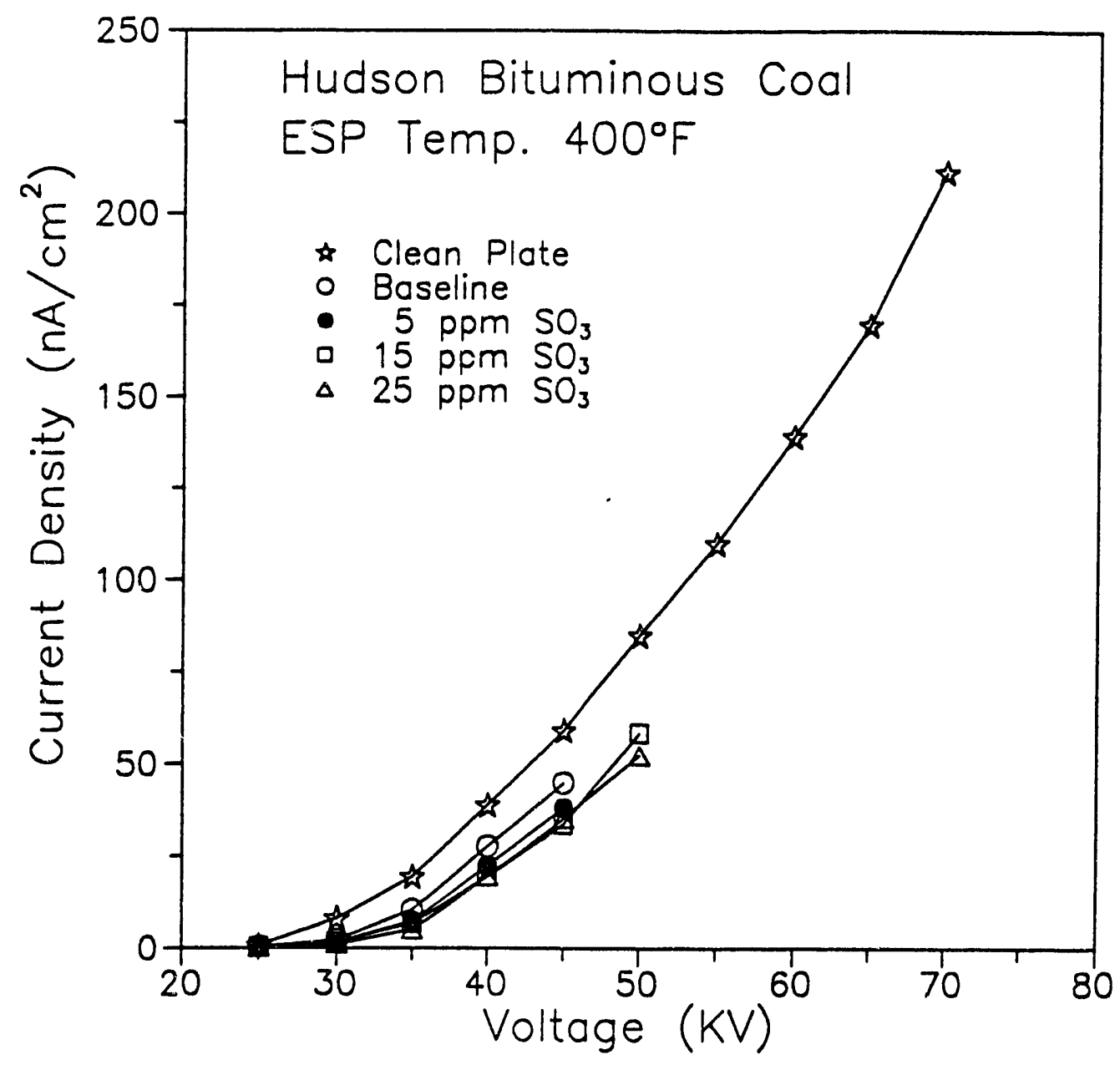

Figure A-3.25. Current-voltage curves for Hudson bituminous coal for Run 357. 


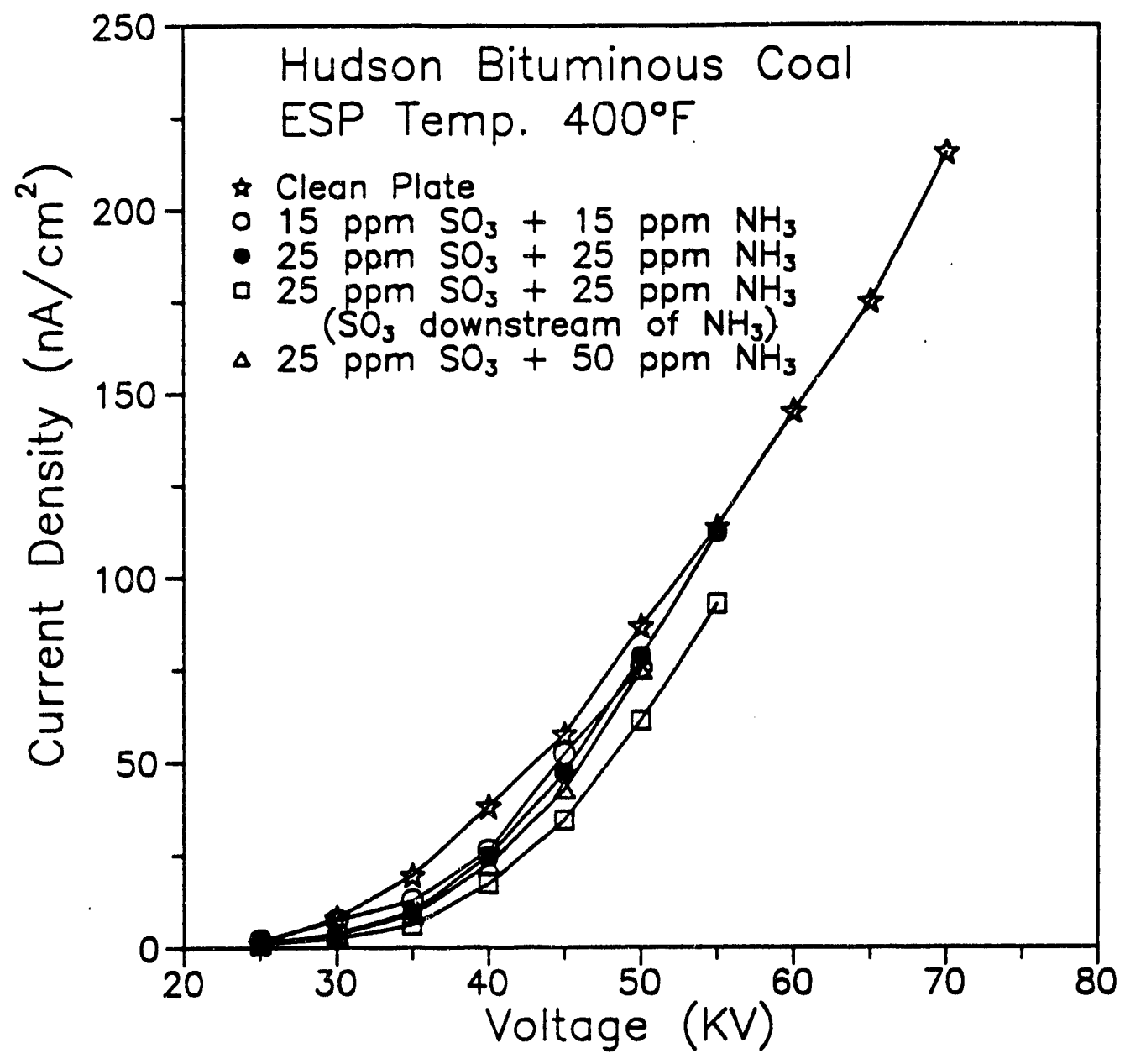

Figure A-3.26. Current-voltage curves for Hudson bituminous coal for Run 358 . 


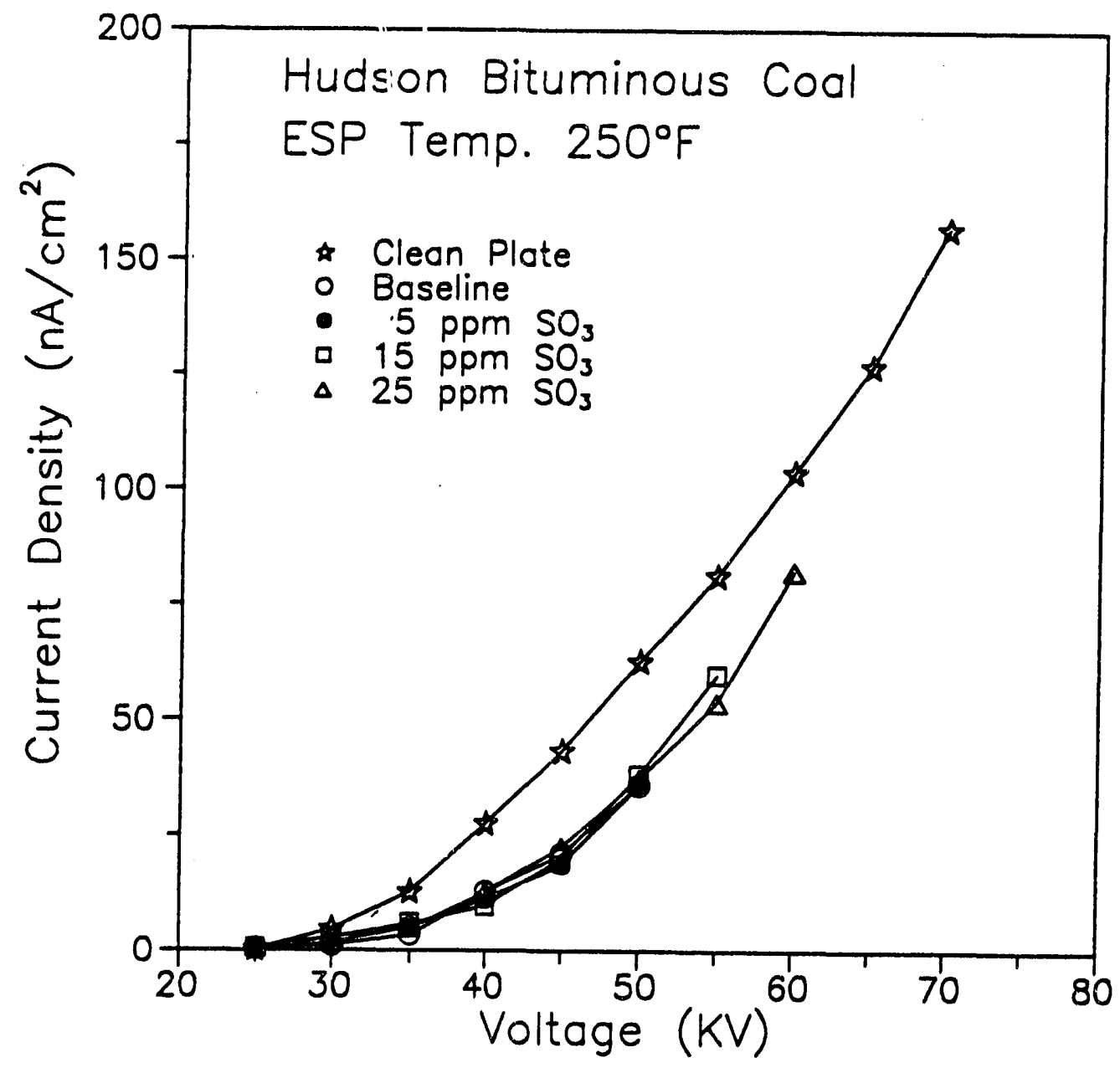

Figure A-3.27. Current-voltage curves for Hudson bituminous coal for Run 359. 


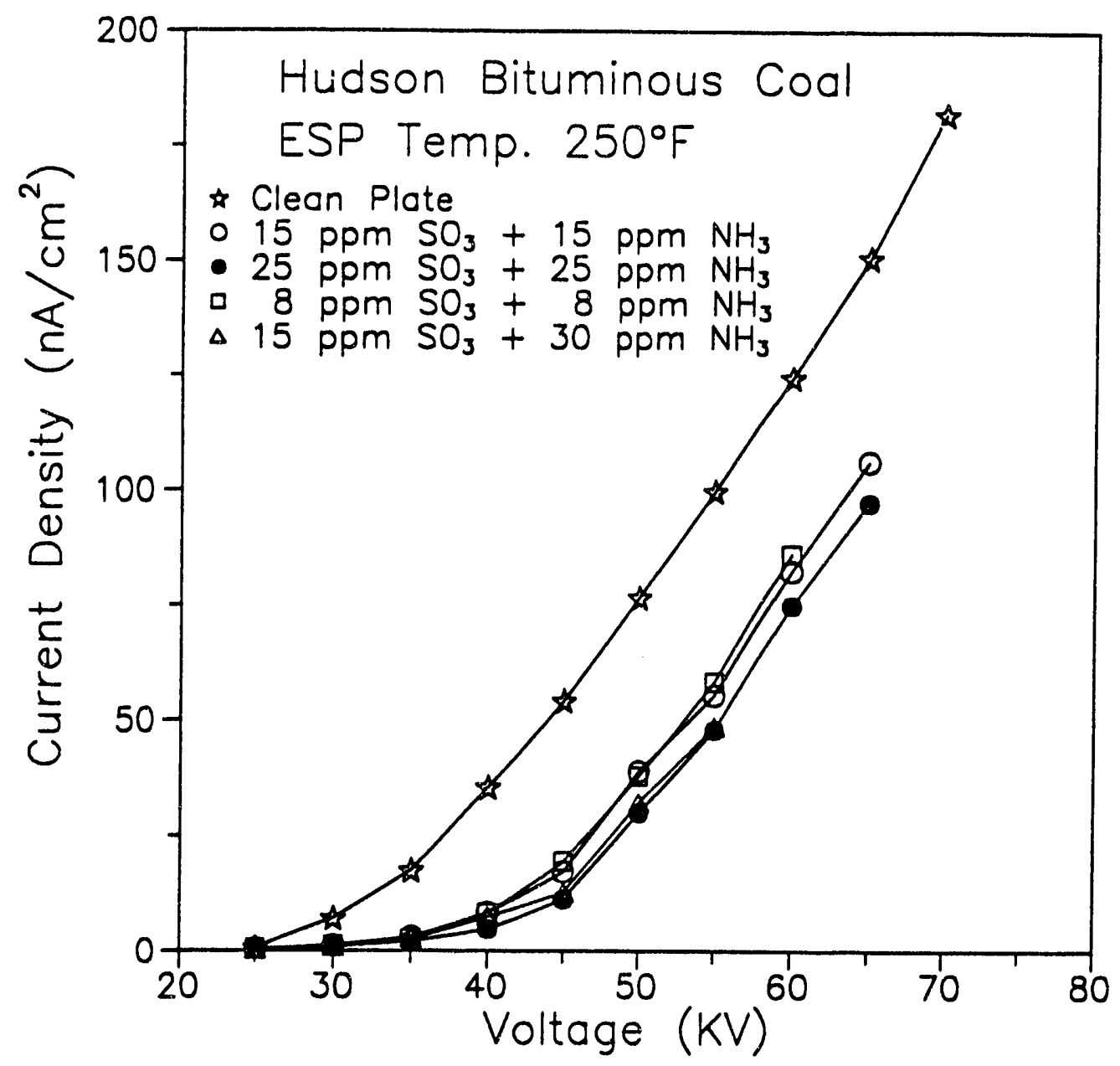

Figure A-3.28. Current-voltage curves for Hudson bituminous coal for Run 360 . 


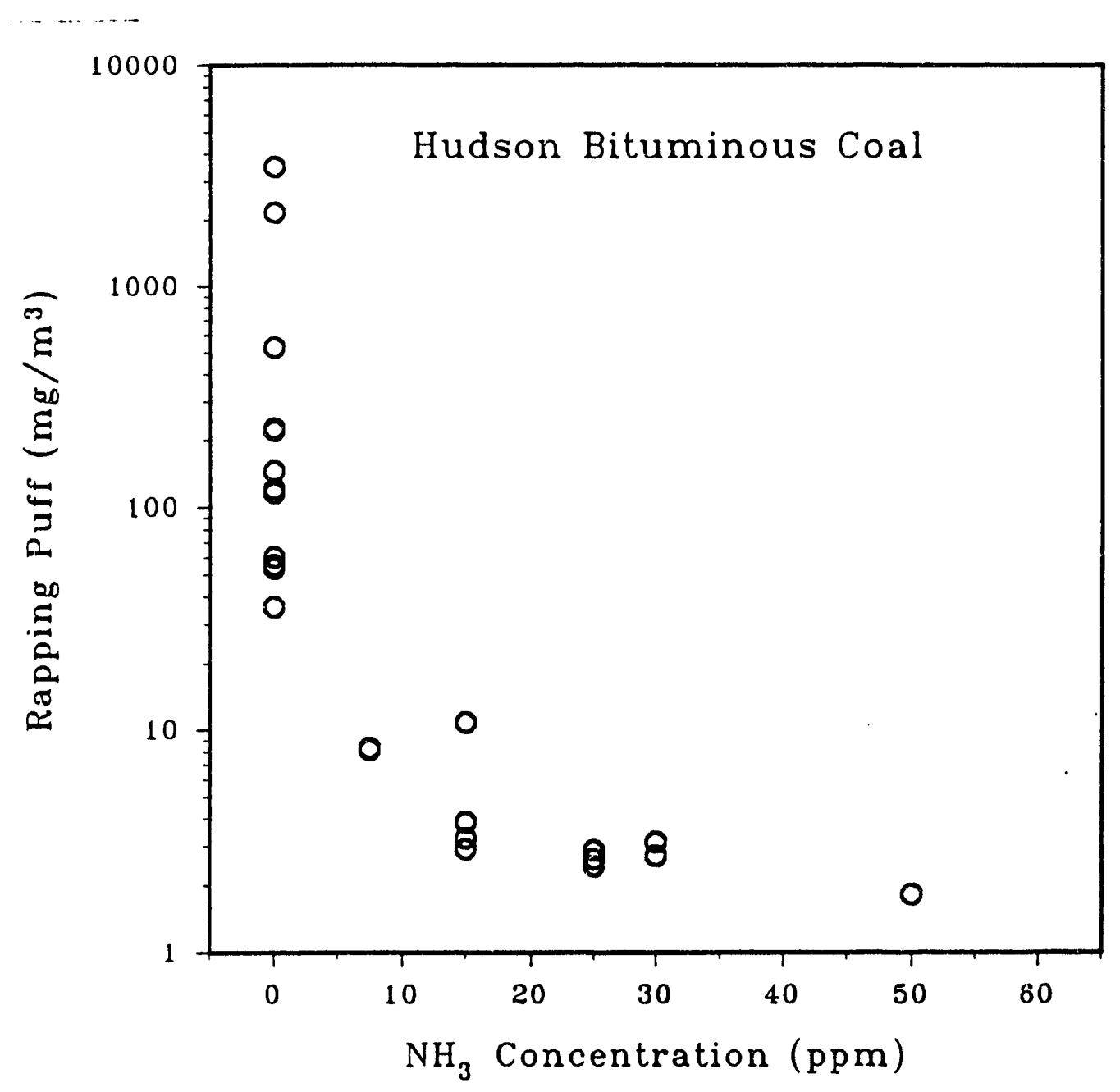

Figure A-3.29. Rapping puff emissions as a function of ammonia concentrations for Hudson bituminous coal for Runs 355-360. 


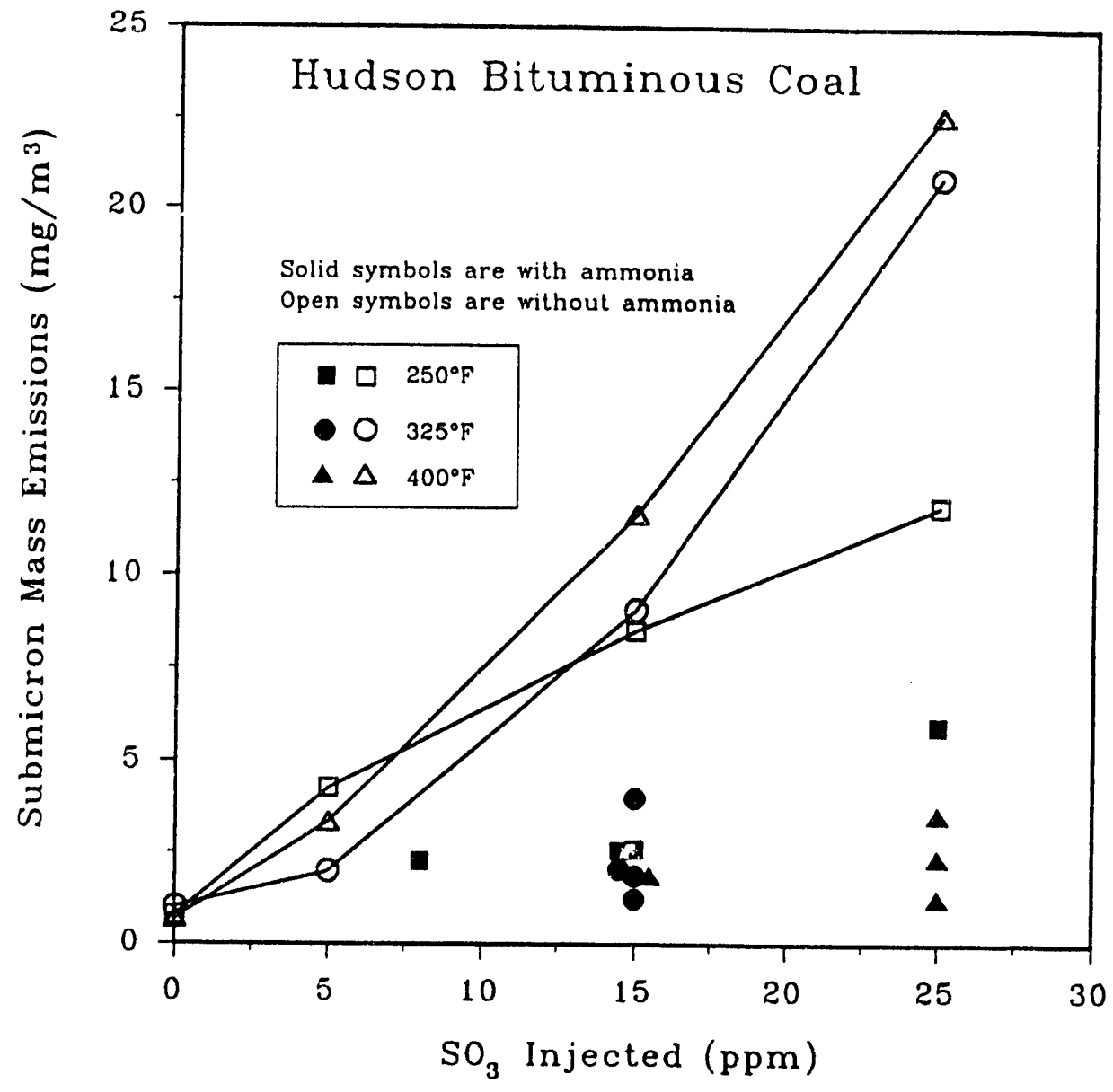

Figure A-3.30. Submicron mass emissions as a function of $\mathrm{SO}_{3}$ concentration with and without ammonia for Hudson bituminous coal for Runs $355-360$. 


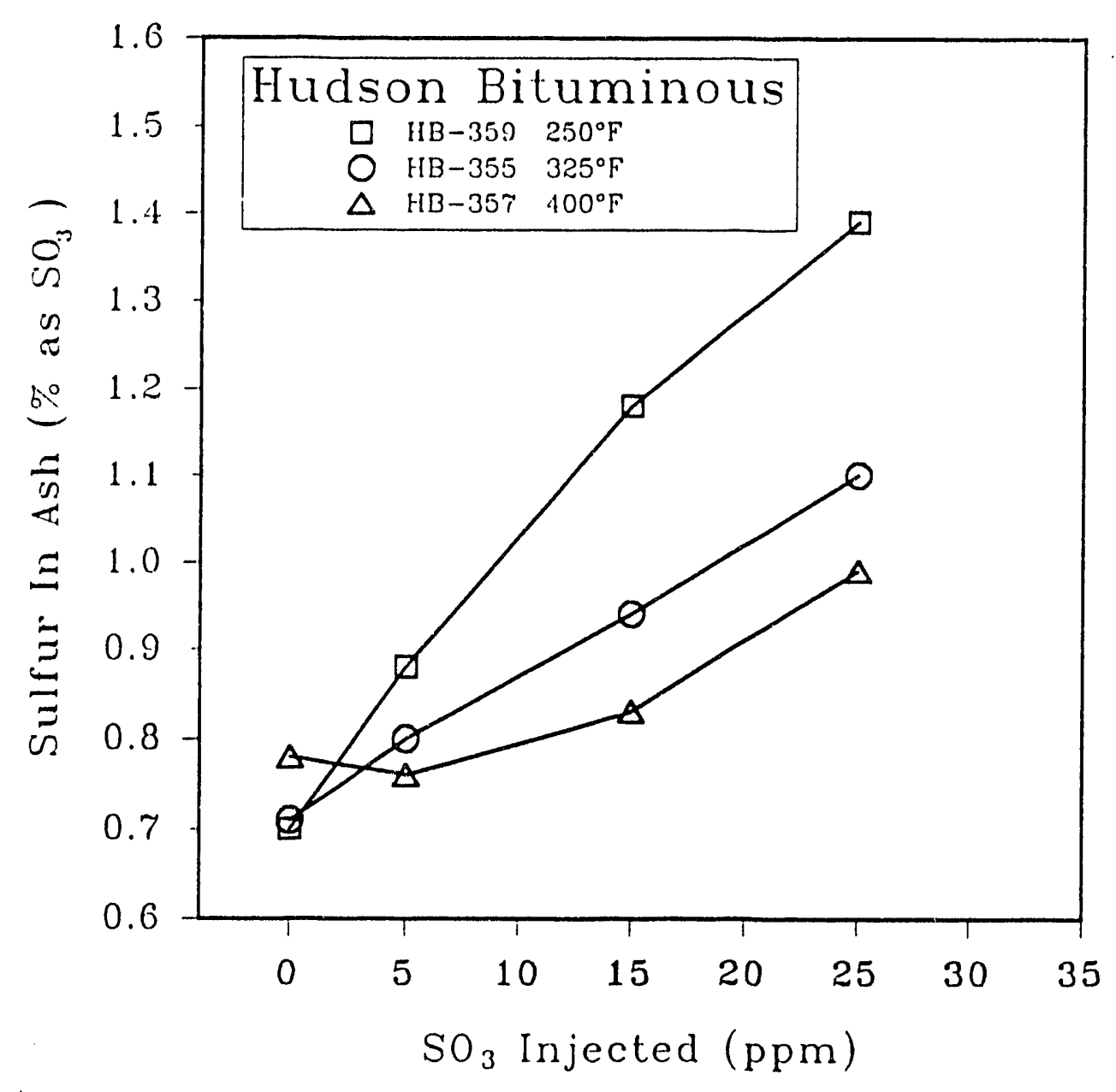

Figure A-3.31. Sulfur retention as a function of $\mathrm{SO}_{3}$ concentration for Hudson bituminous coal for Runs 355, 357, and 359 . 


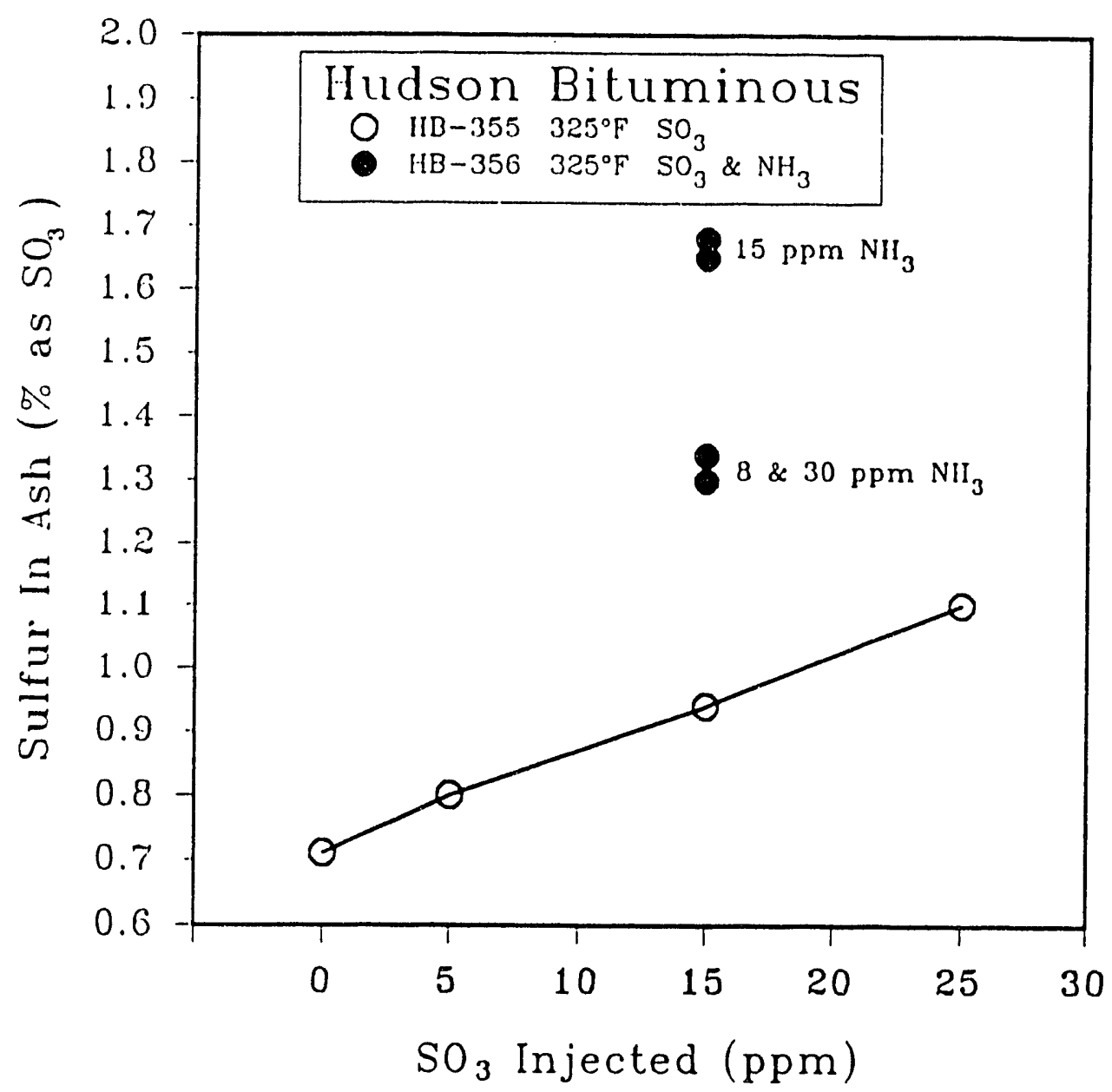

Figure A-3.32. Sulfur retention as a function of $\mathrm{SO}_{3}$ concentration and dual conditioning at $325^{\circ} \mathrm{F}$ for Hudson bituminous coal for Runs 355 and 356 . 


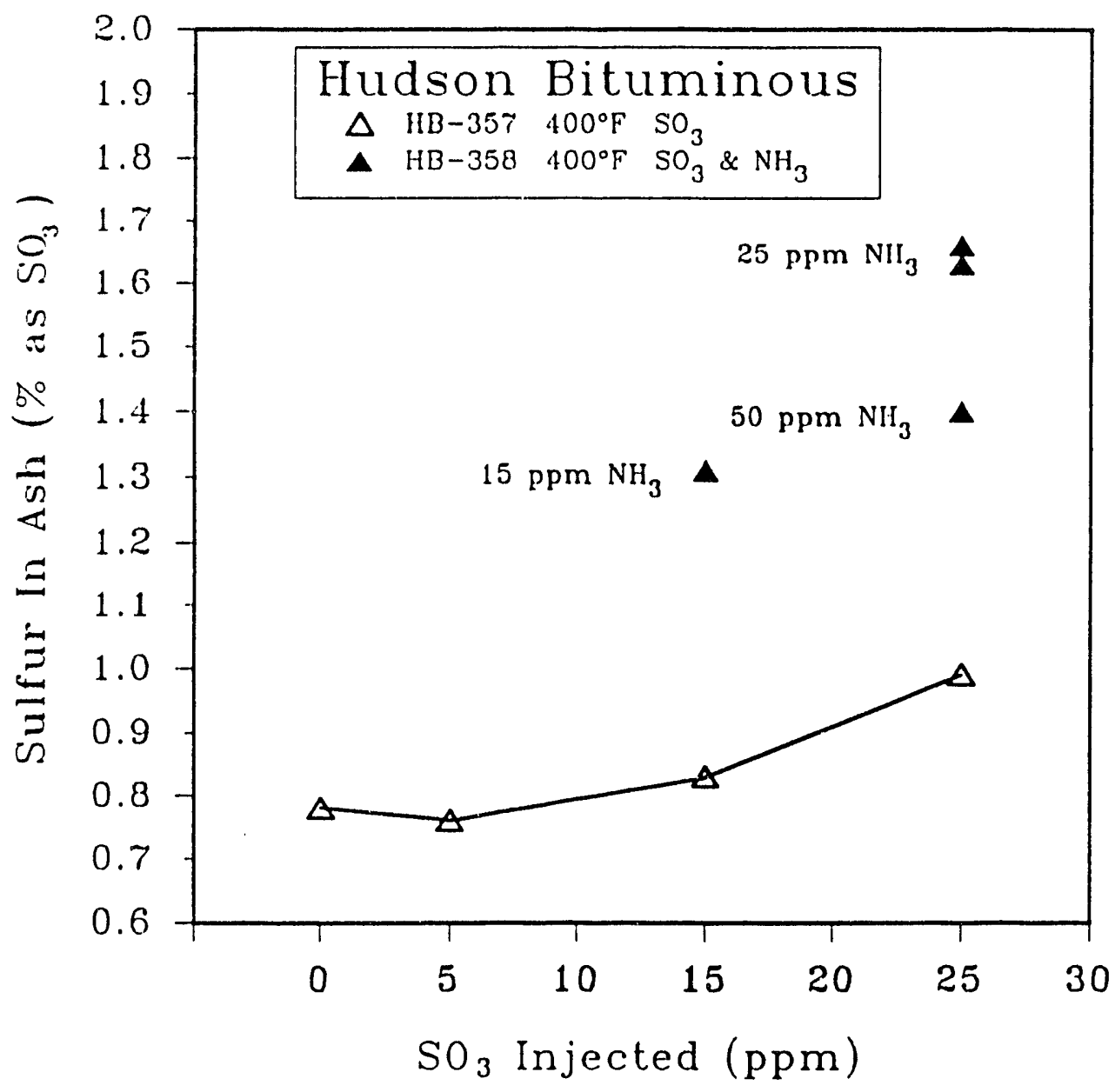

Figure A-3.33. Sulfur retention as a function of $\mathrm{SO}_{3}$ concentration and dual conditioning at $400^{\circ} \mathrm{F}$ for Hudson bituminous coal for Runs 357 and 358 . 


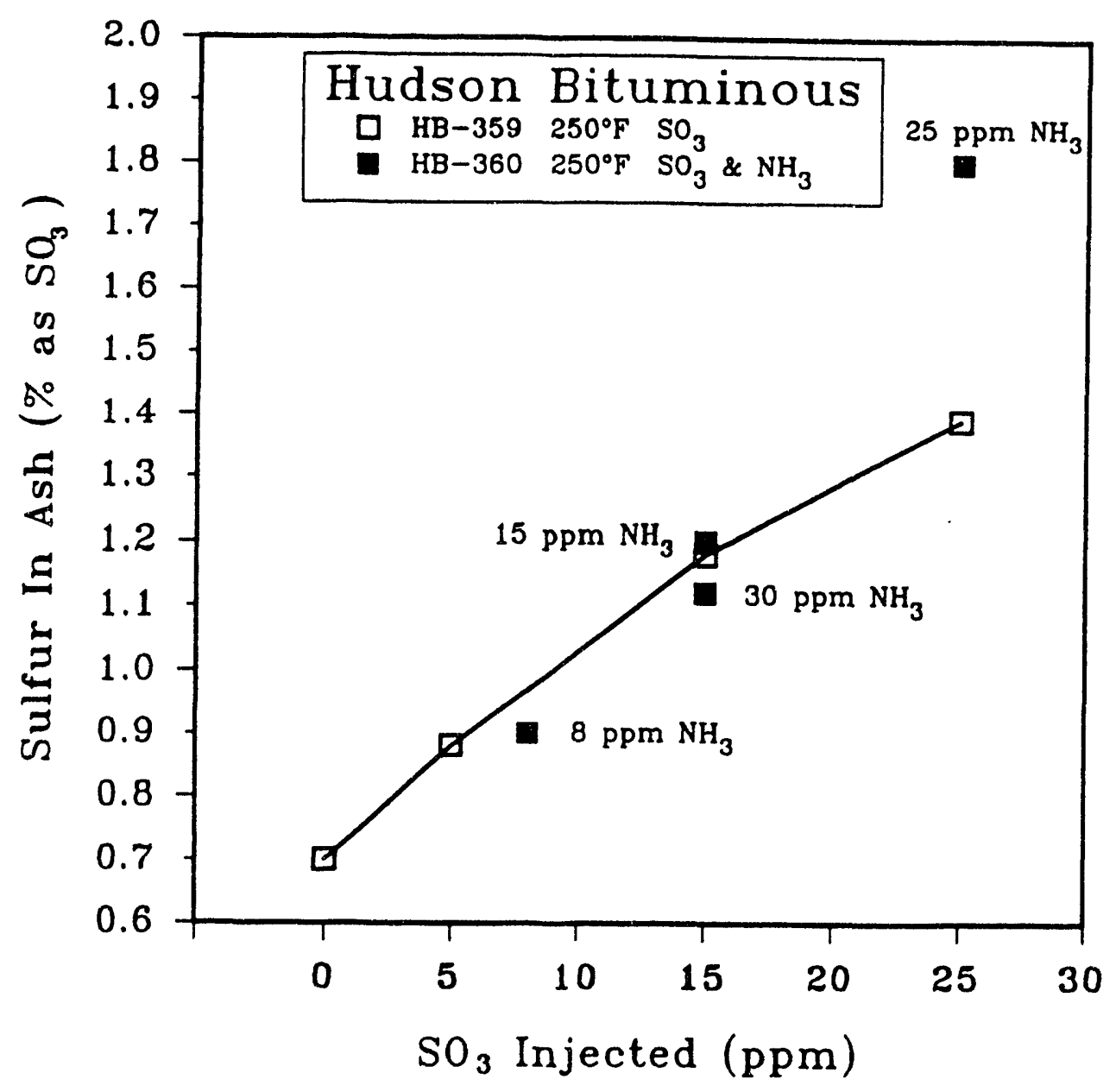

Figure A-3.34. Sulfur ratention as a function of $\mathrm{SO}_{3}$ concentration and dual conditioning at $250^{\circ} \mathrm{F}$ for Hudson bituminous coal for Runs 359 and 360 . 

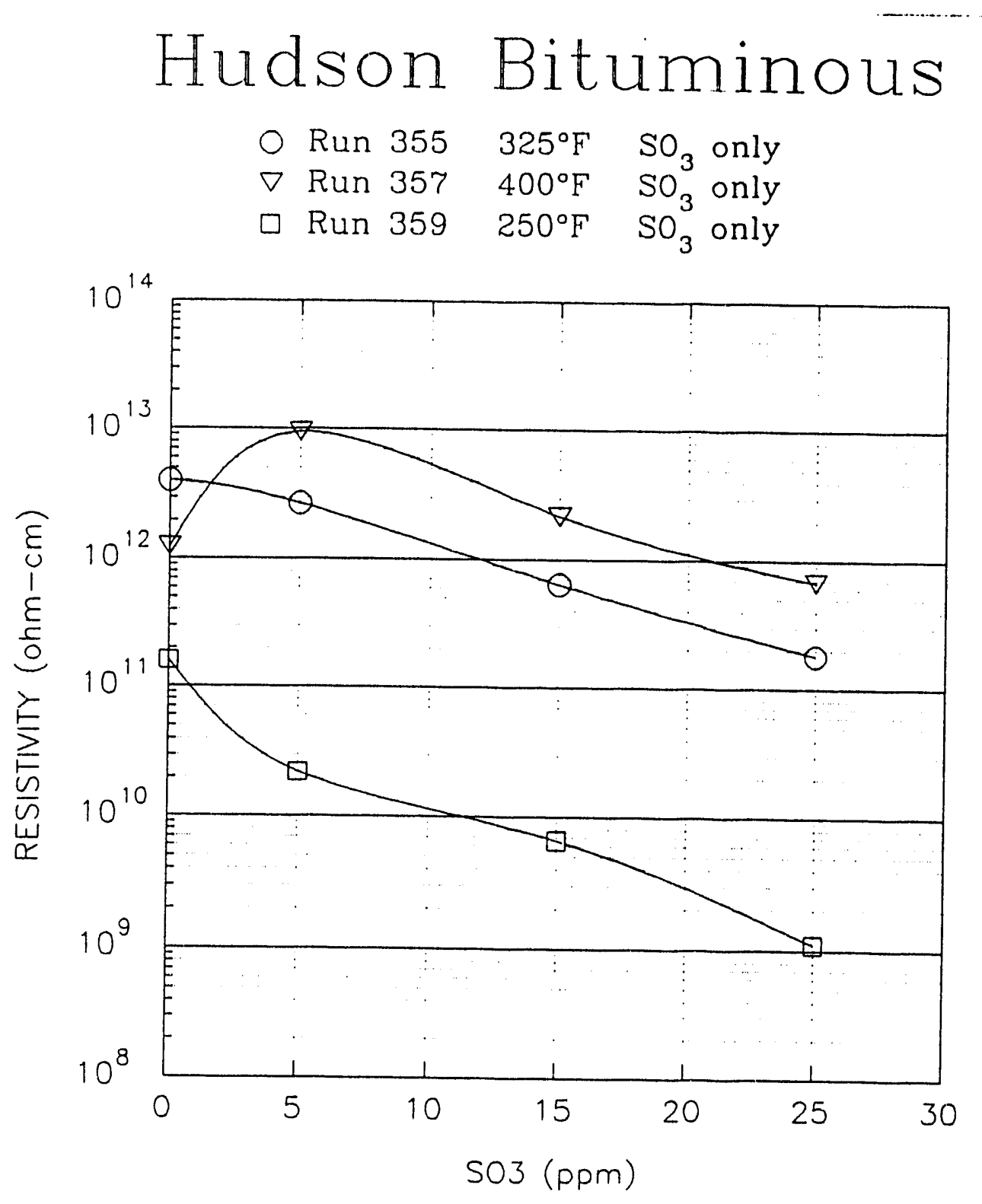

Figure A-3.35. Resistivity as a function of $\mathrm{SO}_{3}$ concentration for Hudson bituminous coal for Runs 355, 357, and 359. 


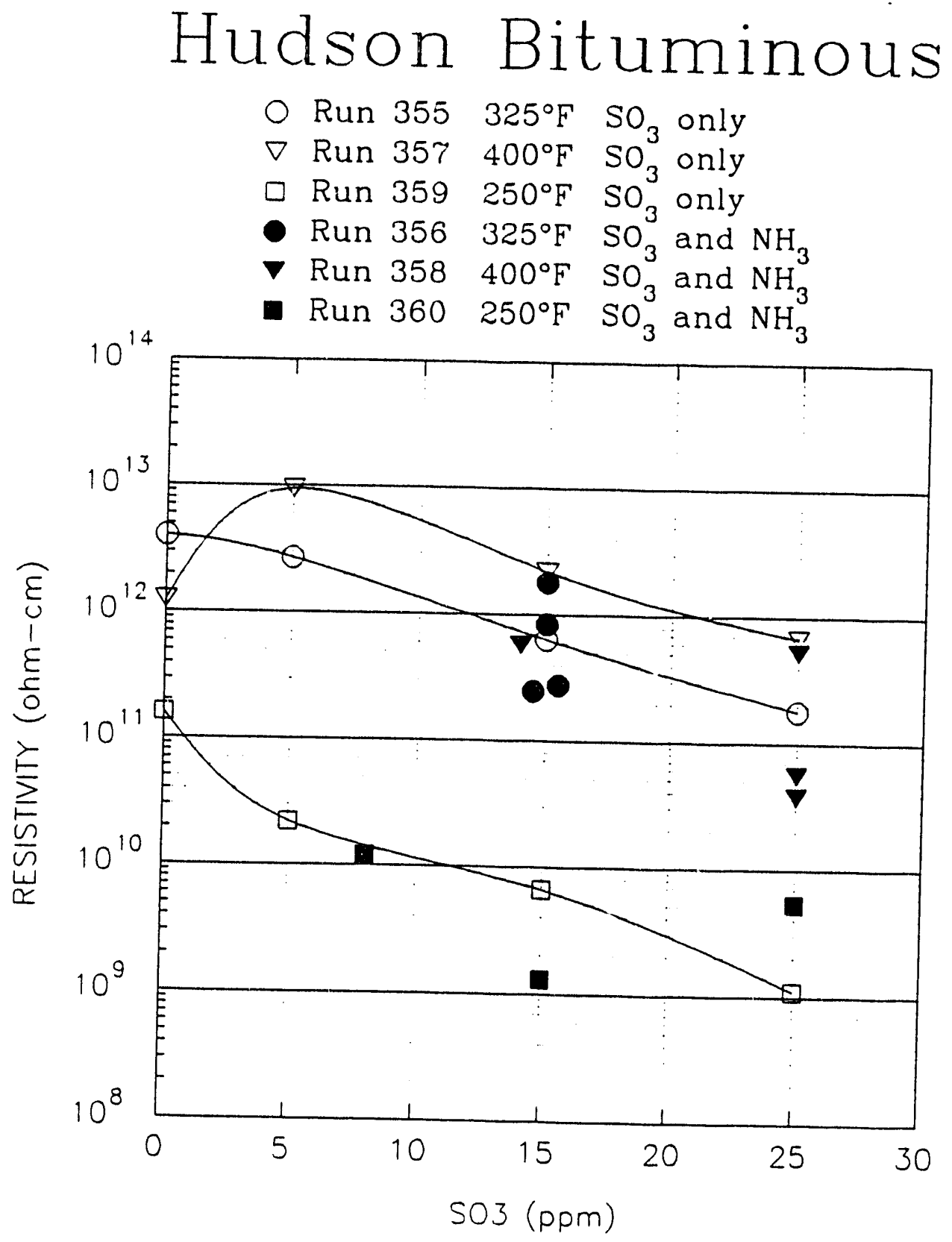

Figure A-3.36. Resistivity as a function of $\mathrm{SO}_{3}$ and ammonia concentration for Hudson bituminous coal for Runs 355-360. 
HUDSON BITUMINUUS $325^{\circ} \mathrm{F}$

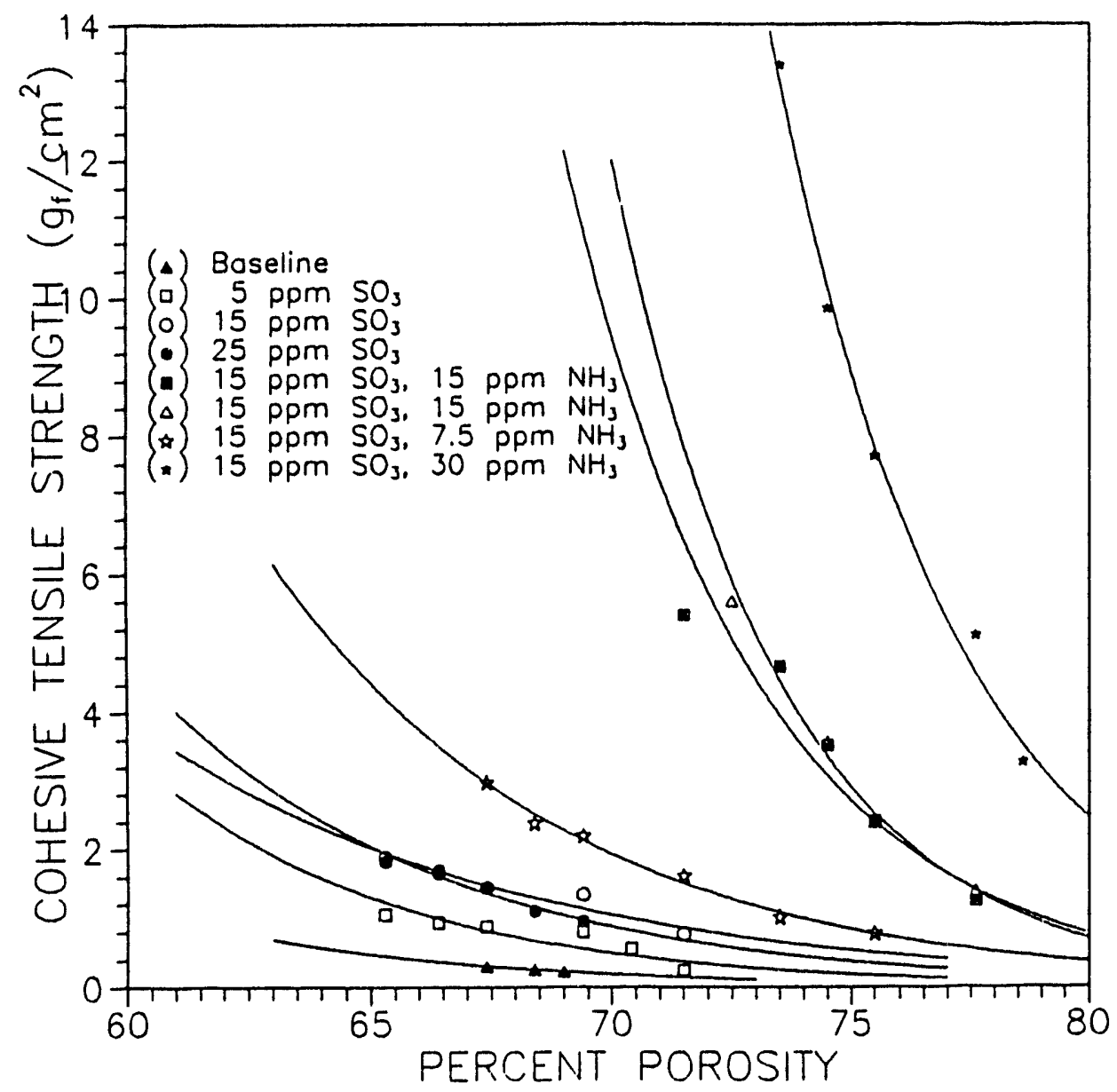

Figure A-3.37. Fly ash tensile strength as a function of ash porosity with $\mathrm{SO}_{3}$ alone and with dual conditioning at $325^{\circ} \mathrm{F}$ for Hudson bituminous coal for Runs 355 and 356. 


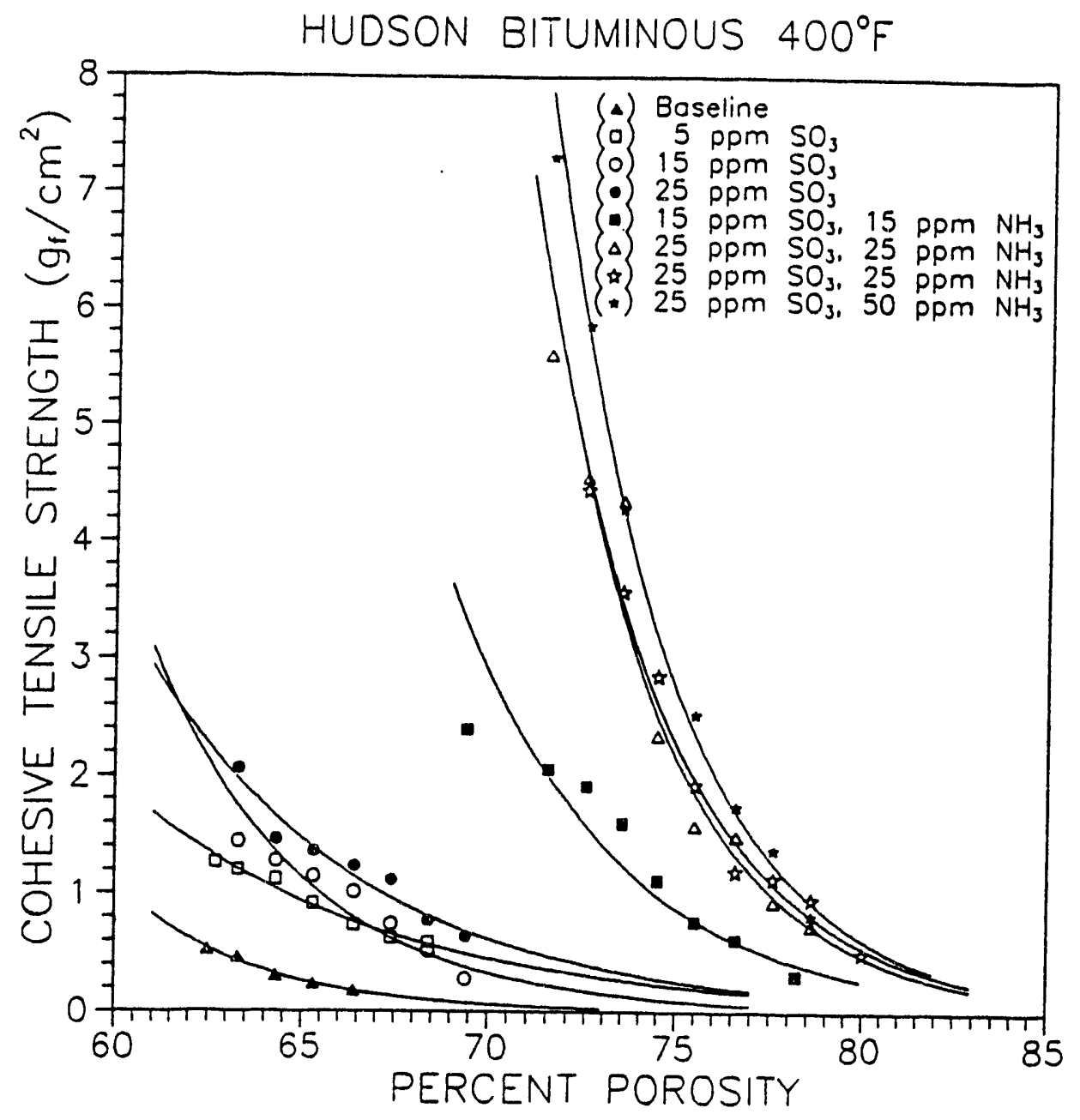

Figure A-3.38. Fly ash tensile strength as a function of ash porosity with $\mathrm{SO}_{3}$ alone and with dual conditioning at $400^{\circ} \mathrm{F}$ for Hudson bituminous coal for Runs 357 and 358. 


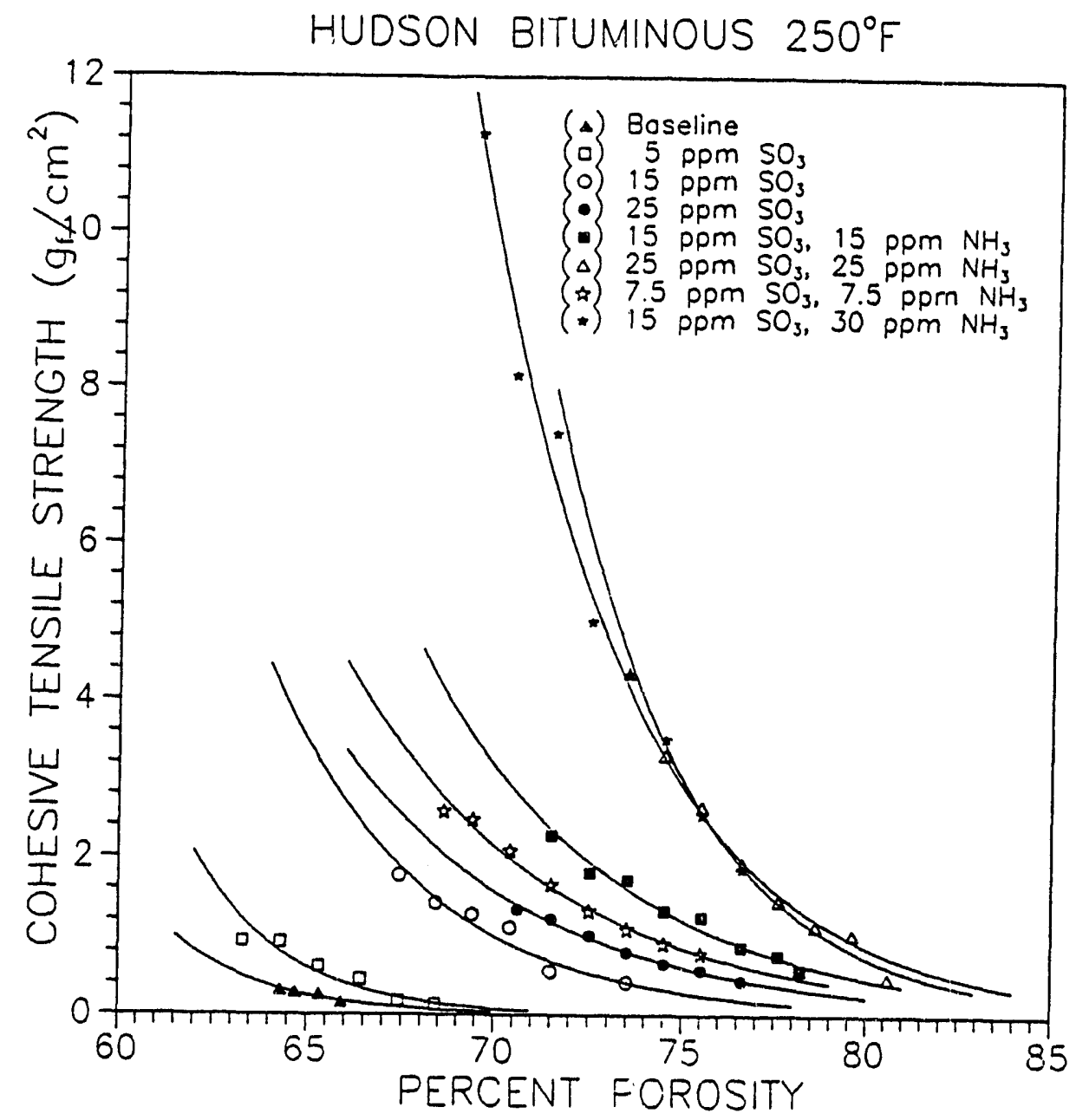

Figure A-3.39. Fly ash tensile strength as a function of ash porosity with $\mathrm{SO}_{3}$ alone and with dual conditioning at $250^{\circ} \mathrm{F}$ for Hudson bituminous coal for Runs 359 and 360 . 


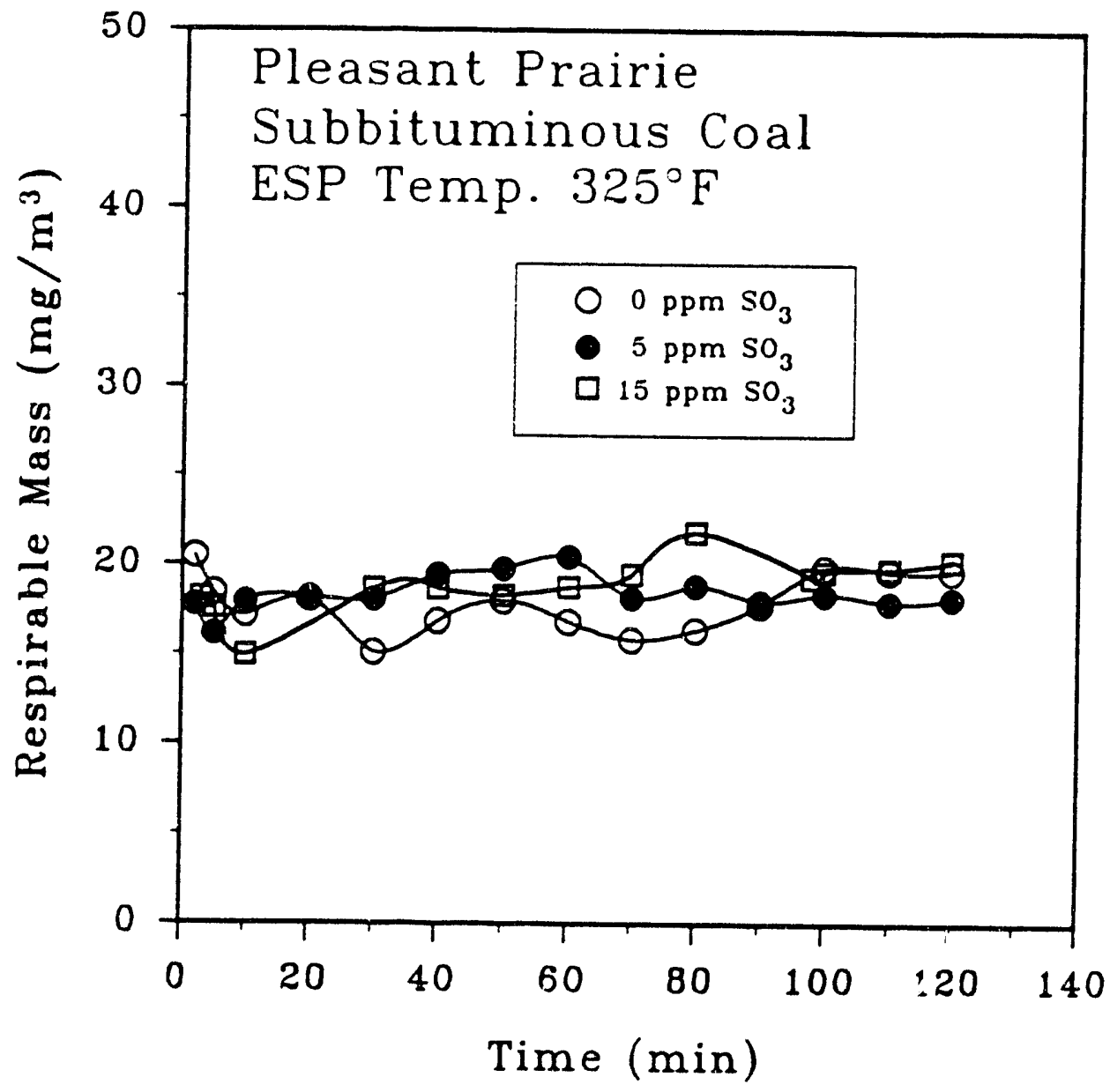

Figure A-4.1. Respirable mass emissions as a function of time for Pleasant Prairie coal for Run 361 . 


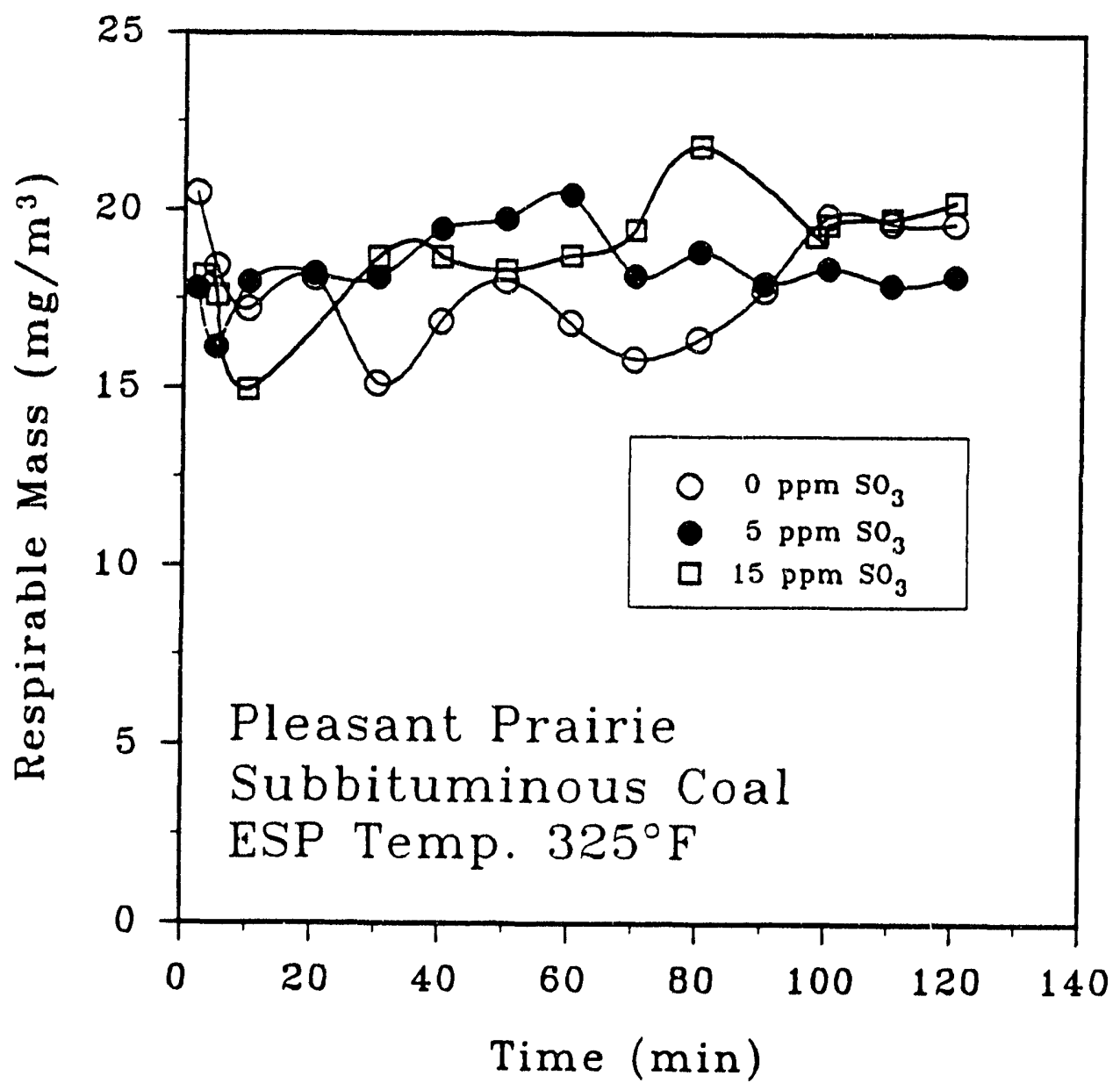

Figure A-4.2. Respirable mass emissions as a function of time (expanded scale) for Pleasant Prairie coal for Run 361. 


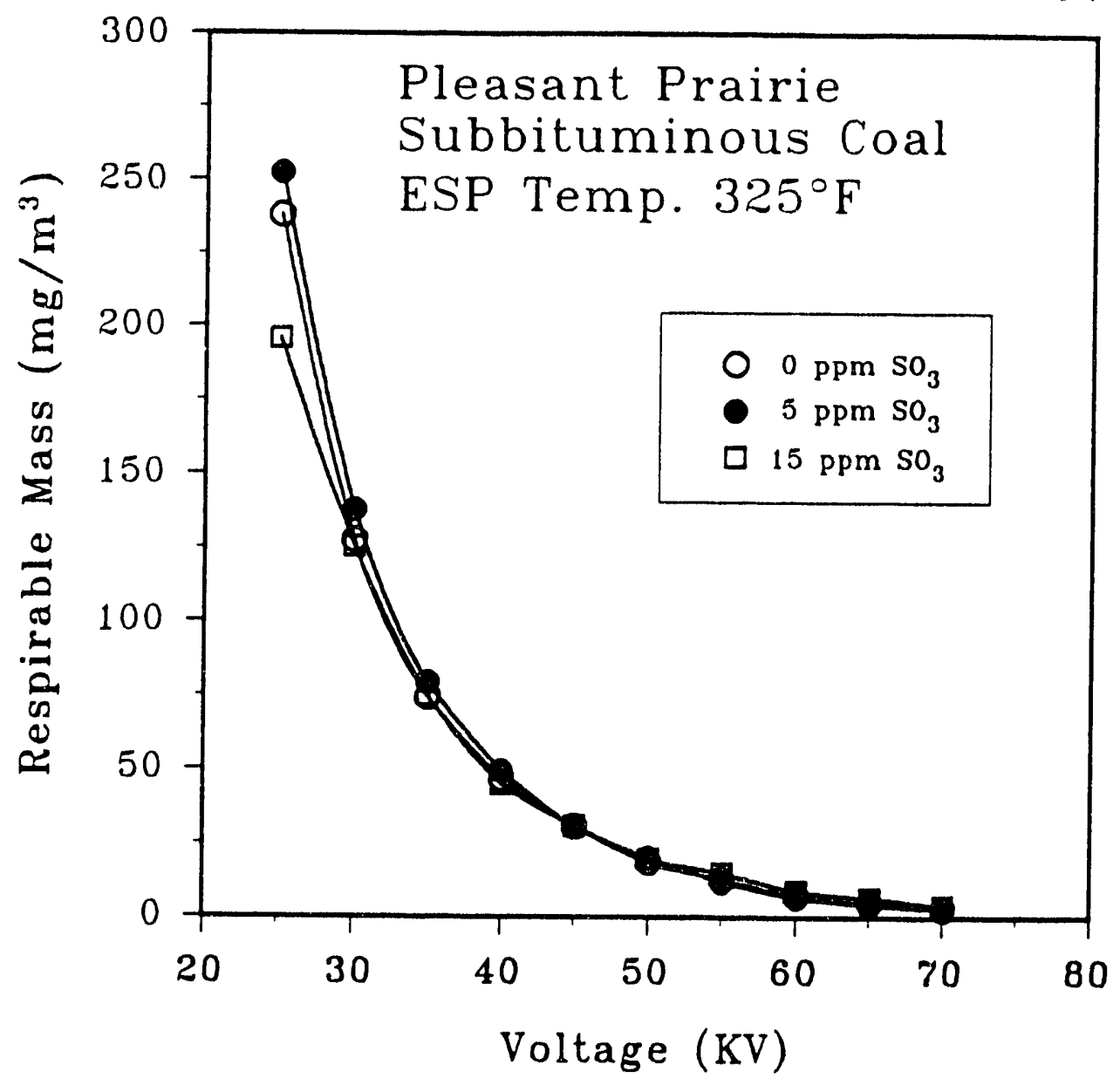

Figure A-4.3. Respirable mass emissions as a function of voltage for Pleasant Prairie coal for Run 361. 


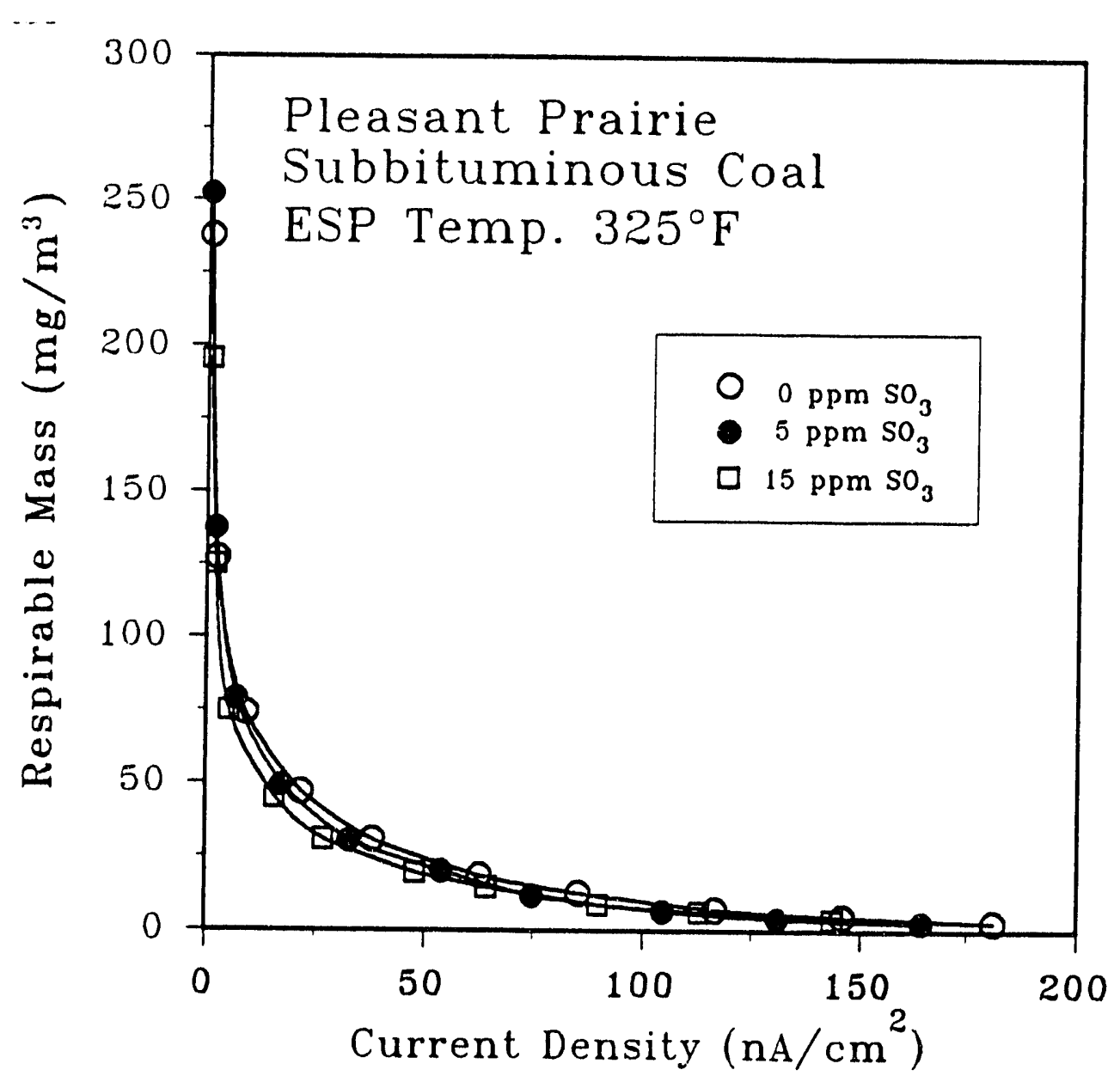

Figure A-4.4. Respirable mass emissions as a function of current density for Pleasant Prairie coal for Run 361. 


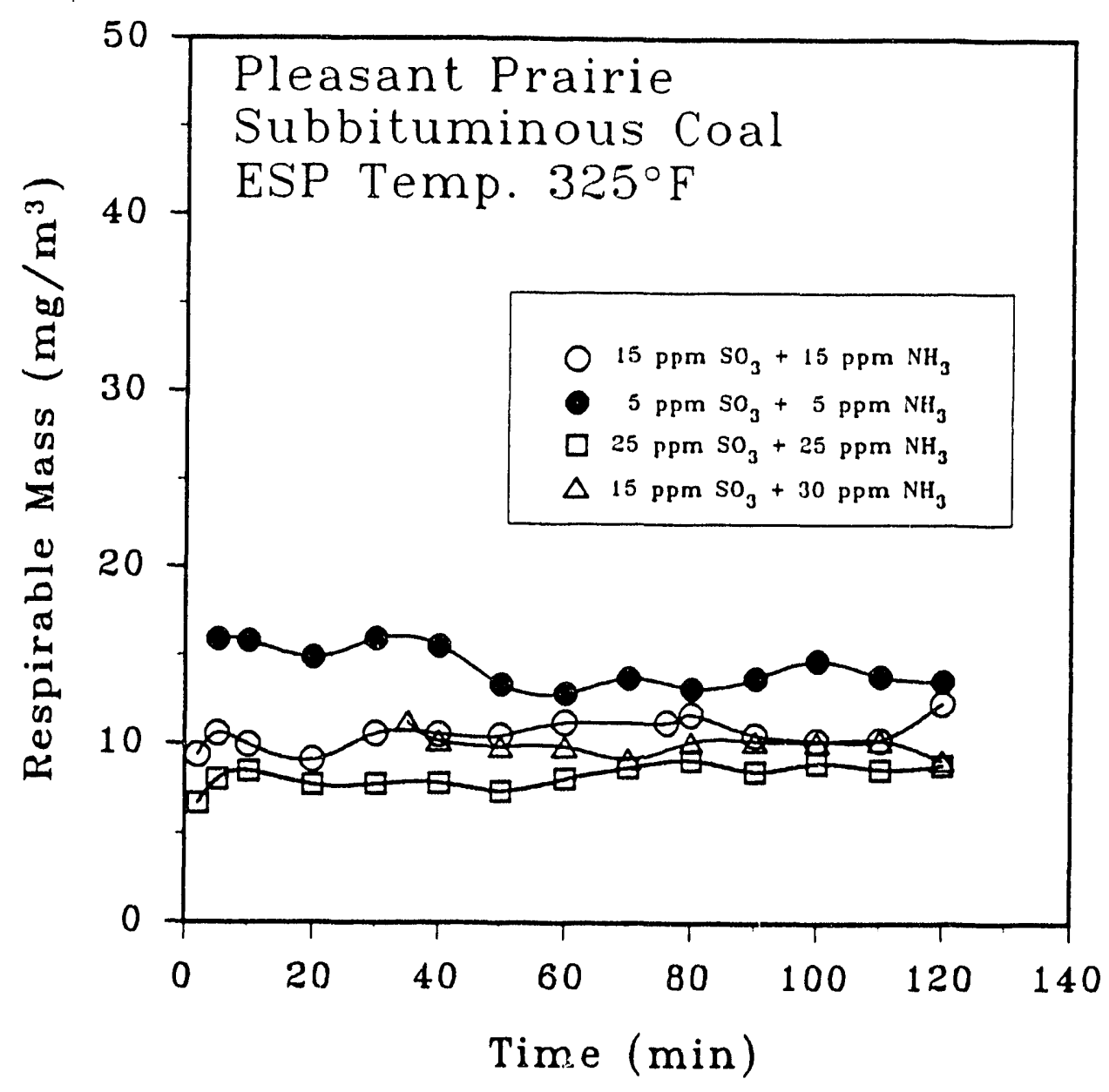

Figure A-4.5. Respirable mass emissions as a function of time for Pleasant Prairie coal for Run 362. 


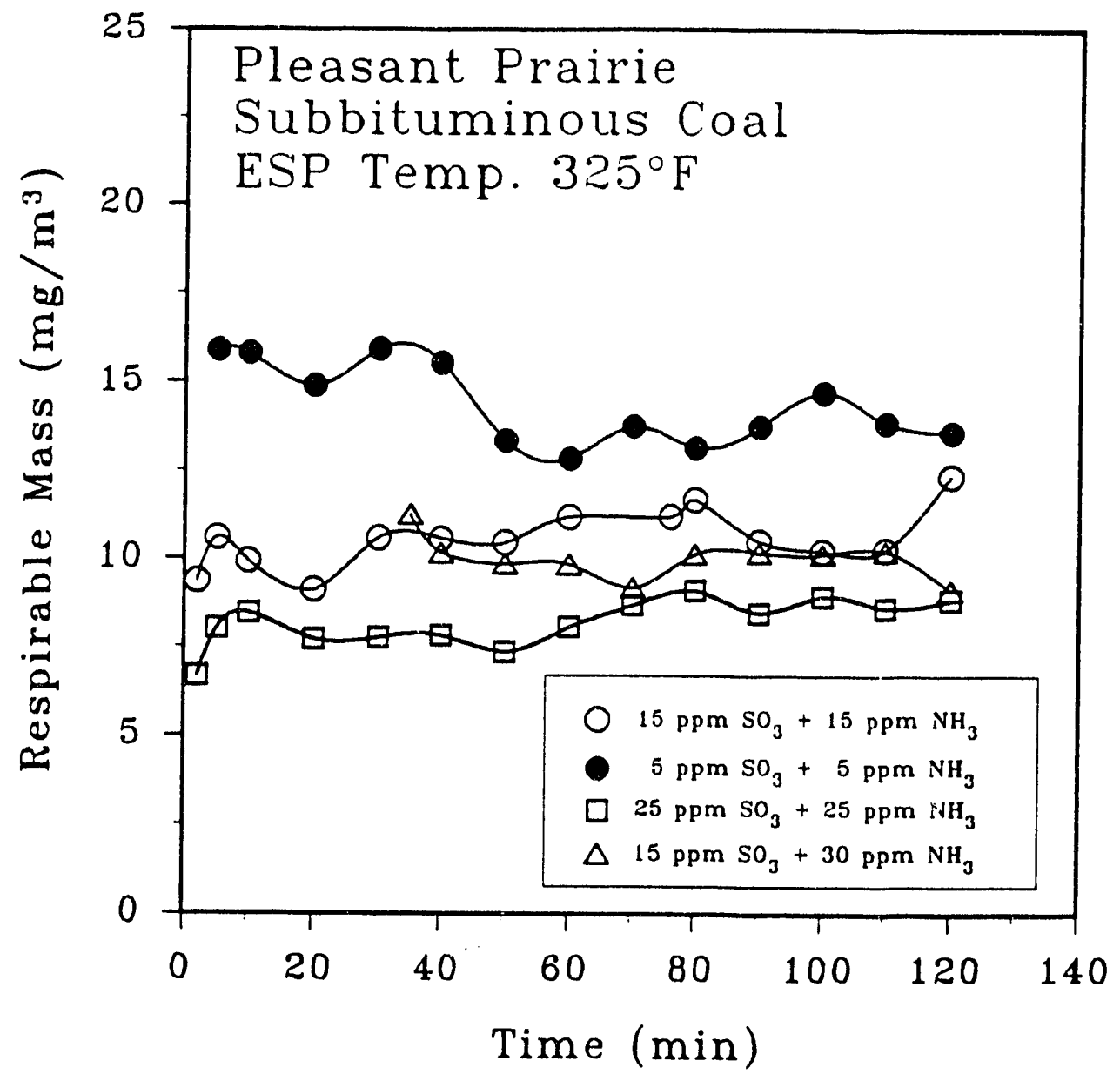

Figure A-4.6. Respirable mass emissions as a function of time (expanded scale) for Pleasant Prairie coal for Run 362. 


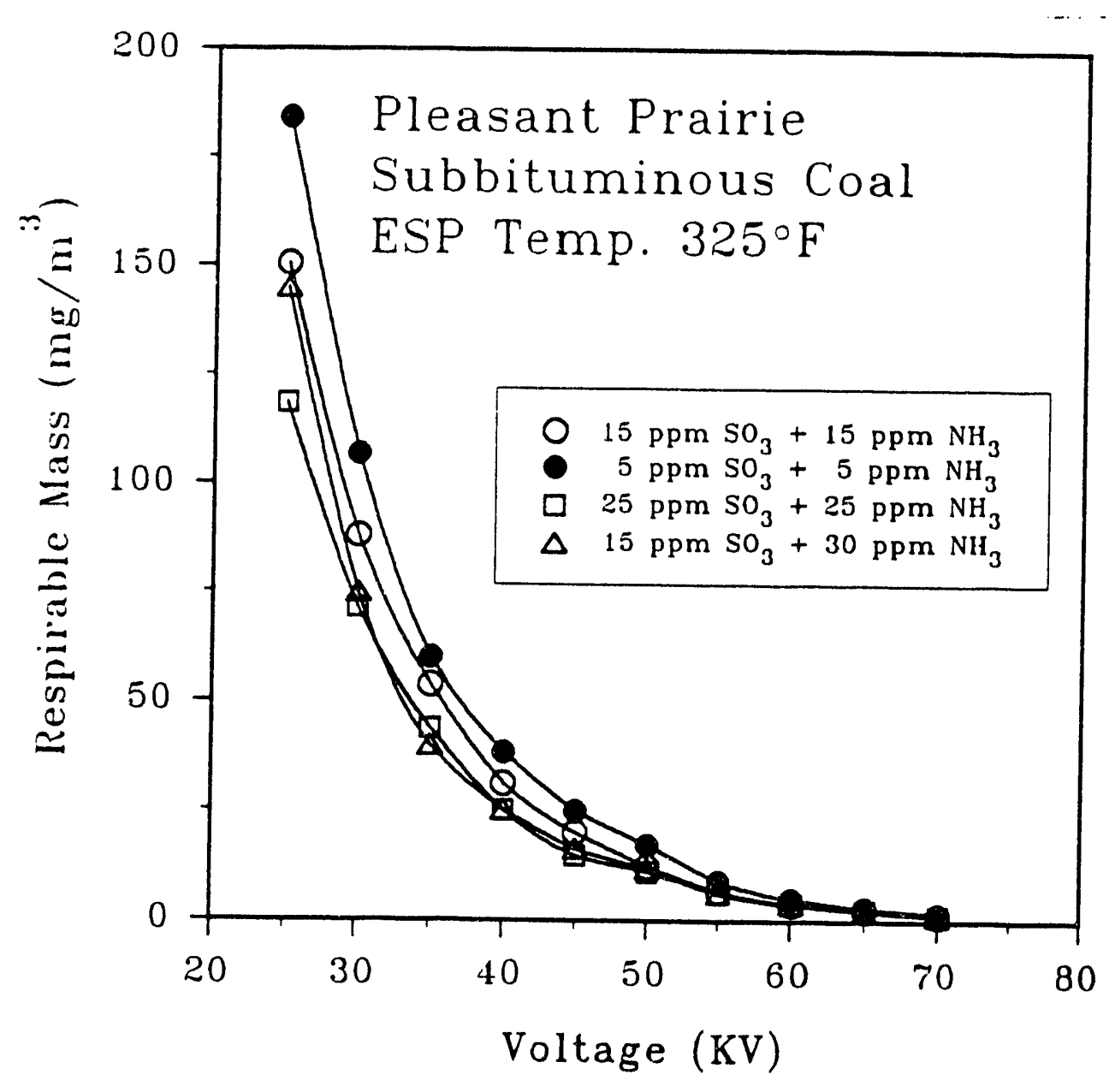

Figure A-4.7. Respirable mass emissions as a function of voltage for Pleasant Prairie coal for Run 362. 


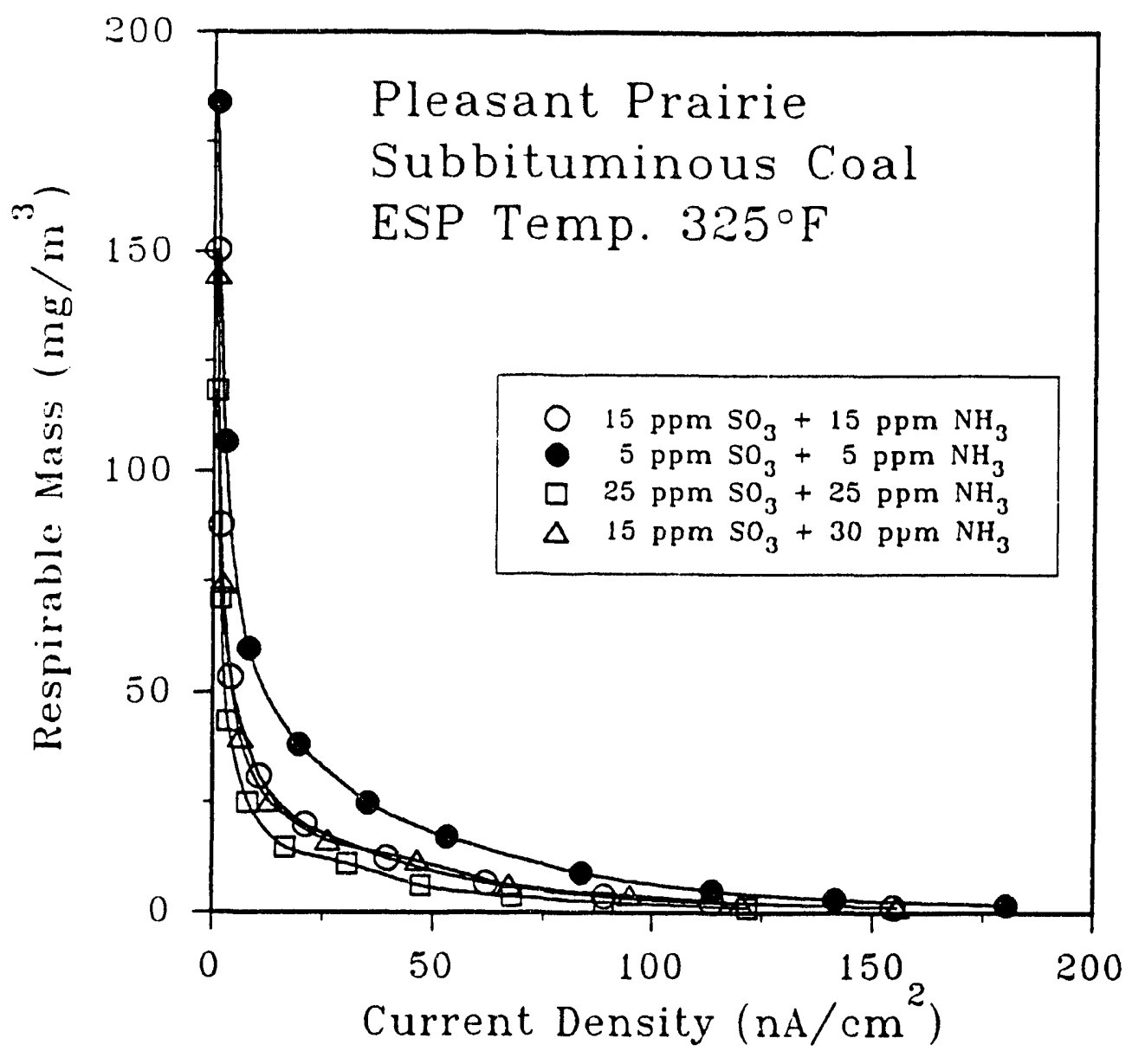

Figure A-4.8. Respirable mass emissions as a function of current density for Pleasant Prairie coal for Run 362. 


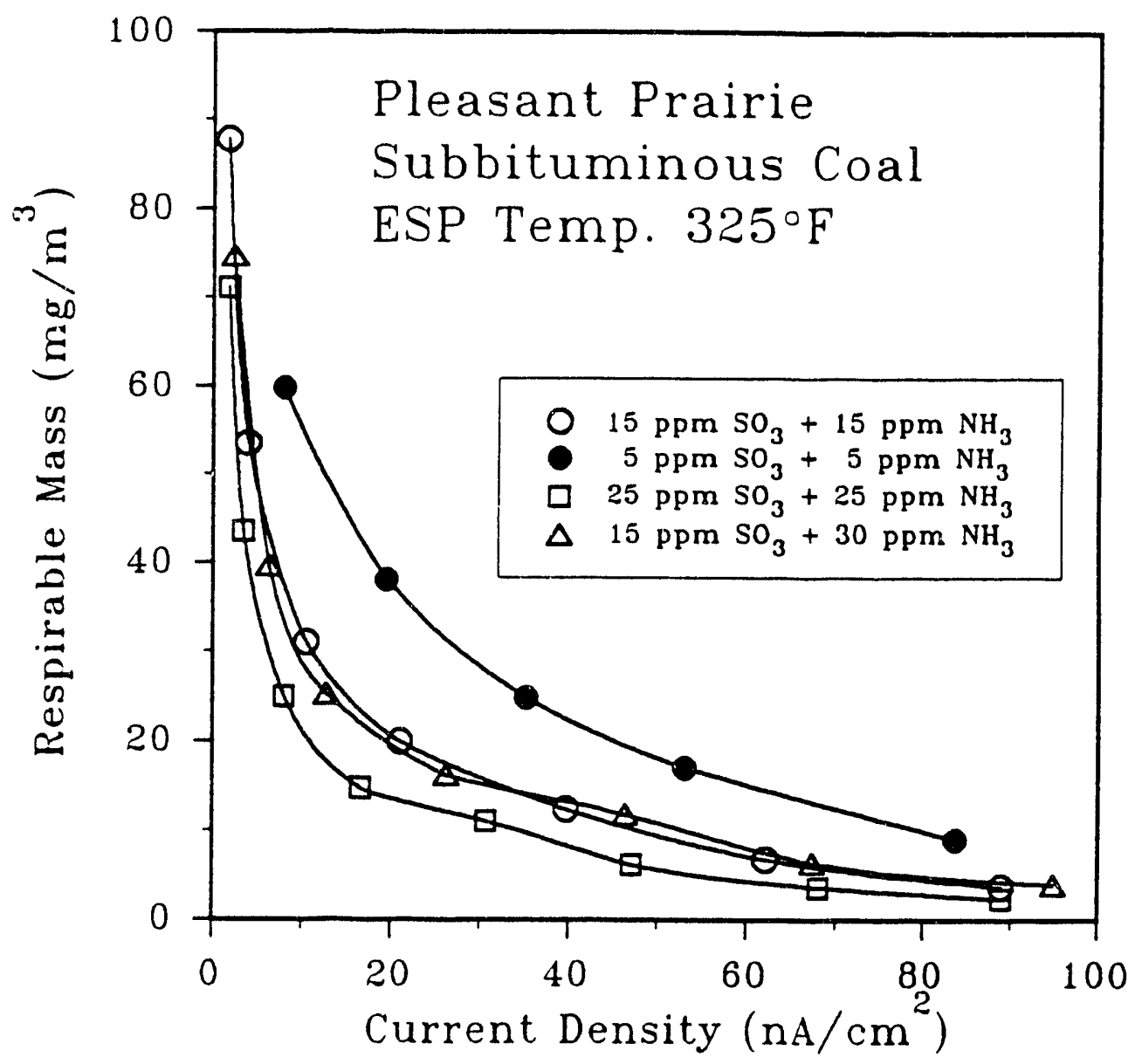

Figure A-4.9. Respirable mass emissions as a function of current density (expanded scale) for Pleasant Prairie coal for Run 362. 


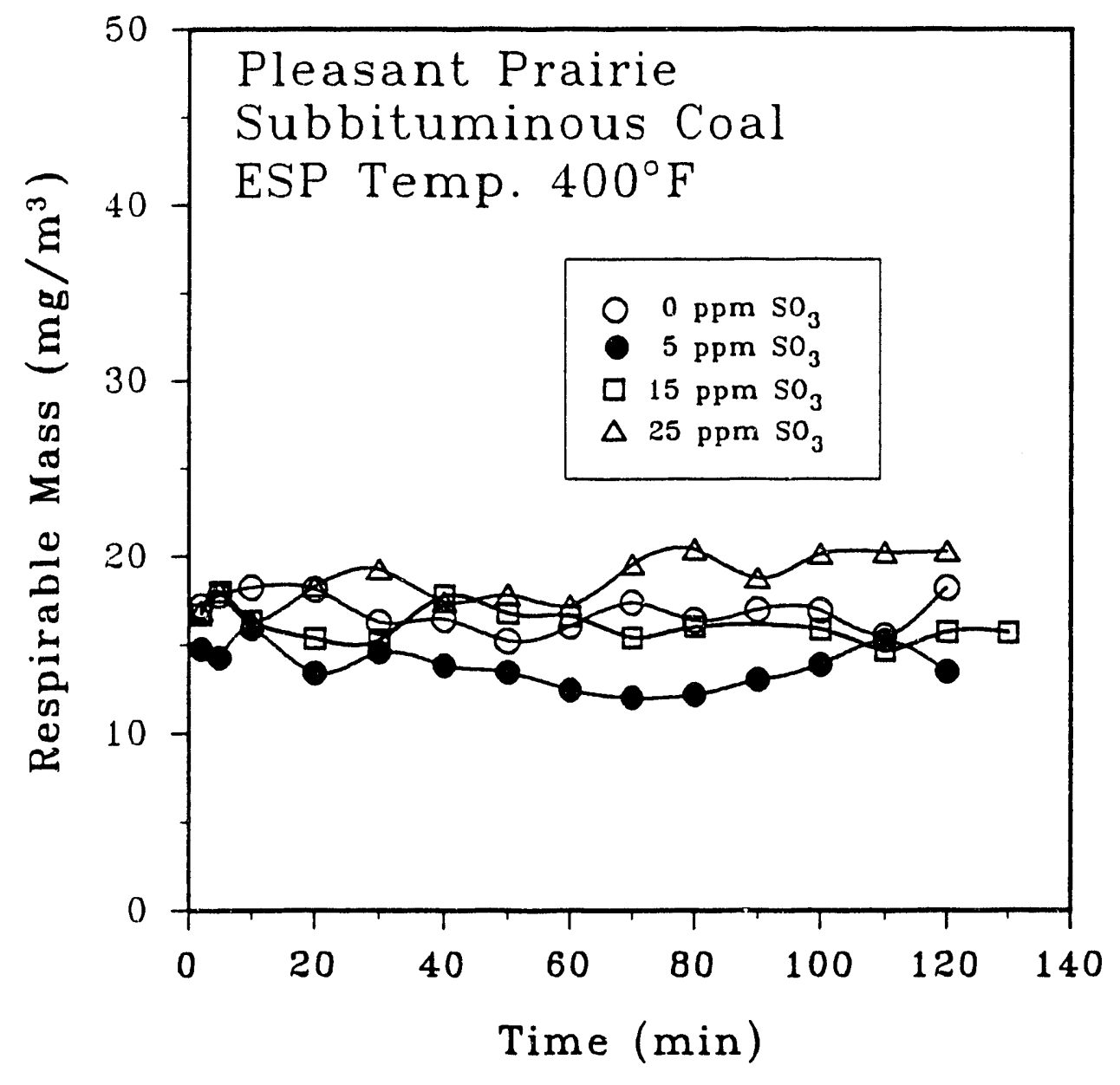

Figure A-4.10. Respirable mass emissions as a function of time for Pleasant Prairie coal for Run 363. 


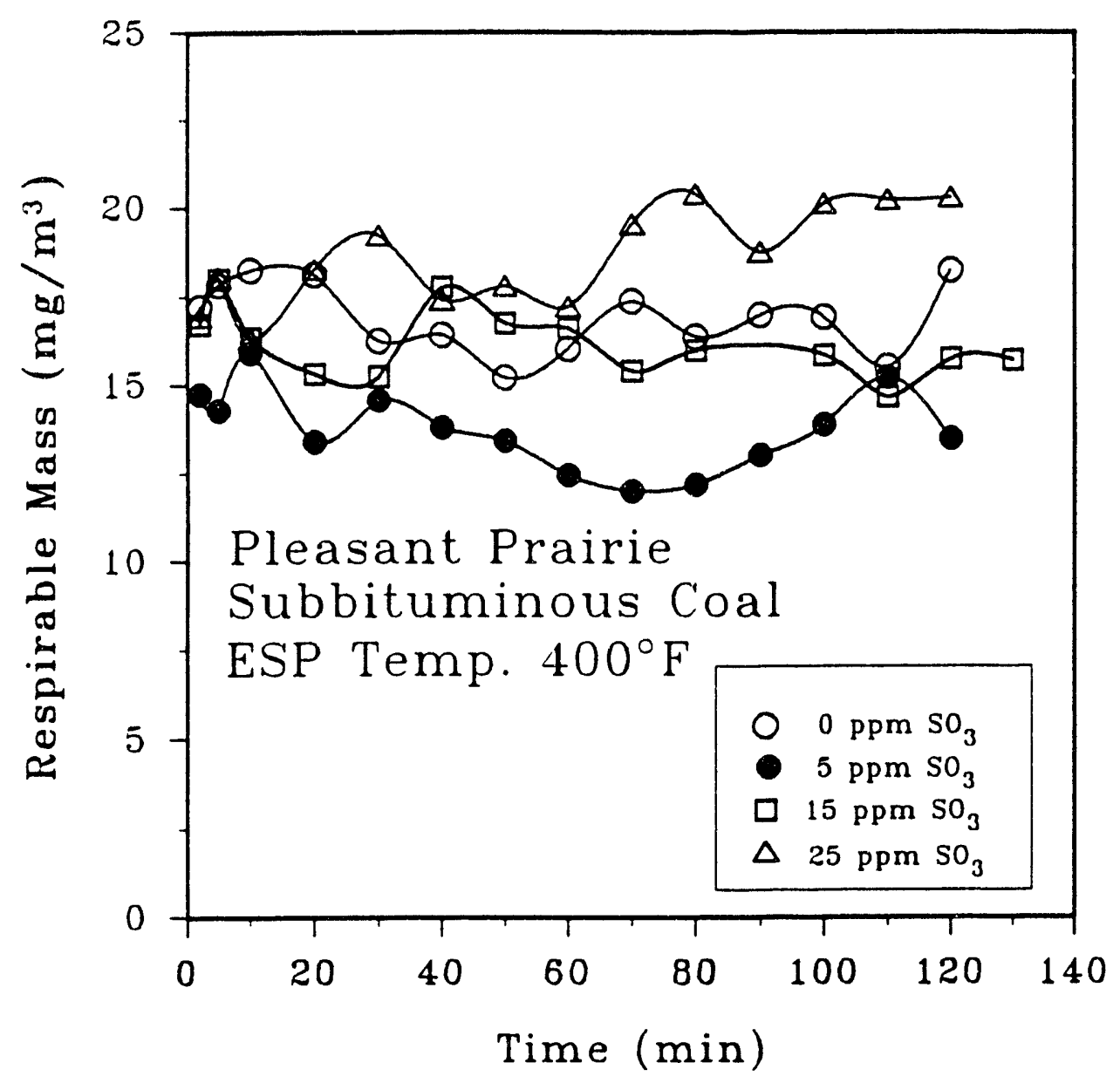

Figure A-4.11. Respirable mass emissions as a function of time (expanded scale) for Pleasant Prairie coal for Run 363. 


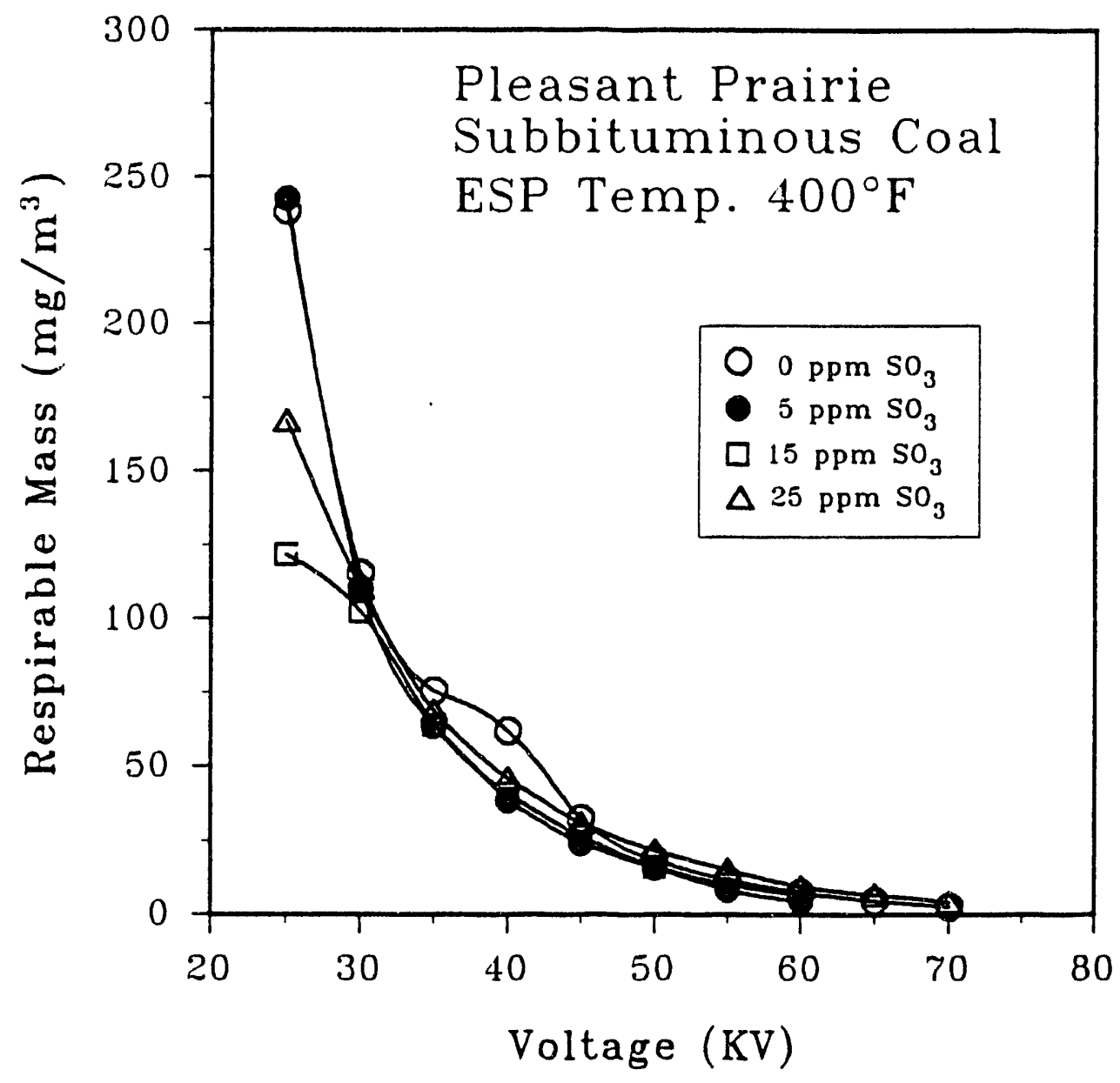

Figure A-4.12. Respirable mass emissions as a function of voltage for Pleasant Prairie coal for Run $30 \overline{3}$. 


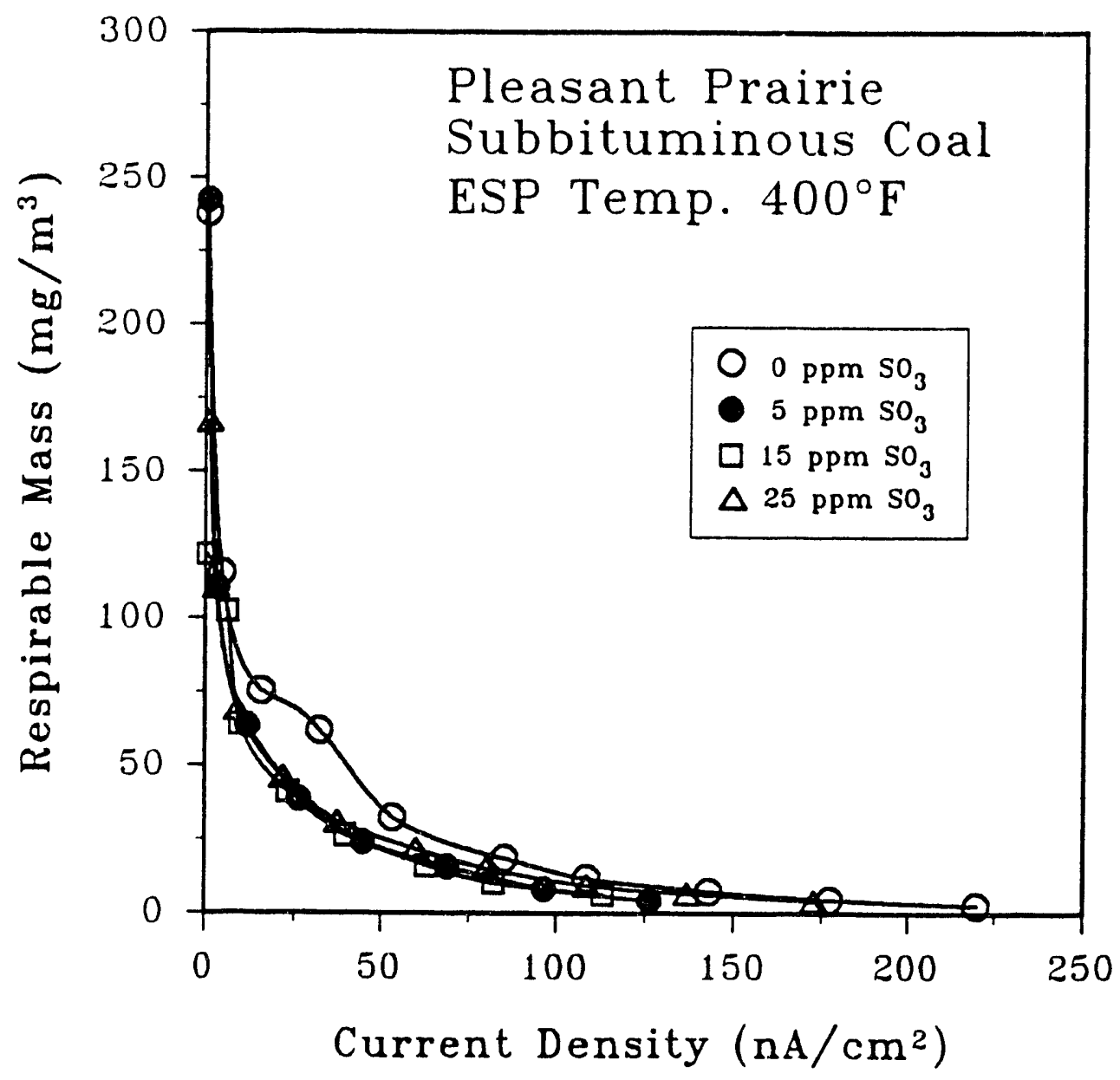

Figure A-4.13. Respirable mass emissions as a function of current density for Pleasant Prairie coal for Run 363. 


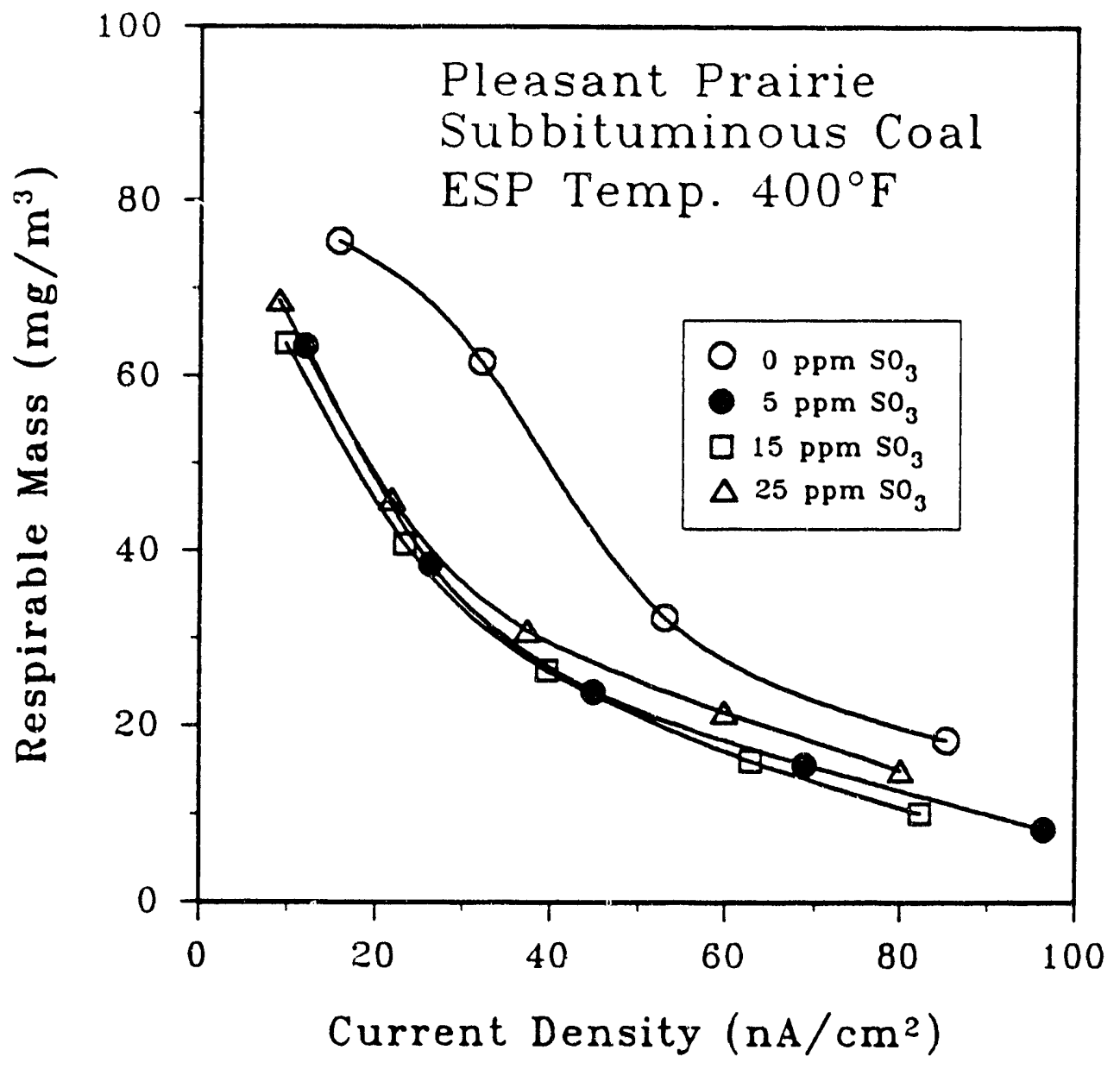

Figure A-4.14. Respirable mass emissions as a function of current density (expanded scale) for Pleasant Prairie coal for Run 363. 


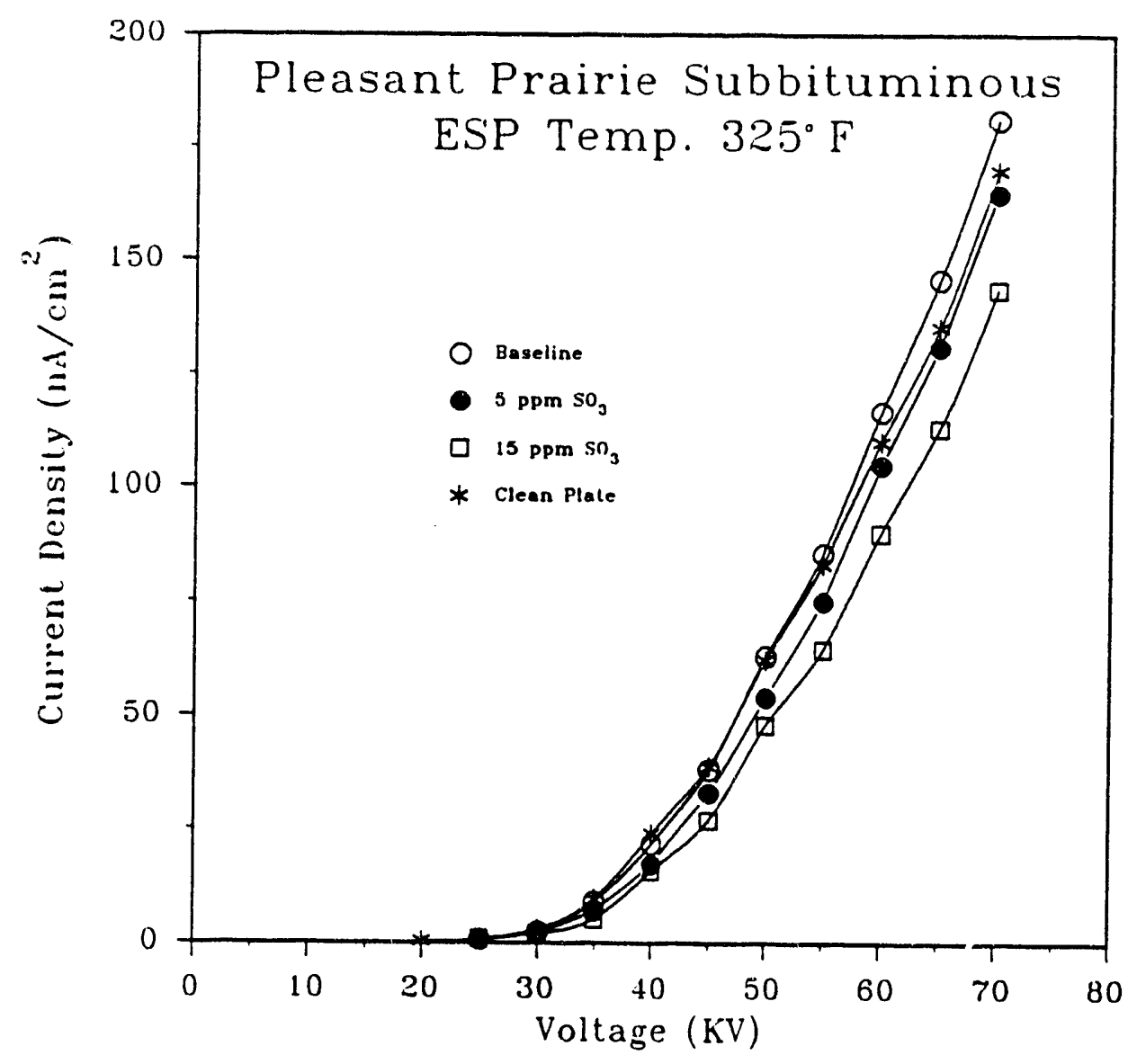

Figure A-4.15. Current-voltage curves for Pleasant Prairie coal for Run 361. 


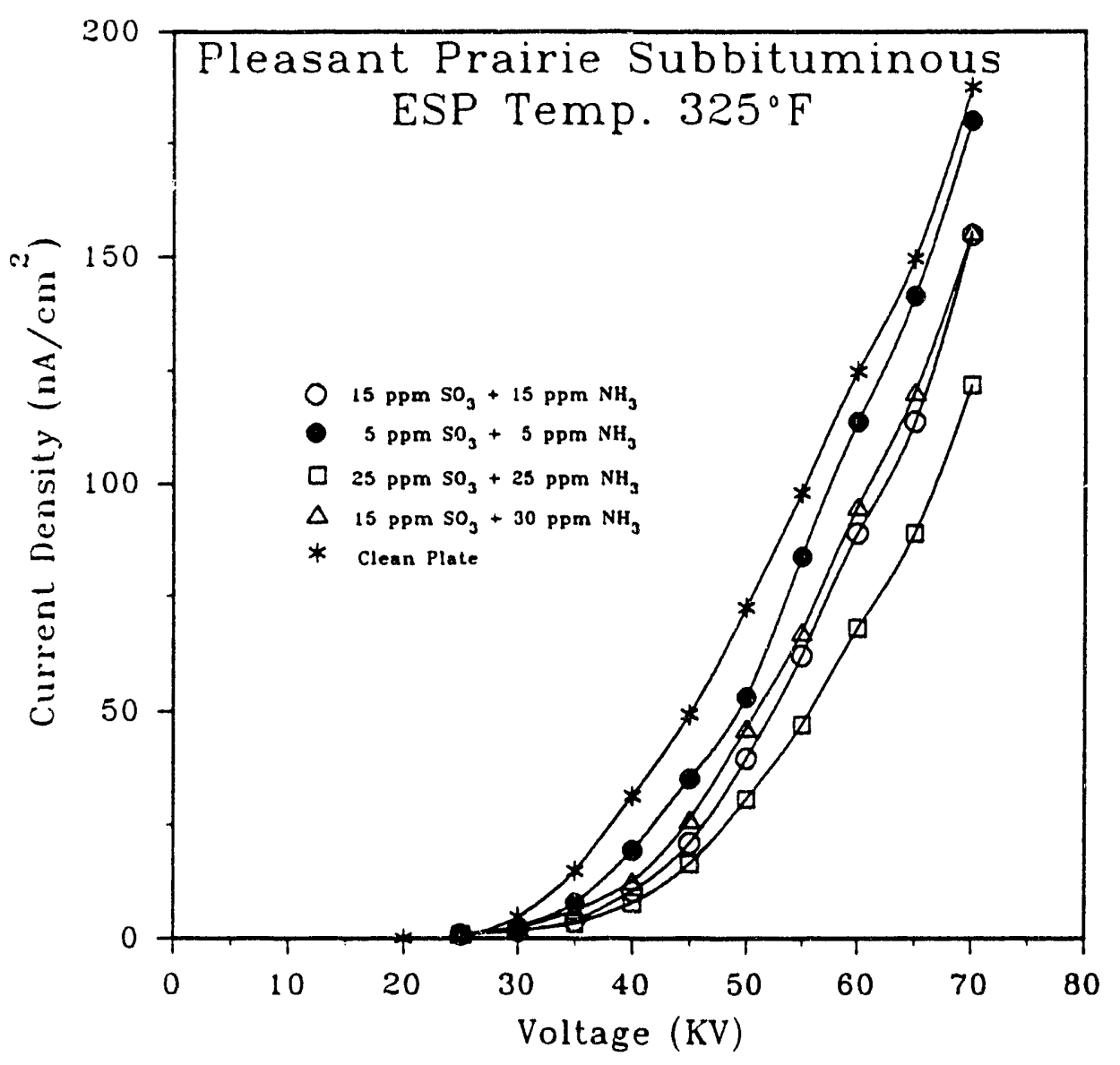

Figure A-4.16. Current-voltage curves for Pleasant Prairie coal for Run 362. 


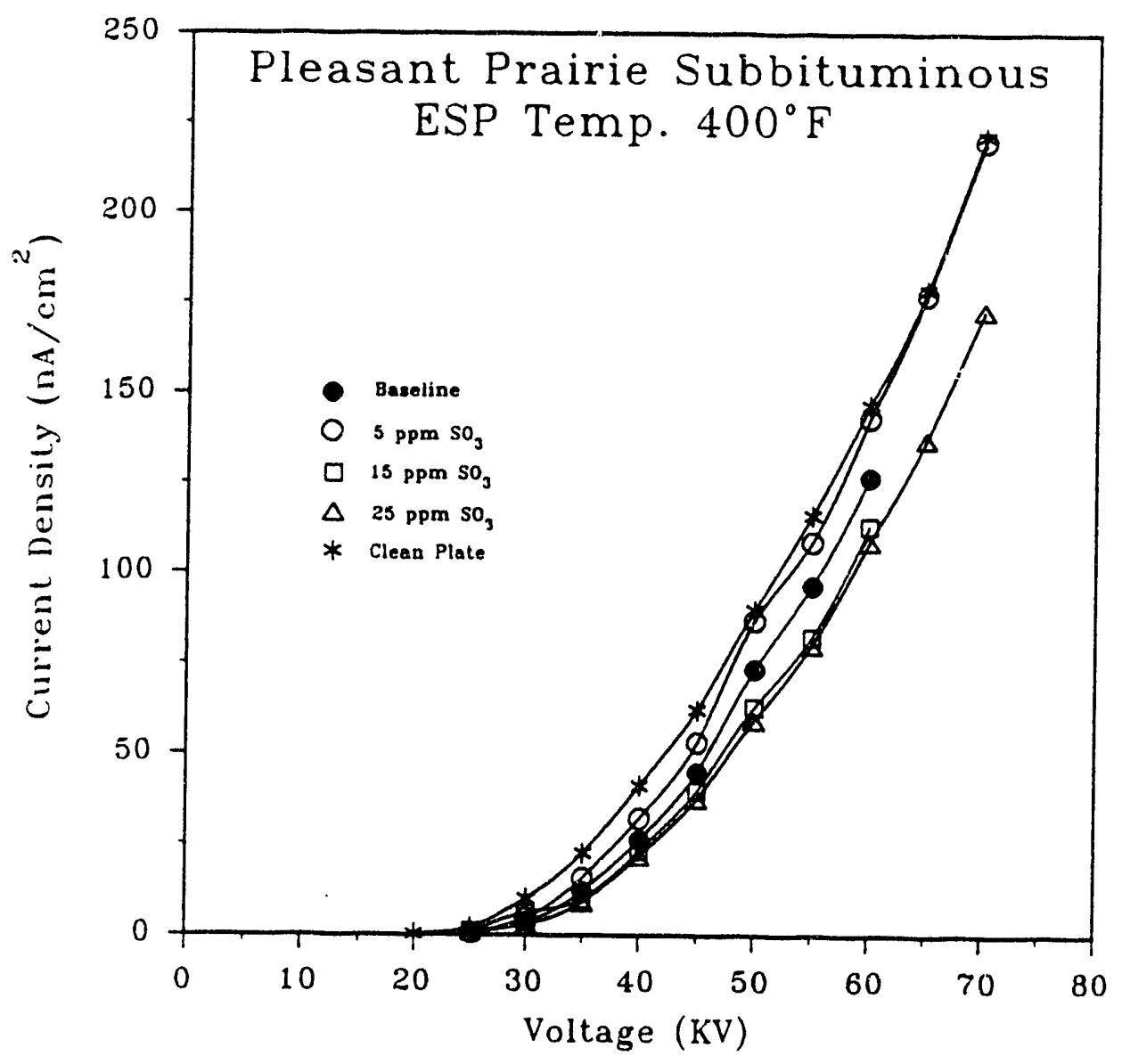

Figure A-4.17. Current-voltage curves for Pleasant Prairie coal for Run 363. 


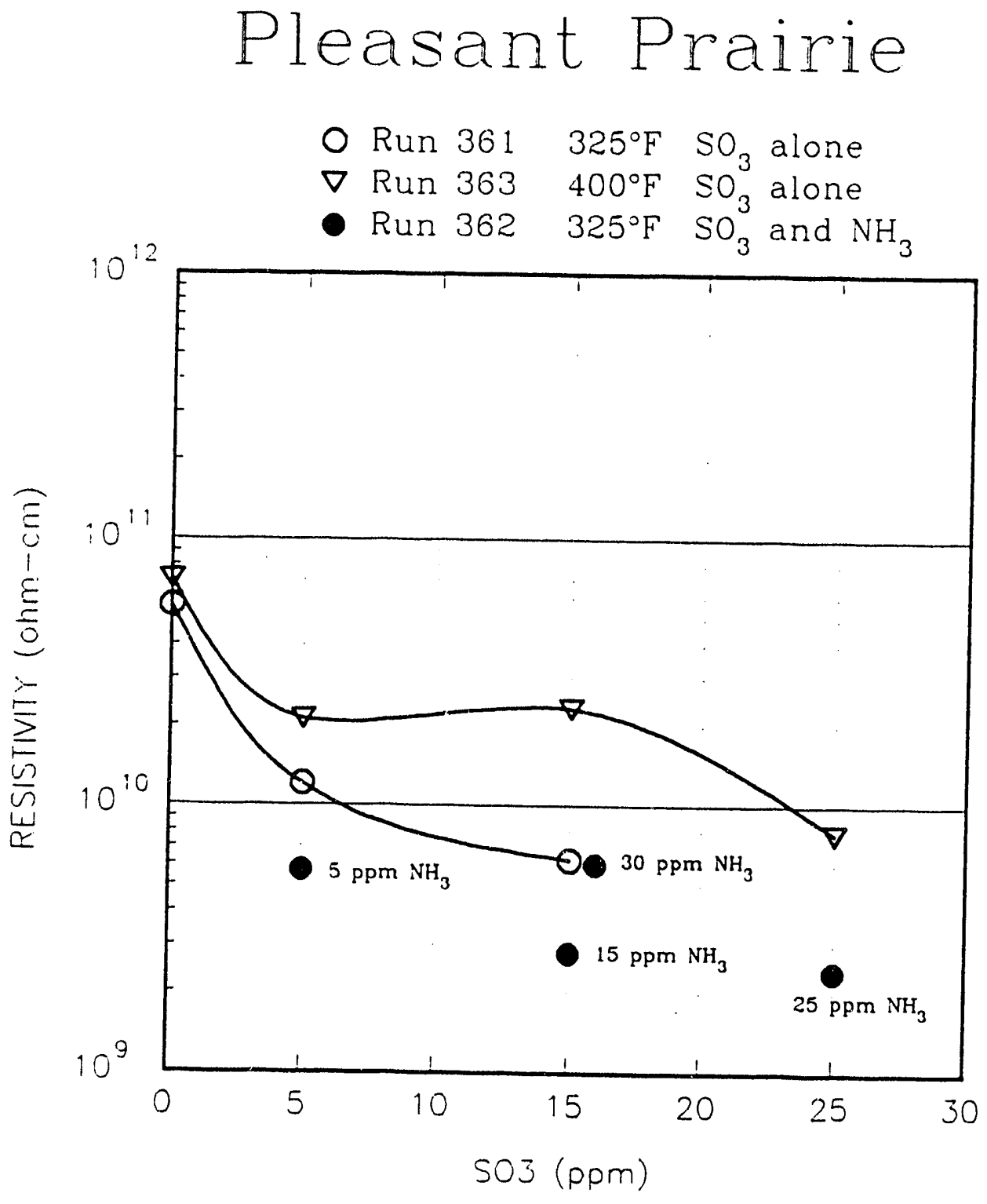

Figure A-4.18. Resistivity as a function of $\mathrm{SO}_{3}$ and ammonia concentration for Pleasant Prairie coal for Runs 361-363. 


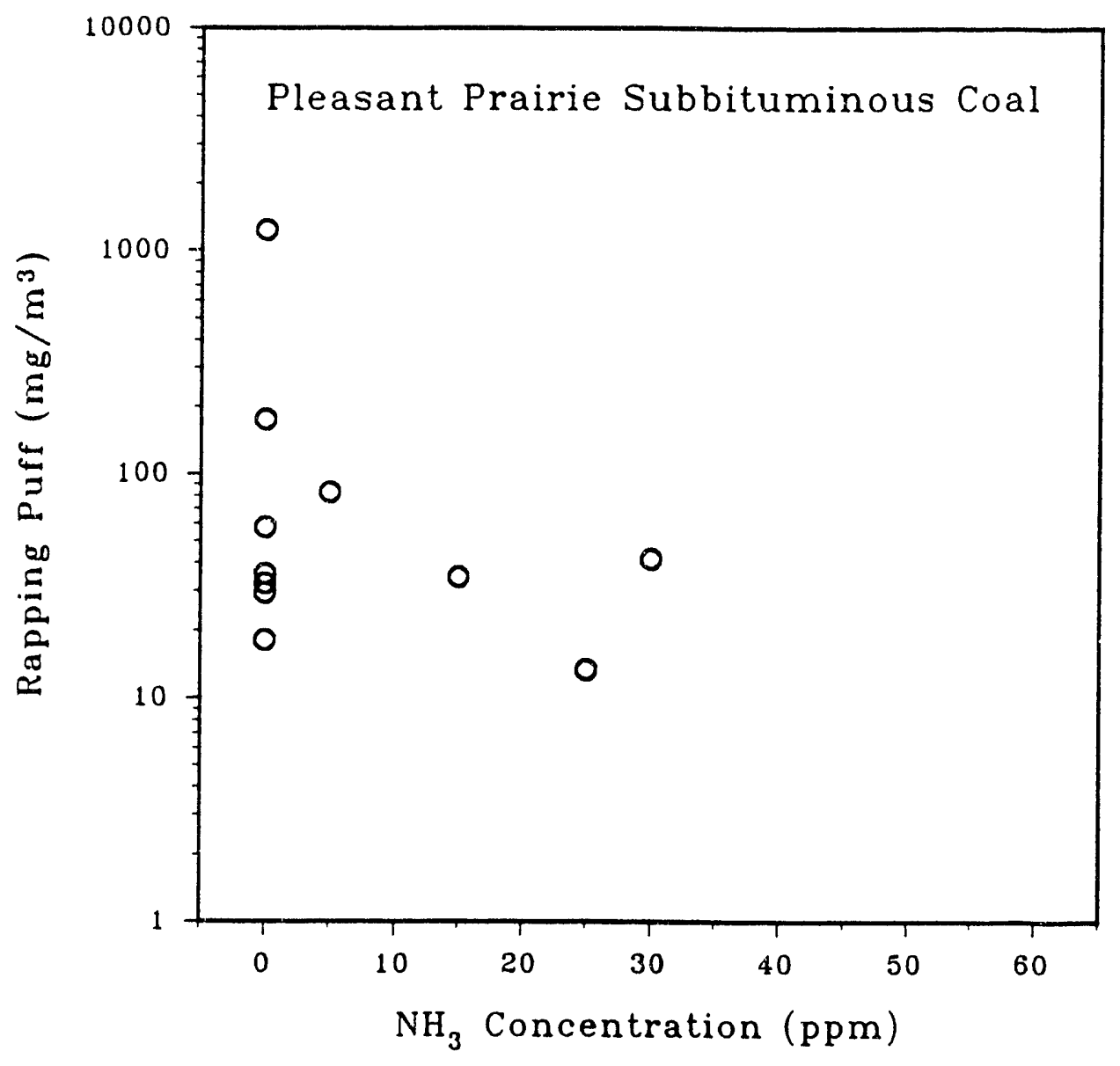

Figure A-4.19. Rapping puff emissions as a function of ammonia concentrations for Pleasant Prairie coal for Runs 361-363. 


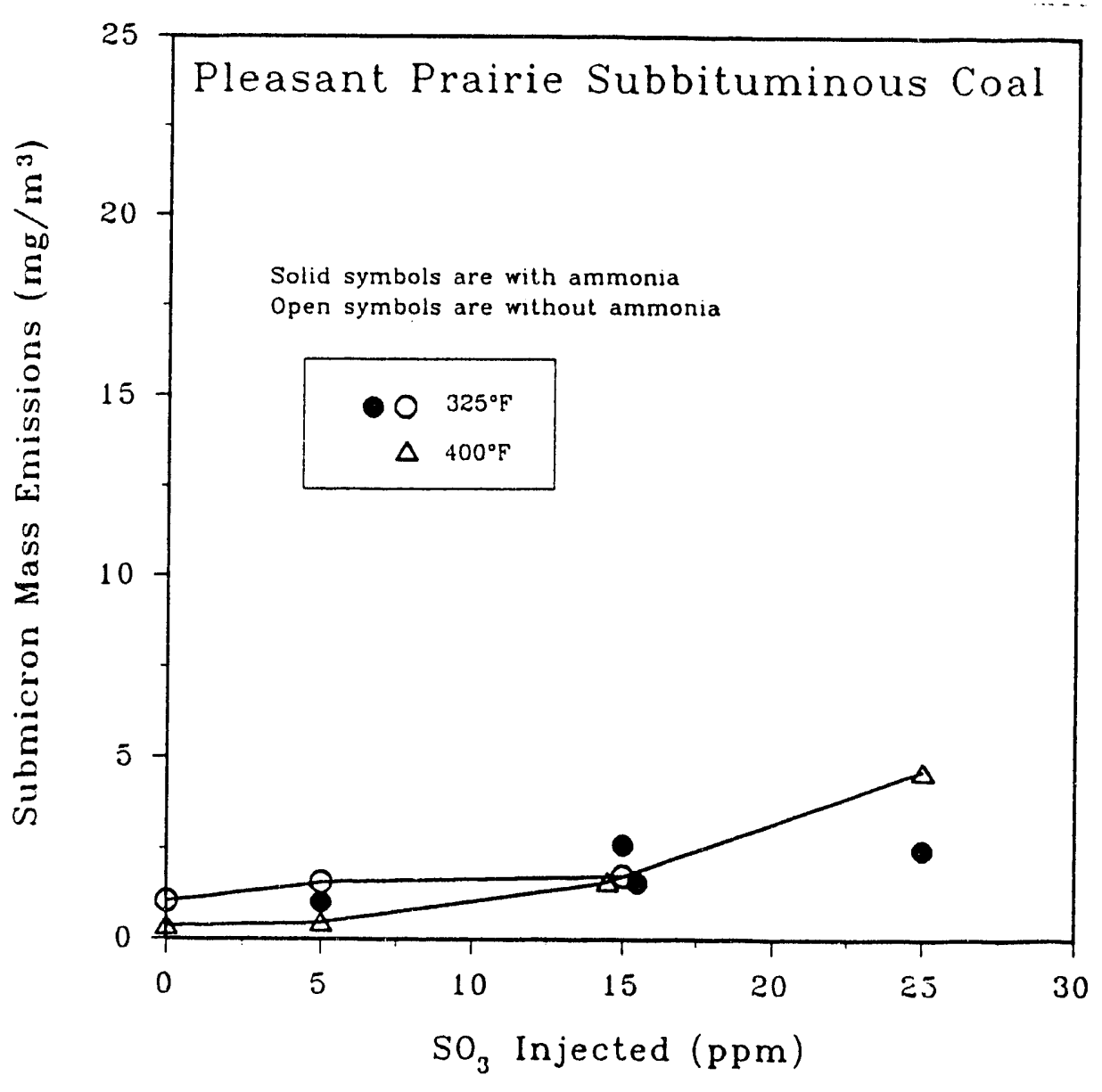

Figure A-4.20. Submicron mass emissions as a function of $\mathrm{SO}_{3}$ concentration with and without ammonia for Pleasant Prairie coal for Runs 361-363. 


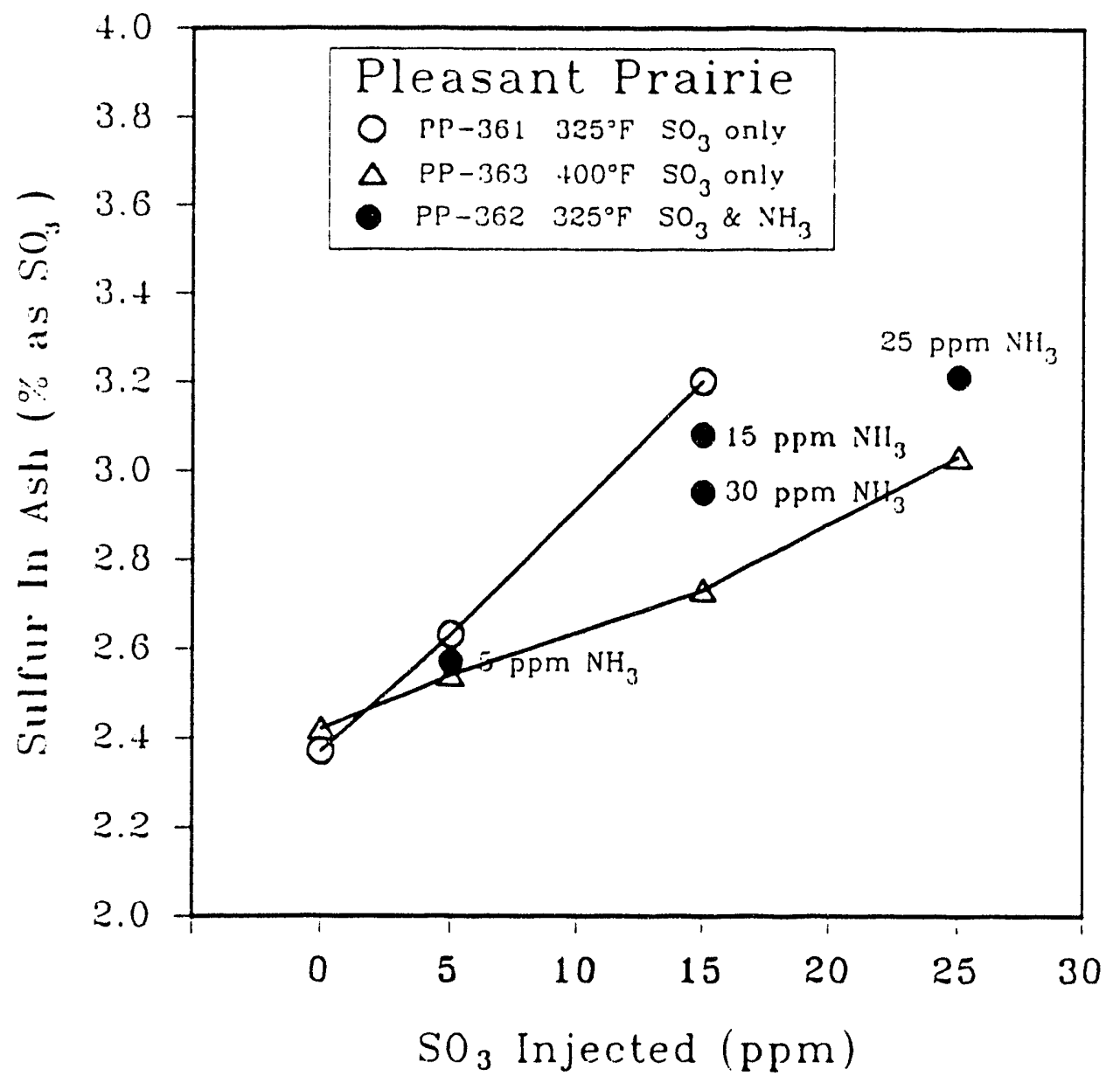

Figure $\mathrm{A}-4.21$. Sulfur retention as a function of $\mathrm{SO}_{3}$ concentration and dual conditioning for Pleasant Prairie coal for Runs 361-363. 


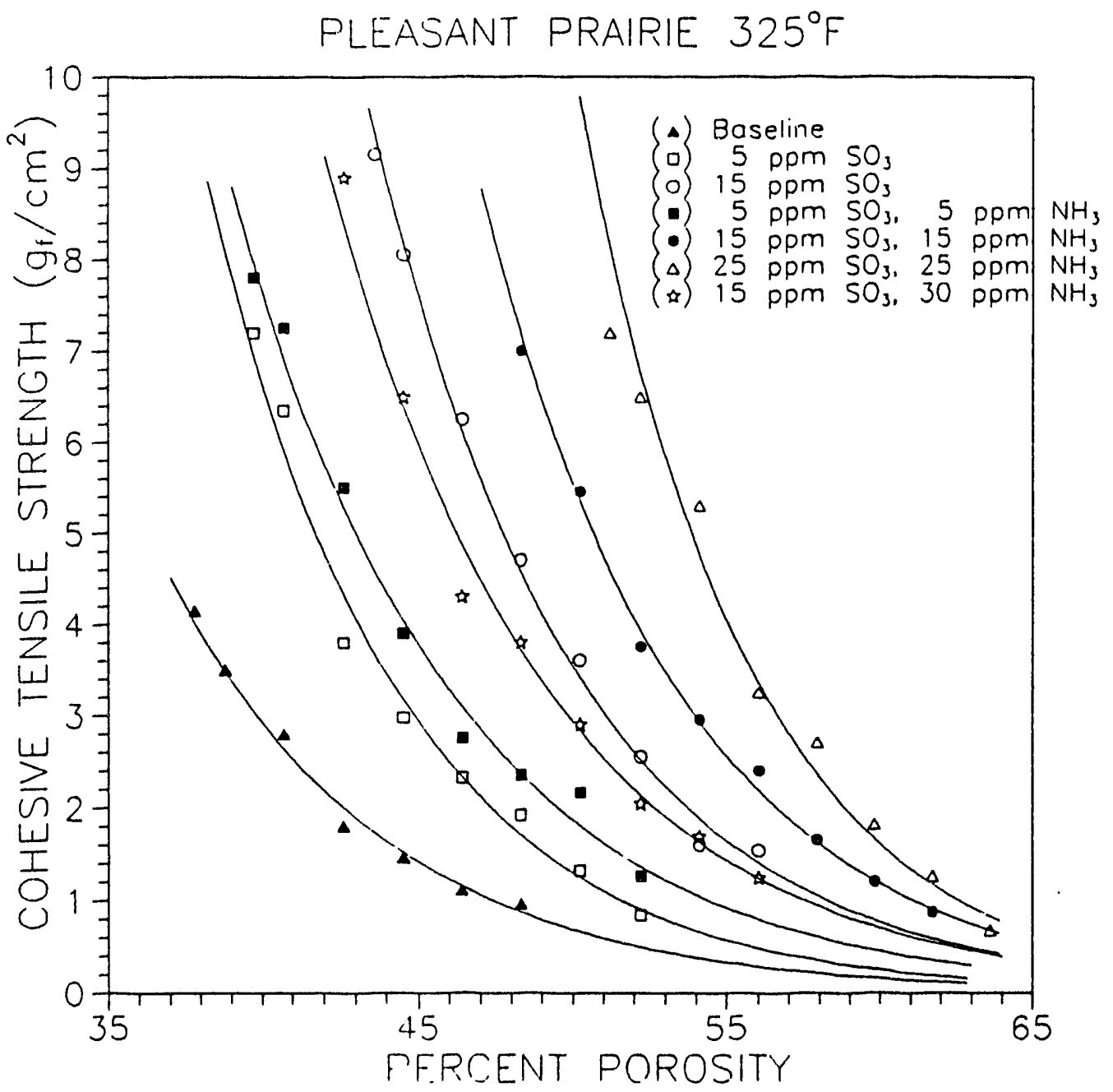

Figure A-4.22. Fly ash tensile strength as a function of ash porosity with $\mathrm{SO}_{3}$ alone and with dual conditioning for Pleasant Prairie coal for Runs 361-363. 


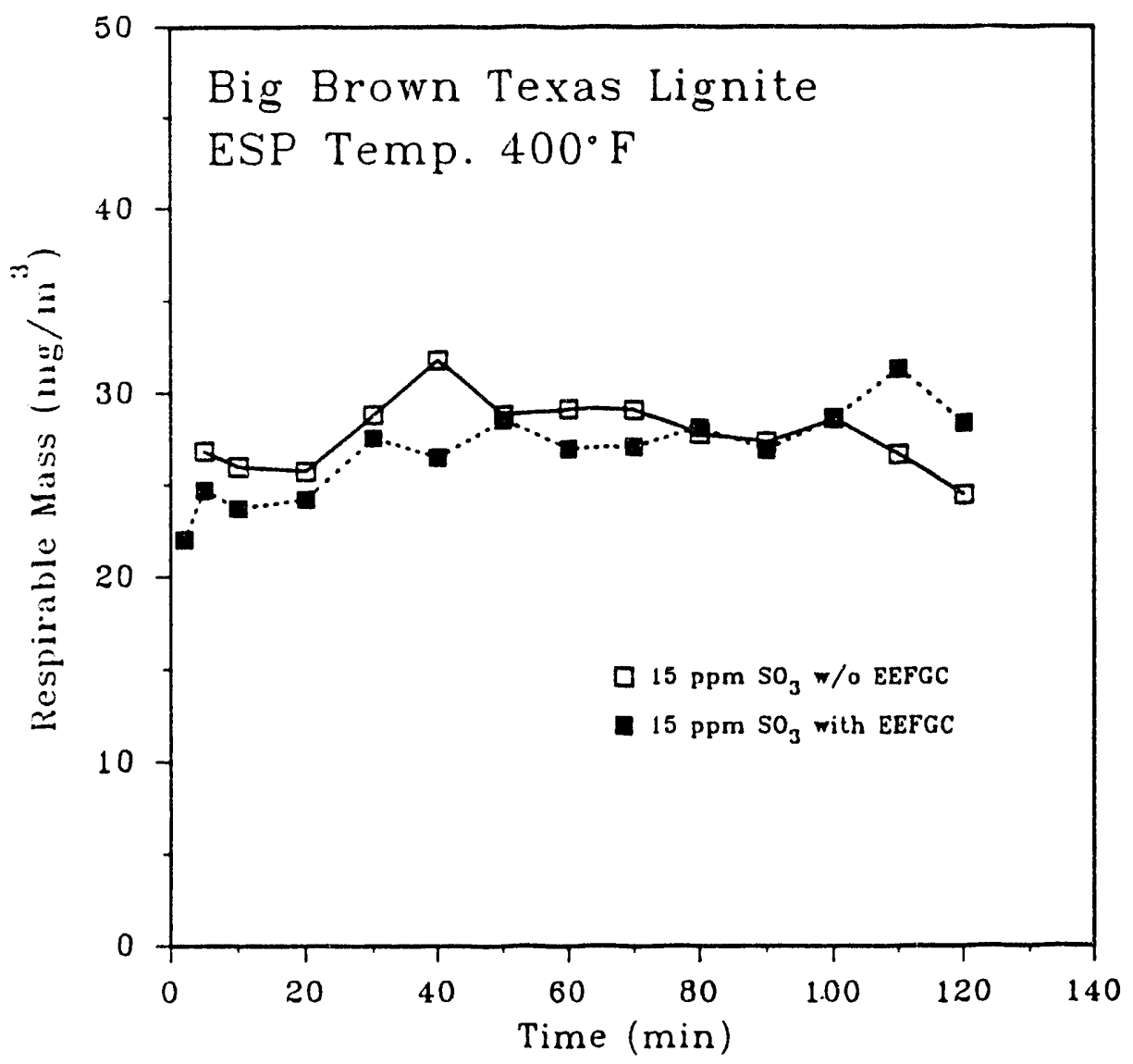

Figure A-5.1. Respirable mass emissions as a function of time for $15 \mathrm{ppm} \mathrm{SO}_{3}$ with and without EFGC for Big Brown coal for Run 368. 


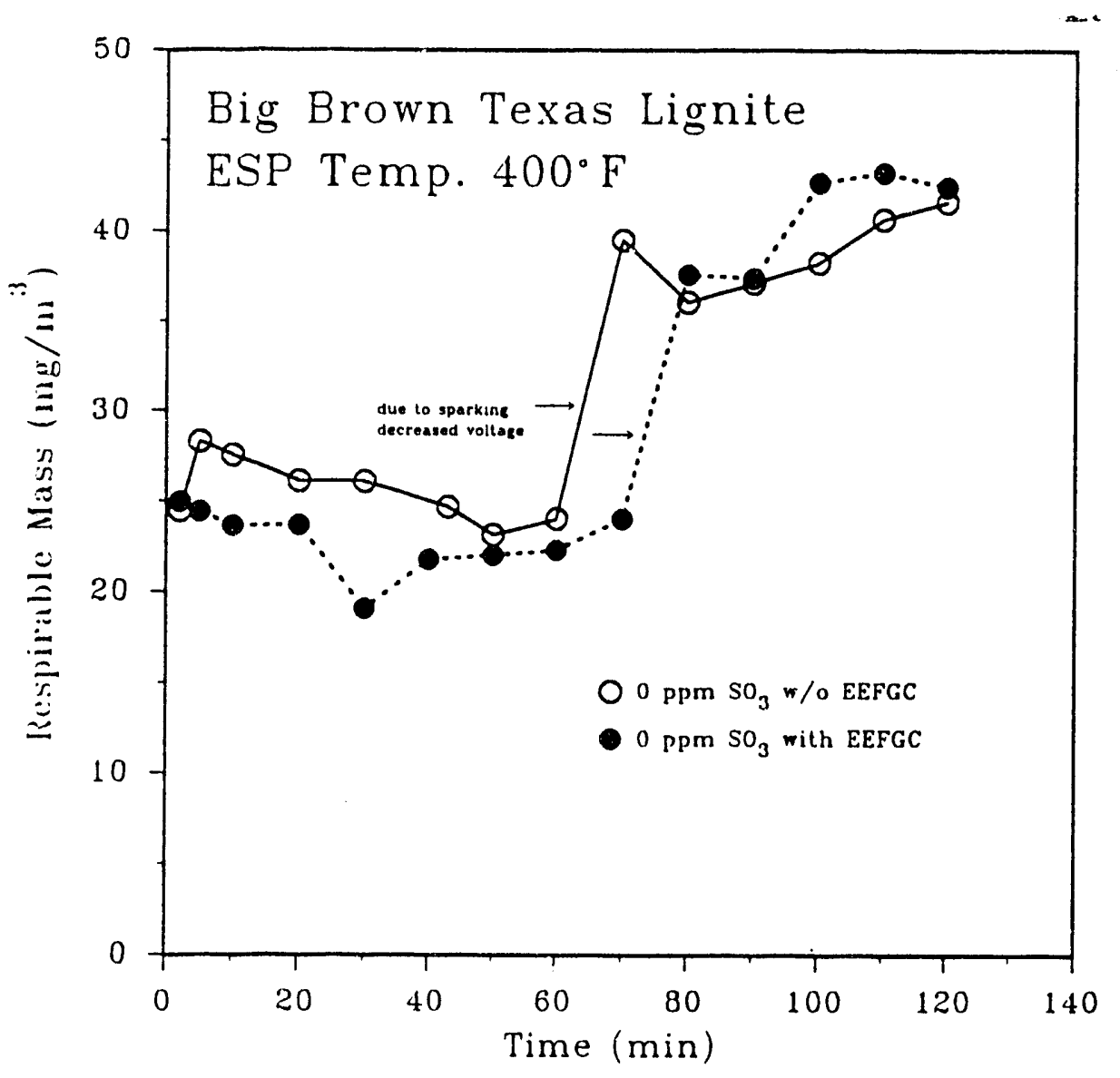

Figure A-5.2. Respirable mass emissions as a function of time for $0 \mathrm{ppm} \mathrm{SO}_{3}$ with and without EFGC for Big Brown coal for Run 368. 


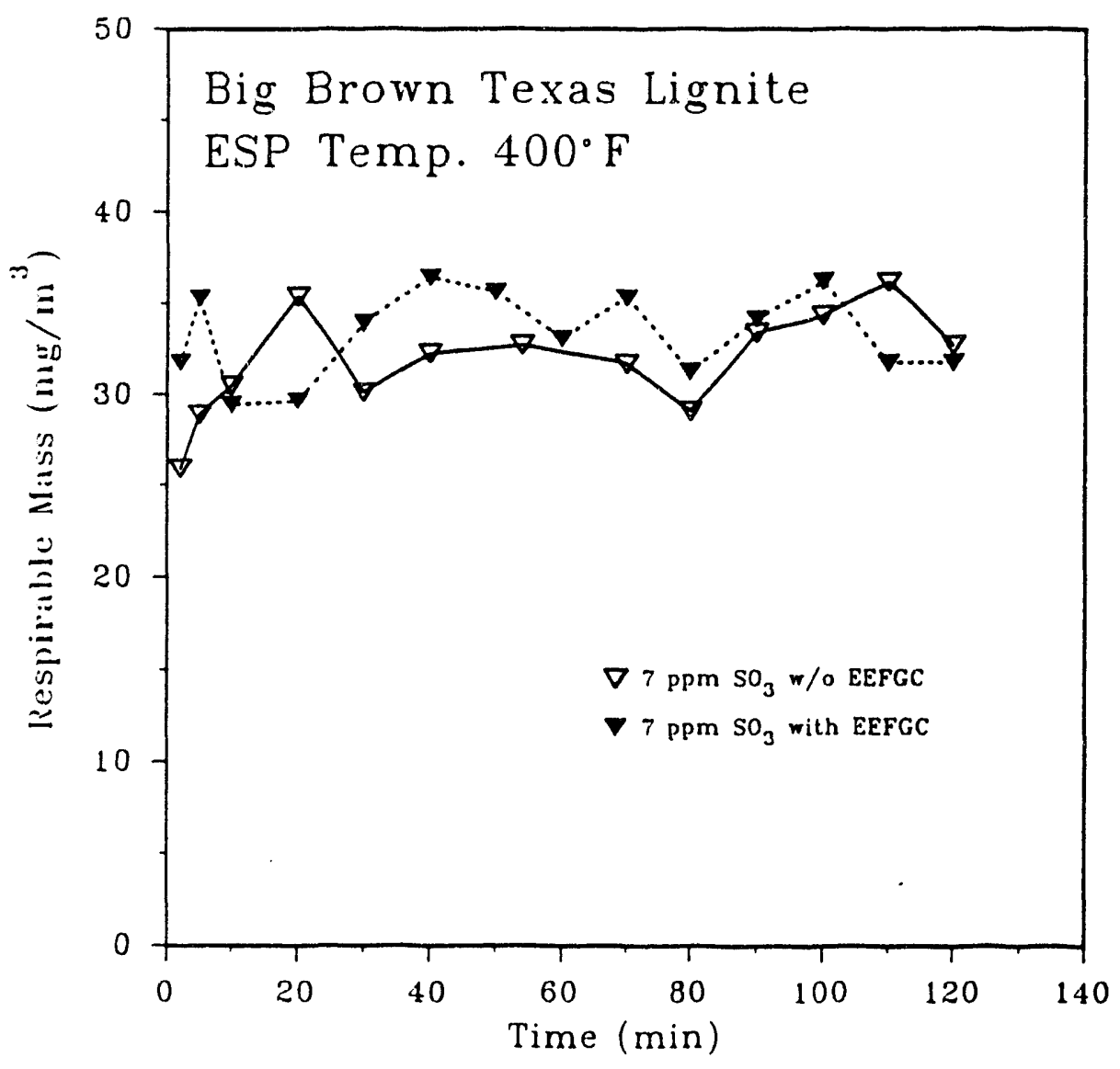

Figure A-5.3. Respirable mass emissions as a function of time for $7 \mathrm{ppm} \mathrm{SO}_{3}$ with and without EFGC for Big Brown coal for Run 369. 


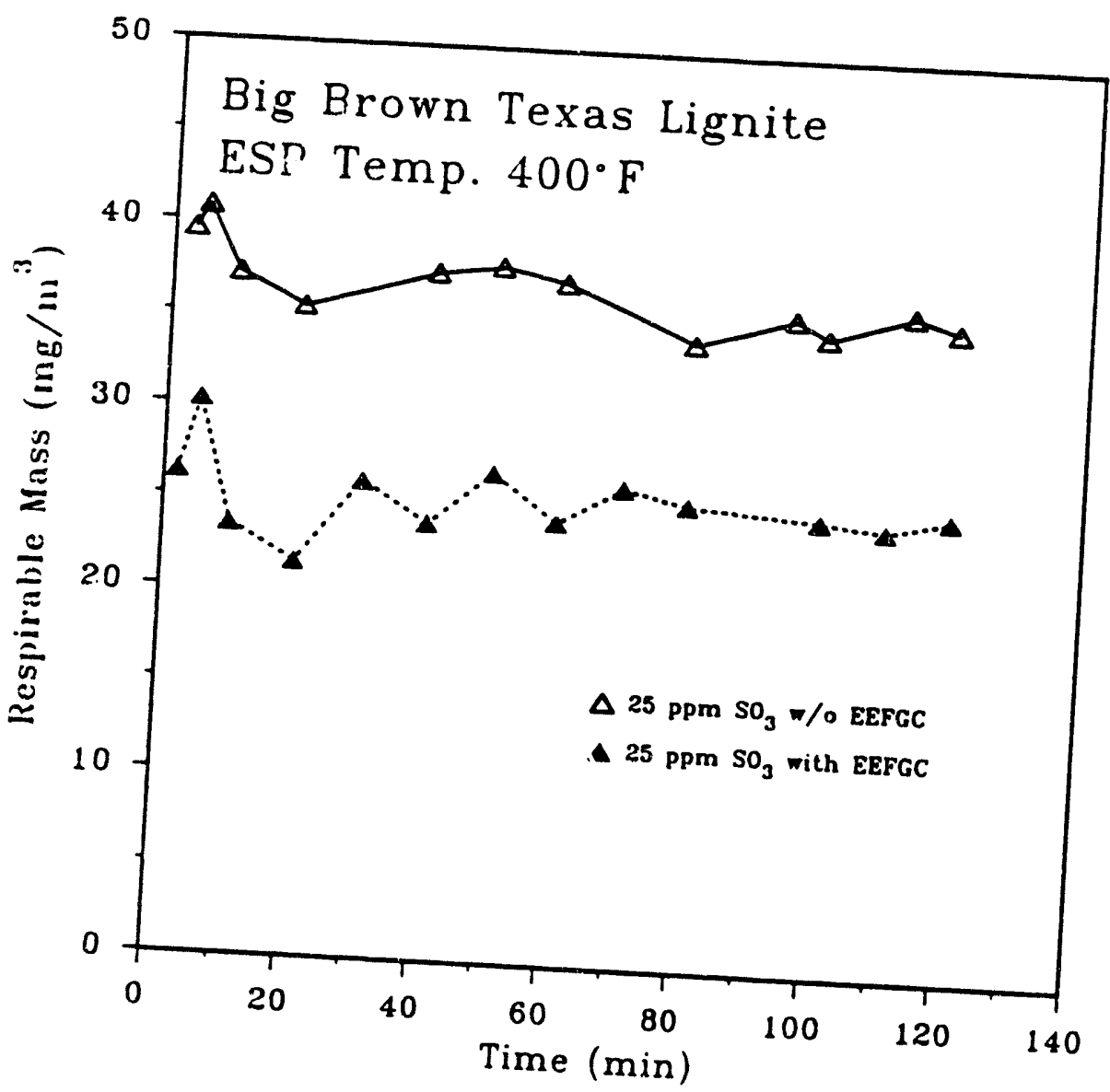

Figure A-5.4. Respirable mass emissions as a function of time for $25 \mathrm{ppm} \mathrm{SO}_{3}$
with and without EFGC for Big Brown coal for Run 369. 


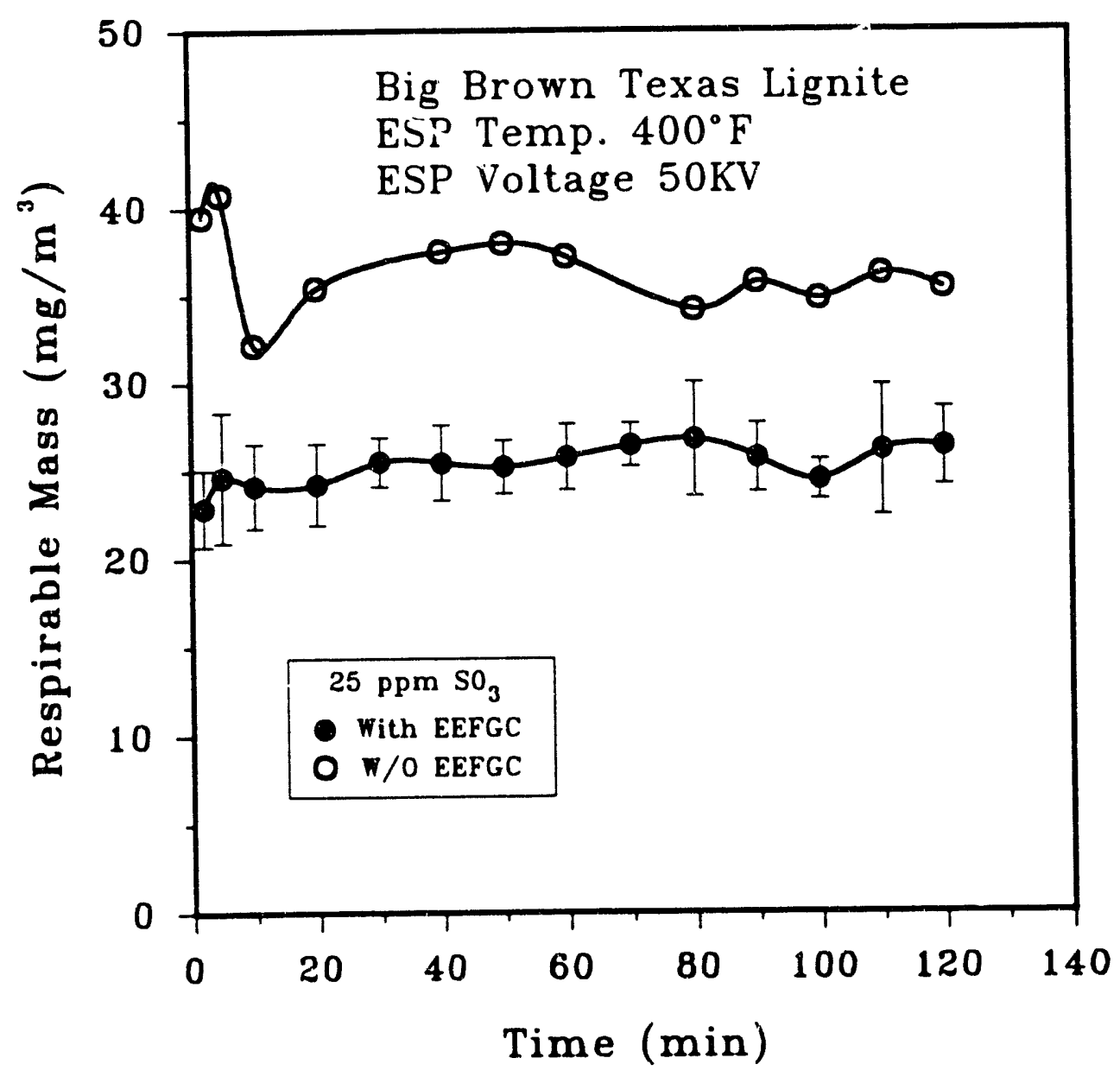

Figure A-5.5. Respirable mass emissions as a function of time for $25 \mathrm{ppm} \mathrm{SO}_{3}$ with and without EFGC for Big Brown coal for Runs 369 and 370. Error bars are plus and minus one standard deviation of EFGC data. 


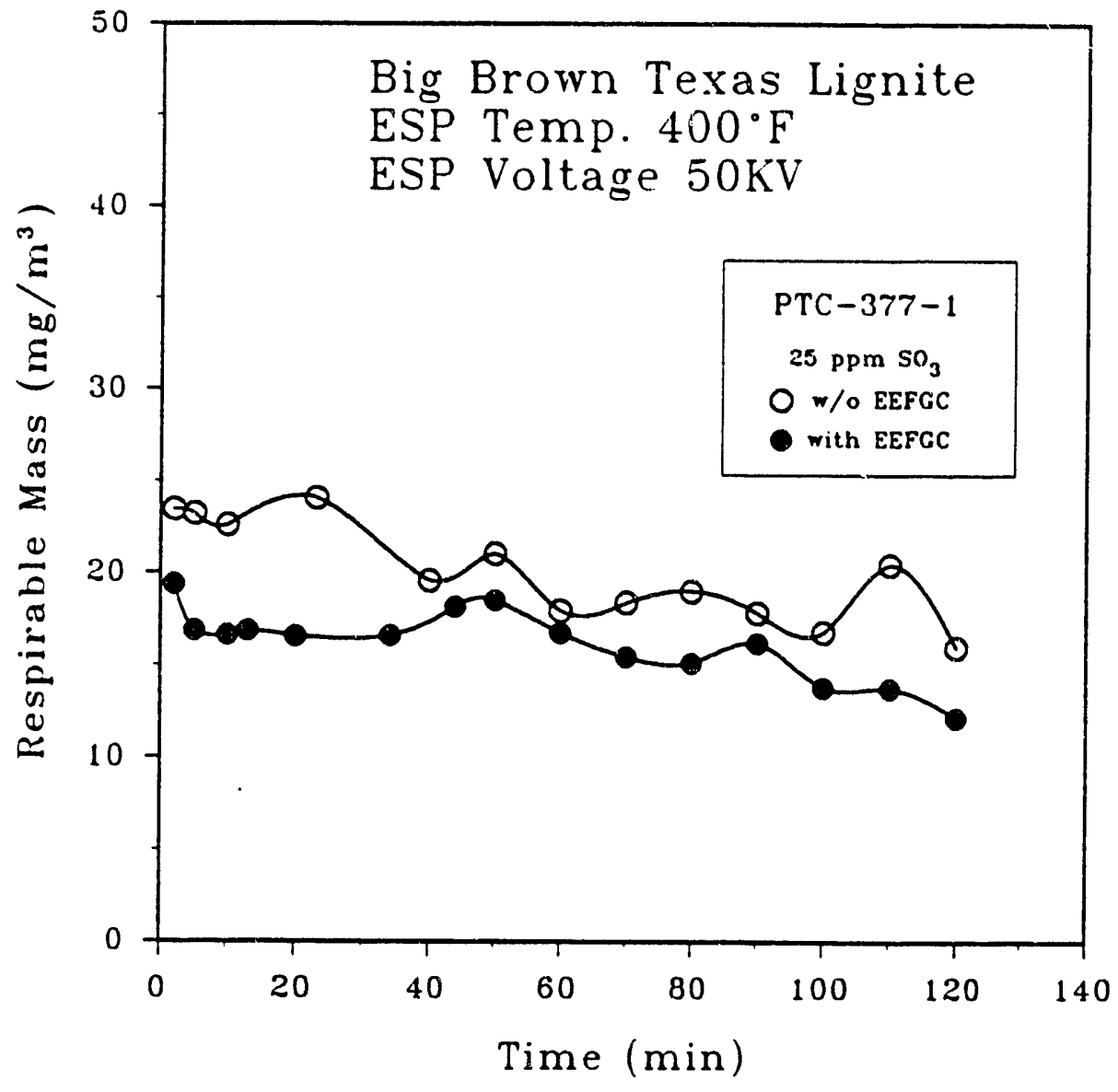

Figure A-5.6. Respirable mass emissions as a function of time for $25 \mathrm{ppm} \mathrm{SO}_{3}$ with and without EFGC for Big Brown coal for Run 377 comparing Tests 1 and 2. 


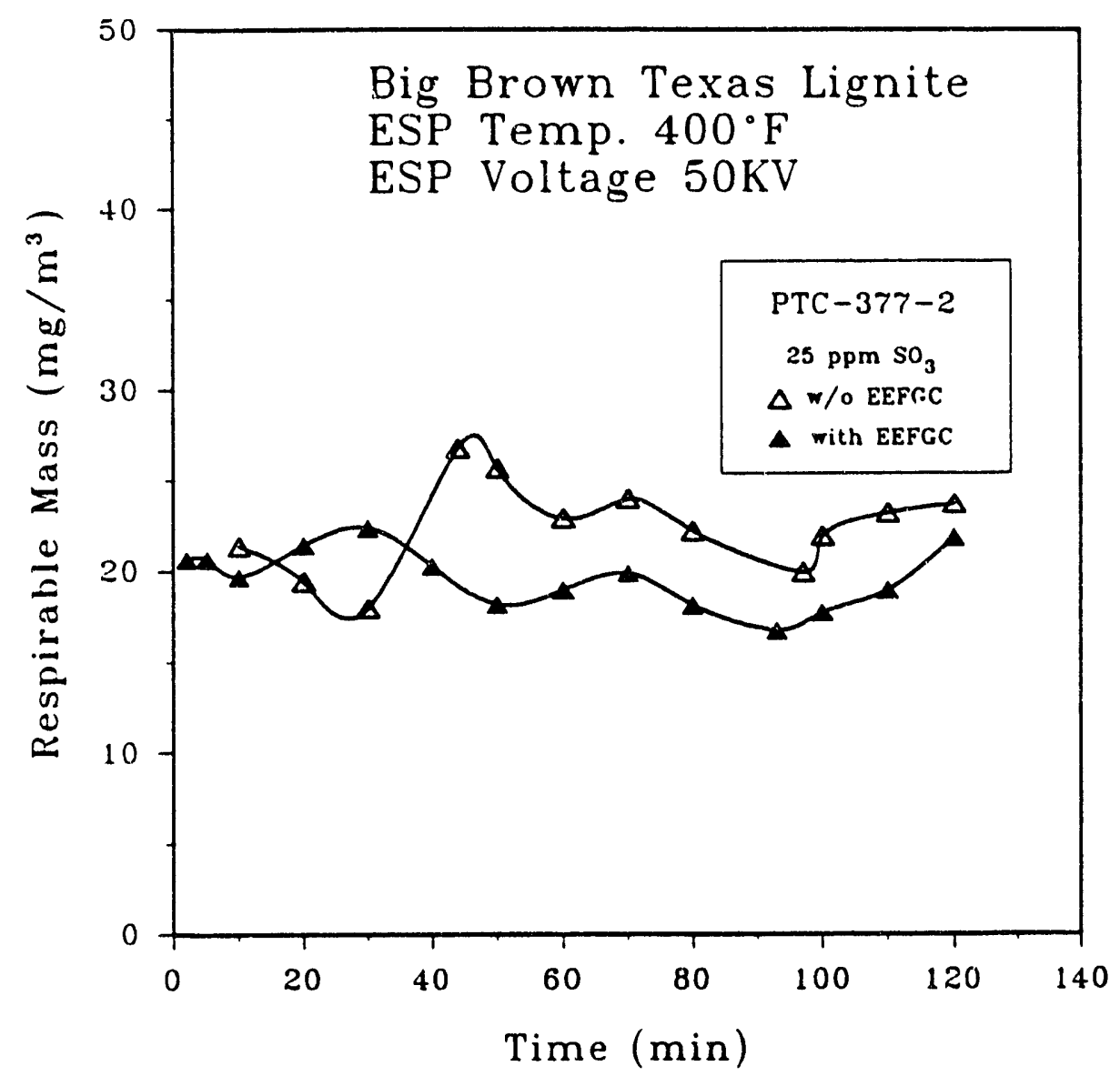

Figure A-5.7. Respirable mass emissions as a function of time for $25 \mathrm{ppm} \mathrm{SO}_{3}$ with and without EFGC for Big Brown coal for Run 377 comparing Tests 3 and 4. 


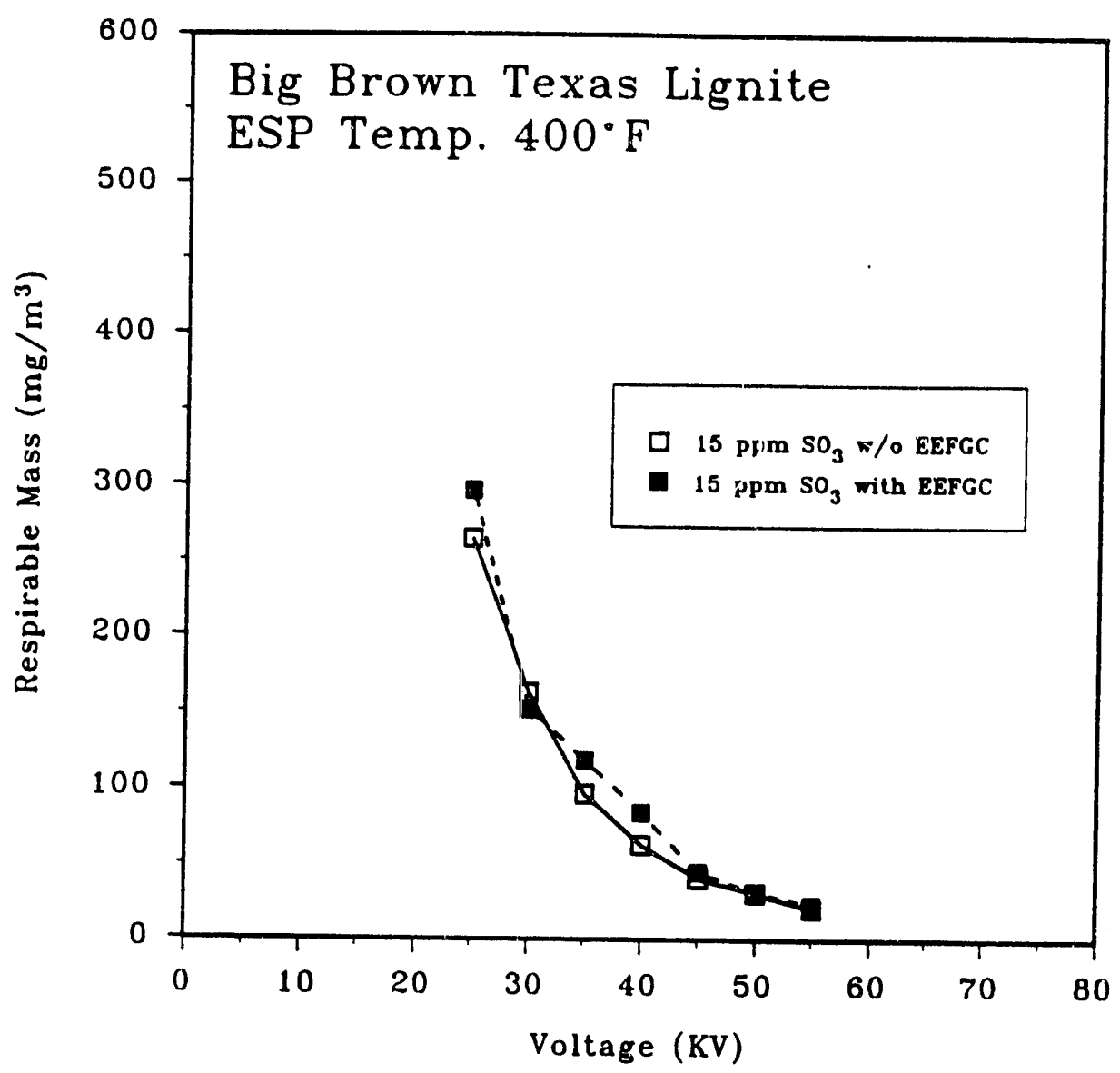

Figure A-5.8. Respirable mass as a function of voltage at $15 \mathrm{ppm} \mathrm{SO}_{3}$ with and without EFGC for Big Brown coal for Run 368. 


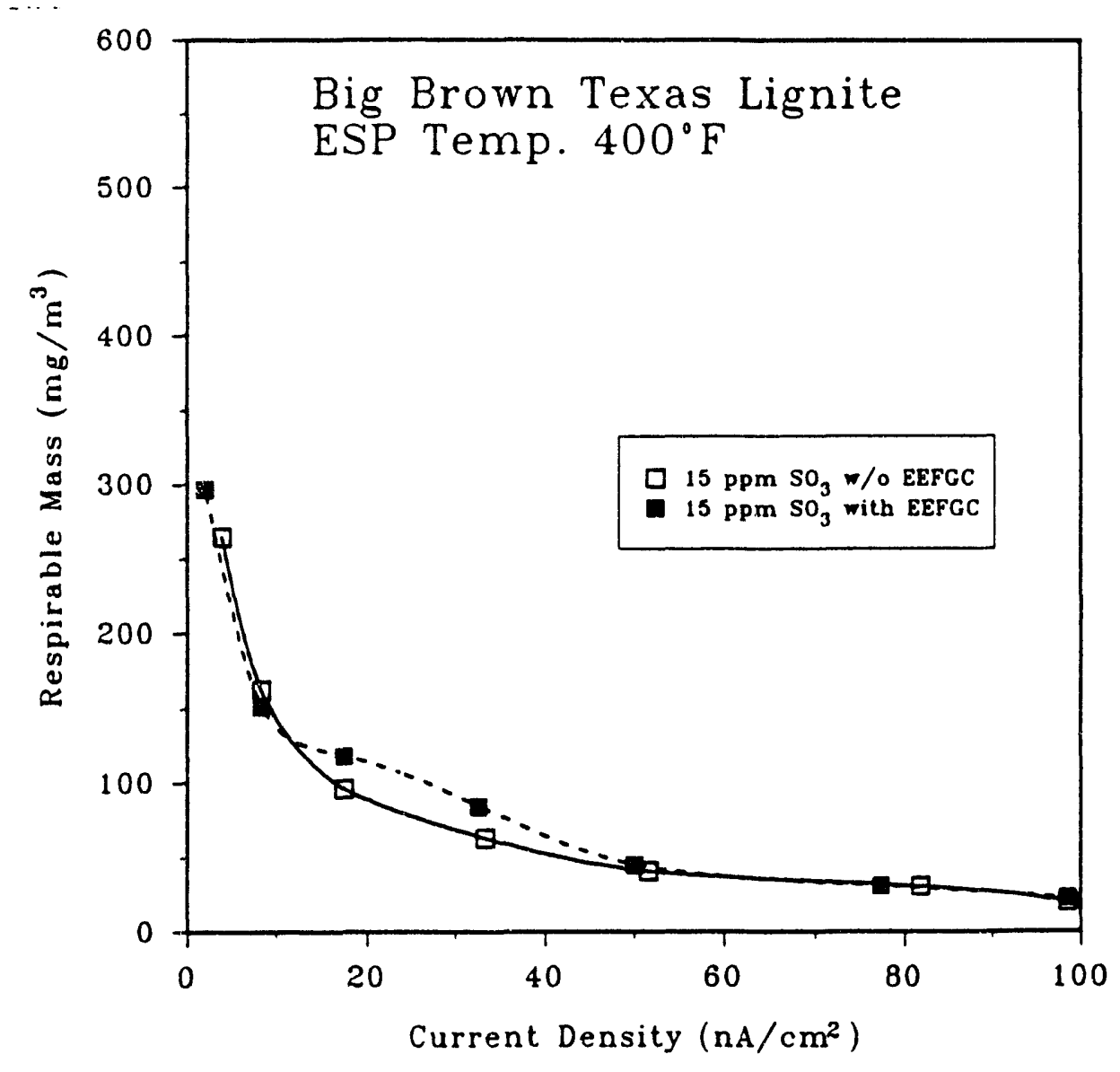

Figure A-5.9. Respirable mass as a function of current density at $15 \mathrm{ppm} \mathrm{SO}_{3}$ with and without EFGC for Big Brown coal for Run 368 . 


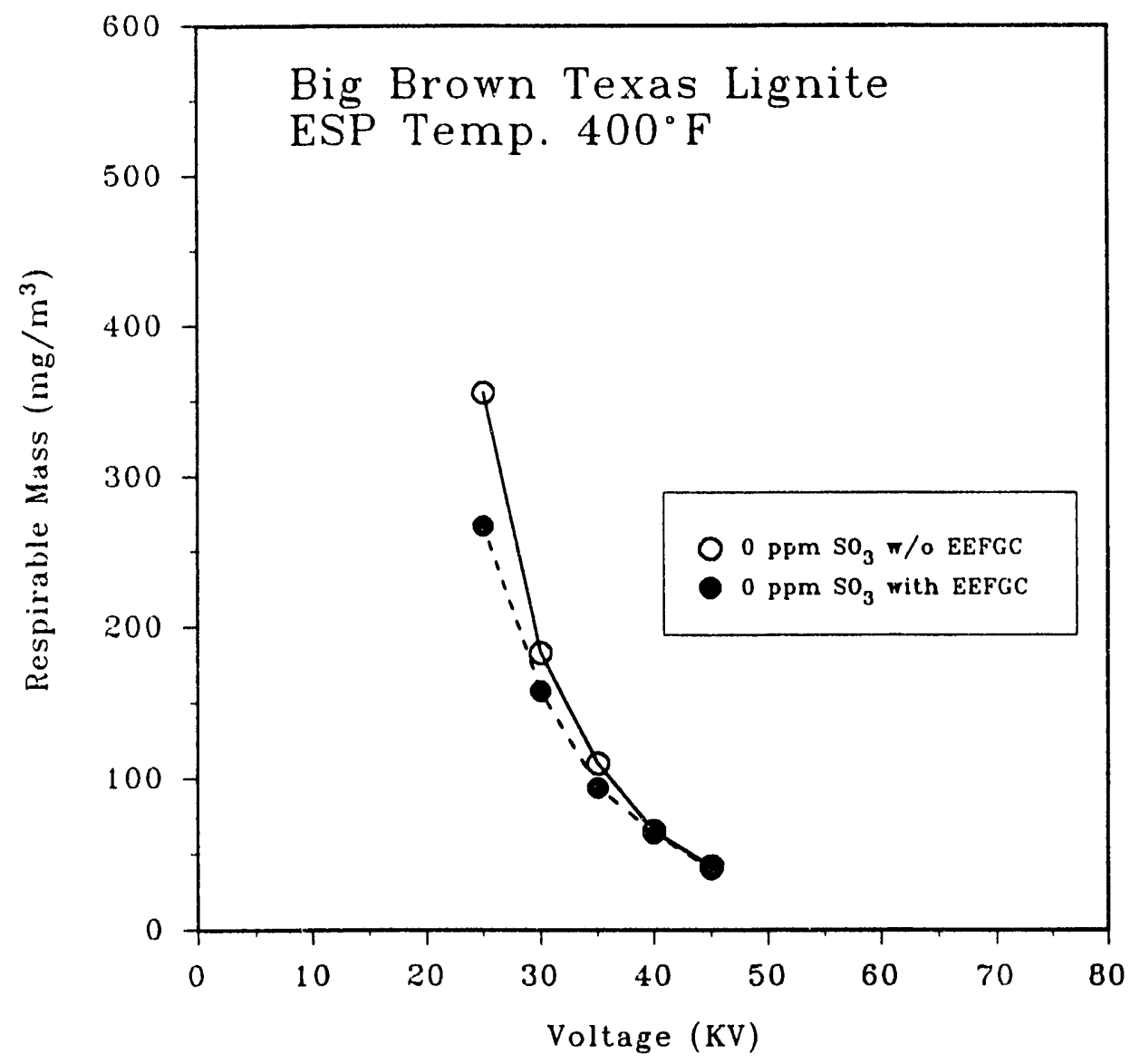

Figure A-5.10. Respirable mass as a function of voltage at $0 \mathrm{ppm} \mathrm{SO}_{3}$ with and without EFGC for Big Brown coal for Run 368. 


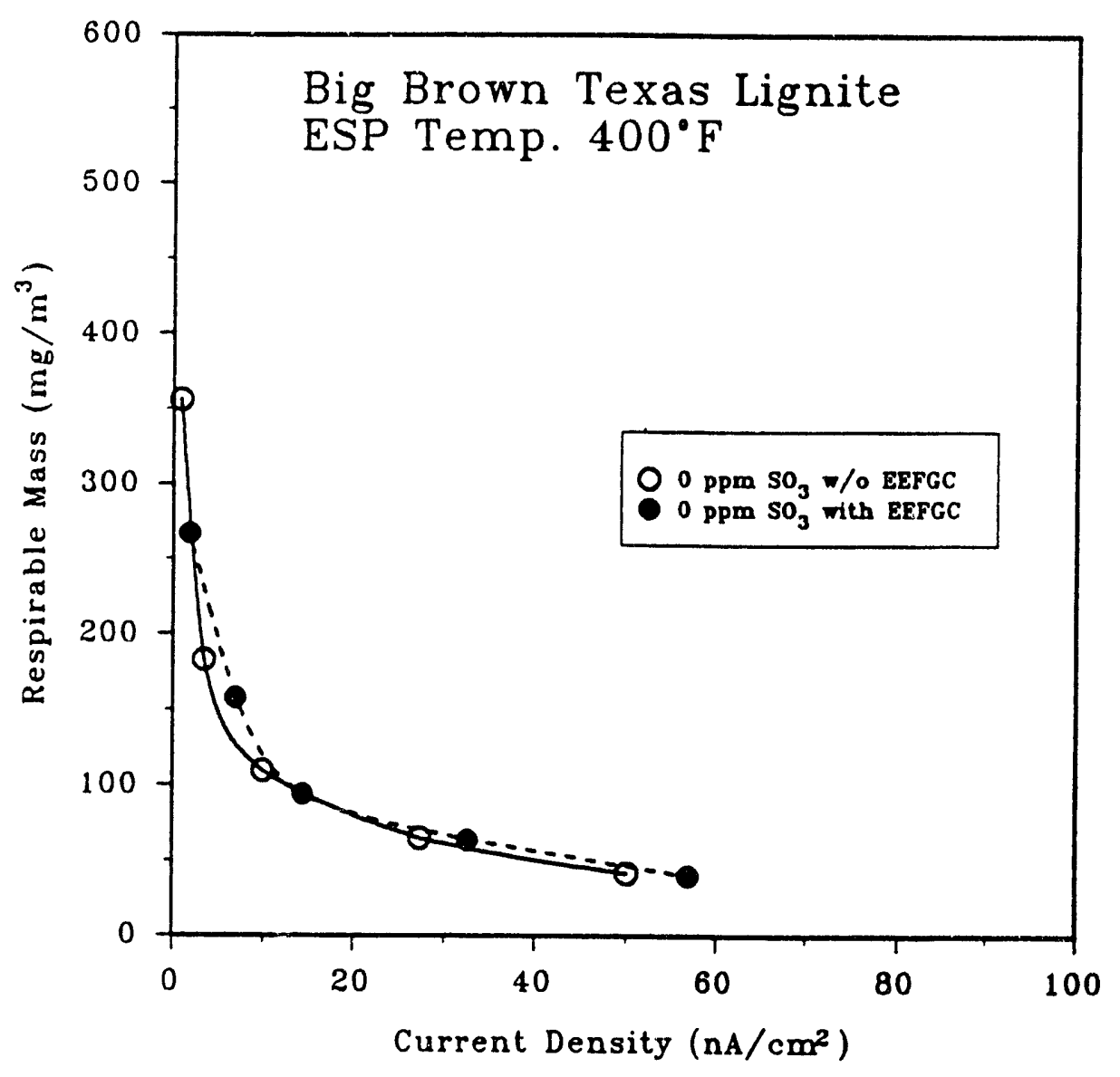

Figure A-5.11. Respirable mass as a function of current density at $0 \mathrm{ppm} \mathrm{SO}_{3}$ with and without EFGC for Big Brown coal for Run 368. 


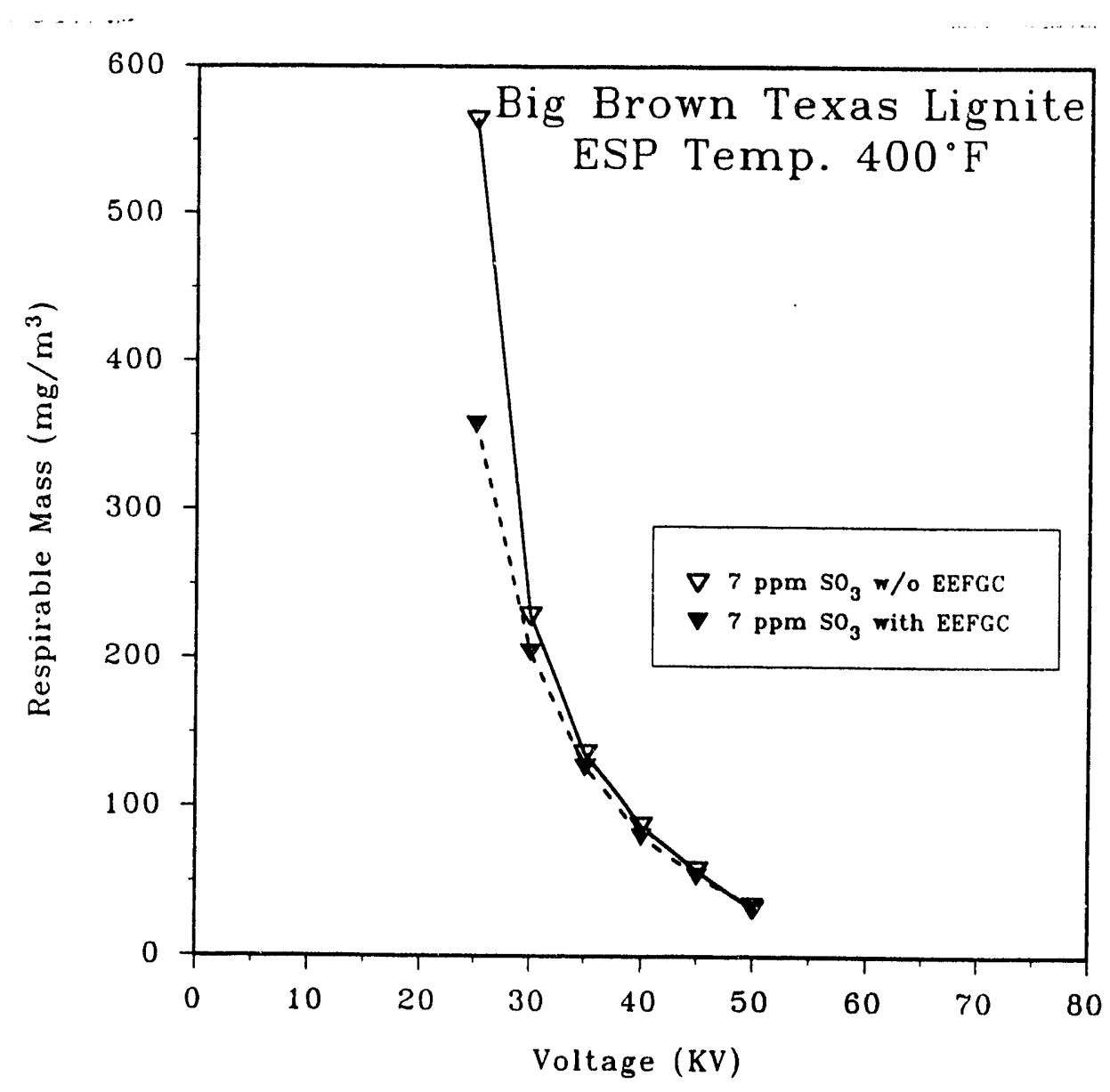

Figure A-5.12. Respirable mass as a function of voltage at $7 \mathrm{ppm} \mathrm{SO}_{3}$ with and without EFGC for Big Brown coal for Run 369. 


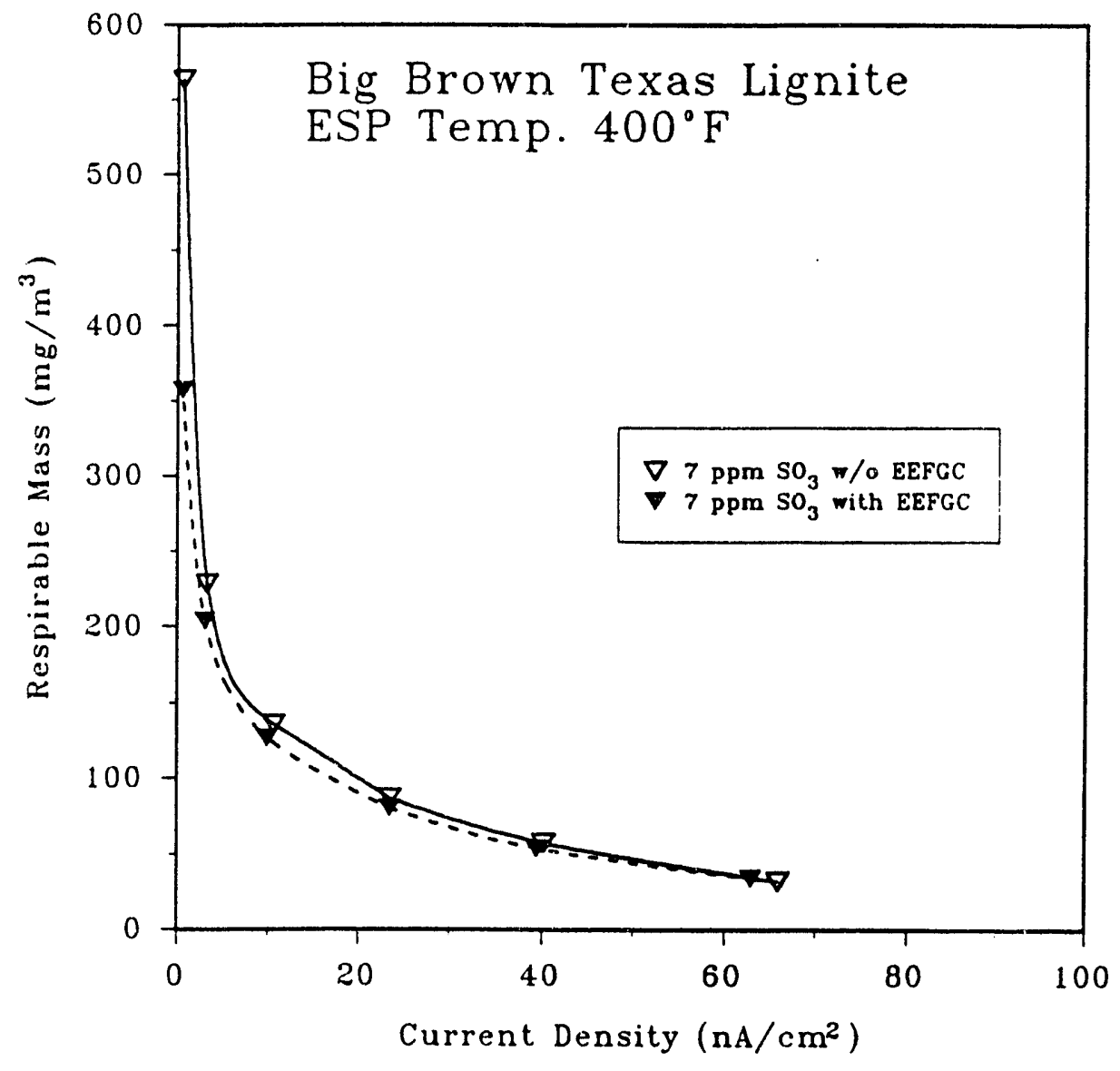

Figure A-5.13. Respirable mass as a function of current density at $7 \mathrm{ppm} \mathrm{SO}_{3}$ with and without EFGC for Big Brown coal for Run 369. 


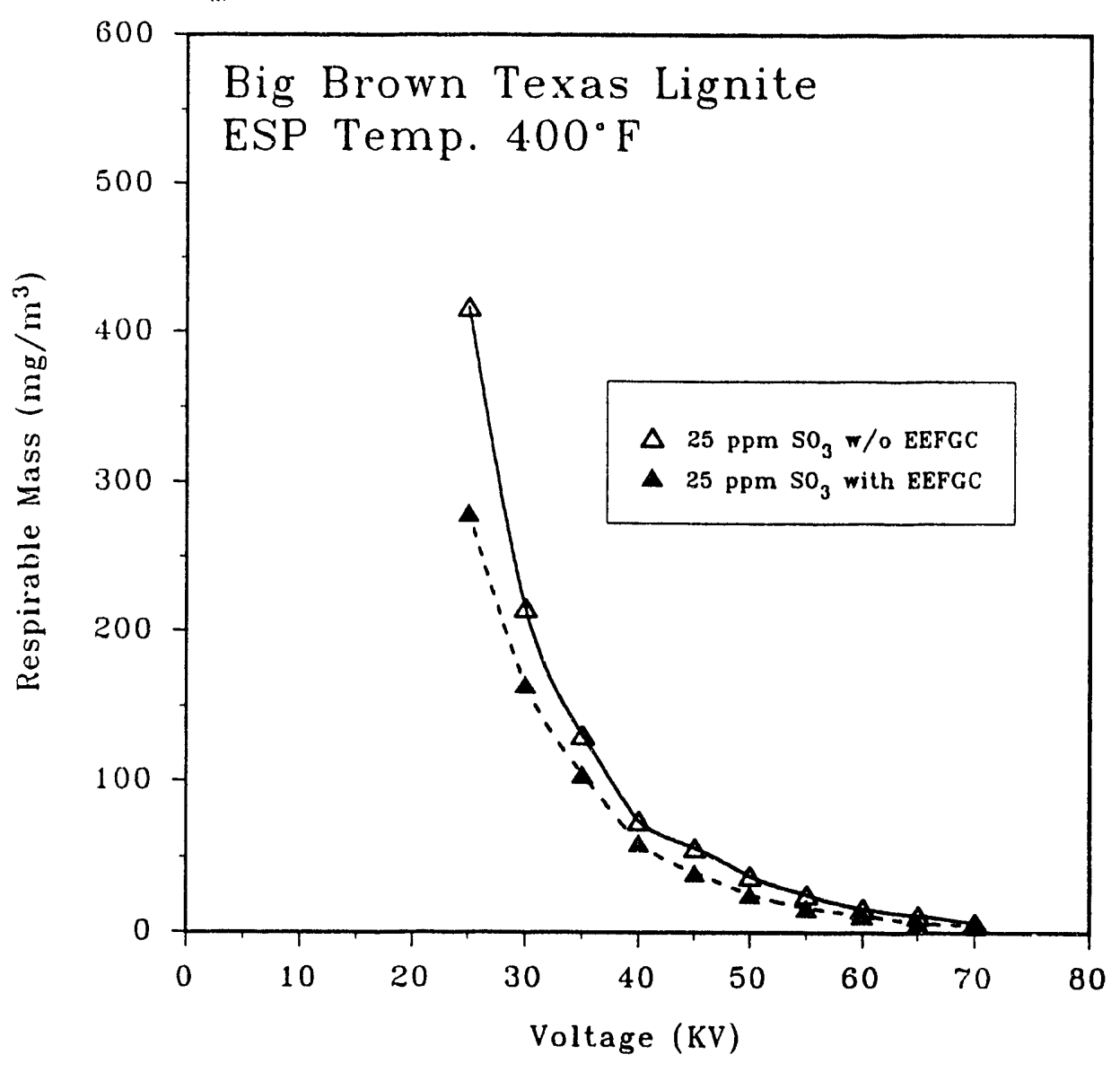

Figure A-5.14. Respirable mass as a function of voltage at $25 \mathrm{ppm} \mathrm{SO}_{3}$ with and without EFGC for Big Brown coal for Run 369. 


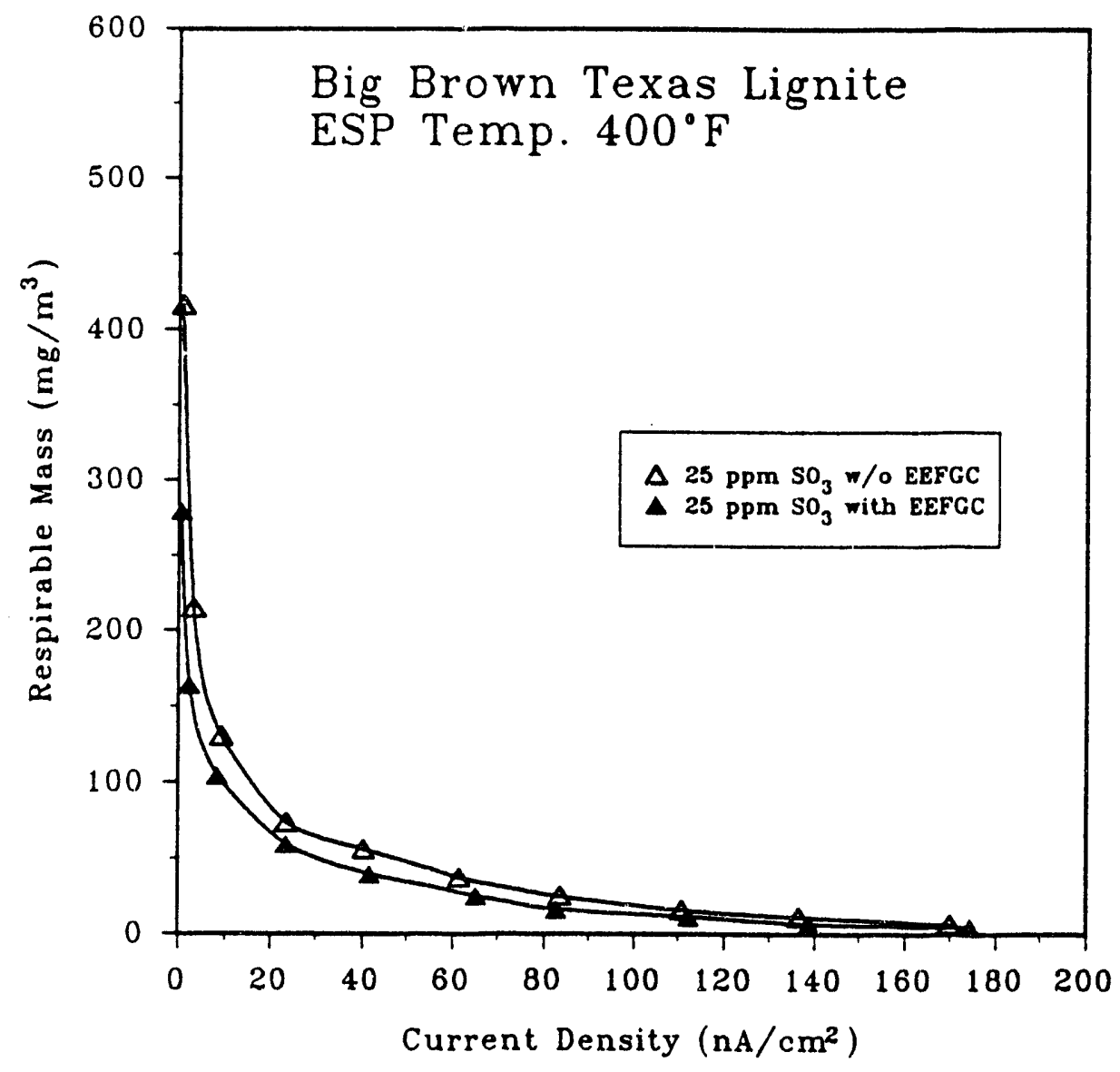

Figure A-5.15. Respirable mass as a function of current density at $25 \mathrm{ppm} \mathrm{SO}_{3}$ with and without EFGC for Big Brown coal for Run 369. 


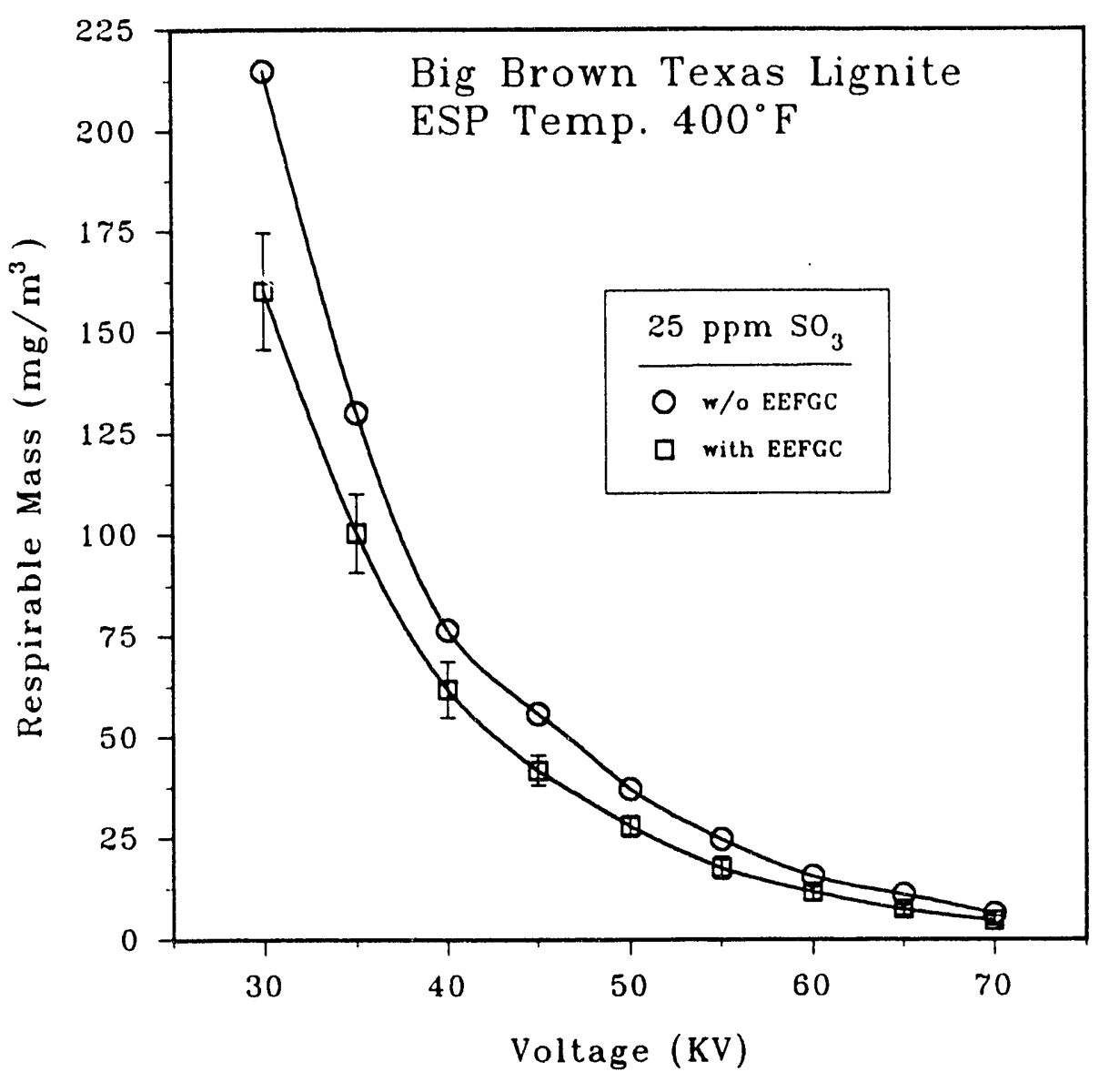

Figure A-5.16. Respirable mass as a function of voltage at $25 \mathrm{ppm} \mathrm{SO}_{3}$ with and without EFGC for Big Brown coal for Runs 369 and 370 . Error bars are plus and minus one standard deviation. 


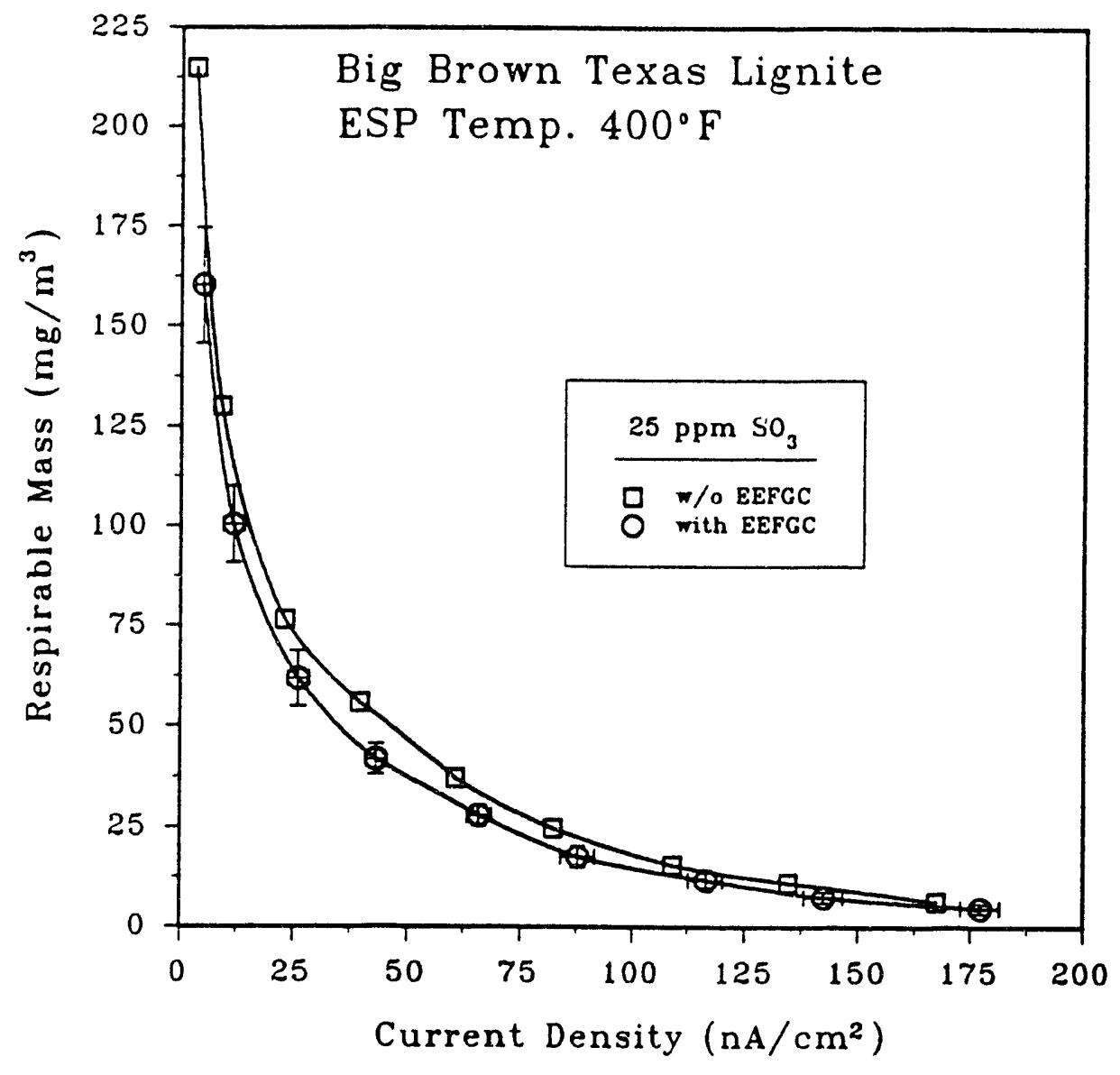

Figure A-5.17. Respirable mass as a function of current density at $25 \mathrm{ppm} \mathrm{SO_{3 }}$ with and without EFGC for Big Brown coal for Runs 369 and 370 . Error bars are plus and minus one standard deviation. 


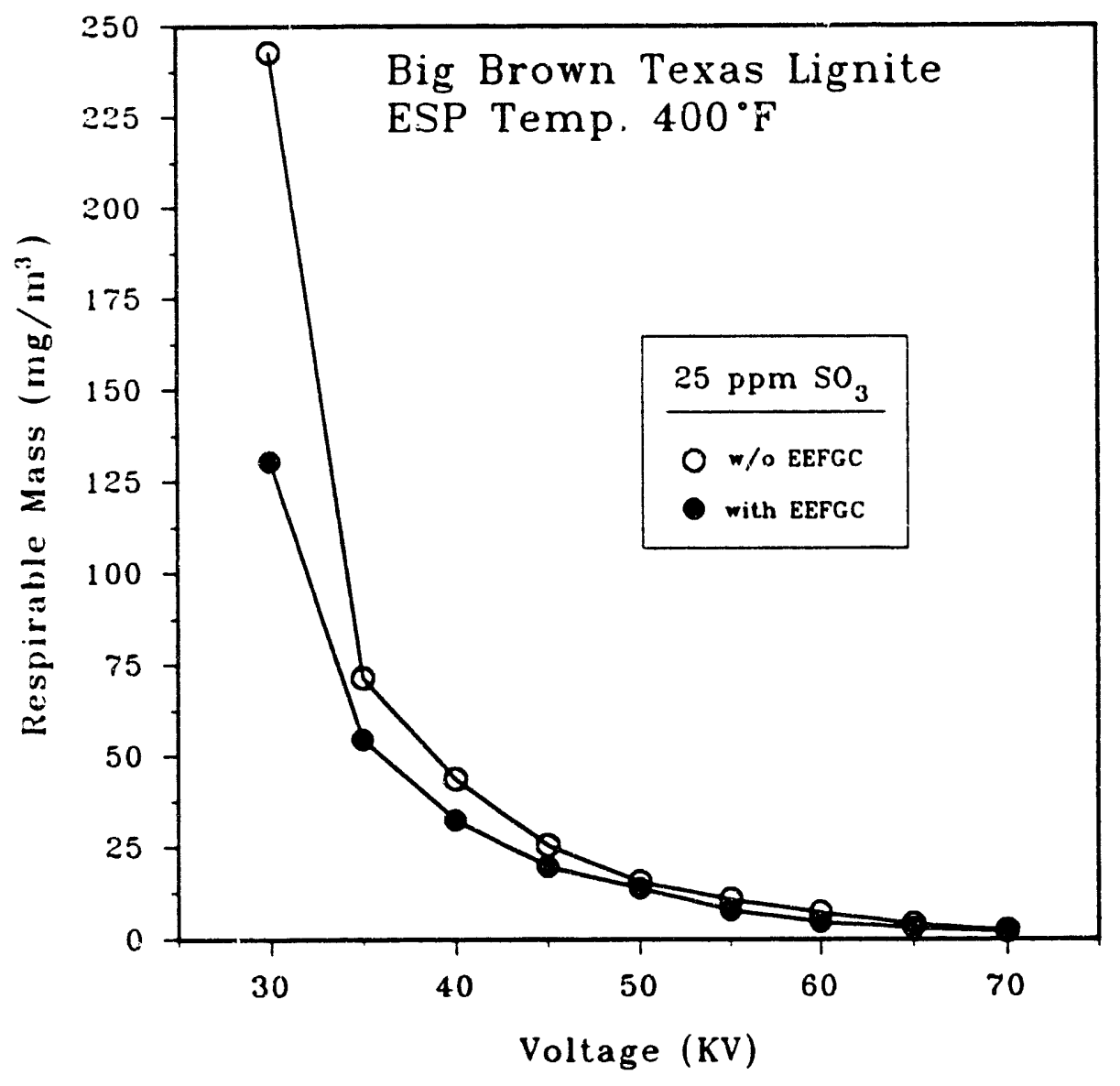

Figure A-5.18. Respirable mass as a function of voltage at $25 \mathrm{ppm} \mathrm{SO} \mathrm{S}_{3}$ with and without EFGC for Big Brown coal for Run 377 comparing Tests 1 and 2. 


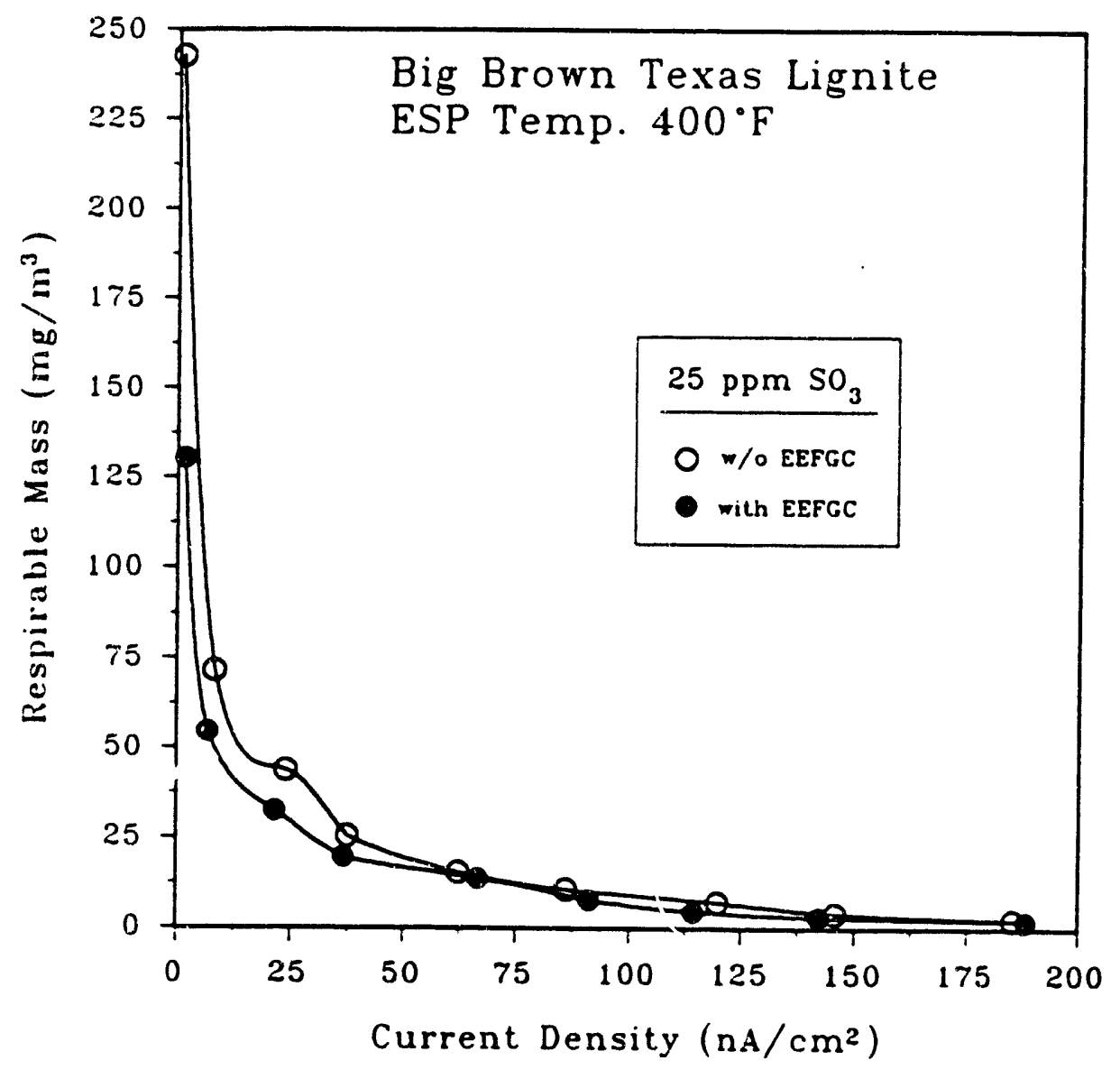

Figure A-5.19. Respirable mass as a function of current density at $25 \mathrm{ppm} \mathrm{SO_{3 }}$ with and without EFGC for Big Brown coal for Run 377 comparing Tests 1 and 2. 


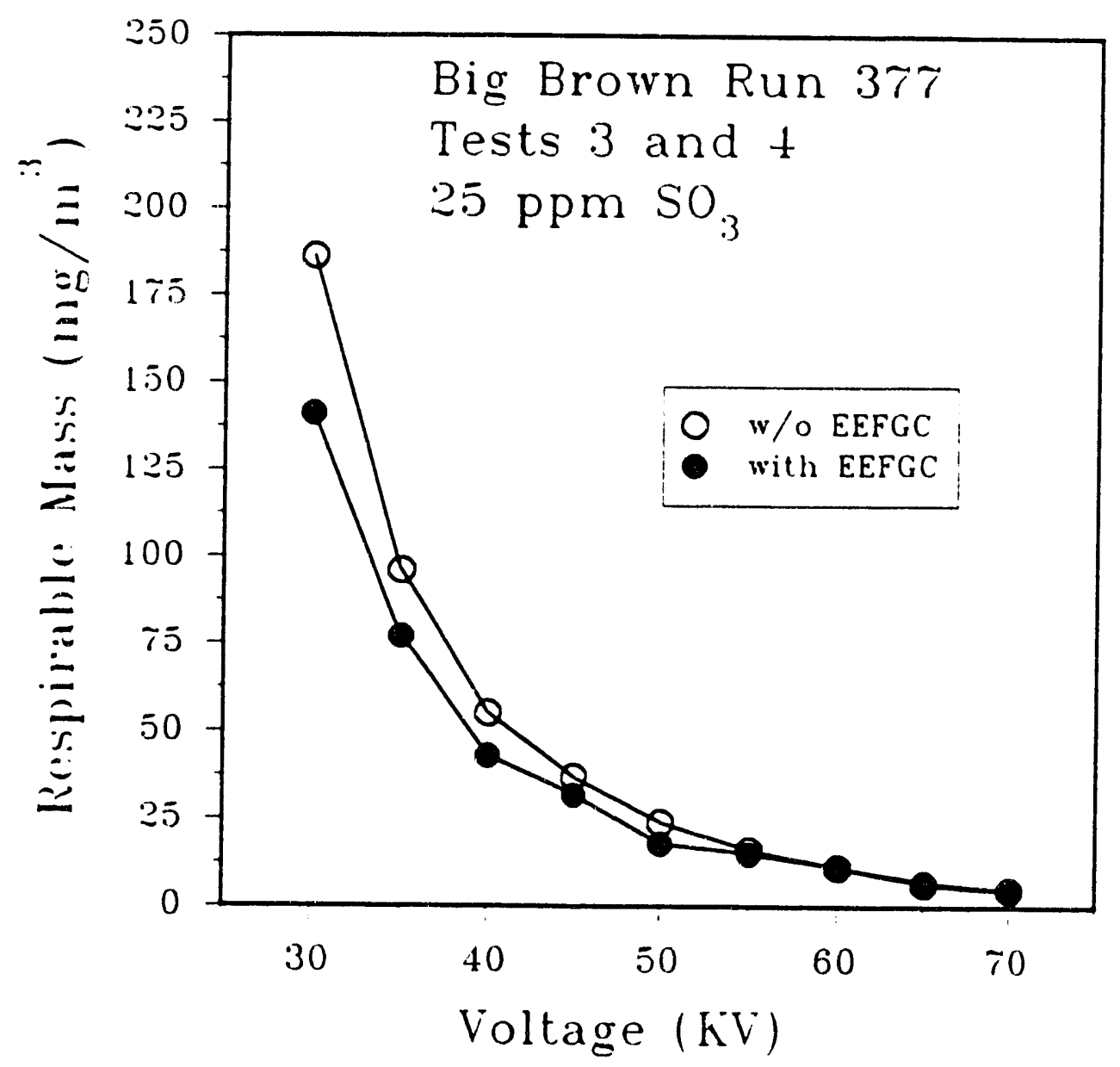

Figure A-5.20. Respirable mass as a function of voltage at $25 \mathrm{ppm} \mathrm{SO}$, with and without EFGC for Big Brown coal for Run 377 comparing Tests 3 and 4. 


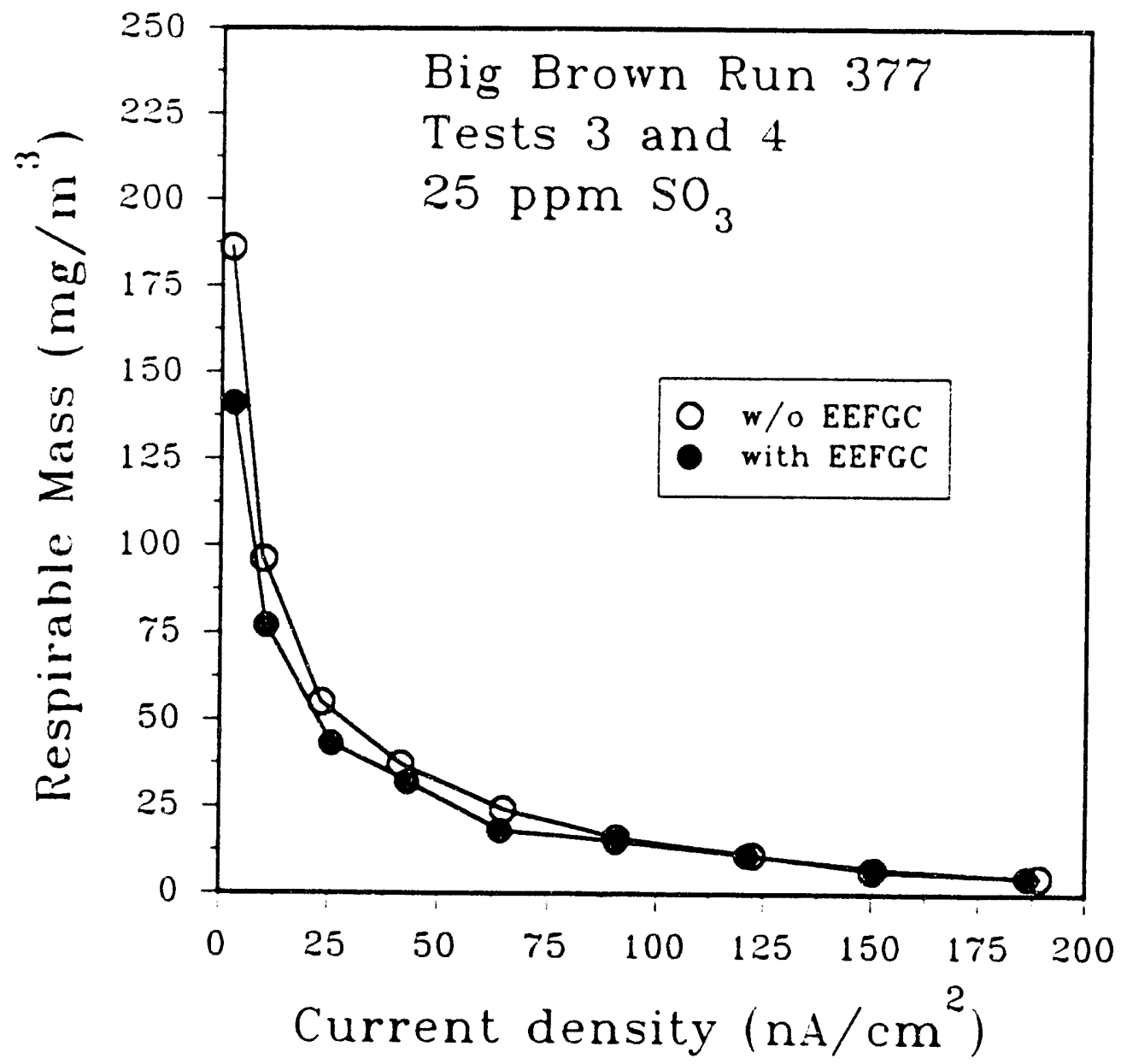

Figure A-5.21. Respirable mass as a function of current density at $25 \mathrm{ppm} \mathrm{SO}$ with and without EFGC for Big Brown coal for Run 377 comparing Tests 3 and 4. 


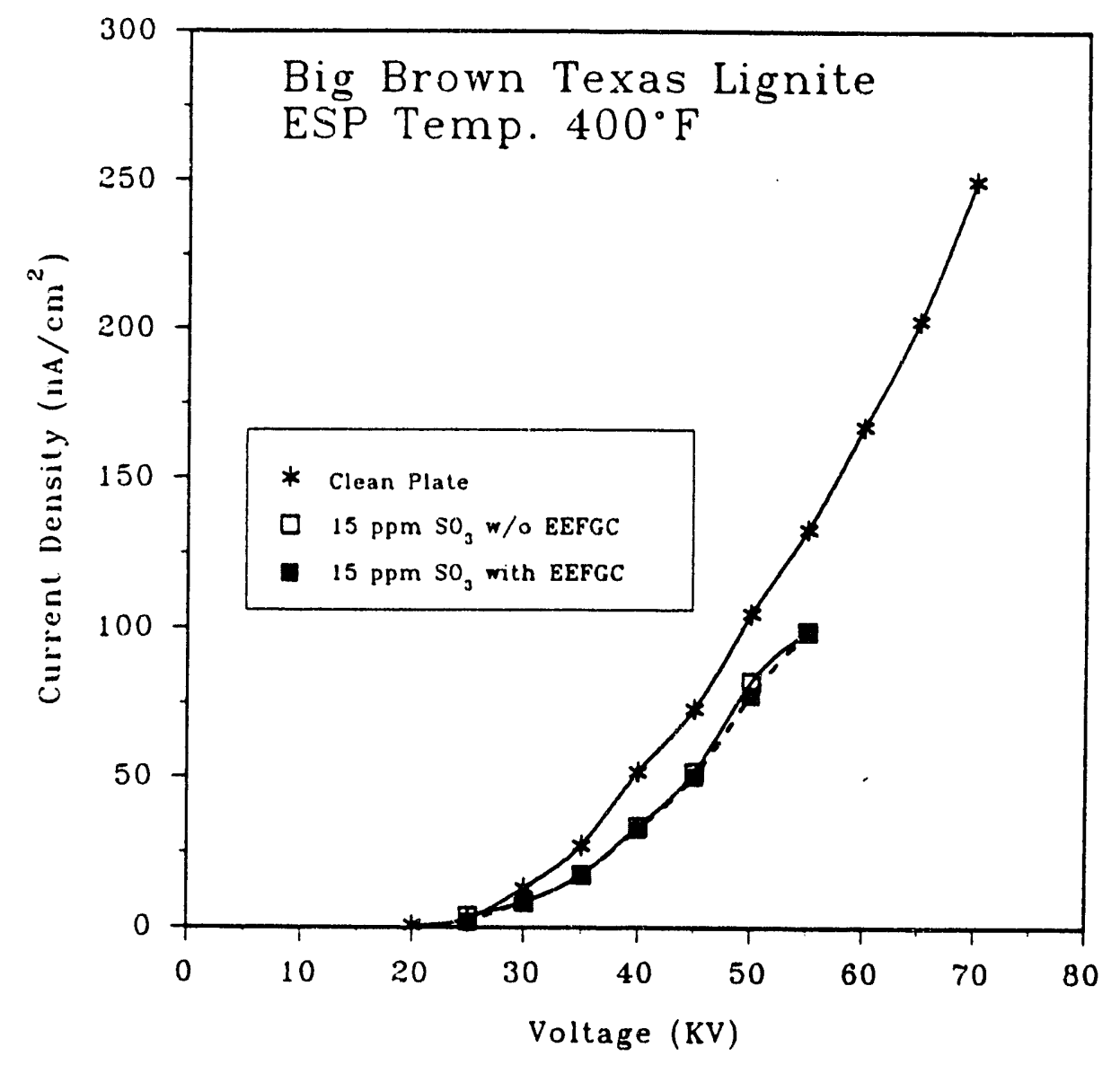

Figure A-5.22. Current-voltage curves for $15 \mathrm{ppm} \mathrm{SO}_{3}$ with and without EFGC for Big Brown coal for Run 368. 


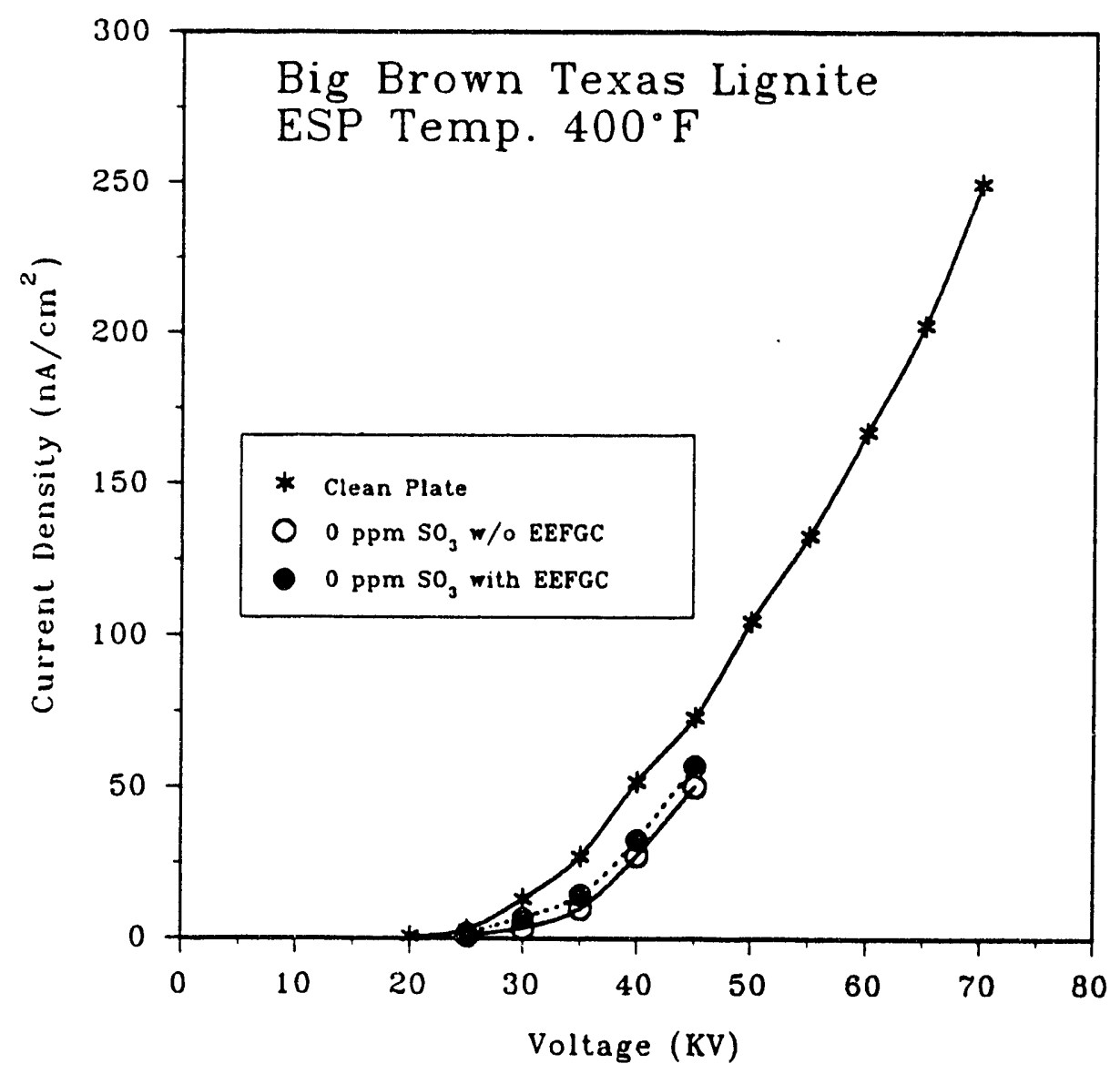

Figure A-5.23. Current-voltage curves for $0 \mathrm{ppm} \mathrm{SO}$, with and without EFGC for Big Brown coal for Run 368. 


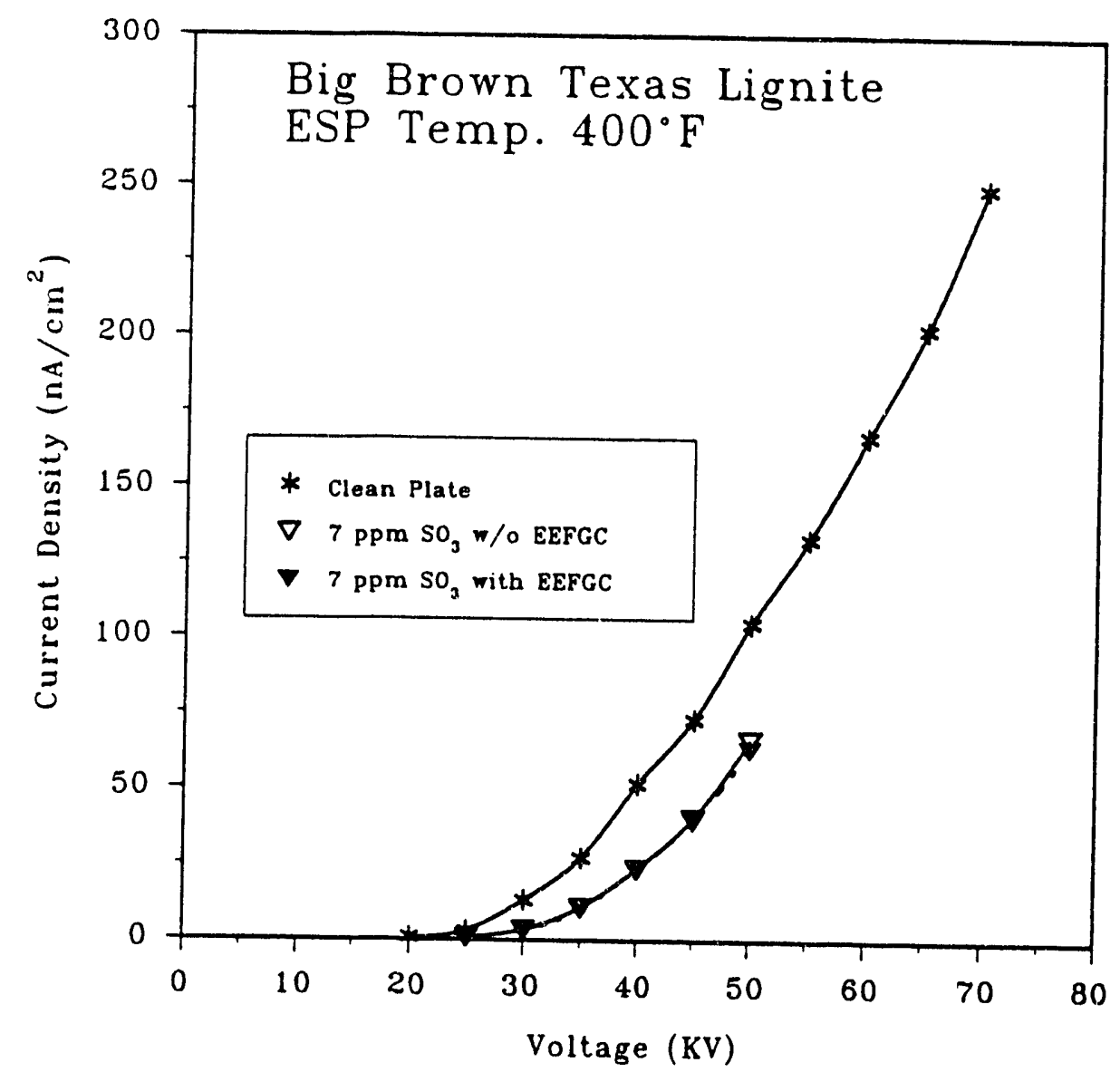

Figure A-5.24. Current-voltage curves for $7 \mathrm{ppm} \mathrm{SO}_{3}$ with and without EFGC for Big Brown coal for Run 369. 


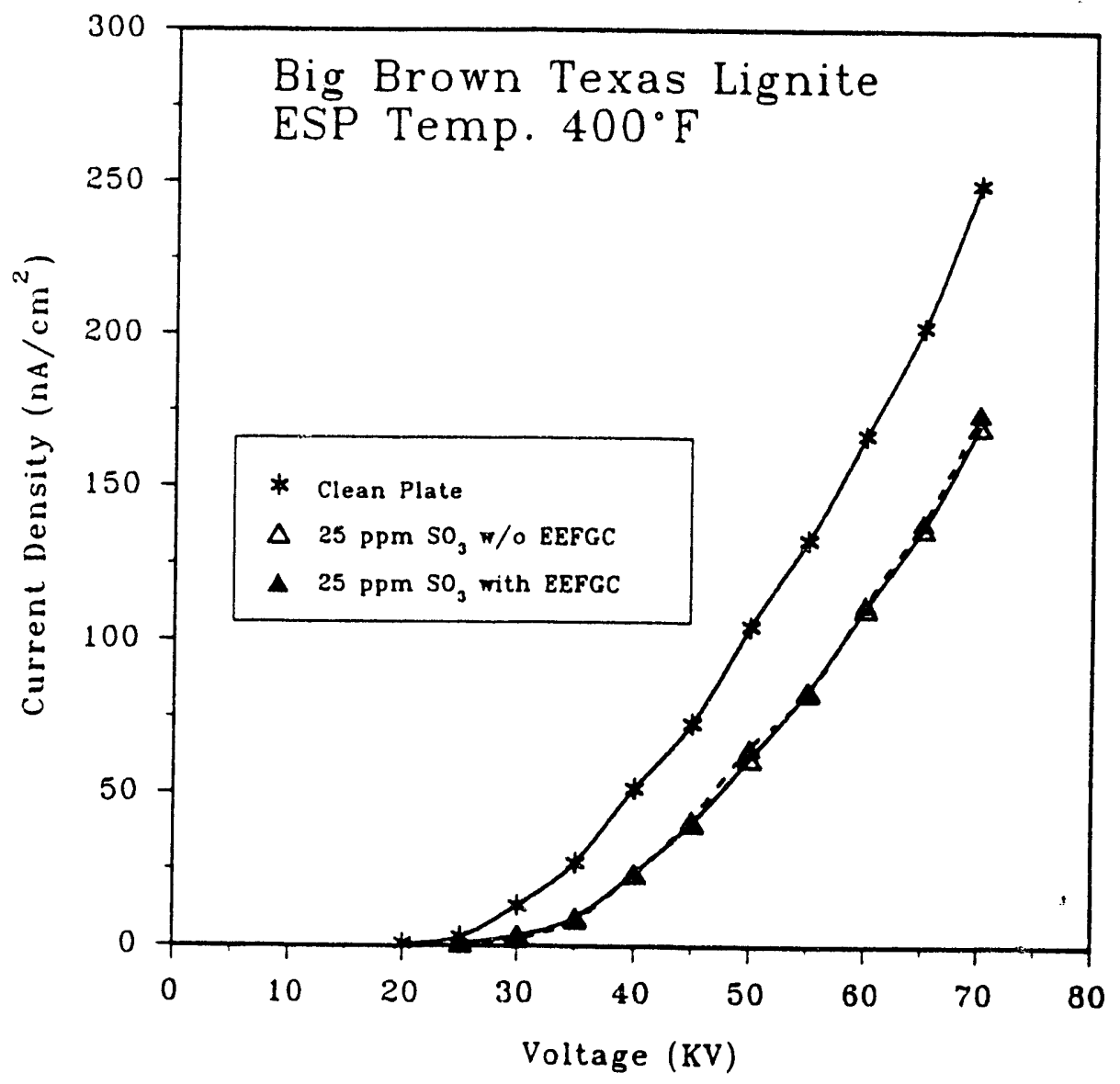

Figure A-5.25. Current-voltage curves for $25 \mathrm{ppm} \mathrm{SO} \mathrm{S}_{3}$ with and without EFGC for Big Brown coal for Run 369. 


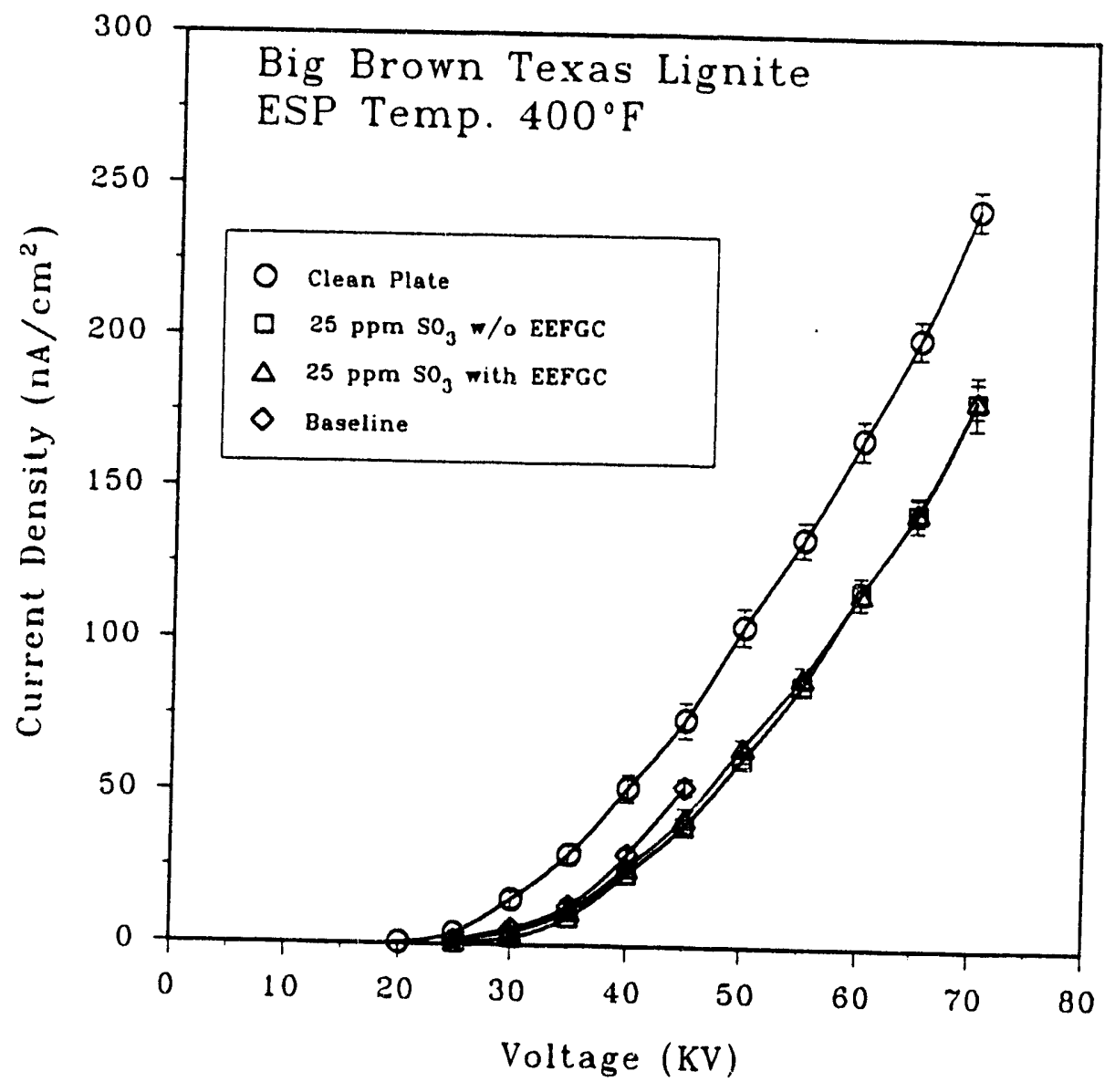

Figure A-5.26. Current-voltage curves for $25 \mathrm{ppm} \mathrm{SO}$, with and without EFGC for Big Brown coal for Runs 369, 370, and 377. Error bars are plus and minus one standard deviation. 


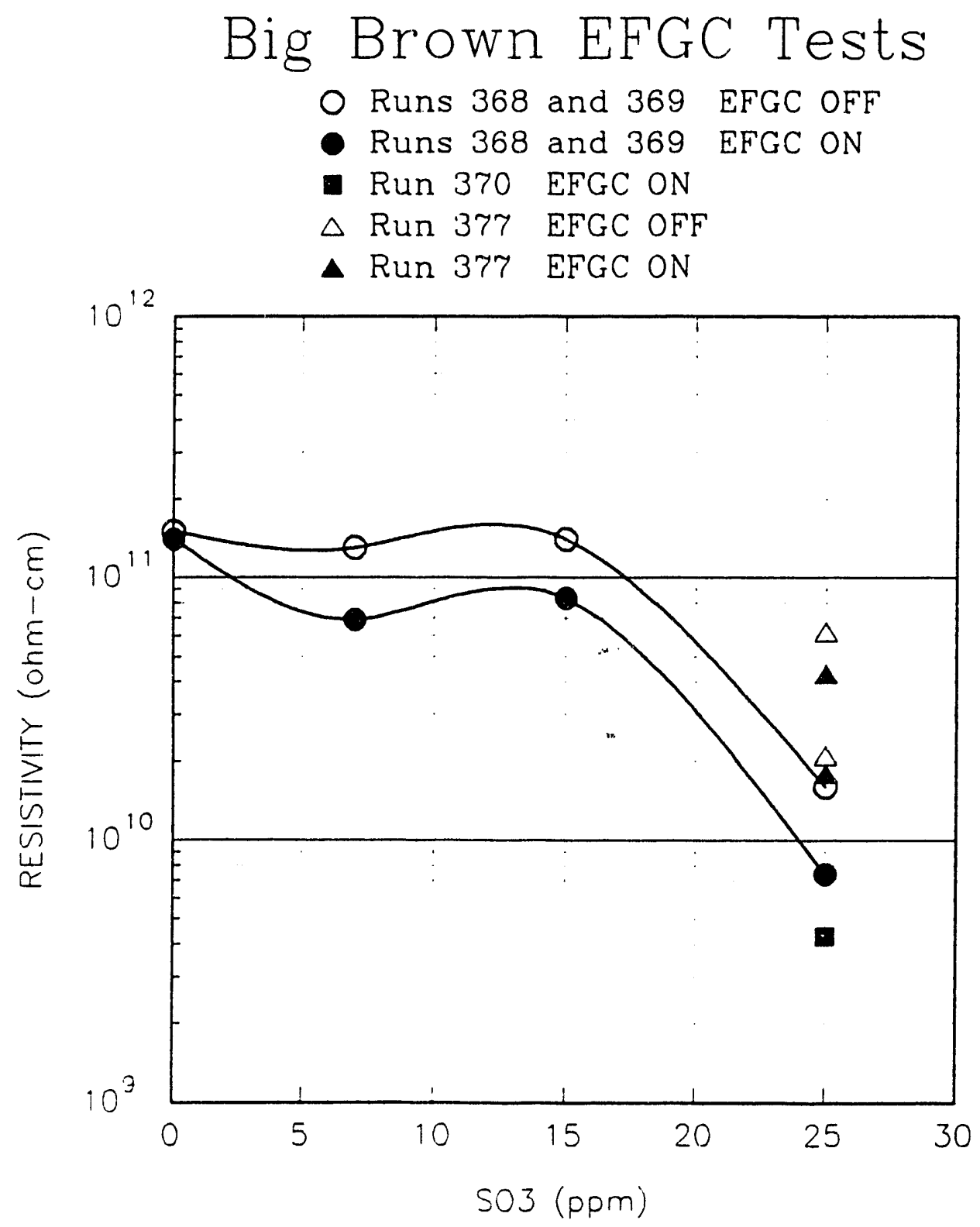

Figure A-5.27. Resistivity as a function of $\mathrm{SO}_{3}$ concentration with and without EFGC for Big Brown coal for Runs 368-370 and 377 . 


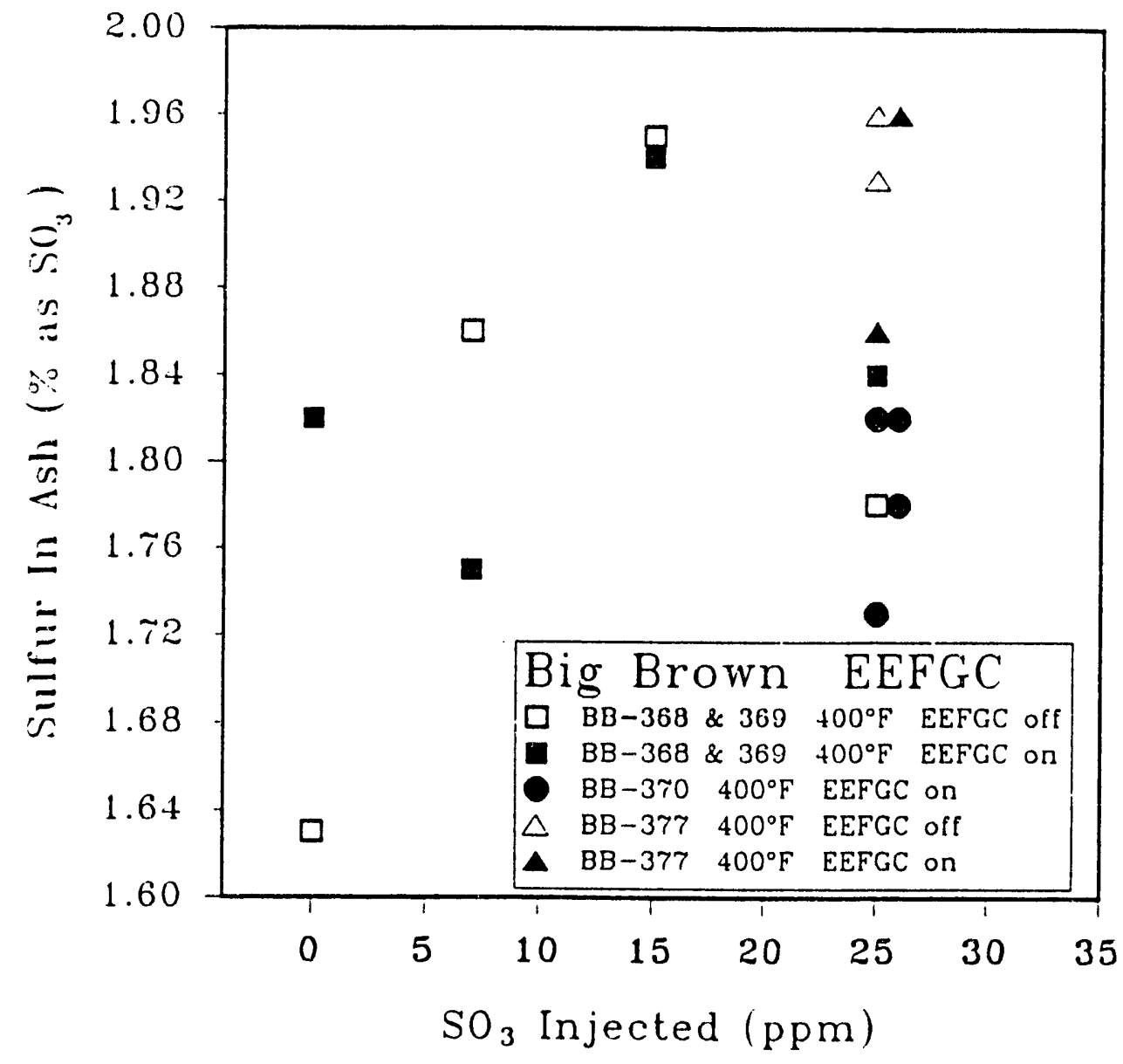

Figure A-5.28. Sulfur retention as a function of $\mathrm{SO}_{3}$ concentration with and without EFGC for Big Brown coal for Runs 368-370 and 377 . 


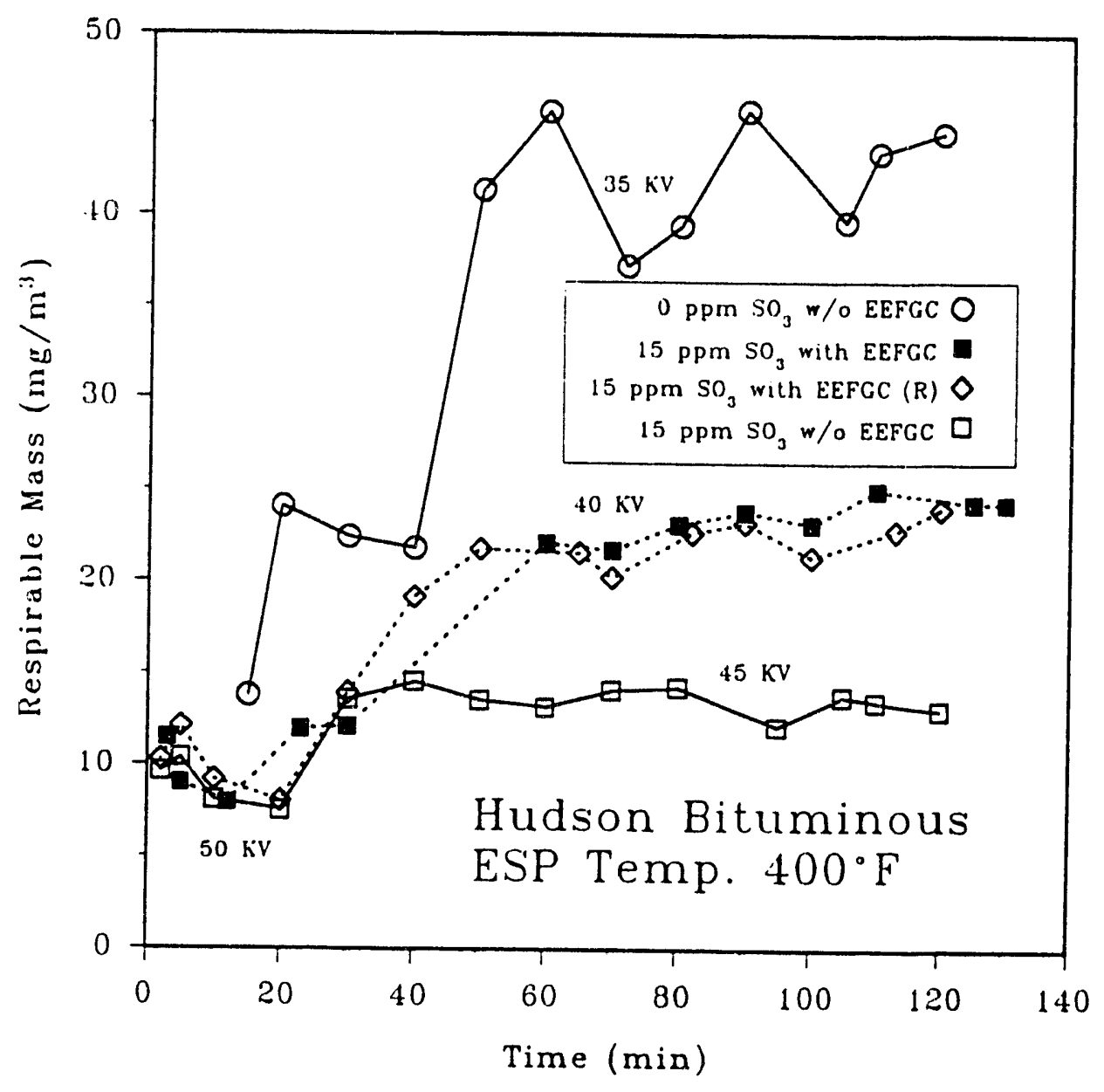

Figure A-6.1. Respirable mass emissions as a function of time with and without EFGC at $400^{\circ} \mathrm{F}$ for Hudson bituminous coal for Run 371 . 


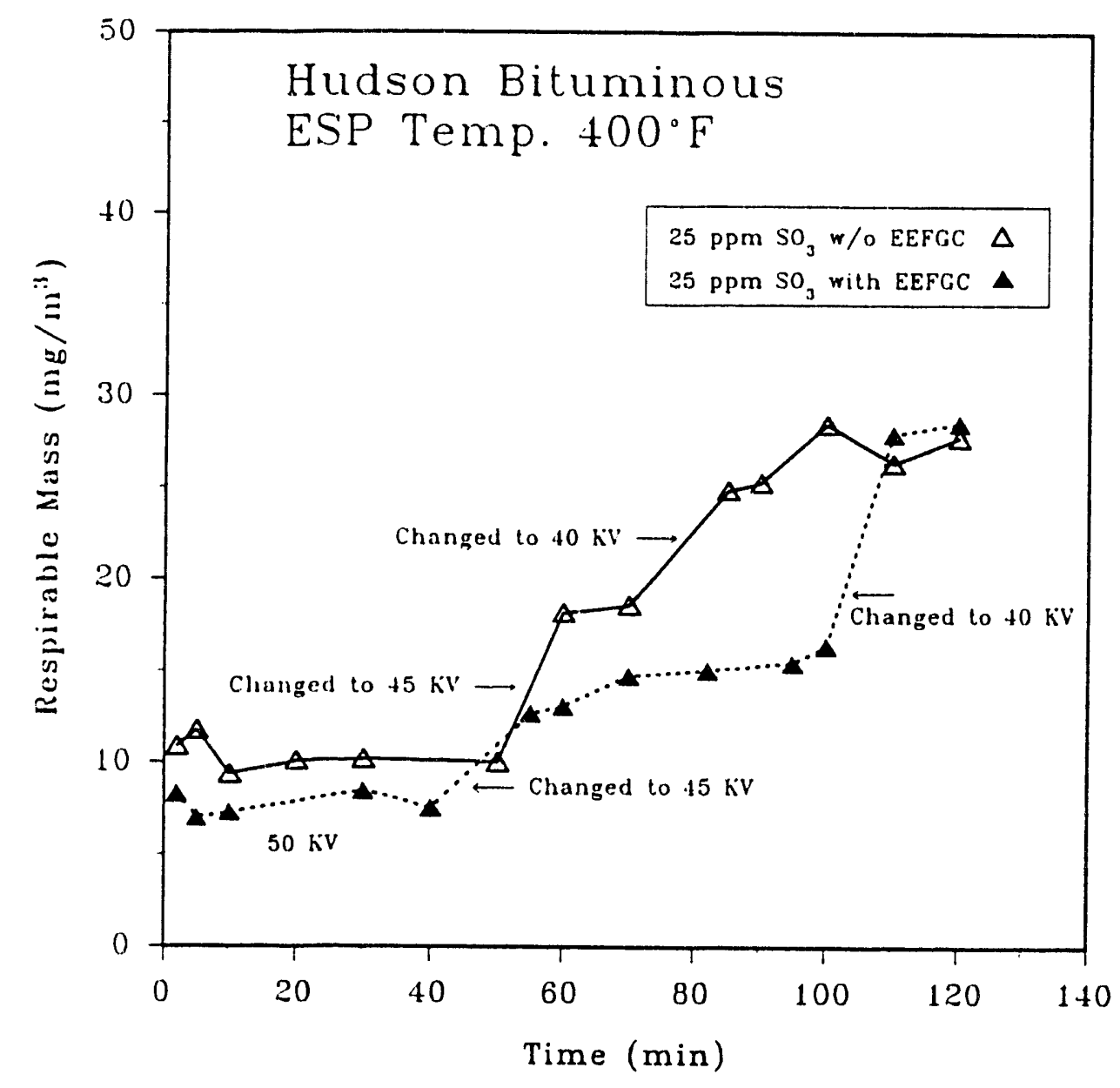

Figure A-6.2. Respirable mass emissions as a function of time at $25 \mathrm{ppm} \mathrm{SO}$ with and without $E F G C$ at $400^{\circ} \mathrm{F}$ for Hudson bituminous coal for Run 372. 


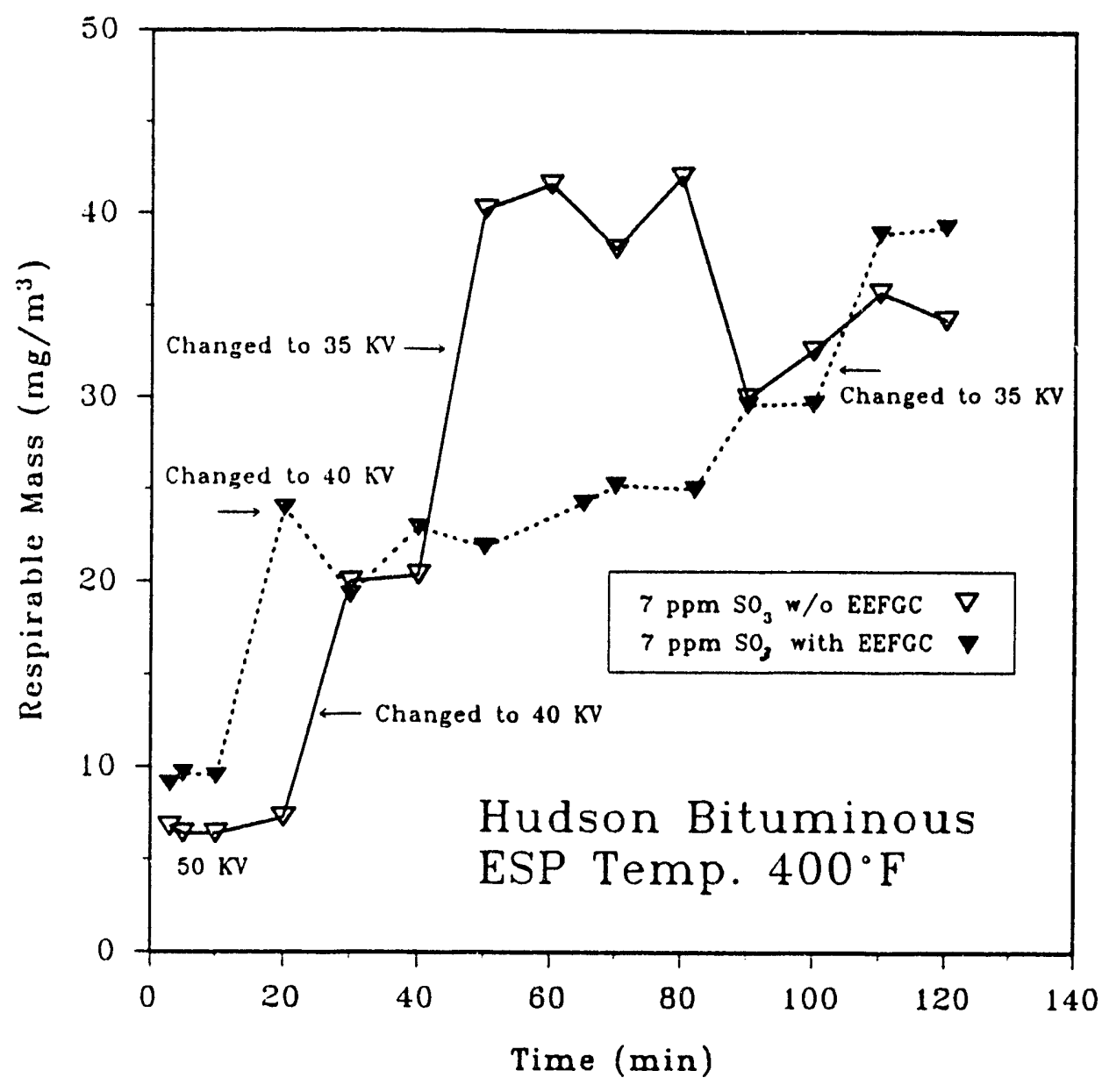

Figure A-6.3. Respirable mass emissions as a function of time at $7 \mathrm{ppm} \mathrm{SO}_{3}$ with and without EFGC at $400^{\circ} \mathrm{F}$ for Hudson bituminous coal for Run 372 . 


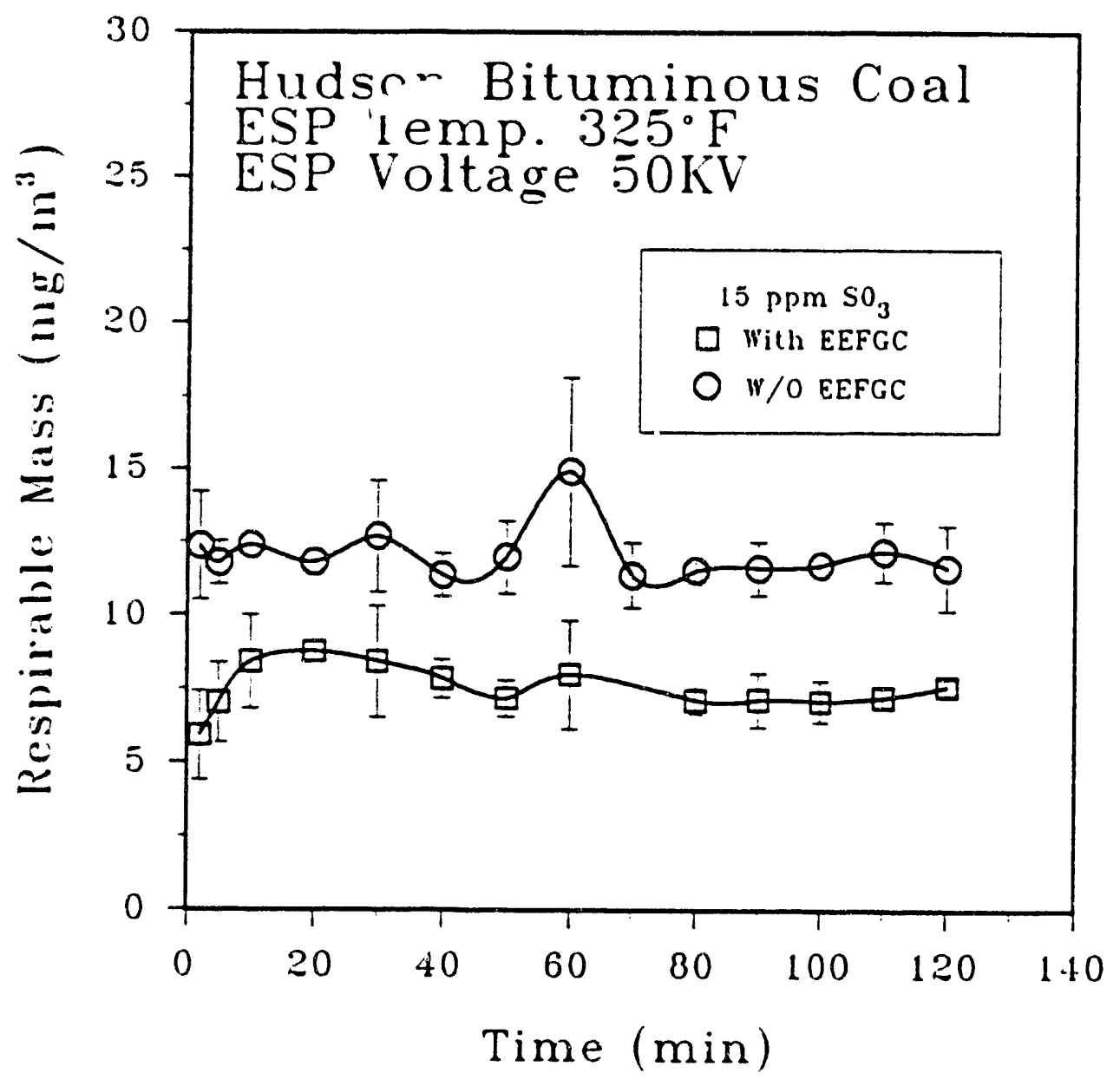

Bigure A-6.4. Respirable mass emissions as a function of time at $15 \mathrm{ppm} \mathrm{SO}_{3}$ with and without EFGC at $325^{\circ} \mathrm{F}$ for Hudson bituminous coal for Runs 373, 374, and 378. Error bars are plus and minus one standard deviation. 


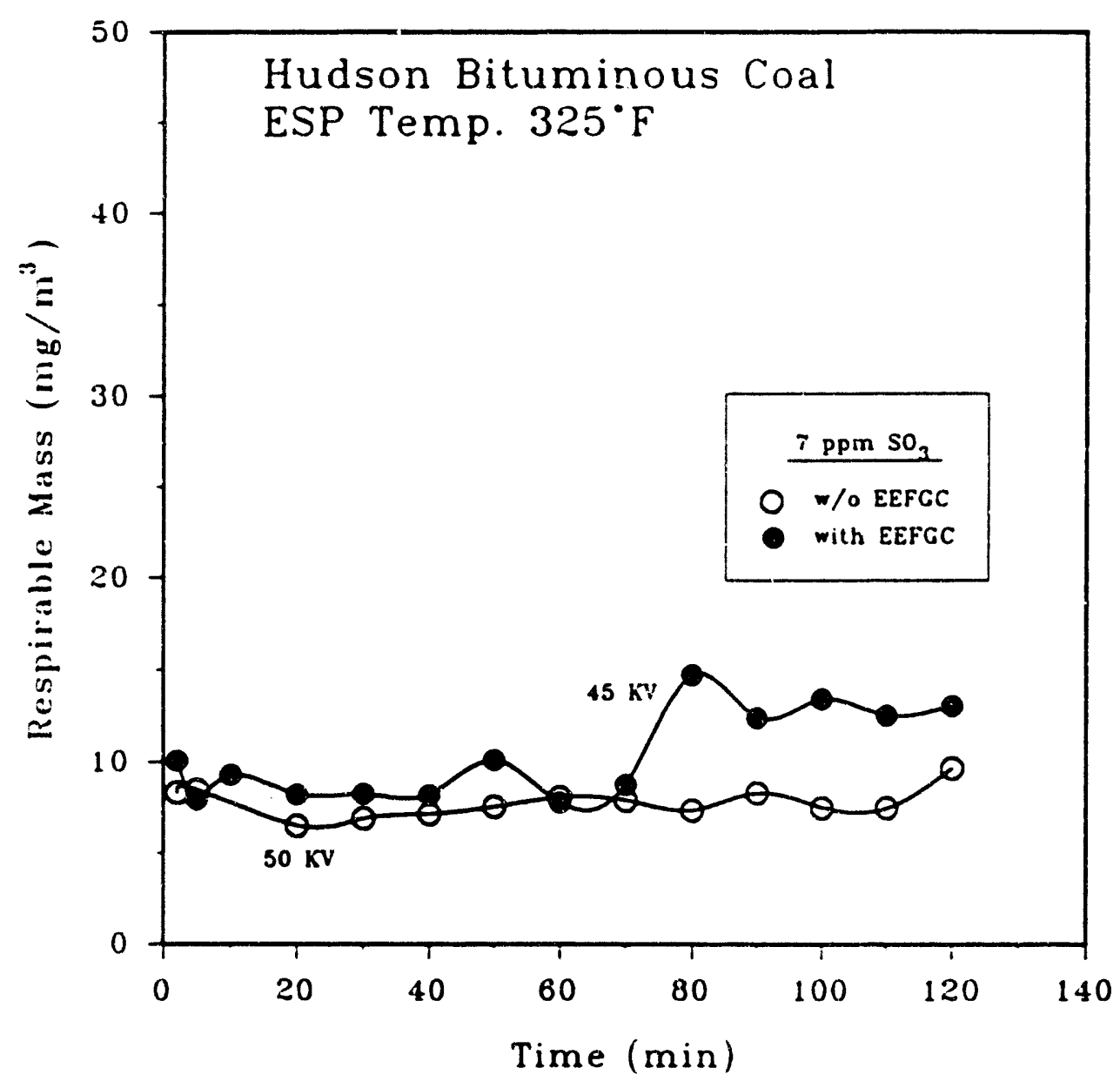

Figure A-6.5. Respirable mass emissions as a function of time at $7 \mathrm{ppm}$ SO, with and without EFGC at $325^{\circ} \mathrm{F}$ for Hudson bituminous coal for Run 374 . 


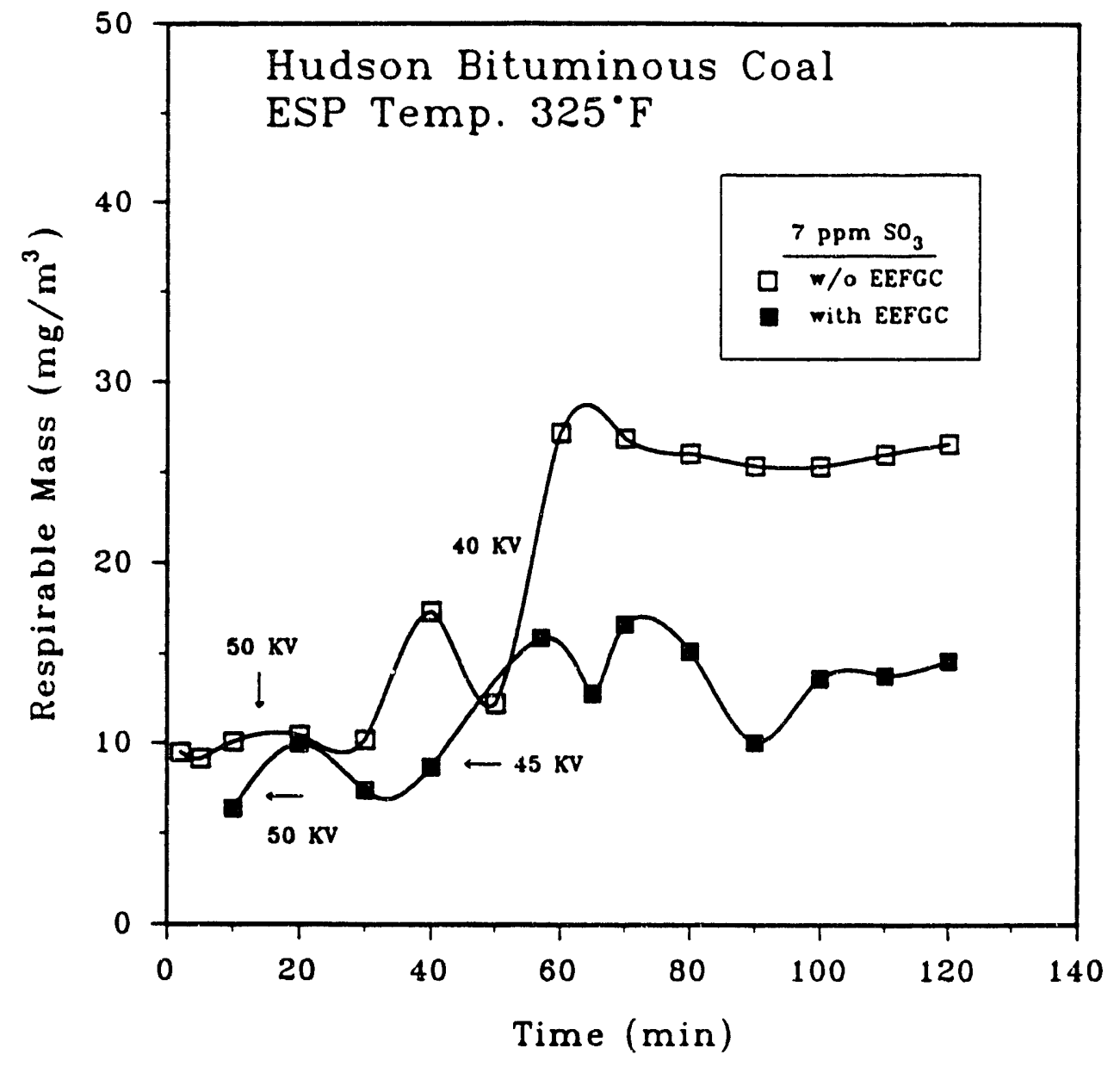

Figure A-6.6. Respirable mass emissions as a function of time at $7 \mathrm{ppm} \mathrm{SO}_{3}$ with and without EFGC at $325^{\circ} \mathrm{F}$ for Hudson bituminous coal for Run 378. 


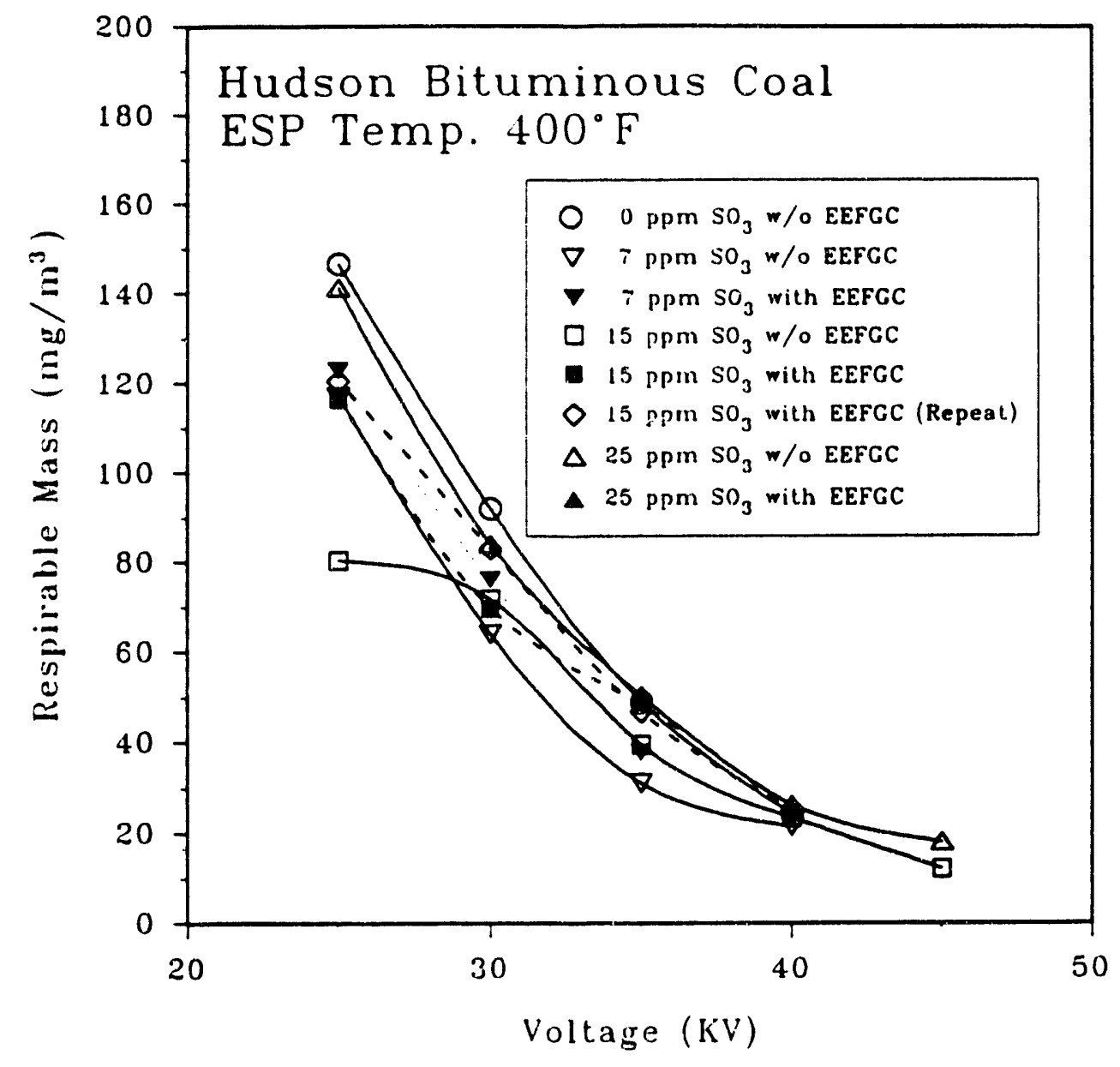

Figure A-6.i. Respirable mass emissions as a function of voltage with and without EFGC at $400^{\circ} \mathrm{F}$ for Hudson bituminous coal for Runs 371 and 372 . 


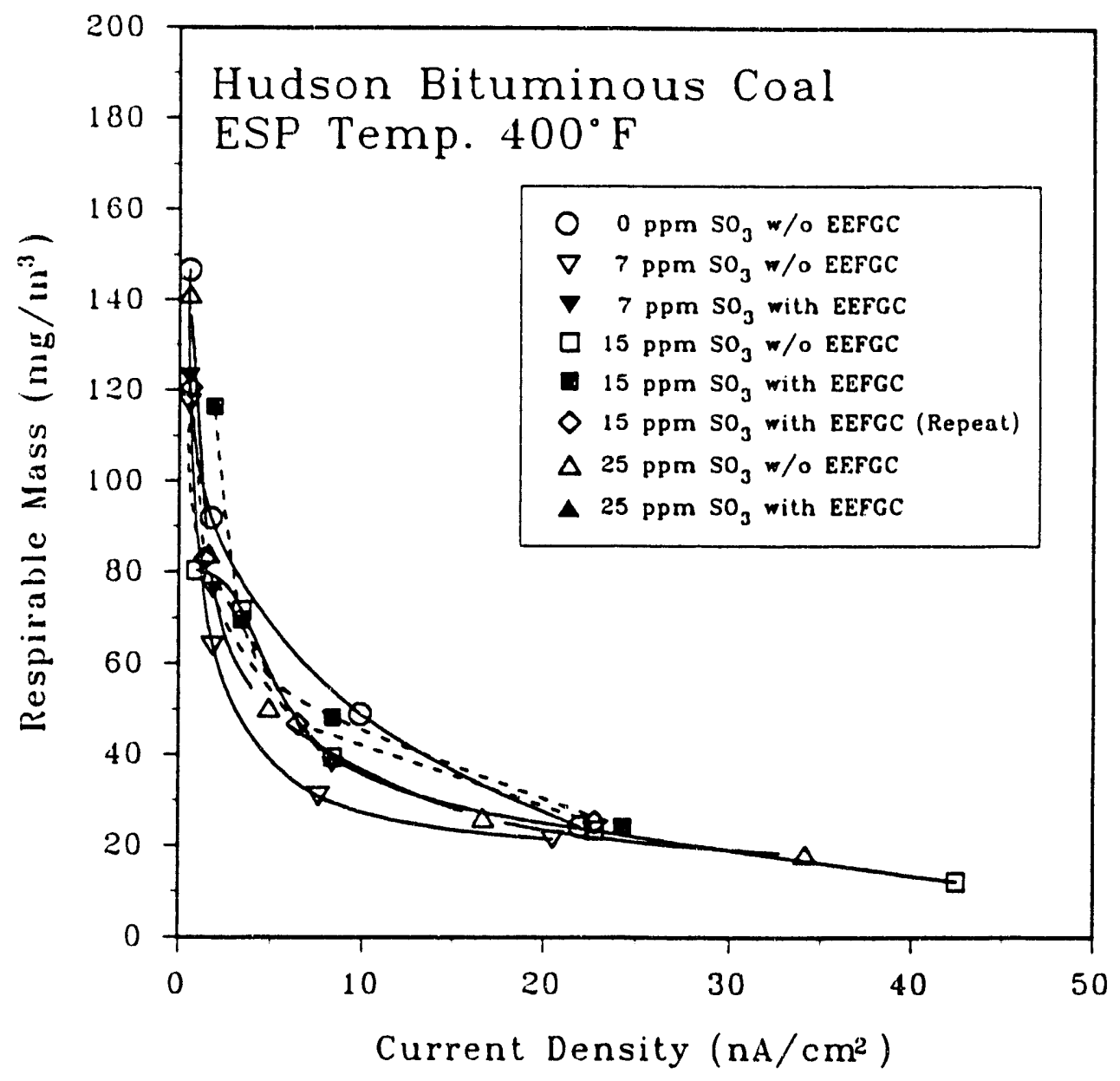

Figure A-6.8. Respirable mass emissions as a function of current density with and without EFGC at $400^{\circ} \mathrm{F}$ for Hudson bituminous coal for Runs 371 and 372. 


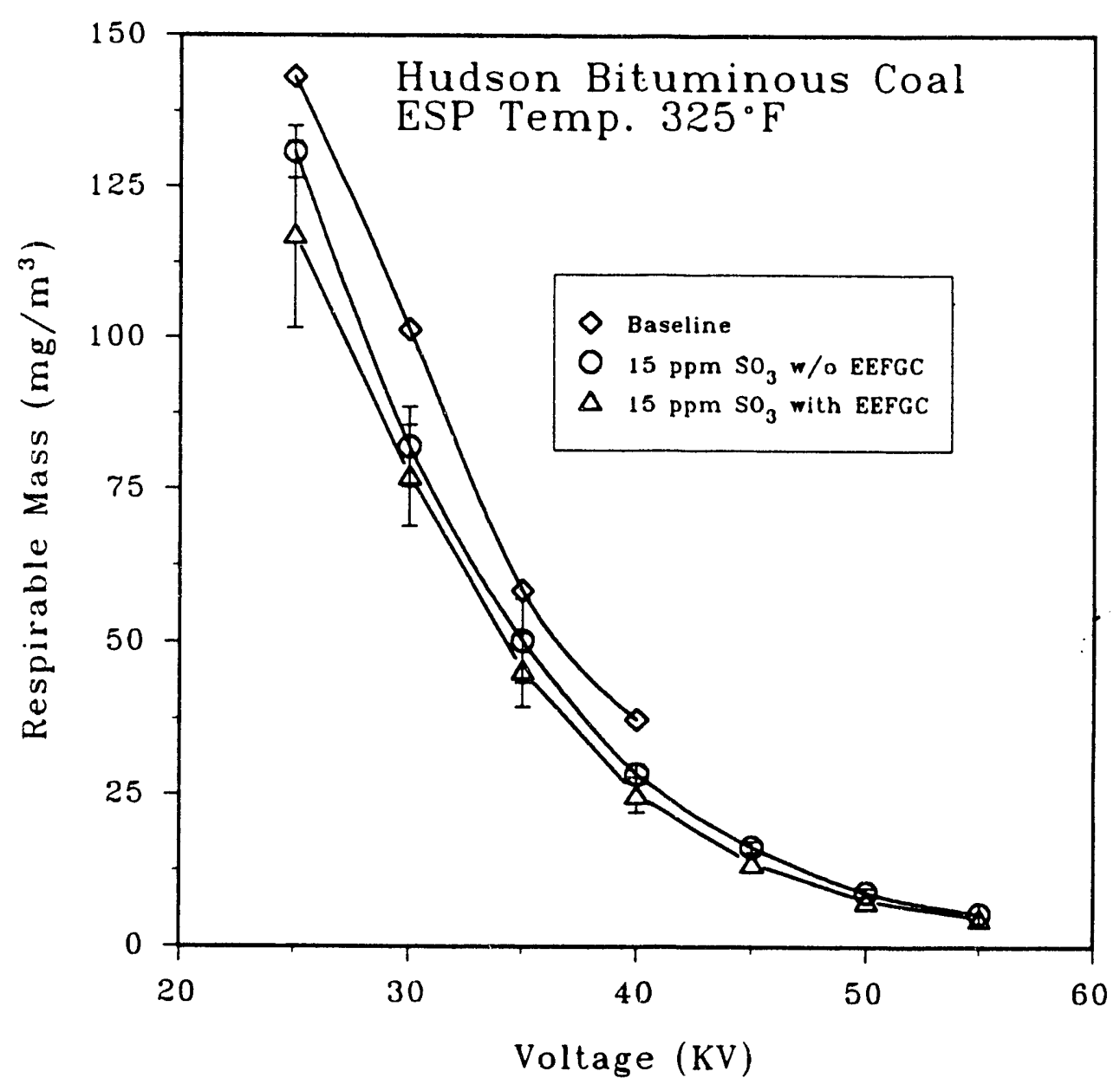

Figure A-6.9. Respirable mass emissions as a function of voltage with and without EFGC at $325^{\circ} \mathrm{F}$ for Hudson bituminous coal for Runs 373 , 374, and 378. Baseline is from Run 355. Error bars are plus and minus one standard deviation. 


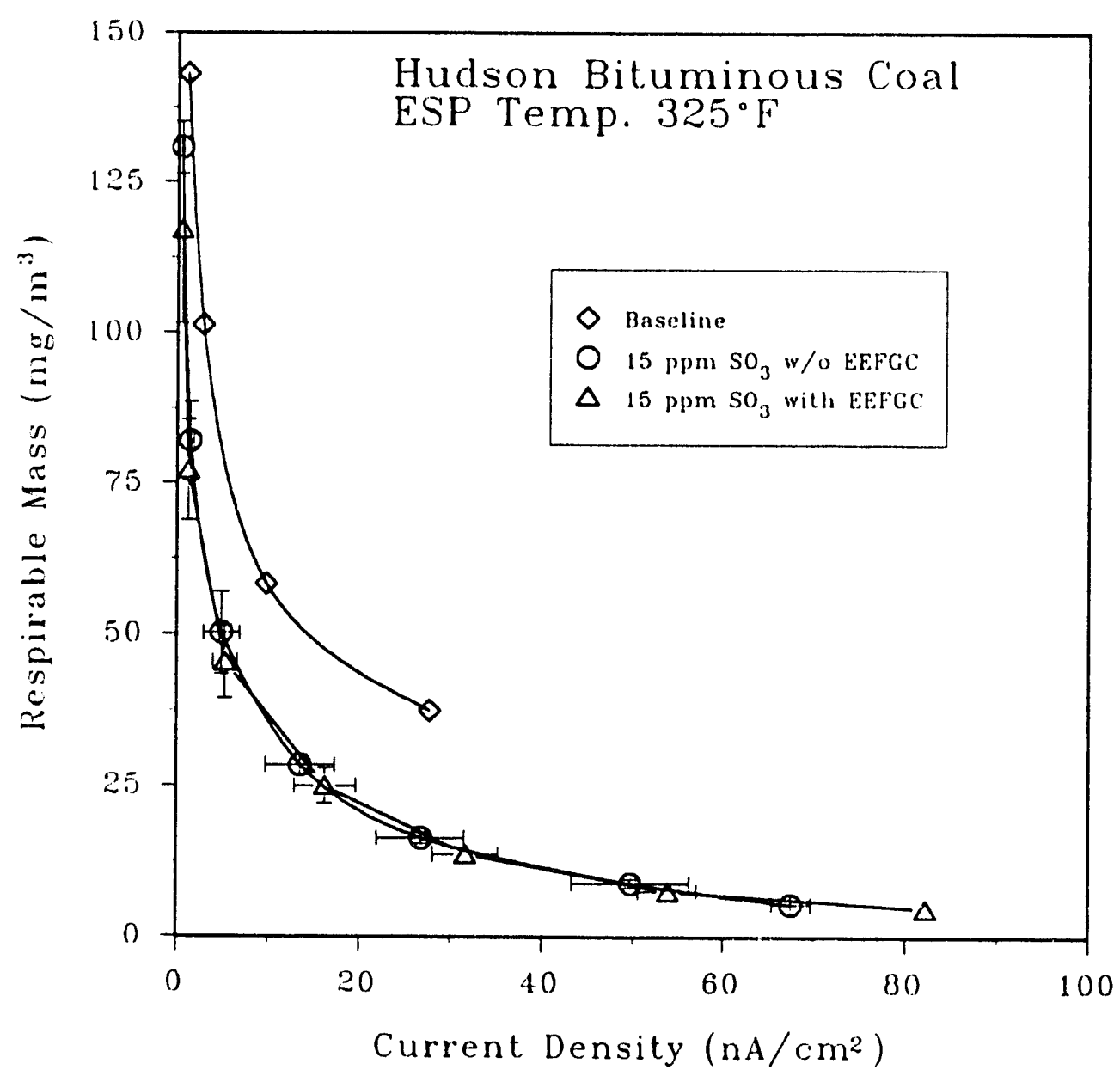

Figure A-6.10. Respirable mass emissions as a function of current density with and without EFGC at $325^{\circ} \mathrm{F}$ for Hudson bituminous coal for Runs 373, 374, and 378. Baseline is from Run 355. Error bars are plus and minus one standard deviation. 


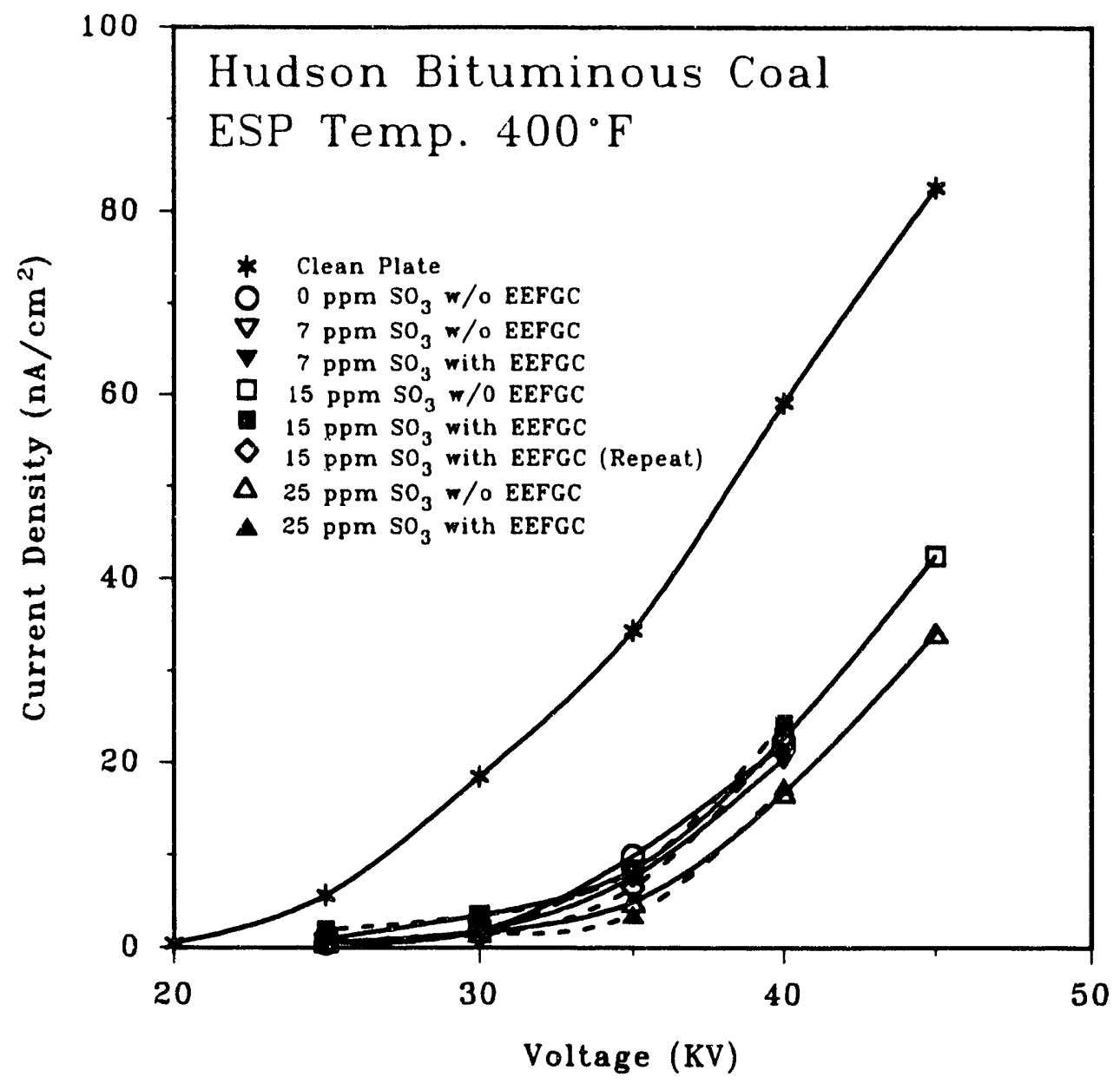

Figure A-6.11. Current-voltage curves with and without EFGC at $400^{\circ} \mathrm{F}$ for Hudson bituminous coal for Runs 371 and 372 . 


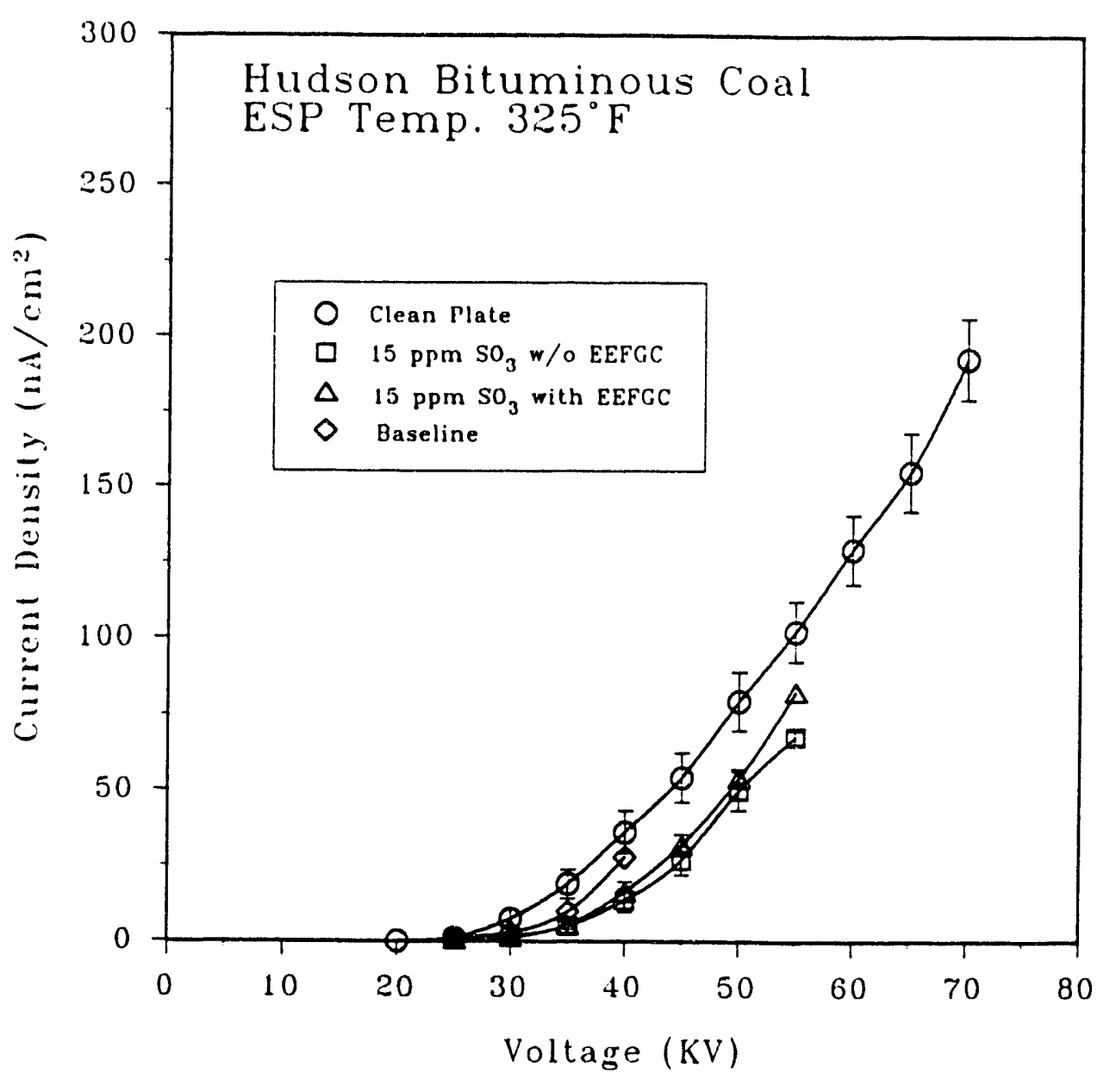

Figure A-6.12. Current-voltage curves with and without EFGC at $325^{\circ} \mathrm{F}$ for Hudson bituminous coal for Runs 373, 374, and 378. Error bars are plus and minus one standard deviation. 


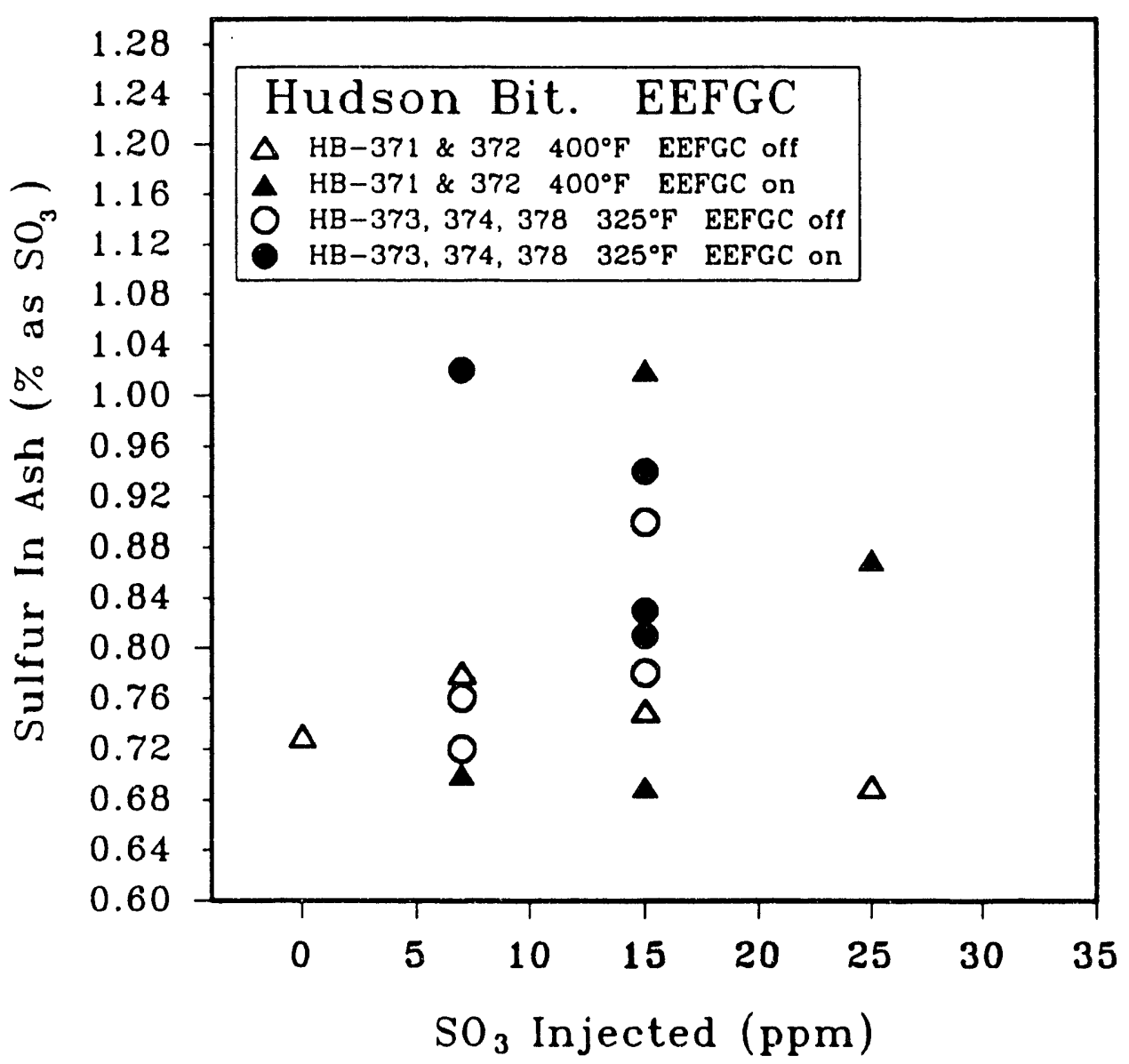

Figure $\mathrm{A}-6.13$. Sulfur retention as a function of $\mathrm{SO}_{3}$ concentration with and without EFGC for Hudson bituminous coal for Runs 371-374 and 378. 


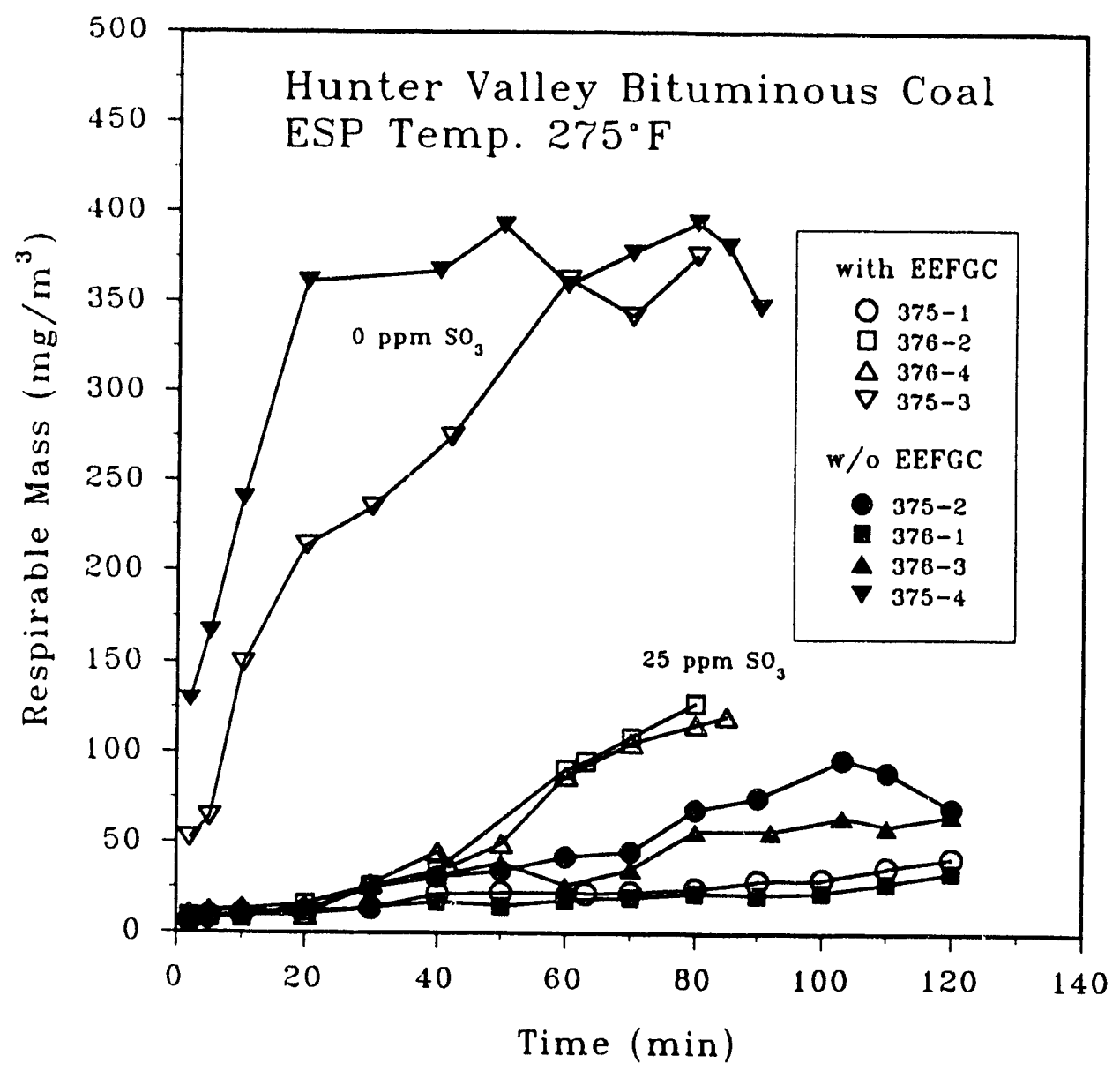

Figure A-7.1. Respirable mass emissions as a function of time with and without EFGC at $275^{\circ} \mathrm{F}$ for Hunter Valley coal for Runs 375 and 376. 


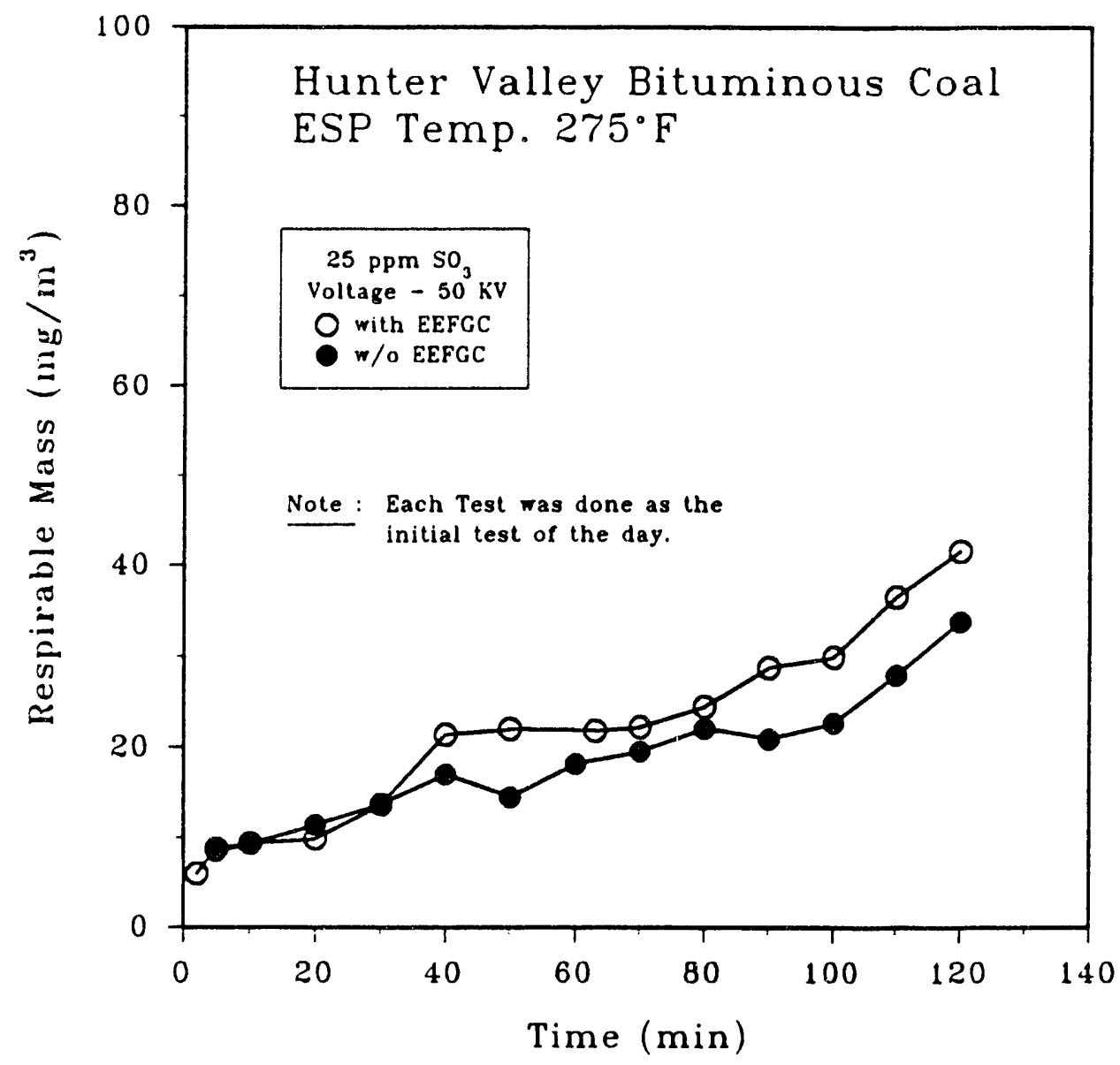

Figure A-7.2. Respirable mass emissions as a function of time at $25 \mathrm{ppm} \mathrm{\textrm {SO } _ { 3 }}$ with and without EFGC at $275^{\circ} \mathrm{F}$ for Hunter Valley coal for Runs 375 and 376 comparing Test 1 each day. 


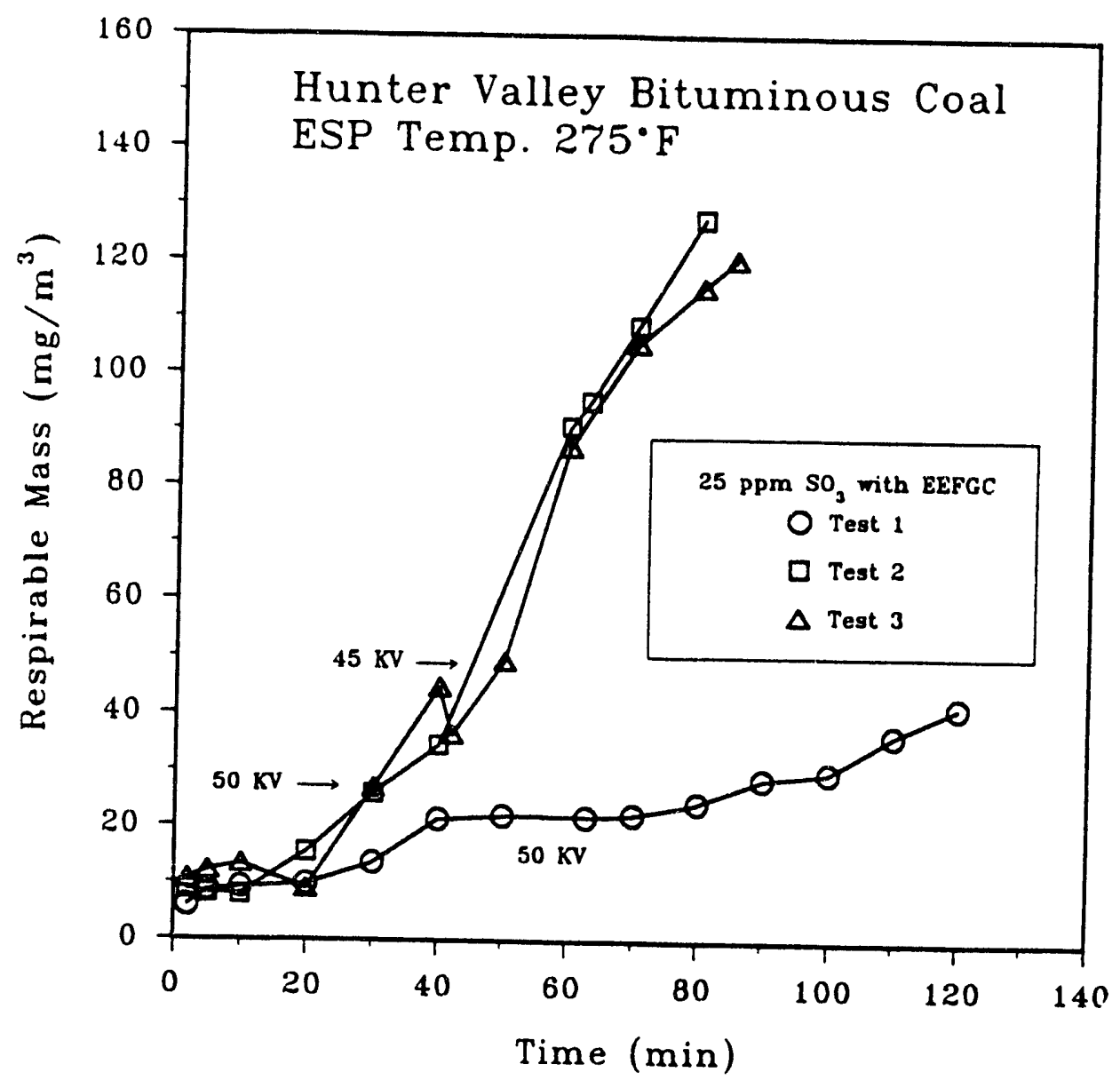

Figure A-7.3. Respirable mass emissions as a function of time at $25 \mathrm{ppm} \mathrm{SO}$ with EFGC at $275^{\circ} \mathrm{F}$ for Hunter Valley coal for Runs 375 and 376. Data show significant variability. 


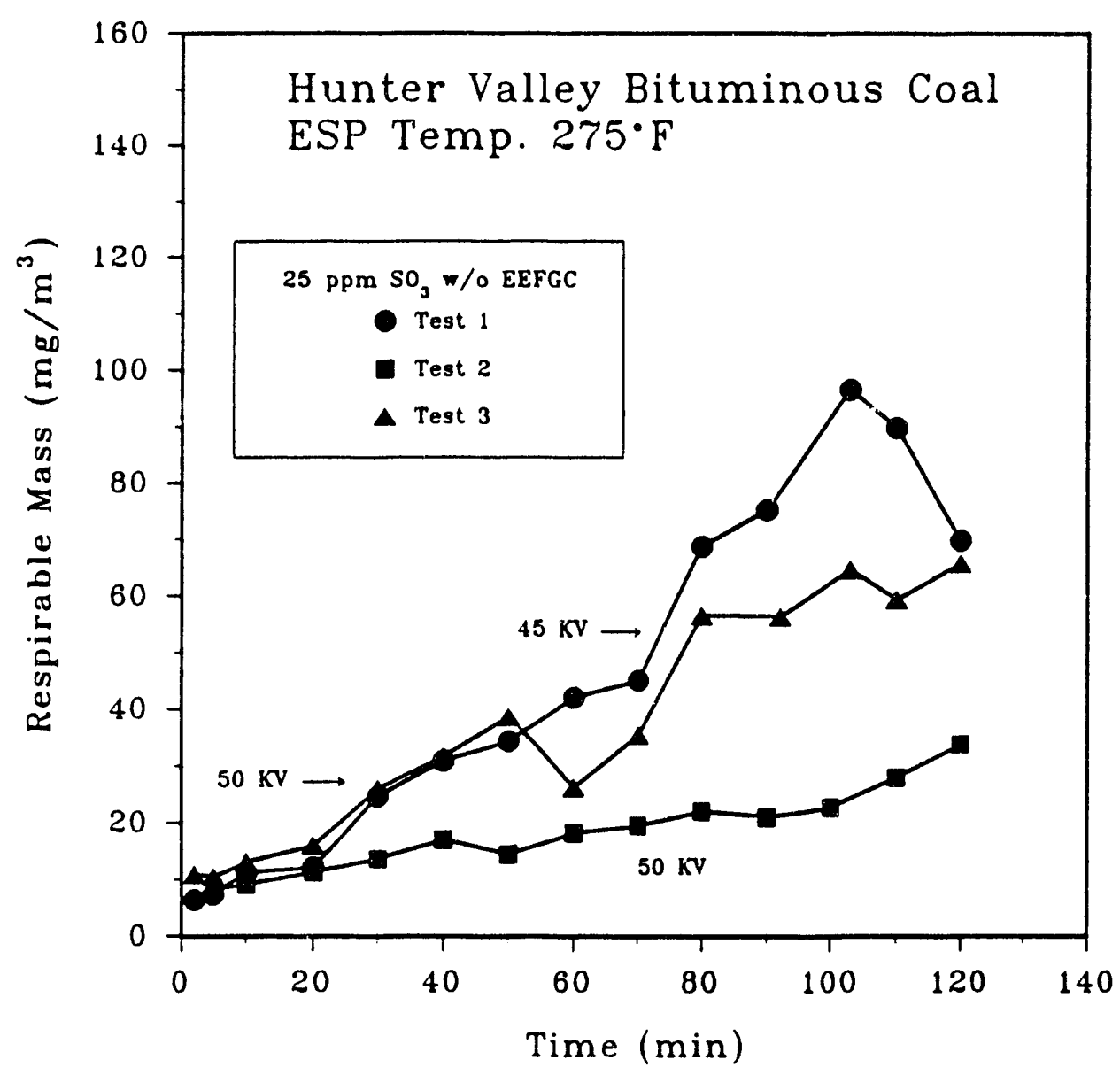

Figure A-7.4. Respirable mass emissions as a function of time at $25 \mathrm{ppm} \mathrm{SO}$ without EFGC at $275^{\circ} \mathrm{F}$ for Hunter Valley coal for Runs 375 and 376. Data show significant variability. 

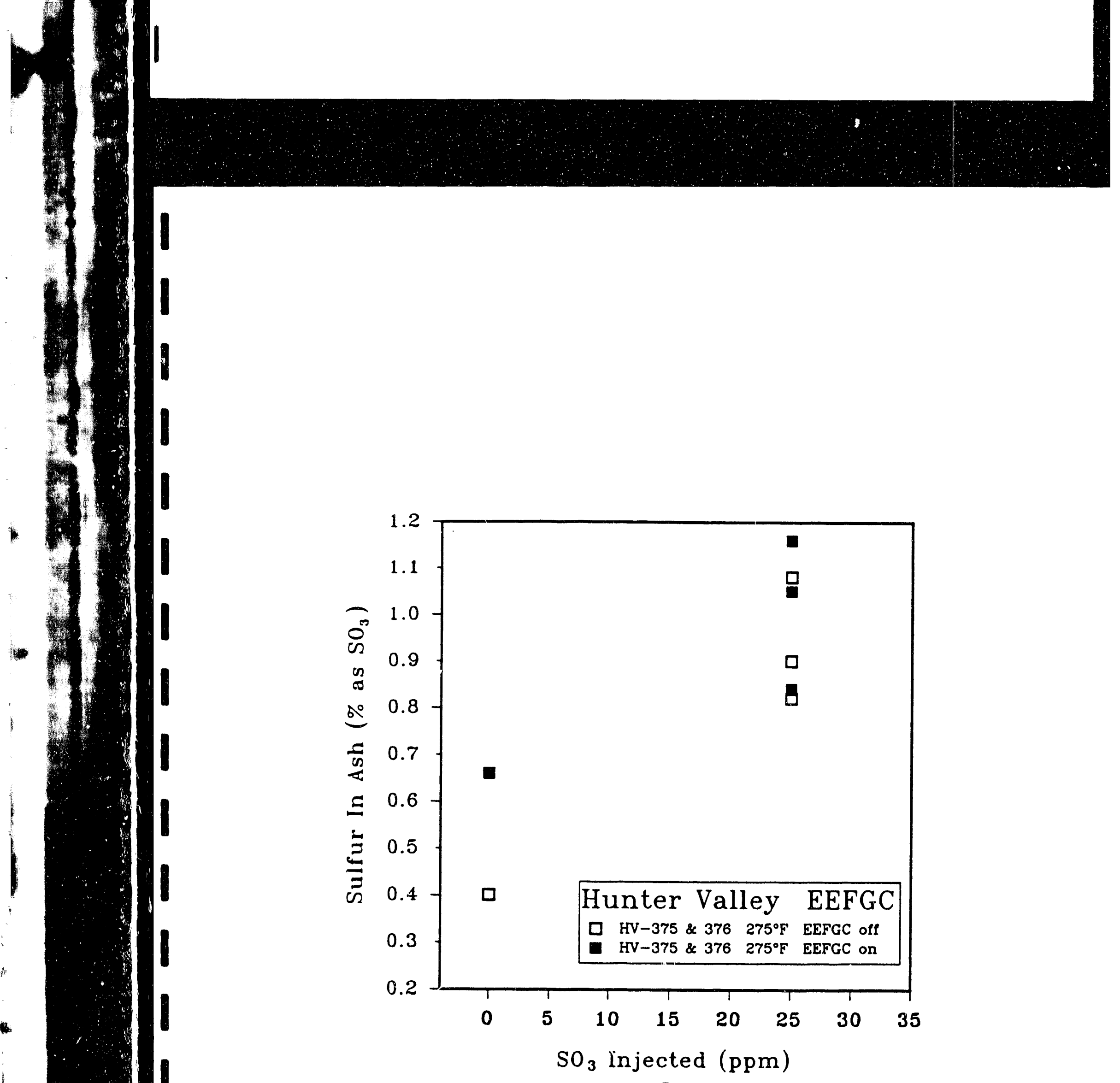

Figure A-7.5. Sulfur retention as a function of $\mathrm{SO}_{3}$ concentration with and without EFGC for Hunter Valley coal for Runs 375 and 376. 


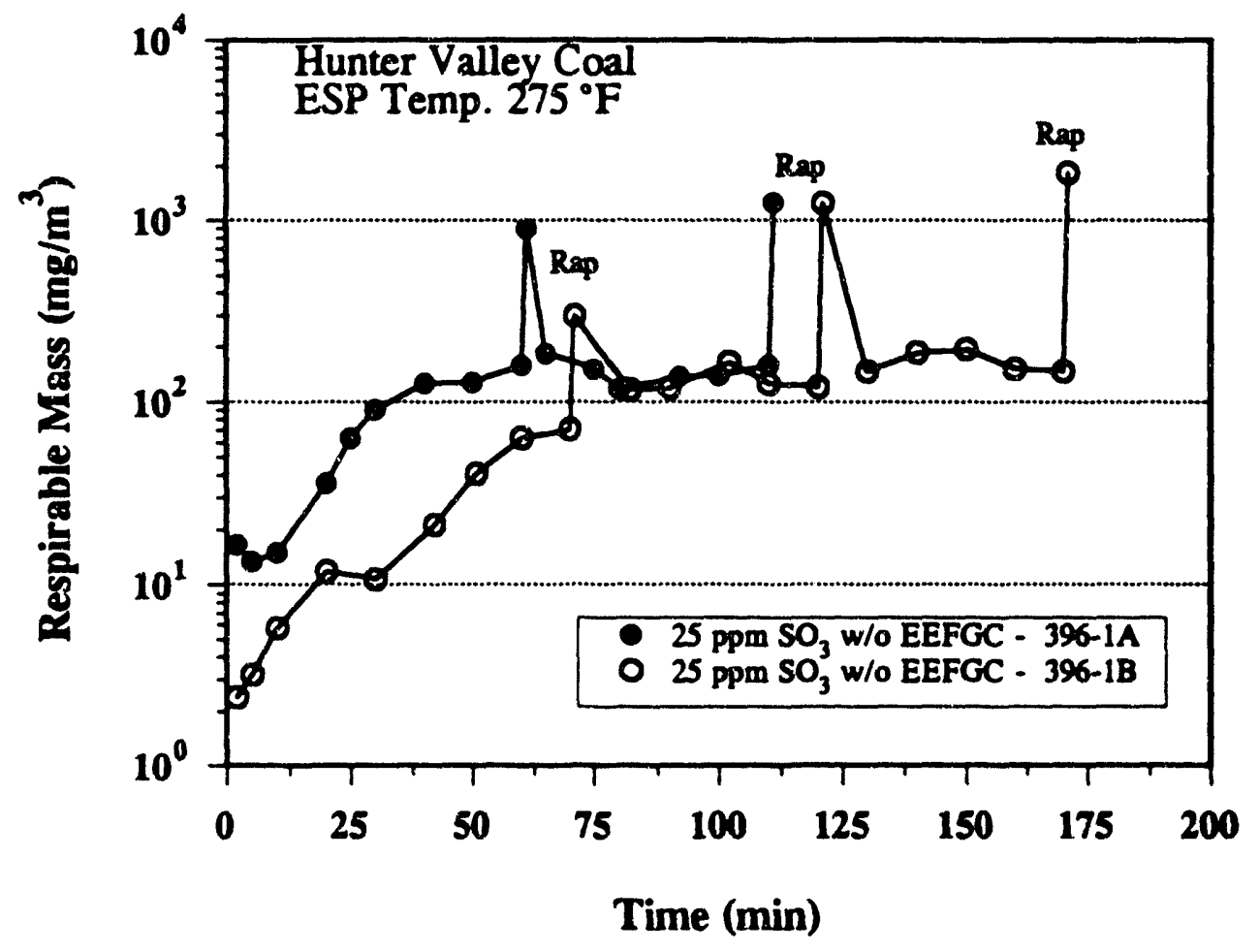

Figure A-7.6. Respirable mass emissions as a function of time at $25 \mathrm{ppm} \mathrm{SO}_{3}$ without EFGC at $275^{\circ} \mathrm{F}$ for Hunter Valley coal for Run 396. 


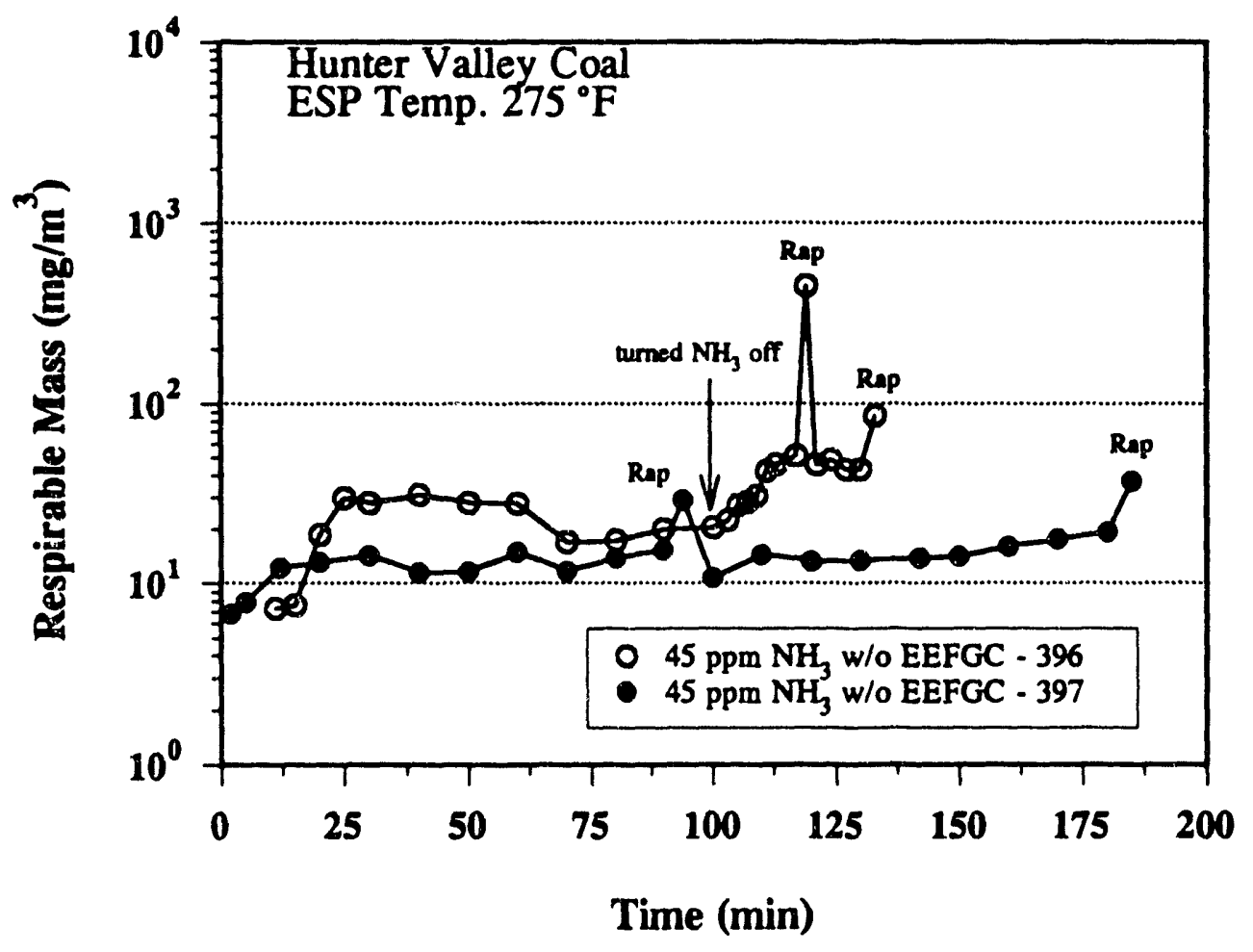

Figure A-7.7 Respirable mass emissions as a function of time with $45 \mathrm{ppm}$ of ammonia alone at $275^{\circ} \mathrm{F}$ for Hunter Valley coal for Runs 396 and 397. 


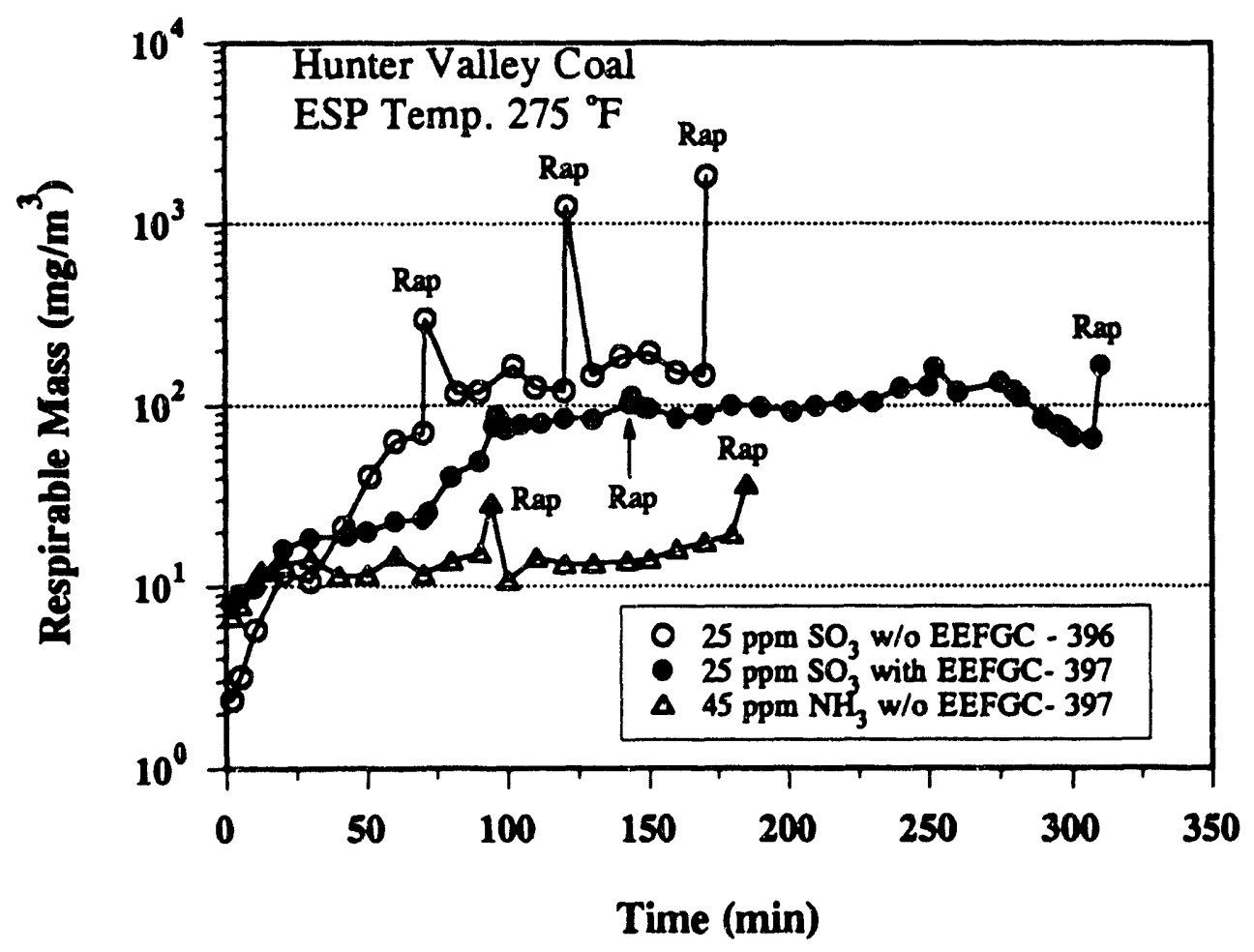

Figure A-7.8. Respirable mass emissions as a function of time for $25 \mathrm{ppm} \mathrm{SO}_{3}$ without EFGC, for $25 \mathrm{ppm}$ of $\mathrm{SO}_{3}$ with $\mathrm{EFGC}$, and for $45 \mathrm{ppm}$ of ammonia alone all at an ESP temperature of $275^{\circ} \mathrm{F}$ with Hunter Valley coal for Runs 396 and 397. 


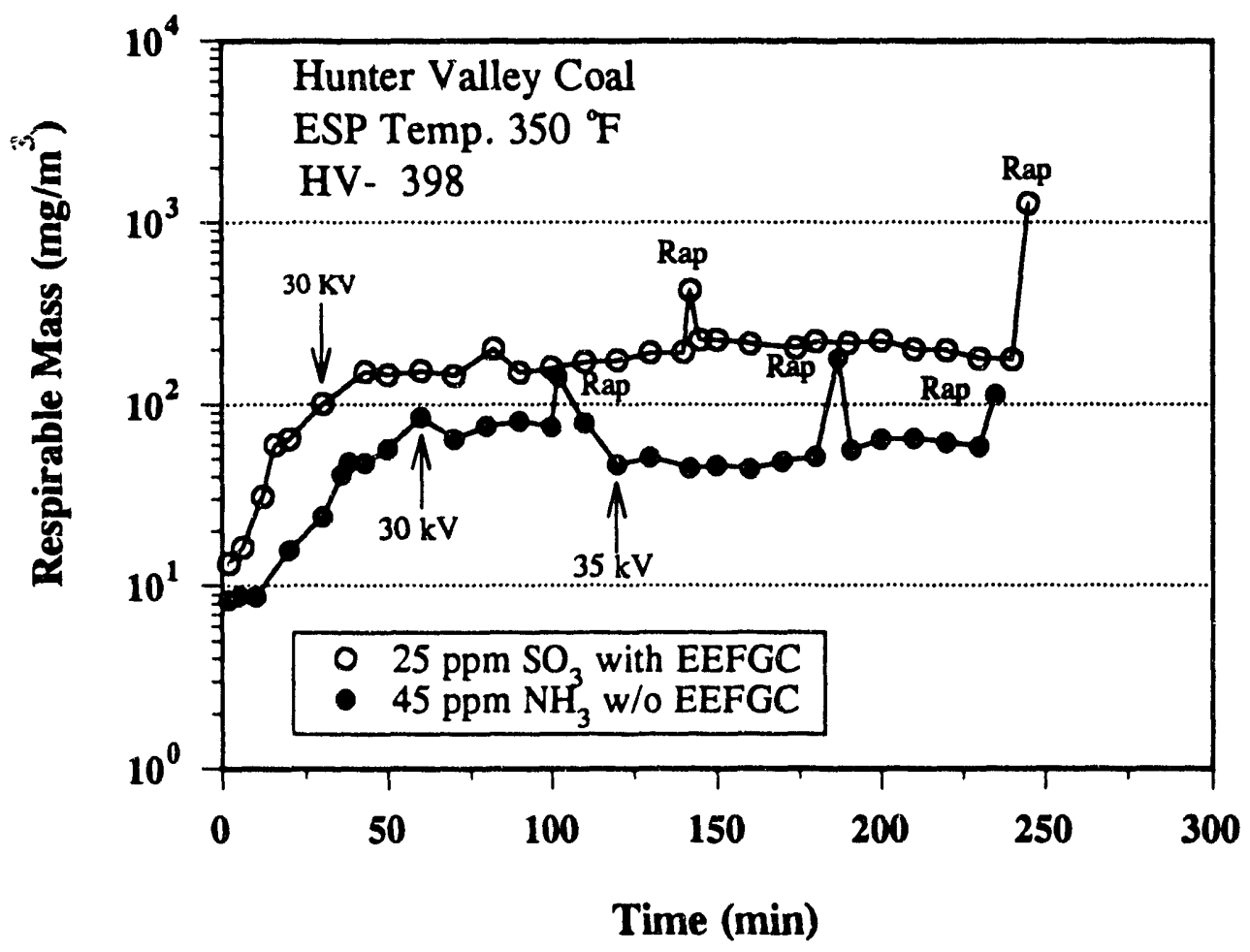

Figure A-7.9. Respirable mass emissions as a function of time for $25 \mathrm{ppm}$ of $\mathrm{SO}_{3}$ with EFGC and for $45 \mathrm{ppm}$ of ammonia alone at an ESP temperature of $350^{\circ} \mathrm{F}$ with Hunter Valley coal for Run 398. 


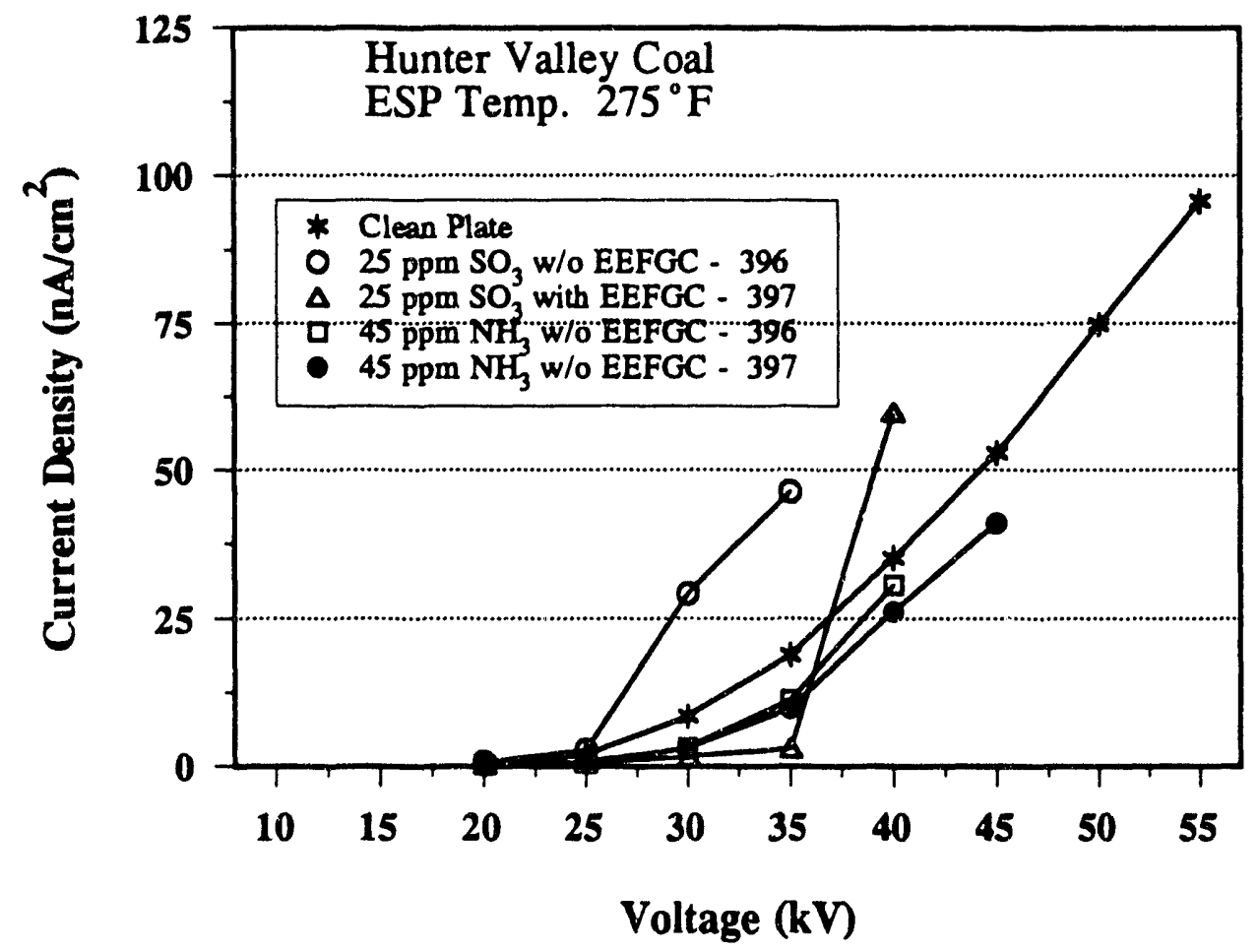

Figure A-7.10. Current-voltage curves with and without EFGC and with ammonia alone at $275^{\circ} \mathrm{F}$ for Hunter Valley coal for Runs 396 and 397. 


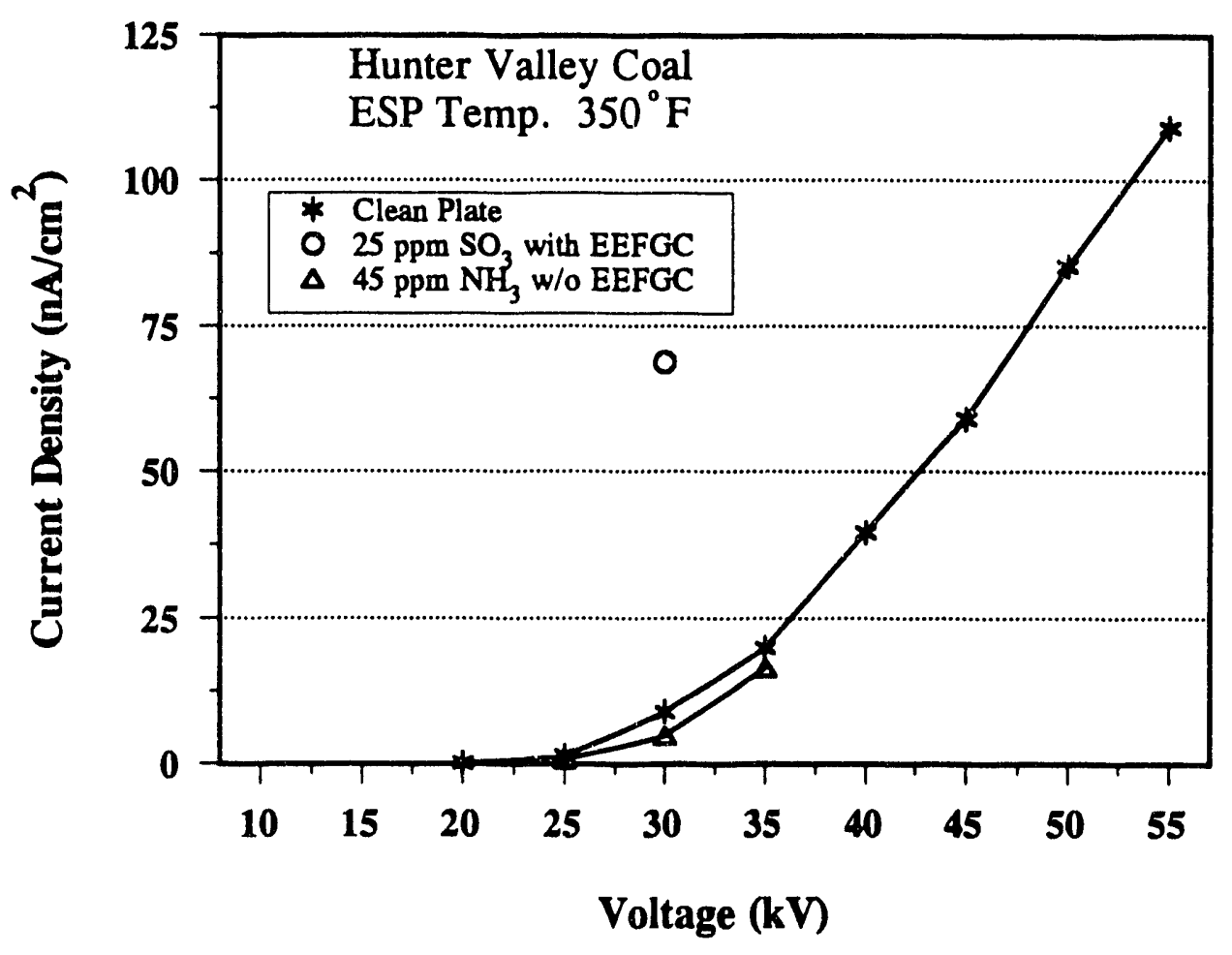

Figure A-T.11. Current-voltage curves with EFGC and with ammonia alone at $350^{\circ} \mathrm{F}$ for Hunter Valley coal for Run 398. 


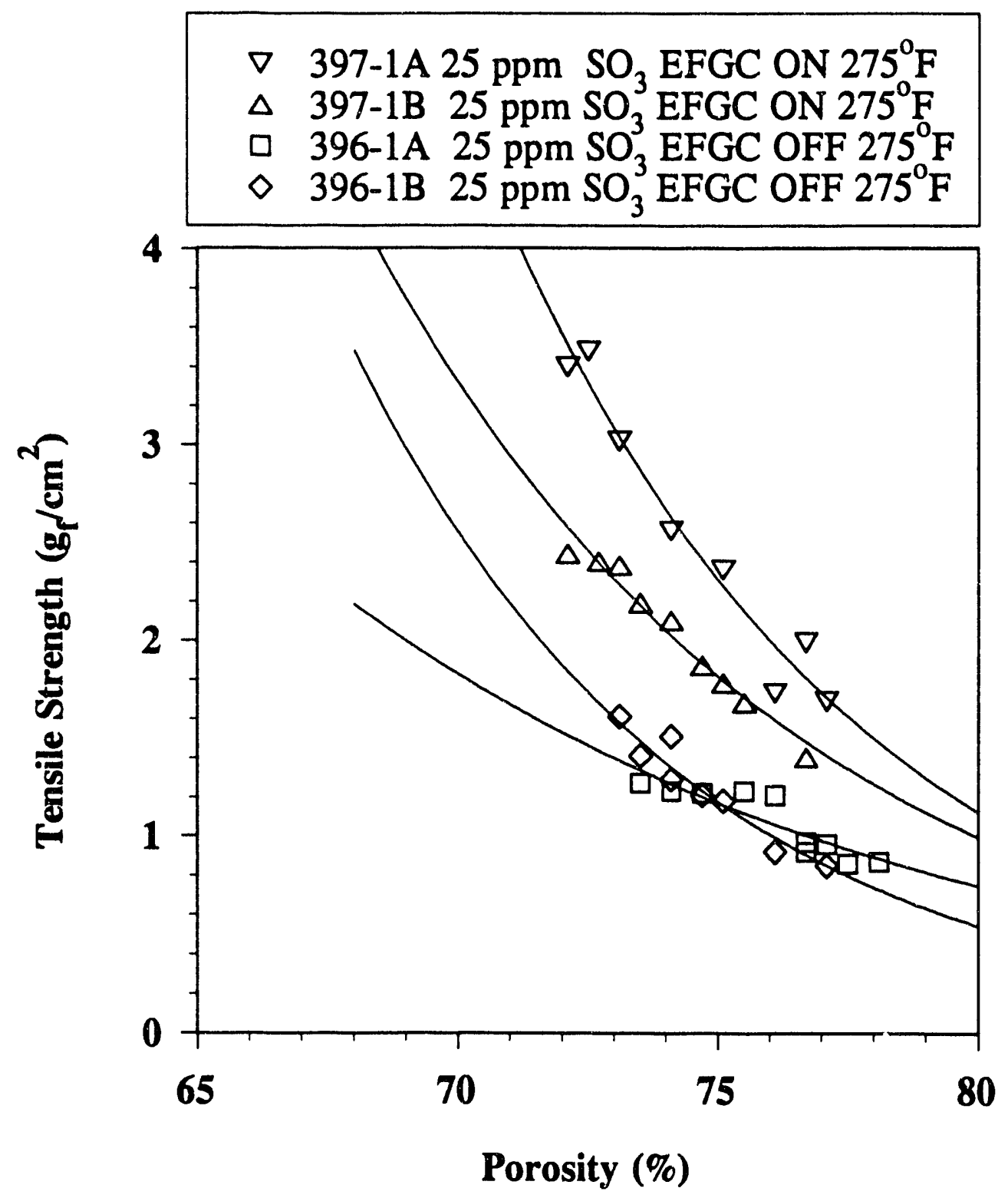

Figure A-7.12. Fly ash tensile strength as a function of ash porosity with and without EFGC for Hunter Valley coal for Runs 396 and 397. 


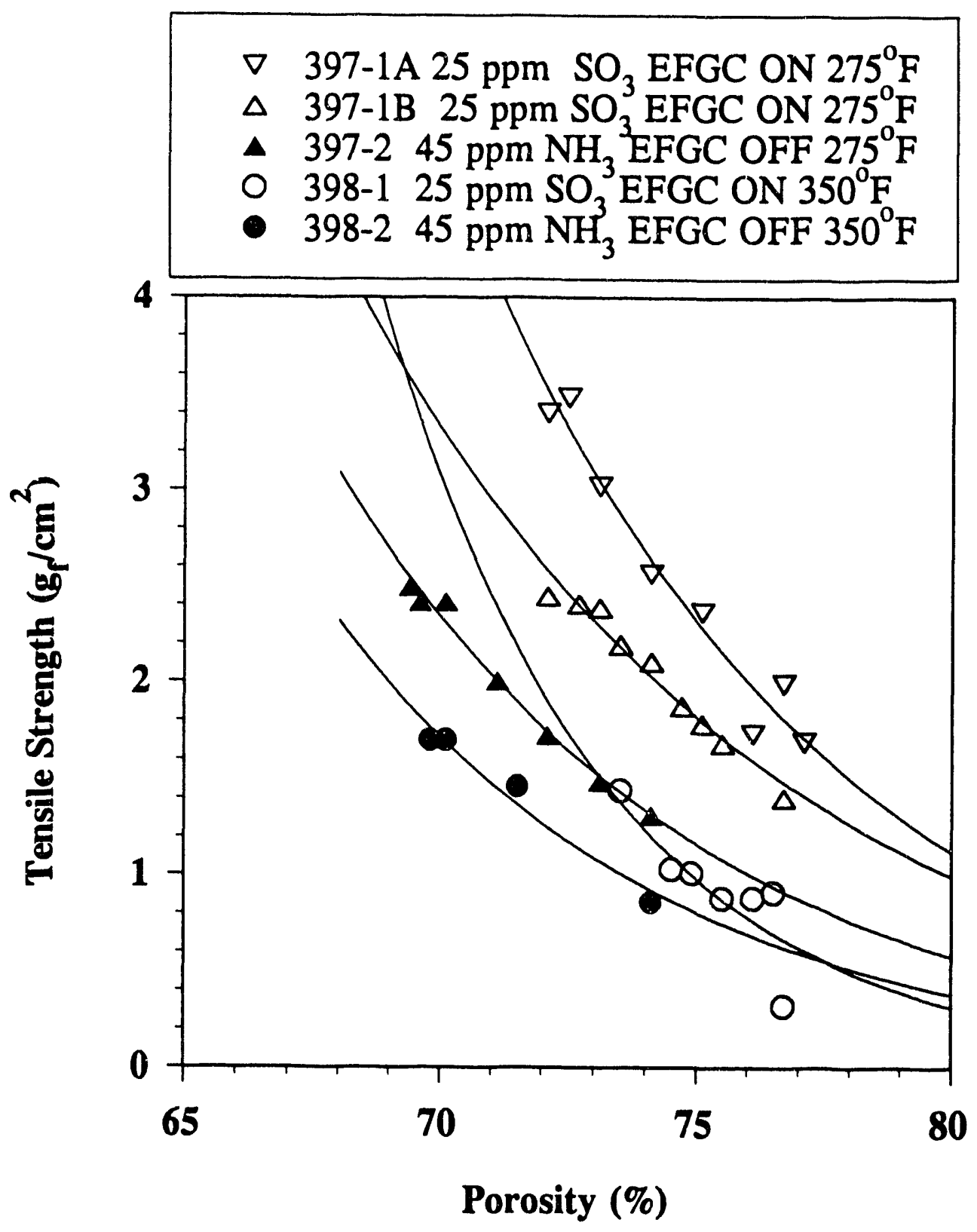

Figure A-7.13. Fly ash tensile strength as a function of ash porosity with EFGC and ammonia alone for Hunter Valley coal for Runs 397 and 398. 

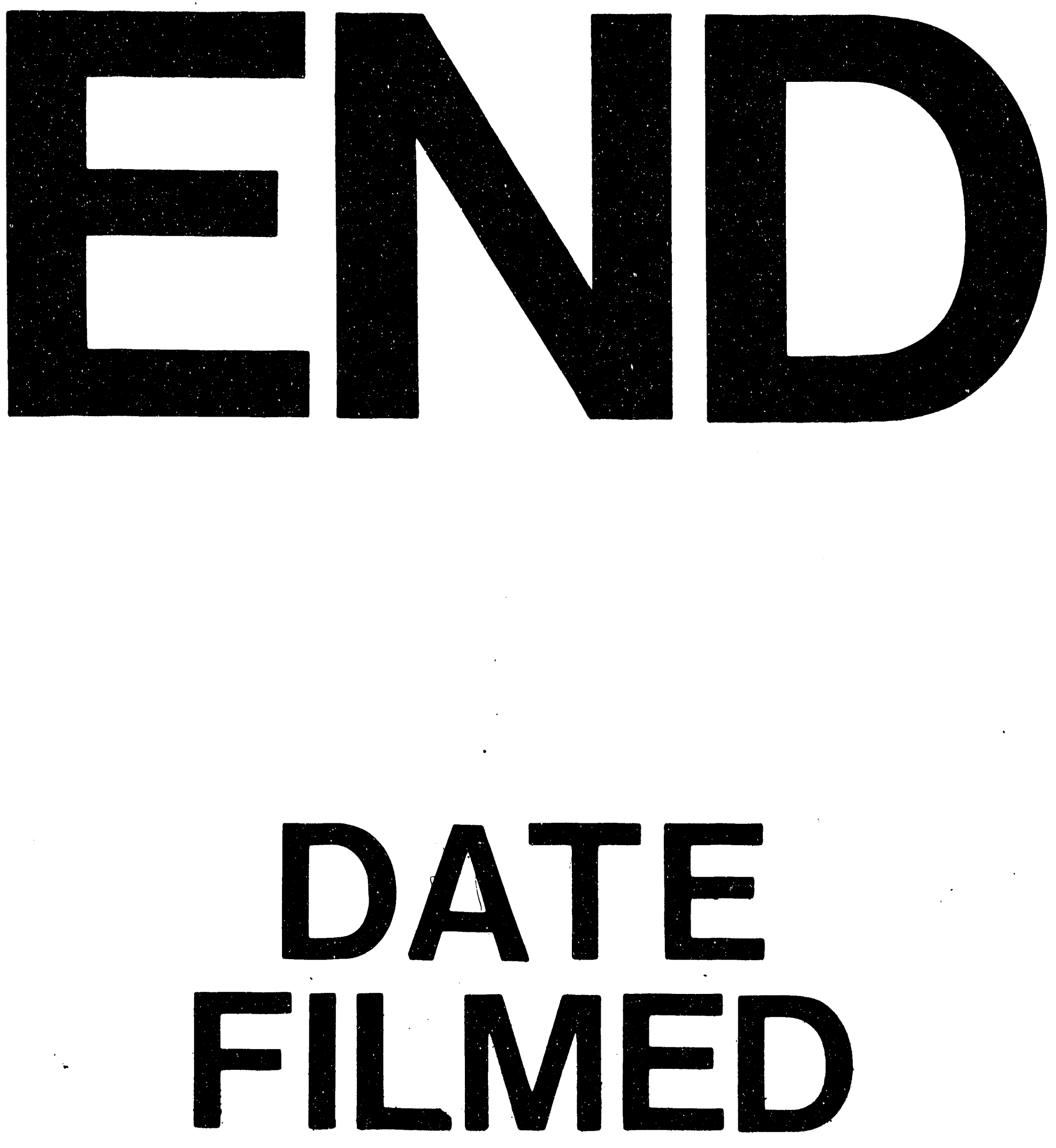

I

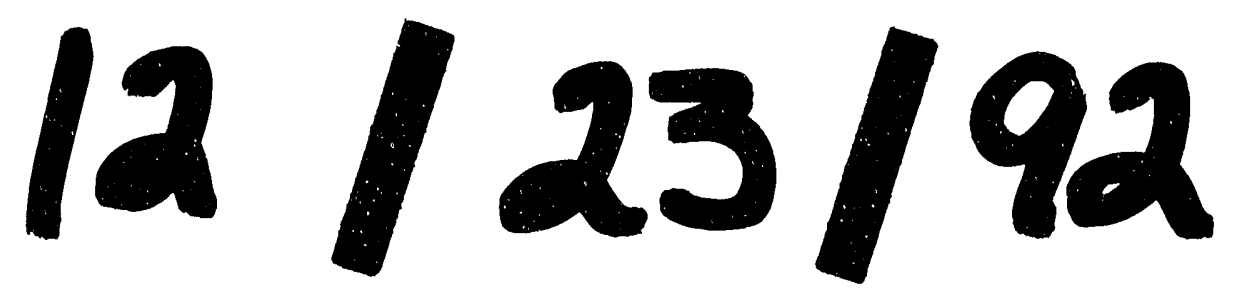


